THALES COUTO BRAGUIM

UTILIZAÇÃO DE MODELOS DE CÁLCULO PARA PROJETO DE EDIFÍCIOS DE PAREDES DE CONCRETO ARMADO MOLDADAS NO LOCAL 

THALES COUTO BRAGUIM

\title{
UTILIZAÇÃO DE MODELOS DE CÁLCULO PARA PROJETO DE EDIFÍCIOS DE PAREDES DE CONCRETO ARMADO MOLDADAS NO
} LOCAL

\begin{abstract}
Dissertação apresentada à Escola Politécnica da Universidade de São Paulo para a obtenção do título de Mestre em Engenharia Civil
\end{abstract}

São Paulo 

THALES COUTO BRAGUIM

\title{
UTILIZAÇÃO DE MODELOS DE CÁLCULO PARA PROJETO DE EDIFÍCIOS DE PAREDES DE CONCRETO ARMADO MOLDADAS NO LOCAL
}

\author{
Dissertação apresentada à Escola \\ Politécnica da Universidade de São Paulo \\ para a obtenção do título de Mestre em \\ Engenharia Civil \\ Área de concentração: \\ Engenharia de Estruturas \\ Orientador: \\ Prof. Titular Túlio Nogueira Bittencourt
}




Este exemplar foi revisado e corrigido em relação à versão original, sob responsabilidade única do autor e com a anuência de seu orientador.

São Paulo, de setembro de 2013.

Assinatura do autor

Assinatura do orientador

\section{FICHA CATALOGRÁFICA}

\section{Braguim, Thales Couto}

Utilização de modelos de cálculo para projeto de edifícios de paredes de concreto armado moldadas no local / T.C.

Braguim. -- versão corr. -- São Paulo, 2013.

$188 \mathrm{p}$.

Dissertação (Mestrado) - Escola Politécnica da Universidade de São Paulo. Departamento de Engenharia de Estruturas e Geotécnica.

1.Paredes (Dimensionamento) 2.Concreto armado I.Universidade de São Paulo. Escola Politécnica. Departamento de Engenharia de Estruturas e Geotécnica II.t. 
Dedico este trabalho aos meus pais, especialmente ao meu pai que tanto me orientou e incentivou a vencer desafios. 



\section{AGRADECIMENTOS}

Primeiramente agradeço a Deus pelas graças recebidas, e por proporcionar o momento certo das coisas acontecerem.

Agradeço aos meus pais, José Roberto Braguim e Maria Regina Couto Braguim, pelo amor, sabedoria, educação e perseverança transmitidos.

Agradeço ao meu pai, por sempre ter me incentivado a fazer o Mestrado.

Agradeço à minha irmã Thaisa Couto Braguim pela amizade, carinho e companheirismo que sempre me deram forças nos principais momentos da minha vida. Também ao meu cunhado Thiago Cássio de Aguiar por ter me ajudado com momentos de descontração.

Ao meu orientador Professor Túlio Nogueira Bittencourt pela confiança, orientação e por sempre ter me motivado.

Agradeço à amizade, ensinamentos, paciência e compreensão de Marcos de Carvalho, o qual foi fundamental ao longo do desenvolvimento deste trabalho.

Agradeço ao Professor Márcio Corrêa, pela amizade, pelos importantes e diversos ensinamentos transmitidos, além das conversas e sugestões para o desenvolvimento deste trabalho.

Ao Professor Edgard Sant'Anna de Almeida Neto, por não ter me deixado desistir, além de vários ensinamentos transmitidos.

Aos amigos do Mestrado Fábio Prado, Rodolfo G. M. de Andrade, Juliana Carandina, Pedro H. C. de Lyra, Heloisa M. Reketis, Marcelo Lima e Luiz Alberto Leal que me ajudaram com esclarecimento de dúvidas, materiais de aulas perdidas, seminários, dicas e diversos estudos. 
Aos meus tios Hélio Araújo Cardoso e Maria Alice Couto Cardoso, e meus primos Marília Couto Cardoso e Pedro Couto Cardoso, pelo suporte recebido em São Carlos e o incentivo em terminar este trabalho.

Agradeço à Emília Borges da Silva pela força e motivação, além de impressões de referências bibliográficas, que me foram importantes na etapa final deste trabalho.

Ao apoio recebido por todos da OSMB Engenheiros e Associados S/S Ltda.

Agradeço ao Dênis Delázari e Vinícios César Pereira Nunes por várias vezes terem me esclarecido dúvidas teóricas.

Agradeço ao GMEC principalmente à Luciana Tiemi Kataoka e Ana Carolina Marques por compartilharem dicas importantes.

A todos os professores de quem fui aluno algum dia, por participarem de minha formação.

Aos funcionários da secretaria do PEF e à Wandréa por ter me esclarecido várias dúvidas.

Agradeço ao amigo Pe. Carlos, por sempre estar presente.

Pelo incentivo e apoio recebido dos irmãos do meu pai, Amadeu Braguim Neto e Marisa Braguim Basile, dos meus tios, primos e do meu primo Rafael Braguim Basile.

A toda minha família, especialmente à minha querida e doce sobrinha Gabriela Braguim de Aguiar.

Agradeço a todos que me ajudaram a desenvolver este trabalho. 
"Já paraste a considerar a enorme soma que podem vir a dar 'muitos poucos'?"

(Mons. Josemaría Escrivá) 



\section{RESUMO}

Desde meados de 2007, um aumento significativo de unidades construídas pelo sistema Paredes de concreto tem influenciado o mercado da construção habitacional no Brasil. Em abril de 2012, foi publicada uma norma brasileira que trata exclusivamente desse sistema. Além disso, o desafio em minimizar o déficit habitacional estimula a utilização desse método alternativo, pois quando aplicado adequadamente proporciona alta produtividade e menor custo em relação a outros métodos construtivos. Por essas razões, é importante conhecer quais modelos de cálculo são seguros e pertinentes para a análise estrutural de edificações construídas pelo sistema Paredes de Concreto. Neste trabalho são avaliados, por meio da comparação de resultados, quatro modelos de cálculo, dos quais dois são numéricos, utilizados para o pré-dimensionamento e dimensionamento de paredes de concreto armado, moldadas no local. Este tipo de estrutura tem sido bastante utilizada na construção de edifícios. Deste modo utilizou-se como estudo de caso, um projeto adaptado de um edifício real com quinze pavimentos tipo, para a aplicação dos modelos de cálculo e algumas normas de projeto. Os dois modelos numéricos foram desenvolvidos no software SAP2000, baseado no Método dos Elementos Finitos, considerando análise elástica linear. O primeiro discretiza as paredes com elementos de casca e o segundo com elementos de barra. A interação entre o solo e a estrutura não foi considerada neste trabalho. Normas de projeto foram comparadas na etapa de pré-dimensionamento quanto às resistências últimas à compressão com objetivo de avaliar a recente norma brasileira. A verificação ao dimensionamento das paredes quanto às tensões normais de compressão e tração e tensões de cisalhamento foi realizada baseada nas expressões da NBR 16055:2012. Por fim, verificou-se o Estado Limite de Serviço das deformações excessivas globais, referentes à movimentação lateral do edifício e a estabilidade global do edifício estudado, pela NBR 6118:2007.

Palavras-chave: sistema Paredes de Concreto. modelos numéricos. edifício. dimensionamento de paredes. método dos elementos finitos. 



\begin{abstract}
Since 2007, a significant use of the system known as Concrete Wall has been influenced the Brazilian residential construction market. In April 2012, a Brazilian code exclusively devoted to this system was published. Besides that, the challenge in reducing housing deficit estimulate the use of this alternative method, because when properly applied it provides high productivity and lower costs compared with other construction methods. For these reasons it is important to evaluate which designing models are safe and appropriate to structural analysis of buildings constructed in Concrete Wall system. In this work it is evaluated, through results comparison, four designing models, of which two are numerical, used to pre-design and to design reinforced concrete walls casted in place. This kind of structure has been widely used in buildings construction. Thus, an adapted project from a real building with fifteen floors was used as a case study in order to apply the designing models and some project design codes. Both numerical models were developed in SAP2000 software, based on Finite Element Method, considering elastic linear analysis. The former used shell elements to represent the walls and the latter used frame elements. The soilstructure interaction has not been considered in this work. Project design codes were compared at the pre-design stage in terms of the ultimate compression resistance, aiming evaluate the recent Brazilian code. The check of normal stress of compression, normal stress of tension, and shear stress, was made based on NBR 16055:2012 expressions. Finally, the service limit state related to global excessive deformation due to the lateral movement of the building and the global stability was verified through NBR 6118:2007.
\end{abstract}

Keywords: Concrete Wall system. numerical model. building. design of walls. finite element method. 



\section{LISTA DE SÍMBOLOS}

$f_{c 14 h}$

$f_{c k}$

$f_{c d}$

$f_{c t, d}$

$f_{\text {scd }}$

$f_{v d}$

$f_{v d, \text { int }}$

$f_{y k}$

$f_{y d}$

$\eta_{d, r e s i s t}$

$\eta_{k, v e r t}$

$\eta_{\text {Cd,est }}$

$\gamma$

$\gamma_{f}$

$\gamma_{s}$

$\gamma_{c}$

$\gamma_{g}$

$\gamma_{q}$

$\psi_{0}$

$\lambda$

$\rho$

$\delta$

$\delta_{C F}$

$\delta_{\lim }$

resistência característica à compressão do concreto às 14 horas;

resistência característica à compressão do concreto aos 28 dias;

resistência de cálculo à compressão do concreto;

resistência de cálculo à tração do concreto;

resistência de cálculo à compressão do aço;

força cortante resistente de cálculo;

força cortante resistente de cálculo da interface vertical;

resistência característica do aço;

resistência de cálculo do aço;

resistência última à compressão de paredes de concreto armado;

força normal distribuída característica, obtida apenas por cargas

verticais;

estimativa da máxima força normal distribuída de cálculo;

peso específico;

coeficiente de ponderação das ações;

coeficiente redutor da resistência do aço;

coeficiente redutor da resistência do concreto;

coeficiente majorador das ações permanentes;

coeficiente majorador das ações variáveis;

coeficiente redutor das ações variáveis secundárias;

índice de esbeltez;

taxa geométrica da armadura vertical da parede de concreto;

translação horizontal devida apenas às ações horizontais;

translação horizontal considerando a combinação frequente de ações;

translação horizontal limite dada pela NBR 6118:2007; 


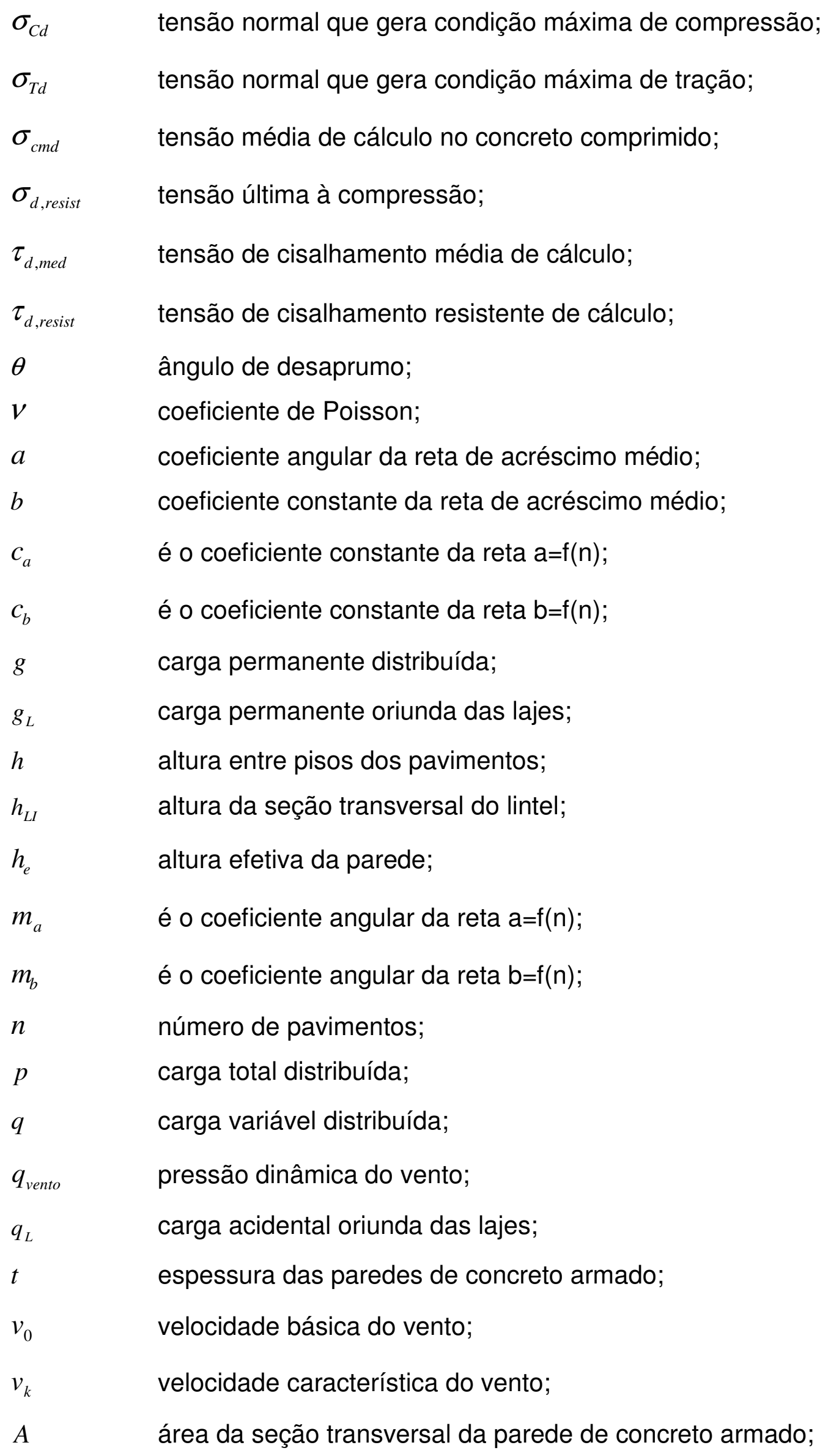


$A_{\text {int }}$

$A_{L}$

$A_{s, p a r}$

$A_{e}$

$C_{A H}$

$C_{a}$

$E_{C S}$

$E_{s}$

$F_{a}$

$F_{d}$

$F_{d, \text { ser }}$

$F_{g k}$

$F_{q k}$

$F_{q 1}$

$F_{d p}$

$F_{d, \text { traçã̃o }}$

G

$H$

$H_{i}$

I

$L$

$L_{L I}$

$L_{\text {inf }}$

$L_{x}$

$L_{y}$

área da interface vertical;

área de influência das lajes;

área de aço necessária na parede de concreto para resistir a força resultante da tensão normal de tração;

área frontal efetiva sobre o plano normal à direção do vento;

coeficiente majorador das tensões normais obtidas apenas por cargas

verticais para estimar o acréscimo delas devido às ações horizontais;

coeficiente de arrasto do vento conforme sua direção;

módulo de elasticidade secante do concreto;

módulo de elasticidade do aço;

força de arrasto do vento;

valor de cálculo das ações para a combinação última;

valor de cálculo das ações para a combinação de serviço;

ações permanentes diretas;

ações variáveis diretas;

ação variável principal;

força devido ao desaprumo;

força de tração de cálculo, resultante da tensão normal de tração;

carga permanente concentrada;

altura total do edifício;

altura do edifício no pavimento $n$ considerado;

momento de inércia da direção principal da seção transversal;

comprimento da parede em planta;

comprimento do lintel em planta;

comprimento de influência das lajes;

comprimento do edifício na direção X;

comprimento do edifício na direção Y; 


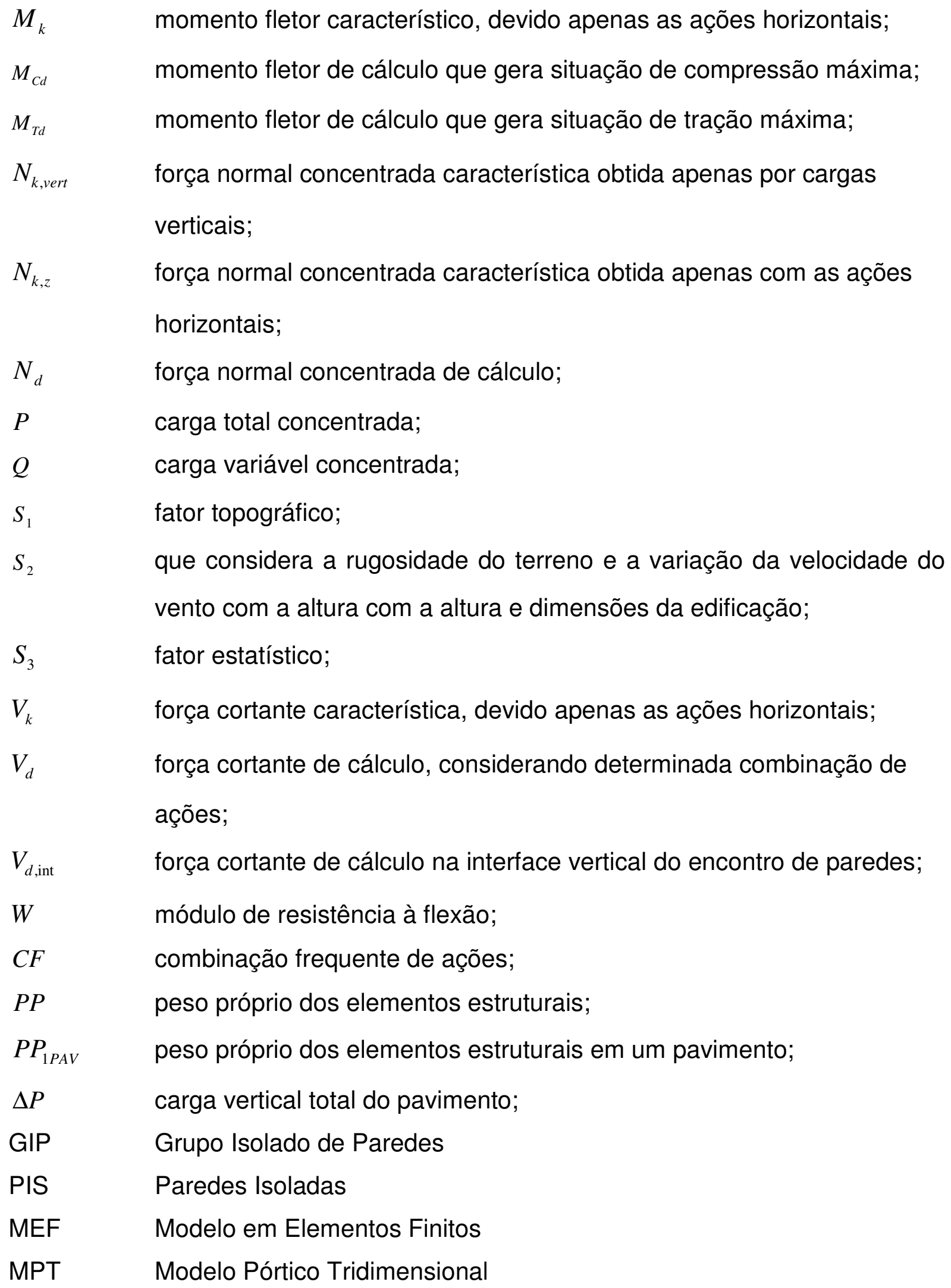




\section{LISTA DE FIGURAS}

Figura 1.1 - Sistema Gethal: exemplo de paredes de concreto celular executados com forma metálica (GETHAL).

Figura 1.2 - Sistema Outinord: exemplo de paredes e lajes concretadas com a utilização de formas metálicas tipo túnel (Fonte: Universidad Nacional de Colombia, archivo particular).

Figura 1.3 - Porcentagem dos métodos executivos praticados nos empreendimentos de 39 grandes construtoras (Fonte: ABCP ago/2012);

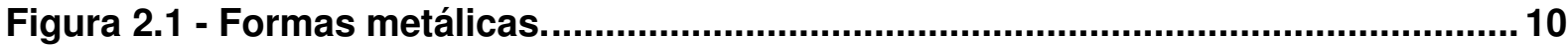

Figura 2.2 - Formas metálicas com compensado (ABCP). ....................................... 10

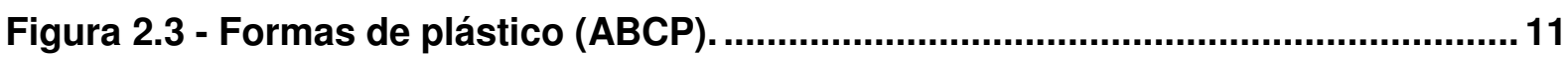

Figura 2.4 - Armadura com tela simples centrada na parede. ........................................13

Figura 2.5 - Armadura com tela dupla, uma em cada face da parede, respeitando o cobrimento.

Figura 2.6 - Eletrodutos fixados na caixa elétrica que é posicionada com o auxílio da

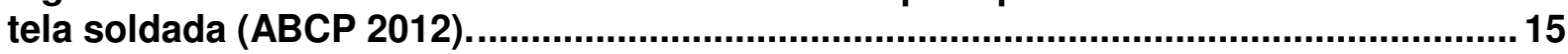

Figura 2.7 - Fundação nivelada contendo os arranques e as instalações sanitárias. .. 15

Figura 2.8 - Montagem das telas, reforços e fixação dos espaçadores......................... 16

Figura 2.9 - Fixação dos eletrodutos e caixas elétricas...............................................16

Figura 2.10 - Colocação das instalações hidráulicas (IBTS 2012)................................17

Figura 2.11 - Concretagem das paredes (Comunidade da Construção 2013)...............17

Figura 2.12 - Ensaios Slump test e Slump flow (Comunidade da Construção 2013).... 18

Figura 2.13 - Resumo comparativo de custos (NACIMBA, 2009). ................................ 19

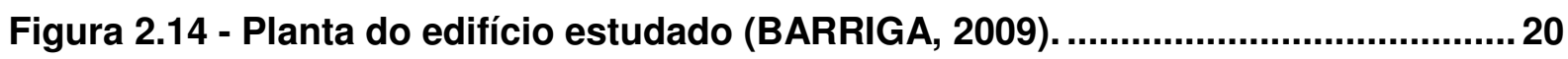

Figura 2.15 - Casa com um térreo e um pavimento superior (ALVES; PEIXOTO, 2011). 
Figura 2.16 - Edifício com um térreo e mais três pavimentos (ALVES; PEIXOTO 2011).

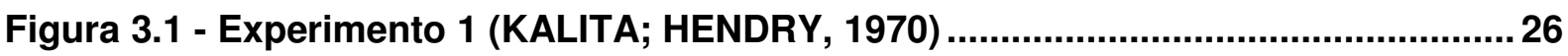

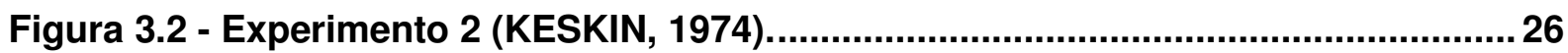

Figura 3.3 - Modelo Pórtico Tridimensional do experimento 1 (NASCIMENTO NETO, 1999).

Figura 3.4 - Modelo Pórtico Tridimensional do experimento 2 (NASCIMENTO NETO, 1999).

Figura 3.5 - Deslocamentos horizontais na Parede A do experimento 1 (NASCIMENTO

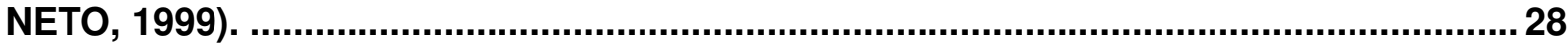

Figura 3.6 - Rotações das lajes do experimento 2 (NASCIMENTO NETO, 1999)........... 28

Figura 3.7 - Modelo referência a) x Modelo básico b); nomenclatura de paredes e

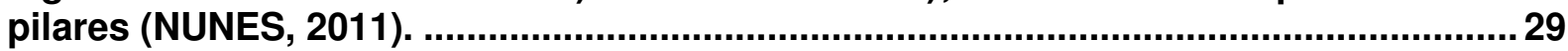

Figura 3.8 - Comparação das translações horizontais entre os modelos MEF e MPT

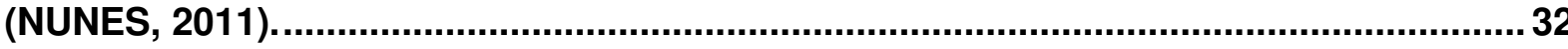

Figura 3.9 - Paredes sem e com vinculações laterais; a) um plano de flexão; b) dois

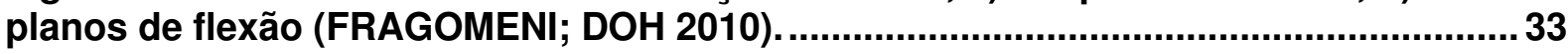

Figura 3.10 - Nomenclatura das principais variáveis no cálculo de resistência última à

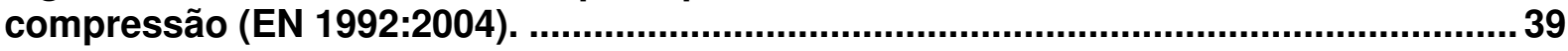

Figura 3.11 - Cálculo de $\beta$ conforme vinculações da parede (EN 1992:2004).............. 39

Figura 3.12 - Cálculo de $\ell_{e}$ conforme vinculações da parede (NBR 16055:2012)......... 42

Figura 3.13 - Decréscimo da tensão última à compressão com aumento do índice de esbeltez, conforme NBR 16055:2012 ............................................................................... 42

Figura 3.14 - Verificação à flexão simples em paredes com vento maior que $0,1 \mathrm{tf} / \mathrm{m}^{2} .44$

Figura 4.1 - Esquema para cálculo das reações das lajes (OLIVEIRA, 2009). 49

Figura 4.2 - Espalhamento de cargas concentradas ou parcialmente distribuídas (ABNT NBR 16055).

Figura 4.3 - Espalhamento de cargas em paredes adjacentes (NUNES, 2011). 51 
Figura 4.4 - Forças de interação em regiões de aberturas.

Figura 4.5 - Medidas de deformações realizadas num edifício de alvenaria estrutural com cinco pavimentos (OLIVEIRA, 2009).

Figura 4.6 - Distribuição das ações do vento entre painéis de contraventamento (CORRÉA e RAMALHO, 2003).

Figura 4.7 - Modelagem do diafragma rígido no SAP2000 (CSI - SAP2000, 2011).

Figura 4.8 - Simetria em planta e ações horizontais não excêntricas: apenas translações horizontais; não há esforço de torção. 58

Figura 4.9 - Assimetria em planta ou ações horizontais excêntricas: translações horizontais e rotação em torno da altura do edifício; há esforço de torção. 58

Figura 4.10 - Ação horizontal equivalente ao desaprumo. 61

Figura 4.11 - Direção e sentido das ações horizontais. 62

Figura 4.12 - Modelagem estrutural do núcleo - elemento Yagui (1971) (PEREIRA 2000).

Figura 4.13 - Modelo Pórtico Tridimensional (CORRÊA, 2003).....................................65

Figura 4.14 - Aplicação do Modelo Pórtico Tridimensional. ......................................... 66

Figura 4.15 - Sistema de eixos local do elemento Frame (CSI - SAP2000, 2011). 67

Figura 4.16 - Graus de liberdade por nó de determinado elemento finito (CSI SAP2000, 2011). 68

Figura 4.17 - Sistema de eixos local do elemento Shell (CSI - SAP2000, 2011). 69

Figura 4.18 - Considerações sobre a largura útil de mesas em vigas (TIMOSHENKO, 1966).

Figura 5.1 - Edifício estudo preliminar: casos A e B; medidas (cm). 72

Figura 5.2 - Áreas de influência das lajes nas paredes - Caso A.................................75

Figura 5.3 - Áreas de influência das lajes nas paredes - Caso B...............................75

Figura 5.4 - Definição dos Grupos Isolados de Paredes para o EP. ............................. 77

Figura 5.5 - Modelo Pórtico Tridimensional do EP. 78 
Figura 5.6 - Modelo em Elementos Finitos: malhas de 20x20 e $40 \times 40$ para os casos A e B.

Figura 5.7 - Diagrama de $M_{k, y}$ da parede PH01 para os casos A e B. 82

Figura 5.8 - Diagrama de $V_{k, x}$ da parede PH01 para os casos A e B. 83

Figura 5.9 - Diagrama de $N_{k, z}$ da parede PH01 para os casos A e B. 83

Figura 5.10 - Diagramas de tensões normais (MEF20) e forças normais (MPT) - caso A. 86

Figura 5.11 - Diagramas de tensões normais (MEF20) e forças normais (MPT) - caso B. 86

Figura 5.12 - Diagrama de $M_{k, x}$ da parede PV01 para os casos A e B. 87

Figura 5.13 - Diagrama de $V_{k, y}$ da parede PV01 para os casos A e B 88

Figura 5.14 - Diagrama de $N_{k, z}$ da parede PV01 para os casos A e B. 88

Figura 5.15 - Diagramas de $M_{C d, y}$ e $N_{C d, z}$ para combinação $\mathbf{C}_{1-\mathrm{S} 180}$ da PH01 no caso B. 93

Figura 5.16 - Tensões normais para a condição máxima de compressão - PH01 - Caso B. 95

Figura 5.17 - Translações horizontais na direção X - Caso A. 95

Figura 5.18 - Translações horizontais na direção Y - Caso A. 96

Figura 5.19 - Translações horizontais na direção X - Caso B. 96

Figura 5.20 - Translações horizontais na direção Y - Caso B. 97

Figura 6.1 - Edifício Condomínio das Árvores do empreendimento Reserva Jardim Botânico.

Figura 6.2 - Planta do pavimento tipo do edifício exemplo; Nomenclatura das paredes e lintéis; cotas apresentadas em $\mathrm{cm}$; 99

Figura 6.3 - Cotagem horizontal dos eixos das paredes, lintéis e pilar. 100 
Figura 6.4 - Cotagem vertical dos eixos das paredes, lintéis e pilar. 100

Figura 6.5 - Parâmetros para o cálculo das forças de arrasto do vento - (EE). 102

Figura 6.6 - Definição dos Grupos Isolados de Paredes para o edifício exemplo 104

Figura 6.7 - Edifício exemplo representado pelo Modelo Pórtico Tridimensional. 105

Figura 6.8 - Edifício exemplo representado pelo Modelo em Elementos Finitos. 105

Figura 6.9 - Áreas de influências das lajes sobre paredes e lintéis - (EE). 107

Figura 6.10 - Diagrama de $N_{k, v e r t}$ obtido pelos modelos GIP, MPT e MEF das paredes PH13, PH16 e PH34 com espessura de $10 \mathrm{~cm}$.

Figura 6.11 - Diagrama de $N_{k, v e r t}$ obtido pelos modelos GIP, MPT e MEF das paredes PV08, PV12 e PV15 com espessura de $10 \mathrm{~cm}$.

Figura 6.12 - Acréscimo médio da tensão normal de compressão em função do comprimento das paredes do edifício exemplo com 15 pavimentos.

Figura 6.13 - Acréscimo médio da tensão normal de compressão em função do comprimento das paredes do edifício exemplo com 12 pavimentos.

Figura 6.14 - Acréscimo médio da tensão normal de compressão em função do comprimento das paredes do edifício exemplo com 10 pavimentos.

Figura 6.15 - Acréscimo médio da tensão normal de compressão em função do comprimento das paredes do edifício exemplo com 8 pavimentos.

Figura 6.16 - Acréscimo médio da tensão normal de compressão em função do comprimento das paredes do edifício exemplo com 5 pavimentos.

Figura 6.17 - Acréscimo médio da tensão normal de compressão em função do comprimento das paredes do edifício exemplo com 2 pavimentos.

Figura 6.18 - Resumo do acréscimo médio da tensão de compressão nas paredes, devido às ações horizontais, para as alturas do edifício exemplo estudadas.

Figura 6.19 - Reta do coeficiente angular do acréscimo médio em função de n Pavs.

Figura 6.20 - Reta do coeficiente constante do acréscimo médio em função de n Pavs.

Figura 6.21 - Diagramas de $M_{k, y}, V_{k, x}$ e $N_{k, z}$ da parede PH13. 
Figura 6.22 - Diagramas de $M_{k, y}, V_{k, x}$ e $N_{k, z}$ da parede PH16.

Figura 6.23 - Diagramas de $M_{k, y}, V_{k, x}$ e $N_{k, z}$ da parede PH34. 134

Figura 6.24 - Diagramas de $M_{k, x}, V_{k, y}$ e $N_{k, z}$ da parede PV08. 135

Figura 6.25 - Diagramas de $M_{k, x}, V_{k, y}$ e $N_{k, z}$ da parede PV12. 136

Figura 6.26 - Diagramas de $M_{k, x}, V_{k, y}$ e $N_{k, z}$ da parede PV15. 137

Figura 6.27 - Diagrama de $M_{C d, y}$ das PH13, PH16 e PH34 conforme combinação $\mathbf{C}_{1} .138$ Figura 6.28 - Diagrama de $M_{C d, x}$ das PV08, PV12 e PV15 conforme combinação $\mathrm{C}_{1} .140$ Figura 6.29 - Diagrama de $N_{C d, z}$ das PH13, PH16 e PH34 conforme combinação $\mathrm{C}_{1}$. 140 Figura 6.30 - Diagrama de $N_{C d, z}$ das PV08, PV12 e PV15 conforme combinação $\mathbf{C}_{1} \cdot 141$ Figura 6.31 - Diagrama de $\sigma_{C d}$ das paredes PH13 e PH16. 142

Figura 6.32 - Diagrama de $\sigma_{C d}$ das paredes PH34 e PV08. 142

Figura 6.33 - Diagrama de $\sigma_{C d}$ da parede PV12. 143

Figura 6.34 - Diagrama de $\sigma_{C d}$ da parede PV15. 143

Figura 6.35 - Diagrama de $M_{T d, y}$ das PH13, PH16 e PH34 conforme combinação $\mathrm{C}_{2} .145$ Figura 6.36 - Diagrama de $M_{T d, x}$ das PV08, PV12 e PV15 conforme combinação $\mathrm{C}_{2 . .} 146$ Figura 6.37 - Diagrama de $N_{T d, z}$ das PH13, PH16 e PH34 conforme combinação $\mathbf{C}_{2 . .} 146$ Figura 6.38 - Diagrama de $N_{T d, z}$ das PV08, PV12 e PV15 conforme combinação $\mathbf{C}_{2} \ldots 147$ Figura 6.39 - Diagrama de $\sigma_{T d}$ da parede PV15. 
Figura 6.40 - Diagrama de $\sigma_{T d}$ da parede PV15 (tf $\left./ \mathrm{m}^{2}\right)$; a) Diagrama ao longo de toda altura da parede; b) Diagrama até $6 \mathrm{~m}$ de altura da parede;

Figura 6.41 - Diagrama de $V_{d, x}$ das PH13, PH16 e PH34 conforme combinação $\mathrm{C}_{2} \ldots 149$

Figura 6.42 - Diagrama de $V_{d, y}$ das PV08, PV12 e PV15 conforme combinação $\mathbf{C}_{2 .} \ldots 150$

Figura 6.43 - $V_{d \text {,int }}$ na interface PH13-PV04, considerando combinação de ações $\mathbf{C}_{1} \mathbf{e}$ sentido das ações horizontais $180^{\circ}$, obtida pelo MPT.

Figura 6.44 - Procedimento para obter a força cortante de cálculo na interface PH13-

PV04, pelo MEF.

Figura 6.45 - Translações horizontais na direção X - (EE).......................................... 155

Figura 6.46 - Translações horizontais na direção Y - (EE)......................................... 155

Figura 6.47 - Translações horizontais na direção X considerando a combinação frequente de ações - (EE).

Figura 6.48 - Translações horizontais na direção Y considerando a combinação frequente de ações - (EE).

Figura 6B-1 - Diagrama de $N_{k, v e r t}$ obtido pelos modelos GIP, MPT e MEF das paredes PH13, PH16 e PH34 com espessura de $12 \mathrm{~cm}$.

Figura 6B-2 - Diagrama de $N_{k, v e r t}$ obtido pelos modelos GIP, MPT e MEF das paredes PV08, PV12 e PV15 com espessura de $12 \mathrm{~cm}$.

Figura 6C-1 - Diagrama de $\sigma_{T d}$ das paredes PH13 e PH16. 183

Figura 6C-2 - Diagrama de $\sigma_{T d}$ das paredes PH34 e PV08. 183

Figura 6C-3 - Diagrama de $\sigma_{T d}$ da parede PV12. 183

Figura 6C-4 - Diagrama de $\sigma_{T d}$ da parede PH13 (tf/m²); a) Diagrama ao longo de toda altura da parede; b) Diagrama até $6 \mathrm{~m}$ de altura da parede;

Figura 6C-5 - Diagrama de $\sigma_{T d}$ da parede PH16 (tf/ $\left.\mathrm{m}^{2}\right)$; a) Diagrama ao longo de toda altura da parede; b) Diagrama até $6 \mathrm{~m}$ de altura da parede; 
Figura 6C-6 - Diagrama de $\sigma_{T d}$ da parede PH34 (tf $\left./ \mathrm{m}^{2}\right)$; a) Diagrama ao longo de toda altura da parede; b) Diagrama até $6 \mathrm{~m}$ de altura da parede;

Figura 6C-7 - Diagrama de $\sigma_{T d}$ da parede PV08 (tf/ $\left.\mathrm{m}^{2}\right)$; a) Diagrama ao longo de toda altura da parede; b) Diagrama até $6 \mathrm{~m}$ de altura da parede;

Figura 6C-8 - Diagrama de $\sigma_{T d}$ da parede PV12 (tf $\left./ \mathrm{m}^{2}\right)$; a) Diagrama ao longo de toda altura da parede; b) Diagrama até $6 \mathrm{~m}$ de altura da parede; 188 


\section{LISTA DE TABELAS}

Tabela 2.1 - Resumo de custos (BARRIGA, 2009).

Tabela 2.2 - Resumo de custos para uma casa tipo com térreo e mais um pavimento superior (ALVES; PEIXOTO, 2011).

Tabela 2.3 - Resumo de custos para um edifício tipo com térreo e mais três pavimentos (ALVES; PEIXOTO, 2011).

Tabela 2.4 - Resumo de custos para três edifícios tipo com térreo e mais três pavimentos (ALVES; PEIXOTO, 2011).

Tabela 3.1 - Comparação da Força normal obtida por cargas verticais (NUNES, 2011).

Tabela 3.2 - Comparação de Momentos Fletores e Esforços Cortantes obtidos pelas ações horizontais (NÛNES, 2011).

Tabela 3.3 - Comparação dos esforços solicitantes na base dos pilares considerando apenas ações horizontais (NUNES, 2011).

Tabela 3.4 - Comparação dos esforços solicitantes na base dos pilares considerando combinação de cargas verticais com ações horizontais (NUNES, 2011).

Tabela 5.1 - Parâmetros para o cálculo das forças de arrasto do vento - (EP) 73

Tabela 5.2 - Forças de arrasto oriundas do vento, nas direções X e Y, por pavimento (EP).

Tabela 5.3 - Forças devido ao desaprumo, nas direções X e Y, por pavimento - (EP).. 74

Tabela 5.4 - PIS-EP: $N_{k, v e r t}$ e $\eta_{k, v e r t}$ ao nível da fundação - Caso A. 76

Tabela 5.5 - EP: Carga vertical total nos lintéis em apenas um pavimento - Caso B... 76

Tabela 5.6 - PIS-EP: $N_{k, v e r t}$ e $\eta_{k, v e r t}$ ao nível da fundação - Caso B. 77

Tabela 5.7 - GIP-EP: $N_{k, v e r t}$ e $\eta_{k, v e r t}$ ao nível da fundação - Caso A. 78

Tabela 5.8 - GIP-EP: $N_{k, v e r t}$ e $\eta_{k, v e r t}$ ao nível da fundação - Caso B. 78

Tabela 5.9 - MPT-EP: $N_{k, v e r t}$ e $\eta_{k, v e r t}$ ao nível da fundação 79 
Tabela 5.10 - MEF20-EP e MEF40-EP: $N_{k, v e r t}$ e $\eta_{k, v e r t}$ ao nível da fundação - Caso A.. 80

Tabela 5.11 - MEF20-EP e MEF40-EP: $N_{k, v e r t}$ e $\eta_{k, v e r t}$ ao nível da fundação - Caso B.. 80

Tabela 5.12 - EP: Comparação de $N_{k, v e r t}$ ao nível da fundação - Caso A. 81

Tabela 5.13 - EP: Comparação de $N_{k, v e r t}$ ao nível da fundação - Caso B 81

Tabela 5.14 - Comparação de $M_{k, y}$ entre MEF20 x MPT no $1^{\circ}$ pav. da PH01. 84

Tabela 5.15 - Comparação de $N_{k, z}$ entre MEF20 e MPT nos níveis mais solicitados da PH01 nos casos A e B. 85

Tabela 5.16 - Comparação de $M_{k, x}$ entre MEF20 x MPT no $1^{\circ}$ pav. da PV01. 89

Tabela 5.17 - Comparação do $N_{k, z}$ entre MEF20 x MPT nos níveis mais solicitados da PV01 nos casos A e B. 89

Tabela 5.18 - Comparação da máxima $N_{C d, z}$ entre MEF20 x MPT da PH01. 94

Tabela 5.19 - Comparação do $\sigma_{C d}$ entre MEF20 x MEF40 x MPT ao nível 0,00m da PH01. 94

Tabela 6.1 - Cálculo da força de arrasto do vento nas direções X e Y - (EE). 103

Tabela 6.2 - Cálculo da força de desaprumo nas direções X e Y - (EE). 103

Tabela 6.3 - Valores das áreas de influência e suas respectivas cargas - (EE). 107

Tabela 6.4 - EE: Carga vertical total nos lintéis em apenas um pavimento tipo. 108

Tabela 6.5 - PIS-EE: $N_{k, v e r t}$ e $\eta_{k, v e r t}$ ao nível da fundação 109

Tabela 6.6 - GIP-EE - Cargas por grupo: $N_{k, v e r t}$ e $\eta_{k, v e r t}$ ao nível da fundação. 110

Tabela 6.7 - GIP-EE - Cargas por paredes: $N_{k, v e r t}$ e $\eta_{k, v e r t}$ ao nível da fundação........ 110 Tabela 6.8 - MPT-EE: $N_{k, v e r t}$ e $\eta_{k, v e r t}$ ao nível da fundação 
Tabela 6.9 - MEF-EE: $N_{k, v e r t}$ e $\eta_{k, v e r t}$ ao nível da fundação.

Tabela 6.10 - EE: Comparação de $N_{k, v e r t}$ ao nível da fundação.

Tabela 6.11 - Estudo para a formulação de $C_{A H}$ - Edifício exemplo com 15 pavimentos.

Tabela $6.12-\eta_{d, \text { resist }}$ conforme AS 3600:2001. 125

Tabela 6.13 - $\eta_{d, \text { resist }}$ conforme AS 3600:2009. 125

Tabela $6.14-\eta_{d, \text { resist }}$ conforme ACI 318:2011. 126

Tabela $6.15-\eta_{d, \text { resist }}$ conforme EN 1992:2004 126

Tabela $6.16-\eta_{d, \text { resist }}$ conforme NBR 16055:2012 127

Tabela $6.17-\eta_{C d, e s t} \times \eta_{d, \text { resist }}$ para paredes com $10 \mathrm{~cm}$ de espessura. 128

Tabela $6.18-\eta_{C d, \text { est }} \times \eta_{d, \text { resist }}$ para paredes com $12 \mathrm{~cm}$ de espessura. 131

Tabela 6.19 - Comparação entre os esforços máximos característicos da PH16. 134

Tabela 6.20 - Comparação entre os esforços máximos característicos da PV08 136

Tabela 6.21 - Comparação entre os esforços máximos característicos da PV15. 137

Tabela 6.22 - Comparação dos máximos $M_{k, y}$ e $M_{C d, y}$ nas paredes PH13, PH16 e PH34.

Tabela 6.23 - Comparação dos máximos $M_{k, x}$ e $M_{C d, x}$ nas paredes PV08, PV12 e PV15. 139

Tabela 6.24 - Comparação dos máximos $N_{k, z}$ e $N_{C d, z}$ nas paredes PH13, PH16, PH34, PV08, PV12 e PV15................................................................................................... 142

Tabela 6.25 - Verificação ao dimensionamento quanto à tensão normal de compressão. 
Tabela 6.26 - Verificação ao dimensionamento quanto à força cortante na alma das paredes de contraventamento.

Tabela 6.27 - Verificação da tensão de cisalhamento em algumas interfaces verticais.

Tabela 6.28 - Verificação das translações horizontais - (EE). 156

Tabela 6.29 - Verificação das translações horizontais considerando a CF - (EE)....... 158

Tabela 6.30 - Cálculo de $\gamma_{z, x}$ 159

Tabela 6.31 - Cálculo de $\gamma_{z, y}$ 159

Tabela 6A-1 - Estudo para a formulação de $\mathrm{C}_{\mathrm{AH}}$ - Edifício exemplo com 12 pavimentos. 169

Tabela 6A-2 - Estudo para a formulação de $C_{A H}$ - Edifício exemplo com 10 pavimentos. 169

Tabela 6A-3 - Estudo para a formulação de $C_{A H}$ - Edifício exemplo com 8 pavimentos. 170

Tabela 6A-4 - Estudo para a formulação de $C_{A H}$ - Edifício exemplo com 5 pavimentos. 170

Tabela 6A-5 - Estudo para a formulação de $\mathrm{C}_{\mathrm{AH}}$ - Edifício exemplo com 2 pavimentos. 171

Tabela 6B-1 - EE: Carga vertical total nos lintéis em apenas um pavimento tipo $(\mathrm{t}=12 \mathrm{~cm})$.

Tabela 6B-2 - PIS-EE: $N_{k, v e r t}$ e $\eta_{k, v e r t}$ ao nível da fundação (t=12cm). 173

Tabela 6B-3 - GIP-EE - Cargas por grupo: $N_{k, v e r t}$ e $\eta_{k, v e r t}$ ao nível da fundação $(\mathrm{t}=12 \mathrm{~cm})$.

Tabela 6B-4 - GIP-EE - Cargas por paredes: $N_{k, v e r t}$ e $\eta_{k, v e r t}$ ao nível da fundação $(\mathrm{t}=12 \mathrm{~cm})$.

Tabela 6B-5 - MPT-EE: $N_{k, v e r t}$ e $\eta_{k, v e r t}$ ao nível da fundação (t=12cm). 175

Tabela 6B-6 - MEF-EE: $N_{k, v e r t}$ e $\eta_{k, v e r t}$ ao nível da fundação (t=12cm). 176 
Tabela 6B-7 - EE: Comparação de $N_{k, v e r t}$ ao nível da fundação (t=12cm).

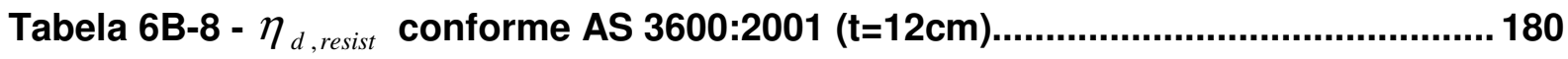

Tabela 6B-9 $-\eta_{d, \text { resist }}$ conforme AS 3600:2009 (t=12cm)............................................ 180

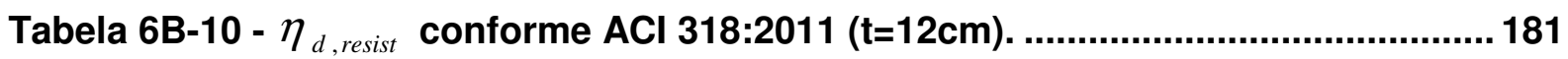

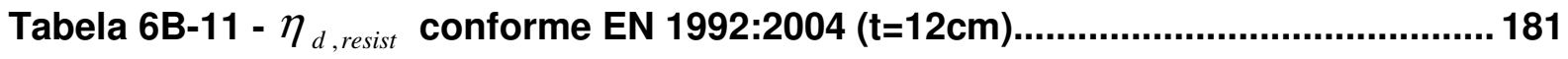

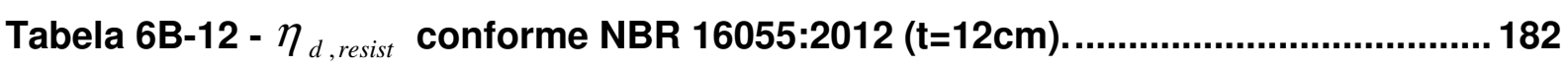




\section{SUMÁRIO}

1 INTRODUÇÃO.................................................................................................

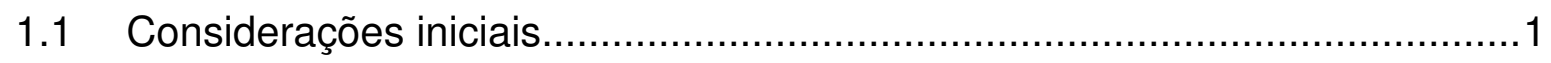

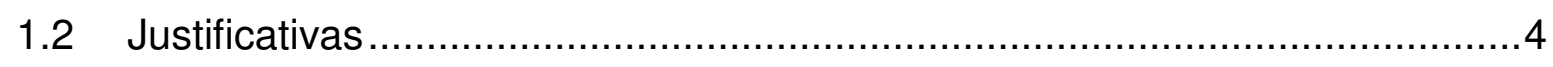

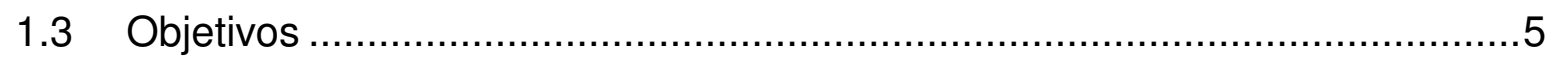

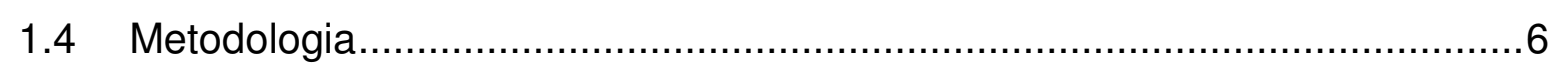

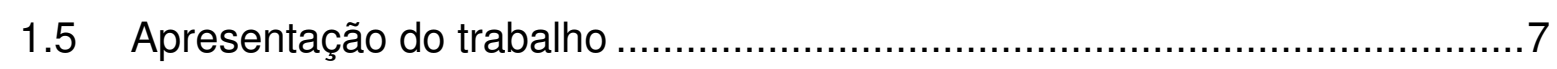

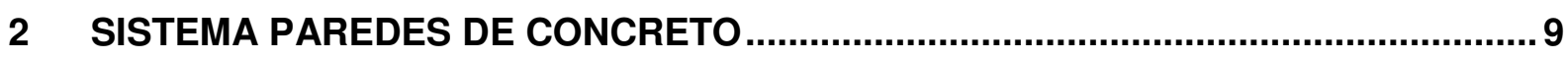

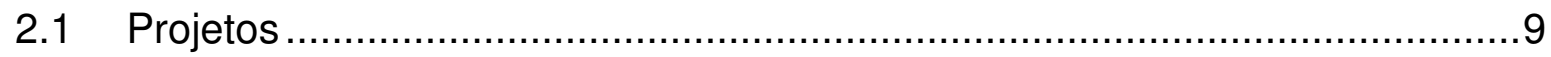

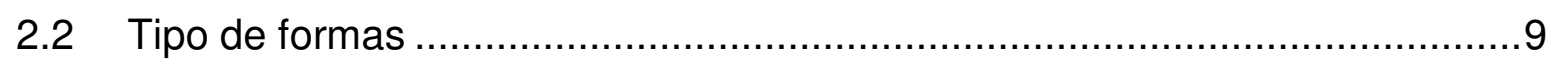

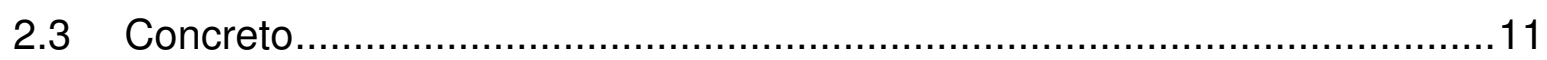

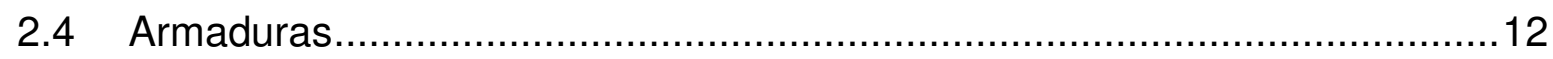

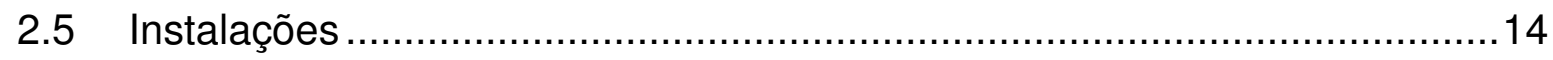

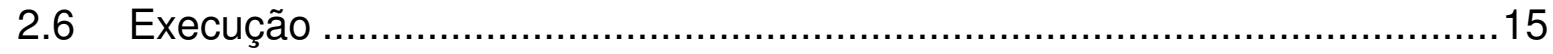

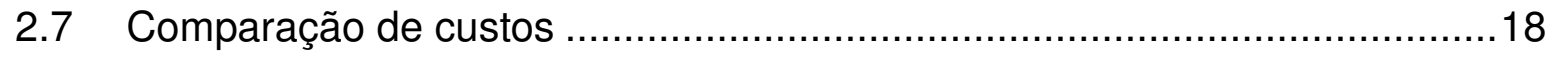

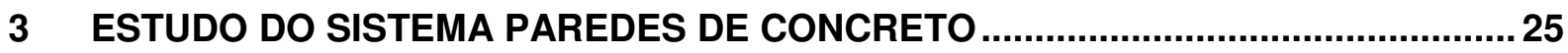

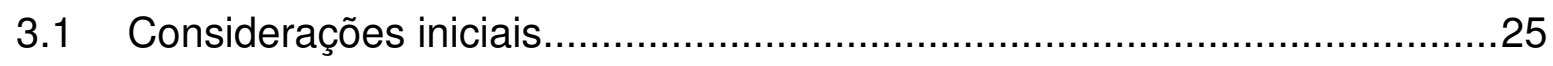

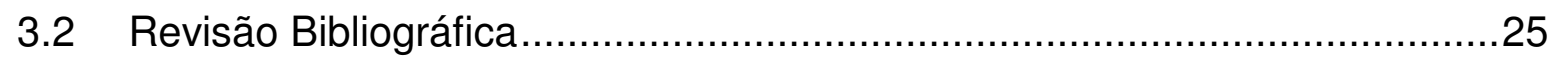

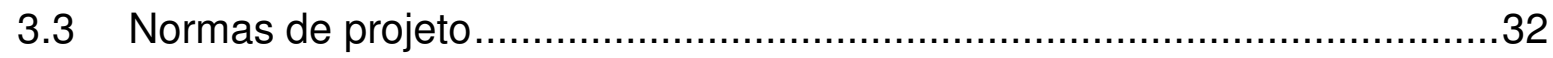

3.3.1 AS 3600:2009 - Concrete Structures ......................................... 33

3.3.2 ACl 318:2011 - Building Code Requirement for Structural Concrete ....35

3.3.3 EN 1992 Eurocode 2:2004 - Design of Concrete Structure ..................37

3.3.4 ABNT NBR 16055:2012 - Paredes de concreto moldada no local para a construção de edificações - Requisitos e procedimentos..............................40

4 MODELOS DE CÁLCULO.............................................................................. 48

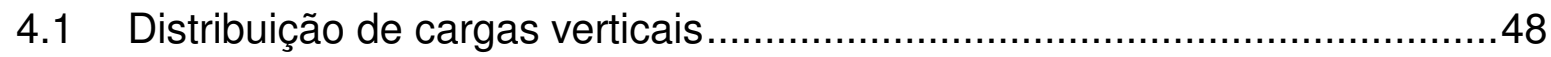

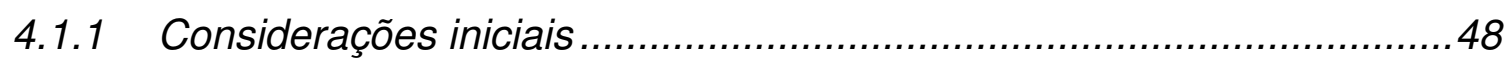

4.1.2 Ações das lajes...................................................................... 49 


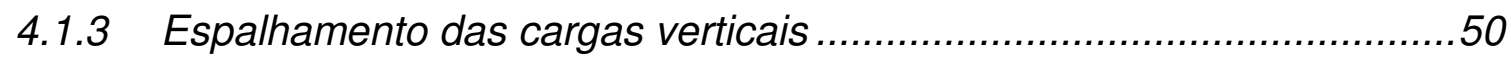

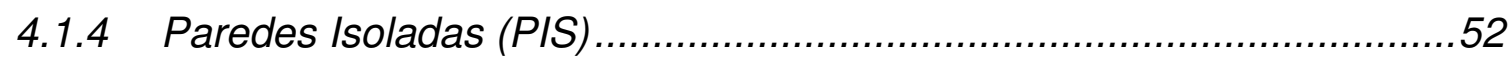

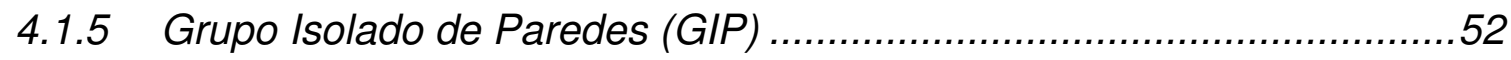

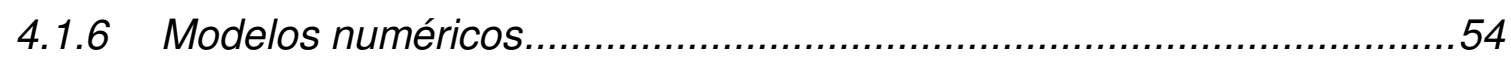

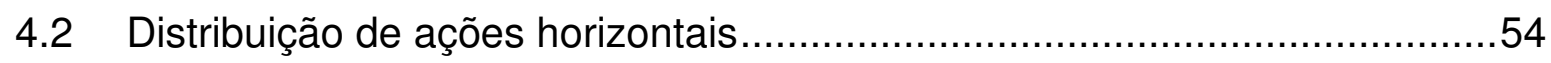

4.2.1 Considerações iniciais .....................................................................

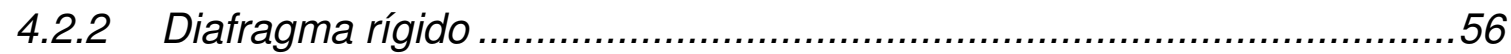

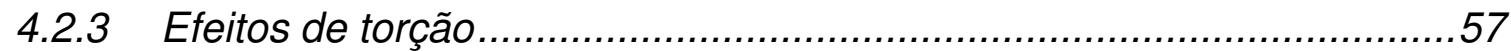

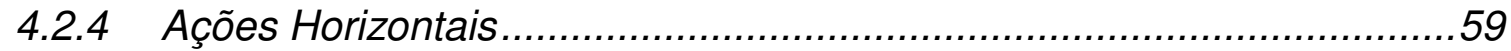

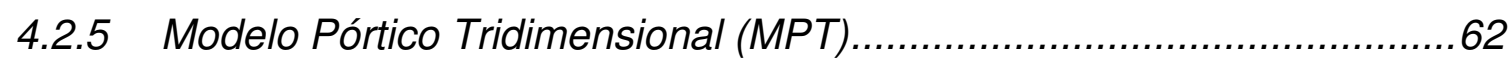

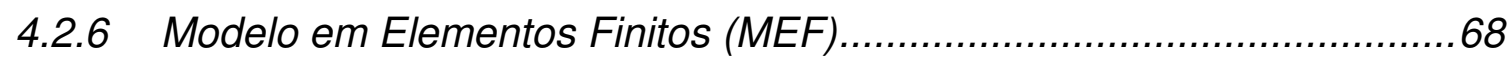

4.2.7 Consideração de abas em paredes de contraventamento ....................69

4.3 Propriedades mecânicas do concreto .......................................................71

5 CONSOLIDAÇÃO DOS MODELOS DE CÁLCULO ……….................................... 72

5.1 Características gerais do edifício estudo preliminar (EP) ........................72

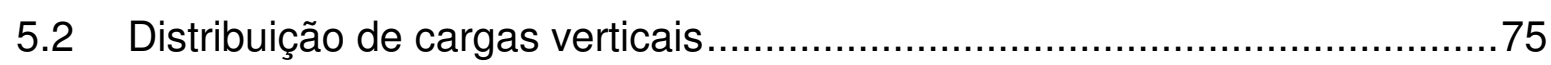

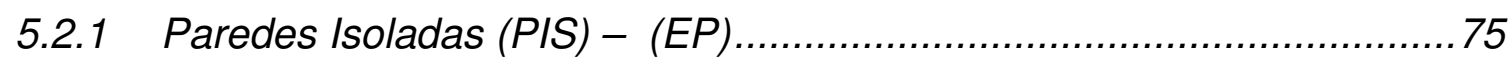

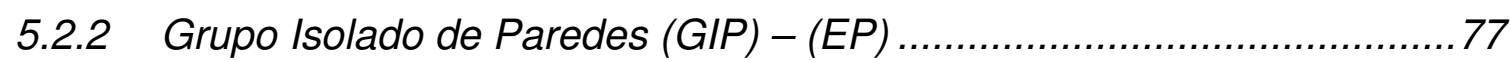

5.2.3 Modelo Pórtico Tridimensional (MPT) - (EP) ................................... 78

5.2.4 Modelo em Elementos Finitos (MEF) - (EP) …….......................... 79

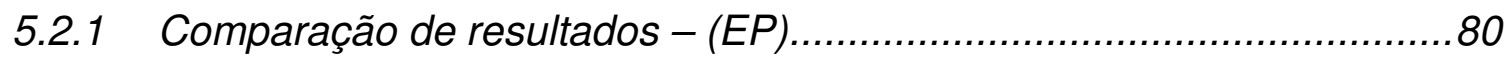

5.3 Esforços solicitantes devido às ações horizontais .....................................

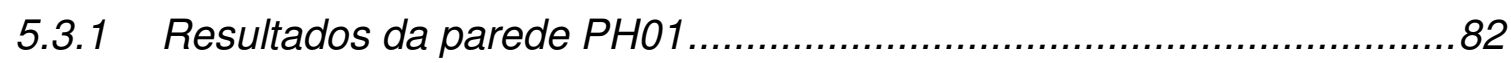

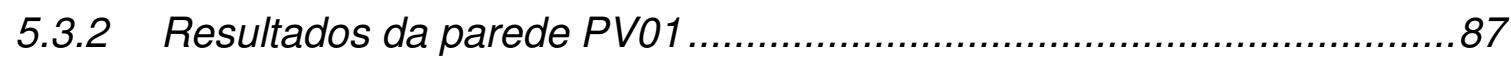

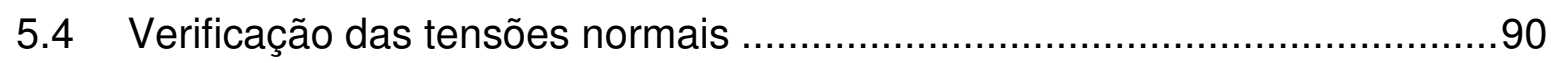

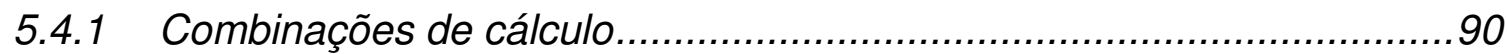

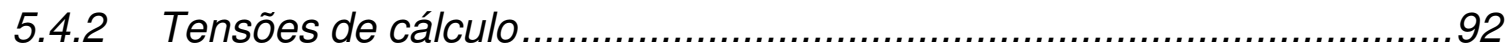

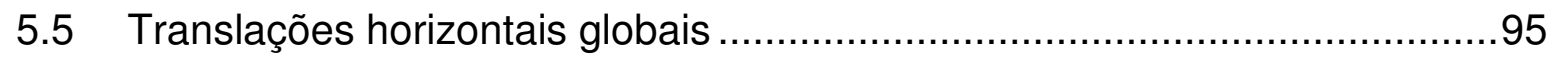

5.6 Discussões sobre os resultados do edifício estudo preliminar .....................97

6 EDIFÍCIO EXEMPLO PARA O ESTUDO DE CASO ..................................................98

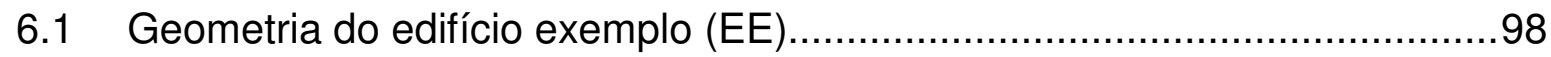




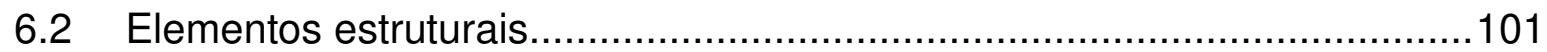

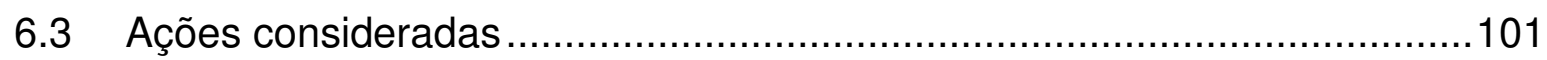

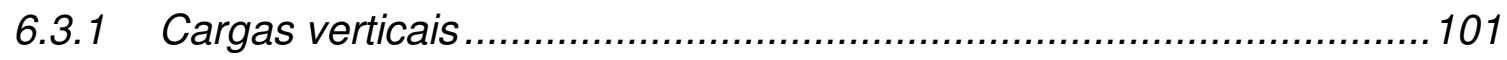

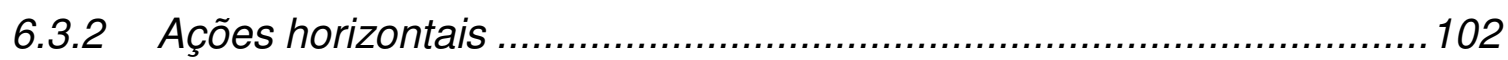

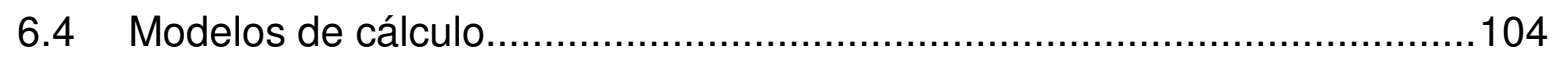

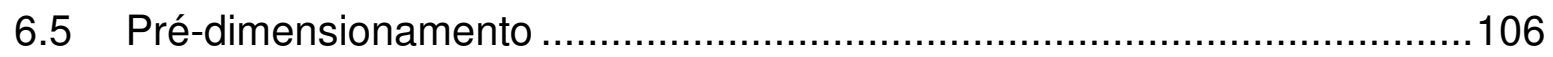

6.5.1 Paredes Isoladas (PIS) - (EE) ............................................... 107

6.5.2 Grupo Isolado de Paredes (GIP) - (EE) .....................................110

6.5.3 Modelo Pórtico Tridimensional (MPT) - (EE) .................................111

6.5.4 Modelo em Elementos Finitos - (EE) ......................................... 112

6.5.5 Comparação da distribuição de cargas verticais - (EE) ......................112

6.5.6 Estimativa da máxima tensão normal de compressão.........................116

6.5.7 Verificação ao pré-dimensionamento ………….............................. 123

6.6 Esforços solicitantes devido às ações horizontais - edifício exemplo........132

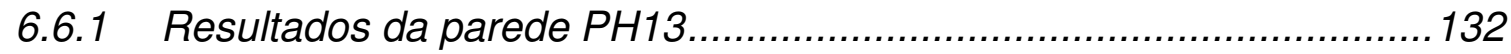

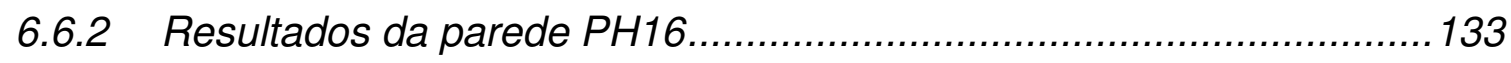

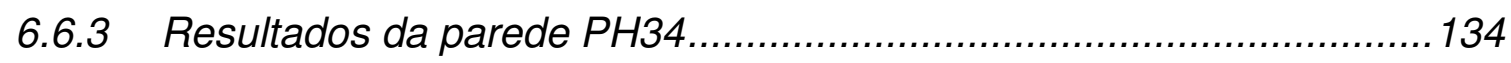

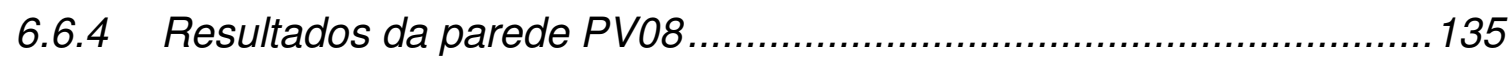

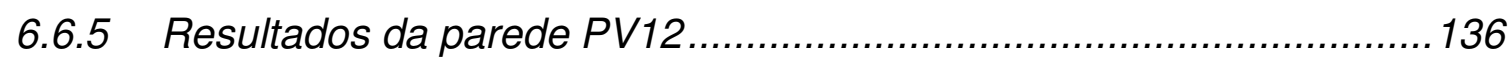

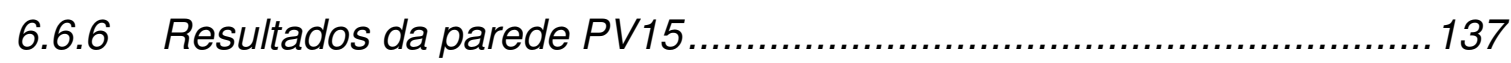

6.7 Verificação da máxima tensão normal de compressão ............................138

6.7.1 Resultados de cálculo considerando a combinação de ações $C_{1} \ldots \ldots .138$

6.7.2 Discussões sobre os resultados .........................................................143

6.8 Verificação da eventual máxima tensão normal de tração........................145

6.8.1 Resultados de cálculo considerando a combinação de ações $C_{2} \ldots \ldots . .145$

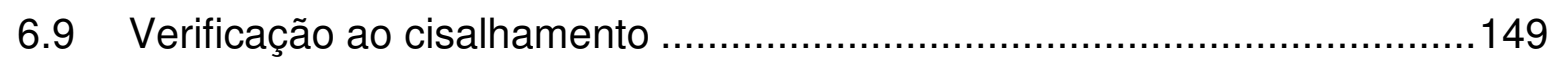

6.9.1 Verificação da força cortante nas almas das paredes de

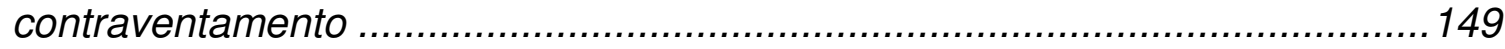

6.9.2 Verificação da força cortante na interface vertical do encontro de paredes.

6.10 Verificação quanto ao Estado Limite de Serviço de deformações

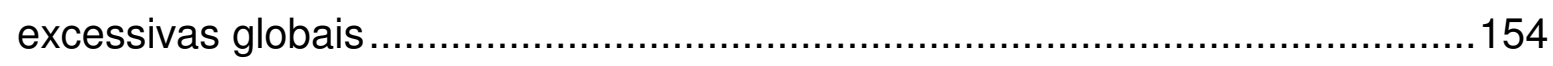

6.11 Verificação da estabilidade global......................................................158 


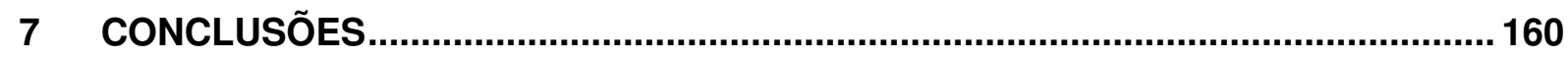

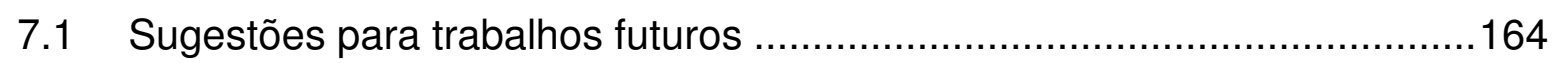

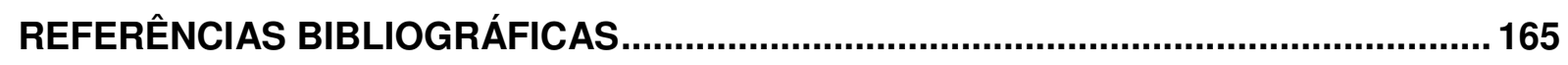

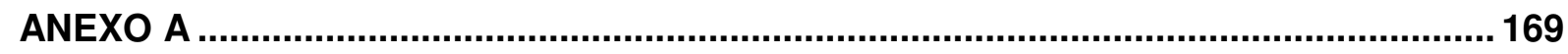

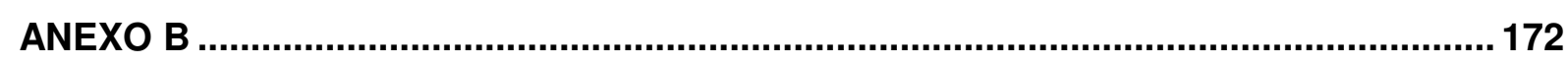

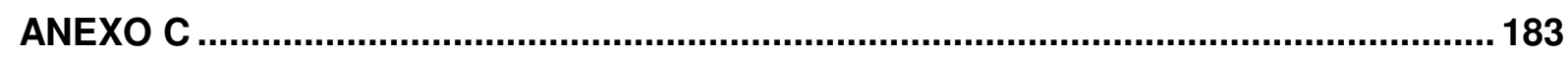




\section{INTRODUÇÃO}

\subsection{Considerações iniciais}

O sistema construtivo Paredes de Concreto teve sua solidificação confirmada no Brasil com a publicação da norma ABNT NBR 16055:2012- Parede de concreto moldada no local para a construção de edificação - Requisitos e procedimentos, em 10 de abril de 2012.

Como o próprio nome da norma diz, o sistema é voltado para construções, em sua maioria residenciais, cuja estrutura é composta por paredes de concreto armado moldadas no local, com ou sem lajes de concreto armado (uma casa térrea, por exemplo, pode ser feita com as paredes de concreto armado sem as lajes desse material para a cobertura).

Segundo Sacht, Rossignolo e Bueno (2011), a utilização de sistemas construtivos não convencionais no Brasil foi impulsionada após a extinção do Banco Nacional de Habitação (BNH), em 1986, período em que as construtoras buscavam novas tecnologias que pudessem racionalizar a produção de edifícios, otimizando suas atividades e minimizando seus custos. Dentre os sistemas construtivos desenvolvidos nesse período, destaca-se o sistema de painéis monolíticos moldados in loco.

Em 1980 a empresa brasileira Gethal, fundada em 1946 em Caxias do Sul, desenvolveu a tecnologia de Paredes e Lajes em Concreto Celular moldadas no local, produto que demonstrou ser melhor tecnicamente e de menor custo comparado ao concreto convencional até então utilizado.

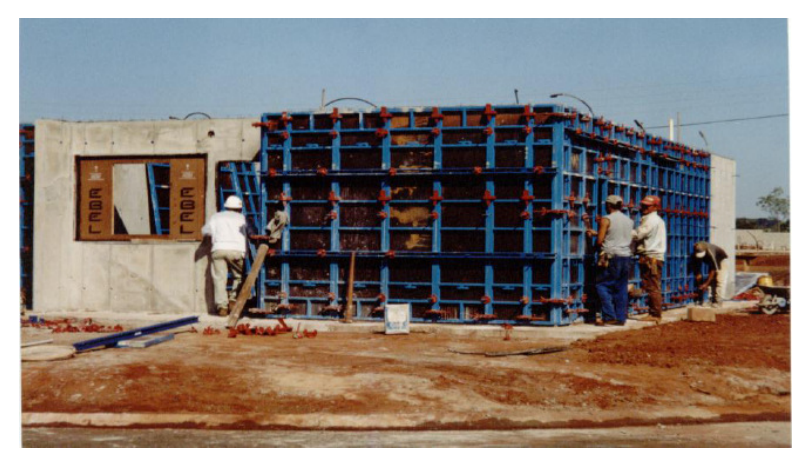

Figura 1.1 - Sistema Gethal: exemplo de paredes de concreto celular executados com forma metálica (GETHAL). 
Outro exemplo foi a importação da tecnologia criada pela empresa francesa Outinord. Seu sistema de paredes de concreto moldadas no local, utilizando formas metálicas tipo túnel, permitia executar simultaneamente paredes e lajes.

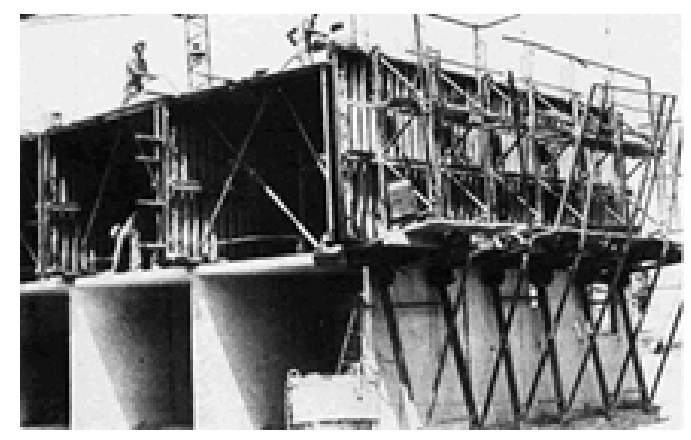

Figura 1.2 - Sistema Outinord: exemplo de paredes e lajes concretadas com a utilização de formas metálicas tipo túnel (Fonte: Universidad Nacional de Colombia, archivo particular).

Os sistemas Gethal e Outinord são exemplos pioneiros do sistema Paredes de Concreto no Brasil, e que já visavam à industrialização da construção. Entretanto, o alto investimento inicial necessário, a pouca flexibilidade do sistema na época e as limitações do sistema financeiro da habitação daquele período provocaram uma descontinuidade dessa tecnologia no Brasil.

Em 2009 o Governo Federal brasileiro criou o programa Minha Casa Minha Vida 1, que tinha como objetivo a construção de um milhão de moradias. Em seguida, em 2012, o programa Minha Casa Minha Vida 2 foi anunciado como o maior programa habitacional do Brasil até então, tendo como meta a construção de dois milhões de casas e apartamentos até 2014.

Atualmente a conjuntura socioeconômica do país justifica a criação dos programas habitacionais citados, tendo em vista o alto déficit habitacional, que está em torno de 5,5 milhões de moradias (Fonte: Ministério das Cidades), a alta demanda da população mais jovem que constituirá compradores em potencial nos próximos anos, o aumento do crédito imobiliário, sendo que esse quando relacionado ao PIB nacional gera um índice próximo a 5,1 (o índice americano é 72,7; Fonte: BCB/Banco Mundial) e taxas de juros declinantes.

Desse modo, o cenário nacional demanda construções de qualidade, em grande quantidade, realizadas no menor tempo possível. É inevitável atrelar novamente o conceito da industrialização da construção civil como estratégia de ação aos desafios apresentados. Por esse motivo, o sistema Paredes de Concreto é 
um dos processos construtivos mais indicados, não somente para suprir a necessidade de moradia da população de baixa renda, mas também como forma alternativa de construir edificações de maneira sustentável, econômica e com qualidade.

Conhecido por gerar alta produtividade, reduzir os desperdícios em obra, ser versátil, ter um custo $\mathrm{x}$ benefício bastante competitivo em relação a outros sistemas construtivos, possibilitar maior controle de qualidade e caracterizar um exemplo de industrialização da construção civil, o sistema Paredes de Concreto requer alguns pré-requisitos essenciais para que suas características sejam aproveitadas.

Primeiramente é importante que os projetos arquitetônicos sejam pensados para o sistema Paredes de Concreto. A padronização das unidades, utilização de simetrias e medidas modulares, facilita desde a fabricação da forma que receberá o concreto até a montagem delas em obra. Para aproveitar a capacidade de alta produtividade do sistema, é interessante que os empreendimentos sejam de grande porte e caracterizados por um alto índice de repetição de edificações. A escolha do concreto, tipo de armação das paredes e tipo de forma para moldar o concreto são fundamentais para obtenção da qualidade esperada, no tempo esperado. É importante que a obra tenha todos os insumos nos momentos apropriados, pois os ciclos de concretagem de paredes e lajes ocorrem diariamente. Por fim, é necessário que a cadeia produtiva esteja completamente interligada, projetistas, fornecedores de matéria prima e construtores, caracterizando assim uma logística e planejamento sistêmico, típico do setor industrial.

Desde meados de 2007, o número de unidades entregues pelo sistema Paredes de Concreto só vem aumentando. Não coincidentemente, em 2007, a ABCP (Associação Brasileira de Cimento Portland), Abesc (Associação Brasileira das Empresas de Serviços de Concretagem) e o IBTS (Instituto Brasileiro de Telas Soldadas) começaram a desenvolver ações de pesquisa sobre edificações feitas com parede de concreto moldada in loco, tomando como exemplo alguns empreendimentos realizados na Colômbia, país onde o sistema Paredes de Concreto já era consolidado. Uma das ações foi a criação do Grupo Paredes de Concreto o qual teve a participação de projetistas estruturais, professores de universidades e outros profissionais da cadeia produtiva, com o objetivo de criar um texto pré-normativo abordando os procedimentos e cálculos para edifícios em parede de concreto de até 5 pavimentos. $O$ fruto deste trabalho já é percebido hoje, 
principalmente com a publicação da norma brasileira NBR 16055:2012, a qual não limita o número de pavimentos para a aplicação do sistema.

A Figura 1.3 apresenta a porcentagem dos métodos construtivos utilizados no mercado da construção civil brasileira por 39 grandes construtoras (considerando a pesquisa feita em agosto de 2012). Nota-se que o sistema Paredes de Concreto corresponde a uma parcela significativa do mercado da construção de habitações.

Portanto, o presente trabalho demonstra-se interessante por apresentar alguns modelos possíveis para o desenvolvimento do projeto estrutural voltado para o sistema Paredes de Concreto, num momento em que esse método vem sendo cada vez mais utilizado na construção civil brasileira.

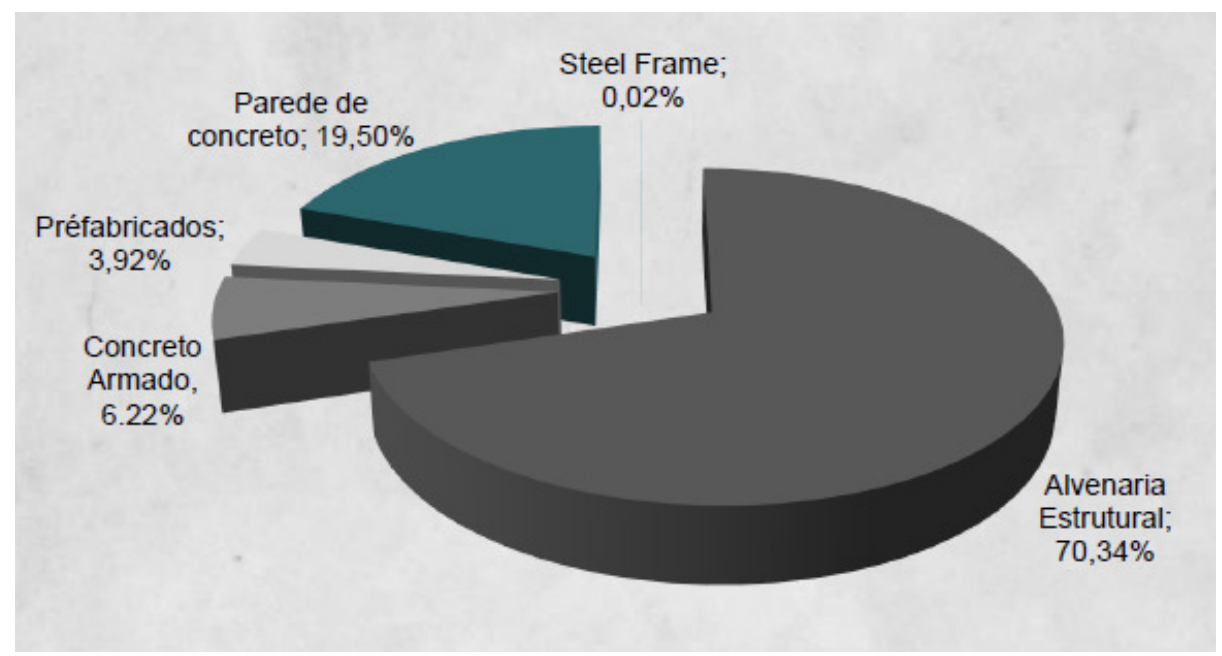

Figura 1.3 - Porcentagem dos métodos executivos praticados nos empreendimentos de 39 grandes construtoras (Fonte: ABCP ago/2012);

\subsection{Justificativas}

Por se tratar de um sistema estrutural diferente, o método construtivo Paredes de Concreto aborda conceitos que vão além da NBR 6118:2007 - Projeto de estruturas de concreto - Procedimentos. Há alguns anos, a prática de se recorrer a referências e normas internacionais, por não se ter até então uma norma brasileira que tratasse do assunto, era alternativa para os projetistas estruturais desenvolverem seus trabalhos.

Após a publicação da NBR 16055:2012, o mercado de construção de casas e edifícios em paredes de concreto também é estimulado devido ao fato das construtoras não precisarem mais apresentar o Documento de Avaliação Técnica 
(DATec). Esse certificado fornecido, se aprovado pelo Sistema Nacional de Avaliações Técnicas (Sinat), um órgão do Ministério das Cidades, garante o desempenho e a qualidade da construção na falta de uma norma brasileira. Esse processo era demorado e podia inviabilizar e escolha pelo sistema. Além disso, e tão importante quanto, projetistas estruturais ganharam mais um parâmetro para dimensionar suas estruturas em Paredes de Concreto.

A comparação dos procedimentos para o dimensionamento das paredes de concreto indicados na NBR16055:2012, com os equivalentes indicados em normas internacionais, é de extrema importância para se adquirir sensibilidade quanto aos parâmetros de uma nova norma.

Outro fator de extrema importância é a consolidação de modelos de cálculos alternativos para o sistema Paredes de Concreto, já utilizados em métodos construtivos análogos como a Alvenaria Estrutural, por exemplo.

Portanto, o presente trabalho torna-se útil ao meio técnico-científico por apresentar comparações entre resultados obtidos por algumas normas internacionais com a NBR 16055:2012. Além disso, comparam-se modelos de cálculo distintos ao se fazer a análise estrutural de edifícios em Paredes de Concreto.

\subsection{Objetivos}

O objetivo principal deste trabalho é avaliar por meio da comparação de resultados, os modelos de cálculo, utilizados para o pré-dimensionamento e dimensionamento de paredes de concreto armado, moldadas no local. Este tipo de estrutura tem sido bastante utilizada em edifícios construídos pelo sistema Paredes de Concreto.

Para atingir o objetivo principal, os objetivos específicos foram definidos, como:

- avaliar os modelos de cálculo para a distribuição de cargas verticais nas paredes;

- verificar o pré-dimensionamento da espessura das paredes conforme normas AS 3600:2001, AS3600:2009, ACl 318:2011, EN 1992:2004 e NBR 16055:2012 e avaliar os resultados dessas normas; 
- avaliar os modelos numéricos para a distribuição das ações horizontais nas paredes;

- verificar o dimensionamento das paredes considerando a combinação de ações verticais e horizontais;

- verificar o estado limite de serviço das deformações excessivas globais;

- avaliar a estabilidade global.

\subsection{Metodologia}

Inicialmente apresentam-se as características do método construtivo chamado sistema Paredes de Concreto e resultados de pesquisas que compararam a viabilidade econômica entre o sistema Paredes de Concreto com outros métodos construtivos.

Em seguida, uma revisão bibliográfica é feita sobre a aplicação e a comparação dos dois modelos numéricos utilizados neste trabalho e sobre as expressões de resistência última à compressão propostas pelas normas AS 3600:2001, AS3600:2009, ACI318:2011, EN 1992:2004 e NBR 16055:2012.

Os fundamentos teóricos dos modelos de cálculo Paredes Isoladas (PIS), Grupo Isolado de Paredes (GIP), Modelo Pórtico Tridimensional (MPT) e Modelo em Elementos Finitos (MEF) são apresentados e posteriormente consolidados aplicando-os em um edifício hipotético, chamado edifício estudo preliminar. Observase que o MPT e o MEF são modelos numéricos.

Um estudo de caso é realizado, no chamado edifício exemplo (EE), no qual são comparados os resultados dos modelos de cálculo desenvolvidos, assim como resultados obtidos pelas normas citadas, a fim de serem atingidos os objetivos específicos.

Primeiramente, a distribuição de cargas verticais é realizada de acordo com cada modelo de cálculo. As forças normais ao nível da fundação são comparadas a fim de verificar as diferenças obtidas entre cada modelo considerado. O prédimensionamento das paredes é realizado comparando a estimativa da máxima tensão de compressão nas paredes com a resistência última à compressão calculada pelas normas AS 3600:2001, AS3600:2009, ACI 318:2011, EN 1992:2004 e NBR 16055:2012. Nesta etapa, a recente norma brasileira é comparada com as 
demais com o objetivo de avaliar as diferenças entre elas, e adquirir sensibilidade da nova norma brasileira.

Em seguida, os esforços solicitantes característicos das paredes do EE, obtidos pelos modelos numéricos e considerando apenas as ações horizontais, são comparados por meio de seus diagramas, a fim de avaliar as diferenças entre eles na distribuição das ações horizontais.

O dimensionamento das paredes do EE, considerando a combinação de ações verticais e horizontais, é realizado quanto às máximas tensões normais de compressão e tração e às máximas tensões tangencias, conforme a NBR 16055:2012.

O Estado Limite de Serviço das deformações excessivas globais é verificado ao longo da altura do edifício exemplo, por meio da comparação das translações horizontais obtidas nos modelos numéricos com a translação limite definida pela NBR 6118:2007.

Finalmente, a análise da estabilidade global do edifício exemplo é feita calculando-se o coeficiente $\gamma_{z}$ em suas direções principais.

Os modelos numéricos (MEF e MPT) foram desenvolvidos no software SAP2000, baseado no Método dos Elementos Finitos, considerando análise elástica linear. A interação entre o solo e a estrutura não foi considerada.

\subsection{Apresentação do trabalho}

Este trabalho está dividido em sete capítulos, sendo que o primeiro aborda a as considerações iniciais, as justificativas, os objetivos e a metodologia do tema proposto.

No capítulo dois, as características intrínsecas ao sistema Paredes de Concreto, as quais são necessárias para que o método apresente suas vantagens em relação aos outros, são apresentadas. Resultados de pesquisas em que comparam o custo da construção de determinadas edificações, entre os métodos construtivos, incluindo o sistema Paredes de Concreto, são mostrados.

A revisão bibliográfica dos modelos numéricos e das normas de projetos utilizadas é apresentada no capítulo três, "Estudo sobre o sistema Paredes de Concreto". 
Todo fundamento teórico associado aos modelos de cálculo constam no quarto capítulo.

No capítulo cinco, os modelos de cálculo são empregados em um edifício hipotético, chamado edifício estudo preliminar, a fim de consolidar os fundamentos teóricos apresentados no capítulo quatro.

O estudo de caso é apresentado no capítulo seis, onde constam os resultados e comparações dos objetivos propostos, obtidos pelo desenvolvimento dos modelos de cálculo no edifício exemplo.

O sétimo capítulo apresenta a conclusão e sugestões para trabalhos futuros.

Por fim, são apresentadas as referências bibliográficas e os Anexos A a $C$, onde são apresentadas Tabelas e Figuras com resultados complementares. 


\section{SISTEMA PAREDES DE CONCRETO}

Paredes de Concreto é um sistema estrutural, composto por paredes autoportantes e, em geral, lajes maciças de concreto armado, sendo as paredes moldadas no local com formas removíveis. É um sistema que tem como características intrínsecas a alta produtividade, principalmente em empreendimentos de grande extensão e/ou alto índice de edificações repetidas e, a integração da cadeia produtiva de forma a tornar o método mais industrial possível. A seguir exemplifica-se algumas particularidades voltadas para o sistema Paredes de Concreto, de alguns setores da cadeia produtiva, a fim de potencializar os benefícios que o sistema é capaz de proporcionar.

\subsection{Projetos}

Como o sistema prima pela velocidade de execução, há algumas decisões de projeto que precisam ser tomadas de forma a atender esse requisito. Um exemplo que pode prejudicar a produtividade em obra é a existência de paredes de vedação que não são estruturais. Como o sistema proporciona o benefício em se ter todas as vedações prontas logo após a concretagem das paredes estruturais (pois a estrutura é composta por paredes que, consequentemente, vedam os ambientes) a existência de paredes de vedação não estruturais, construídas com blocos de alvenaria, por exemplo, pode atrapalhar significativamente a velocidade de execução da obra ao criar-se mais uma atividade que não seria necessária.

Outras medidas a fim de facilitar e otimizar a fabricação das formas, o que gera consequência direta na facilidade de montagem delas em obra, é a modulação de medidas, existência de simetria na geometria da edificação em planta, alinhamento de paredes e a padronização das distâncias entre pisos no caso de construções com mais de um pavimento.

\subsection{Tipo de formas}

A escolha do tipo de forma para moldar o concreto armado das paredes também é fundamental para potencializar os ganhos do sistema Paredes de 
Concreto. Os tipos de formas, segundo a ABCP (Associação Brasileira de Cimento Portland), são:

- formas metálicas: quadros e chapas em alumínio ou aço que estruturam o painel da forma e dão acabamento à peça concretada; quando feitas em alumínio são mais leves, diferentes de quando feitas em aço que as tornam pesadas. Nos dois casos, há grande durabilidade (Figura 2.1);

- formas metálicas com compensados: são compostas por quadros em aço ou alumínio e utilizam chapas de compensado de madeira ou material sintético para dar o acabamento na peça concretada; são mais pesadas que as formas em alumínio e mais leves das feitas com aço. A durabilidade é menor em relação a essas duas (Figura 2.2);

- formas plásticas: os quadros e chapas são feitos com plástico reciclável, tanto para a estruturação de seus painéis como para dar acabamento à peça concretada. Necessitam de contraventamento por estruturas metálicas. São tão leves quanto às formas de alumínio, no entanto tem baixa durabilidade. (Figura 2.3).

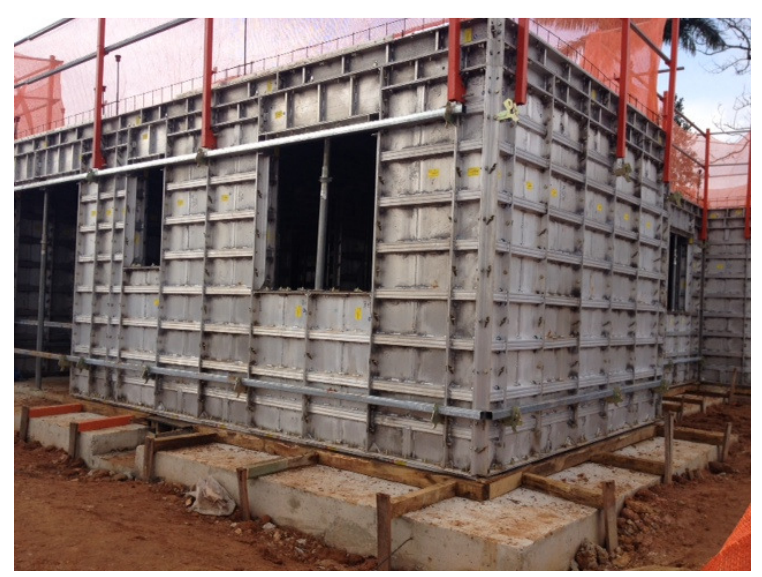

Figura 2.1 - Formas metálicas.

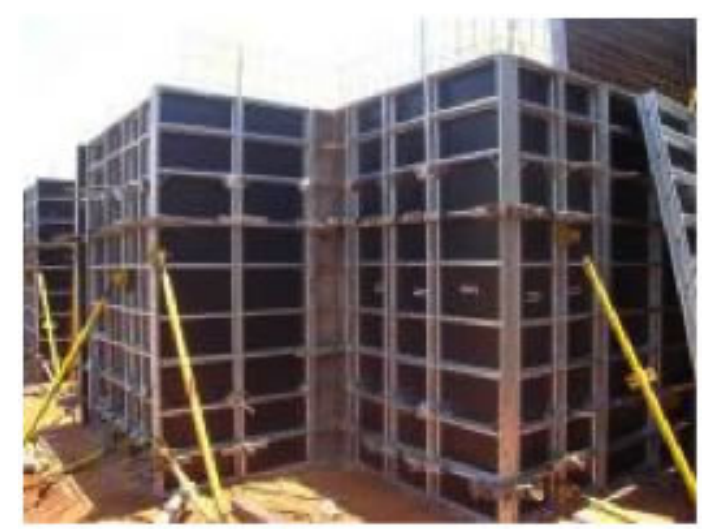

Figura 2.2 - Formas metálicas com compensado (ABCP). 


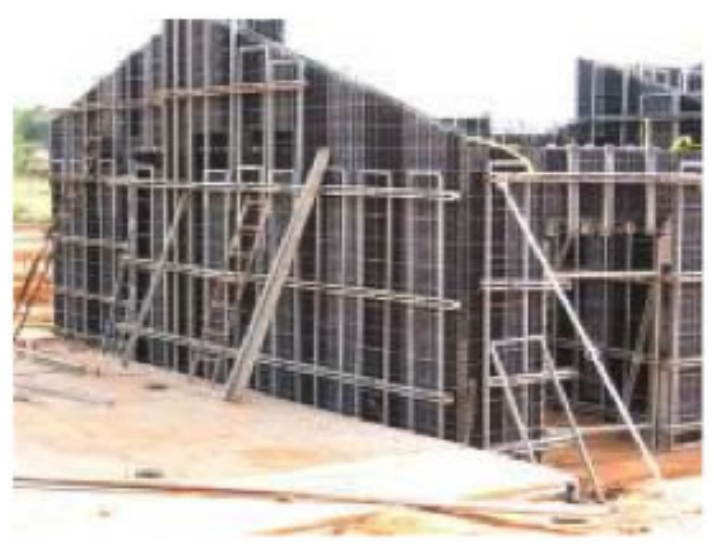

Figura 2.3 - Formas de plástico (ABCP).

Ao escolher o tipo de forma, a Abesc (Associação Brasileira das Empresas de Serviço de Concretagem) lista algumas características significativas que variam conforme o tipo:

- Produtividade de mão de obra na operação do conjunto;

- Peso por $\mathrm{m}^{2}$ dos painéis;

- Número de peças do sistema;

- Durabilidade da chapa e número de reutilizações;

- Durabilidade da estrutura (quadros);

- Modulação dos painéis;

- Flexibilidade diante das opções de projeto;

- Adequação à fixação de embutidos;

- Análise econômica e comercialização (locação, vendas, etc.);

- Suporte técnico do fornecedor.

\subsection{Concreto}

Além de seguir as especificações da NBR 6118:2007 - Projeto de estruturas de concreto, a NBR 16055:2012 - Parede de Concreto moldada no local para a construção de edificações, diz que a especificação do concreto para o sistema Paredes de Concreto deve apresentar:

a) resistência à compressão para desforma, compatível com o ciclo de concretagem. Geralmente a desforma ocorre 14 horas após a concretagem, sendo $f_{c 14 h}=3 \mathrm{MPa}$; 
b) resistência à compressão característica aos 28 dias $\left(f_{c k}\right)$. Geralmente especifica-se $f_{c k}$ não menor que $25 \mathrm{MPa}$, de forma que 14 horas após a concretagem o concreto já tenha atingido resistência de $3 \mathrm{MPa}$.

c) classe de agressividade do local de implantação da estrutura conforme NBR 12566 - Concreto de cimento Portland;

d) trabalhabilidade, a qual é medida pelo teste de abatimento do tronco de cone (slump test) conforme NBR NM 67 - Concreto (recomenda-se um valor entre 180 e $230 \mathrm{~mm}$ ), ou pelo espalhamento do concreto (slump flow), conforme NBR 15823-2 - Concreto autoadensável (recomenda-se um valor entre 660 e $750 \mathrm{~mm}$ ).

Outro aspecto importante é o controle do módulo de elasticidade, pois geralmente as lajes são maciças e concretadas em conjunto com as paredes. A partir do módulo obtido, define-se a quantidade de dias necessários para que as lajes fiquem escoradas.

Recomenda-se utilizar concreto autoadensável pela sua grande fluidez e plasticidade, características que eliminam a necessidade de vibrar o concreto. Além disso, sua alta viscosidade evita a segregação dos materiais.

\subsection{Armaduras}

Como a principal característica do sistema é a produtividade, o que só se consegue com velocidade de execução, o tipo de armadura das paredes é um fator significativo para a viabilidade do sistema Paredes de Concreto. Dessa maneira, opta-se como armadura principal das paredes, ou seja, aquela que é distribuída em toda parede, telas soldadas simples ou telas soldadas duplas, sempre em função do projeto estrutural. No primeiro caso, uma única tela é posicionada próximo ao eixo longitudinal da parede (Figura 2.4). No caso de telas duplas, duas telas são utilizadas, sendo que cada uma é posicionada na face da parede respeitando o cobrimento mínimo definido no projeto estrutural (Figura 2.5). Armaduras em vergalhões são utilizadas também, porém como função de reforço em apenas alguns pontos específicos, como o entorno de aberturas, bordas livres, periferia de furos, vergas, ou alguma região onde a tensão de tração seja alta e localizada. 


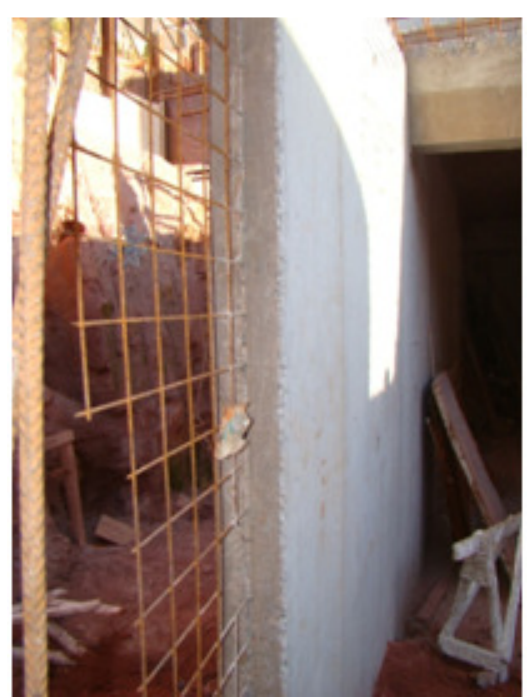

Figura 2.4 - Armadura com tela simples centrada na parede.

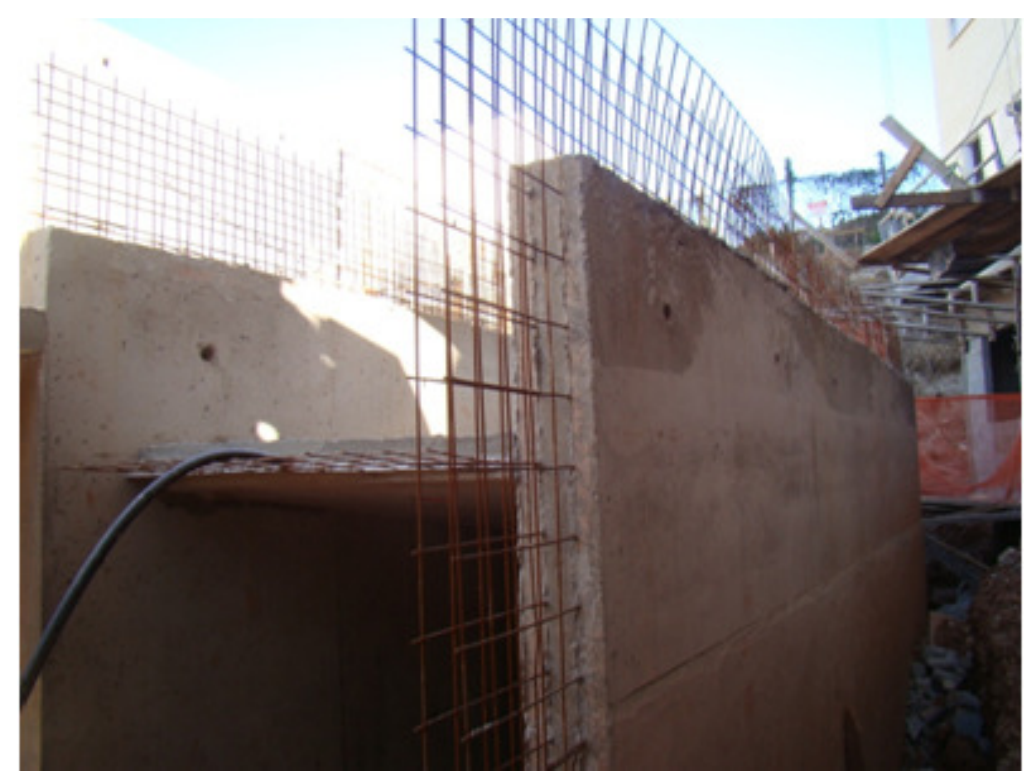

Figura 2.5 - Armadura com tela dupla, uma em cada face da parede, respeitando o cobrimento.

Em pilares, estribos horizontais são utilizados para evitar a instabilidade das barras de aço verticais sob compressão. Quando se opta pela solução em telas soldadas, não há estribos horizontais que evitem a instabilidade dos fios de aço verticais das telas sob compressão. Por essa razão, a NBR 16055:2012, inspirada no $\mathrm{ACl}$ 318:2011, limita a taxa geométrica de armadura vertical das paredes em $\rho \leq 1 \%$, a fim de garantir tal estabilidade apenas com o confinamento entre a armadura e o concreto.

Caso a armadura principal das paredes fosse em vergalhões de aço, armadores teriam que montar uma gaiola composta por barras verticais e barras horizontais, o que seria a alternativa às telas duplas, ou então montar uma malha de 
barras verticais e horizontais, o que seria a alternativa às telas simples. O processo seria mais demorado. A disposição da armadura na parede seria muito mais difícil em relação à simples atividade de se posicionar as telas soldadas nas demarcações das paredes. Portanto, as diferenças entre os dois tipos de armaduras são significativas quanto à velocidade de montagem.

Ressalta-se que a definição das áreas de aço é responsabilidade do projetista estrutural. Tal definição é feita em função dos esforços solicitantes da parede, controle da retração do concreto e também esforços oriundos da variação de temperatura.

\subsection{Instalações}

O sistema Paredes de Concreto permite que alguns elementos de instalações hidráulica e elétrica sejam embutidos nas paredes. No caso de tubulações verticais, a NBR 16055:2012 estabelece alguns limites que devem ser atendidos, como:

- diâmetro máximo de 50 mm;

- diâmetro menor que a metade da largura da parede;

- pressão interna menor que 0,3 MPa;

- a diferença de temperatura no contato entre a tubulação e o concreto não pode ultrapassar $15^{\circ} \mathrm{C}$;

- tubos metálicos não podem entrar em contato com as armaduras da parede a fim de evitar-se corrosão galvânica.

A Figura 2.6 mostra a fixação de eletrodutos na caixa elétrica. Percebe-se também que a utilização de telas soldadas ajuda a fixar elementos de instalações embutidos nas paredes. Quando as limitações acima não são atendidas, a utilização de shafts é uma boa alternativa.

Não são permitidas tubulações horizontais embutidas. 


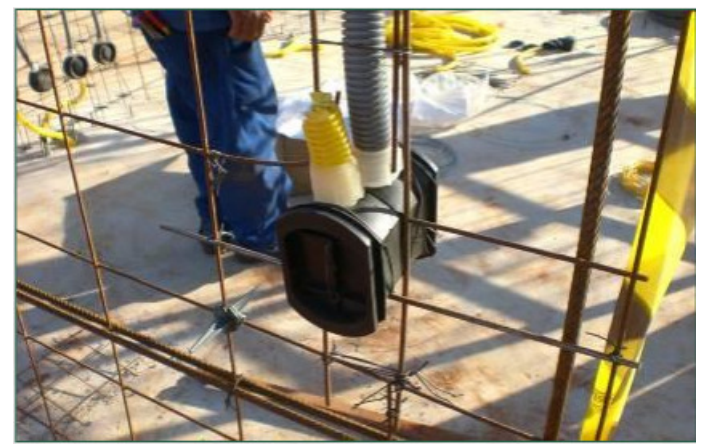

Figura 2.6 - Eletrodutos fixados na caixa elétrica que é posicionada com o auxílio da tela soldada (ABCP 2012).

Os elementos de esquadrias (batentes de portas e caixilhos de janelas) podem ser embutidos diretamente nos painéis das formas, ou então contramarcos (negativos) são posicionados dentro dos painéis, contornando a região das esquadrias, para que elas sejam colocadas após a concretagem da parede.

\subsection{Execução}

A seguir apresentam-se resumidamente as etapas executivas do sistema Paredes de Concreto, como indica a Comunidade da Construção.

a) Antes da montagem das formas, as fundações devem conter os arranques verticais das paredes, a localização das instalações sanitárias definidas e receber nivelamento rigoroso. (Figura 2.7).

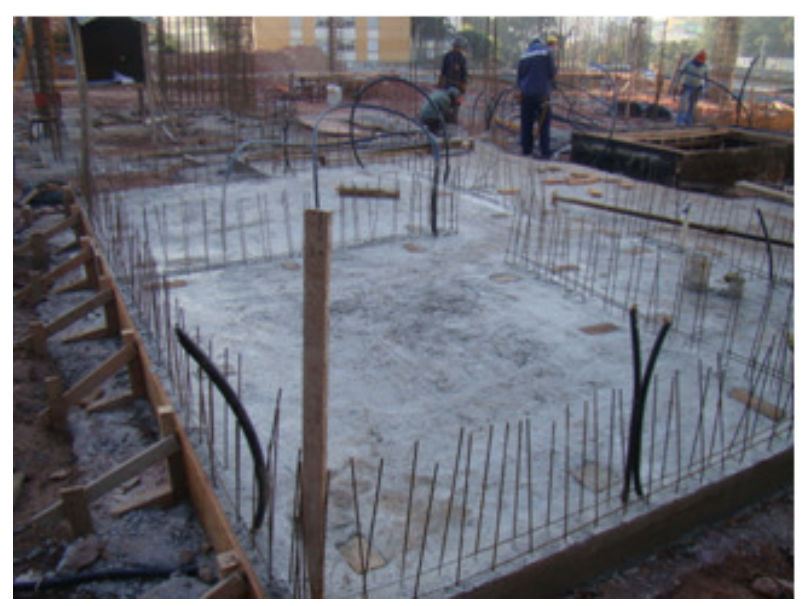

Figura 2.7 - Fundação nivelada contendo os arranques e as instalações sanitárias. 
b) Montagem das telas soldadas, dos reforços previstos no detalhamento do projeto estrutural e fixação dos espaçadores (Figura 2.8). Espaçadores são colocados nas telas soldadas para mantê-las na posição correta, de forma a respeitar os cobrimentos previstos no projeto estrutural.

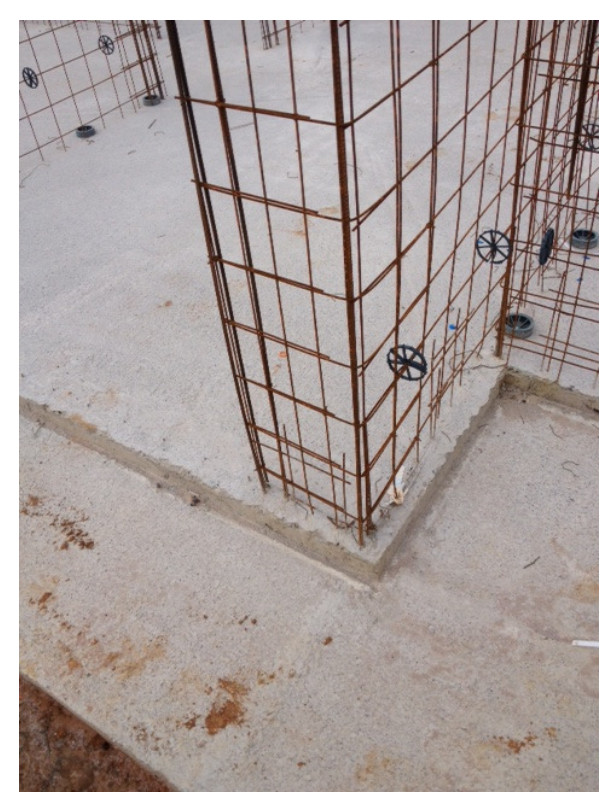

Figura 2.8 - Montagem das telas, reforços e fixação dos espaçadores.

c) Fixação dos eletrodutos e caixas elétricas às telas soldadas, para que não sejam deslocados no momento da concretagem. As caixas elétricas devem ser preenchidas com papel ou pó de serra para evitar a entrada do concreto.

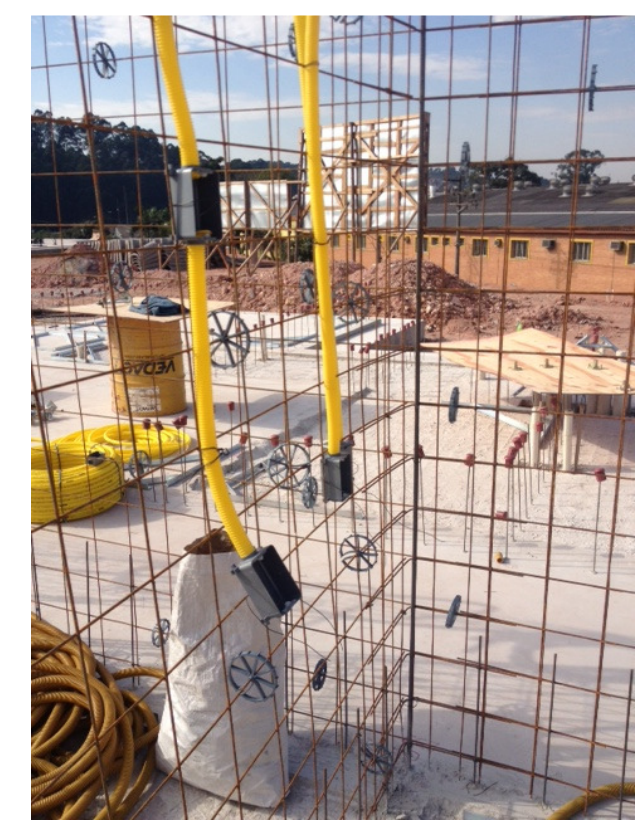

Figura 2.9 - Fixação dos eletrodutos e caixas elétricas. 
d) As instalações hidráulicas são amarradas às telas soldadas (Figura 2.10).

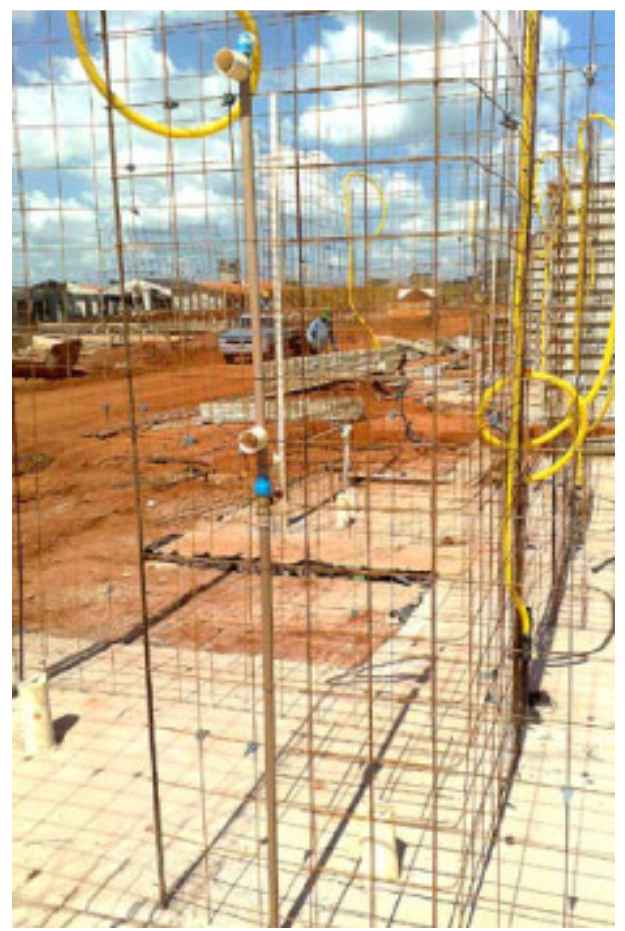

Figura 2.10 - Colocação das instalações hidráulicas (IBTS 2012).

e) montagem dos painéis de formas (Figuras 2.1 a 2.3);

f) concretagem (Figura 2.11). Antes de lançar o concreto, o slump test ou o slump flow são verificados. A Figura 2.12a mostra o ensaio do abatimento do tronco de cone (slump test) e a Figura 2.12b o ensaio do espalhamento do concreto (slump flow).

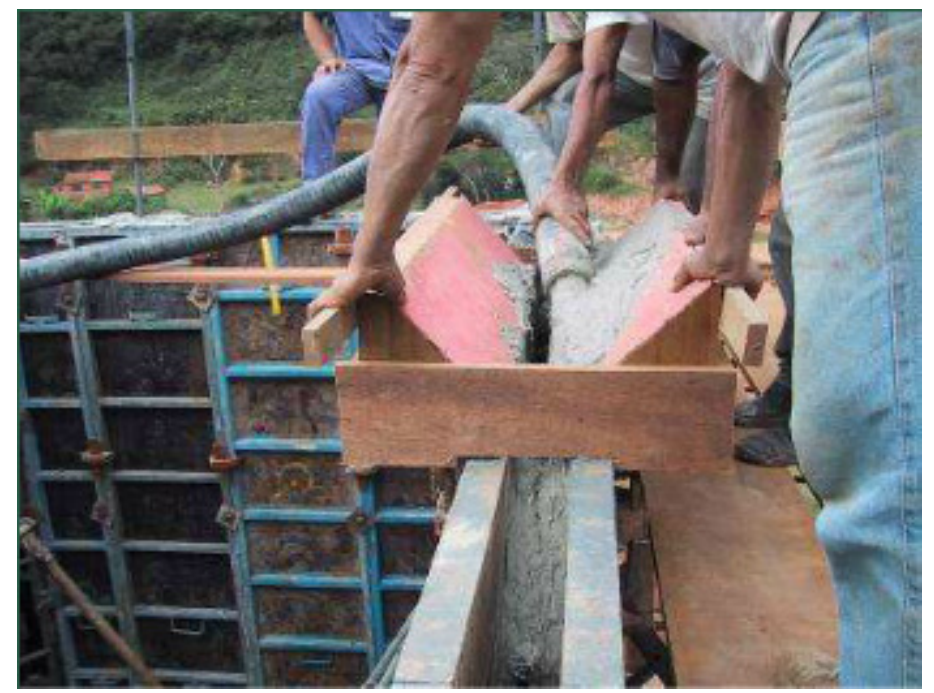

Figura 2.11 - Concretagem das paredes (Comunidade da Construção 2013). 


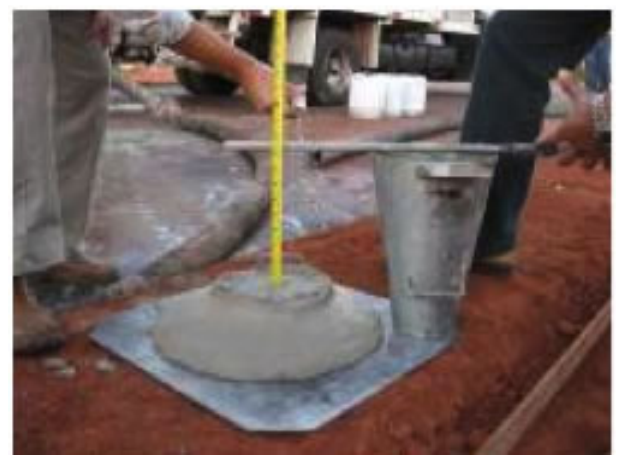

a) Slump test

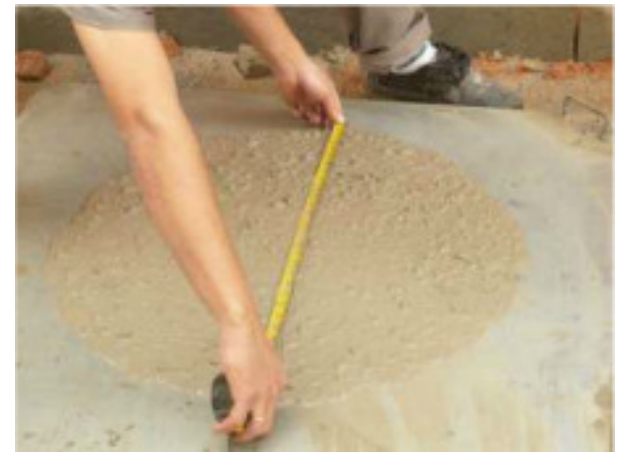

b) Slump flow

Figura 2.12 - Ensaios Slump test e Slump flow (Comunidade da Construção 2013).

g) a desforma é realizada após o concreto ter atingido a resistência à compressão especificada para essa atividade. Normalmente a desforma ocorre quatorze horas após a concretagem.

h) por fim é feita a cura do concreto a fim de diminuir o surgimento de fissuras superficiais.

\subsection{Comparação de custos}

Alguns estudos simularam os custos de determinadas construções admitindo diferentes métodos executivos.

Nacimba (2009) simulou os custos de casas térreas construídas pelo método convencional (pilares, vigas e lajes) e pelo o sistema Paredes de Concreto. O estudo de caso foi baseado no conjunto habitacional Orión que possui quarenta e oito casas de $140 \mathrm{~m}^{2}$ de área útil.

A Figura 2.13 apresenta o estudo comparativo de custos por etapas de obra, entre os dois métodos. Ao final, a diferença por metro quadrado de uma casa construída pelo sistema Paredes de Concreto seria de USD 47,71 (USD = US\$ = dólares americanos) a menos em relação ao outro método.

Por fim Nacimba (2009) concluiu que a metodologia em Paredes de Concreto é mais econômica em relação ao método convencional.

Barriga (2009) simulou os custos da construção de um edifício com $24 \mathrm{~m}$ de comprimento e $6 \mathrm{~m}$ de largura, conforme Figura 2.14, quando construído pelo método convencional e pelo sistema Paredes de Concreto. O estudo foi feito para 0 
caso do edifício com dois pavimentos e cinco pavimentos. Barriga (2009) definiu os projetos 1 e 2 , aqueles construídos pelo método convencional, sendo o primeiro com cinco pavimentos; e os projetos 3 e 4 construídos pelo sistema Paredes de Concreto, sendo o terceiro com cinco pavimentos.

ANALISIS COMPARATIVO*

\begin{tabular}{|c|c|}
\hline $\begin{array}{l}\text { PRESUPUESTO DE } \\
\text { ALTERNATIVA }\end{array}$ & PRESUPUESTO DE ALTERNATIVA \\
\hline $\begin{array}{l}\text { CONSTRUCTIVA METODOLOGIA } \\
\text { TRADICIONAL }\end{array}$ & $\begin{array}{l}\text { CONSTRUCTIVA METODOLOGIA } \\
\text { DE PAREDES PORTANTES }\end{array}$ \\
\hline
\end{tabular}

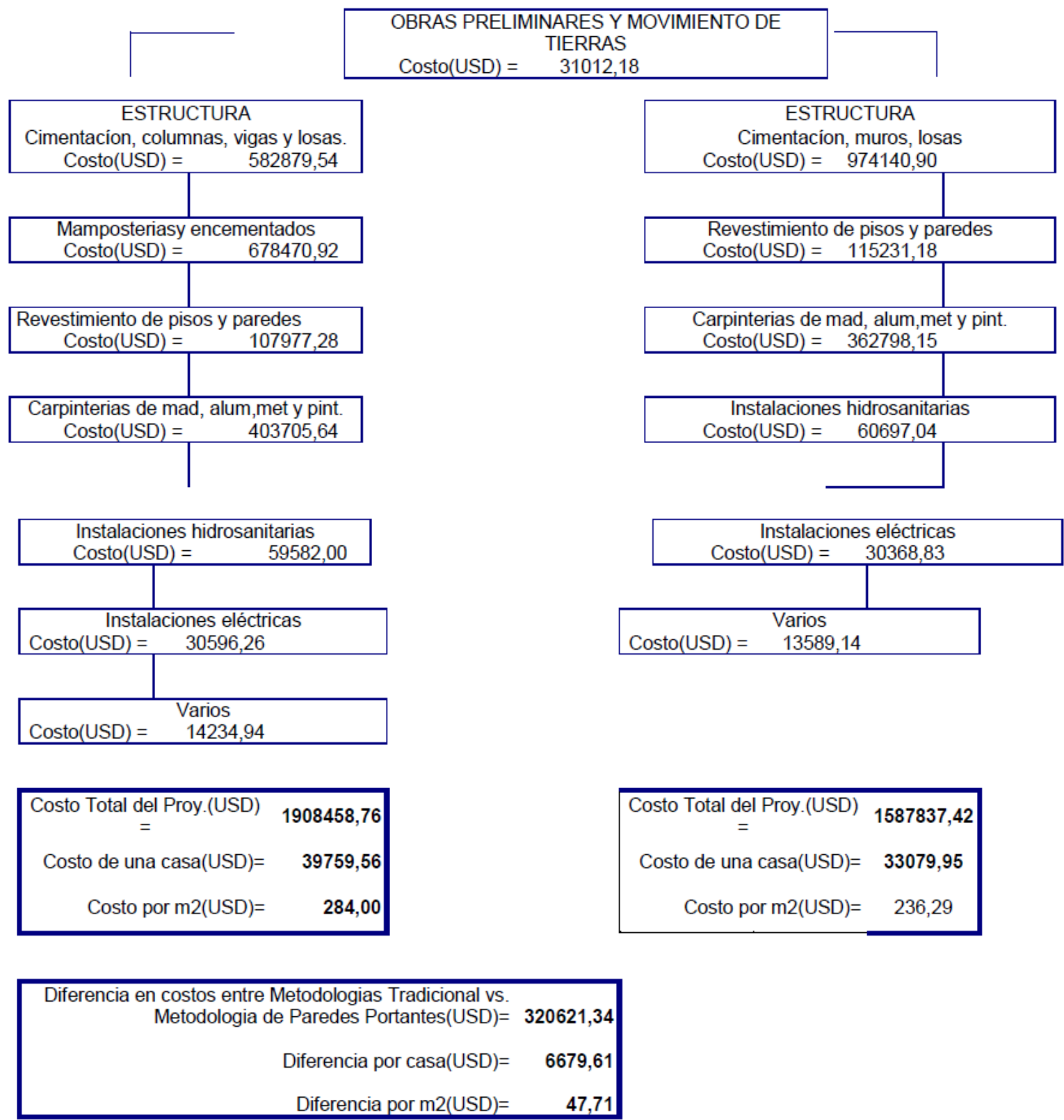

Figura 2.13 - Resumo comparativo de custos (NACIMBA, 2009). 


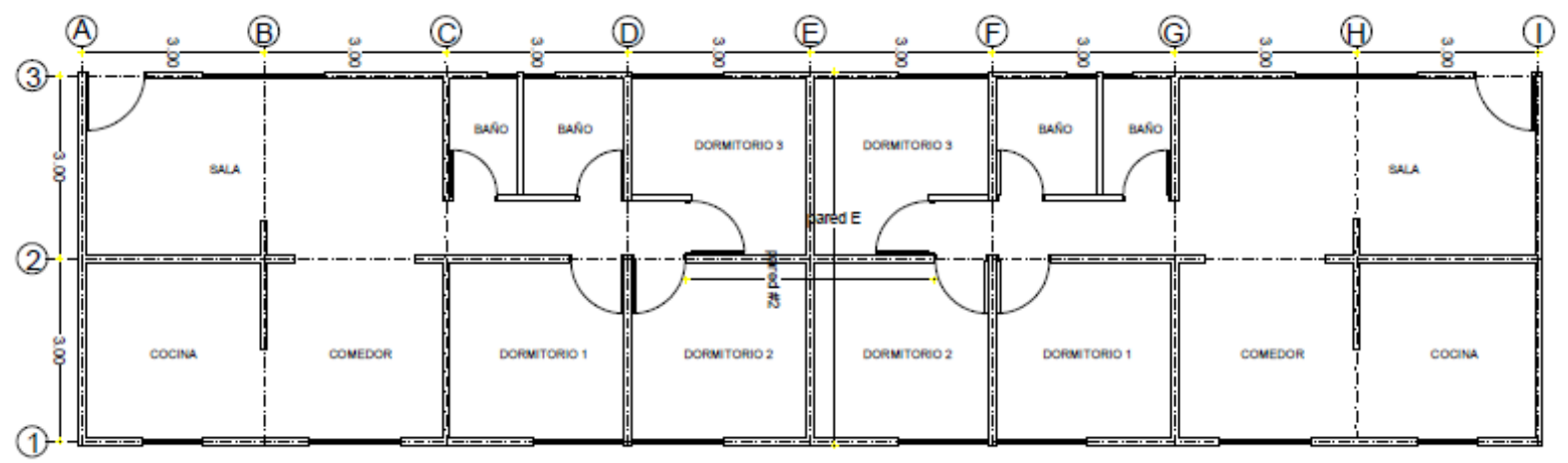

Figura 2.14 - Planta do edifício estudado (BARRIGA, 2009).

Tabela 2.1 - Resumo de custos (BARRIGA, 2009).

RESUMEN DE COSTOS

\begin{tabular}{|c|c|c|c|c|c|c|c|c|}
\hline \multirow{2}{*}{ COSTO } & \multicolumn{8}{|c|}{ PROYECTO } \\
\hline & & No.1 & & No. 2 & & No. 3 & & No.4 \\
\hline MATERIALES & $\$$ & $60.544,69$ & $\$$ & $23.604,11$ & $\$$ & $38.517,00$ & $\$$ & $15.836,00$ \\
\hline ENCOFRADOS & $\$$ & $1.393,56$ & $\$$ & 557,42 & $\$$ & $5.842,60$ & $\$$ & $2.337,04$ \\
\hline MANO DE OBRA & $\$$ & $24.115,52$ & $\$$ & $9.344,37$ & $\$$ & $9.495,09$ & $\$$ & $3.922,54$ \\
\hline COSTO TOTAL & & $86.053,77$ & $\$$ & $33.505,90$ & $\$$ & $53.854,69$ & s & $22.095,58$ \\
\hline
\end{tabular}

Comparando-se os custos obtidos nos projetos 1 e 3 , nota-se que o método executivo sistema Paredes de Concreto seria significativamente mais econômico que o método convencional (principalmente nos custos de materiais e mão de obra). O mesmo verifica-se para os casos dos projetos 2 e 4.

Barriga (2009) concluiu que o sistema Paredes de Concreto possibilita produção sistematizada, otimização de materiais e mão de obra e, tempo de execução e custo total, menores em relação ao método convencional. Afirmou que essas características se destacam em construções de grande porte.

Alves e Peixoto (2011) simularam os custos da construção de um sobrado e de um edifício com quatro pavimentos, quando utilizados os métodos executivos Alvenaria Estrutural e Paredes de Concreto. A Figura 2.15 mostra o sobrado estudado com área construída total de $652 \mathrm{~m}^{2}$. O edifício estudado é apresentado na Figura 2.16, contendo área construída total de $1356 \mathrm{~m}^{2}$.

Na simulação dos custos para a construção do sobrado, a Tabela 2.2 mostra que a Alvenaria Estrutural seria 19,9\% mais econômica em relação ao sistema Paredes de Concreto. Alves e Peixoto (2011) concluíram que o custo das formas 
das paredes seria muito alto devido à sua baixa utilização, já que seriam aplicadas em apenas dois pavimentos com área relativamente pequena.
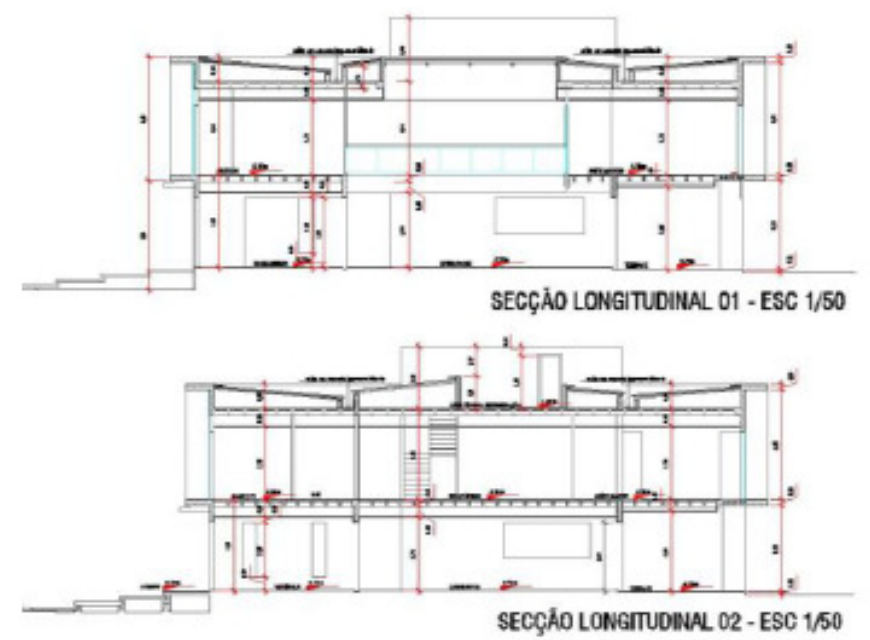
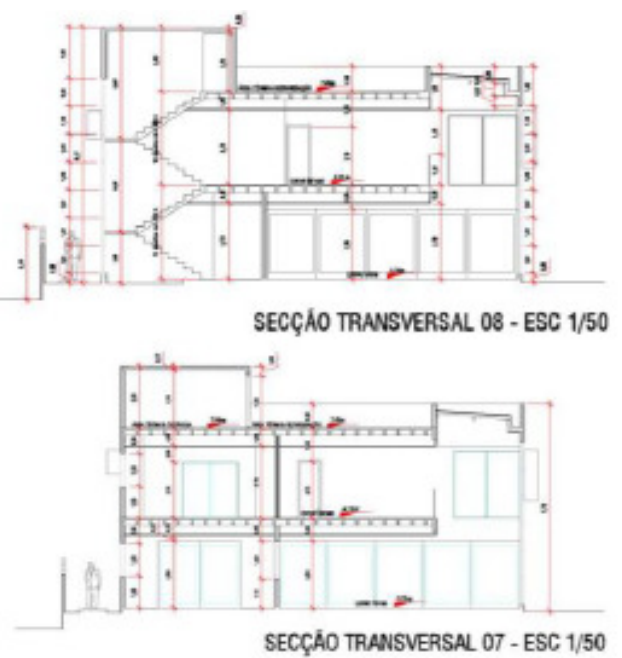

Figura 2.15 - Casa com um térreo e um pavimento superior (ALVES; PEIXOTO, 2011).
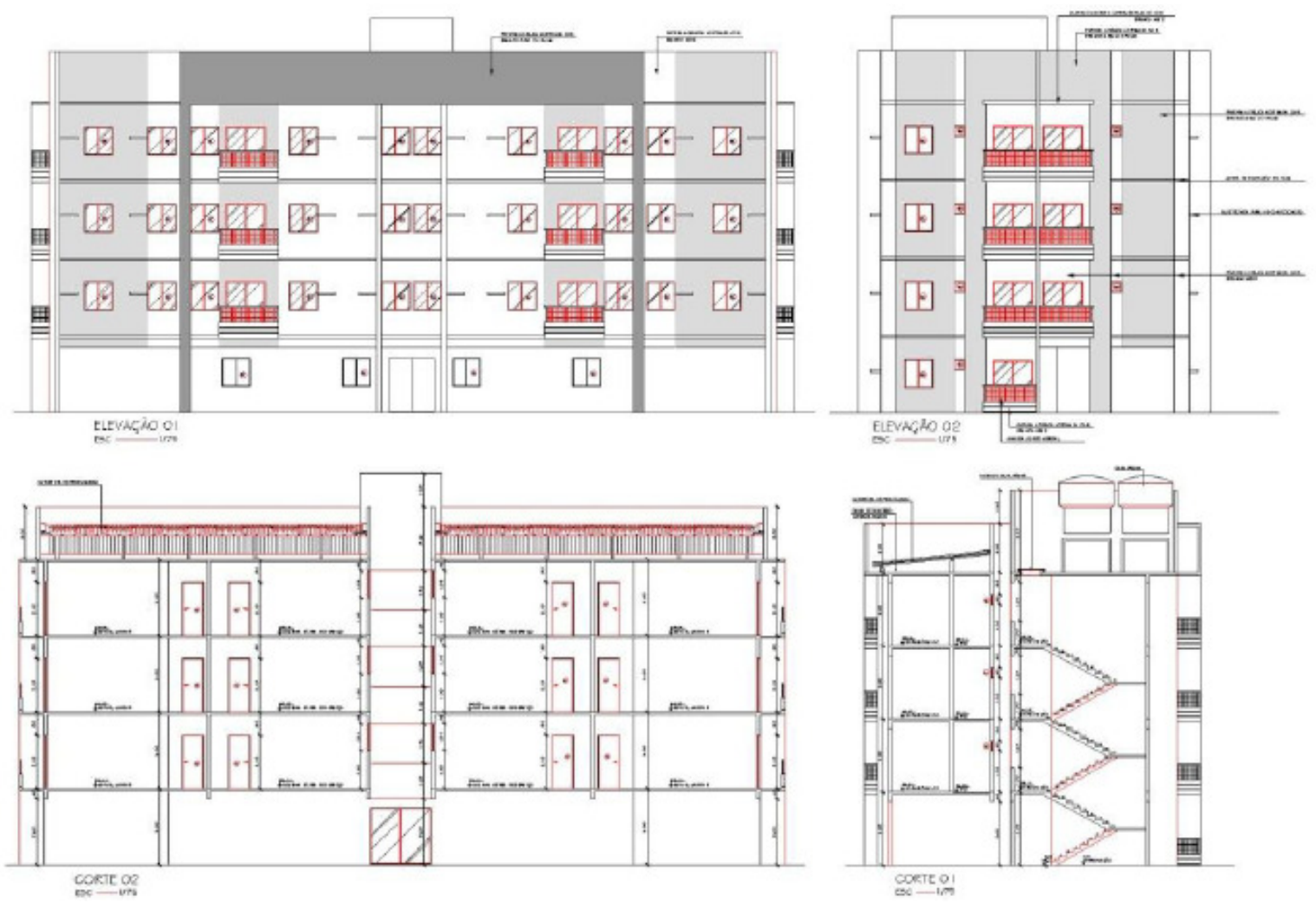

Figura 2.16 - Edifício com um térreo e mais três pavimentos (ALVES; PEIXOTO 2011).

O resumo dos custos para a construção do edifício com quatro pavimentos é apresentado na Tabela 2.3. Constatou-se que se ele fosse construído pelo sistema Paredes de Concreto a economia seria de $1,5 \%$ em relação à construção em Alvenaria Estrutural. A Tabela 2.4 apresenta o custo da construção do mesmo 
edifício, porém o repetindo três vezes. Observou-se que o custo pelo sistema Paredes de Concreto seria 7,8\% mais econômico em relação à Alvenaria Estrutural.

Alves e Peixoto (2011) concluíram que quando há um número grande de unidades iguais a serem construídas, os custos obtidos pelo sistema Paredes de Concreto são menores em relação à Alvenaria Estrutural. Isso se justifica pelo primeiro método proporcionar maior velocidade de execução, o que consequentemente reduz os custos de insumos e mão de obra. Concluíram também que quando a forma das paredes é bastante reutilizada, seu custo não é significativo.

Tabela 2.2 - Resumo de custos para uma casa tipo com térreo e mais um pavimento superior (ALVES; PEIXOTO, 2011).

\begin{tabular}{|c|}
\hline ITEM \\
\hline Terraplanagem \\
\hline Fundactes \\
\hline Förmss \\
\hline Armaço \\
\hline Concreto \\
\hline MSO de Cora - LA.FS \\
\hline M.O. - PAR. CONOCRETO \\
\hline M.O, - ALV VEDACAOO \\
\hline M.D.- ALV. ESTRUTLRAL \\
\hline Elocos e Argamassa - Alv, Vedaço \\
\hline Alcoos e Argamassa - Ak , Estruturd \\
\hline Revestim./Acabamentos internos \\
\hline Revestim /hcabamentos Externos \\
\hline Inst. Eletricas \\
\hline Inst. Hdabicas \\
\hline Outras Inetalacóes \\
\hline Controle Tecnabovo \\
\hline MO Indreta I Seguranca \\
\hline Equparmentos \\
\hline Esquadras \\
\hline Coberturas \\
\hline Impermesb, Isolamentos \\
\hline Plsos e Fứmos \\
\hline Yidos \\
\hline Cutros \\
\hline
\end{tabular}

\begin{tabular}{|c|c|}
\hline \multicolumn{2}{|c|}{ ALV. ESTRUTURAL } \\
\hline \multicolumn{2}{|c|}{ Tempo de Obra $=4,2$ meses } \\
\hline RS & $\%$ \\
\hline $8.606,40$ & $1,0 \%$ \\
\hline $99.997,24$ & $12,0 \%$ \\
\hline $23.894,20$ & $2,9 \%$ \\
\hline $51.263,04$ & $6,2 \%$ \\
\hline $106.875,84$ & $\$ 2,8 \%$ \\
\hline $34.556,00$ & $4,1 \%$ \\
\hline- & \\
\hline- & \\
\hline $26.289,81$ & $3,2 \%$ \\
\hline- & \\
\hline $27,416,60$ & $3,3 \%$ \\
\hline $81.500,00$ & $9,8 \%$ \\
\hline $21.517,28$ & $2,6 \%$ \\
\hline $16.300,00$ & $2,0 \%$ \\
\hline $39.120,00$ & $4,7 \%$ \\
\hline $2.282,00$ & $0,3 \%$ \\
\hline 567,34 & $0,7 \%$ \\
\hline $72.083,13$ & $8,7 \%$ \\
\hline $35.213,30$ & $4,2 \%$ \\
\hline $18.438,56$ & $2,2 \%$ \\
\hline $9.780,00$ & $1,2 \%$ \\
\hline $9.004,12$ & $1,1 \%$ \\
\hline $33.936,60$ & $4,1 \%$ \\
\hline $14.181,00$ & $1,7 \%$ \\
\hline $100,000,00$ & $12,0 \%$ \\
\hline
\end{tabular}

\begin{tabular}{|c|c|}
\hline \multicolumn{2}{|c|}{ PAREDE DE CONCRETO } \\
\hline \multicolumn{2}{|c|}{ Tempo de Obra $=4.2$ mescs } \\
\hline RS & $\%$ \\
\hline $8.606,40$ & $0.8 \%$ \\
\hline $\mathbf{9 9 . 9 9 7 , 2 4}$ & $9,6 \%$ \\
\hline $233.192,00$ & $22,4 \%$ \\
\hline $54.081,41$ & $5,2 \%$ \\
\hline $150.148,98$ & $14,4 \%$ \\
\hline $34.556,00$ & $3,3 \%$ \\
\hline $10.890,03$ & $1,0 \%$ \\
\hline- & \\
\hline$\cdot$ & \\
\hline- & \\
\hline- & \\
\hline $81.500,00$ & $7,8 \%$ \\
\hline $15.517,60$ & $1,5 \%$ \\
\hline $15.933,25$ & $1,5 \%$ \\
\hline $37.653,00$ & $3.6 \%$ \\
\hline $2.282,00$ & $0.2 \%$ \\
\hline $9.657,37$ & $0,9 \%$ \\
\hline $65.443,18$ & $6,3 \%$ \\
\hline $35.244,46$ & $3,4 \%$ \\
\hline $18.438,56$ & $1,8 \%$ \\
\hline $9.780,00$ & $0,9 \%$ \\
\hline $9.004,12$ & $0.9 \%$ \\
\hline $33.936,60$ & $3.3 \%$ \\
\hline $14.181,00$ & $1,4 \%$ \\
\hline $100.000,00$ & $9.6 \%$ \\
\hline $1.040 .043,20$ & $100,0 \%$ \\
\hline $\mathbf{R} \$ 1.595,16 / \mathrm{m} 2$ & \\
\hline
\end{tabular}

\begin{tabular}{|lr|r|}
\hline R\$ & $832.822,48$ & $100,0 \%$ \\
\hline \hline \multicolumn{2}{|l|}{$\mathbf{R} \$$} & $1.277,34 / \mathrm{m} 2$ \\
\hline
\end{tabular}

R\$ 1.595, $16 \mathrm{fm} 2$

\begin{tabular}{|c|l|}
\hline ALV. ESTRUTURAL & DIF. $=\mathbf{R} \$ 207.220,73$ \\
EMAIS VIÁVEL & DIF. $=19,9 \%$ \\
\hline
\end{tabular}


Tabela 2.3 - Resumo de custos para um edifício tipo com térreo e mais três pavimentos (ALVES; PEIXOTO, 2011).

\begin{tabular}{|c|}
\hline ITEM \\
\hline Tertaplanayem \\
\hline Funda, \\
\hline Fôrmax \\
\hline Árma, हैo \\
\hline Concreto \\
\hline MẼo de Dora-LAES \\
\hline M.O. - PAR. CONCRETO \\
\hline MO, - ALV VEDACAOO \\
\hline M.O-- ALV. ESTRLTLRAL \\
\hline Elooose Argamassa - Alv, Vedaga \\
\hline Elcoos e Árgamassa - Alv. Estrutural \\
\hline Rervestim./Acsosmentos internos \\
\hline Revestim. /Acabamentos Extermos \\
\hline Inst. Elétricas \\
\hline lnst. Hidádicas \\
\hline Outres instalases \\
\hline Controle Tecnológico \\
\hline MO Indireta / Seguranca \\
\hline Equipamentos \\
\hline Esquatios \\
\hline Coberturas \\
\hline Impermeab /lsolamentos \\
\hline Fisas e Förros \\
\hline Vidros \\
\hline Outros \\
\hline
\end{tabular}

\begin{tabular}{|c|c|}
\hline \multicolumn{2}{|c|}{ ALV. ESTRUTURAL } \\
\hline \multicolumn{2}{|c|}{ Tempo de Obra $=8.1$ meses } \\
\hline $\mathbf{R} \$$ & $\%$ \\
\hline $10.712,72$ & $0,6 \%$ \\
\hline $152.934,19$ & $8,3 \%$ \\
\hline $63.027,51$ & $3,4 \%$ \\
\hline $23,073,56$ & $1,3 \%$ \\
\hline $222.282,08$ & $12,1 \%$ \\
\hline $71.870,12$ & $3,9 \%$ \\
\hline- & \\
\hline- & \\
\hline $130.101,19$ & $7,1 \%$ \\
\hline - & \\
\hline $143.609,38$ & $7,8 \%$ \\
\hline $169.505,00$ & $9,2 \%$ \\
\hline $45.898,57$ & $2,5 \%$ \\
\hline $33.901,00$ & $1,8 \%$ \\
\hline $81.362,40$ & $4,4 \%$ \\
\hline $4.746,14$ & $0,3 \%$ \\
\hline $2.922,14$ & $0,2 \%$ \\
\hline $225.543,55$ & $12,3 \%$ \\
\hline $166.199,12$ & $9,1 \%$ \\
\hline $58.540,25$ & $3,2 \%$ \\
\hline $13.221,39$ & $0,7 \%$ \\
\hline $15.757,18$ & $0,9 \%$ \\
\hline $66.425,62$ & $3,6 \%$ \\
\hline $32.151,71$ & $1,8 \%$ \\
\hline $100,000,00$ & $5,5 \%$ \\
\hline
\end{tabular}

\begin{tabular}{|c|c|}
\hline \multicolumn{2}{|c|}{ PAREDE DE CONCRETO } \\
\hline \multicolumn{2}{|c|}{ Tempo de Obra $=5,6$ meses } \\
\hline R\$ & $\%$ \\
\hline $10.712,72$ & $0,6 \%$ \\
\hline $152.934,19$ & $8,5 \%$ \\
\hline $177.425,99$ & $9,8 \%$ \\
\hline $35.623,65$ & $2,0 \%$ \\
\hline $362.549,50$ & $20,1 \%$ \\
\hline $71.870,12$ & $4,0 \%$ \\
\hline $81.628,86$ & $4,5 \%$ \\
\hline- & \\
\hline- & \\
\hline- & \\
\hline- & \\
\hline $169.505,00$ & $9,4 \%$ \\
\hline $32.273,75$ & $1,8 \%$ \\
\hline $33.392,49$ & $1,8 \%$ \\
\hline $79.328,34$ & $4,4 \%$ \\
\hline $4.746,14$ & $0,3 \%$ \\
\hline $14.581,96$ & $0,8 \%$ \\
\hline $163.727,27$ & $9,1 \%$ \\
\hline $129,961,82$ & $7,2 \%$ \\
\hline $58.540,25$ & $3,2 \%$ \\
\hline $13.221,39$ & $0,7 \%$ \\
\hline $15.757,18$ & $0,9 \%$ \\
\hline $66.425,62$ & $3,7 \%$ \\
\hline $32.151,71$ & $1,8 \%$ \\
\hline $100,000,00$ & $5,5 \%$ \\
\hline $1.806 .357,94$ & $100,0 \%$ \\
\hline $\mathrm{R} \$ 1.332,08 / \mathrm{m} 2$ & \\
\hline
\end{tabular}

\begin{tabular}{|c|c|c|}
\hline RS & $1.833 .784,81$ & $100,0 \%$ \\
\hline & $352,31 / \mathrm{m} 2$ & \\
\hline
\end{tabular}

\begin{tabular}{c|l} 
PAREDE DE CONCRETO & DIF. $=\mathrm{R} \$ 27.426,87$ \\
E MAIS VIAVEL & DIF. $=1,5 \%$
\end{tabular}


Tabela 2.4 - Resumo de custos para três edifícios tipo com térreo e mais três pavimentos (ALVES; PEIXOTO, 2011).

\begin{tabular}{|c|}
\hline ITEM \\
\hline Terr aplanogem \\
\hline Fundagtes \\
\hline Fốrmas \\
\hline Almo, $\$ 0$ \\
\hline Concreto \\
\hline MBo de Ora - LAES \\
\hline M.Q. - PAR. CONCRETO \\
\hline M.O. - ALV. VEDAÇĀO \\
\hline MO. ALV. ESTRUTURAL \\
\hline Elocos e Argamassa - Alv. Veda;do \\
\hline Elocos e Argamassa - Alv. Estutural \\
\hline Revestin./Acctormentos internos \\
\hline Revestim /Acabaimentos Extornos \\
\hline Inst. Eetricas \\
\hline Inst. Hiaraulicas \\
\hline O.tr $x$ Inctalsgoxes \\
\hline Conirale Teconologico \\
\hline MO Indreta / Segraxa \\
\hline Equpamentos \\
\hline Esquatias \\
\hline Coberturas \\
\hline Impermeda/isolamentus \\
\hline Piscs efótros \\
\hline Vidroc \\
\hline Ontos \\
\hline
\end{tabular}

\begin{tabular}{|c|c|}
\hline \multicolumn{2}{|c|}{ ALV. ESTRUTURAL } \\
\hline \multicolumn{2}{|c|}{ Tempo de Obra $=14.2$ moses } \\
\hline RS & $\%$ \\
\hline $32.138,15$ & $0,7 \%$ \\
\hline $458.802,57$ & $9,6 \%$ \\
\hline $189.082,53$ & $4,0 \%$ \\
\hline 69.220 .69 & $1,5 \%$ \\
\hline $666.846,23$ & $14,0 \%$ \\
\hline $215.610,36$ & $4,5 \%$ \\
\hline - & \\
\hline- & \\
\hline $390.303,57$ & $8,2 \%$ \\
\hline - & \\
\hline $430.828,15$ & $9,0 \%$ \\
\hline 508.515 .00 & $10,7 \%$ \\
\hline $137.695,70$ & $2,9 \%$ \\
\hline $101.703,00$ & $2,1 \%$ \\
\hline $244.087,20$ & $5,1 \%$ \\
\hline $14.238,42$ & $0,3 \%$ \\
\hline 8. 766,42 & $0,2 \%$ \\
\hline $381.630,64$ & $8,0 \%$ \\
\hline $258.220,35$ & $5,4 \%$ \\
\hline 175.620 .74 & $3,7 \%$ \\
\hline $39.664,17$ & $0,8 \%$ \\
\hline $47.271,55$ & $1,0 \%$ \\
\hline $199.276,86$ & $4,2 \%$ \\
\hline $96.455,13$ & $2,0 \%$ \\
\hline $100.000,00$ & $2,1 \%$ \\
\hline
\end{tabular}

\begin{tabular}{|c|c|}
\hline \multicolumn{2}{|c|}{ PAREDE DE CONCRETO } \\
\hline \multicolumn{2}{|c|}{ Ternpo de Otra $=6.9$ moses } \\
\hline R\$ & $\%$ \\
\hline $32.138,15$ & $0,7 \%$ \\
\hline $458,802,57$ & $10,4 \%$ \\
\hline $274.087,94$ & $6,2 \%$ \\
\hline $106.870,94$ & $2,4 \%$ \\
\hline $1.087 .648,50$ & $24,6 \%$ \\
\hline $215.610,36$ & $4,9 \%$ \\
\hline $244.886,59$ & $5,5 \%$ \\
\hline- & \\
\hline - & \\
\hline - & \\
\hline - & \\
\hline $508.515,00$ & $11,5 \%$ \\
\hline $96.821,26$ & $2,2 \%$ \\
\hline $100.177,46$ & $2,3 \%$ \\
\hline $237.985,02$ & $5,4 \%$ \\
\hline $14.238,42$ & $0,3 \%$ \\
\hline $38.582,09$ & $0,9 \%$ \\
\hline 196. 181,82 & $4,4 \%$ \\
\hline $149.655,37$ & $3,4 \%$ \\
\hline 175.620 .74 & $4,0 \%$ \\
\hline $39.664,17$ & $0,9 \%$ \\
\hline $47.271,55$ & $1,1 \%$ \\
\hline $199.276,86$ & $4,5 \%$ \\
\hline $96.455,13$ & 2,29 \\
\hline $100.000,00$ & $2,3 \%$ \\
\hline
\end{tabular}

\begin{tabular}{|c|c|c|}
\hline RS & $4.765 .977,43$ & $100,0 \%$ \\
\hline
\end{tabular}

\begin{tabular}{|c|c|c|}
\hline RS & $4.420 .489,91$ & $100,0 \%$ \\
\hline & $.086,62 / \mathrm{m} 2$ & \\
\hline
\end{tabular}

\begin{tabular}{|c|l|}
\hline PARECE DE COIACRETO & DIF. $=\mathbf{R} \$ \mathbf{3 4 5 . 4 8 7 , 5 2}$ \\
E MAI VIÁVEL & DIF. $=7.8 \%$ \\
\hline
\end{tabular}




\section{ESTUDO DO SISTEMA PAREDES DE CONCRETO}

\subsection{Considerações iniciais}

No projeto estrutural de edifícios construídos pelo sistema Paredes de Concreto, a espessura das paredes é uma das principais definições a serem feitas. Essa definição envolve diversas variáveis, como, por exemplo, a altura do prédio, as ações a que ele está submetido, a resistência dos materiais utilizados e as hipóteses de modelagem.

Dentre os modelos de cálculo, os dois modelos numéricos utilizados neste trabalho, denominados Modelo em Elementos Finitos (MEF) e Modelo Pórtico Tridimensional (MPT), envolvem todas as variáveis citadas acima. Observa-se que o MEF discretiza as paredes com elementos de casca e o MPT as discretiza com elementos de barra, como pode ser visto mais detalhadamente no capítulo quatro. Ambos são ferramentas disponíveis para se obterem os esforços solicitantes nas paredes, tal que elas sejam dimensionadas de acordo com determinado código normativo.

Este capítulo apresenta alguns trabalhos em que os modelos numéricos citados foram estudados e aplicados em edifícios construídos em sistemas estruturais compostos por paredes.

A comparação entre a máxima tensão normal de compressão com a resistência última à compressão (calculada conforme alguma norma de projeto), é uma das principais verificações a serem feitas no dimensionamento de uma parede de concreto. Por isso, ao final deste capítulo, a expressão de resistência última à compressão das normas australiana (AS 3600), americana (ACI 318), europeia (EN 1992) e brasileira (NBR 16055) são apresentadas, para que depois, na etapa de prédimensionamento no capítulo seis (item 6.5), elas sejam comparadas.

\subsection{Revisão Bibliográfica}

Nascimento Neto (1999) validou o Modelo Pórtico Tridimensional utilizando dois estudos experimentais em escala reduzida. $O$ primeiro estudo foi de Kalita e Hendry (1970). A Figura 3.1 mostra a estrutura em escala reduzida 1:6 de tijolos 
maciços cerâmicos, composta por duas paredes simétricas, quatro lajes e os carregamentos aplicados. Nesse experimento, Kalita e Hendry (1970) também desenvolveram um modelo em elementos finitos para comparar os resultados numéricos com os experimentais.

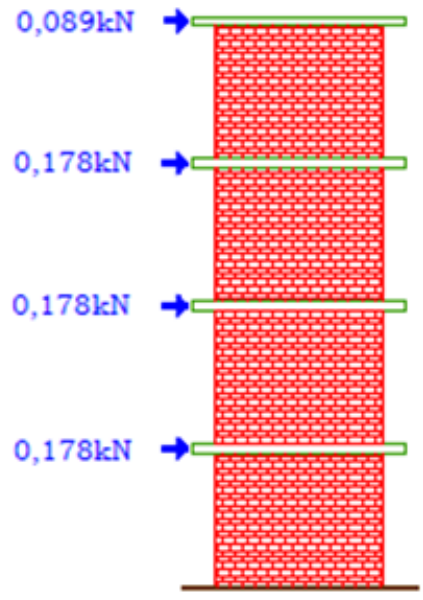

(a) - Vista Lateral

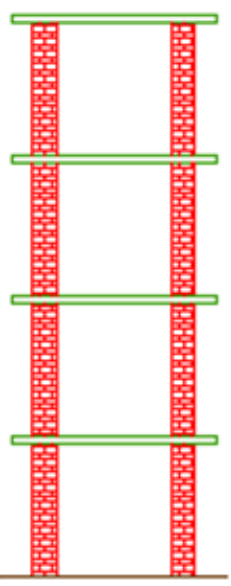

(b) - Vista Frontal

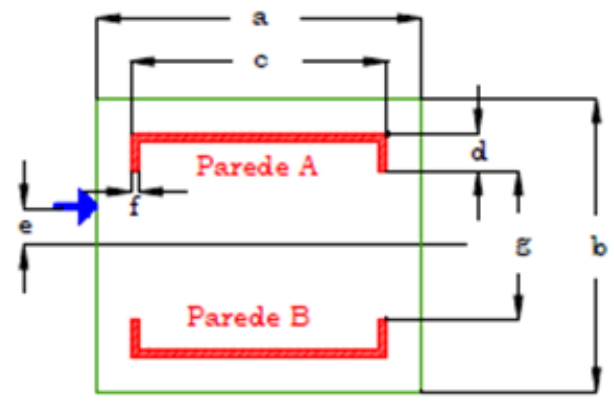

(c) - Planta Baixa

Figura 3.1 - Experimento 1 (KALITA; HENDRY, 1970)

O segundo consiste numa estrutura reduzida na escala 1:3 composta por dez paredes de blocos de alvenaria e cinco lajes, sendo a última laje submetida à ação de momento torçor (Figura 3.2), ensaiada por Keskin (1974). É uma estrutura simétrica cuja disposição e comprimento das paredes permitem que haja uma contribuição mais significativa das abas no sistema de contraventamento.

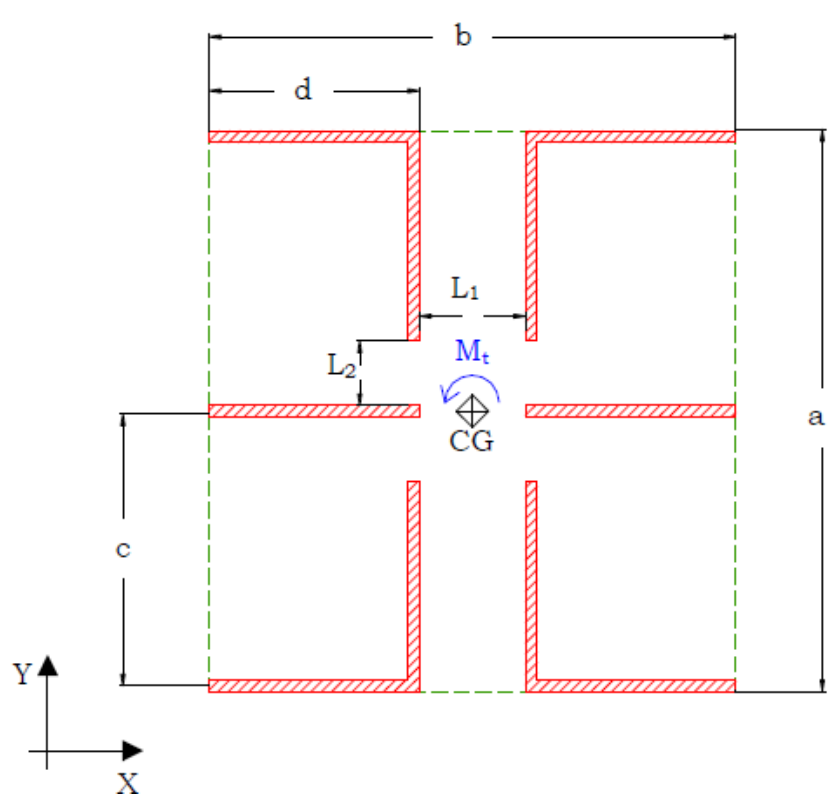

Figura 3.2 - Experimento 2 (KESKIN, 1974). 
Nascimento Neto (1999) empregou o Modelo Pórtico Tridimensional (MPT) aos experimentos 1 e 2, como mostram as Figuras 3.3 e 3.4, respectivamente.

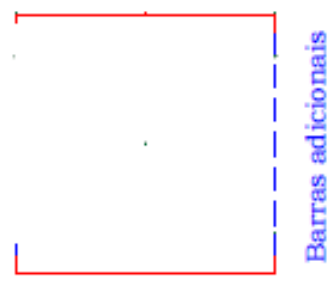

(a) - Vista superior

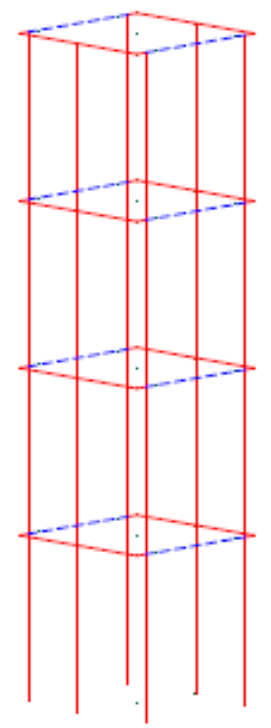

(b) - Vista em perspectiva

Figura 3.3 - Modelo Pórtico Tridimensional do experimento 1 (NASCIMENTO NETO, 1999).

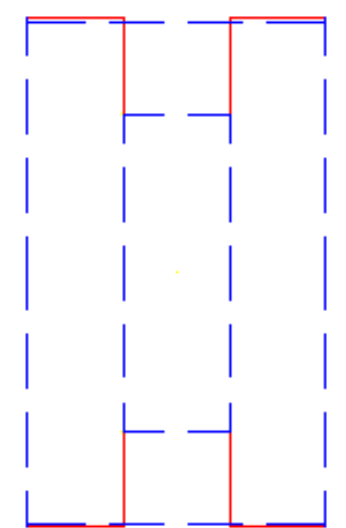

(a) - Vista superior

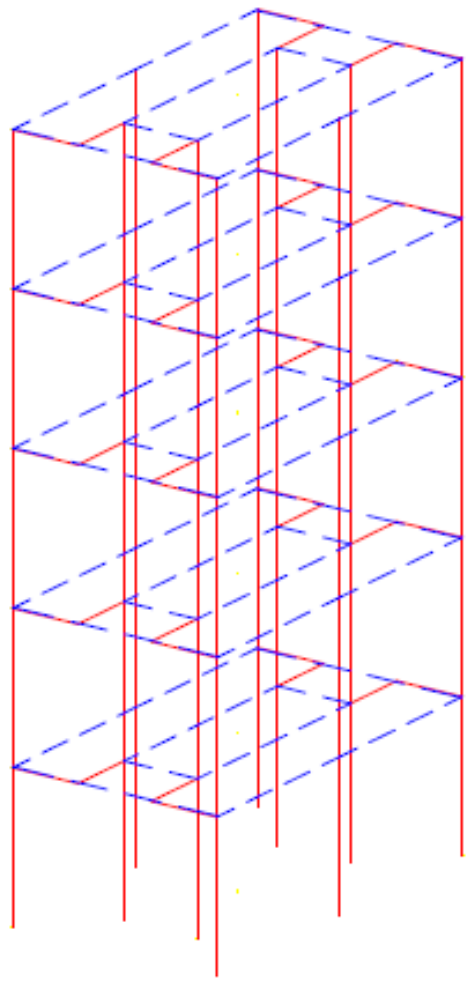

(b) - Vista em perspectiva

Figura 3.4 - Modelo Pórtico Tridimensional do experimento 2 (NASCIMENTO NETO, 1999). 
A fim de validar o MPT, para o caso do experimento 1, Nascimento Neto (1999) comparou os deslocamentos horizontais, não incluindo as rotações das lajes, entre o MPT e o modelo em elementos finitos. Em seguida comparou os deslocamentos horizontais, incluindo-se as rotações das lajes, entre o MPT e o modelo experimental. Os resultados da Parede A, mostrados na Figura 3.5, evidenciam que os valores de deslocamentos obtidos pelo MPT foram muito próximos aos obtidos pelo modelo em elementos finitos e também aos obtidos pelo modelo experimental, confirmando a qualidade desse modelo simplificado.

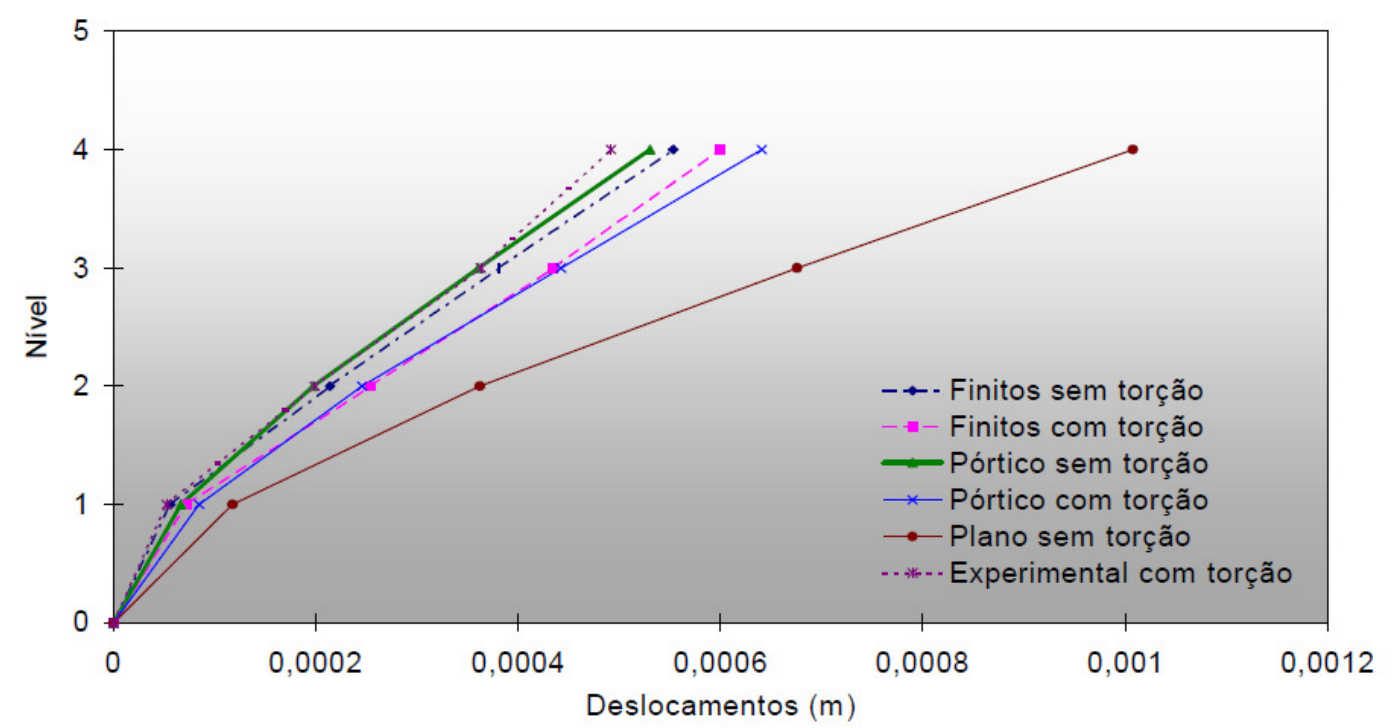

Figura 3.5 - Deslocamentos horizontais na Parede A do experimento 1 (NASCIMENTO NETO, 1999).

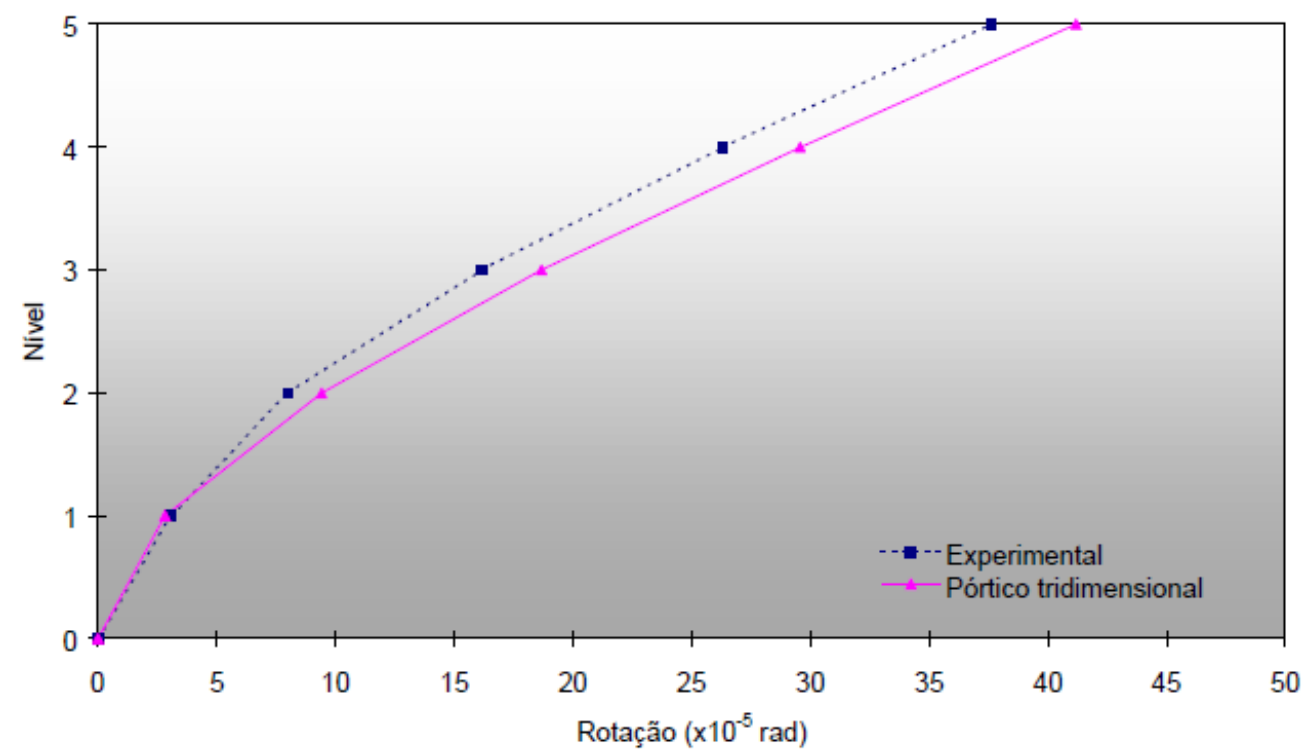

Figura 3.6 - Rotações das lajes do experimento 2 (NASCIMENTO NETO, 1999). 
No experimento 2, Nascimento Neto (1999) analisou as rotações no plano das lajes obtidas pelo MPT e pelo modelo experimental. A Figura 3.6 mostra que o MPT tem comportamento muito semelhante ao modelo experimental, e que as diferenças obtidas são a favor da segurança.

Segundo Nascimento Neto (1999), a boa aproximação de resultados em relação aos dois exemplos experimentais confirmaram a validade do Modelo Pórtico Tridimensional, sendo assim possível sua aplicação na modelagem de edifícios em Alvenaria Estrutural.

Nunes (2011) fez a análise estrutural de um edifício em Paredes de Concreto, com dez pavimentos, sendo o primeiro um pilotis, e os outros compostos apenas por paredes e lajes. Nunes (2011) utilizou um modelo em elementos finitos (modelo referência), no qual os pilares e vigas do pavimento pilotis foram discretizados em elementos de barra, e as paredes dos outros pavimentos (pavimento dois ao dez), foram discretizadas em elementos de casca plana. No outro modelo numérico, chamado de modelo básico, a estrutura foi dicretizada até o terceiro pavimento conforme o modelo referência, e os outros pavimentos foram discretizados em elementos de barra de acordo com o MPT. A Figura 3.7 apresenta os dois modelos e a nomenclatura adotada para paredes e pilares.
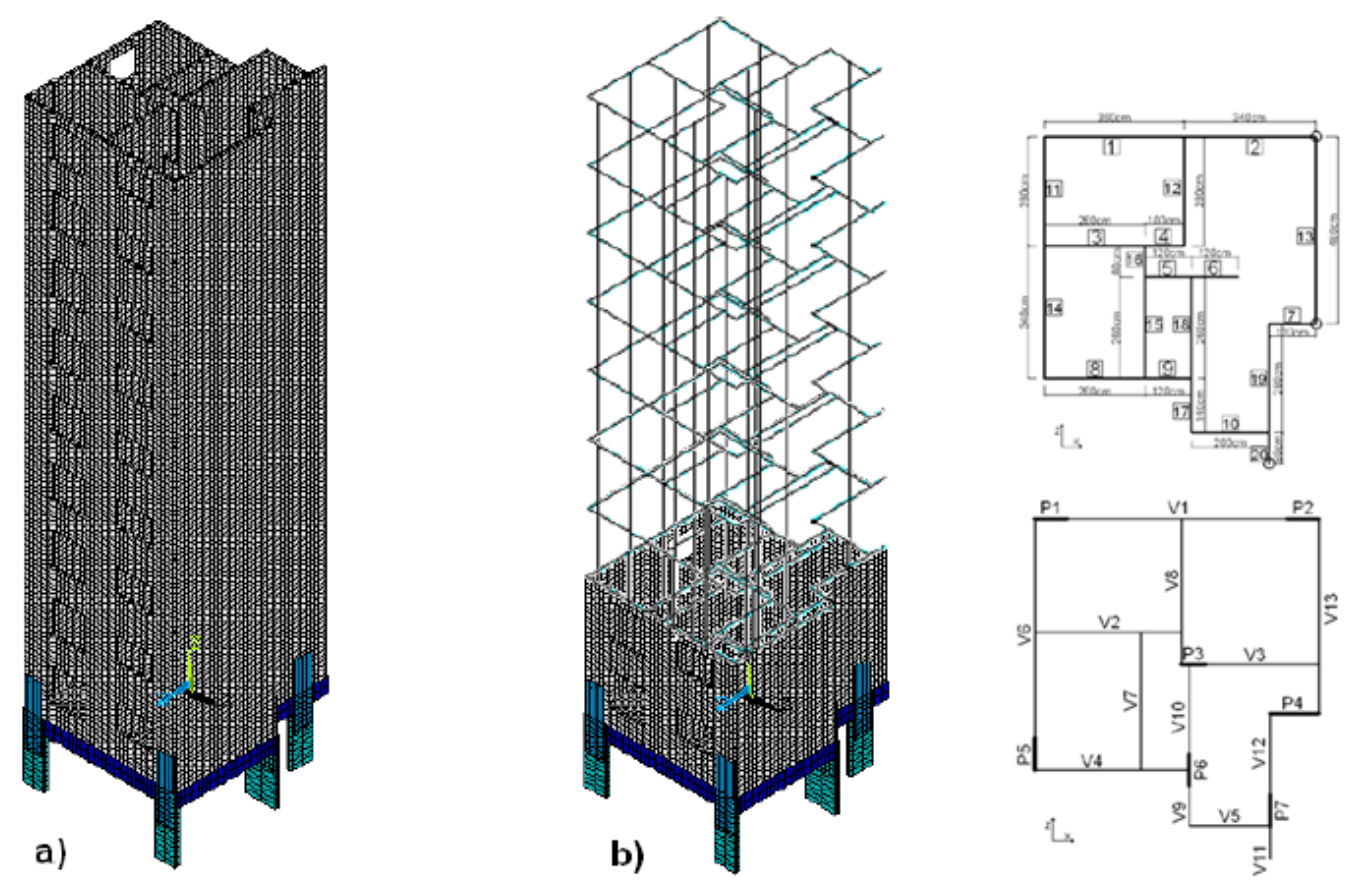

Figura 3.7 - Modelo referência a) x Modelo básico b); nomenclatura de paredes e pilares (NUNES, 2011). 
A Tabela 3.1 compara as Forças Normais das paredes na base do terceiro pavimento obtidas apenas por cargas verticais, entre os modelos referência (MEF) e o modelo básico (MPT misto). Como os resultados obtidos foram muito próximos, Nunes (2011) afirmou que o MPT é viável para análise de esforços normais em edifícios de Paredes de Concreto.

Tabela 3.1 - Comparação da Força normal obtida por cargas verticais (NUNES, 2011).

\begin{tabular}{|c|c|c|c|}
\hline \multicolumn{4}{|c|}{ Esforço Normal - kN - $3^{\circ} \mathrm{PAV}$} \\
\hline Parede & PORTICO & CASCA & $(\mathrm{PT}) /(\mathrm{CA})$ \\
\hline P1 & \begin{tabular}{|l|}
$-296,31$ \\
\end{tabular} & $-273,73$ & 1,08 \\
\hline P2 & $-283,82$ & $-301,81$ & 0,94 \\
\hline P3 & $-301,44$ & $-277,22$ & 1,09 \\
\hline P4 & $-422,76$ & $-443,14$ & 0,95 \\
\hline P5 & $-356,28$ & $-330,83$ & 1,08 \\
\hline P6 & $-661,83$ & $-690,78$ & 0,96 \\
\hline P7 & $-414,43$ & $-386,32$ & 1,07 \\
\hline P8 & $-766,84$ & $-816,17$ & 0,94 \\
\hline $\mathrm{P9}$ & $-440,05$ & $-468,99$ & 0,94 \\
\hline $\mathrm{P} 10$ & $-1135,80$ & $-1207,39$ & 0,94 \\
\hline P11 & $-202,79$ & $-190,74$ & 1,06 \\
\hline P12 & $-449,48$ & $-480,37$ & 0,94 \\
\hline $\mathrm{P} 13$ & $-732,27$ & $-767,09$ & 0,95 \\
\hline P14 & $-805,95$ & $-786,50$ & 1,02 \\
\hline & & MEDIA & 0,96 \\
\hline
\end{tabular}

Os Momentos Fletores e Esforços Cortantes das paredes, também ao nível do terceiro pavimento, provenientes das ações horizontais (vento e desaprumo), foram comparados na Tabela 3.2. Nesse pavimento houve diferenças de até $10 \%$, o que também mostrou a eficiência do MPT.

Tabela 3.2 - Comparação de Momentos Fletores e Esforços Cortantes obtidos pelas ações horizontais (NUNES, 2011).

\begin{tabular}{|c|c|c|c|c|c|c|}
\hline PAV & \multicolumn{3}{|c|}{ Momento Fletor $(\mathrm{kN} . \mathrm{cm})$} & \multicolumn{3}{|c|}{ Esforço Cortante $(\mathrm{kN})$} \\
\hline Parede & Pórtico & Casca & $\mathrm{PT} / \mathrm{CS}$ & Pórtico & Casca & $\mathrm{PT} / \mathrm{CS}$ \\
\hline P8 & $-2345,74$ & $-2128,32$ & 1,10 & $-10,02$ & $-10,24$ & 0,98 \\
\hline $\mathrm{P} 9$ & $-1008,89$ & $-969,69$ & 1,04 & $-5,51$ & $-5,55$ & 0,99 \\
\hline P10 & $-5170,46$ & $-5590,01$ & 0,92 & $-23,17$ & $-25,66$ & 0,90 \\
\hline P11 & $-362,26$ & $-373,21$ & 0,97 & $-1,96$ & $-2,13$ & 0,92 \\
\hline$\overline{\mathrm{P} 12}$ & $-590,58$ & $-578,60$ & 1,02 & $-5,82$ & $-6,00$ & 0,97 \\
\hline$\overline{\mathrm{P} 13}$ & $-1803,00$ & $-1753,12$ & 1,03 & $-8,30$ & $-7,95$ & 1,05 \\
\hline$\overline{\mathrm{P} 14}$ & $-996,07$ & $-1078,17$ & 0,92 & $-13,97$ & $-13,73$ & 1,02 \\
\hline & & MEDIA & 1,02 & & $\overline{\text { MEDIA }}$ & 0,98 \\
\hline
\end{tabular}


Com a finalidade de ressaltar a eficiência do modelo quanto ao caminhamento das tensões, Nunes (2011) analisou os pilares e chegou a conclusões interessantes.

A Tabela 3.3 aponta um resumo comparativo entre os modelos, em termos de Força Normal, Esforço Cortante e Momento Fletor dos pilares, obtidos apenas por ações horizontais. Chegou-se a uma diferença de $51 \%$ nos resultados de Força Normal.

Tabela 3.3 - Comparação dos esforços solicitantes na base dos pilares considerando apenas ações horizontais (NUNES, 2011).

\begin{tabular}{|c|c|c|c|}
\hline \multicolumn{4}{|c|}{ Carregamento Horizontal - Normal (kN) } \\
\hline Pilar & Casca & Pórtico & $\mathrm{PT} / \mathrm{CS}$ \\
\hline 1 & 82,4 & 42,5 & 0.52 \\
\hline 2 & 87,5 & 43,0 & 0,49 \\
\hline 3 & 25,3 & 18,2 & 0,12 \\
\hline 4 & 3,4 & 2,3 & 0,69 \\
\hline 5 & $-55,0$ & $-33,5$ & 0,61 \\
\hline 6 & $-60,5$ & $-31,8$ & 0,53 \\
\hline 7 & $-76,4$ & $-40,8$ & 0,53 \\
\hline \multicolumn{3}{|r|}{ MÉDIA } & 0,53 \\
\hline
\end{tabular}

\begin{tabular}{|c|c|c|c|}
\hline \multicolumn{3}{|c|}{ Carregamento Horizontal - Cortante (kN) } \\
\hline \multirow{2}{*}{ PILAR } & \multicolumn{3}{|c|}{ Direc̃o Z } \\
\cline { 2 - 4 } & Casca & Pórtico & PT/CS \\
\hline 1 & $-1,91$ & $-1,80$ & 0,94 \\
\hline 2 & $-1,98$ & $-1,89$ & 0,95 \\
\hline 3 & $-1,83$ & $-1,85$ & 1,01 \\
\hline 4 & $-2,53$ & $-2,46$ & 0,97 \\
\hline 5 & $-29,44$ & $-29,22$ & 0,99 \\
\hline 6 & $-29,56$ & $-29,84$ & 1,01 \\
\hline 7 & $-28,51$ & $-28,70$ & 1,01 \\
\hline \multicolumn{3}{|c|}{ MÉDIA } & 0,99 \\
\hline
\end{tabular}

\begin{tabular}{|c|c|c|c|}
\hline \multicolumn{3}{|c|}{ Car. Horizontal - Momento Fletor (kN.cm) } \\
\hline \multirow{2}{*}{ PILAR } & \multicolumn{3}{|c|}{ Direção X } \\
\cline { 2 - 4 } & Casca & Pórtico & PT/CS \\
\hline 1 & 297,11 & 280,31 & 0,94 \\
\hline 2 & 305,06 & 290,49 & 0,95 \\
\hline 3 & 285,99 & 282,89 & 0,99 \\
\hline 4 & 398,35 & 385,12 & 0,97 \\
\hline 5 & 5084,70 & 4935,10 & 0,97 \\
\hline 6 & 5056,60 & 4962,30 & 0,98 \\
\hline 7 & 4890,70 & 4794,40 & 0,98 \\
\hline \multicolumn{3}{|c|}{ MÉDIA } & 0,97 \\
\hline
\end{tabular}

A Tabela 3.4 mostra os mesmos resultados, porém considerando a combinação de cargas verticais com ações horizontais. Na nova comparação as diferenças não ultrapassaram $4 \%$.

Tabela 3.4 - Comparação dos esforços solicitantes na base dos pilares considerando combinação de cargas verticais com ações horizontais (NUNES, 2011).

\begin{tabular}{|c|c|c|c|}
\hline \multicolumn{4}{|c|}{ Car. Combinado $(\mathrm{V}+\mathrm{H})$ - Normal $(\mathrm{kN})$} \\
\hline PILAR & \begin{tabular}{|l} 
Casca \\
\end{tabular} & \begin{tabular}{|l|} 
Pórtico \\
\end{tabular} & \\
\hline 1 & $-1513,72$ & $-1446,45$ & 0,96 \\
\hline 2 & $-1336,99$ & $-1316,35$ & \\
\hline 3 & $-1268,24$ & $-1269,29$ & 1,00 \\
\hline 4 & $-1220,90$ & $-1230,54$ & 1,01 \\
\hline 5 & $-1442,59$ & $-1438,69$ & 1,00 \\
\hline 6 & $-1417,67$ & $-1459,25$ &, 00 \\
\hline 7 & $-1111,98$ & $-1160,95$ & 1,04 \\
\hline & & MÉDIA & $\overline{1,00}$ \\
\hline
\end{tabular}

\begin{tabular}{|c|c|c|c|c|c|c|}
\hline \multicolumn{7}{|c|}{ Carregamento Combinado (Horizontal + Vertical) } \\
\hline \multirow{2}{*}{ PILAR } & \multicolumn{3}{|c|}{ Cortante $\mathrm{Z}(\mathrm{kN})$} & \multicolumn{3}{|c|}{ Momento Fletor X (kN.cm) } \\
\hline & Casca & Pórtico & PT/CS & Casca & Pórtico & PIISS \\
\hline 1 & 2,63 & 2,64 & 1,00 & $-171,74$ & $-165,23$ & 0,96 \\
\hline 2 & $-2,51$ & $-2,42$ & 0,97 & 349,31 & 340,96 & $\overline{0,98}$ \\
\hline 3 & $-3,00$ & $-3,04$ & 1,01 & 427,83 & 426,71 & 1,00 \\
\hline 4 & $-2,57$ & $-2,57$ & 1,00 & 452,55 & 446,33 & 0,99 \\
\hline 5 & $-69,06$ & $-69,37$ & 1,00 & 9000,58 & 8953,64 & 0,99 \\
\hline 6 & $-35,12$ & $-35,52$ & 4,04 & 6153,40 & 6172,07 & 1,00 \\
\hline 7 & $-24,73$ & $-23,77$ & 0,96 & 4635,18 & 4666,16 & 1,01 \\
\hline \multicolumn{4}{|c|}{ MÉDIA } & & MÉDIA & 0,99 \\
\hline
\end{tabular}

Nunes (2011) concluiu que a grande diferença obtida entre os dois modelos quanto à Força Normal na base do pilar, considerando apenas ações horizontais, não é relevante, pois os valores obtidos correspondentes às ações horizontais são pequenos quando comparados ao esforço proveniente do carregamento vertical. 
Quando a combinação de ações foi feita, este fato ficou evidenciado, e a diferença obtida entre os modelos tornou-se insignificante. Ressalta-se que essa conclusão foi tirada a partir do estudo de um edifício não esbelto.

A máxima diferença obtida entre os dois modelos quanto às translações horizontais ao longo dos pavimentos do edifício é de $9 \%$ no topo do edifício, sendo o modelo MPT o mais flexível, portanto, a favor da segurança (Figura 3.8).

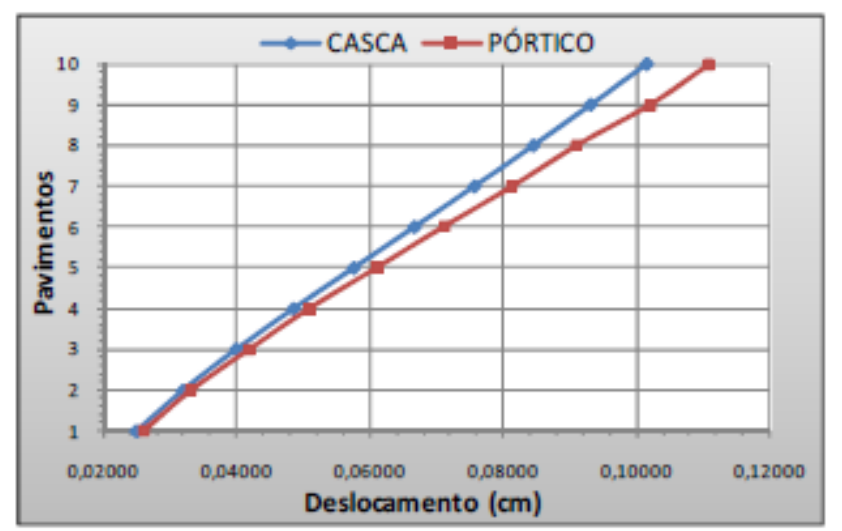

Figura 3.8 - Comparação das translações horizontais entre os modelos MEF e MPT (NUNES, 2011).

Nunes (2011) concluiu que há bastante semelhança de resultados entre o modelo em elementos finitos e o modelo pórtico tridimensional, quando eles são obtidos a partir da combinação de cargas verticais e ações horizontais.

\subsection{Normas de projeto}

A expressão de resistência última à compressão proposta pelas normas australiana, americana, europeia e brasileira é apresentada neste item com o objetivo de compará-las na etapa do pré-dimensionamento das paredes de um edifício construído pelo sistema Paredes de Concreto. A comparação entre as normas se limitará quanto a essa expressão, devido ela ser aplicada na verificação das tensões normais de compressão, a qual é a mais importante ao se dimensionar uma parede. Ressalta-se que não é objetivo discutir o embasamento teórico das expressões apresentadas a seguir. 


\subsubsection{AS 3600:2009 - Concrete Structures}

A norma australiana de concreto apresenta em sua seção 11 um método simplificado para dimensionar paredes de concreto. Sua versão de 2001, a qual foi revisada em 2009, considerava vinculações possíveis apenas na base e topo das paredes, sendo possível, portanto, apenas um plano de flexão (Figura 3.9a). Segundo FRAGOMENI e DOH (2010), o código de 2001 falhava em não admitir a hipótese da contribuição de vinculações laterais, que quando consideradas, faz com que a parede tenha dois planos de flexão, mesmo quando submetida a cargas verticais (Figura 3.9b).

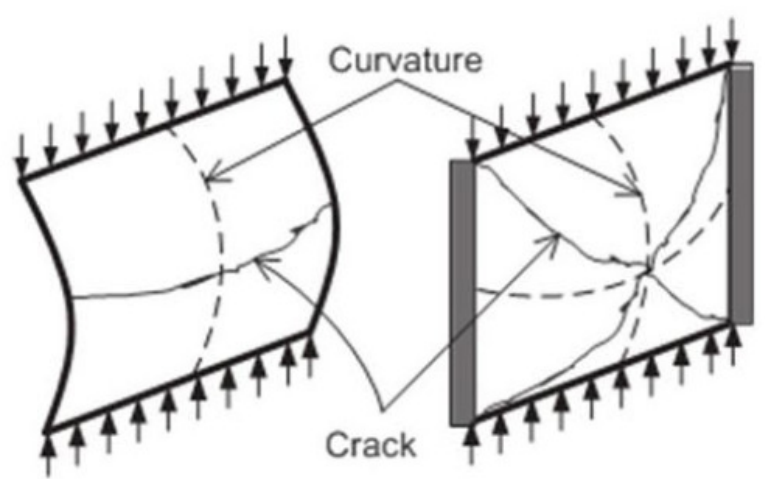

(a)

(b)

Figura 3.9 - Paredes sem e com vinculações laterais; a) um plano de flexão; b) dois planos de flexão (FRAGOMENI; DOH 2010).

O novo AS 3600:2009 - Concrete Structures, agora permite que o dimensionamento das paredes de concreto, pelo método simplificado, considere vinculações em duas, três ou quatro extremidades, sendo, portanto, muito mais realista em relação à sua última versão.

$\mathrm{Na}$ versão de 2009, a expressão para o cálculo da resistência última à compressão de uma parede de concreto se manteve igual à versão de 2001. Contudo, o cálculo da altura efetiva da parede mudou em função da nova hipótese admitida para as condições de contorno da parede.

A Equação (3.1) define a expressão pelo método simplificado de resistência última à compressão proposta pelo AS 3600:2001 a qual é igual ao AS 3600:2009.

$\phi \cdot N_{u}=\phi \cdot\left(t_{w}-1,2 \cdot e-2 e_{a}\right) \cdot 0,6 . f_{c}{ }^{\prime}$ 
onde:

$N_{u}$ : resistência última à compressão por unidade de comprimento;

$\phi$ : fator de minoração da resistência; $\phi=0,6$ para elementos comprimidos;

$t_{w}:$ espessura da parede;

$e:$ excentricidade inicial de $1^{\mathrm{a}}$ ordem; $e \geq 0,05 . t_{w}$;

$f_{c}{ }_{c}:$ resistência característica à compressão do concreto;

$e_{a}:$ excentricidade de $2^{\mathrm{a}}$ ordem;

A excentricidade de $2^{a}$ ordem é definida pela Equação (3.2), onde $H_{w e}$ é a altura efetiva da parede:

$e_{a}=\frac{\left(H_{w e}\right)^{2}}{2500 \cdot t_{w}}$

Se o cálculo da altura efetiva for realizado pelo AS 3600:2001, essa é igual ao menor valor obtido entre as Equações (3.3) e (3.4), onde $H_{w}$ é a altura livre da parede entre pisos consecutivos, $L$ a distância horizontal em planta entre eixos de paredes transversais (quando existirem) e $k$, o fator que considera o tipo de vinculação da parede.

$$
\begin{aligned}
H_{w e} & =k \cdot H_{w} \\
H_{w e} & =k \cdot L
\end{aligned}
$$

O valor de $k$, quando obtido pelo AS3600:2001 é calculado conforme abaixo:

- quando as vinculações na base e no topo impedem translações horizontais e rotações, $k=0,75$;

- quando as vinculações na base e no topo impedem apenas as translações horizontais e não impedem rotações, $k=1,00$. 
Se o cálculo da altura efetiva for feito pelo AS 3600:2009, considera-se apenas a equação (3.3) e $k$ é obtido como segue:

(i) paredes com um plano de flexão, portanto com vinculações apenas em suas bases e topos; $k=0,75$ quando elas impedem translações horizontais e rotações e, $k=1,00$ quando elas impedem apenas as translações horizontais e não rotações.

(ii) paredes com dois planos de flexão com vinculações em três extremidades; $k=\frac{1}{1+\left(H_{w} / 3 L\right)^{2}} \geq 0,3$, sendo $k$ menor que o obtido no item (i); neste caso $L$ é o comprimento da parede.

(iii) paredes com dois planos de flexão com vinculações nas quatro extremidades; $\quad k=\frac{1}{1+\left(H_{w} / L\right)^{2}}$ quando $H_{w} \leq L$ e $k=\frac{L}{2 \cdot H_{w}}$ quando $H_{w}>L$; neste caso $L$ é a distância horizontal em planta entre os eixos das vinculações laterais.

Outra mudança no código revisado é referente aos limites de resistência característica à compressão do concreto em que o método simplificado pode ser aplicado. No AS 3600:2001 este limite era de $20 \leq f_{c} \leq 65 M P a$. O código revisado considera $20 \leq f_{c} \leq 100 M P a$, englobando concretos de alta resistência.

Este código australiano limita a esbeltez da parede em 30, ou seja, $H_{w e} / t_{w} \leq 30$.

Quanto às armaduras mínimas, a taxa vertical é de $\rho_{v}=0,15 \%$ da área de concreto da seção transversal da parede e a taxa horizontal de $\rho_{h}=0,25 \%$.

\subsubsection{ACl 318:2011 - Building Code Requirement for Structural Concrete}

O código americano apresenta um método simplificado no qual o dimensionamento das paredes de concreto pode ser verificado com a expressão empírica da Equação (3.5), desde que as características das paredes atendam às limitações do método. 
$\phi \cdot P_{n}=0,55 \cdot \phi \cdot f_{c} \cdot A_{g} \cdot\left[1-\left(\frac{k \cdot \ell_{c}}{32 \cdot h}\right)^{2}\right]$

onde:

$P_{n}$ : resistência última à compressão;

$\phi$ : fator de minoração da resistência; $\phi=0,65$ para elementos comprimidos;

$f_{c}$ ` : resistência característica à compressão do concreto;

$A_{g}$ : área bruta da seção transversal da parede;

$\ell_{c}:$ altura total da parede;

$h$ : espessura da parede;

$k$ : fator que considera o tipo de vinculação da parede e define a altura efetiva dela;

O ACl 318:2011 adota como hipótese a ocorrência de apenas um plano de flexão em paredes submetidas a cargas verticais e por isso considera vinculações apenas em suas bases e topos, assim como fazia o AS 3600:2001. A altura efetiva da parede é definida por $k \cdot \ell_{c}$, onde:

- $k=0,8$ quando as vinculações impedem na base e topo, rotações e translações horizontais;

- $\quad k=1,0$ quando as vinculações impedem na base e topo, apenas translações horizontais;

- $\quad k=2,0$ quando as paredes forem engastadas na base e livres no topo.

A norma americana limita a aplicação da expressão apresentada na Equação (3.5), em paredes com as seguintes condições:

- $\quad$ paredes devem ter seção transversal maciça e retangular;

- paredes com relação $\ell_{c} / t_{w} \leq 25$ (esbeltez) ou $L / t_{w} \leq 25$ (considera-se a menor entre as duas), onde $L$ é o comprimento da parede em planta;

- excentricidade máxima de $t_{w} / 6$;

- espessuras das paredes devem ter no mínimo $10 \mathrm{~cm}$; 
- a resistência característica à compressão mínima do concreto deve ser 17 MPa, não havendo limitação para resistência máxima;

- armadura mínima vertical:

$\rho_{\ell}=0,15 \%$ para barras de aço deformáveis com diâmetro maior

que $16 \mathrm{~mm}$ e resistência do aço não menor que $410 \mathrm{MPa}$;

$\rho_{\ell}=0,12 \%$ para barras de aço deformáveis com diâmetro até

$16 \mathrm{~mm}$ e resistência do aço não menor que $410 \mathrm{MPa}$;

- armadura mínima horizontal:

$\rho_{t}=0,25 \%$ para barras de aço deformáveis com diâmetro maior que $16 \mathrm{~mm}$ e resistência do aço não menor que $410 \mathrm{MPa}$;

$\rho_{t}=0,20 \%$ para barras de aço deformáveis com diâmetro até $16 \mathrm{~mm}$ e resistência do aço não menor que $410 \mathrm{MPa}$;

Segundo Doh (2002), a expressão empírica do código americano é inteiramente baseada em resultados experimentais como os de Saheb e Desayi (1989) e Fragomeni (1995). Fragomeni, Mendis e Grayson (1994) dizem que o código americano falha em não considerar vinculações laterais nas paredes, e que há uma necessidade urgente em investigar seu comportamento quando há dois planos de flexão.

A expressão americana para o dimensionamento de paredes de concreto, pelo método simplificado, o qual é empírico, considera praticamente as mesmas hipóteses adotadas desde 1989. Os pesquisadores citados reconhecem a necessidade de revisar a expressão do método, de forma a considerar vinculações possíveis nas quatro extremidades das paredes. Dessa forma, se poderia admitir como hipótese, o comportamento da parede com dois planos de flexão quando submetida à carregamentos verticais, o que é mais realista e menos conservador.

\subsubsection{EN 1992 Eurocode 2:2004 - Design of Concrete Structure}

O código europeu também disponibiliza, em sua seção 12 , um método simplificado para o cálculo da resistência última à compressão de paredes de concreto submetidas a cargas verticais. A expressão apresentada na Equação (3.6) admite a hipótese de que a parede possa ter vinculações em suas quatro bordas. 
$N_{R d}=b \cdot h_{w} \cdot f_{c d} \cdot \phi$

onde:

$N_{R d}$ : resistência última à compressão;

$b \quad$ : comprimento da parede em planta;

$h_{w} \quad$ : espessura da parede;

$f_{c d}$ : resistência de cálculo à compressão do concreto;

$\phi \quad$ : parâmetro que inclui excentricidades e efeitos de $2^{\mathrm{a}}$ ordem;

O parâmetro que inclui as excentricidades e os efeitos $2^{\mathrm{a}}$ ordem é definido pela Equação (3.7), onde a excentricidade total $\left(e_{t o t}\right)$ é soma da excentricidade de $1^{\mathrm{a}}$ ordem $\left(e_{0}\right)$ com a excentricidade adicional $\left(e_{i}\right)$, a qual considera os efeitos de imperfeições geométricas.

$\phi=1,14 .\left(1-2 . e_{t o t} / h_{w}\right)-0,02 . l_{0} / h_{w} \leq\left(1-2 . e_{t o t} / h_{w}\right)$

A excentricidade adicional é obtida pela Equação (3.8), onde $l_{0}$ é a altura efetiva da parede.

$e_{i}=l_{0} / 400$

A altura efetiva da parede é obtida pela Equação (3.9), onde $l_{w}$ é a altura livre da parede e $\beta$ é obtido em função das vinculações da parede.

$l_{0}=\beta \cdot l_{w}$

A Figura 3.10 resume as nomenclaturas que o código europeu adota para as principais variáveis do cálculo de resistência última compressão de uma parede de concreto. A carga vertical de cálculo é representada por $N_{E d}$. 
A Figura 3.11 é uma adaptação da Tabela 12.1 do EN 1992:2004 a qual apresenta o cálculo de $\beta$ conforme as vinculações das paredes.

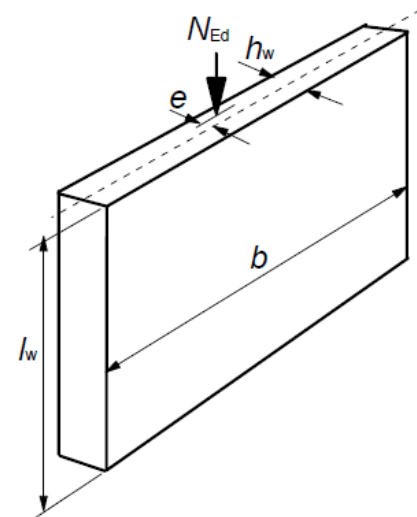

Figura 3.10 - Nomenclatura das principais variáveis no cálculo de resistência última à compressão (EN 1992:2004).

VINCULAÇÃO TIPO I

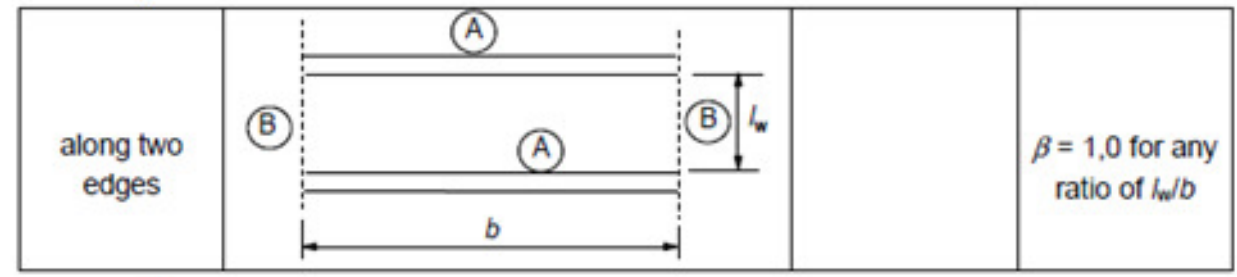

VINCULAÇÃO TIPO ॥

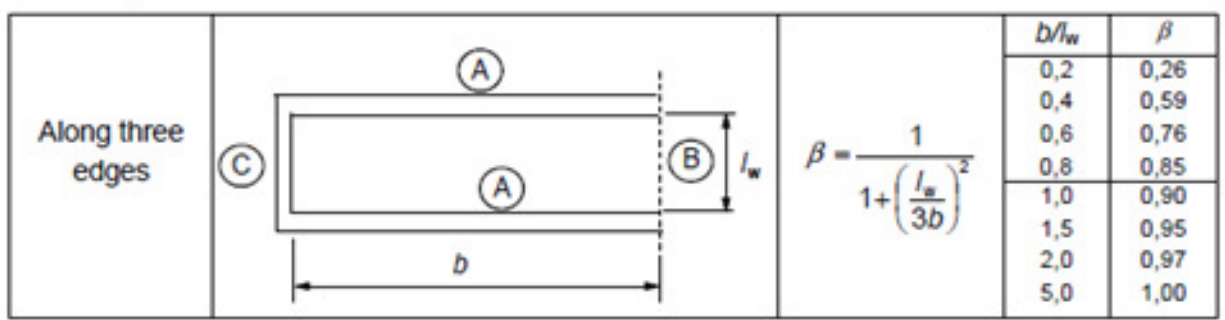

VINCULAÇÃO TIPO III

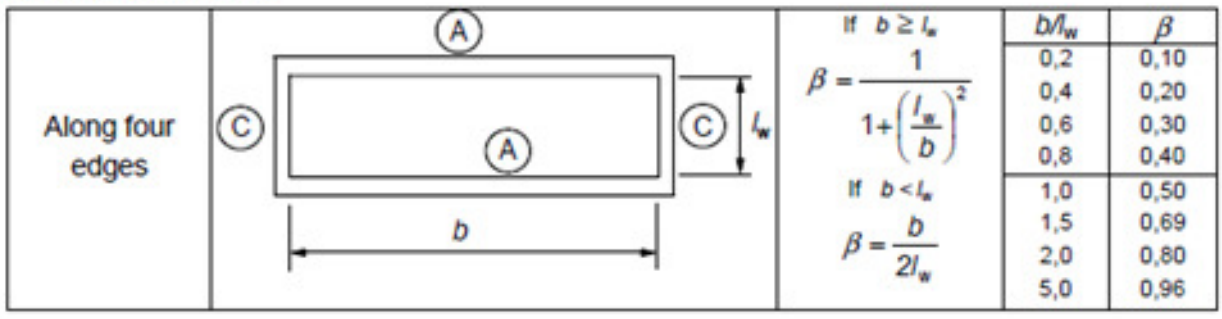

LEGENDA

A - Floor slab (B) - Free edge (C) - Transverse wall

Figura 3.11 - Cálculo de $\beta$ conforme vinculações da parede (EN 1992:2004).

A vinculação tipo I considera a parede apoiada em duas extremidades (along two edges), sendo elas a base e o topo da parede. Nesta situação $\beta=1,0$ para qualquer relação de $l_{w} / b$; a vinculação tipo II considera três lados apoiados (along three edges), sendo uma extremidade lateral, a base e o topo da parede. $O$ 
coeficiente $\beta$ é obtido pela expressão apresentada ao lado do esquema da parede; a vinculação III considera as quatro extremidades da parede apoiadas (along four edges). O valor de $\beta$ é calculado em função de $b$ e $l_{w}$, conforme equações apresentadas ao lado do esquema da parede (Figura 3.11).

As letras A, B e C da Figura 3.11 representam a laje do pavimento, borda livre e parede transversal, respectivamente.

O código europeu indica que o índice de esbeltez $\lambda$ não deve exceder o valor 86, o que equivale a dizer que a relação altura/espessura não deve exceder o valor 25. E quanto às armaduras mínimas recomenda que na direção vertical deve-se ter $A_{s, v \min }=0,002 \cdot A_{c}$, onde $A_{c}$ é a área de concreto da seção transversal e na direção horizontal o valor é definido por face da parede, sendo $A_{s, h \min }=0,001 . A_{c}$.

3.3.4 ABNT NBR 16055:2012 - Paredes de concreto moldada no local para a construção de edificações - Requisitos e procedimentos

Como um dos objetivos deste trabalho é dimensionar paredes de concreto armado de um edifício residencial de múltiplos andares, utilizando a NBR 16055:2012, além da expressão de resistência última à compressão, são apresentadas premissas básicas de dimensionamento indicadas nessa norma de forma mais detalhada.

A NBR 16055:2012 define o elemento estrutural parede de concreto, aquele em que o comprimento da seção transversal é maior ou igual a dez vezes a sua espessura. Essa norma pode ser aplicada em edificações com número ilimitado de pavimentos. A espessura da parede deve ser maior ou igual a $10 \mathrm{~cm}$, exceto para o caso de edifícios com até 2 pavimentos, em que a espessura deve ser maior ou igual a $8 \mathrm{~cm}$. Admite-se resistência característica à compressão do concreto de até $40 \mathrm{MPa}$.

Permite-se calcular a parede como estrutura de casca plana. Os esforços característicos podem ser obtidos em regime elástico desde que respeitada as condições citadas e, verificado-se o dimensionamento conforme a seguir.

A expressão de resistência última à compressão é apresentada na Equação (3.10): 
$\eta_{d, r e s i s t}=\frac{\left(0,85 \cdot f_{c d}+\rho \cdot f_{s c d}\right) \cdot t}{k_{1}\left[1+3 k_{2}\left(2-k_{2}\right)\right]} \leq \frac{\left(0,85 \cdot f_{c d}+\rho \cdot f_{s c d}\right) \cdot t}{1,643} \leq 0,4 \cdot f_{c d} \cdot t$

onde:

$\eta_{d, \text { resist }}$ : resistência última à compressão por unidade de comprimento;

$f_{c d} \quad$ : resistência de cálculo à compressão do concreto;

$\rho \quad$ : taxa geométrica da armadura vertical da parede, não maior que $1 \%$;

$t \quad$ : espessura da parede;

$f_{s c d} \quad$ : resistência de cálculo do aço à compressão; $f_{s c d}=\frac{E_{s} \cdot 0,002}{\gamma_{s}}$;

$E_{s} \quad$ : módulo de elasticidade do aço;

$\gamma_{s} \quad$ : coeficiente redutor de resistência do aço igual a 1,15;

A definição dos coeficientes $k_{1}$ e $k_{2}$ dependem do índice de esbeltez da parede, que é definido pela Equação (3.11).

$\lambda=\frac{\ell_{e} \cdot \sqrt{12}}{t}$

A Figura 2 da NBR 16055, apresentada aqui na Figura 3.12 de forma adaptada, define o comprimento equivalente $\ell_{e}$ da parede, em função das suas vinculações.

O coeficiente $k_{1}$ é definido por $k_{1}=\lambda / 35$ para qualquer valor de $\lambda$. Quando 0 índice de esbeltez estiver no intervalo $35 \leq \lambda \leq 86, k_{2}$ vale zero. Se o índice de esbeltez estiver no intervalo $86<\lambda \leq 120, k_{2}$ é definido pela Equação (3.12).

$k_{2}=\frac{(\lambda-86)}{120}$ 
Os coeficientes $k_{1}$ e $k_{2}$ consideram a minoração da resistência última à compressão referente à instabilidade localizada causada por efeitos de $2^{\mathrm{a}}$ ordem.

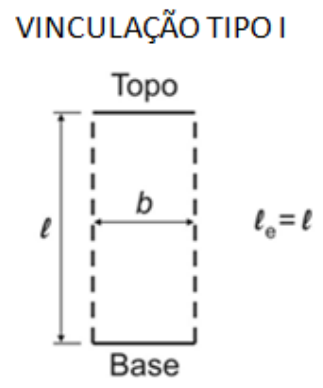

VINCULAÇÃO TIPO III

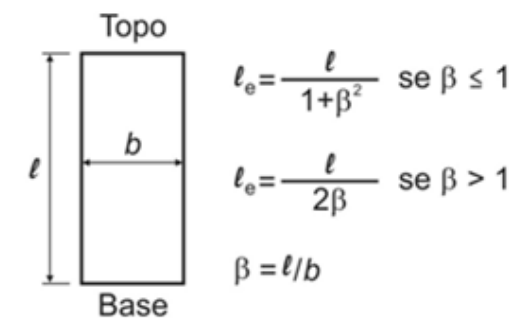

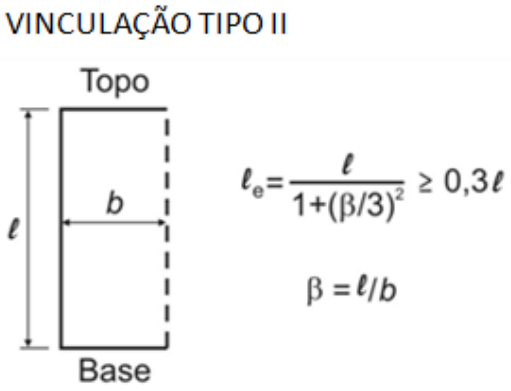

VINCULAÇÃO TIPO IV

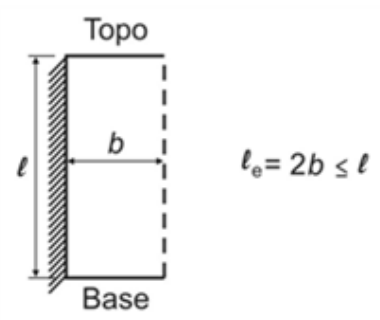

Figura 3.12 - Cálculo de $\ell_{e}$ conforme vinculações da parede (NBR 16055:2012).

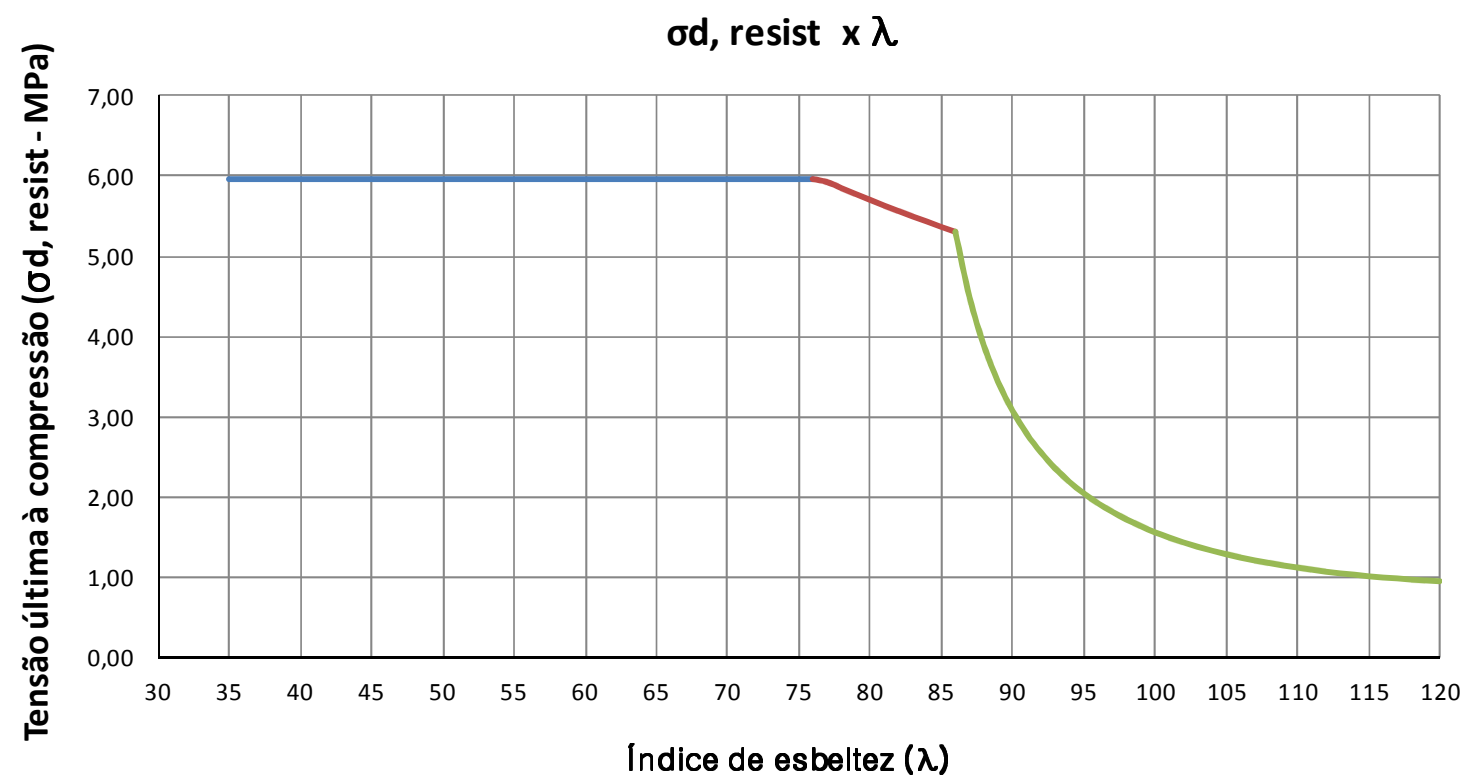

$\sigma d$, resist $=f(35 \leq \lambda \leq 76)=0,4 . f c d$

$\sigma d$, resist $=f(76<\lambda \leq 86)=(0,85 . f c d+p . f s c d) /(k 1 \cdot[1+3 \cdot k 2 \cdot(2-k 2)])<0,4 . f c d$ com $k 2=0$

$\sigma d$, resist $=f(86<\lambda \leq 120)=(0,85 . f c d+p \cdot f s c d) /(k 1 \cdot[1+3 \cdot k 2 \cdot(2-k 2)])<0,4 . f c d$ com $k 2 \neq 0$

Figura 3.13 - Decréscimo da tensão última à compressão com aumento do índice de esbeltez, conforme NBR 16055:2012. 
Para se ter ordem de grandeza, o gráfico da Figura 3.13 mostra o decréscimo da tensão última à compressão a medida que o índice de esbeltez aumenta, considerando $f_{c k}=25 \mathrm{MPa}, f_{s c d}=365,2 \mathrm{MPa}$ e $\rho=0,1 \%$. Ao traçar o gráfico, a expressão de resistência última à compressão, descrita na Equação (3.10), foi aplicada sem considerar a espessura da parede para que os valores ficassem em termos de tensão. A perda de resistência é visível e significativa quando $\lambda>86$, limite a partir do qual $k_{2}$ é diferente de zero e que, consequentemente, a influência da instabilidade localizada é bem maior. Caso se queira fazer uma análise mais precisa de instabilidades locais e localizadas, devem ser utilizadas as expressões dos itens 15.8 e 15.9 da NBR 6118:2007 - Projeto de estruturas de concreto.

É importante mencionar que a NBR 16055:2012 considera o coeficiente redutor de resistência à compressão do concreto $\gamma_{c}=1,68$.

A expressão ainda incorpora automaticamente a excentricidade mínima transversal ao plano médio da parede, que deve ser considerada, e tem valor igual ao maior valor entre:

a) excentricidade obtida por pressão de vento de $0,1 \mathrm{tf} / \mathrm{m}^{2}$ (no caso de paredes externas);

b) excentricidade obtida pela expressão $(1,5+0,03 . t)$, onde t é a espessura da parede (válida para todas as paredes).

Portanto, quando a expressão de $\eta_{d \text {,resist }}$ for utilizada ao dimensionar uma parede, não há necessidade de considerar flexão composta oblíqua, já que o momento fletor em relação à menor inércia da parede é considerado pela excentricidade mínima incorporada à expressão. Dessa maneira basta verificar as tensões normais devido à flexão composta reta, mais especificamente da flexo-compressão no plano da parede, como diz a premissa básica de dimensionamento da NBR 16055:2012 no item 17.2.

Caso haja pressões de vento superiores a $0,1 \mathrm{tf} / \mathrm{m}^{2}$, mais comuns nos últimos andares de prédios altos, devem ser feitas verificações adicionais de flexão simples em torno das direções de menor inércia nas paredes externas do edifício. As paredes do último pavimento devem ser calculadas como engastadas em sua base e apoiadas na laje de cobertura em seu topo. As paredes externas dos demais pavimentos devem ser calculadas como biengastadas (Figura 3.14). 


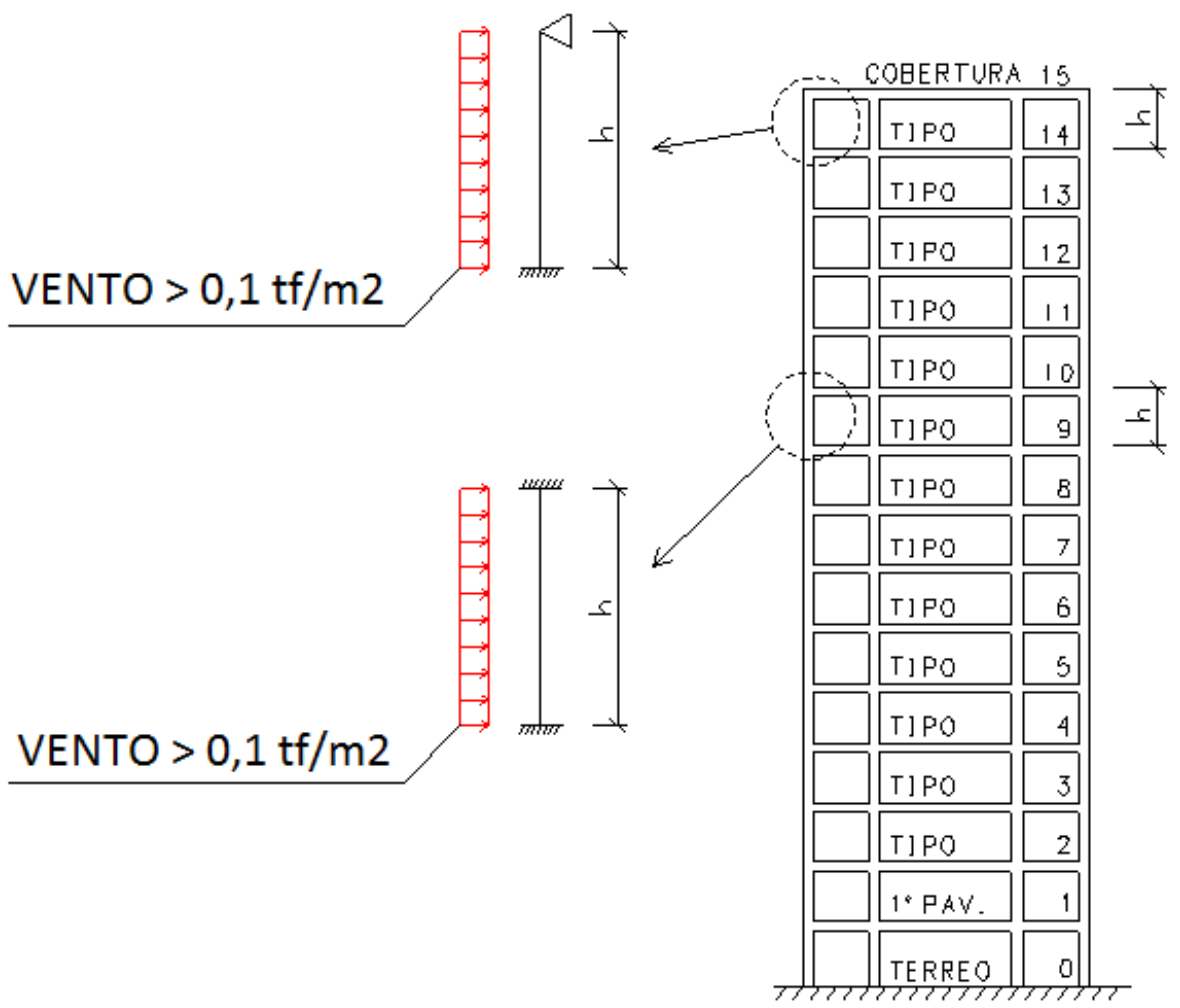

Figura 3.14 - Verificação à flexão simples em paredes com vento maior que $0,1 \mathrm{tf} / \mathrm{m}^{2}$.

Quanto à verificação da compressão, a norma brasileira permite reduzir o esforço solicitante máximo por metro linear, conforme a Equação (3.13):

$\eta_{d, \text { resist }} \geq \frac{3 \cdot \eta_{d, \max }+\eta_{d, \min }}{4}$

onde:

$\eta_{d, \max }$ : é a maior força normal por unidade de comprimento, obtida com o caso mais desfavorável de combinação para a compressão;

$\eta_{d, \text { min }}$ : é a menor força normal por unidade de comprimento, obtida com o caso mais favorável de combinação para a compressão.

Caso a combinação favorável resulte em esforço de tração, numa das extremidades da seção transversal da parede, deve-se considerar então $\eta_{d \text {,min }}=0$, 
como indica a Figura 3 na NBR 16055:2012. Apesar dessa possibilidade em amenizar a máxima tensão normal de compressão, as verificações deste trabalho consideram a máxima tensão normal de compressão íntegra.

No dimensionamento à tração, quando ocorrerem tensões normais de tração devido aos momentos fletores atuantes no plano da parede, a força total de tração, que é a resultante da integração do bloco de tensões normais de tração, deve ser resistida pela área de aço calculada conforme procedimento simplificado indicado na Equação (3.14):

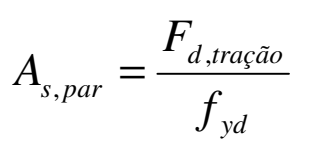

onde:

$A_{s, p a r}$ : área de aço necessária na parede de concreto para resistir a força resultante da tensão normal de tração;

$F_{d, \text { tração }}:$ força de tração de cálculo, resultante da tensão normal de tração;

$f_{y d} \quad$ : resistência de cálculo do aço; $f_{y d}=f_{y k} / \gamma_{s}$ onde $f_{y k}$ é a resistência característica de tração do aço e $\gamma_{s}$ é o redutor da resistência igual a 1,15 .

Mesmo nos casos em que não há tração na parede, a norma brasileira estabelece uma armadura mínima em aço CA-60, que pode ser uma tela soldada disposta no plano médio da parede, respeitando-se os limites:

- armadura mínima vertical:

$\rho_{v}=0,09 \%$ da seção transversal de concreto;

$\rho_{v, 2 p}=0,06 \%$ da seção transversal de concreto em construções de até 2 pavimentos;

- armadura mínima horizontal:

$\rho_{h} \quad=0,15 \%$ da seção transversal de concreto; 


$$
\begin{aligned}
\rho_{h, p a r i n t} & =0,09 \% \text { da seção transversal de concreto no caso de paredes } \\
& \text { internas; } \\
\rho_{h, p a r e x t 6} & =0,09 \% \text { da seção transversal de concreto no caso de paredes } \\
& \text { externas com até } 6 \mathrm{~m} \text { de comprimento e entre juntas de controle; }
\end{aligned}
$$

Em construções com até dois pavimentos, permite-se utilizar $40 \%$ das taxas de armadura mínima horizontal.

Como mencionado, as paredes podem ser armadas com uma tela soldada centrada, no entanto, para paredes com espessura maior que $15 \mathrm{~cm}$, e também paredes no andar térreo sujeitas a choque de veículos ou que engastam marquises em balanço, deve-se utilizar tela dupla, uma em cada face da parede, respeitando o cobrimento. Observa-se que a norma brasileira permite diminuir a armadura mínima na direção vertical no caso de paredes com espessura maior que $15 \mathrm{~cm}$, em $67 \%$ dos valores apresentados. No entanto neste caso, o cálculo é feito por face da parede.

A expressão de resistência última à compressão, apresentada na Equação (3.10), limita a taxa geométrica de armadura vertical em $\rho \leq 1 \%$ (valor e premissa idêntica ao ACI 318:2011) com o objetivo de garantir a estabilidade desta armadura sob compressão apenas com o confinamento do concreto, evitando-se, assim, a necessidade de estribos horizontais, os quais prejudicariam imensamente a produtividade do sistema Paredes de Concreto.

A verificação das tensões tangenciais é realizada nas almas das paredes de contraventamento. A força cortante solicitante de cálculo $V_{d}$, obtida pela combinação de ações apropriada deve ser menor que a força cortante resistente de cálculo $f_{v d}$ definida no item 17.6.2 da NBR 16055, conforme Equação (3.15).

$$
f_{v d}=0,3 \cdot f_{c t, d} \cdot\left(1+3 \cdot \sigma_{c m d} / f_{c k}\right) \cdot t \cdot L
$$

onde:

$f_{v d} \quad$ : força cortante resistente de cálculo; 
$f_{c k}$ : resistência característica à compressão do concreto expressa em $\mathrm{MPa}$;

$f_{c t, d}$ : resistência de cálculo à tração do concreto; $f_{c t, d}=\frac{0,21 \cdot f_{c k}^{2 / 3}}{\gamma_{c}}$, sendo $\gamma_{c}$ o redutor de resistência do concreto igual a 1,4 neste caso.

$\sigma_{c m d}$ : tensão normal obtida apenas por cargas verticais permanentes; é chamada tensão média de cálculo no concreto comprimido, expressa em MPa;

$t$ : espessura da parede;

$L \quad$ : comprimento da parede em planta; é o comprimento da alma;

A expressão $\left(1+3 \cdot \sigma_{c m d} / f_{c k}\right)$ deve ser no máximo igual a 2,00.

Caso $V_{d}>f_{v d}$ deve-se armar a parede ao cisalhamento com área de aço calculada como mostram as Equações (3.16) e (3.17).

$$
\begin{aligned}
A_{s h / s} & =V_{d} / f_{y d} \\
A_{s v / s} & =\frac{\left(V_{d}-\frac{\eta_{d}}{2}\right)}{f_{y d}}
\end{aligned}
$$

onde:

$A_{s h / s}:$ área de aço por unidade de comprimento na direção horizontal;

$A_{s v / s}$ : área de aço por unidade de comprimento na direção vertical;

$\eta_{d} \quad$ : força normal de cálculo por unidade de comprimento;

Outra verificação importante, referente às tensões tangenciais, deve ser feita na interface vertical do encontro de paredes. Neste caso a expressão da força cortante resistente de cálculo não considera a tensão média de cálculo no concreto comprimido, como explicado no item 6.9.2. 


\section{MODELOS DE CÁLCULO}

O presente capítulo apresenta os modelos de cálculo utilizados neste trabalho para distribuir as cargas verticais e as ações horizontais em um edifício construído no sistema Paredes de Concreto. Dentre eles, há dois modelos numéricos, o Modelo em Elementos Finitos e o Modelo Pórtico Tridimensional.

Segundo Nunes (2011), atualmente, para o cálculo de edifícios de paredes de concreto armado, são utilizados procedimentos análogos aos empregados na alvenaria estrutural. Dessa maneira, os modelos propostos nesta pesquisa já foram consolidados quando aplicados para o caso da alvenaria estrutural, sistema análogo ao das Paredes de Concreto.

\subsection{Distribuição de cargas verticais}

\subsubsection{Considerações iniciais}

Num edifício residencial, as cargas verticais são determinadas somando-se o peso próprio dos elementos estruturais com as ações permanentes e variáveis, conforme indica a norma ABNT NBR 6120:1980 - Cargas para o cálculo de estruturas de edificações. No caso do sistema Paredes de Concreto, usualmente a estrutura é composta apenas por lajes e paredes. Portanto, deve-se somar o peso próprio desses elementos com as ações permanentes e variáveis oriundas das lajes e considerá-las atuantes nas paredes estruturais, que as transmitirão até a fundação ou a estruturas de transição.

A norma ABNT NBR 16055:2012 - Paredes de concreto moldada no local para a construção de edificações - Requisitos e procedimentos, considera que as cargas verticais atuam paralelamente ao plano médio das paredes de concreto.

Corrêa e Ramalho (2003) ressaltam que a definição de como a ação das lajes sobre as paredes que the servem de apoio se realiza, e também como ocorrem as interações entre paredes, são aspectos determinantes para se obter uma análise estrutural coerente das paredes. 


\subsubsection{Ações das lajes}

Para o cálculo das reações das lajes nas paredes, utilizou-se o método das charneiras plásticas o qual se baseia na posição aproximada das linhas de ruptura que definem as áreas de influência das lajes sobre as paredes. As áreas podem ser divididas seguindo as considerações abaixo:

- Quando a laje for armada em uma direção (Figura 4.1a):

- 0,5.L entre dois apoios do mesmo tipo;

- 0,38.L do lado apoiado e 0,62L do lado engastado;

- 1,0.L do lado engastado, se a outra borda for livre.

- Quando a laje for armada em duas direções (Figura 4.1b):

- $45^{\circ}$ entre dois apoios do mesmo tipo;

- $60^{\circ}$ a partir do lado engastado se o outro for apoiado;

- $90^{\circ}$ a partir de qualquer apoio se a borda vizinha for livre.

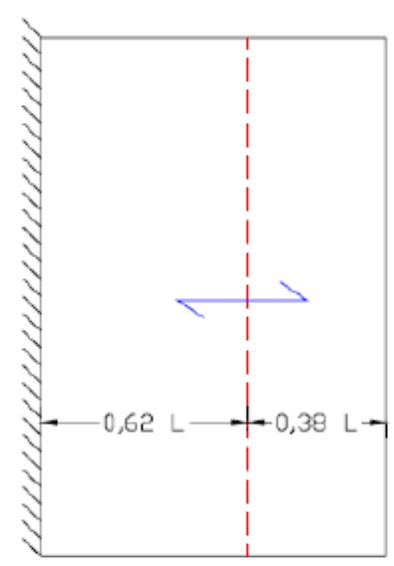

(a)

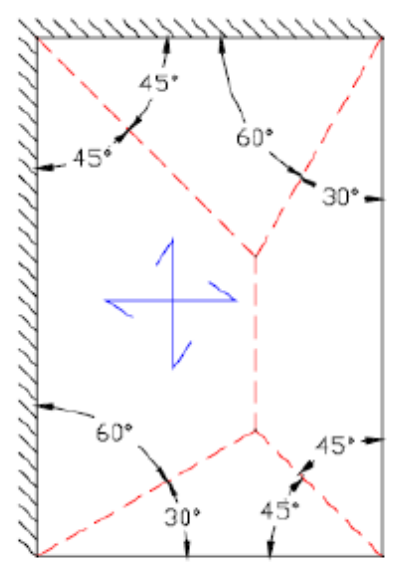

(b)

Figura 4.1 - Esquema para cálculo das reações das lajes (OLIVEIRA, 2009). 


\subsubsection{Espalhamento das cargas verticais}

Ao se distribuírem cargas verticais nas paredes de concreto, quando elas são concentradas ou parcialmente distribuídas, pode-se assumir, conforme ABNT NBR 16055, um espalhamento ao longo da altura da parede, seguindo um ângulo limite de $45^{\circ}$. Esse ângulo é definido no plano da parede sobre uma linha vertical passando no ponto de aplicação da carga, como indica a Figura 4.2. Consequentemente, esse espalhamento gera uma uniformização de cargas.

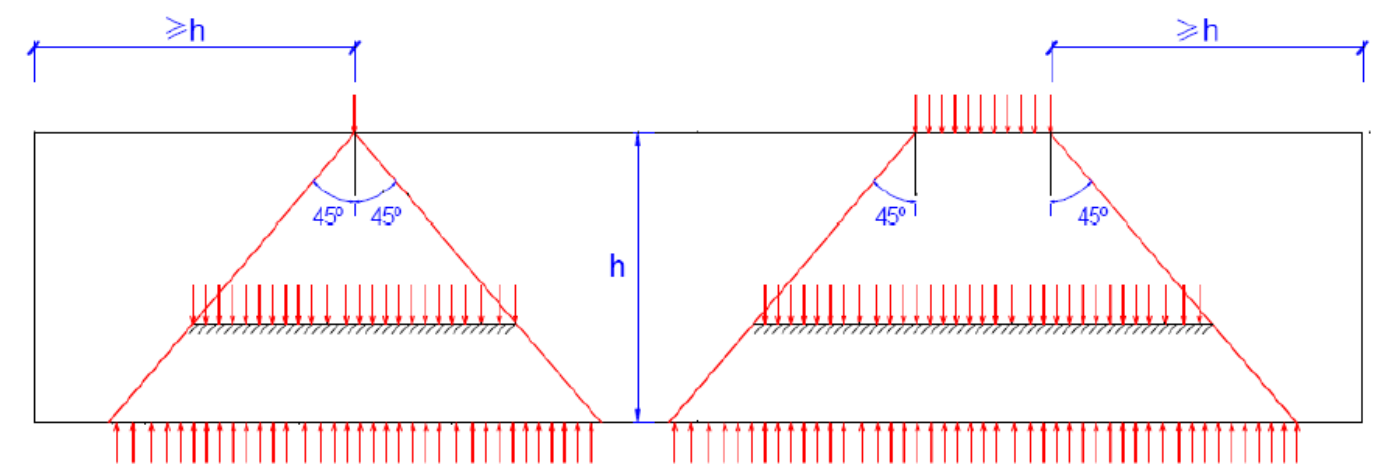

Figura 4.2 - Espalhamento de cargas concentradas ou parcialmente distribuídas (ABNT NBR 16055).

Tal comportamento também é válido em paredes adjacentes devido à interação que ocorre entre elas, ou seja, há transferência de forças na interface comum. Essas forças, chamadas de força de interação, são causadas pela tendência de deslocamento relativo na interface vertical, e ocorrem para carregamentos diferenciados. Portanto, o espalhamento das cargas verticais, e consequente uniformização, ocorre também entre paredes adjacentes desde que haja interação entre elas (Figura 4.3). Além disso, a transferência de forças acontece somente se a tensão de cisalhamento resistente na interface vertical comum for maior que a tensão de cisalhamento induzida pelas forças de interação.

Embora sejam de menor intensidade, as forças de interação entre lintéis e paredes, sendo os lintéis definidos pelas regiões acima e abaixo de aberturas, como portas e janelas por exemplo, também contribuem no espalhamento de cargas verticais, desde que a tensão de cisalhamento seja verificada na interface comum. $A$ Figura 4.4 exemplifica esta situação para o caso de uma abertura de janela numa parede de concreto. 


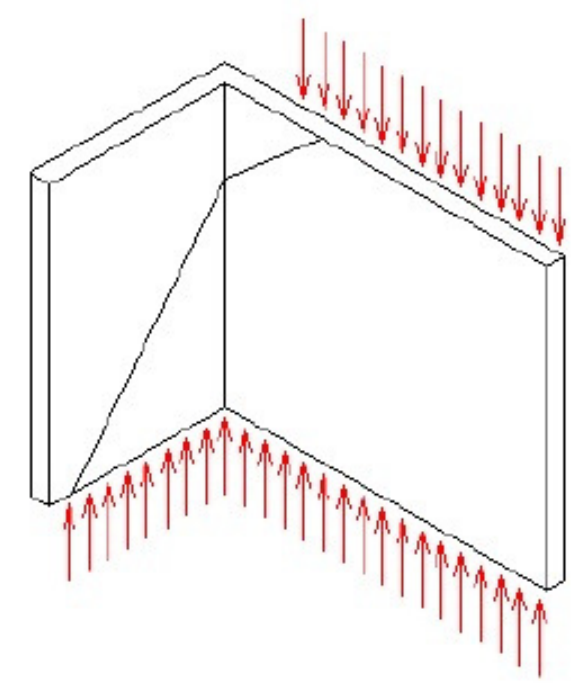

Figura 4.3 - Espalhamento de cargas em paredes adjacentes (NUNES, 2011).
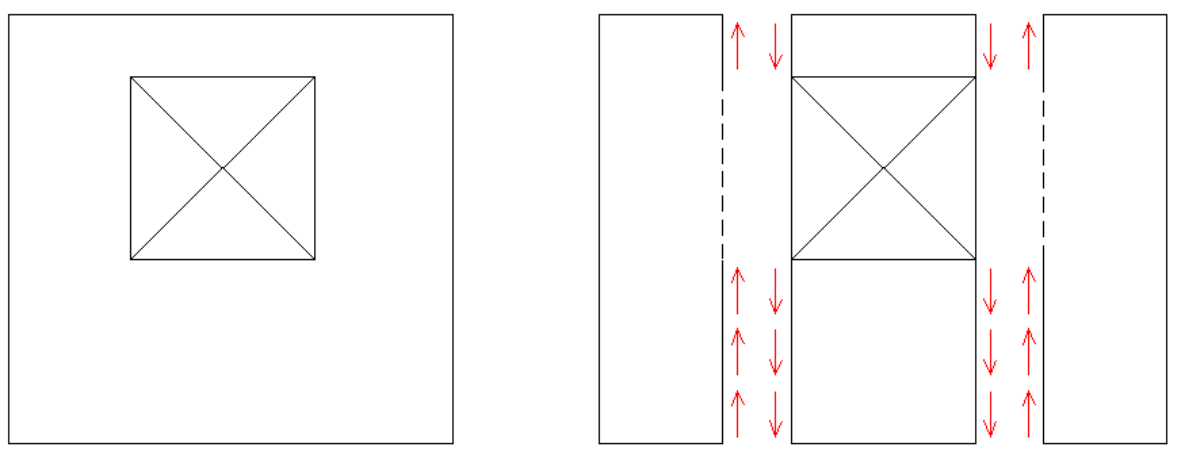

Figura 4.4 - Forças de interação em regiões de aberturas.

Portanto, é importante avaliar como as paredes e os lintéis vão interagir de modo a distribuir corretamente as cargas verticais nas paredes.

Hendry (1981) comenta que pode haver consideráveis diferenças na estimativa das ações atuantes nas paredes dependendo do procedimento adotado para a distribuição de cargas verticais de um edifício com um arranjo complexo de paredes.

A seguir apresentam-se os modelos de cálculo adotados neste trabalho para a distribuição de cargas verticais. 


\subsubsection{Paredes Isoladas (PIS)}

As paredes são consideradas como elementos isolados, não havendo forças de interação entre elas. É um modelos simples e rápido em que consiste no somatório das cargas atuantes em determinada parede, contabilizando a influência de todos os pavimentos acima daquele em que a análise está sendo feita.

A vantagem do modelo está na sua rapidez e simplicidade, no entanto tem como desvantagem as possíveis distorções de resultados nas cargas das paredes bem como em suas regiões de apoio, como vigas de transições e vigas baldrame.

\subsubsection{Grupo Isolado de Paredes (GIP)}

Segundo Corrêa e Ramalho (2003), um grupo é um conjunto de paredes que são supostas totalmente solidárias. Essa hipótese é válida devido à existência de forças de interação entre as paredes, e desde que a tensão de cisalhamento gerada por essas forças, na interface vertical do encontro das paredes, seja menor que a tensão de cisalhamento resistente.

O grupo de paredes é isolado pelo fato de o modelo considerar que não há forças de interação entre lintéis e paredes (elas existem apenas entre paredes). Assim, os grupos não interagem entre si. Portanto, geralmente os limites dos grupos são as aberturas de portas e janelas, regiões onde se encontram os lintéis.

Nesse modelo, consideram-se as cargas totalmente uniformizadas em cada grupo de paredes. A força atuante no grupo é a soma das forças atuantes em cada uma das paredes que o compõe. Para tanto, o espalhamento das cargas verticais é considerado conforme premissas das Figuras 4.2 e 4.3. O comprimento total do grupo é a soma dos comprimentos de cada parede contida nele. Dessa maneira, a carga uniformizada do grupo é definida pela razão entre a força atuante e o comprimento total dele.

O modelo é seguro e também econômico quando a escolha de grupos é feita corretamente. Contudo é fundamental que se avalie a possibilidade de ocorrerem forças de interação em cantos e bordas pela verificação da tensão de cisalhamento nas interfaces verticais do encontro de paredes, condição essencial para aplicação 
do modelo. Também é simples e rápido e resulta em cargas adequadas para estruturas de apoio.

Para comprovar a eficiência do modelo, medições de deformações em um edifício de alvenaria estrutural com cinco pavimentos, realizadas por Stockbridge (1967) apud Oliveira (2009), evidenciaram que em edifícios suficientemente altos há uma tendência das tensões se uniformizarem em pavimentos inferiores. A Figura 4.5 mostra as leituras de deformações em uma parede do edifício durante sua construção. Conforme posição dos extensômetros 1, 2 e 3, apresentada na Figura 4.5b, era de se esperar que o ponto 1, por ter área de influência das lajes menor que o ponto 2 (como mostra a Figura 4.5c), apresentasse uma deformação consideravelmente menor que a do ponto 2 , no entanto não é o que ocorre devido à uniformização de cargas verticais. Por isso a Figura 4.5a mostra que as deformações dos extensômetros 1 e 2 são praticamente iguais. A deformação do extensômetro 3 teve influência da presença do lintel xy (Figura 4.5c). No início houve uma forte atração das forças, mas quando a construção alcançou o primeiro pavimento, as deformações reduziram-se a valores próximos aos observados nos pontos 1 e 2, o que comprovou a forte tendência de uniformização de cargas verticais. Mais informações sobre resultados experimentais envolvendo o estudo do modelo Grupo Isolado de Paredes, podem ser encontradas em Oliveira (2009).

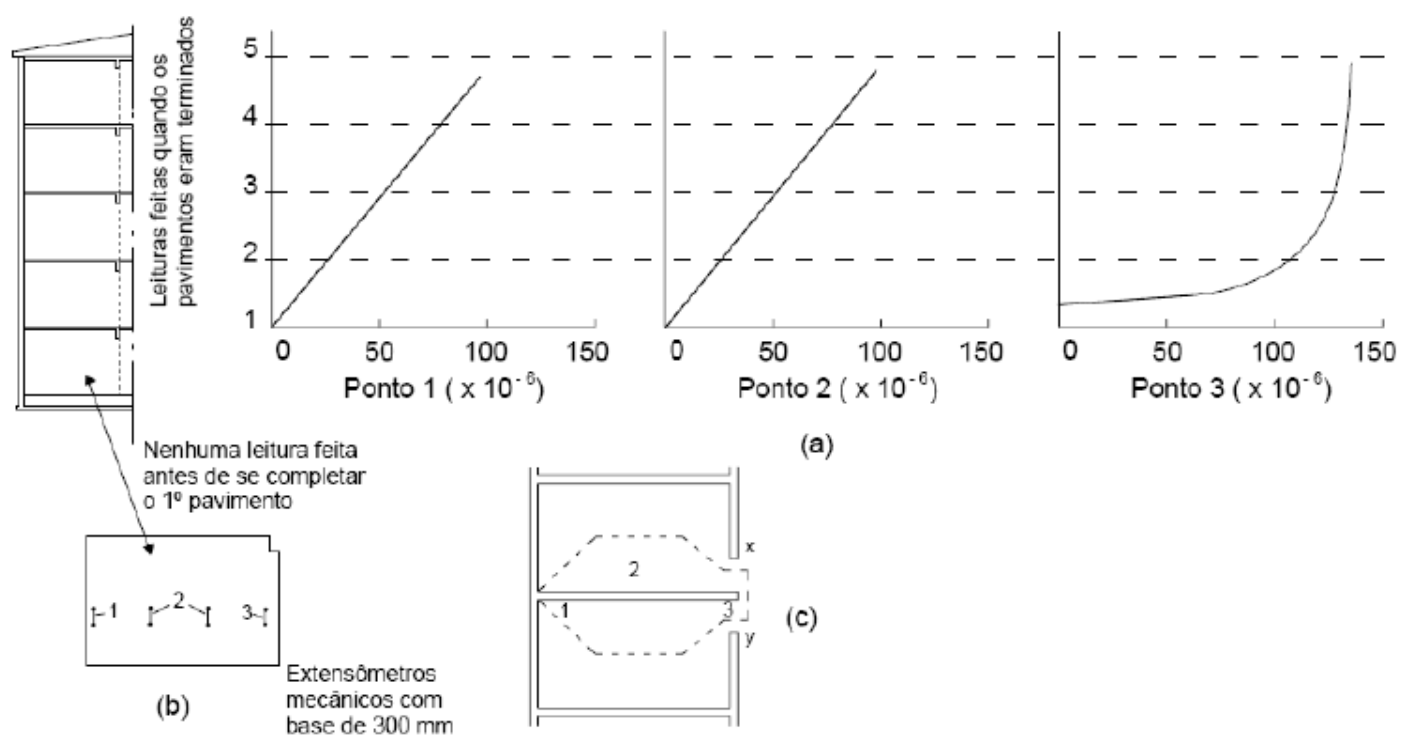
(a) Medidas no $1^{\circ}$ pav.
; (b) Localização dos extensômetros;
(c) Área de contribuição.

Figura 4.5 - Medidas de deformações realizadas num edifício de alvenaria estrutural com cinco pavimentos (OLIVEIRA, 2009). 
Normalmente os grupos são definidos pela soma dos seguimentos de paredes até o encontro de aberturas ou vãos. Caso haja lintel na respectiva abertura ou vão, a carga atuante nele será dividida por dois e aplicada de forma concentrada no ponto de apoio dos dois grupos adjacentes ao lintel.

A fim de resumir o modelo, em que consiste na homogeneização das cargas verticais dentro de um grupo isolado de paredes, Capuzzo Neto (2000) enunciou o algoritmo da Equação (4.1):

$$
p_{G I P}=\sum\left(p_{0 i} \cdot L_{i}+P_{i}\right) / \sum L_{i}
$$

onde:

$$
\begin{array}{ll}
p_{G I P} \quad \text { : ações homogeneizadas uniformemente distribuídas no nível } \\
\\
\text { considerado; } \\
p_{0 i} \quad \text { : ações uniformemente distribuídas nas paredes do grupo no nível } \\
\quad \text { considerado; } \\
P_{i} \quad \text { : ações concentradas nas paredes do grupo no nível considerado; } \\
L_{i} \quad \text { : comprimento da parede i que constitui o grupo. }
\end{array}
$$

\subsubsection{Modelos numéricos}

O Modelo em Elementos Finitos e o Modelo Pórtico Tridimensional possibilitam a distribuição de cargas verticais e também de ações horizontais. Por isso eles são detalhados no item 4.2, relativo à distribuição de ações horizontais.

\subsection{Distribuição de ações horizontais}

\subsubsection{Considerações iniciais}

A presença de sistemas de contraventamento em qualquer edificação submetida a ações horizontais de qualquer natureza é fundamental para que se confira segurança e estabilidade às edificações. 
Os sistemas de contraventamento podem ser definidos em função do sistema estrutural adotado. Numa estrutura reticulada, por exemplo, é usual adotar pórticos e núcleos rígidos para tal função. Já em sistemas estruturais compostos por paredes, como é o caso da Alvenaria Estrutural e o sistema Paredes de Concreto, o contraventamento é realizado pelo conjunto de painéis de paredes. Painéis treliçados e pilares isolados são outros exemplos de estruturas com esta função. Elementos horizontais, tais como lajes e vigas, também influenciam no contraventamento da estrutura global e podem ser denominadas estruturas horizontais de contraventamento.

No caso de sistemas estruturais compostos por paredes, as lajes agindo como diafragma rígido distribuem as ações horizontais entre as paredes de contraventamento, de acordo com suas rigidezes. A Figura 4.6 representa a distribuição da ação do vento em painéis de contraventamento. Para que esse fenômeno ocorra, ressalta-se que as interfaces horizontais entre paredes e lajes (alma das paredes), devem ser capazes a resistir às tensões de cisalhamento provocadas pelas ações horizontais.

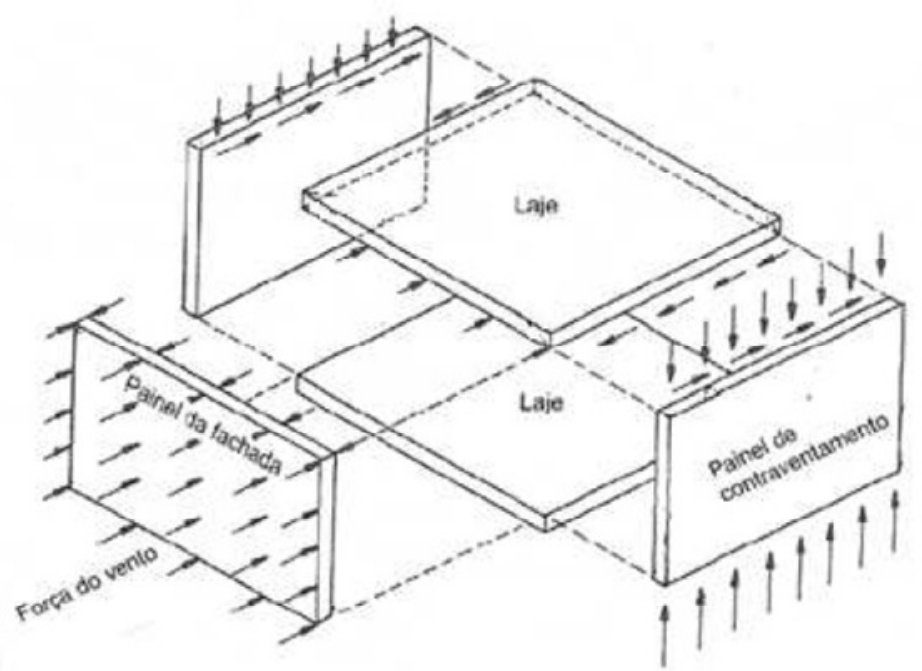

Figura 4.6 - Distribuição das ações do vento entre painéis de contraventamento (CORRÊA e RAMALHO, 2003).

Dois modelos numéricos são utilizados neste trabalho a fim de distribuir as ações horizontais, e que também possibilitam distribuir cargas verticais. Ambos são modelados no software comercial SAP2000, o qual possibilita a discretização da estrutura em elementos finitos. Da biblioteca do programa, são utilizados o elemento de casca Shell (detalhes do elemento podem ser vistos no item 4.2.6), para o modelo denominado nesta pesquisa por Modelo em Elementos Finitos (MEF), e o 
elemento de barra Frame, utilizado na concepção do Modelo Pórtico Tridimensional (MPT). Outro recurso do programa utilizado nos dois modelos foi a modelagem das lajes como diafragma rígido.

\subsubsection{Diafragma rígido}

A simulação de lajes em concreto armado atuando como diafragmas rígidos em seu plano é razoável, segundo Corrêa (1991), desde que as lajes não apresentem aberturas muito grandes ou o pavimento não apresente em planta uma das dimensões muito maior que a outra.

Conforme Corrêa (1991), nesse recurso, os graus de liberdade de cada nó do pavimento, associados aos deslocamentos de corpo rígido do diafragma, são dependentes dos graus de liberdade do nó mestre, que é criado arbitrariamente em algum ponto do plano do pavimento para caracterizar o comportamento de corpo rígido do diafragma. Ou seja, as duas translações horizontais no plano da laje e uma rotação em torno do eixo do edifício, de todos os nós do pavimento onde o diafragma rígido foi considerado, são compatibilizadas. Além disso, a distribuição das ações horizontais numa direção entre as paredes de contraventamento dessa mesma direção ocorre em função das rigidezes delas.

Corelhano (2010) complementa que em função da aplicação do diafragma rígido, a discretização da laje na estrutura de contraventamento pode ser dispensada, uma vez que é considerada infinitamente rígida em seu plano e compatibiliza as translações e rotações do pavimento.

Observa-se que as lajes são flexíveis em relação à sua direção normal e, portanto, sua análise e verificação estrutural são imprescindíveis. Ressalta-se que este trabalho não tem como objetivo analisar o comportamento estrutural das lajes.

Neste trabalho utilizou-se o diafragma rígido nos dois modelos desenvolvidos no software SAP2000, a fim de estudar exclusivamente o comportamento das paredes de contraventamento.

As equações que regem os deslocamentos de dois nós quaisquer do pavimento, associados ao nó mestre, são descritas abaixo:

$$
\begin{aligned}
& u_{1 j}=u_{1 i}-r_{3 i} \cdot \Delta x_{2} \\
& u_{2 j}=u_{2 i}-r_{3 i} \cdot \Delta x_{1}
\end{aligned}
$$


$r_{3 i}=r_{3 j}$

onde, $\Delta x_{1}=x_{1 j}-x_{1 i}$ e $\Delta x_{2}=x_{2 j}-x_{2 i}$.

As equações são expressas em termos de translações horizontais, $u_{1}$ e $u_{2}$, uma rotação $r_{3}$ em torno do eixo do edifício e das coordenadas locais adotadas no plano do diafragma rígido, $x_{1}$ e $x_{2}$.

Para a validade dessa hipótese, o programa conecta todos os nós associados ao nó mestre, por links rígidos no plano, sem que eles influenciem as deformações fora do plano. A Figura 4.7 mostra tal procedimento.

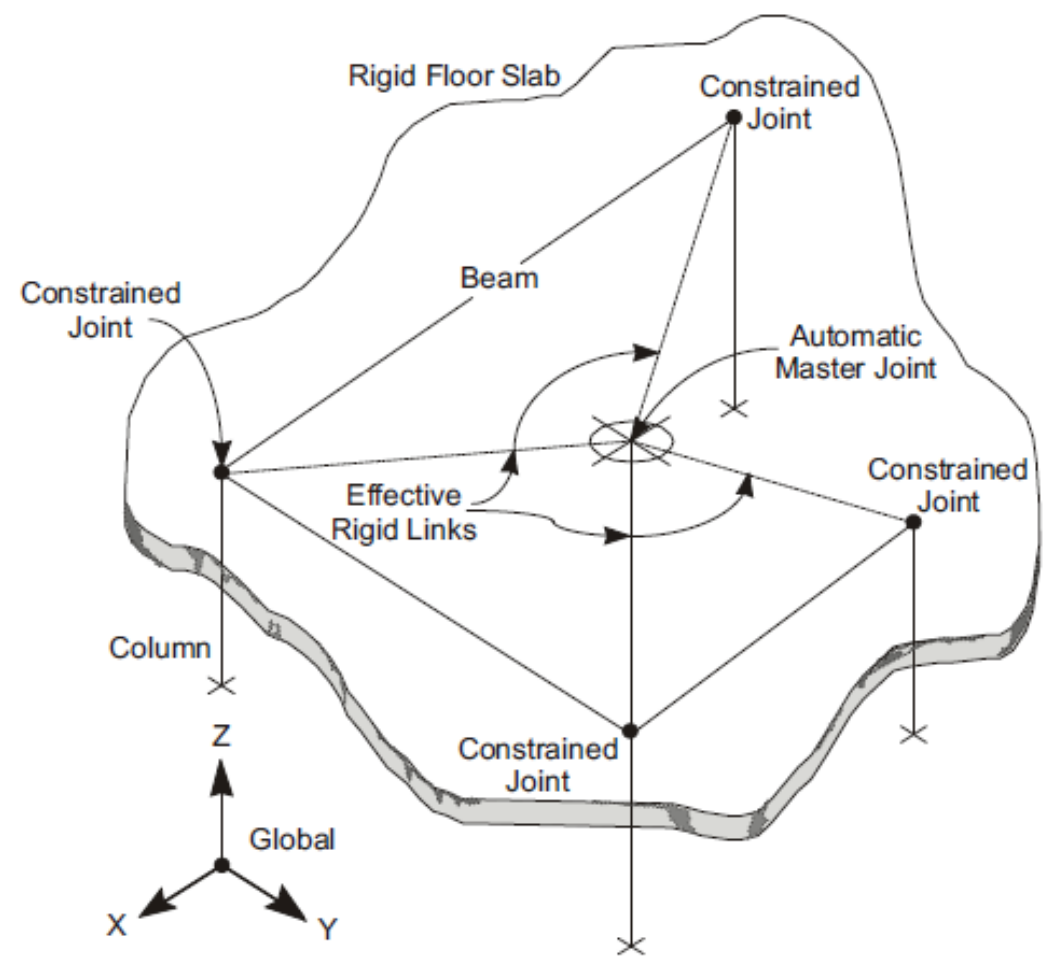

Figura 4.7 - Modelagem do diafragma rígido no SAP2000 (CSI - SAP2000, 2011).

\subsubsection{Efeitos de torção}

Segundo Blessmann (1989) apud Nascimento Neto (1999), os efeitos de torção podem ser associados a várias causas, podendo-se citar: desigual distribuição das pressões do vento, assimetria do sistema estrutural de contraventamento, turbulência do vento incidente, incidência oblíqua do vento. Acrescenta-se ainda a aplicação de ações excêntricas à estrutura. 
No presente trabalho, o esforço de torção nas paredes de contraventamento não foi discutido. Os edifícios estudados têm planta duplamente simétrica, ou próximo disso, e as ações horizontais foram aplicadas em seus eixos de simetria. Portanto, nos casos estudados o centro geométrico da estrutura é coincidente, ou praticamente coincidente, com seu centro de torção. Como as ações foram aplicadas nos eixos de simetria (sem excentricidades), não há ocorrência do esforço de torção. A Figura 4.8 exemplifica essa situação.
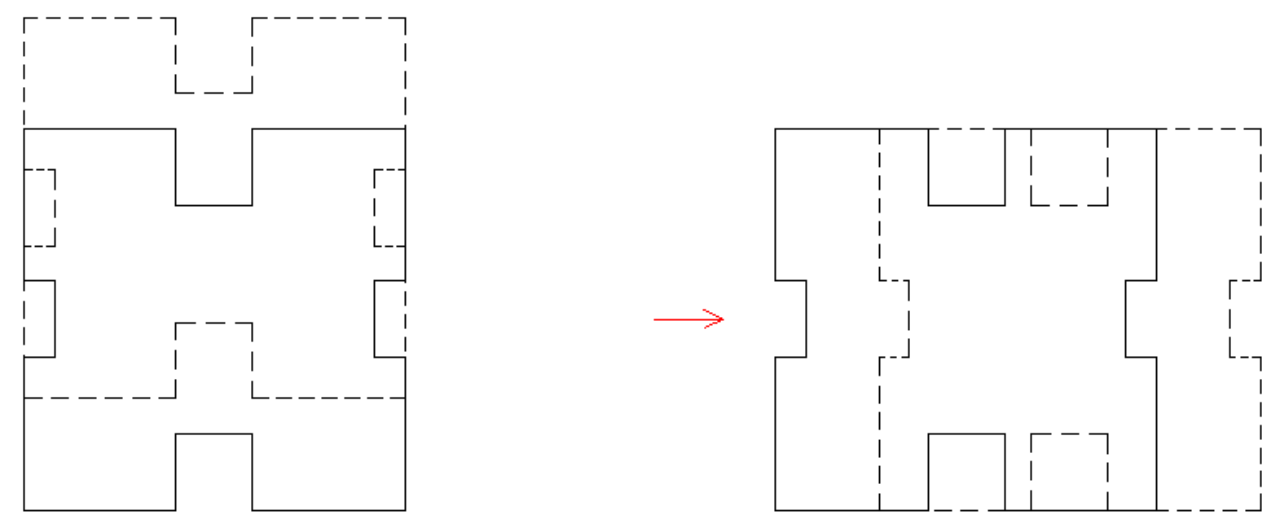

Figura 4.8 - Simetria em planta e ações horizontais não excêntricas: apenas translações horizontais; não há esforço de torção.

A Figura 4.9 exemplifica duas situações em que o efeito de torção ocorre. Primeiramente quando as ações horizontais são aplicadas de forma excêntrica, e em seguida quando a estrutura apresenta assimetria numa de suas direções principais.
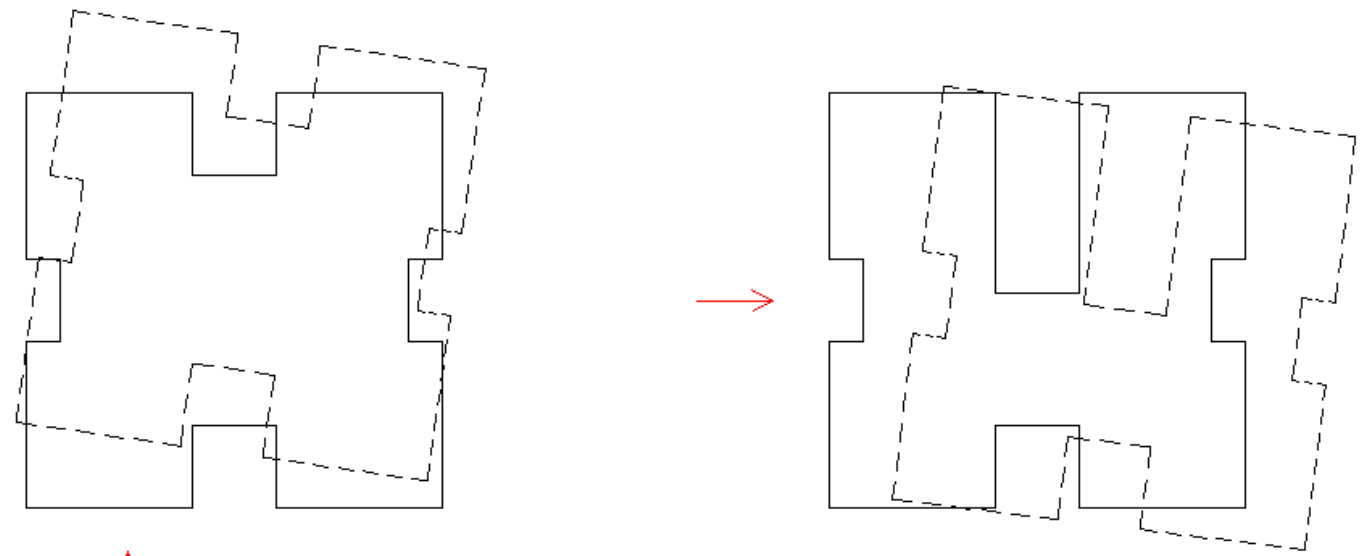

Figura 4.9 - Assimetria em planta ou ações horizontais excêntricas: translações horizontais e rotação em torno da altura do edifício; há esforço de torção. 


\subsubsection{Ações Horizontais}

Ações horizontais sobre a estrutura de um edifício podem ser causadas por fenômenos naturais, como, por exemplo, a ação do vento e de sismos, por imperfeições geométricas, como o desaprumo da construção e por empuxos desequilibrados.

A NBR 16055 diz que as ações horizontais que devem ser consideradas obrigatoriamente são as originadas pelo vento e pelo desaprumo, não se prescindindo das demais ações que, na avaliação do projetista, possam produzir esforços relevantes.

Neste trabalho foram consideradas apenas as ações horizontais devido ao vento e ao desaprumo, centradas.

A norma ABNT NBR 6123:1988 - Forças devidas ao vento em edificações, permite transformar as pressões do vento que incidem perpendicularmente na superfície das paredes em forças estáticas. Para isso é necessário definir a velocidade característica do vento que é definida pela Equação (4.5):

$v_{k}=v_{0} \cdot S_{1} \cdot S_{2} \cdot S_{3}$

onde:

$v_{k}:$ velocidade característica do vento $(\mathrm{m} / \mathrm{s}) ;$

$v_{0}$ : velocidade básica do vento $(\mathrm{m} / \mathrm{s})$;

$S_{1}$ : fator topográfico;

$S_{2}$ : fator que considera a rugosidade do terreno e a variação da velocidade do vento com a altura e dimensões da edificação;

$S_{3}$ : fator estatístico;

Todos os parâmetros da Equação (4.5) são fornecidos pela norma citada.

A pressão dinâmica do vento $q_{\text {vento }}\left(\mathrm{N} / \mathrm{m}^{2}\right)$ é determinada em função da velocidade característica conforme item 4.2 da NBR 6123, descrita na Equação (4.6): 
$q_{\text {vento }}=0,613 v_{k}^{2}$

Finalmente a força de arrasto que é a componente da força global do vento numa determinada direção é definida pela Equação (4.7):

$$
F_{a}=C_{a} \cdot q_{\text {vento }} . A_{e}
$$

na qual:

$F_{a}$ : força de arrasto na direção do vento;

$C_{a}$ : coeficiente de arrasto conforme direção do vento;

$A_{e}$ : área frontal efetiva sobre um plano perpendicular à direção do vento.

Para edificações paralelepipédicas, o coeficiente de arrasto é obtido a partir das relações $L_{1} / L_{2}$ e $H / L_{1}$ pelos ábacos das Figuras 4 e 5 da NBR 6123, para ventos de baixa e alta turbulência, respectivamente. A dimensão em planta da edificação, perpendicular à direção do vento é definida por $L_{1}$, sendo $L_{2}$ a direção paralela. A altura total do edifício é representada por $H$.

O desaprumo causado por excentricidades originadas durante a construção de um edifício pode ser considerado na estrutura por meio de forças horizontais equivalentes a esses deslocamentos. Conforme indica a NBR 16055, para edifícios de múltiplos andares, deve ser considerado um desaprumo global através de um ângulo de desaprumo $\theta$, calculado pela Equação (4.8):

$$
\theta=\frac{1}{170 \cdot \sqrt{H}}
$$

onde:

$\theta$ : ângulo de desaprumo, expresso em radianos (rad);

$H$ : altura total do edifício expressa em metros (m). 
A Equação (4.9) transforma o efeito do desaprumo em uma força horizontal equivalente $\left(F_{d p}\right)$, em função de $\theta$ e da carga vertical total do pavimento, representada por $\Delta P$ (Figura 4.10).

$F_{d p}=\Delta P . \theta$
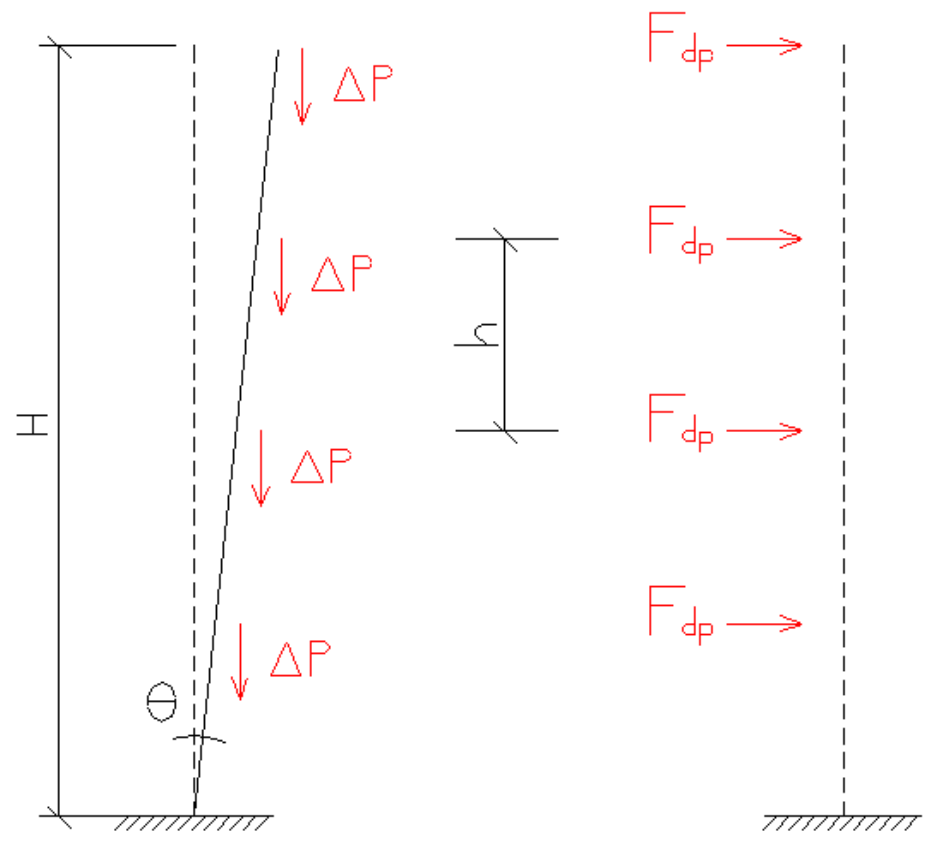

Figura 4.10 - Ação horizontal equivalente ao desaprumo.

A NBR 16055 diz que entre o vento e o desaprumo deve-se considerar aquela que proporcionar a situação mais desfavorável na estrutura. Corrêa e Ramalho (2003) divergem desta premissa e sugerem que o desaprumo seja considerado junto com a ação do vento, já que não é possível evitar que as duas ações atuem simultaneamente. Neste trabalho foram consideradas as ações do vento e devido ao desaprumo atuando simultaneamente nos edifícios estudados.

Observa-se que a NBR 6118:2007 - Projetos de estruturas de concretoProcedimentos, considera o desaprumo dos elementos verticais de modo mais agressivo em relação à norma de paredes, como indica a Equação (4.10), onde $\theta_{1}$ é o ângulo de desaprumo.

$$
\theta_{1}=\frac{1}{100 \cdot \sqrt{H}}
$$


Para uma mesma altura de qualquer edificação, o desaprumo calculado pela NBR16055 será menor que o calculado pela NBR6118. Esta diferença decorre das paredes de concreto serem moldadas por formas, em geral metálicas, cuja montagem envolve um conjunto de paredes que são concretadas em um mesmo ciclo. Esse processo torna mais difícil a parede sair do prumo.

Neste trabalho, as ações horizontais foram consideradas como atuantes nas direções $X$ e $Y$ das respectivas edificações estudadas, nos sentidos, $0^{\circ}, 90^{\circ}, 180^{\circ} \mathrm{e}$ $270^{\circ}$, como mostra a Figura 4.11.

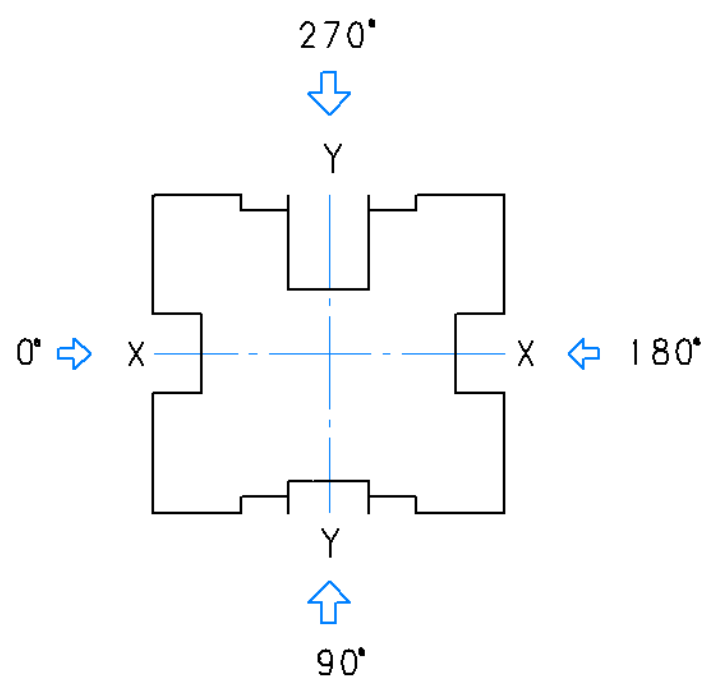

Figura 4.11 - Direção e sentido das ações horizontais.

\subsubsection{Modelo Pórtico Tridimensional (MPT)}

O Modelo Pórtico Tridimensional, assim denominado por Nascimento Neto (1999), é uma adaptação do modelo proposto por Yagui (1971), o qual faz a discretização de núcleos rígidos em elementos de barra, travados horizontalmente pelas lajes atuando como diafragma rígido. Ambos os modelos possibilitam tanto a distribuição de cargas verticais como a de ações horizontais.

No modelo de Yagui, as paredes planas de um núcleo rígido, geralmente encontradas nos poços de elevadores e escadas de edifícios, e que conferem grande rigidez à estrutura global, são substituídas por um conjunto de vigas horizontais, com suas extremidades em balanço e engastadas ao meio em pilares verticais. Portanto, ocorre a substituição das paredes dos núcleos por pórticos equivalentes, como mostra a Figura 4.12: 


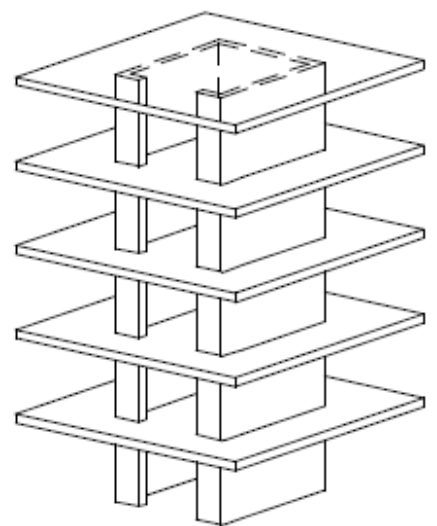

a) Núcleo resistente

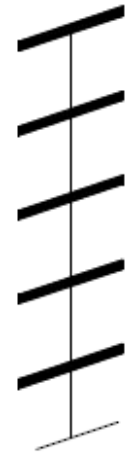

b) Segmentode paredePórtico plano equivalente

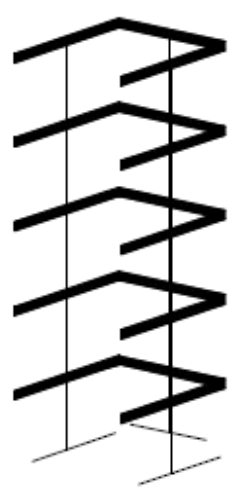
c)Associação de pórticos

Figura 4.12 - Modelagem estrutural do núcleo - elemento Yagui (1971) (PEREIRA 2000).

Conforme Serra (1994), os segmentos de parede situados entre duas lajes (diafragma) são substituídos por elementos formados por duas vigas de rigidez infinita, unidas por uma coluna central, que conserva as mesmas características elásticas e geométricas do segmento de parede que substitui.

A rigidez à força normal, ao momento fletor e torçor e à força cortante de um tramo do pilar são correspondentes às das paredes substituídas.

A formulação do elemento envolve as seguintes hipóteses:

- as lajes devem exercer a função de diafragma rígido, impedindo, portanto, as distorções das seções transversais do núcleo;

- as paredes planas que constituem o núcleo são desprovidas de rigidez à flexão segundo seu eixo de menor inércia, devido às espessuras relativamente delgadas;

- as únicas interações a serem consideradas entre as paredes são as forças de cisalhamento longitudinais ao longo de suas interseções;

- as vigas (barras rígidas horizontais ao nível do pavimento) têm rigidez infinita à flexão no plano da parede e têm como objetivo simular o efeito do comprimento das paredes e a interação que se desenvolve entre elas.

- o pilar (barra flexível vertical posicionada no eixo da parede) tem altura da sua seção transversal igual ao comprimento da parede e largura igual à 
espessura da parede, conservando as mesmas características elásticas e geométricas do segmento de parede que substitui;

- considera-se a deformação por cisalhamento na barra flexível vertical (pilar);

- o comprimento das paredes planas deve ser constante, no entanto sua espessura pode variar aos níveis dos pavimentos;

- o sistema contínuo constituído por paredes planas fica substituído pelo sistema de pórticos.

Os lintéis podem ser incluídos no modelo ligando-os às extremidades dos elementos de paredes adjacentes (as barras de lintéis são ligadas de forma contínua às barras rígidas horizontais).

A adaptação do modelo Yagui (1971) proposta por Nascimento Neto (1999), e denominada Modelo Pórtico Tridimensional, tem pequenas alterações na formulação do elemento, tornando-o mais abrangente. Além disso, sua aplicação foi feita em sistemas estruturais compostos por paredes, como é o caso de edifícios construídos em Alvenaria Estrutural e Paredes de Concreto. Nunes (2011) utilizou o Modelo Pórtico Tridimensional para a análise dos esforços de um edifício de Paredes de Concreto, assim como Nascimento Neto (1999) o avaliou para o caso da Alvenaria Estrutural.

Diferente do modelo Yagui, o Modelo Pórtico Tridimensional considera a rigidez à flexão na direção de menor inércia da parede, pelo fato dela ser modelada por barras tridimensionais com seis graus de liberdade em cada extremidade. Contudo, a disposição e algumas características das barras no Modelo Pórtico Tridimensional, são as mesmas que no modelo Yagui, ou seja:

- a barra flexível vertical é posicionada no eixo vertical da parede, possuindo as características elásticas e geométricas do segmento de parede que substitui;

- além da deformação por flexão, a deformação por cisalhamento é considerada nas barras flexíveis verticais;

- as barras rígidas horizontais são dispostas ao nível do pavimento e ligam as extremidades das paredes à barra flexível vertical; a altura e espessura da seção transversal é igual à da parede que representa; 
- os nós de extremidade das barras rígidas horizontais são articulados (exceto quando a extremidade é ligada à um lintel ou à outra barra rígida horizontal colinear), e o nó comum à barra flexível vertical é contínuo;

- as barras rígidas horizontais têm rigidez infinita à flexão no plano e simulam o comprimento das paredes e a interação entre elas;

É importante a consideração da deformação por cisalhamento nos elementos de barra vertical, devido às dimensões relativamente grandes das paredes quando comparadas a uma viga, por exemplo. Segunda a NBR 16055, em seu item 14.3, para a consideração da parede como componente de um sistema estrutural de contraventamento, representada por elemento linear, é necessário considerar além da deformação por flexão, a deformação por cisalhamento. As barras horizontais são rígidas e, portanto, tal deformação não é considerada nelas.

A Figura 4.13 mostra o Modelo Pórtico Tridimensional em planta e em perspectiva.

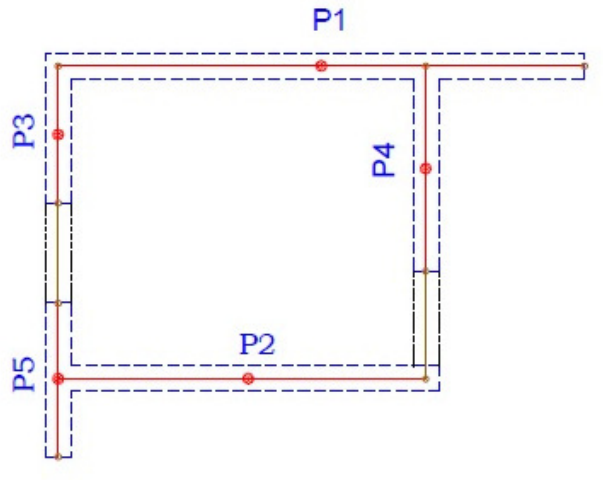

(a) Visão em planta

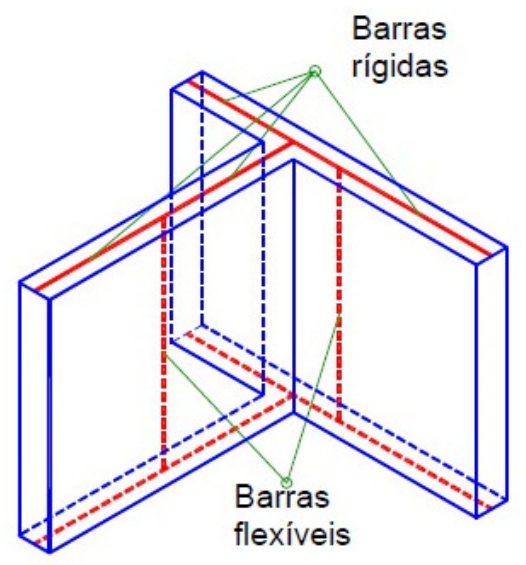

(b) Visão em perspectiva

Figura 4.13 - Modelo Pórtico Tridimensional (CORRÊA, 2003).

Conforme Nascimento e Corrêa (2002), as paredes que se interceptam são interligadas/conectadas por barras rígidas horizontais, de modo a considerar a interação que efetivamente se desenvolve entre paredes, a qual é simulada pelo esforço cortante que surge no nó de interseção. Assim, as barras rígidas horizontais não colineares que se encontram, tem este nó de extremidade e de interseção, articulado, de forma que o único grau de liberdade associado a ele é a translação vertical. 
A inclusão de lintéis também é possível nesse modelo, o que aumenta consideravelmente a rigidez do edifício. Quando considerados, é necessário que a ligação entre os lintéis e as barras horizontais rígidas seja contínua, de modo a simular a sua efetiva contribuição.

A Figura 4.14 mostra uma aplicação do Modelo Pórtico Tridimensional a fim de ilustrar algumas de suas características. Na Figura 4.14a, as paredes e lintéis são apresentadas com suas seções transversais "cheias". Na Figura 4.14b, observam-se as barras tridimensionais verticais e horizontais, com suas nomenclaturas. Analisando-se as extremidades das barras horizontais não colineares, nota-se que elas foram articuladas (a articulação é representada pelo círculo de cor verde). Percebe-se também que a continuidade entre as barras rígidas horizontais e lintéis foi mantida (exemplo: ligação da barra 102 com a barra 5). Também houve continuidade no encontro de barras verticais com as barras horizontais (exemplo: encontro da barra 1 com barras 101 e 102).

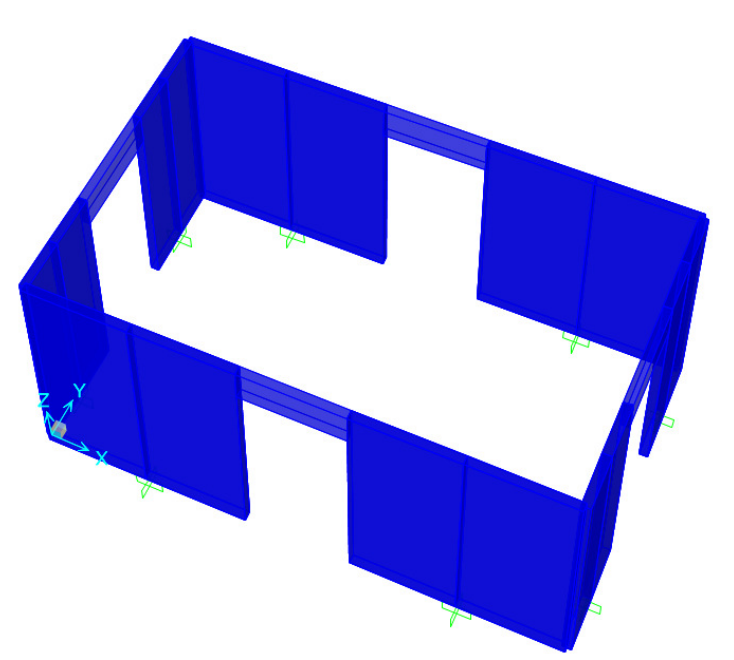

a) Paredes e lintéis com seção transversal "cheia";

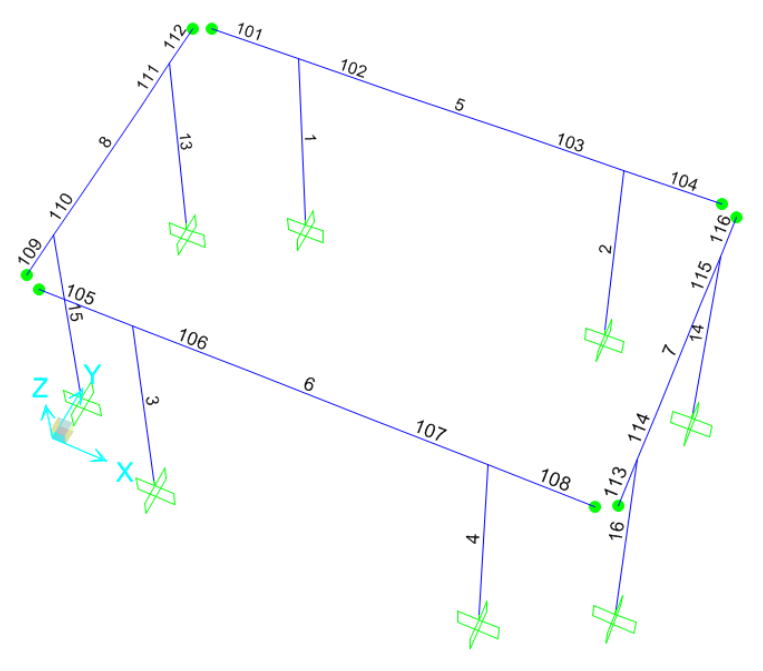

b) Barras tridimensionais verticais e horizontais;

Figura 4.14 - Aplicação do Modelo Pórtico Tridimensional.

É importante lembrar que, como a parede é representada por uma barra vertical que tem as características geométricas da parede e por barras horizontais que têm altura e espessura iguais à da parede e simulam seu comprimento, é necessário desconsiderar o peso próprio das barras horizontais. Caso contrário, o peso da parede seria contabilizado duas vezes. 
Nos estudos realizados neste trabalho, multiplicou-se por 100 a rigidez à flexão na direção de maior inércia, das barras rígidas horizontais, a fim de torná-las infinitamente rígidas no plano da parede.

A hipótese das lajes agindo como diafragma rígido também é considerada no Modelo Pórtico Tridimensional. Sendo assim, os nós iniciais e finais das barras verticais são associados ao nó mestre do respectivo pavimento. Dessa maneira, dos seis graus de liberdade em cada extremidade da barra vertical, três são "escravizados" ao nó mestre do pavimento, os quais são os relativos às duas translações horizontais e à rotação em torno do eixo longitudinal da barra vertical.

Como citado anteriormente, o Modelo Pórtico Tridimensional foi desenvolvido pelo método dos elementos finitos no software comercial SAP2000. Para modelar as barras rígidas horizontais e flexíveis verticais, utilizou-se o elemento Frame, da biblioteca de elementos finitos do programa, o qual tem formulação conforme Bathe e Wilson (1976) apud CSI (2011). A deformação por cisalhamento é considerada nesta formulação, no entanto, ela não foi considerada nas barras rígidas horizontais.

O sistema de eixos local e os graus de liberdade existentes por nó são apresentados nas Figuras 4.15 e 4.16, respectivamente.
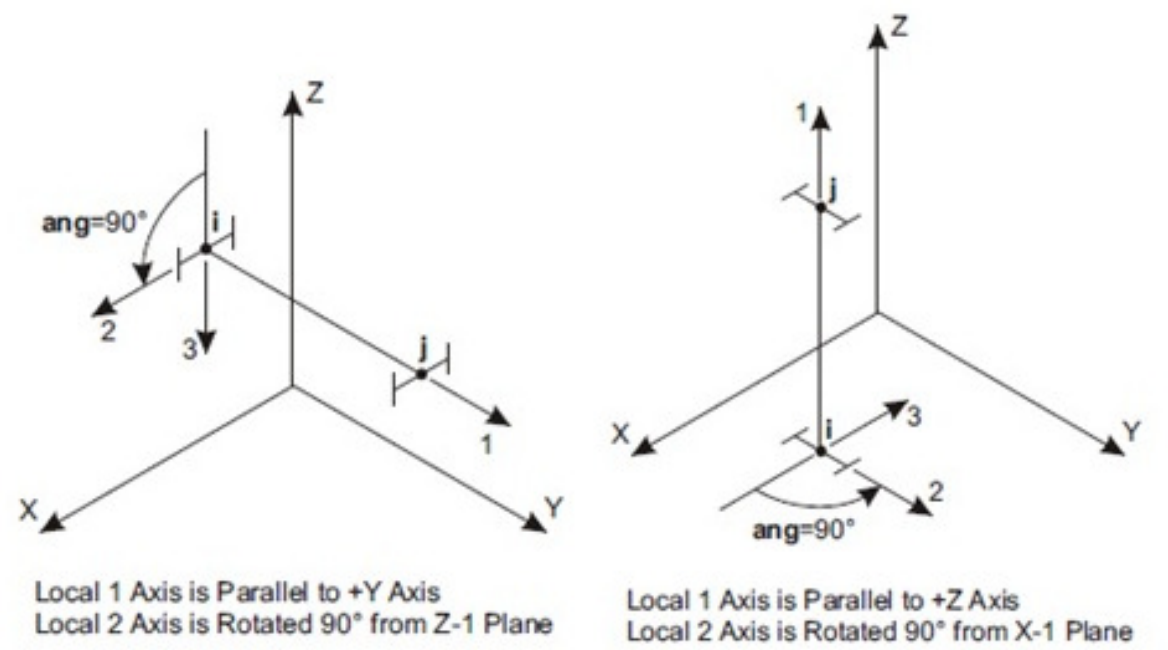

Figura 4.15 - Sistema de eixos local do elemento Frame (CSI - SAP2000, 2011). 


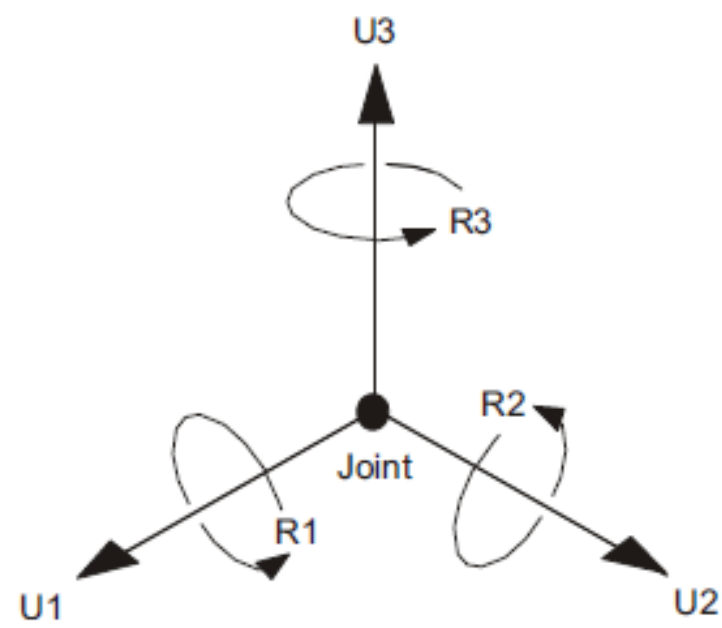

Figura 4.16 - Graus de liberdade por nó de determinado elemento finito (CSI - SAP2000, 2011).

\subsubsection{Modelo em Elementos Finitos (MEF)}

Neste modelo a estrutura é discretizada numa malha de elementos finitos, cuja formulação corresponde ao comportamento estrutural adequado ao elemento estrutural modelado. Os elementos são interconectados pelos nós onde uma solução aproximada pode ser adotada e as equações de equilíbrio são estabelecidas.

Souza (2004) observa que a dimensão dos elementos tem influência significativa na convergência da solução e, por isso, deve ser escolhido com bastante cuidado. Ao modelar um determinado elemento estrutural, quanto menor $o$ elemento finito, mais precisa será a solução, no entanto, maior será a matriz de rigidez da estrutura e maior será o esforço computacional.

As distribuições de cargas verticais e ações horizontais ocorrem de forma automática pelo fluxo de tensões e compatibilidade de deslocamentos nodais.

É um modelo mais refinado, no entanto demanda cuidadosa definição dos elementos finitos e da malha que esses formarão para se obter bons resultados. Além disso, tem como desvantagem a complexidade na entrada de dados e na análise de resultados.

O Modelo em Elementos Finitos denominado neste trabalho se refere à discretização das paredes dos edifícios analisados, em elementos de casca plana quadrados, com nós apenas nos vértices. Foi utilizado o elemento Shell do software 
SAP2000 para tal modelagem. O sistema de eixos local do elemento e seus quatro nós são apresentados na Figura 4.17. Os graus de liberdade por nó do elemento são mostrados na Figura 4.16. As lajes não foram discretizadas, e para simular seu comportamento, utilizou-se a ferramenta do diafragma rígido.

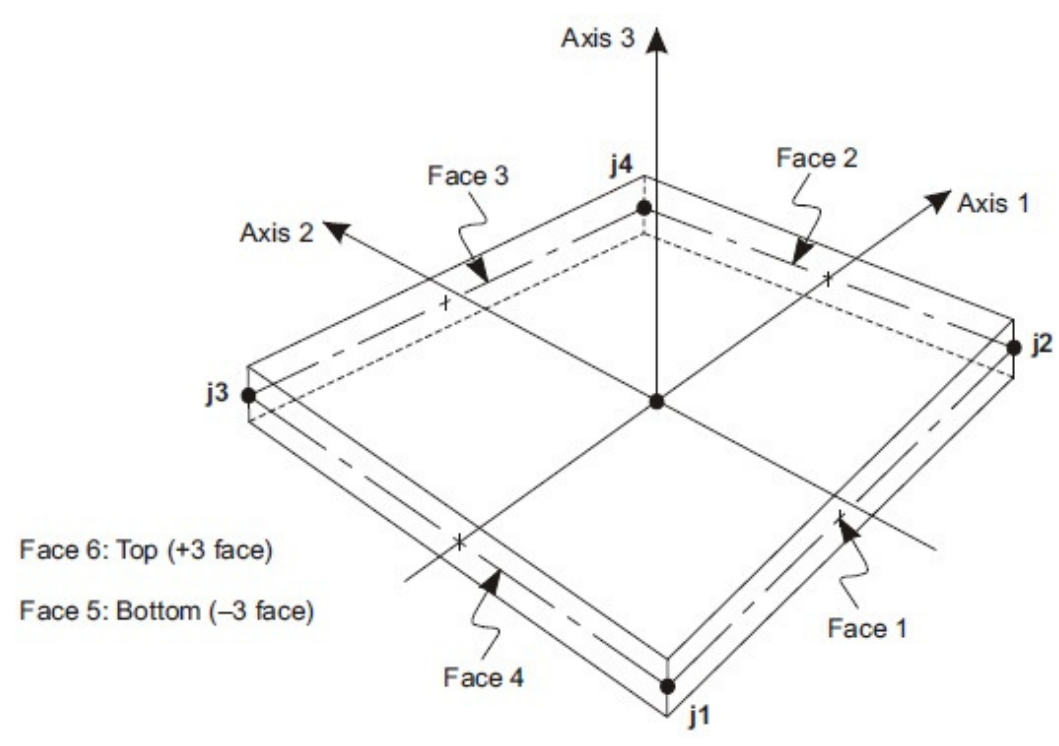

Four-node Quadrilateral Shell Element

Figura 4.17 - Sistema de eixos local do elemento Shell (CSI - SAP2000, 2011).

\subsubsection{Consideração de abas em paredes de contraventamento}

A largura útil definida por Timoshenko em vigas é aplicada em sistemas de contraventamento compostos por paredes, fazendo-se o raciocínio análogo. As contribuições de abas ou flanges das paredes dispostas perpendicularmente à direção das paredes de contraventamento analisadas, formam seções compostas e conferem maior rigidez ao sistema. Porém essa contribuição é limitada pelas normas de projeto, as quais definem as dimensões máximas das abas das paredes colaborantes como seis vezes a espessura dela como é o caso da norma NBR 15961-1:2011 - Alvenaria Estrutural - Blocos de concreto Parte 1: Projeto.

Conforme Timoshenko (1966), admitindo uma viga simplesmente apoiada nas extremidades, submetida a um carregamento no plano médio xy, conforme Figura 4.18, observa-se que há tensões de cisalhamento atuando entre as abas da mesa e 
a alma, nas superfícies de contato mn (vide Figura 4.18a) e que elas estão dirigidas conforme Figura 4.18b. Essas tensões são devidas à tensão normal de compressão que aparece na fibra superior da seção transversal da viga em decorrência do carregamento citado. Portanto a mesa e a alma são comprimidas. Observa-se que a tensão de compressão nas mesas, não se distribui uniformemente, sendo a máxima tensão da aba igual à máxima da mesa (Figuras 4.18c).

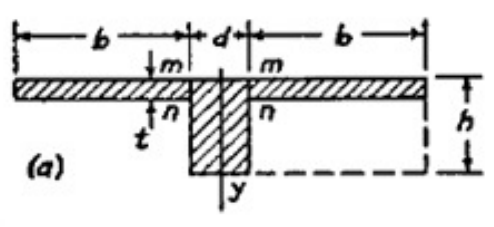

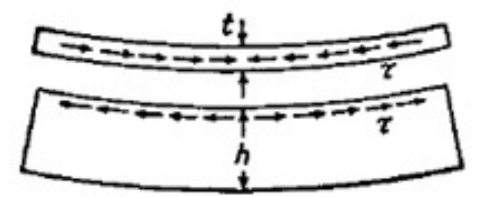

(b)

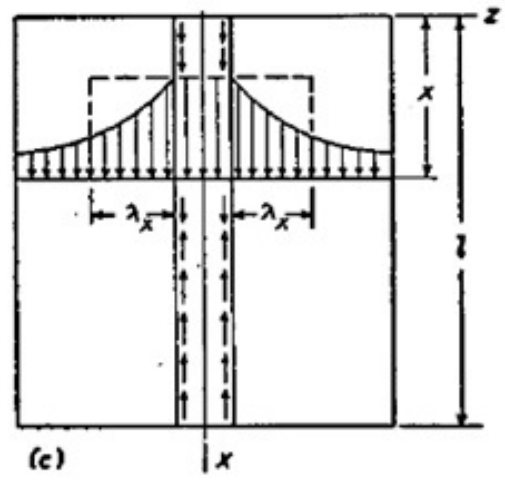

Figura 4.18 - Considerações sobre a largura útil de mesas em vigas (TIMOSHENKO, 1966).

Desta não uniformidade da distribuição de tensões, conclui-se que ao aplicar à viga da Figura 4.18 a expressão da máxima tensão normal de flexão, deve-se usar uma largura reduzida $2 \lambda_{x}$ (Figura 4.18c), ao invés da largura real $2 b$ das duas abas (Figura 4.18a), com o fim de se obter o valor exato da tensão. Esta largura reduzida comumente chamada largura útil é calculada considerando-se um retângulo com largura $\lambda_{x}$, conforme Figura 4.18c, onde a tensão de compressão é considerada uniforme tal que sua área seja igual á área da real distribuição (e não uniforme) da tensão de compressão na mesa considerada. Desta forma se obtêm um valor médio da tensão de compressão na largura útil colaborante, aumentando assim a rigidez da viga.

A contribuição das abas nas paredes de contraventamento nos modelos de casca (MEF) desenvolvidos neste trabalho, ocorre de forma automática através da compatibilidade de deslocamentos nodais, o qual ocorre ao longo de toda interação das paredes que se encontram.

Já nos modelos de barra (MPT), como existe uma articulação no encontro de barras horizontais não colineares, uma parede de contraventamento, ao ser submetida à ações horizontais, se deforma num plano diferente do plano deformado observado na eventual aba colaborante. Isso só ocorre devido à articulação 
existente no encontro dessas paredes. Esse efeito garante que não haja uma colaboração exagerada e não realista da aba colaborante.

Os resultados apresentados nos itens 5.5 e 6.10, referentes às translações horizontais dos edifícios estudado, ao longo de sua altura, mostram que o MPT é mais flexível em relação ao MEF, o que mostra de certa maneira, que as contribuições das abas nas paredes de contraventamento são menores no modelo de barras quando comparadas ao modelo de casca. Esse resultado é coerente e importante, já que o MPT é um modelo muito menos refinado que o MEF, e portanto seus resultados relativos à colaboração das abas nas paredes de contraventamento, são a favor da segurança.

\subsection{Propriedades mecânicas do concreto}

Considerou-se linearidade física para o material concreto utilizado nos dois modelos numéricos (MEF e MPT).

As propriedades mecânicas consideradas para o material concreto foram: resistência à compressão de $25 \mathrm{MPa}\left(2500 \mathrm{tf} / \mathrm{m}^{2}\right)$, módulo de elasticidade secante $E_{C S}=2400000 \mathrm{tt} / \mathrm{m}^{2}$, coeficiente de poisson $v=0,2$ e peso específico $\gamma=2,5 \mathrm{tt} / \mathrm{m}^{3}$. O material foi considerado como isotrópico. 


\section{CONSOLIDAÇÃO DOS MODELOS DE CÁLCULO}

Os modelos de cálculo apresentados no capítulo quatro são aplicados em um edifício hipotético, chamado edifício estudo preliminar, e seus resultados são comparados com o objetivo de consolidar a teoria apresentada.

\subsection{Características gerais do edifício estudo preliminar (EP)}

Consideraram-se duas situações para o edifício estudo preliminar. $\mathrm{Na}$ primeira, ele é composto apenas por paredes e lajes (caso A) e, na segunda, composto por paredes, lintéis e lajes (caso B), como mostra a Figura 5.1, a qual também apresenta as medidas dos eixos das paredes e lintéis em centímetros.

\section{CASO A: SEM LINTÉIS}
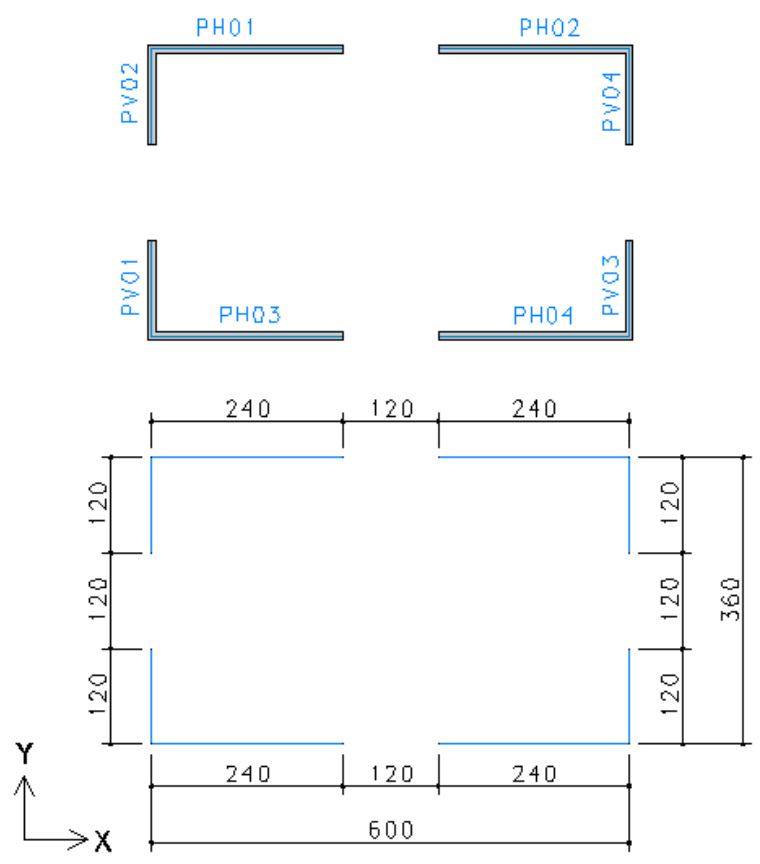

\section{CASO B: COM LINTÉIS}
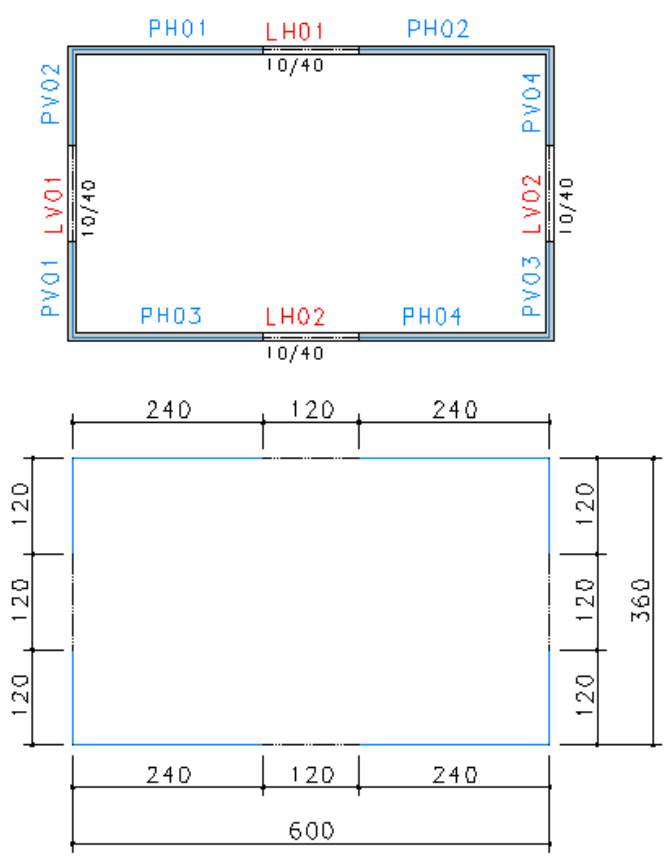

Figura 5.1 - Edifício estudo preliminar: casos A e B; medidas (cm).

O edifício tem seis pavimentos, sendo a distância entre pisos igual a 2,80 m. Portanto a altura total é de $16,80 \mathrm{~m}$. As paredes e lajes foram consideradas com espessura de $10 \mathrm{~cm}$. Os lintéis têm largura de $10 \mathrm{~cm}$ e altura de $40 \mathrm{~cm}$, como pode ser visto na Figura 5.1. O material de todos os elementos estruturais citados é o concreto, com características mecânicas conforme item 4.3. 
Quanto às cargas verticais, as cargas permanentes foram definidas pela soma do peso próprio dos elementos com o peso dos revestimentos das lajes, o qual é equivalente a $0,10 \mathrm{tf} / \mathrm{m}^{2}$; e as cargas acidentais, atuantes nas lajes dos pavimentos, igual a $0,15 \mathrm{t} / \mathrm{m}^{2}$.

As ações horizontais consideradas são referentes ao vento e ao desaprumo, aplicadas conforme direções e sentidos definidos na Figura 4.11. As forças de arrasto devido ao vento (Tabela 5.2) são calculadas em função dos parâmetros da Tabela 5.1, considerando vento não turbulento. As forças devido ao desaprumo são apresentadas na Tabela 5.3.

Tabela 5.1 - Parâmetros para o cálculo das forças de arrasto do vento - (EP).

\begin{tabular}{|c|c|}
\hline $\mathrm{Lx}$ & $6,0 \mathrm{~m}$ \\
\hline $\mathrm{Ly}$ & $3,6 \mathrm{~m}$ \\
\hline $\mathrm{H}$ & $16,8 \mathrm{~m}$ \\
\hline $\mathrm{V}_{0}$ & $45,0 \mathrm{~m} / \mathrm{s}$ \\
\hline Categoria & $\mathrm{IV}$ \\
\hline Classe & $\mathrm{A}$ \\
\hline $\mathrm{S} 1$ & 1 \\
\hline $\mathrm{S} 3$ & 1 \\
\hline $\mathrm{Ca}, \mathrm{x}$ & 1,15 \\
\hline $\mathrm{Ca}, \mathrm{y}$ & 1,40 \\
\hline $\mathrm{Ae}, \mathrm{x}$ & $10,08 \mathrm{~m}^{2}$ \\
\hline $\mathrm{Ae}, \mathrm{y}$ & $16,80 \mathrm{~m}^{2}$ \\
\hline
\end{tabular}

onde:

$L_{x}$ : comprimento do edifício na direção definida como X;

$L_{y}$ : comprimento do edifício na direção definida como Y;

$H$ : altura total do edifício;

$v_{0} \quad$ : velocidade básica do vento;

$C_{a, x}$ : coeficiente de arrasto na direção $\mathrm{X}$;

$C_{a, y}$ : coeficiente de arrasto na direção $\mathrm{Y}$;

$A_{e, x}$ : área frontal efetiva sobre o plano normal à direção do vento $\mathrm{X}$;

$A_{e, y}$ : área frontal efetiva sobre o plano normal à direção do vento $\mathrm{Y}$. 
Tabela 5.2 - Forças de arrasto oriundas do vento, nas direções $\mathrm{X}$ e $\mathrm{Y}$, por pavimento - (EP).

\begin{tabular}{|c|c|c|c|c|c|c|}
\hline $\mathrm{n}$ & $\mathrm{Hi}(\mathrm{m})$ & $\mathrm{S} 2$ & $\mathrm{v}_{\mathrm{k}}(\mathrm{m} / \mathrm{s})$ & $\mathrm{q}_{\mathrm{vento}}\left(\mathrm{tf} / \mathrm{m}^{2}\right)$ & $F_{a, x}(\mathrm{tf})$ & $F_{a, y}(\mathrm{tf})$ \\
\hline 1 & 2,8 & 0,790 & 35,55 & 0,0790 & 0,92 & 1,86 \\
\hline 2 & 5,6 & 0,798 & 35,93 & 0,0807 & 0,94 & 1,90 \\
\hline 3 & 8,4 & 0,838 & 37,69 & 0,0888 & 1,03 & 2,09 \\
\hline 4 & 11,2 & 0,870 & 39,13 & 0,0957 & 1,11 & 2,25 \\
\hline 5 & 14,0 & 0,892 & 40,14 & 0,1007 & 1,17 & 2,37 \\
\hline 6 & 16,8 & 0,911 & 40,99 & 0,1050 & 1,22 & 2,47 \\
\hline
\end{tabular}

onde:

$n$ : número do pavimento;

$H_{i}$ : altura do pavimento $n$ considerado;

$F_{a, x}$ : força de arrasto do vento na direção X;

$F_{a, y}$ : força de arrasto do vento na direção $\mathrm{Y}$.

Os fatores $S_{1}, S_{2}$ e $S_{3}$, velocidade $v_{k}$, e pressão $q_{\text {vento }}$ foram definidos no item 4.2.4.

Tabela 5.3 - Forças devido ao desaprumo, nas direções X e Y, por pavimento - (EP).

\begin{tabular}{|c|c|c|c|c|c|}
\hline $\mathrm{n}$ & $\mathrm{Hi}(\mathrm{m})$ & $\Theta(\mathrm{rad})$ & $\Delta \mathrm{P}(\mathrm{tf})$ & $\mathrm{F}_{\mathrm{dp}, \mathrm{x}}(\mathrm{tf})$ & $\mathrm{F}_{\mathrm{dp}, \mathrm{y}}(\mathrm{tf})$ \\
\hline 1 & 2,8 & 0,001435 & 20,88 & 0,03 & 0,03 \\
\hline 2 & 5,6 & 0,001435 & 20,88 & 0,03 & 0,03 \\
\hline 3 & 8,4 & 0,001435 & 20,88 & 0,03 & 0,03 \\
\hline 4 & 11,2 & 0,001435 & 20,88 & 0,03 & 0,03 \\
\hline 5 & 14,0 & 0,001435 & 20,88 & 0,03 & 0,03 \\
\hline 6 & 16,8 & 0,001435 & 20,88 & 0,03 & 0,03 \\
\hline
\end{tabular}

onde:

$F_{d p, x}$ : força devido ao desaprumo na direção $\mathrm{X}$.

$F_{d p, y}:$ força devido ao desaprumo na direção $\mathrm{Y}$.

O ângulo $\theta$ e a força $\Delta P$ foram definidos no item 4.2.4. 


\subsection{Distribuição de cargas verticais}

As cargas verticais ao nível da fundação foram comparadas entre os modelos de cálculo adotados. Nas análises de distribuição de cargas verticais, os valores das forças normais obtidas estão com o sinal positivo, apesar de serem de compressão.

\subsubsection{Paredes Isoladas (PIS) - (EP)}

A distribuição das cargas provenientes das lajes nas paredes foi feita pelo método das charneiras plásticas. As Figuras 5.2 e 5.3 apresentam, para os casos A e $\mathrm{B}$, respectivamente, o valor da área de influência de cada laje $\left(A_{L}\right)$, seu comprimento de influência ( $L_{\text {inf }}$ ), ao longo do qual a carga da respectiva área de influência é distribuída em paredes e/ou lintéis, sua carga total concentrada $(P)$ (considerando as cargas permanentes e acidentais) e a carga total distribuída ( $p$ ) que atuará ao longo de seu comprimento de influência.

\begin{tabular}{|c|c|c|c|c|}
\hline ÁREA & $\mathrm{A}_{\mathrm{L}}(\mathrm{m} 2)$ & $\mathrm{L}$ inf $(\mathrm{m})$ & $\mathrm{P}(\mathrm{tf})$ & $\mathrm{p}(\mathrm{tf} / \mathrm{m})$ \\
\hline $\mathrm{A} 1$ & 3,78 & 2,40 & 1,89 & 0,79 \\
\hline $\mathrm{A} 2$ & 3,78 & 2,40 & 1,89 & 0,79 \\
\hline $\mathrm{A} 3$ & 1,62 & 1,20 & 0,81 & 0,68 \\
\hline $\mathrm{A} 4$ & 1,62 & 1,20 & 0,81 & 0,68 \\
\hline $\mathrm{A} 5$ & 1,62 & 1,20 & 0,81 & 0,68 \\
\hline $\mathrm{A} 6$ & 1,62 & 1,20 & 0,81 & 0,68 \\
\hline $\mathrm{A} 7$ & 3,78 & 2,40 & 1,89 & 0,79 \\
\hline $\mathrm{A} 8$ & 3,78 & 2,40 & 1,89 & 0,79 \\
\hline
\end{tabular}
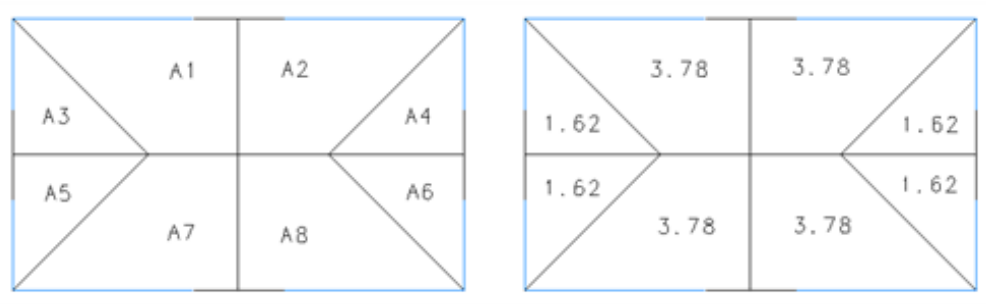

Figura 5.2 - Áreas de influência das lajes nas paredes - Caso A.

\begin{tabular}{|c|c|c|c|c|}
\hline ÁREA & $\mathrm{A}_{\mathrm{L}}(\mathrm{m} 2)$ & $\operatorname{Linf}(\mathrm{m})$ & $\mathrm{P}(\mathrm{tf})$ & $\mathrm{P}(\mathrm{tf} / \mathrm{m})$ \\
\hline $\mathrm{A} 1$ & 7,56 & 6,00 & 3,78 & 0,63 \\
\hline $\mathrm{A} 2$ & 3,24 & 3,60 & 1,62 & 0,45 \\
\hline $\mathrm{A} 3$ & 3,24 & 3,60 & 1,62 & 0,45 \\
\hline $\mathrm{A} 4$ & 7,56 & 6,00 & 3,78 & 0,63 \\
\hline
\end{tabular}
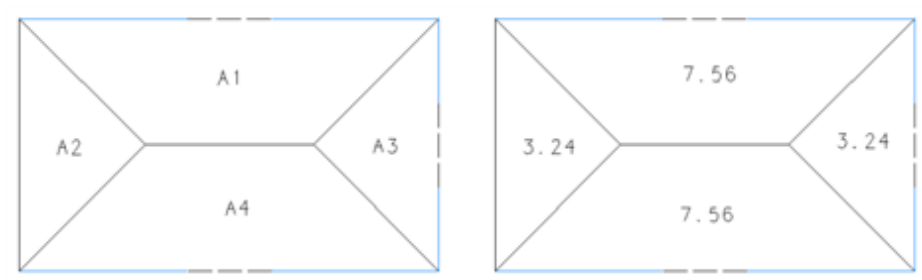

Figura 5.3 - Áreas de influência das lajes nas paredes - Caso B.

A força normal concentrada característica devido apenas às cargas verticais $\left(N_{k, v e r t}\right)$, e a força normal distribuída característica devido apenas às cargas verticais $\left(\eta_{k, v e r t}\right)$, ambas obtidas ao nível da fundação de cada parede do edifício estudo 
preliminar (EP) para o caso A, são apresentadas na Tabela 5.4, considerando que as paredes se comportam de forma isolada.

Tabela 5.4 - PIS-EP: $N_{k, v e r t}$ e $\eta_{k, v e r t}$ ao nível da fundação - Caso A.

\begin{tabular}{|c|c|c|c|c|c|c|c|}
\hline \multicolumn{7}{|c|}{ PIS-EP - CASO A - nível 0,00 m } \\
\hline PAREDE & $\mathrm{L}(\mathrm{m})$ & $\mathrm{PP}_{1 \text { PAV }}(\mathrm{tf})$ & Areas Lajes & P lajes (tf) & P parede (tf) & Nk,vert (tf) & $\eta \mathrm{k}$, vert (tf/m) \\
\hline PH01 & 2,40 & 1,68 & $\mathrm{~A} 1$ & 1,89 & 3,57 & 21,42 & 8,93 \\
\hline PH02 & 2,40 & 1,68 & $\mathrm{~A} 2$ & 1,89 & 3,57 & 21,42 & 8,93 \\
\hline PH03 & 2,40 & 1,68 & $\mathrm{~A} 7$ & 1,89 & 3,57 & 21,42 & 8,93 \\
\hline PH04 & 2,40 & 1,68 & $\mathrm{~A} 8$ & 1,89 & 3,57 & 21,42 & 8,93 \\
\hline PV01 & 1,20 & 0,84 & $\mathrm{~A} 5$ & 0,81 & 1,65 & 9,90 & 8,25 \\
\hline PV02 & 1,20 & 0,84 & $\mathrm{~A} 3$ & 0,81 & 1,65 & 9,90 & 8,25 \\
\hline PV03 & 1,20 & 0,84 & $\mathrm{~A} 6$ & 0,81 & 1,65 & 9,90 & 8,25 \\
\hline PV04 & 1,20 & 0,84 & A4 & 0,81 & 1,65 & 9,90 & 8,25 \\
\hline
\end{tabular}

onde:

$L \quad$ : comprimento da parede em planta;

$P P_{1 P A V} \quad$ : peso próprio do elemento estrutural em um pavimento;

Áreas Lajes : áreas de influência das lajes que descarregam carga em paredes e/ou lintéis;

P lajes : carga concentrada atuante em paredes e/ou lintéis oriunda das lajes, considerando apenas um pavimento do edifício estudado;

$\mathrm{P}$ parede : carga concentrada total da parede (PP $+\mathrm{P}$ lajes) considerando apenas um pavimento do edifício estudado;

No caso da presença de lintéis, é preciso considerar o quinhão de carga das lajes que descarregam nos lintéis, para então descarregar a carga total dos lintéis nas paredes. A Tabela 5.5 mostra a carga total dos lintéis e, finalmente, a Tabela 5.6 apresenta a resultante de forças normais atuantes nas paredes do caso B, considerando as paredes isoladas.

Tabela 5.5 - EP: Carga vertical total nos lintéis em apenas um pavimento - Caso B.

\begin{tabular}{|c|c|c|c|c|c|}
\hline LINTEL & $\mathrm{LL}_{\mathrm{L}}(\mathrm{m})$ & $\mathrm{PP}_{1 \text { PAV }}(\mathrm{tf})$ & Areas Lajes & P lajes (tf) & P lintel (tf) \\
\hline LH01 & 1,20 & 0,12 & $\mathrm{~A} 1$ & 0,76 & 0,88 \\
\hline LH02 & 1,20 & 0,12 & $\mathrm{~A} 4$ & 0,76 & 0,88 \\
\hline LV01 & 1,20 & 0,12 & $\mathrm{~A} 2$ & 0,54 & 0,66 \\
\hline LV02 & 1,20 & 0,12 & $\mathrm{~A} 3$ & 0,54 & 0,66 \\
\hline
\end{tabular}

onde:

$P$ lintel : carga concentrada total do lintel (PP + $P$ lajes) em um pavimento. 
LLI : : comprimento do lintel em planta;

Tabela 5.6 - PIS-EP: $N_{k, v e r t}$ e $\eta_{k, v e r t}$ ao nível da fundação - Caso B.

\begin{tabular}{|c|c|c|c|c|c|c|c|c|c|}
\hline \multicolumn{10}{|c|}{ PIS-EP - CASO B - nível 0,00 m } \\
\hline PAREDE & L $(\mathrm{m})$ & PP $_{\text {1PAV }}$ (tf) & Areas Lajes & P lajes (tf) & Lintéis & Plintéis & P parede (tf) & Nk,vert (tf) & $\eta \mathrm{k}$, vert (tf/m) \\
\hline PH01 & 2,40 & 1,68 & A1 & 1,51 & LH01 & 0,44 & 3,63 & 21,78 & 9,08 \\
\hline PH02 & 2,40 & 1,68 & A1 & 1,51 & LH01 & 0,44 & 3,63 & 21,78 & 9,08 \\
\hline PH03 & 2,40 & 1,68 & A4 & 1,51 & LH02 & 0,44 & 3,63 & 21,78 & 9,08 \\
\hline PH04 & 2,40 & 1,68 & A4 & 1,51 & LH02 & 0,44 & 3,63 & 21,78 & 9,08 \\
\hline PV01 & 1,20 & 0,84 & A2 & 0,54 & LV01 & 0,33 & 1,71 & 10,26 & 8,55 \\
\hline PV02 & 1,20 & 0,84 & A2 & 0,54 & LV01 & 0,33 & 1,71 & 10,26 & 8,55 \\
\hline PV03 & 1,20 & 0,84 & A3 & 0,54 & LV02 & 0,33 & 1,71 & 10,26 & 8,55 \\
\hline PV04 & 1,20 & 0,84 & A3 & 0,54 & LV02 & 0,33 & 1,71 & 10,26 & 8,55 \\
\hline
\end{tabular}

5.2.2 Grupo Isolado de Paredes (GIP) - (EP)

Os Grupos Isolados de Paredes do EP são definidos conforme Figura 5.4. GIP: CASO A GIP: CASO B
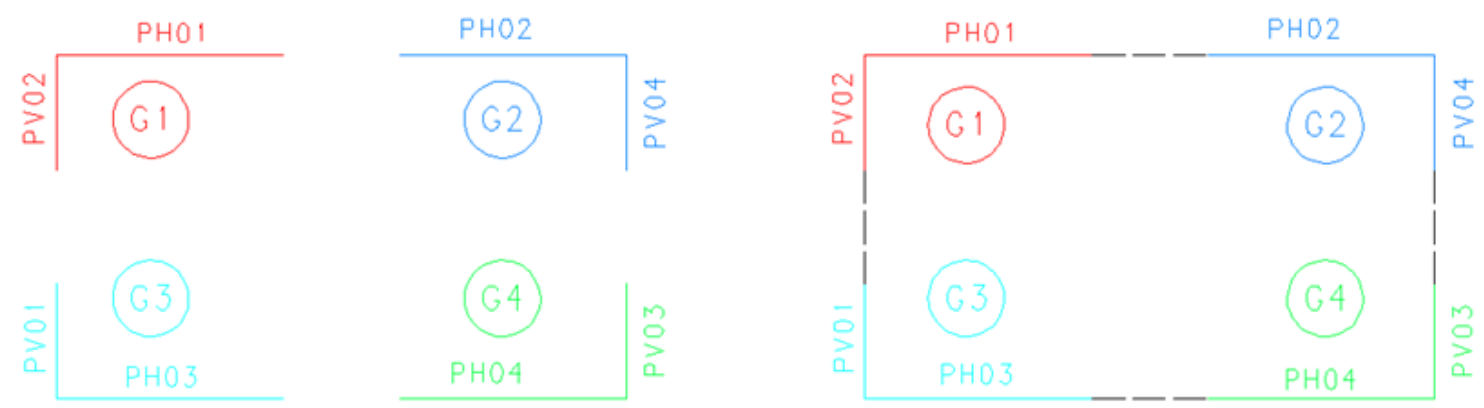

Figura 5.4 - Definição dos Grupos Isolados de Paredes para o EP.

Como definido anteriormente, a carga de um grupo isolado de paredes é completamente homogeneizada, fazendo-se a soma das cargas das paredes participantes do grupo e dividindo-se pelo comprimento total do grupo.

A Tabela 5.7a apresenta para o caso $A$ as paredes que definem um grupo, conforme Figura 5.4, o comprimento total do grupo $\left(\mathrm{L}_{\mathrm{GIP}}\right)$, o somatório das forças normais concentradas das paredes contidas num mesmo grupo, ao nível da fundação $\left(N_{k, v e r t}\right)$ e finalmente a uniformização da carga ao nível da fundação para cada grupo (força normal distribuída $\eta_{k, v e r t}$ ). A Tabela $5.7 \mathrm{~b}$ apresenta os mesmos resultados da $5.7 \mathrm{a}$, porém considerados por paredes. Os resultados equivalentes para o caso B encontram-se nas tabelas $5.8 \mathrm{a}$ e $5.8 \mathrm{~b}$. 
Tabela 5.7 - GIP-EP: $N_{k, v e r t}$ e $\eta_{k, v e r t}$ ao nível da fundação - Caso A.

\begin{tabular}{|c|c|c|c|c|}
\hline \multicolumn{4}{|c|}{} & \multicolumn{3}{c|}{ GIP-EP - CASO A - nível } \\
\hline GRUPO & PAREDES & $\mathrm{L}_{\mathrm{GIP}}(\mathrm{m})$ & Nk,vert (tf) & $\eta$ k,vert (tf/m) \\
\hline 1 & PH01 e PV02 & 3,60 & 31,32 & 8,70 \\
\hline 2 & PH02 e PV04 & 3,60 & 31,32 & 8,70 \\
\hline 3 & PH03 e PV01 & 3,60 & 31,32 & 8,70 \\
\hline 4 & PH04 e PV03 & 3,60 & 31,32 & 8,70 \\
\hline
\end{tabular}

a) Cargas por grupo

\begin{tabular}{|c|c|c|c|}
\hline PAREDE & $L(\mathrm{~m})$ & Nk,vert (tf) & $\eta \mathrm{k}$, vert $(\mathrm{tf} / \mathrm{m})$ \\
\hline PH01 & 2,40 & 20,88 & 8,70 \\
\hline PH02 & 2,40 & 20,88 & 8,70 \\
\hline PH03 & 2,40 & 20,88 & 8,70 \\
\hline PH04 & 2,40 & 20,88 & 8,70 \\
\hline PV01 & 1,20 & 10,44 & 8,70 \\
\hline PV02 & 1,20 & 10,44 & 8,70 \\
\hline PV03 & 1,20 & 10,44 & 8,70 \\
\hline PV04 & 1,20 & 10,44 & 8,70 \\
\hline
\end{tabular}

b) Cargas por parede

Tabela 5.8 - GIP-EP: $N_{k, v e r t}$ e $\eta_{k, v e r t}$ ao nível da fundação - Caso B.

\begin{tabular}{|c|c|c|c|c|}
\hline \multicolumn{3}{|c|}{} & \multicolumn{3}{c|}{ GIP-EP - CASO B - níve } \\
\hline GRUPO & PAREDES & L $_{\text {GIP }}(\mathrm{m})$ & Nk,vert (tf) & $\eta$ k,vert (tf/m) \\
\hline 1 & PH01 e PV02 & 3,60 & 32,04 & 8,90 \\
\hline 2 & PH02 e PV04 & 3,60 & 32,04 & 8,90 \\
\hline 3 & PH03 e PV01 & 3,60 & 32,04 & 8,90 \\
\hline 4 & PH04 e PV03 & 3,60 & 32,04 & 8,90 \\
\hline
\end{tabular}

a) Cargas por grupo

\begin{tabular}{|c|c|c|c|}
\hline PAREDE & $\mathrm{L}(\mathrm{m})$ & Nk,vert (tf) & $\eta \mathrm{k}$, vert (tf/m) \\
\hline PH01 & 2,40 & 21,36 & 8,90 \\
\hline PH02 & 2,40 & 21,36 & 8,90 \\
\hline PH03 & 2,40 & 21,36 & 8,90 \\
\hline PH04 & 2,40 & 21,36 & 8,90 \\
\hline PV01 & 1,20 & 10,68 & 8,90 \\
\hline PV02 & 1,20 & 10,68 & 8,90 \\
\hline PV03 & 1,20 & 10,68 & 8,90 \\
\hline PV04 & 1,20 & 10,68 & 8,90 \\
\hline
\end{tabular}

b) Cargas por paredes

5.2.3 Modelo Pórtico Tridimensional (MPT) - (EP)

O Modelo Pórtico Tridimensional aplicado ao edifício estudo preliminar pode ser visto na Figura 5.5

MPT: CASO A

MPT: CASO B
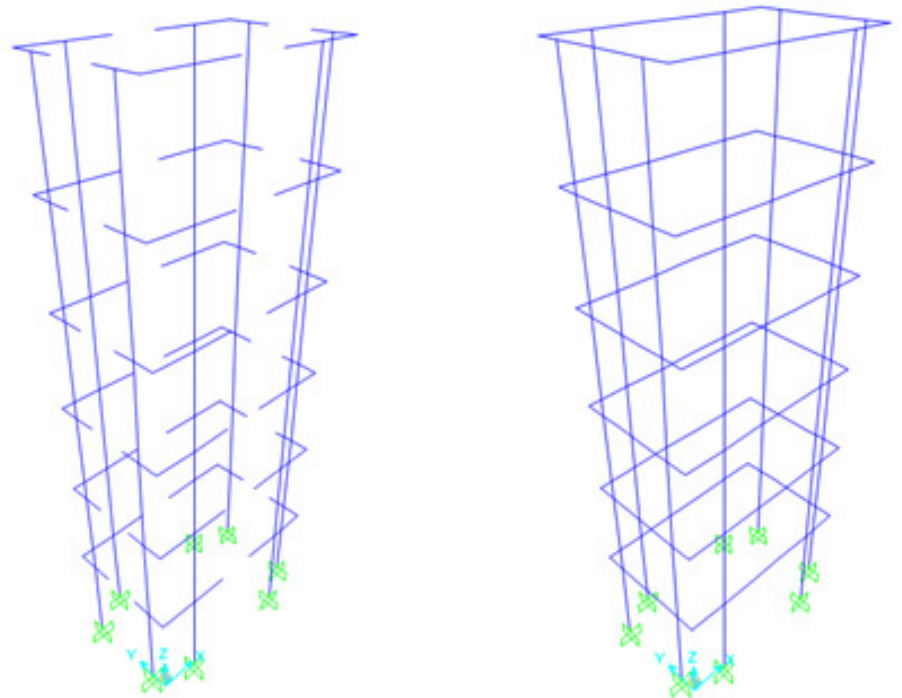

Figura 5.5 - Modelo Pórtico Tridimensional do EP. 
As Tabelas 5.9a e 5.9b apresentam a Força Normal concentra e distribuída por parede ao nível da fundação, nos casos $A$ e B, respectivamente.

Tabela 5.9 - MPT-EP: $N_{k, v e r t}$ e

e $\eta_{k, v e r t}$ ao nível da fundação.

\begin{tabular}{|c|c|c|c|}
\hline \multicolumn{4}{|c|}{ MPT-EP - CASO A - nível 0,00 m } \\
\hline PAREDE & $\mathrm{L}(\mathrm{m})$ & Nk,vert (tf) & $\eta \mathrm{k}$, vert (tf/m) \\
\hline PH01 & 2,40 & 20,91 & 8,71 \\
\hline PH02 & 2,40 & 20,91 & 8,71 \\
\hline PH03 & 2,40 & 20,91 & 8,71 \\
\hline PH04 & 2,40 & 20,91 & 8,71 \\
\hline PV01 & 1,20 & 10,41 & 8,67 \\
\hline PV02 & 1,20 & 10,41 & 8,67 \\
\hline PV03 & 1,20 & 10,41 & 8,67 \\
\hline PV04 & 1,20 & 10,41 & 8,67 \\
\hline
\end{tabular}

a) MPT - caso $A$

\begin{tabular}{|c|c|c|c|}
\hline \multicolumn{4}{|c|}{ MPT-EP - CASO B - nível 0,00 m } \\
\hline PAREDE & $\mathrm{L}(\mathrm{m})$ & Nk,vert (tf) & $\eta$ k,vert (tf/m) \\
\hline PH01 & 2,40 & 21,38 & 8,91 \\
\hline PH02 & 2,40 & 21,38 & 8,91 \\
\hline PH03 & 2,40 & 21,38 & 8,91 \\
\hline PH04 & 2,40 & 21,38 & 8,91 \\
\hline PV01 & 1,20 & 10,66 & 8,88 \\
\hline PV02 & 1,20 & 10,66 & 8,88 \\
\hline PV03 & 1,20 & 10,66 & 8,88 \\
\hline PV04 & 1,20 & 10,66 & 8,88 \\
\hline
\end{tabular}

b) MPT - caso B

\subsubsection{Modelo em Elementos Finitos (MEF) - (EP)}

Com o objetivo de comparar os resultados entre diferentes malhas, adotou-se um modelo cuja discretização das paredes é feita por cascas planas com lados de $20 \mathrm{~cm}$ por $20 \mathrm{~cm}$, chamado de MEF20 e outro cuja discretização das paredes é feita por cascas planas com lados de $40 \mathrm{~cm}$ por $40 \mathrm{~cm}$ denominado MEF40, conforme Figura 5.6. O modelo MEF20, por ser mais refinado, é utilizado como referência para comparação de resultados.

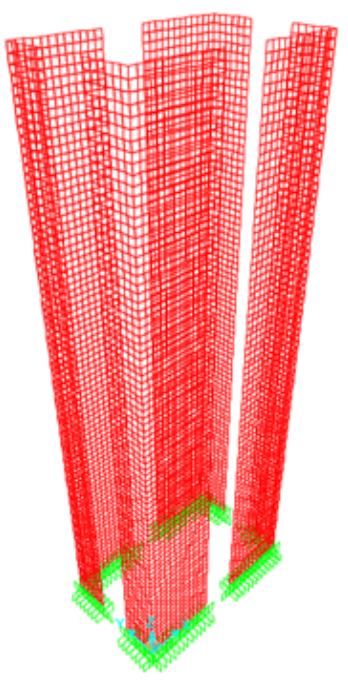

a) MEF20: CASO A

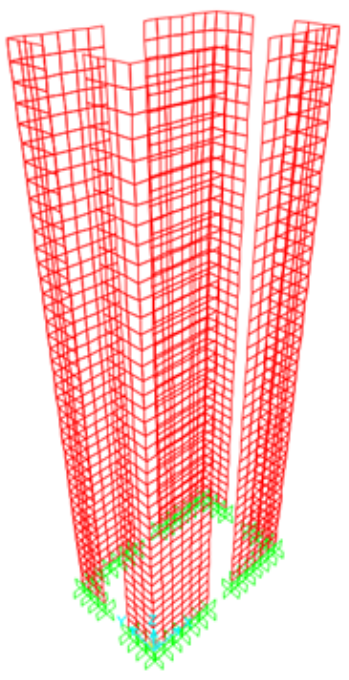

b) MEF40: CASO A

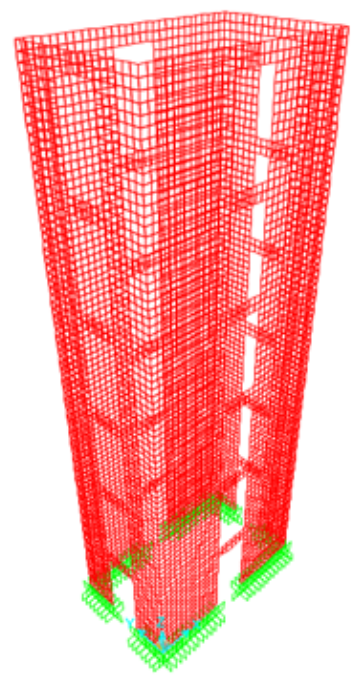

c) MEF20: CASO B

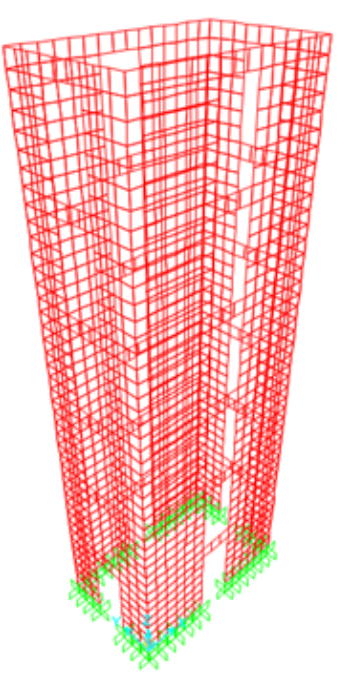

d) MEF40: CASO B

Figura 5.6 - Modelo em Elementos Finitos: malhas de 20x20 e 40×40 para os casos A e B. 
As Tabelas 5.10 e 5.11 mostram os resultados da força normal concentrada e distribuída nas paredes, obtidas pelas modelos MEF20 e MEF 40, para os casos A e B.

Tabela 5.10 - MEF20-EP e MEF40-EP: $N_{k, v e r t}$ e $\eta_{k, v e r t}$ ao nível da fundação - Caso A.

\begin{tabular}{|c|c|c|c|}
\hline \multicolumn{4}{|c|}{ MEF20-EP - CASO A - nível 0,00 m } \\
\hline PAREDE & $\mathrm{L}(\mathrm{m})$ & Nk,vert (tf) & $\eta$ k,vert (tf/m) \\
\hline PH01 & 2,40 & 20,84 & 8,68 \\
\hline PH02 & 2,40 & 20,84 & 8,68 \\
\hline PH03 & 2,40 & 20,84 & 8,68 \\
\hline PH04 & 2,40 & 20,84 & 8,68 \\
\hline PV01 & 1,20 & 10,48 & 8,73 \\
\hline PV02 & 1,20 & 10,48 & 8,73 \\
\hline PV03 & 1,20 & 10,48 & 8,73 \\
\hline PV04 & 1,20 & 10,48 & 8,73 \\
\hline
\end{tabular}

a) MEF20 - caso $A$

\begin{tabular}{|c|c|c|c|}
\hline \multicolumn{4}{|c|}{ MEF40-EP - CASO A - nível 0,00 m } \\
\hline PAREDE & $L(\mathrm{~m})$ & Nk,vert (tf) & $\eta$ k,vert (tf/m) \\
\hline PH01 & 2,40 & 20,85 & 8,69 \\
\hline PH02 & 2,40 & 20,85 & 8,69 \\
\hline PH03 & 2,40 & 20,85 & 8,69 \\
\hline PH04 & 2,40 & 20,85 & 8,69 \\
\hline PV01 & 1,20 & 10,47 & 8,72 \\
\hline PV02 & 1,20 & 10,47 & 8,72 \\
\hline PV03 & 1,20 & 10,47 & 8,72 \\
\hline PV04 & 1,20 & 10,47 & 8,72 \\
\hline
\end{tabular}

b) MEF40 - caso A

Tabela 5.11 - MEF20-EP e MEF40-EP: $N_{k, v e r t}$ e $\eta_{k, v e r t}$ ao nível da fundação - Caso B.

\begin{tabular}{|c|c|c|c|}
\hline \multicolumn{4}{|c|}{ MEF20-EP - CASO B - nível 0,00 m } \\
\hline PAREDE & $L(\mathrm{~m})$ & Nk,vert (tf) & $\eta$ k,vert (tf/m) \\
\hline PH01 & 2,40 & 21,33 & 8,89 \\
\hline PH02 & 2,40 & 21,33 & 8,89 \\
\hline PH03 & 2,40 & 21,33 & 8,89 \\
\hline PH04 & 2,40 & 21,33 & 8,89 \\
\hline PV01 & 1,20 & 10,71 & 8,93 \\
\hline PV02 & 1,20 & 10,71 & 8,93 \\
\hline PV03 & 1,20 & 10,71 & 8,93 \\
\hline PV04 & 1,20 & 10,71 & 8,93 \\
\hline
\end{tabular}

a) MEF20 - caso B

\begin{tabular}{|c|c|c|c|}
\hline \multicolumn{4}{|c|}{ MEF40-EP - CASO B - nível 0,00 m } \\
\hline PAREDE & $\mathrm{L}(\mathrm{m})$ & Nk,vert (tf) & $\eta$ k,vert (tf/m) \\
\hline PH01 & 2,40 & 21,34 & 8,89 \\
\hline PH02 & 2,40 & 21,34 & 8,89 \\
\hline PH03 & 2,40 & 21,34 & 8,89 \\
\hline PH04 & 2,40 & 21,34 & 8,89 \\
\hline PV01 & 1,20 & 10,70 & 8,92 \\
\hline PV02 & 1,20 & 10,70 & 8,92 \\
\hline PV03 & 1,20 & 10,70 & 8,92 \\
\hline PV04 & 1,20 & 10,70 & 8,92 \\
\hline
\end{tabular}

b) MEF40 - caso B

\subsubsection{Comparação de resultados - (EP)}

As Tabelas 5.12 e 5.13 comparam os resultados dos casos $A$ e $B$, respectivamente, entre os quatro modelos utilizados para distribuir cargas verticais nas paredes. Aproveitando a condição de simetria, o que gerou resultados sempre iguais entre paredes de mesma direção, os resultados são comparados apenas nas paredes PH01 e PV01, as quais representam o comportamento das paredes horizontais e verticais, respectivamente. 
Tabela 5.12 - EP: Comparação de $N_{k, v e r t}$ ao nível da fundação - Caso A.

\begin{tabular}{|c|c|c|c|c|c|c|c|c|c|c|}
\hline \multicolumn{1}{|c|}{ DISTRIBUIÇ̃̃O DE CARGAS VERTICAIS - Nk,vert (tf) - CASO A - nível 0,00 m } \\
\hline PAREDE & $\mathrm{L}(\mathrm{m})$ & MEF20 & MEF 40 & $\%$ & MPT & $\%$ & GIP & $\%$ & PIS & $\%$ \\
\hline PH01 & 2,40 & 20,84 & 20,85 & 0,07 & 20,91 & 0,36 & 21,36 & 2,50 & 21,78 & 4,52 \\
\hline PV01 & 1,20 & 10,48 & 10,47 & $-0,15$ & 10,41 & $-0,72$ & 10,68 & 1,90 & 10,26 & $-2,11$ \\
\hline
\end{tabular}

Tabela 5.13 - EP: Comparação de $N_{k, v e r t}$ ao nível da fundação - Caso B.

\begin{tabular}{|c|c|c|c|c|c|c|c|c|c|c|}
\hline \multicolumn{1}{|c|}{ DISTRIBUIÇÃO DE CARGAS VERTICAIS - Nk,vert (tf) - CASO B - nível 0,00 m } \\
\hline PAREDE & L(m) & MEF20 & MEF40 & $\%$ & MPT & $\%$ & GIP & $\%$ & PIS & $\%$ \\
\hline PH01 & 2,40 & 21,33 & 21,34 & 0,06 & 21,38 & 0,26 & 20,88 & $-2,10$ & 21,42 & 0,43 \\
\hline PV01 & 1,20 & 10,71 & 10,70 & $-0,12$ & 10,66 & $-0,51$ & 10,44 & $-2,53$ & 9,9 & $-7,58$ \\
\hline
\end{tabular}

As diferenças entre os modelos MEF20 e MEF40 são praticamente nulas. $O$ Modelo Pórtico Tridimensional também apresenta resultados muito bons com diferenças menores que 1\% em relação ao MEF20. O Grupo Isolado de Paredes difere do modelo adotado como referência em até 2,53\%, valor muito baixo. O pior resultado é obtido pelo Paredes Isoladas, cuja força normal ao nível da fundação da parede PV01 é 7,58\% menor da obtida pelo modelo MEF20.

Ressalta-se que a simplicidade da geometria do edifício estudo preliminar faz com que as diferenças dos resultados obtidos entre os modelos não seja tão acentuada. Mesmo assim, fica clara a hierarquia da qualidade dos modelos, em função da aproximação de resultados em relação ao modelo mais refinado (MEF20): MEF40 o que fornece os melhores resultados, MPT, GIP e PIS sendo o modelo que fornece os piores resultados de distribuição de cargas verticais.

\subsection{Esforços solicitantes devido às ações horizontais}

Os modelos que possibilitam análise quanto à distribuição de ações horizontais são o MEF20, MEF40 e o MPT. Os resultados obtidos com o emprego de cada modelo, nas paredes de contraventamento, em termos dos esforços solicitantes força normal (sinal negativo representa compressão), força cortante e momento fletor, devido apenas às ações horizontais, são apresentados e comparados nos respectivos diagramas ao longo da altura da parede.

São apresentados os esforços característicos das paredes PH01 e PV01, para os casos A e B. No caso da PH01, os resultados apresentados são obtidos em função da ação do vento somada à do desaprumo, aplicadas na direção $X$, no 
sentido $0^{\circ}$. Os resultados apresentados da PV01 são obtidos em função da ação do vento somada à do desaprumo, aplicadas na direção $Y$, no sentido $90^{\circ}$.

\subsubsection{Resultados da parede $\mathrm{PHO1}$}

Seguindo a notação vetorial e as direções do eixo global de coordenadas, apresentado na Figura 5.1, os resultados apresentados para parede PH01 são: momentos fletores característicos na direção $\mathrm{Y}\left(M_{k, y}\right)$, forças cortantes características na direção $\mathrm{X}\left(V_{k, x}\right)$ e forças normais características na direção Z $\left(N_{k, z}\right)$, para os casos A e B, conforme Figuras 5.7 a 5.9, respectivamente.
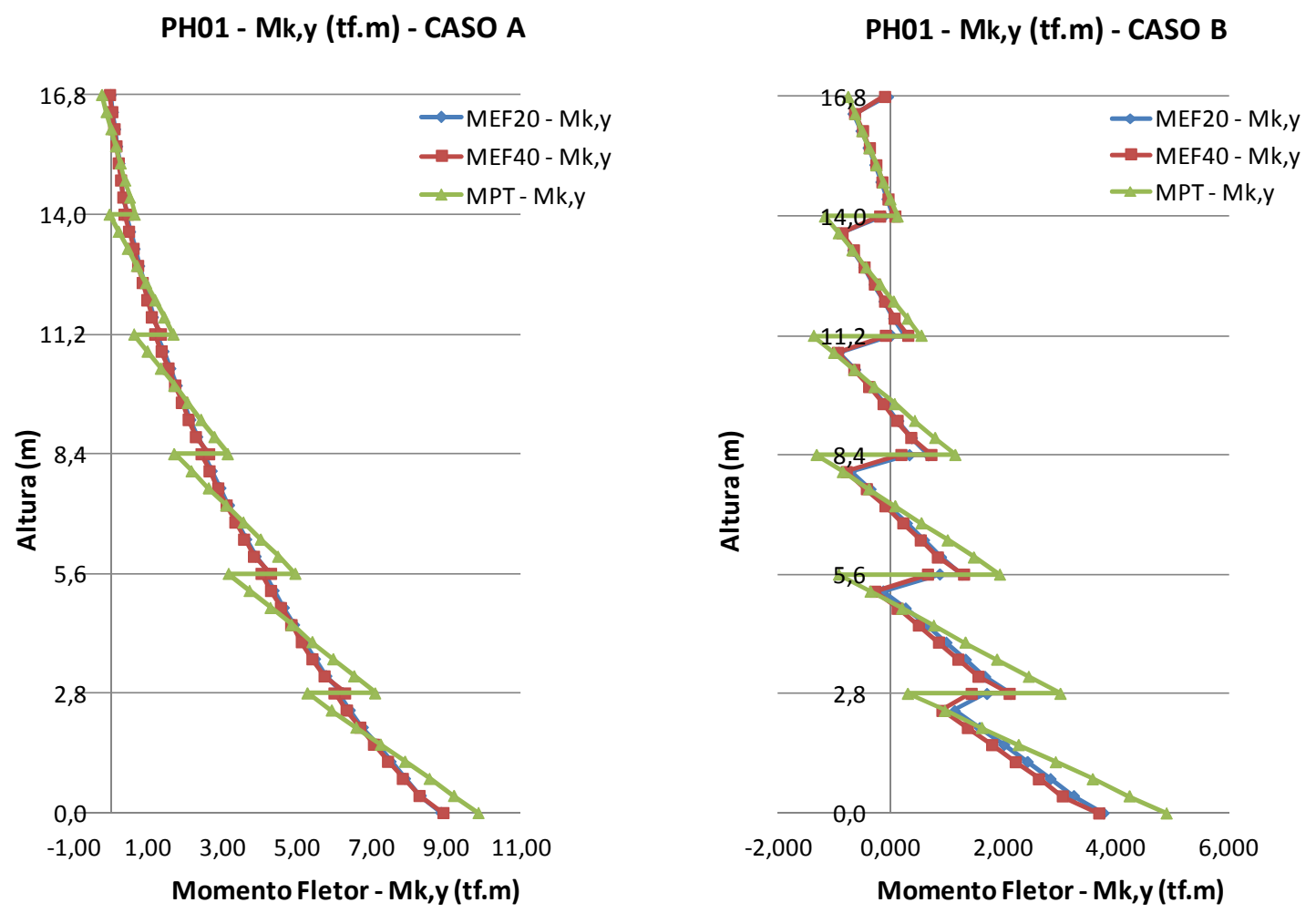

Figura 5.7 - Diagrama de $M_{k, y}$ da parede $\mathrm{PH} 01$ para os casos A e B. 

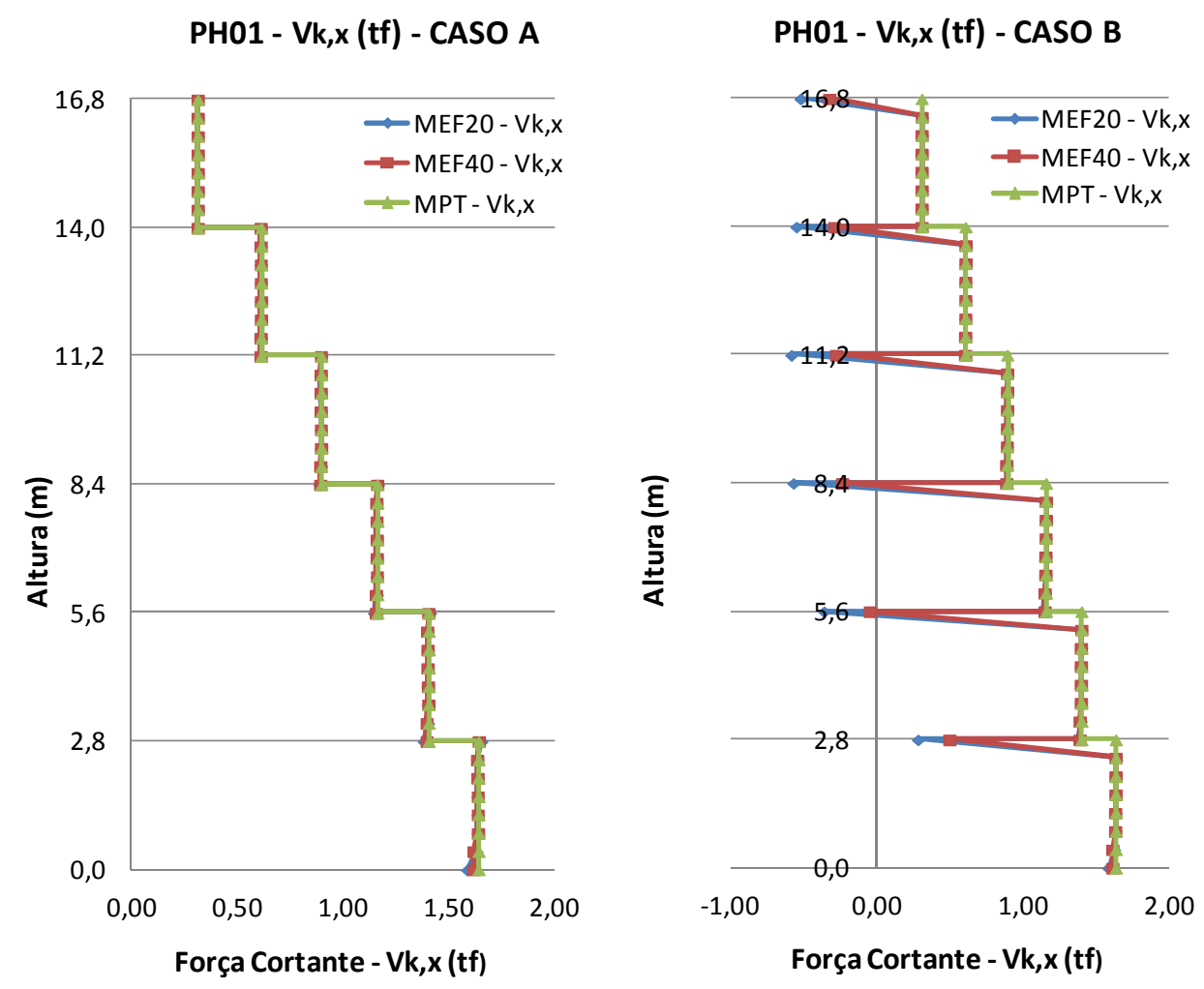

Figura 5.8 - Diagrama de $V_{k, x}$ da parede $\mathrm{PH} 01$ para os casos A e B.

PHO1 - Nk,z (tf) - CASO A

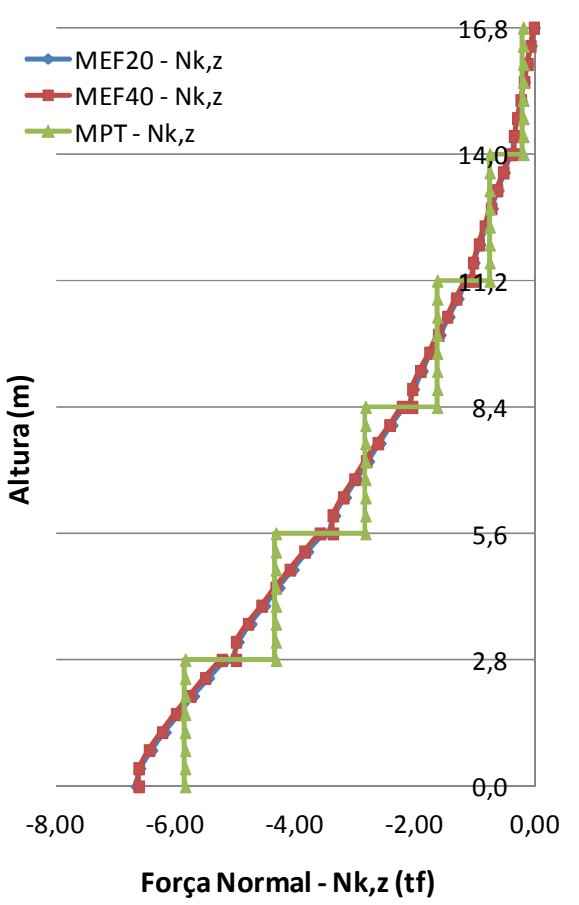

PH01 - Nk,z (tf) - CASO B

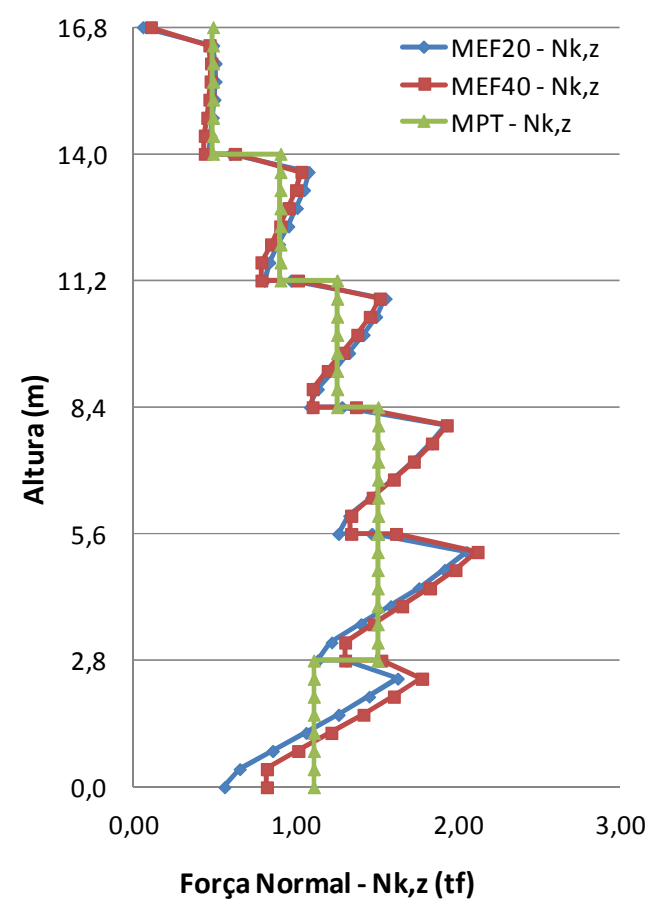

Figura 5.9 - Diagrama de $N_{k, z}$ da parede $\mathrm{PH} 01$ para os casos A e B. 
Os diagramas de momentos fletores (Figura 5.7), obtidos pelos modelos MEF20 e MEF40, são praticamente coincidentes para os dois casos A e B. Observase que o comportamento da parede quando analisada pelo MPT é muito similar aos modelos em elementos finitos.

Por serem mais solicitados, os pavimentos inferiores geralmente são os mais importantes ao dimensionar uma parede. Dessa maneira, comparando a diferença do máximo momento fletor da PH01, o qual ocorre ao nível da fundação, obtido pelo MPT em relação ao MEF20, é de mais $11,26 \%$ para o caso A e de mais $29,54 \%$ no caso B. Quando a mesma análise é feita ao nível 1,40 m (metade do primeiro tramo da parede) as diferenças diminuem como mostra a Tabela 5.14. Também fica perceptível que os diagramas de momentos fletores tendem a se igualar nos pavimentos superiores.

Tabela 5.14 - Comparação de $M_{k, y}$ entre MEF20 x MPT no $1^{\circ}$ pav. da PH01.

\begin{tabular}{|c|c|c|c|}
\hline \multicolumn{4}{|c|}{ PHO1 - Mk,y - CASO A } \\
\hline nível (m) & MEF20 & MPT & $\%$ \\
\hline 0,00 & 8,86 & 9,86 & 11,26 \\
\hline 1,40 & 7,31 & 7,56 & 3,44 \\
\hline \multicolumn{4}{|c|}{ PH01 - Mk,y - CASO B } \\
\hline nível (m) & MEF20 & MPT & $\%$ \\
\hline 0,00 & 3,78 & 4,89 & 29,54 \\
\hline 1,40 & 2,22 & 2,60 & 17,07 \\
\hline
\end{tabular}

As curvas dos diagramas de forças cortante, dos três modelos, para os dois casos, são praticamente coincidentes, como pode ser visto na Figura 5.8. Cabe ressaltar que, no caso $B$, os lintéis formam pórticos com as paredes. Segundo Silva e Giongo (2000), nos nós de pórticos ocorre a mudança de direção do eixo da estrutura, o que provoca alteração dos esforços internos e, consequentemente, modificação na distribuição de tensões na seção. Silva e Giongo (2000) ainda indicam a aplicação do modelo de bielas e tirantes nessas regiões, que eles chamam de tipicamente descontínuas, para análise do comportamento estrutural. Como não é objetivo deste trabalho aplicar o modelo de bielas e tirantes, nem analisar regiões descontínuas, os resultados nas regiões que configuram nós de pórticos não são discutidos. Exemplifica-se essa situação ao analisar as distorções de resultados que ocorrem nos últimos $40 \mathrm{~cm}$ (altura dos lintéis) dos tramos das 
paredes para o caso B, nos modelos MEF20 e MEF40. Na Figura 5.8, a distorção de resultados nessas regiões é evidente.

Analisando-se os diagramas de forças normais (Figura 5.9), evidencia-se a diferença da natureza entre o modelo de barras e os modelos de cascas. Nos modelos de cascas, a parede é dicretizada ao longo de toda sua altura, fazendo com que os esforços e a interação entre paredes sejam representados de forma melhor. No modelo de barras a parede é representada apenas por uma barra vertical e duas barras horizontais, por pavimento; a interação entre elas é simulada através de um único nó no encontro de barras horizontais. Mesmo assim, os resultados são coerentes, como mostra a Tabela 5.15, a qual apresenta o valor da força normal, ao nível médio do pavimento mais solicitado (primeiro pavimento no caso $A$, e segundo pavimento no caso $B$, conforme diagrama da Figura 5.9), o que reforça a qualidade do modelo MPT.

Tabela 5.15 - Comparação de $N_{k, z}$ entre MEF20 e MPT nos níveis mais solicitados da $\mathrm{PH} 01$ nos casos A e B.

\begin{tabular}{|c|c|c|c|}
\hline \multicolumn{4}{|c|}{ PH01 - Nk,z - CASO A } \\
\hline nível $(m)$ & MEF20 & MPT & $\%$ \\
\hline $1,40 m$ & $-6,06$ & $-5,85$ & $-3,48$ \\
\hline \multicolumn{4}{|c|}{ PH01 - Nk,z - CASO B } \\
\hline nível (m) & MEF20 & MPT & $\%$ \\
\hline $4,20 \mathrm{~m}$ & 1,67 & 1,50 & $-10,03$ \\
\hline
\end{tabular}

As forças normais provenientes apenas das ações horizontais nas direções e sentidos citados, obtidas pelo MPT, são constantes em cada tramo da parede PH01, diferentemente do que ocorre nos modelos MEF20 e MEF40, onde a distribuição desse esforço não é constante (tanto no caso A como no B). Isso se justifica, pois no modelo de cascas a interação entre as paredes ocorre ao longo de toda a altura do pavimento, por meio da compatibilidade de deslocamentos nodais, enquanto que no modelo de barras essa simulação é resumida com apenas uma força nodal aplicada ao nível do pavimento, no encontro das barras rígidas horizontais. No caso $\mathrm{B}$, ainda há o espraiamento da força vertical transferida pelo lintel, que segue o mesmo raciocínio da interação entre paredes, ou seja, no MEF esse efeito é melhor representado. Acrescentando, nos modelos de cascas, as tensões normais em cada seção transversal, ao longo da altura das paredes, precisam ser integradas na área da seção transversal para se obter o diagrama do esforço Força Normal, enquanto 
que no modelo MPT o diagrama desse esforço é obtido pela força nodal ao nível de cada pavimento.

As Figuras 5.10 e 5.11 mostram as tensões normais no MEF20 e forças normais no MPT, para os casos A e B, respectivamente, considerando apenas as ações horizontais aplicadas na direção X. Fica claro, que no modelo de cascas, em cada seção transversal das paredes, as tensões normais são diferentes. Por isso o formato do diagrama de forças normais, obtido por esse modelo, não é constante, diferentemente do que ocorre com o modelo de barras. No caso $\mathrm{B}$, onde há presença de lintéis, essa situação fica mais clara.
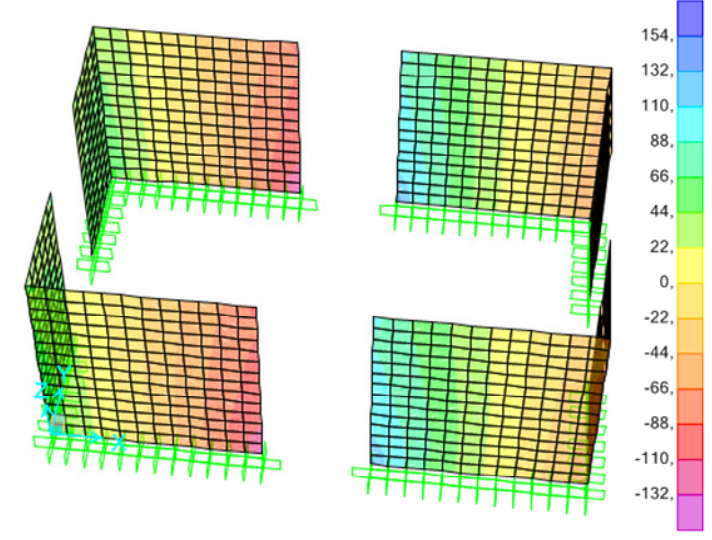

MEF20 - Tensões normais $\left(\mathrm{tt} / \mathrm{m}^{2}\right)-1^{\circ}$ Pav. do Caso A
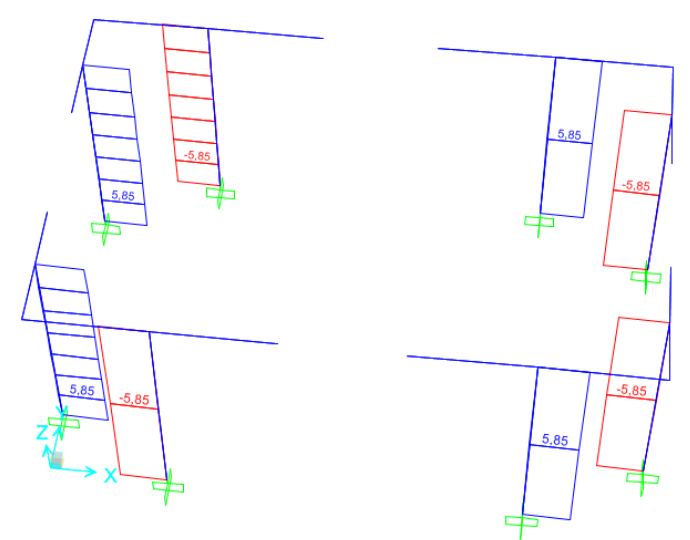

MPT - Forças Normais (tf) - $1^{\circ}$ Pav. do Caso A

Figura 5.10 - Diagramas de tensões normais (MEF20) e forças normais (MPT) - caso A.

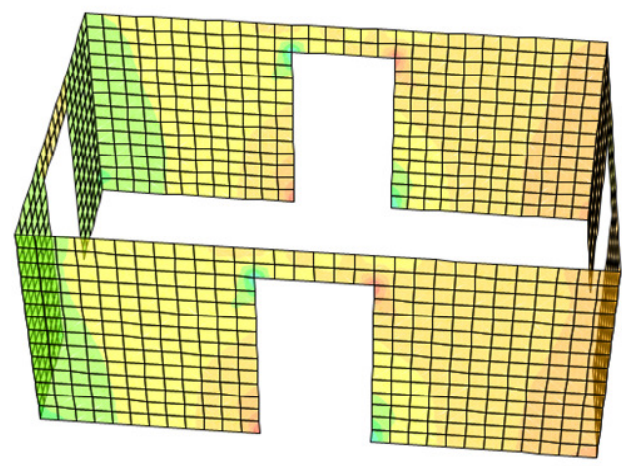

MEF20 - Tensões normais $\left(\mathrm{tt} / \mathrm{m}^{2}\right)-2^{\circ}$ Pav. do Caso B

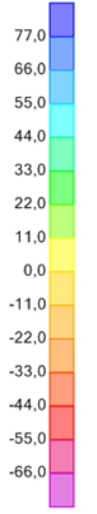

MPT - Forças Normais (tf) - $2^{\circ}$ Pav. do Caso B

Figura 5.11 - Diagramas de tensões normais (MEF20) e forças normais (MPT) - caso B.

Portanto, a própria natureza dos modelos MEF e MPT justifica a diferença no formato dos diagramas de força normal e também as diferenças obtidas nos 
diagramas de momento fletor. Contudo, apesar da diferente natureza os modelos apresentam comportamento muito semelhante.

\subsubsection{Resultados da parede PV01}

Como no caso da PH01, seguiu-se a notação vetorial e as direções do eixo global de coordenadas apresentado na Figura 5.1. Os resultados apresentados para parede PV01 são: momentos fletores característicos na direção $\mathrm{X}\left(M_{k, x}\right)$, forças cortantes características na direção $\mathrm{Y}\left(V_{k, y}\right)$ e forças normais características na direção Z $\left(N_{k, z}\right)$, para os casos A e B, conforme Figuras 5.12 a 5.14, respectivamente.
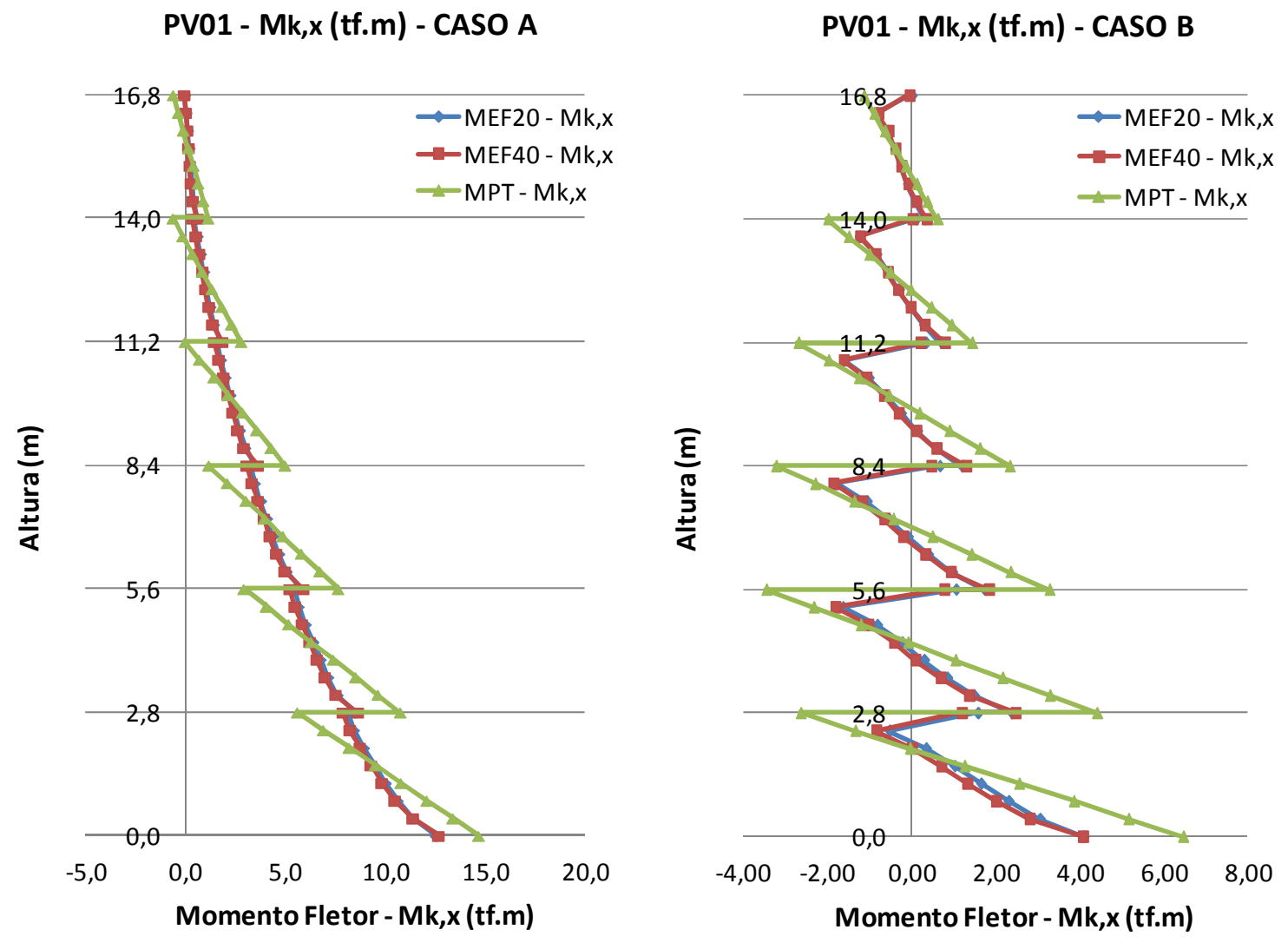

Figura 5.12 - Diagrama de $M_{k, x}$ da parede PV01 para os casos A e B. 
PV01 - Vk,y (tf) - CASO A

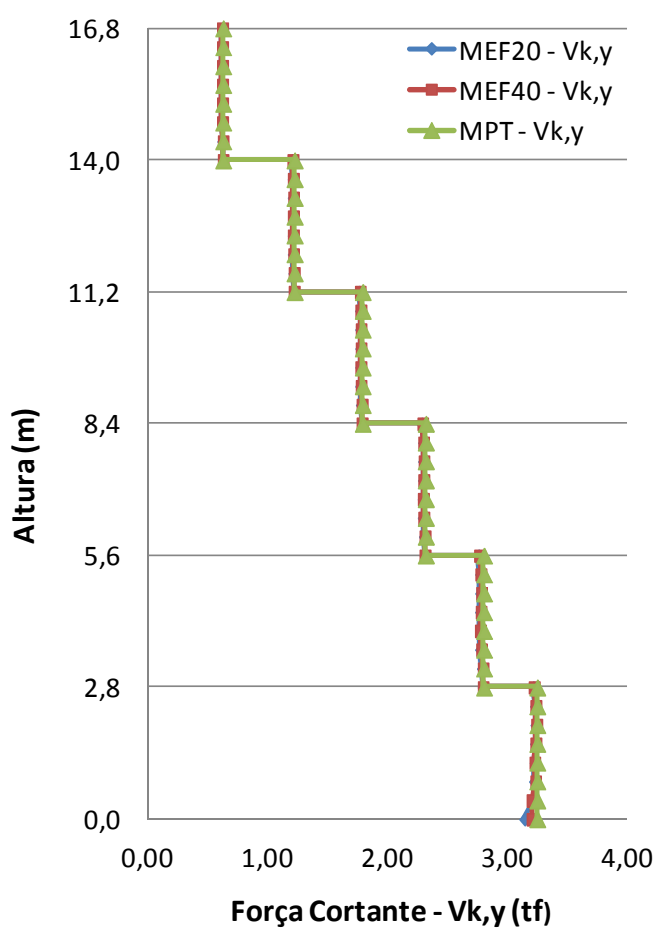

PV01 - Vk,y (tf) - CASO B

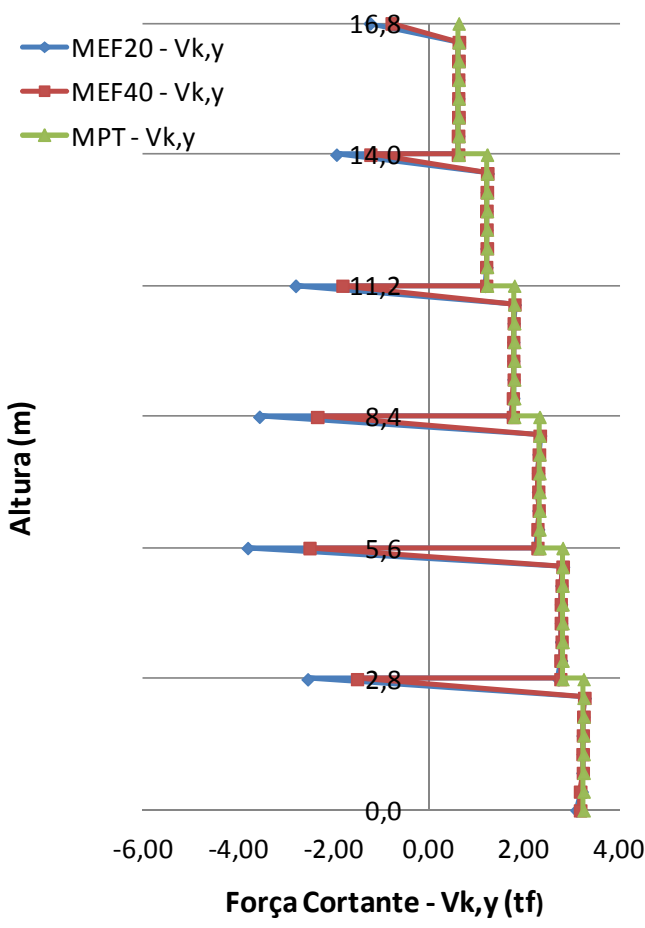

Figura 5.13 - Diagrama de $V_{k, y}$ da parede PV01 para os casos A e B.

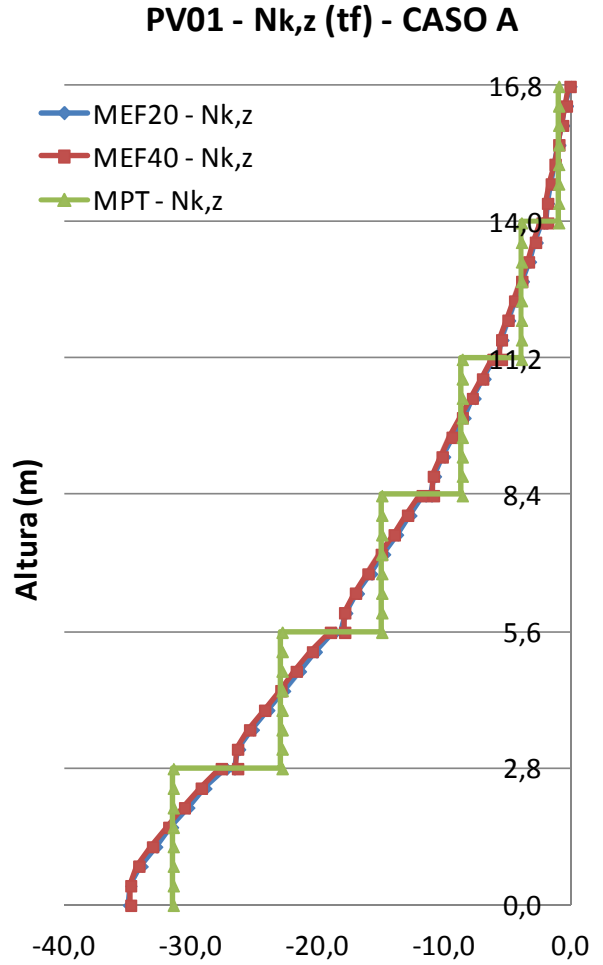

Força Normal - Nk,z (tf)

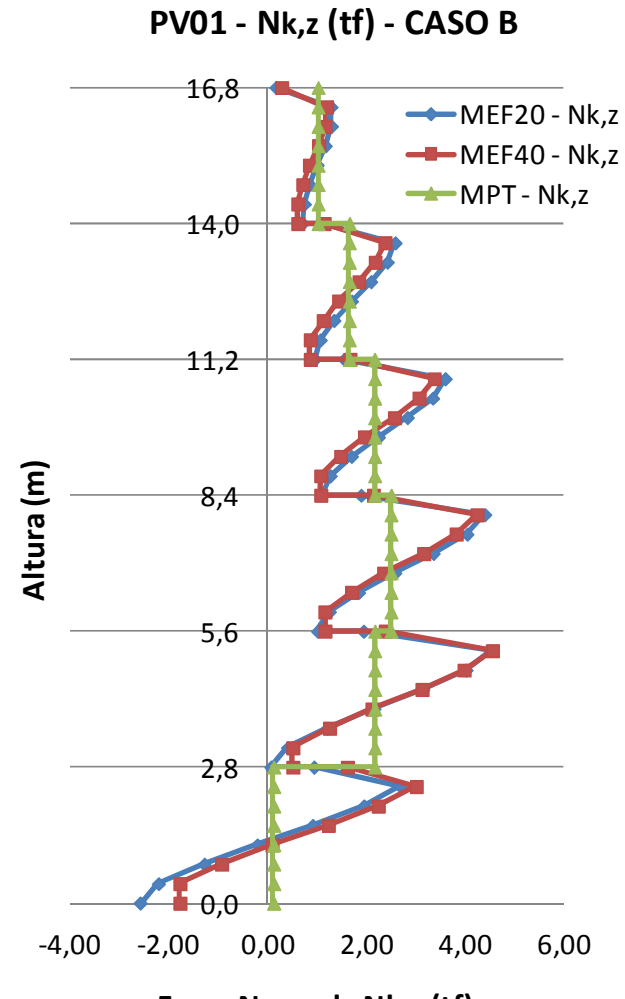

Força Normal - Nk,z (tf)

Figura 5.14 - Diagrama de $N_{k, z}$ da parede PV01 para os casos A e B. 
Os resultados são muito parecidos com os obtidos para a parede $\mathrm{PH} 01$, portanto, valem os mesmos comentários do item 5.3.1.

A Tabela 5.16 compara os momentos fletores em dois níveis do primeiro pavimento da PV01, obtidos pelo MPT e MEF20. Percebe-se que as diferenças no caso A são pequenas, de até $16,96 \%$. No caso B as diferenças são consideráveis, no entanto há que se considerar que nesse caso o Modelo Pórtico Tridimensional está a favor da segurança, além do fato dos valores absolutos dos momentos fletores apresentados serem pequenos.

Tabela 5.16 - Comparação de $M_{k, x}$ entre MEF20 x MPT no $1^{\circ}$ pav. da PV01.

\begin{tabular}{|c|c|c|c|}
\hline \multicolumn{4}{|c|}{ PV01 - Mk,x - CASO A } \\
\hline nível (m) & MEF20 & MPT & $\%$ \\
\hline $0,00 \mathrm{~m}$ & 12,53 & 14,65 & 16,96 \\
\hline $1,40 \mathrm{~m}$ & 9,72 & 10,12 & 4,10 \\
\hline \multicolumn{4}{|c|}{ PV01 - Mk,x - CASO B } \\
\hline nível (m) & MEF20 & MPT & $\%$ \\
\hline $0,00 \mathrm{~m}$ & 4,06 & 6,43 & 58,32 \\
\hline $1,40 \mathrm{~m}$ & 1,31 & 1,88 & 43,68 \\
\hline
\end{tabular}

A Tabela 5.17 compara as forças normais obtidas pelo MPT e MEF20, nos níveis médios dos pavimentos mais solicitados, sendo o primeiro pavimento no caso A, e o terceiro pavimento no caso B, como mostram os diagramas da Figura 5.14. Os resultados são bons, principalmente no caso $A$, onde a diferença chega a $-2,13 \%$. No caso B a diferença não é grande, chegando a $-15,84 \%$.

Tabela 5.17 - Comparação do $N_{k, z}$ entre MEF20 x MPT nos níveis mais solicitados da PV01 nos casos $A$ e $B$.

\begin{tabular}{|c|c|c|c|}
\hline \multicolumn{4}{|c|}{ PV01 - Nk,z - CASO A } \\
\hline nível (m) & MEF20 & MPT & $\%$ \\
\hline $1,40 \mathrm{~m}$ & $-32,18$ & $-31,50$ & $-2,13$ \\
\hline \multicolumn{4}{|c|}{ PV01 - Nk,z - CASO B } \\
\hline nível (m) & MEF20 & MPT & $\%$ \\
\hline $7,00 \mathrm{~m}$ & 2,96 & 2,50 & $-15,84$ \\
\hline
\end{tabular}




\subsection{Verificação das tensões normais}

\subsubsection{Combinações de cálculo}

Ao dimensionar as paredes de concreto, utiliza-se o método dos estados limites, o qual é baseado em métodos probabilísticos que levam em consideração a variabilidade das ações e das resistências por meio de combinações de ações e coeficientes de ponderação para obtenção dos valores de cálculo. Após as devidas considerações, a verificação descrita na Equação (5.1) deve ser sempre respeitada:

$$
S_{d} \leq R_{d}
$$

onde:

$S_{d}$ : solicitações de cálculo;

$R_{d}$ : resistências de cálculo

Normalmente os valores de cálculo são obtidos seguindo-se alguma norma. No caso deste trabalho, as paredes que forem dimensionadas seguem o recomendado pelas normas brasileiras, tanto a NBR 8186:2004 - Ações e Segurança nas Estruturas - Procedimentos, como as NBR 16055:2012 e NBR 6118:2007.

Conforme a NBR 6118:2007, as combinações das ações devem ser feitas de forma que possam ser determinados os efeitos mais desfavoráveis para a estrutura. Neste trabalho, utilizam-se combinações últimas normais, definida na Equação (5.2) para a verificação ao dimensionamento das tensões normais e tangenciais das paredes de concreto.

$$
F_{d}=\gamma_{g} \cdot F_{g k}+\gamma_{q} \cdot\left(F_{q 1 k}+\sum \psi_{0 j} \cdot F_{q j k}\right)
$$

onde:

$F_{d}:$ valor de cálculo das ações para a combinação última; 
$F_{g k}:$ ações permanentes diretas;

$F_{q k}$ : ações variáveis diretas, sendo $F_{q 1}$ a ação variável principal;

$\gamma_{g}$ : coeficiente majorador das ações permanentes diretas; $\gamma_{g}=1,4$ para ações com efeito desfavorável; $\gamma_{g}=1,0$ para ações com efeito favorável;

$\gamma_{q}$ : coeficiente majorador das ações variáveis diretas; $\gamma_{q}=1,4$

$\psi_{0}$ : coeficiente redutor das ações variáveis secundárias; $\psi_{0}=0,5$ no caso das ações variáveis oriundas das lajes de um edifício residencial, serem secundárias; $\psi_{0}=0,6$ no caso do vento ou do desaprumo serem ações variáveis secundárias.

Ao verificar o dimensionamento de determinada seção transversal de uma parede de concreto, são feitas duas combinações últimas normais. Uma para o caso de máxima tensão normal de compressão chamada de combinação um $\left(\mathrm{C}_{1}\right)$, onde as ações permanentes têm efeito desfavorável e o vento é considerado como ação variável principal; e outra para a eventual máxima tensão normal de tração, chamada de combinação dois $\left(\mathrm{C}_{2}\right)$, onde as ações permanentes têm efeito favorável e o vento é considerado como ação variável principal. Quando a ação variável secundária tiver efeito favorável, ela não deve ser considerada na respectiva combinação. As expressões das combinações $C_{1}$ e $C_{2}$ ficam conforme Equações (5.3) e (5.4):

$$
\begin{aligned}
& C_{1}: F_{C d}=1,4 .(P P)+1,4 \cdot\left(G_{\text {LAJE }}\right)+1,4 .\left(Q_{V E N T O}\right)+0,7 \cdot\left(Q_{\text {LAJE }}\right)+0,84 \cdot\left(Q_{\text {DESAPRUMO }}\right) \\
& C_{2}: F_{T d}=1,0 .(P P)+1,0 .\left(G_{\text {LAJE }}\right)+1,4 \cdot\left(Q_{V E N T O}\right)+0,84 .\left(Q_{\text {DESAPRUMO }}\right)
\end{aligned}
$$

onde:

$F_{C d} \quad$ : esforço que gera situação de máxima tensão normal de compressão;

$F_{T d} \quad$ : esforço que gera situação de máxima tensão normal de tração;

$P P \quad$ : peso próprio dos elementos estruturais;

$G_{L A J E}$ : revestimento considerado nas lajes dos pavimentos; 
$Q_{\text {LAJE }}$ : ação variável das lajes conforme NBR 6120;

$Q_{V E N T O}$ : ação do vento na direção da parede de contraventamento;

$Q_{\text {DESAPRUMO }}$ : ação do desaprumo na mesma direção do vento.

\subsubsection{Tensões de cálculo}

Consequentemente ao apresentado no item 5.4.1, ao verificar as tensões normais de uma parede de concreto, é preciso compor os esforços obtidos pelas cargas verticais (força normal), com os esforços obtidos pelas ações horizontais (momento fletor e força normal), conforme equações (5.5) e (5.6).

$$
\begin{gathered}
\sigma_{C d}=\frac{N_{C d}}{A} \pm \frac{M_{C d}}{W} \\
\sigma_{T d}=\frac{N_{T d}}{A} \pm \frac{M_{T d}}{W}
\end{gathered}
$$

onde:

$\sigma_{C d}$ : tensão normal para a condição máxima de compressão;

$\sigma_{T d}$ : tensão normal para a condição máxima de tração;

$N_{C d} \quad$ : força normal que gera situação de compressão máxima;

$M_{C d}$ : momento fletor que gera situação de compressão máxima;

$N_{T d}$ : força Normal que gera situação de tração máxima;

$M_{T d} \quad$ : momento fletor que gera situação de tração máxima;

A : área da seção transversal da parede;

W : módulo de resistência à flexão.

Analisando os diagramas dos esforços característicos, das paredes $\mathrm{PH} 01$ e PV01, nos casos A e B (Figuras 5.7 a 5.9 e 5.12 a 5.14), constata-se que as maiores diferenças entre os modelos considerados ocorrem no caso $B$, nos diagramas de momentos fletores e forças normais. Em contrapartida, as forças normais obtidas 
somente por carregamentos verticais fornecem resultados com diferenças insignificantes. Como visto no item 5.4.1, após as devidas combinações de carregamento para se chegar a esses dois esforços de cálculo, eles são "somados" com o objetivo de se obterem as tensões máximas de compressão ou tensões máximas de tração, ou seja, com o objetivo de verificar o dimensionamento da parede.

A seguir apresentam-se os diagramas dos momentos fletores e forças normais de cálculo da $\mathrm{PH} 01$, para o caso $\mathrm{B}$, de modo a destacar que as diferenças antes obtidas nos esforços característicos oriundos das ações horizontais se tornam insignificantes ao se fazerem as combinações de ações de cálculo e ao se obterem as tensões máximas de compressão.

A Figura 5.15 apresenta o diagrama de cálculo dos momentos fletores e forças normais na parede PH01, considerando a combinação um de carregamentos, sendo a direção do vento e do desaprumo em $\mathrm{X}$ no sentido $180^{\circ}$ no caso $\mathrm{B}$.
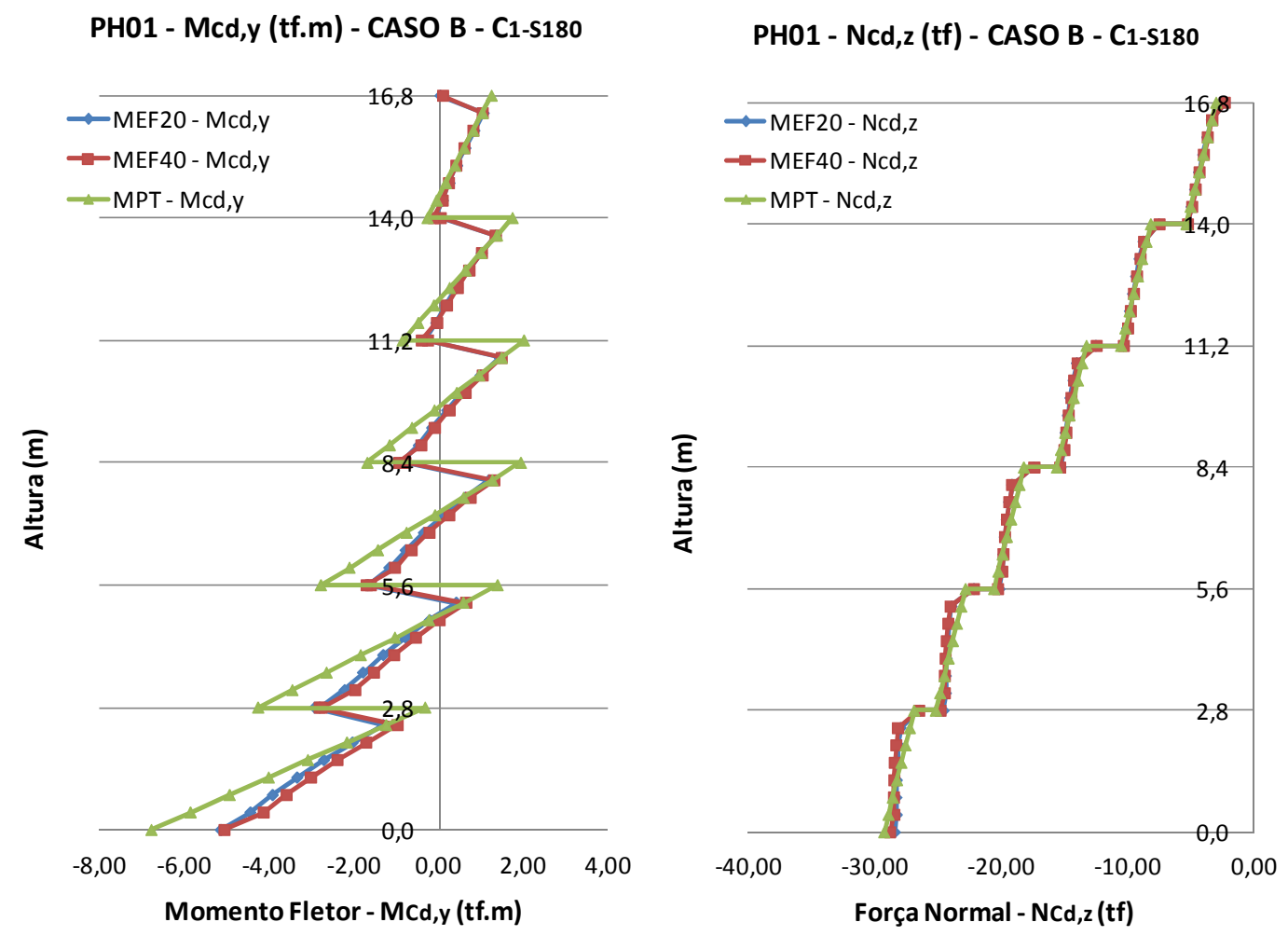

Figura 5.15 - Diagramas de $M_{C d, y}$ e $N_{C d, z}$ para combinação $\mathrm{C}_{1-\mathrm{S} 180}$ da PH01 no caso B.

Conforme diagrama da Figura 5.9, a máxima diferença da força normal característica da PH01, entre os modelos MEF20 e MPT, obtida apenas por ações horizontais, ocorria ao nível da fundação e era de $98,26 \%$. O diagrama de cálculo 
das forças normais (Figura 5.15), obtidas pela combinação um, conforme Equação (5.3), mostra que as diferenças entre os modelos se reduzem a praticamente zero. A Tabela 5.18 compara o maior valor de $N_{C d, z}$, obtido pelos modelos MEF20 e MPT. Constata-se que a diferença entre eles é de apenas 2,91\%.

Tabela 5.18 - Comparação da máxima $N_{C d, z}$ entre MEF20 x MPT da PH01.

\begin{tabular}{|c|c|c|c|}
\hline \multicolumn{4}{|c|}{ PH01 - NCd, z - CASO B - C1-S180 } \\
\hline nível (m) & MEF20 & MPT & $\%$ \\
\hline $0,00 m$ & $-28,37$ & $-29,20$ & 2,91 \\
\hline
\end{tabular}

A principal razão da diferença das forças normais entre os modelos ter diminuído bastante, em relação àquelas obtidas considerando apenas as ações horizontais, é o fato de que as forças normais obtidas apenas pelos carregamentos verticais são maiores em relação às obtidas pelas ações horizontais, e as diferenças delas entre os modelos, quando consideradas apenas cargas verticais, são praticamente nulas, como pode ser visto nas Tabelas 5.12 e 5.13 .

Comparando o diagrama de momentos fletores da Figura 5.15 (de cálculo), com o da Figura 5.7 (característico), nota-se que as diferenças de valores entre os modelos permanecem, e que os sinais estão invertidos (isto pelo fato de que a condição de máxima compressão para parede PH01 é devida às ações horizontais na direção $X$ e no sentido $180^{\circ}$, diferente do diagrama da Figura 5.7 , onde se apresentam os resultados considerando as ações horizontais na direção $X$ e no sentido $0^{\circ}$ ). Apesar das diferenças entre os momentos fletores permanecerem no diagrama de cálculo, quando eles são "somados" às forças normais, a fim de se obter o diagrama de tensões normais de uma determinada seção transversal da parede, as diferenças entre os modelos praticamente desaparecem, como mostra o diagrama da Figura 5.16. A Tabela 5.19 compara as tensões máximas de compressão entre os três modelos. O MPT obteve valor 5,53\% menor que o modelo de referência, o que mostra novamente a qualidade do modelo de barras, a despeito de sua simplicidade.

Tabela 5.19 - Comparação do $\sigma_{C d}$ entre MEF20 x MEF40 x MPT ao nível 0,00m da PH01.

\begin{tabular}{|c|c|c|c|c|c|}
\hline \multicolumn{5}{|c|}{ PHO1 - $\sigma_{\mathrm{Cd}}\left(\mathrm{tf} / \mathrm{m}^{2}\right)$ - Caso B - C1-S180 } \\
\hline nível $(\mathrm{m})$ & MEF20 & MEF40 & $\%$ & MPT & $\%$ \\
\hline 0,00 & $-203,50$ & $-185,48$ & $-8,86$ & $-192,25$ & $-5,53$ \\
\hline
\end{tabular}


Ressalta-se que o edifício estudo preliminar não possui alta esbeltez. Sua altura total é de 16,80 m e seu menor comprimento em planta é de 3,6 m.

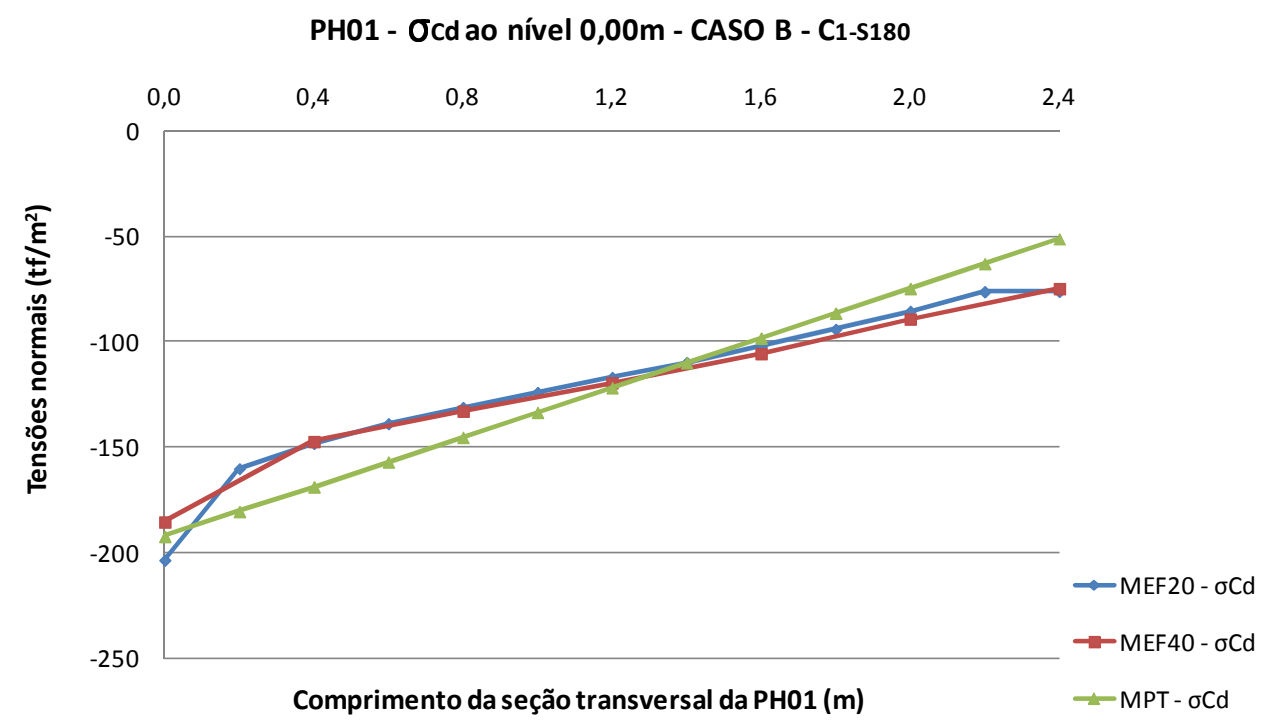

Figura 5.16 - Tensões normais para a condição máxima de compressão - PH01 - Caso B.

\subsection{Translações horizontais globais}

As Figuras 5.17 e 5.18 comparam as translações horizontais na direção $X$ $\left(\delta_{x}\right)$ e $\mathrm{Y}\left(\delta_{y}\right)$, respectivamente, ao nível de cada pavimento do edifício estudo preliminar para o caso A. As ações permanentes não foram consideradas. As ações horizontais foram consideradas nas direções $X$ e $Y$ e sentidos $0^{\circ}$ e $90^{\circ}$. Observa-se que os resultados são praticamente iguais para os três modelos.

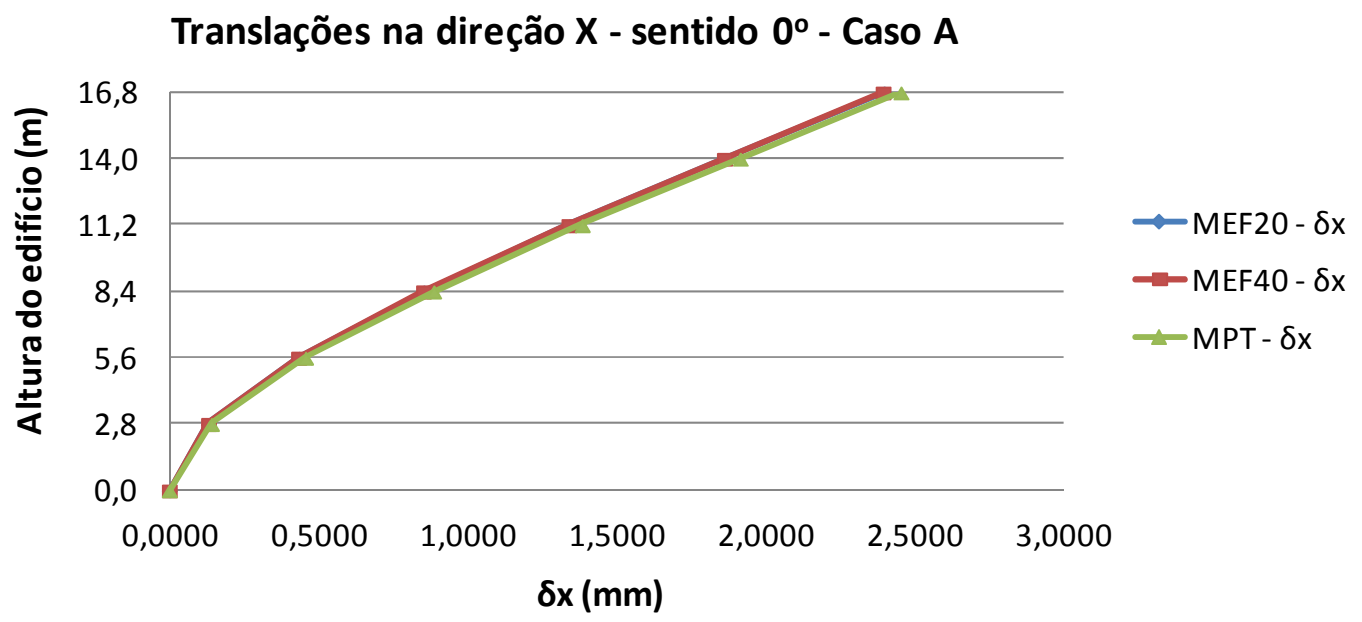

Figura 5.17 - Translações horizontais na direção X - Caso A. 


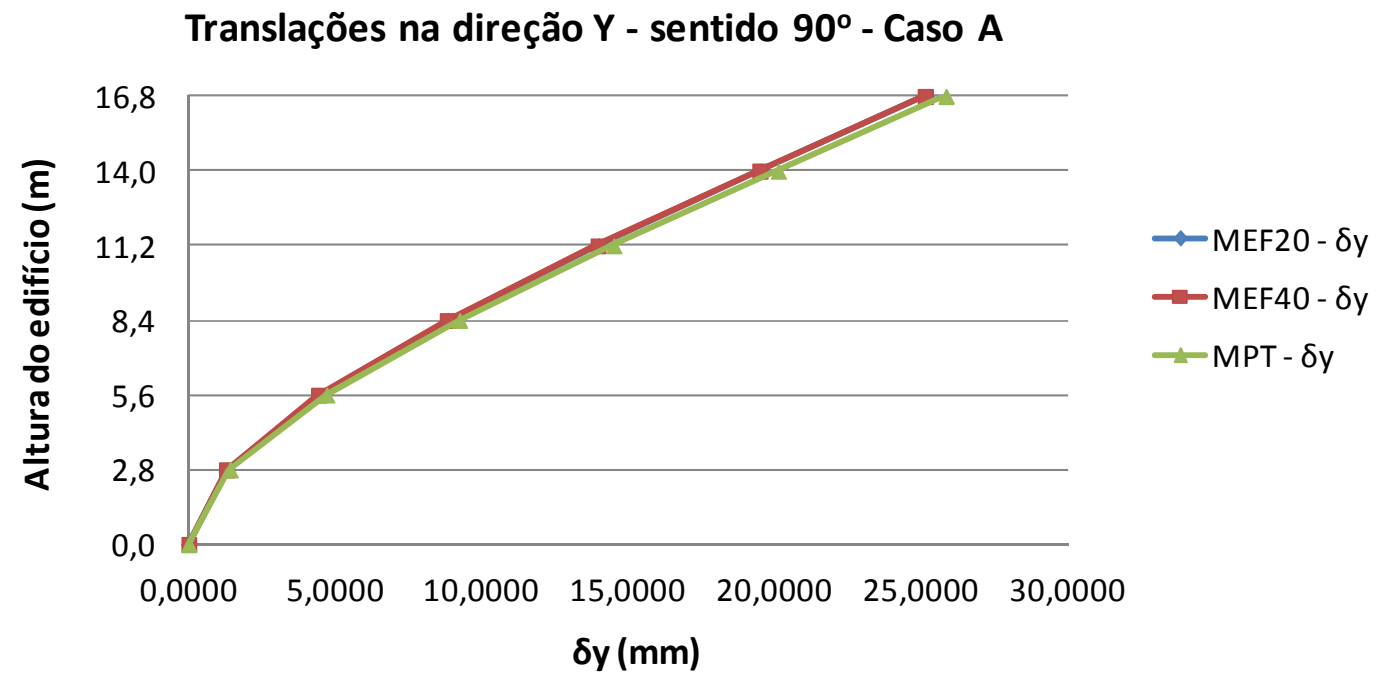

Figura 5.18 - Translações horizontais na direção Y - Caso A.

As Figuras 5.19 e 5.20 mostram os mesmos resultados para o Caso B.

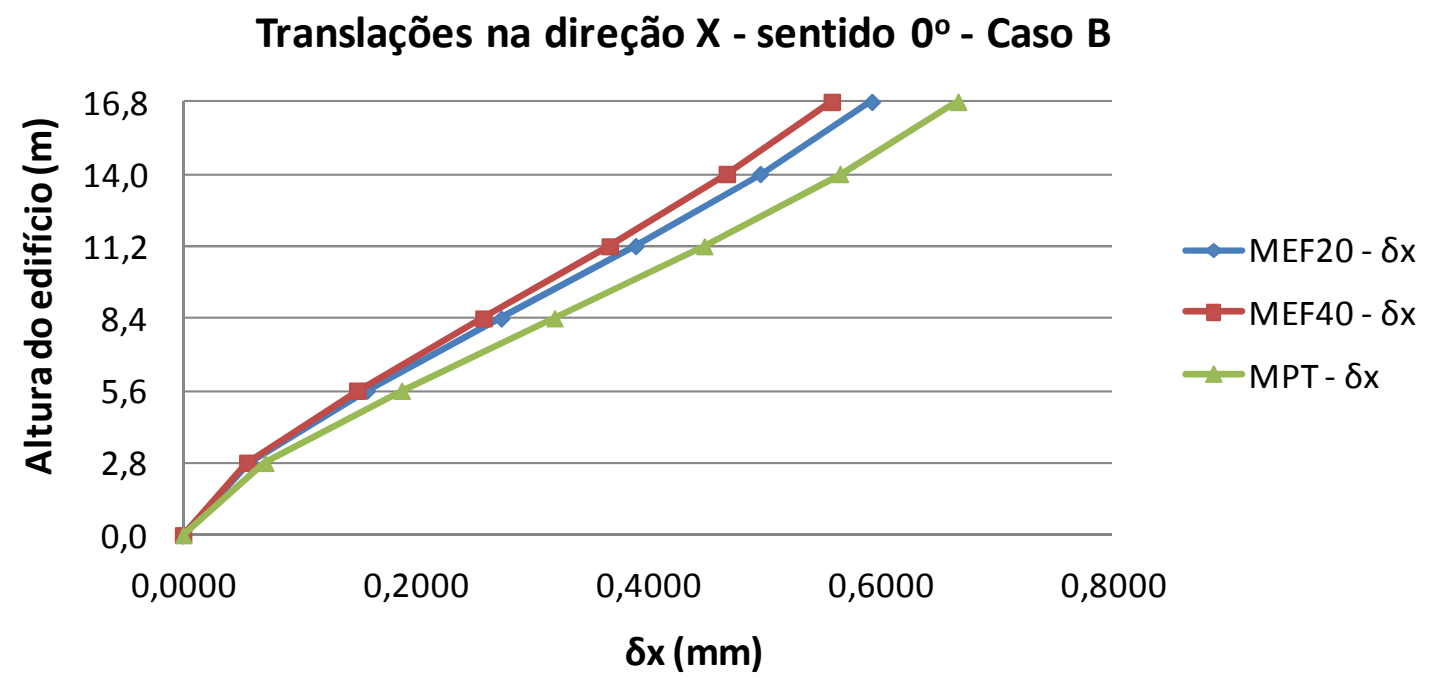

Figura 5.19 - Translações horizontais na direção X - Caso B.

Observa-se que o MPT é mais flexível em relação aos modelos de cascas, nas duas situações apresentados para o caso $\mathrm{B}$. Em relação à translação horizontal na direção X (Figura 5.19), o valor no topo do edifício obtido pelo MPT é de $0,6666 \mathrm{~mm}$, ou seja, $12,54 \%$ maior que o valor obtido pelo MEF20, que foi de $0,5923 \mathrm{~mm}$. Quanto à translação horizontal no topo do edifício, na direção Y (Figura 5.20), essa diferença é aumentada, sendo $3,5248 \mathrm{~mm}$ o valor obtido pelo MPT, contra 2,7785 mm, valor obtido pelo MEF20, o que dá uma diferença de $26,85 \%$ a mais. 


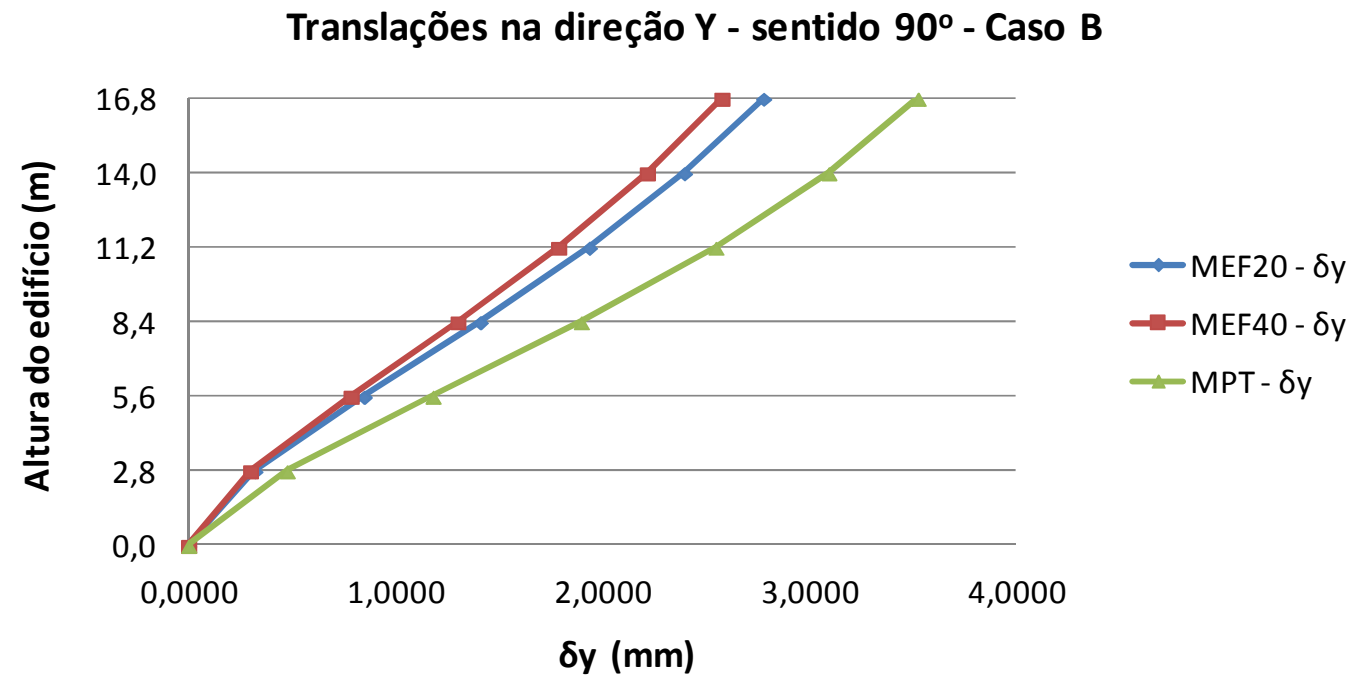

Figura 5.20 - Translações horizontais na direção Y - Caso B.

No caso $\mathrm{B}$, onde as diferenças são maiores, a relação da maior translação horizontal obtida no topo do edifício (modelo MPT na direção Y), pela altura dele, é de 4766, ou seja, a translação horizontal é muito pequena. Além disso, se utilizado o modelo MPT, quanto à verificação de serviço de deformações excessivas globais, referentes à movimentação lateral do edifício, se estará a favor da segurança.

\subsection{Discussões sobre os resultados do edifício estudo preliminar}

Os resultados obtidos entre os modelos MEF20 e MEF40 são muito próximos, concluindo-se que para o tipo de análise apresentada não é necessário discretizar as paredes em malhas tão pequenas. Por essa razão, no estudo de caso, o edifício exemplo apresentado no capítulo seis tem suas paredes discretizadas em malhas de $40 \mathrm{~cm}$ por $40 \mathrm{~cm}$, quando utilizado o modelo de cascas.

Outra conclusão é a proximidade dos resultados obtidos pelo Modelo Pórtico Tridimensional, principalmente naqueles utilizados quando se verificam as condições para o correto dimensionamento das paredes de concreto.

Portanto, os fundamentos teóricos dos modelos propostos foram consolidados com base na qualidade dos resultados apresentados. 


\section{EDIFÍCIO EXEMPLO PARA O ESTUDO DE CASO}

Com o objetivo de verificar o dimensionamento das paredes de concreto, neste capítulo são aplicados os modelos de cálculo apresentados no capítulo quatro e consolidados no capítulo cinco, em um edifício exemplo (EE) utilizado como estudo de caso.

\subsection{Geometria do edifício exemplo (EE)}

Utilizou-se uma adaptação do edifício Condomínio das Árvores do empreendimento Reserva Jardim Botânico, construído na cidade de São Bernardo do Campo, no ano de 2012, pela construtora Sergus Construções e Comércio Ltda., conforme Figura 6.1. O projeto estrutural foi fornecido pela OSMB Engenheiros e Associados S/S Ltda.

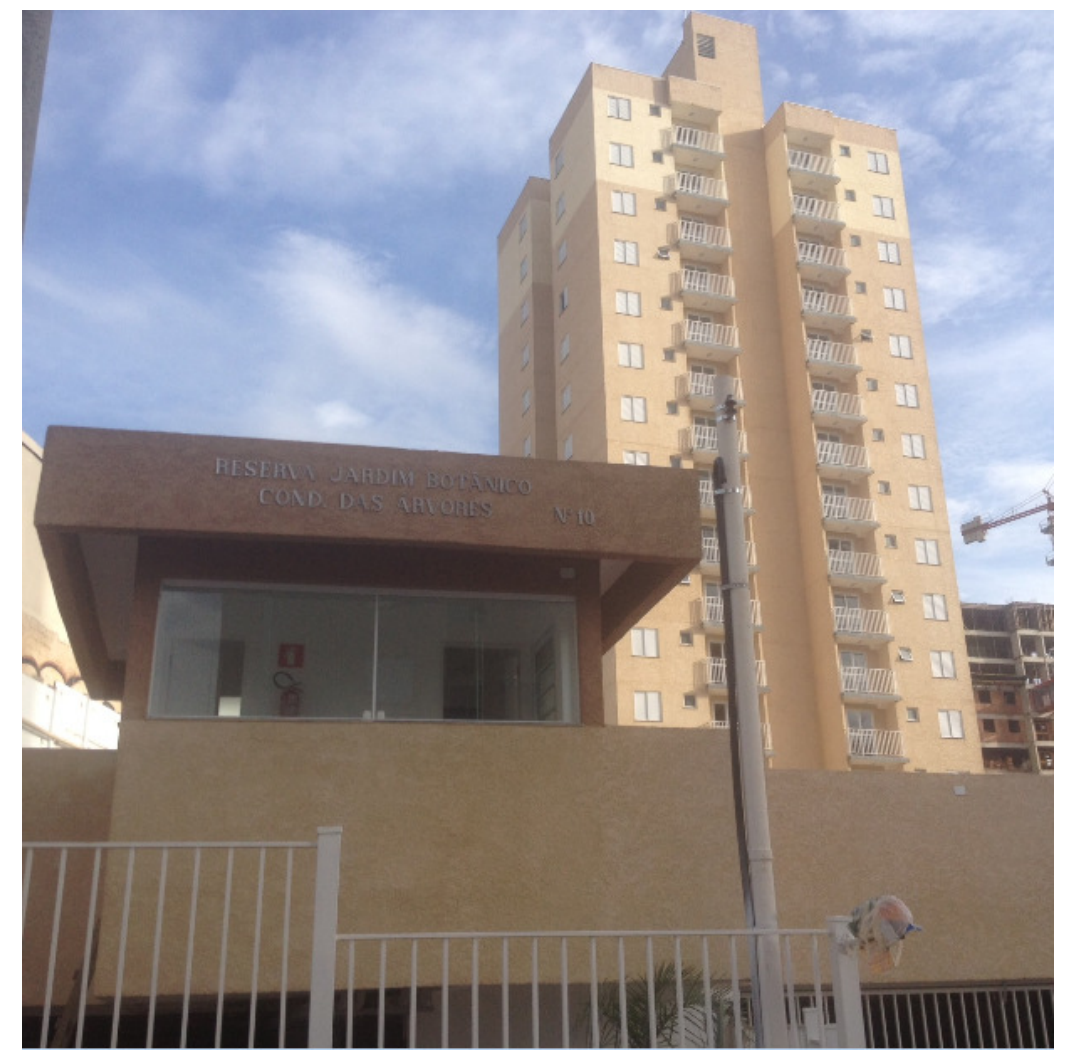

Figura 6.1 - Edifício Condomínio das Árvores do empreendimento Reserva Jardim Botânico. 
A geometria do EE foi adaptada em relação ao edifício construído com o objetivo de simplificar as modelagens numéricas. Contudo, suas características principais foram mantidas. Todas as medidas ficaram múltiplas de $40 \mathrm{~cm}$, e o número de pavimentos foi adotado igual a quinze tipos, não havendo, portanto, a transição do térreo para o primeiro pavimento, nem o ático, previstos no projeto original. Considerou-se a distância entre pisos de 2,80 m. A Figura 6.2 mostra a planta do pavimento tipo com as paredes e os lintéis nomeados conforme as direções horizontal e vertical.

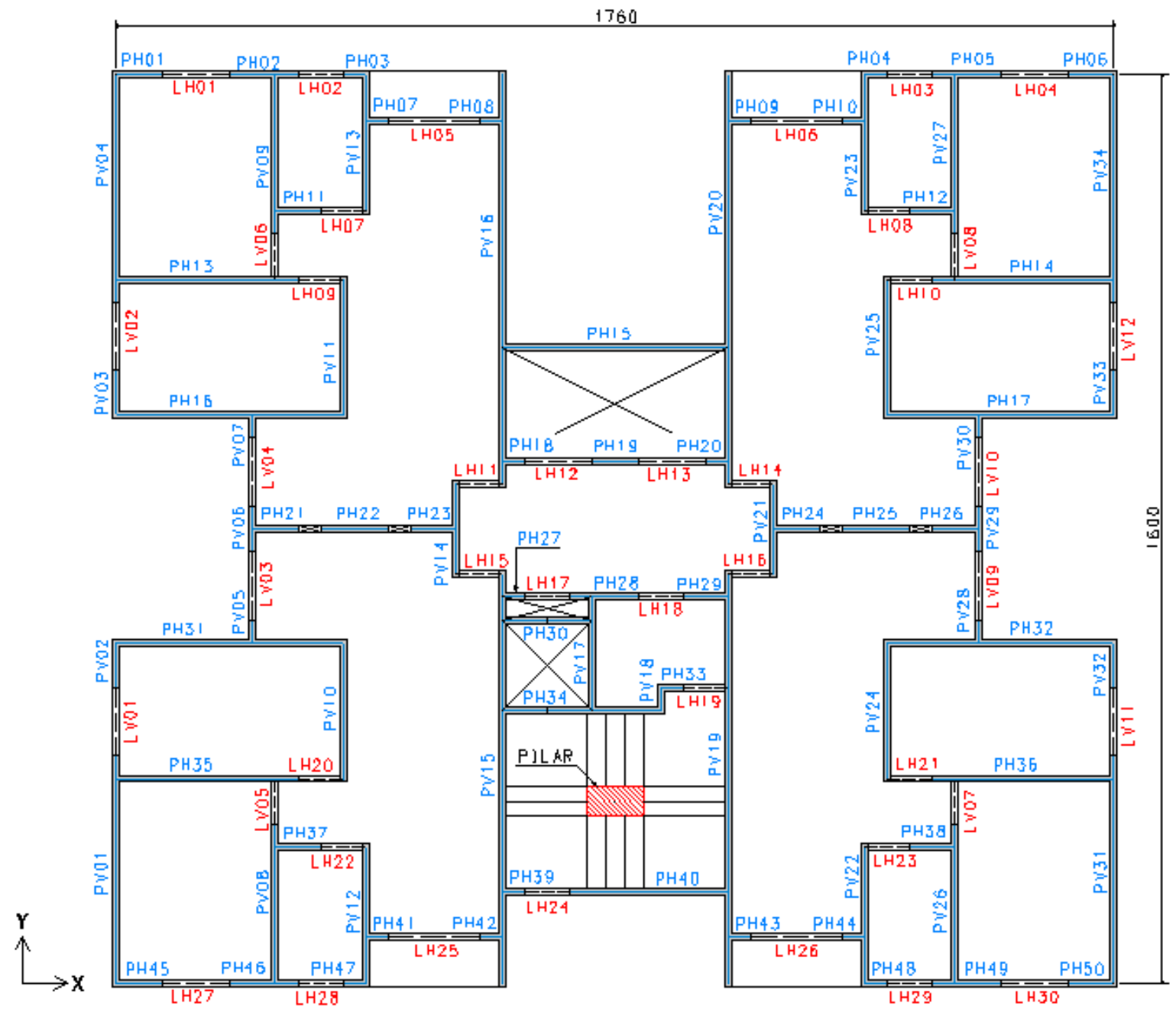

Figura 6.2 - Planta do pavimento tipo do edifício exemplo; Nomenclatura das paredes e lintéis; cotas apresentadas em cm;

As cotagens horizontais e verticais das paredes, lintéis e do pilar são apresentadas, a partir de seus eixos, nas Figuras 6.3 e 6.4, respectivamente. 


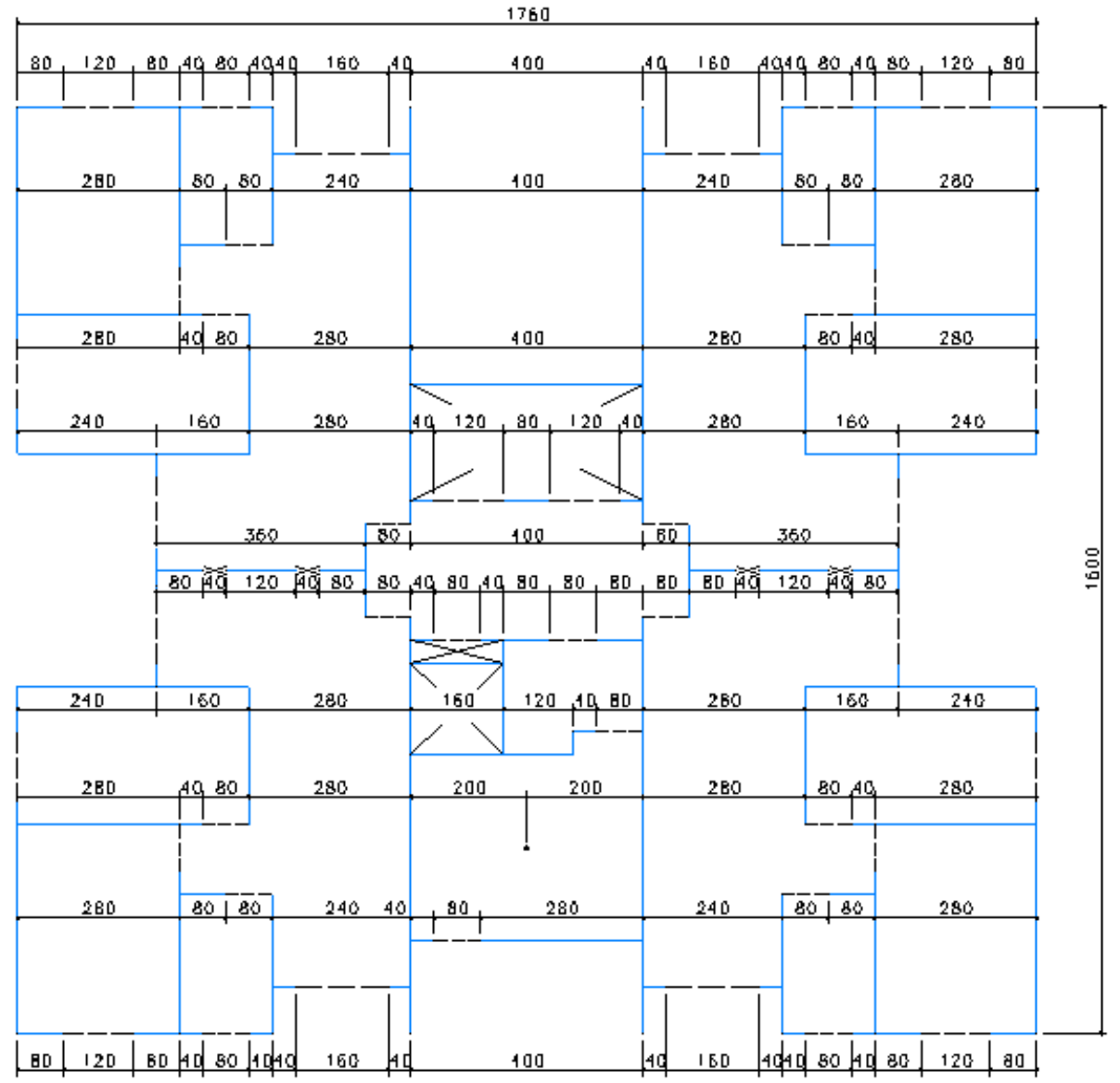

Figura 6.3 - Cotagem horizontal dos eixos das paredes, lintéis e pilar.

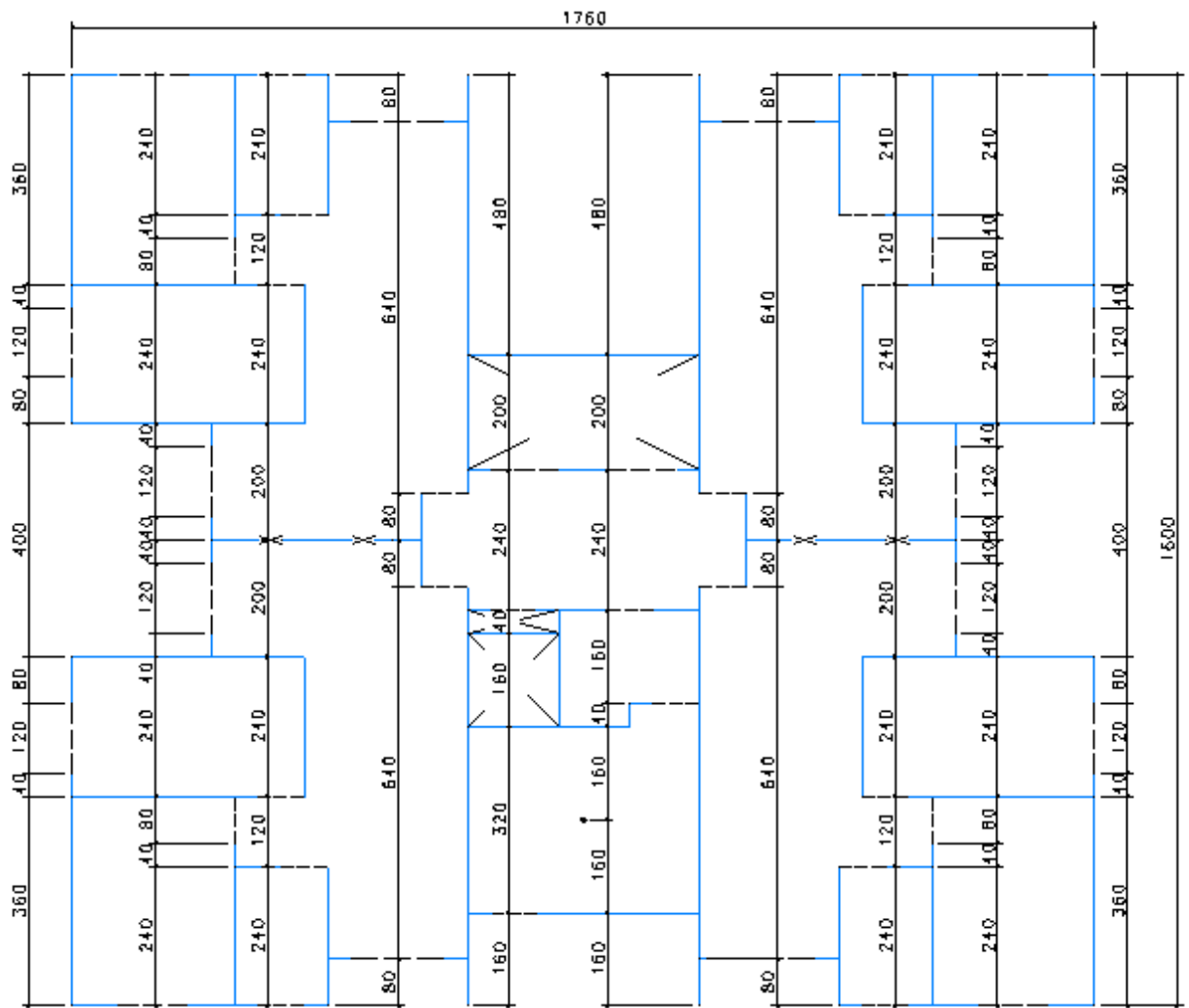

Figura 6.4 - Cotagem vertical dos eixos das paredes, lintéis e pilar. 


\subsection{Elementos estruturais}

Conforme Figura 6.2, as paredes de concreto armado estão hachuradas com a cor cinza e foram divididas em paredes horizontais ( $\mathrm{PHxx}$ ) e verticais (PVyy).Os lintéis são representados por duas linhas paralelas simples e também foram nomeados separando-se as direções horizontal (LHxx) e vertical (LVyy). Os eixos das paredes são representados em linha azul contínua e o eixo dos lintéis em linha preta tracejada.

Apesar das lajes maciças em concreto armado não estarem nomeadas na Figura 6.2, elas foram consideradas em toda planta, com espessura de $10 \mathrm{~cm}$, exceto nos poços de elevador e pressurização e nos shafts de instalações, onde um furo é representado com um X. O poço de escada foi considerado como sendo uma laje maciça com $10 \mathrm{~cm}$ de espessura.

O único pilar da estrutura, também em concreto armado, está localizado no poço de escada e é representado com uma hachura em vermelho.

O material de todos os elementos estruturais, considerados nos modelos numéricos do edifício exemplo, é o concreto com características conforme item 4.3.

\subsection{Ações consideradas}

\subsubsection{Cargas verticais}

As cargas verticais consideradas foram as permanentes (soma do peso próprio da estrutura com as cargas de revestimento das lajes) e as cargas acidentais (sobrecarga das lajes conforme NBR 6120). Para tanto, foram considerados:

- peso próprio dos elementos estruturais:

- cargas permanentes das lajes (revestimentos):

- cargas acidentais nas lajes:

$$
\begin{aligned}
& \gamma=2,50 \mathrm{tf} / \mathrm{m}^{3} \\
& g_{L}=0,10 \mathrm{tt} / \mathrm{m}^{2} \\
& q_{L}=0,15 \mathrm{tf} / \mathrm{m}^{2}
\end{aligned}
$$




\subsubsection{Ações horizontais}

Foram consideradas as ações devido ao vento e ao desaprumo, como apresentado no item 4.2.4, seguindo as direções e sentidos definidos na Figura 4.11. Não foram consideradas excentricidades tanto na aplicação do vento quanto na do desaprumo.

As forças de arrasto do vento foram calculadas considerando-o como não turbulento e seguindo os procedimentos da NBR 6123:1988. Os dados para o cálculo apresentam-se na Figura 6.5.

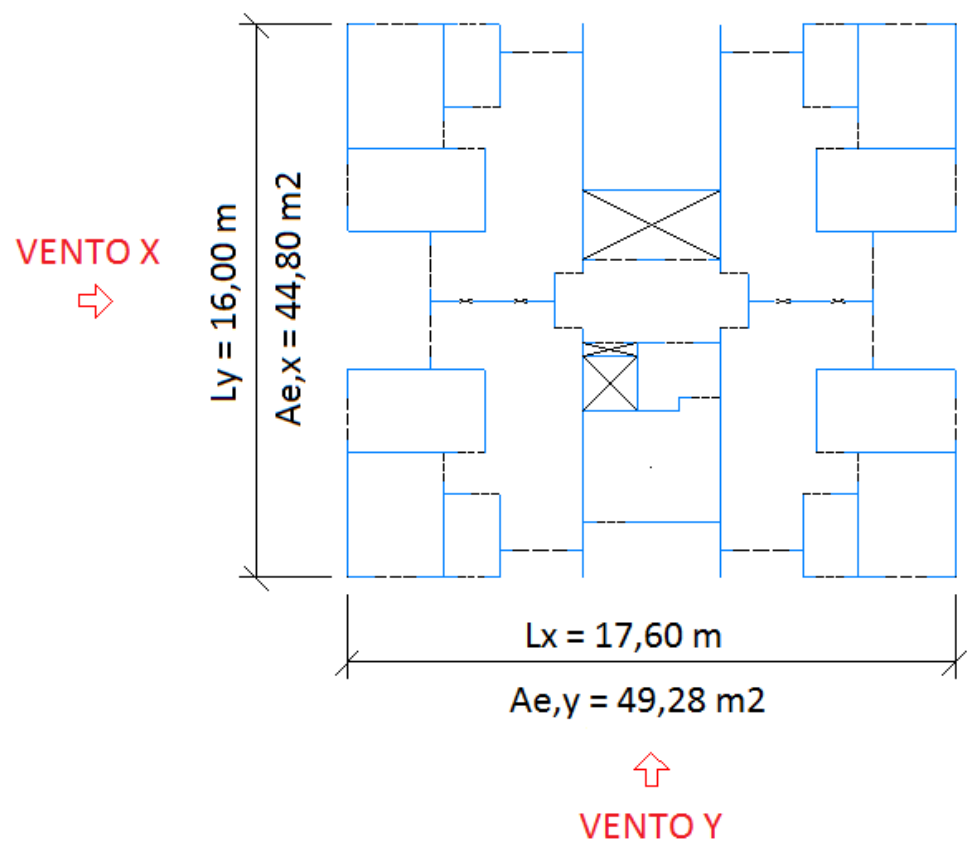

\begin{tabular}{|c|c|}
\hline $\mathrm{Lx}$ & $17,6 \mathrm{~m}$ \\
\hline $\mathrm{Ly}$ & $16,0 \mathrm{~m}$ \\
\hline $\mathrm{H}$ & $42,0 \mathrm{~m}$ \\
\hline $\mathrm{V}_{0}$ & $38,0 \mathrm{~m} / \mathrm{s}$ \\
\hline Categoria & $\mathrm{IV}$ \\
\hline Classe & $B$ \\
\hline $\mathrm{S} 1$ & 1 \\
\hline $\mathrm{S} 3$ & 1 \\
\hline $\mathrm{Ca}, \mathrm{x}$ & 1,25 \\
\hline $\mathrm{Ca}, \mathrm{y}$ & 1,30 \\
\hline $\mathrm{Ae}, \mathrm{x}$ & $44,80 \mathrm{~m}^{2}$ \\
\hline $\mathrm{Ae}, y$ & $49,28 \mathrm{~m}^{2}$ \\
\hline
\end{tabular}

Figura 6.5 - Parâmetros para o cálculo das forças de arrasto do vento - (EE).

A Tabela 6.1 apresenta as forças de arrasto por pavimento, em função do fator $S_{2}$, da velocidade $v_{k}$, da pressão $q_{\text {vento }}$ e dos parâmetros da Figura 6.5.

Como para se chegar nas forças devido ao desaprumo é necessário saber o peso do pavimento do edifício, considerou-se para efeito desse cálculo as paredes com espessura de $12 \mathrm{~cm}$. A Tabela 6.2 mostra as forças devido ao desaprumo nas direções $\mathrm{X}$ e $\mathrm{Y}$. Após o processamento da estrutura, essa espessura deve ser verificada como sendo suficiente ou não para resistir os esforços solicitantes. 
Tabela 6.1 - Cálculo da força de arrasto do vento nas direções X e Y - (EE).

\begin{tabular}{|c|c|c|c|c|c|c|}
\hline $\mathrm{n}$ & $\mathrm{Hi}(\mathrm{m})$ & $\mathrm{S} 2$ & $\mathrm{v}_{\mathrm{k}}(\mathrm{m} / \mathrm{s})$ & $\mathrm{q}_{\mathrm{vento}}\left(\mathrm{tf} / \mathrm{m}^{2}\right)$ & $\mathrm{Fa}, \mathrm{x}(\mathrm{tf})$ & $\mathrm{Fa}, \mathrm{y}(\mathrm{tf})$ \\
\hline 1 & 2,8 & 0,760 & 28,88 & 0,0521 & 2,92 & 3,34 \\
\hline 2 & 5,6 & 0,768 & 29,20 & 0,0533 & 2,98 & 3,41 \\
\hline 3 & 8,4 & 0,808 & 30,69 & 0,0589 & 3,30 & 3,77 \\
\hline 4 & 11,2 & 0,842 & 32,00 & 0,0640 & 3,58 & 4,10 \\
\hline 5 & 14,0 & 0,870 & 33,06 & 0,0683 & 3,83 & 4,38 \\
\hline 6 & 16,8 & 0,891 & 33,85 & 0,0716 & 4,01 & 4,59 \\
\hline 7 & 19,6 & 0,908 & 34,49 & 0,0743 & 4,16 & 4,76 \\
\hline 8 & 22,4 & 0,922 & 35,04 & 0,0767 & 4,30 & 4,91 \\
\hline 9 & 25,2 & 0,936 & 35,57 & 0,0791 & 4,43 & 5,07 \\
\hline 10 & 28,0 & 0,950 & 36,10 & 0,0815 & 4,56 & 5,22 \\
\hline 11 & 30,8 & 0,962 & 36,57 & 0,0836 & 4,68 & 5,36 \\
\hline 12 & 33,6 & 0,971 & 36,89 & 0,0851 & 4,76 & 5,45 \\
\hline 13 & 36,4 & 0,979 & 37,21 & 0,0865 & 4,85 & 5,54 \\
\hline 14 & 39,2 & 0,988 & 37,53 & 0,0880 & 4,93 & 5,64 \\
\hline 15 & 42,0 & 0,996 & 37,85 & 0,0895 & 5,01 & 5,74 \\
\hline
\end{tabular}

Tabela 6.2 - Cálculo da força de desaprumo nas direções X e Y - (EE).

\begin{tabular}{|c|c|c|c|c|c|}
\hline $\mathrm{n}$ & $\mathrm{Hi}(\mathrm{m})$ & $\Theta(\mathrm{rad})$ & $\Delta \mathrm{P}(\mathrm{tf})$ & $\mathrm{F}_{\mathrm{dp}, \mathrm{x}}(\mathrm{tf})$ & $\mathrm{F}_{\mathrm{dp}, \mathrm{y}}(\mathrm{tf})$ \\
\hline 1 & 2,8 & 0,000908 & 257,90 & 0,23 & 0,23 \\
\hline 2 & 5,6 & 0,000908 & 257,90 & 0,23 & 0,23 \\
\hline 3 & 8,4 & 0,000908 & 257,90 & 0,23 & 0,23 \\
\hline 4 & 11,2 & 0,000908 & 257,90 & 0,23 & 0,23 \\
\hline 5 & 14,0 & 0,000908 & 257,90 & 0,23 & 0,23 \\
\hline 6 & 16,8 & 0,000908 & 257,90 & 0,23 & 0,23 \\
\hline 7 & 19,6 & 0,000908 & 257,90 & 0,23 & 0,23 \\
\hline 8 & 22,4 & 0,000908 & 257,90 & 0,23 & 0,23 \\
\hline 9 & 25,2 & 0,000908 & 257,90 & 0,23 & 0,23 \\
\hline 10 & 28,0 & 0,000908 & 257,90 & 0,23 & 0,23 \\
\hline 11 & 30,8 & 0,000908 & 257,90 & 0,23 & 0,23 \\
\hline 12 & 33,6 & 0,000908 & 257,90 & 0,23 & 0,23 \\
\hline 13 & 36,4 & 0,000908 & 257,90 & 0,23 & 0,23 \\
\hline 14 & 39,2 & 0,000908 & 257,90 & 0,23 & 0,23 \\
\hline 15 & 42,0 & 0,000908 & 257,90 & 0,23 & 0,23 \\
\hline
\end{tabular}




\subsection{Modelos de cálculo}

Os modelos de cálculo detalhados no capítulo quatro foram aplicados no edifício exemplo (EE).

Ao utilizar o modelo Paredes Isoladas (PIS), a Figura 6.2 mostra a nomenclatura de todas as paredes do edifício. Portanto, cada parede ali definida, por hipótese do modelo, não interage com as demais.

A definição de quais paredes compõem cada Grupo Isolado de Paredes (GIP) pode ser vista na Figura 6.6.

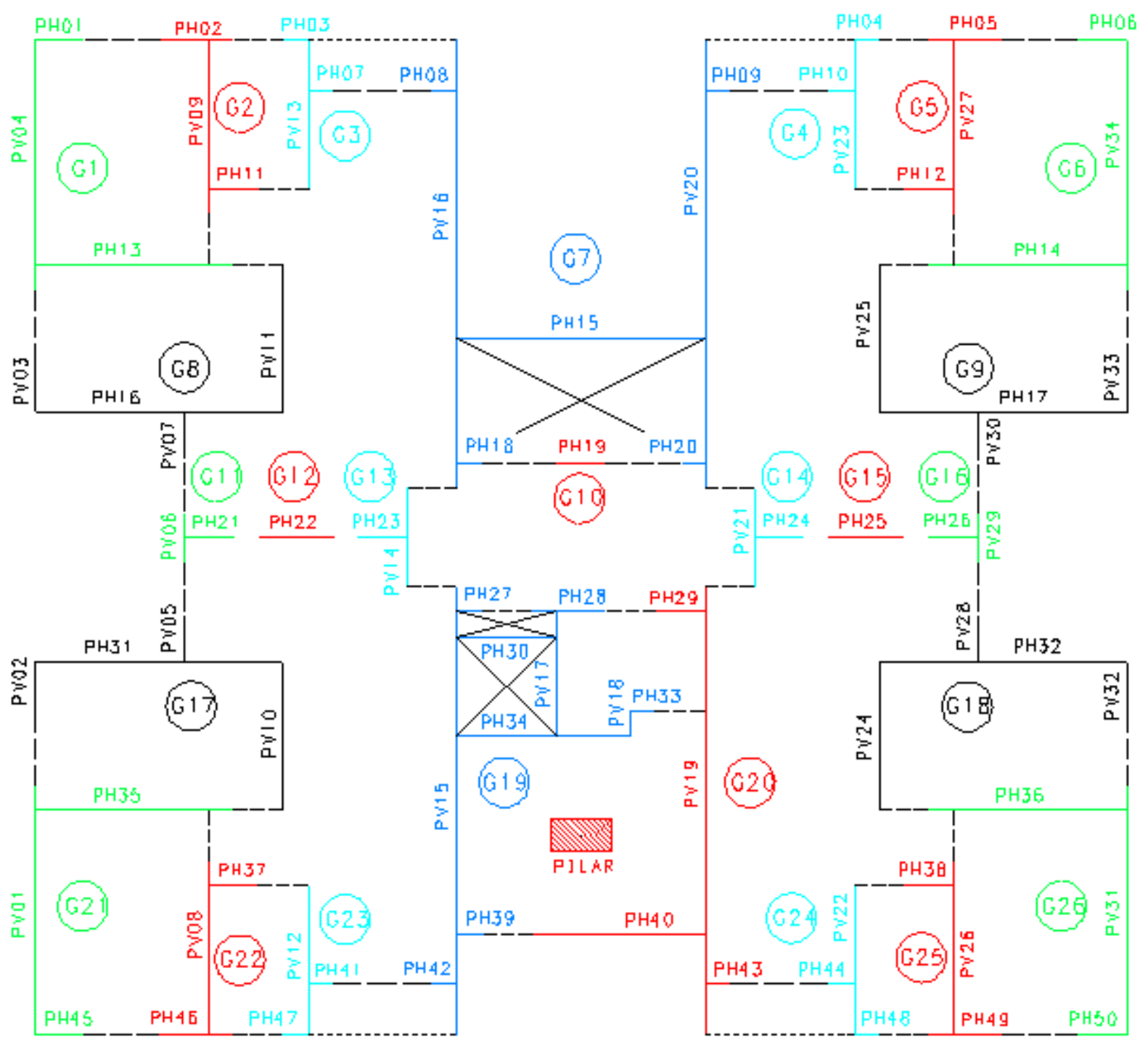

Figura 6.6 - Definição dos Grupos Isolados de Paredes para o edifício exemplo. 
A Figura 6.7 apresenta o Modelo Pórtico Tridimensional (MPT) empregado ao edifício exemplo e a Figura 6.8 o Modelo em Elementos Finitos (MEF).
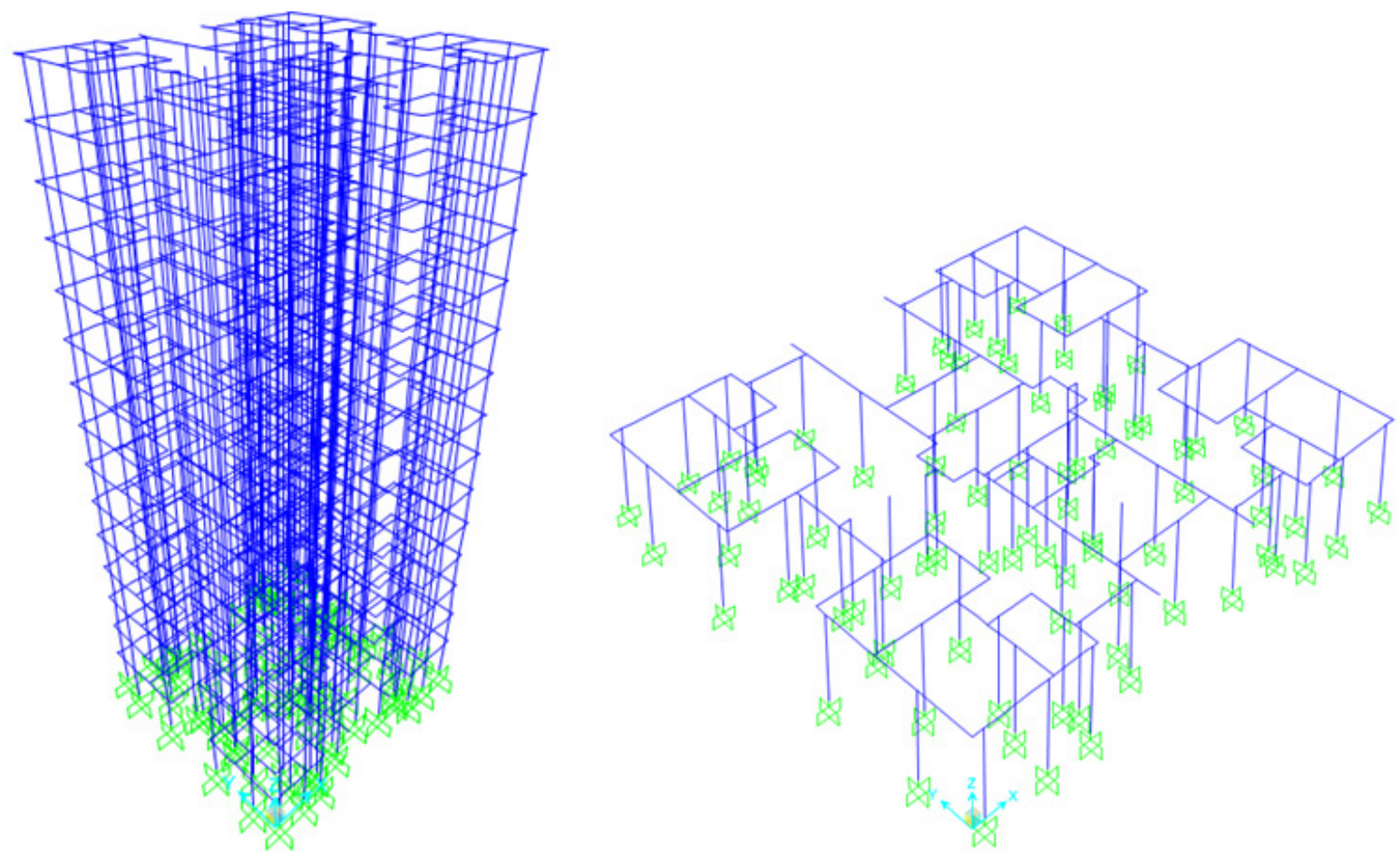

Figura 6.7 - Edifício exemplo representado pelo Modelo Pórtico Tridimensional.
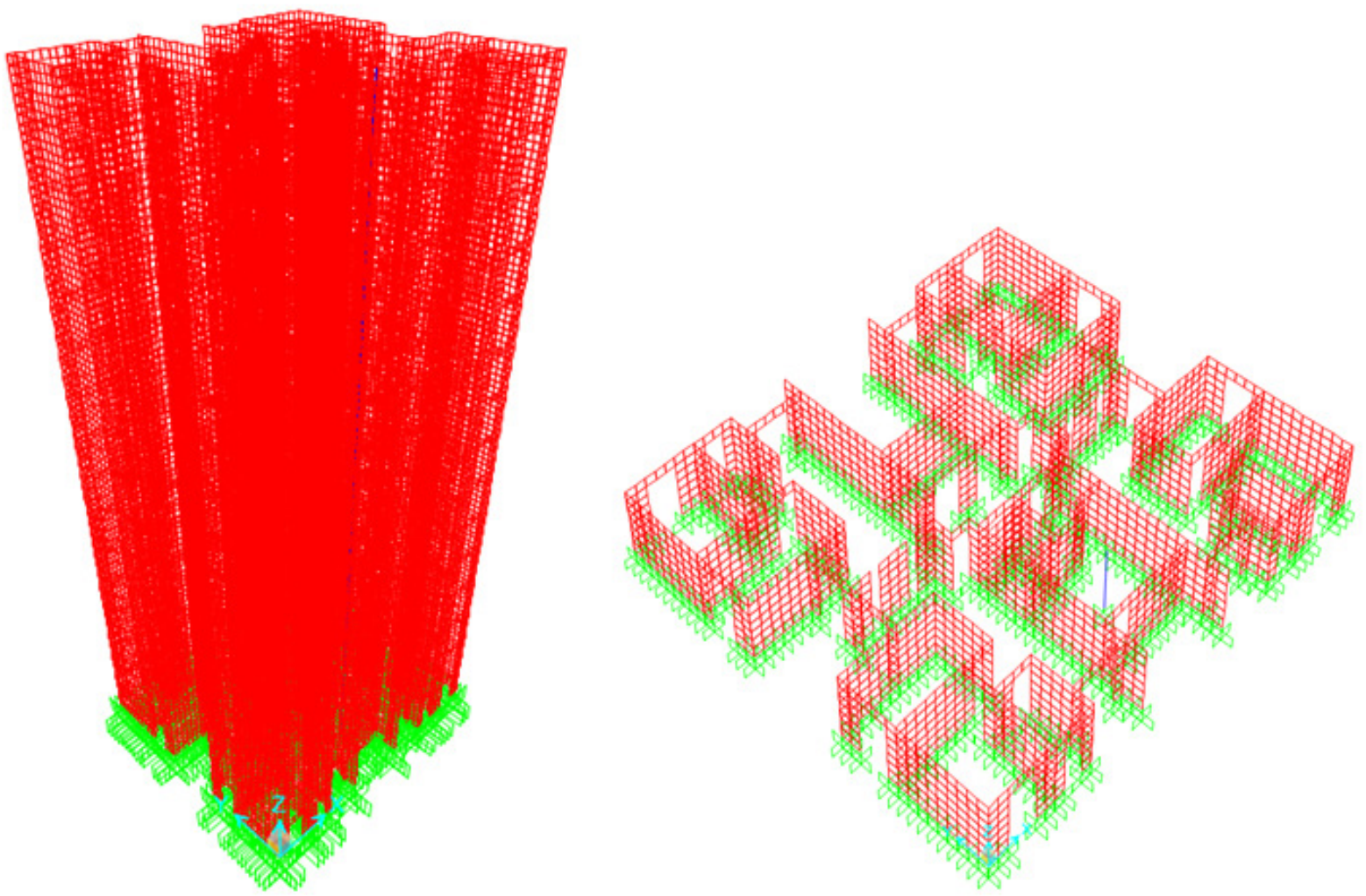

Figura 6.8 - Edifício exemplo representado pelo Modelo em Elementos Finitos. 
Aproveitando os resultados do capítulo cinco, no MEF, as paredes foram discretizadas em elementos de casca plana (elemento Shell do SAP2000), quadrados, com lado de $40 \mathrm{~cm}$. O pilar é único elemento estrutural modelado com elementos de barra (elemento Frame do SAP2000).

Em ambos modelos numéricos, as lajes foram simuladas como diafragma rígido, conforme explicado no capítulo quatro deste trabalho.

\subsection{Pré-dimensionamento}

A primeira etapa de um projeto estrutural de um edifício construído pelo sistema Paredes de Concreto é a definição da espessura das paredes que compõem a estrutura. Nesse item, verificou-se a hipótese das paredes do edifício exemplo serem pré-dimensionadas com $10 \mathrm{~cm}$ de espessura. Caso a sua resistência última à compressão seja maior que a estimativa da máxima tensão normal de compressão, as paredes podem ser pré-dimensionadas.

Chega-se na estimativa da máxima tensão normal de compressão através da multiplicação da tensão normal de compressão, obtida apenas pelas cargas verticais, por um coeficiente que estima o acréscimo dessa tensão devido às ações horizontais. Para tanto, utiliza-se o resultado da força normal distribuída, a qual é equivalente à tensão normal multiplicada pela espessura da parede.

O cálculo da resistência última à compressão é feito com as expressões dadas pelas normas AS 3600:2001, AS 3600:2009, ACI 318:2011, EN 1992:2004 e NBR 16055:2012, conforme item 3.3 deste trabalho.

Os resultados quanto às resistências foram comparados, o que possibilitou avaliar a recente norma brasileira. Da mesma maneira, avaliou-se a qualidade dos modelos de cálculo quanto à distribuição de cargas verticais.

Portanto, neste item, primeiramente são apresentadas e comparadas as forças normais concentradas e distribuídas, características, nas paredes ao nível da fundação, obtidas pelos modelos descritos, considerando-se apenas as cargas verticais. Em seguida, estipula-se a majoração dessas cargas a fim de se estimar o acréscimo da tensão normal de compressão devido às ações horizontais. Finalmente, a estimativa da máxima força normal distribuída de cálculo é verificada pelas resistências últimas à compressão, das normas adotadas e, as resistências são comparadas. 
6.5.1 Paredes Isoladas (PIS) - (EE)

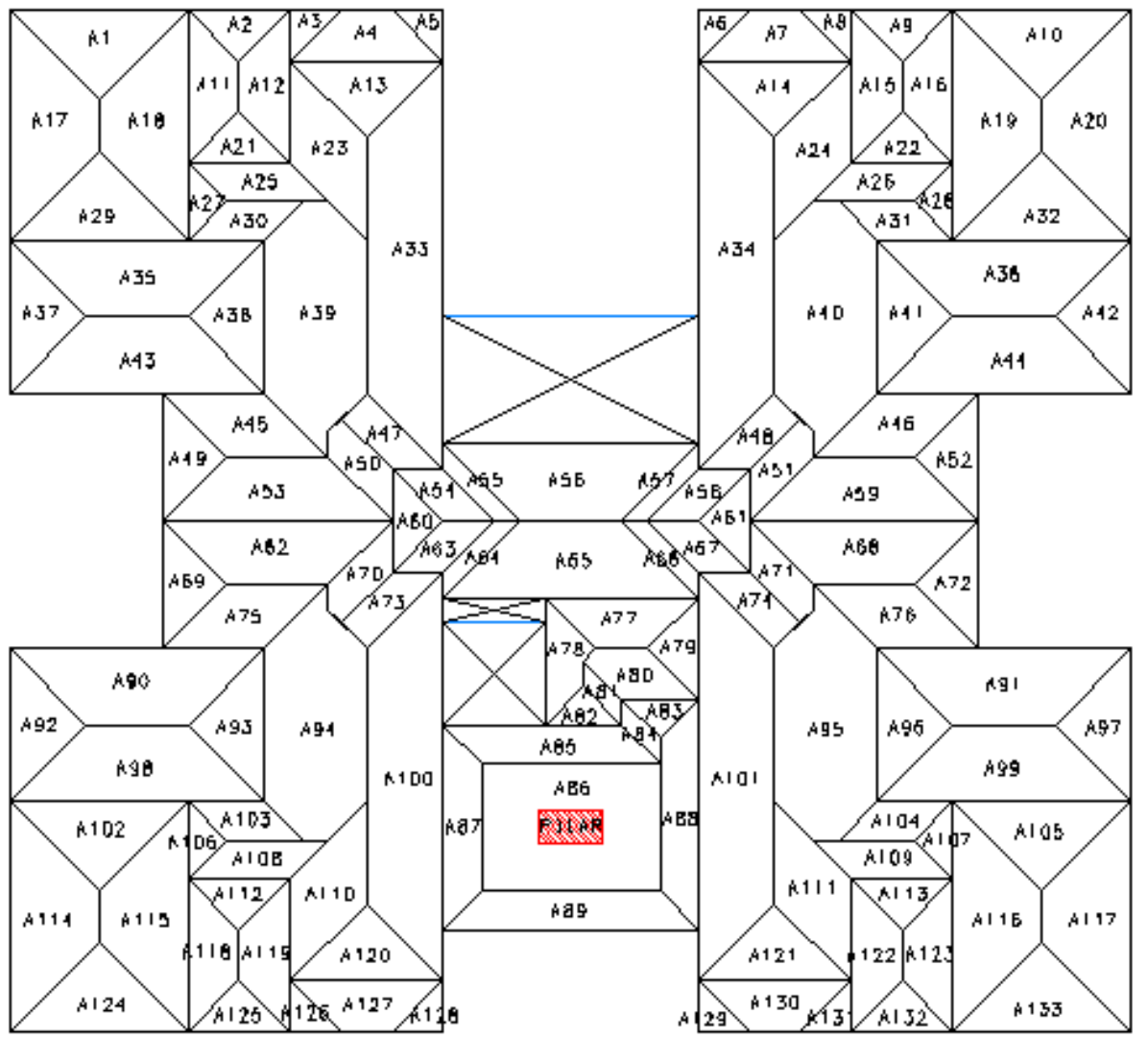

Figura 6.9 - Áreas de influências das lajes sobre paredes e lintéis - (EE).

Tabela 6.3 - Valores das áreas de influência e suas respectivas cargas - (EE).

\begin{tabular}{|c|c|c|c|c|c|c|c|c|c|c|c|c|c|c|c|c|c|c|c|}
\hline \multicolumn{20}{|c|}{ ÁREA DE INFLUENCIA E CARGAS DAS LAJES - EDIFÍCIO EXEMPLO } \\
\hline ÁREA & $A_{L}(m 2)$ & $L \inf (m)$ & $P(t)$ & $p(t f / m)$ & ÁREA & $A_{L}(m 2)$ & $L \inf (m)$ & $P(t f)$ & $p(t f / m)$ & ÁREA & $A_{L}(m 2)$ & $L \inf (m)$ & $P(t f)$ & $p(t f / m)$ & ÁREA & $A_{L}(m 2)$ & $L \inf (m)$ & $P(t f)$ & $p(t / / m)$ \\
\hline A1 & 1,96 & 2,80 & 0,98 & 0,35 & A35 & 3,36 & 4,00 & 1,68 & 0,42 & A69 & 1,00 & 2,00 & 0,50 & 0,25 & A103 & 0,72 & 1,20 & 0,36 & 0,30 \\
\hline $\mathrm{A} 2$ & 0,64 & 1,60 & 0,32 & 0,20 & A36 & 3,36 & 4,00 & 1,68 & 0,42 & A70 & 0,76 & 0,80 & 0,38 & 0,48 & A104 & 0,72 & 1,20 & 0,36 & 0,30 \\
\hline $\mathrm{A} 3$ & 0,32 & 0,80 & 0,16 & 0,20 & A37 & 1,44 & 2,40 & 0,72 & 0,30 & A71 & 0,76 & 0,80 & 0,38 & 0,48 & A105 & 1,96 & 2,80 & 0,98 & 0,35 \\
\hline A4 & 1,28 & 2,40 & 0,64 & 0,27 & A38 & 1,44 & 2,40 & 0,72 & 0,30 & A72 & 1,00 & 2,00 & 0,50 & 0,25 & A106 & 0,36 & 1,20 & 0,18 & 0,15 \\
\hline $\mathrm{A} 5$ & 0,32 & 0,80 & 0,16 & 0,20 & A39 & 5,12 & 2,40 & 2,56 & 1,07 & A73 & 0,80 & 0,80 & 0,40 & 0,50 & A107 & 0,36 & 1,20 & 0,18 & 0,15 \\
\hline $\mathrm{A} 6$ & 0,32 & 0,80 & 0,16 & 0,20 & A40 & 5,12 & 2,40 & 2,56 & 1,07 & A74 & 0,80 & 0,80 & 0,40 & 0,50 & A108 & 0,96 & 1,60 & 0,48 & 0,30 \\
\hline A7 & 1,28 & 2,40 & 0,64 & 0,27 & A41 & 1,44 & 2,40 & 0,72 & 0,30 & A75 & 1,60 & 1,60 & 0,80 & 0,50 & A109 & 0,96 & 1,60 & 0,48 & 0,30 \\
\hline A8 & 0,32 & 0,80 & 0,16 & 0,20 & A42 & 1,44 & 2,40 & 0,72 & 0,30 & A76 & 1,60 & 1,60 & 0,80 & 0,50 & A110 & 1,92 & 1,60 & 0,96 & 0,60 \\
\hline A9 & 0,64 & 1,60 & 0,32 & 0,20 & A43 & 3,36 & 4,00 & 1,68 & 0,42 & A77 & 1,28 & 2,40 & 0,64 & 0,27 & A111 & 1,92 & 1,60 & 0,96 & 0,60 \\
\hline A10 & 1,96 & 2,80 & 0,98 & 0,35 & A44 & 3,36 & 4,00 & 1,68 & 0,42 & A78 & 0,88 & 2,00 & 0,44 & 0,22 & A112 & 0,64 & 1,60 & 0,32 & 0,20 \\
\hline A11 & 1,28 & 2,40 & 0,64 & 0,27 & A45 & 1,60 & 1,60 & 0,80 & 0,50 & A79 & 0,64 & 1,60 & 0,32 & 0,20 & A113 & 0,64 & 1,60 & 0,32 & 0,20 \\
\hline A12 & 1,28 & 2,40 & 0,64 & 0,27 & A46 & 1,60 & 1,60 & 0,80 & 0,50 & A80 & 0,92 & 1,20 & 0,46 & 0,38 & A114 & 3,08 & 3,60 & 1,54 & 0,43 \\
\hline A13 & 1,44 & 2,40 & 0,72 & 0,30 & A47 & 0,80 & 0,80 & 0,40 & 0,50 & A81 & 0,24 & 0,40 & 0,12 & 0,30 & A115 & 3,08 & 3,60 & 1,54 & 0,43 \\
\hline A14 & 1,44 & 2,40 & 0,72 & 0,30 & A48 & 0,80 & 0,80 & 0,40 & 0,50 & A82 & 0,36 & 1,20 & 0,18 & 0,15 & A116 & 3,08 & 3,60 & 1,54 & 0,43 \\
\hline A15 & 1,28 & 2,40 & 0,64 & 0,27 & A49 & 1,00 & 2,00 & 0,50 & 0,25 & A83 & 0,36 & 1,20 & 0,18 & 0,15 & A117 & 3,08 & 3,60 & 1,54 & 0,43 \\
\hline A16 & 1,28 & 2,40 & 0,64 & 0,27 & A50 & 0,76 & 0,80 & 0,38 & 0,48 & A84 & 0,24 & 0,40 & 0,12 & 0,30 & A118 & 1,28 & 2,40 & 0,64 & 0,27 \\
\hline A17 & 3,08 & 3,60 & 1,54 & 0,43 & A51 & 0,76 & 0,80 & 0,38 & 0,48 & A85 & 1,68 & 2,80 & 0,84 & 0,30 & A119 & 1,28 & 2,40 & 0,64 & $\begin{array}{l}0,27 \\
\end{array}$ \\
\hline A18 & 3,08 & 3,60 & 1,54 & 0,43 & A52 & 1,00 & 2,00 & 0,50 & 0,25 & A86 & 5,60 & 1,00 & 2,80 & 2,80 & A120 & 1,44 & 2,40 & 0,72 & 0,30 \\
\hline A19 & 3,08 & 3,60 & 1,54 & 0,43 & A53 & 2,60 & 3,60 & 1,30 & 0,36 & A87 & 1,56 & 3,20 & 0,78 & 0,24 & A121 & 1,44 & 2,40 & 0,72 & 0,30 \\
\hline $\mathrm{A} 20$ & 3,08 & 3,60 & 1,54 & 0,43 & A54 & 0,64 & 0,80 & 0,32 & 0,40 & A88 & 1,80 & 3,60 & 0,90 & 0,25 & A122 & 1,28 & 2,40 & 0,64 & 0,27 \\
\hline A21 & 0,64 & 1,60 & 0,32 & 0,20 & A55 & 0,40 & 0,40 & 0,20 & 0,50 & A89 & 2,04 & 4,00 & 1,02 & 0,26 & A123 & 1,28 & 2,40 & 0,64 & 0,27 \\
\hline A22 & 0,64 & 1,60 & 0,32 & 0,20 & A56 & 3,36 & 4,00 & 1,68 & 0,42 & A90 & 3,36 & 4,00 & 1,68 & 0,42 & A124 & 1,96 & 2,80 & 0,98 & 0,35 \\
\hline $\mathrm{A} 23$ & 1,92 & 1,60 & 0,96 & 0,60 & A57 & 0,40 & 0,40 & 0,20 & 0,50 & A91 & 3,36 & 4,00 & 1,68 & 0,42 & A125 & 0,64 & 1,60 & 0,32 & 0,20 \\
\hline A24 & 1,92 & 1,60 & 0,96 & 0,60 & A58 & 0,64 & 0,80 & 0,32 & 0,40 & A92 & 1,44 & 2,40 & 0,72 & 0,30 & A126 & 0,32 & 0,80 & 0,16 & 0,20 \\
\hline A25 & 0,96 & 1,60 & 0,48 & 0,30 & A59 & 2,60 & 3,60 & 1,30 & 0,36 & A93 & 1,44 & 2,40 & 0,72 & 0,30 & A127 & 1,28 & 2,40 & 0,64 & 0,27 \\
\hline A26 & 0,96 & 1,60 & 0,48 & 0,30 & A60 & 0,64 & 1,60 & 0,32 & 0,20 & A94 & 5,12 & 2,40 & 2,56 & 1,07 & A128 & 0,32 & 0,80 & 0,16 & 0,20 \\
\hline A27 & 0,36 & 1,20 & 0,18 & 0,15 & A61 & 0,64 & 1,60 & 0,32 & 0,20 & A95 & 5,12 & 2,40 & 2,56 & 1,07 & A129 & 0,32 & 0,80 & 0,16 & 0,20 \\
\hline A28 & 0,36 & 1,20 & 0,18 & 0,15 & A62 & 2,60 & 3,60 & 1,30 & 0,36 & A96 & 1,44 & 2,40 & 0,72 & 0,30 & A130 & 1,28 & 2,40 & 0,64 & 0,27 \\
\hline A29 & 1,96 & 2,80 & 0,98 & 0,35 & A63 & 0,64 & 0,80 & 0,32 & 0,40 & A97 & 1,44 & 2,40 & 0,72 & 0,30 & A131 & 0,32 & 0,80 & 0,16 & 0,20 \\
\hline A30 & 0,72 & 1,20 & 0,36 & 0,30 & A64 & 0,40 & 0,40 & 0,20 & 0,50 & A98 & 3,36 & 4,00 & 1,68 & 0,42 & A132 & 0,64 & 1,60 & 0,32 & 0,20 \\
\hline A31 & 0,72 & 1,20 & 0,36 & 0,30 & A65 & 3,36 & 4,00 & 1,68 & 0,42 & A99 & 3,36 & 4,00 & 1,68 & 0,42 & A133 & 1,96 & 2,80 & 0,98 & 0,35 \\
\hline A32 & 1,96 & 2,80 & 0,98 & 0,35 & A66 & 0,40 & 0,40 & 0,20 & 0,50 & A100 & 6,24 & 6,40 & 3,12 & 0,49 & & & & & \\
\hline A33 & 6,24 & 6,40 & 3,12 & 0,49 & A67 & 0,64 & 0,80 & 0,32 & 0,40 & A101 & 6,24 & 6,40 & 3,12 & 0,49 & & & & & \\
\hline A34 & 6,24 & 6,40 & 3,12 & 0,49 & A68 & 2,60 & 3,60 & 1,30 & 0,36 & A102 & 1,96 & 2,80 & 0,98 & 0,35 & & & & & \\
\hline
\end{tabular}


A Figura 6.9 apresenta as áreas de influência das lajes ao descarregar suas cargas pelo método das charneiras plásticas, em paredes e lintéis. Os respectivos valores das áreas $\left(A_{L}\right)$, comprimentos de influência $\left(L_{\text {inf }}\right)$, cargas concentradas $(\mathrm{P})$ e distribuídas (p) encontram-se na Tabela 6.3.

A Tabela 6.4 apresenta as cargas totais nos lintéis que são descarregadas nas paredes que lhe servem de apoio, em um pavimento tipo. A coluna $\left(h_{L I}\right)$ mostra a altura da seção transversal de cada lintel. As forças normais concentradas $\left(N_{k, v e r t}\right)$ e distribuídas $\left(\eta_{k, v e r t}\right)$ das paredes, obtidas pelo PIS, ao nível da fundação, encontram-se na Tabela 6.5. Nota-se que a coluna (G) apresenta a carga permanente concentrada total da respectiva parede em um pavimento tipo; e a coluna $(Q)$, a carga variável concentrada total em um pavimento tipo. As outras colunas têm definições idênticas às Tabelas utilizadas no capítulo cinco.

Tabela 6.4 - EE: Carga vertical total nos lintéis em apenas um pavimento tipo.

\begin{tabular}{|c|c|c|c|c|c|c|c|c|}
\hline \multicolumn{9}{|c|}{ CARGAS TOTAIS DOS LINTÉIS - EE $->t=10 \mathrm{~cm}$} \\
\hline LINTÉL & $\mathrm{L}_{L I}(\mathrm{~m})$ & $h_{L}(m)$ & $\mathrm{PP}_{1 \text { PAV }}(\mathrm{tf})$ & Areas laje & P lajes (tf) & $\mathrm{G}(\mathrm{tf})$ & $Q(t f)$ & P lintel (tf) \\
\hline LH01 & 1,20 & 1,60 & 0,48 & $\mathrm{~A} 1$ & 0,42 & 0,77 & 0,13 & 0,90 \\
\hline LHO2 & 0,80 & 2,00 & 0,40 & $\mathrm{~A} 2$ & 0,16 & 0,51 & 0,05 & 0,56 \\
\hline LHO3 & 0,80 & 2,00 & 0,40 & A9 & 0,16 & 0,51 & 0,05 & 0,56 \\
\hline LH04 & 1,20 & 1,60 & 0,48 & $\mathrm{~A} 10$ & 0,42 & 0,77 & 0,13 & 0,90 \\
\hline LH05 & 1,60 & 0,40 & 0,16 & $\mathrm{~A} 4 \mathrm{e} \mathrm{A} 13$ & 0,91 & 0,79 & 0,27 & 1,07 \\
\hline LH06 & 1,60 & 0,40 & 0,16 & A7 e A14 & 0,91 & 0,79 & 0,27 & 1,07 \\
\hline LH07 & 0,80 & 0,40 & 0,08 & A21e A25 & 0,40 & 0,36 & 0,12 & 0,48 \\
\hline LH08 & 0,80 & 0,40 & 0,08 & $\mathrm{~A} 22 \mathrm{e} A 26$ & 0,40 & 0,36 & 0,12 & 0,48 \\
\hline LHO9 & 0,80 & 0,40 & 0,08 & $\mathrm{~A} 30$ e A35 & 0,58 & 0,48 & 0,17 & 0,66 \\
\hline LH10 & 0,80 & 0,40 & 0,08 & A31 e A36 & 0,58 & 0,48 & 0,17 & 0,66 \\
\hline LH11 & 0,80 & 0,40 & 0,08 & A47e A54 & 0,72 & 0,58 & 0,22 & 0,80 \\
\hline LH12 & 1,20 & 0,40 & 0,12 & A56 & 0,50 & 0,47 & 0,15 & 0,62 \\
\hline LH13 & 1,20 & 0,40 & 0,12 & A56 & 0,50 & 0,47 & 0,15 & 0,62 \\
\hline LH14 & 0,80 & 0,40 & 0,08 & A 48 e A58 & 0,72 & 0,58 & 0,22 & 0,80 \\
\hline LH15 & 0,80 & 0,40 & 0,08 & A63 e A73 & 0,72 & 0,58 & 0,22 & 0,80 \\
\hline LH16 & 0,80 & 0,40 & 0,08 & A67 e A74 & 0,72 & 0,58 & 0,22 & 0,80 \\
\hline LH17 & 0,80 & 2,00 & 0,40 & A65 & 0,34 & 0,64 & 0,10 & 0,74 \\
\hline LH18 & 0,80 & 0,40 & 0,08 & A65 e A77 & 0,55 & 0,46 & 0,16 & 0,63 \\
\hline LH19 & 0,80 & 0,40 & 0,08 & A80 e A83 & 0,43 & 0,38 & 0,13 & 0,51 \\
\hline $\mathrm{LH} 20$ & 0,80 & 0,40 & 0,08 & A98 e A103 & 0,58 & 0,48 & 0,17 & 0,66 \\
\hline LH21 & 0,80 & 0,40 & 0,08 & A99 e A104 & 0,58 & 0,48 & 0,17 & 0,66 \\
\hline LH22 & 0,80 & 0,40 & 0,08 & A108 e A112 & 0,40 & 0,36 & 0,12 & 0,48 \\
\hline LH23 & 0,80 & 0,40 & 0,08 & A109 e A113 & 0,40 & 0,36 & 0,12 & 0,48 \\
\hline LH24 & 0,80 & 2,00 & 0,40 & A89 & 0,20 & 0,54 & 0,06 & 0,60 \\
\hline $\mathrm{LH} 25$ & 1,60 & 0,40 & 0,16 & $\mathrm{~A} 120$ e A127 & 0,91 & 0,79 & 0,27 & 1,07 \\
\hline LH26 & 1,60 & 0,40 & 0,16 & A121 e A130 & 0,91 & 0,79 & 0,27 & 1,07 \\
\hline LH27 & 1,20 & 1,60 & 0,48 & \begin{tabular}{|l|} 
A124 \\
\end{tabular} & 0,42 & 0,77 & 0,13 & 0,90 \\
\hline LH28 & 0,80 & 2,00 & 0,40 & A125 & 0,16 & 0,51 & 0,05 & 0,56 \\
\hline LH29 & 0,80 & 2,00 & 0,40 & A132 & 0,16 & 0,51 & 0,05 & 0,56 \\
\hline LH30 & 1,20 & 1,60 & 0,48 & A133 & 0,42 & 0,77 & 0,13 & 0,90 \\
\hline LV01 & 1,20 & 1,60 & 0,48 & A92 & 0,36 & 0,73 & 0,11 & 0,84 \\
\hline LV02 & 1,20 & 1,60 & 0,48 & A37 & 0,36 & 0,73 & 0,11 & 0,84 \\
\hline LV03 & 1,20 & 1,60 & 0,48 & A69 & 0,30 & 0,69 & 0,09 & 0,78 \\
\hline LV04 & 1,20 & 1,60 & 0,48 & A49 & 0,30 & 0,69 & 0,09 & 0,78 \\
\hline LV05 & 0,80 & 0,40 & 0,08 & A106 e A115 & 0,46 & 0,40 & 0,14 & 0,54 \\
\hline LV06 & 0,80 & 0,40 & 0,08 & A18 e A27 & 0,46 & 0,40 & 0,14 & 0,54 \\
\hline LV07 & 0,80 & 0,40 & 0,08 & A107 e A116 & 0,46 & 0,40 & 0,14 & 0,54 \\
\hline LV08 & 0,80 & 0,40 & 0,08 & A19 e A28 & 0,46 & 0,40 & 0,14 & 0,54 \\
\hline LV09 & 1,20 & 1,60 & 0,48 & A72 & 0,30 & 0,69 & 0,09 & 0,78 \\
\hline LV10 & 1,20 & 1,60 & 0,48 & A52 & 0,30 & 0,69 & 0,09 & 0,78 \\
\hline LV11 & 1,20 & 1,60 & 0,48 & A97 & 0,36 & 0,73 & 0,11 & 0,84 \\
\hline LV12 & 1,20 & 1,60 & 0,48 & A42 & 0,36 & 0,73 & 0,11 & 0,84 \\
\hline
\end{tabular}


Tabela 6.5 - PIS-EE: $N_{k, v e r t}$ e $\eta_{k, v e r t}$ ao nível da fundação

\begin{tabular}{|c|c|c|c|c|c|c|c|c|c|c|c|}
\hline & & & & & $-\mathrm{EE}->\mathrm{t}=10 \mathrm{cr}$ & & & & & & \\
\hline PAREDE & $L(m)$ & $\mathrm{PP}_{1 \mathrm{PAV}}(\mathrm{tf})$ & Areas laje & P lajes (tf) & Lintéis & P lintel (tf) & $\mathrm{G}(\mathrm{tf})$ & $Q(t f)$ & P parede (tf) & $\mathrm{Nk}$,vert (tf) & $\eta \mathrm{k}$, vert $(\mathrm{tf} / \mathrm{m})$ \\
\hline PH01 & 0,80 & 0,56 & A1 & 0,280 & LH01 & 0,45 & 1,14 & 0,15 & 1,29 & 19,35 & 24,19 \\
\hline PH02 & 1,20 & 0,84 & $\mathrm{~A} 1 \mathrm{e} A 2$ & 0,360 & LH01 e LHO2 & 0,73 & 1,74 & 0,20 & 1,93 & 28,95 & 24,13 \\
\hline PHO3 & 0,40 & 0,28 & A2 & 0,080 & LH02 & 0,28 & 0,59 & 0,05 & 0,64 & 9,60 & 24,00 \\
\hline PHO4 & 0,40 & 0,28 & A9 & 0,080 & LHO3 & 0,28 & 0,59 & 0,05 & 0,64 & 9,60 & 24,00 \\
\hline PH05 & 1,20 & 0,84 & $\mathrm{~A} 9 \mathrm{e} \mathrm{A} 10$ & 0,360 & LHO3 e LHO4 & 0,73 & 1,74 & 0,20 & 1,93 & 28,95 & 24,13 \\
\hline PH06 & 0,80 & 0,56 & A10 & 0,280 & LHO4 & 0,45 & 1,14 & 0,15 & 1,29 & 19,35 & 24,19 \\
\hline PH07 & 0,40 & 0,28 & $\mathrm{~A} 4$ e A13 & 0,227 & LHO5 & 0,53 & 0,84 & 0,20 & 1,04 & 15,60 & 39,00 \\
\hline PH08 & 0,40 & 0,28 & $\mathrm{~A} 4 \mathrm{e} \mathrm{A} 13$ & 0,227 & LHO5 & 0,53 & 0,84 & 0,20 & 1,04 & 15,60 & 39,00 \\
\hline PH09 & 0,40 & 0,28 & A7 e A14 & 0,227 & LHO6 & 0,53 & 0,84 & 0,20 & 1,04 & 15,60 & 39,00 \\
\hline PH10 & 0,40 & 0,28 & A7 e A14 & 0,227 & LHOG & 0,53 & 0,84 & 0,20 & 1,04 & 15,60 & 39,00 \\
\hline PH11 & 0,80 & 0,56 & $\mathrm{~A} 21 \mathrm{e} A 25$ & 0,400 & LHO7 & 0,24 & 1,02 & 0,18 & 1,20 & 18,00 & 22,50 \\
\hline PH12 & 0,80 & 0,56 & $\mathrm{~A} 22 \mathrm{e} A 26$ & 0,400 & LH08 & 0,24 & 1,02 & 0,18 & 1,20 & 18,00 & 22,50 \\
\hline PH13 & 3,20 & 2,24 & $\mathrm{~A} 29, \mathrm{~A} 30$ e $\mathrm{A} 35$ & 2,444 & LH09 e LV06 & 0,60 & 4,39 & 0,89 & 5,28 & 79,25 & 24,76 \\
\hline PH14 & 3,20 & 2,24 & A31, A32 e A36 & 2,444 & LH10 e LV08 & 0,60 & 4,39 & 0,89 & 5,28 & 79,25 & 24,76 \\
\hline PH15 & 4,00 & 2,80 & ---- & 0,000 & ---- & 0,00 & 2,80 & 0,00 & 2,80 & 42,00 & 10,50 \\
\hline PH16 & 4,00 & 2,80 & $\mathrm{~A} 43 \mathrm{e} \mathrm{A} 45$ & 2,480 & $-\cdots-$ & 0,00 & 4,54 & 0,74 & 5,28 & 79,20 & 19,80 \\
\hline PH17 & 4,00 & 2,80 & $\mathrm{~A} 44 \mathrm{e}$ A46 & 2,480 & ---- & 0,00 & 4,54 & 0,74 & 5,28 & 79,20 & 19,80 \\
\hline PH18 & 0,40 & 0,28 & A56 & 0,168 & LH12 & 0,31 & 0,63 & 0,13 & 0,76 & 11,40 & 28,50 \\
\hline PH19 & 0,80 & 0,56 & A56 & 0,336 & LH12 e LH13 & 0,62 & 1,27 & 0,25 & 1,52 & 22,80 & 28,50 \\
\hline $\mathrm{PH} 20$ & 0,40 & 0,28 & A56 & 0,168 & LH13 & 0,31 & 0,63 & 0,13 & 0,76 & 11,40 & 28,50 \\
\hline PH21 & 0,80 & 0,56 & A53 e A62 & 0,722 & ---- & 0,00 & 1,07 & 0,22 & 1,28 & 19,23 & 24,04 \\
\hline PH22 & 1,20 & 0,84 & $\mathrm{~A} 53 \mathrm{e} \mathrm{A} 62$ & 1,156 & $-\cdots$ & 0,00 & 1,65 & 0,35 & 2,00 & 29,93 & 24,94 \\
\hline $\mathrm{PH} 23$ & 0,80 & 0,56 & A53 e A62 & 0,722 & --.- & 0,00 & 1,07 & 0,22 & 1,28 & 19,23 & 24,04 \\
\hline PH24 & 0,80 & 0,56 & A59 e A68 & 0,722 & $-\cdots$ & 0,00 & 1,07 & 0,22 & 1,28 & 19,23 & 24,04 \\
\hline PH25 & 1,20 & 0,84 & A59 e A68 & 1,156 & --.- & 0,00 & 1,65 & 0,35 & 2,00 & 29,93 & 24,94 \\
\hline PH26 & 0,80 & 0,56 & A59 e A68 & 0,722 & ---- & 0,00 & 1,07 & 0,22 & 1,28 & 19,23 & 24,04 \\
\hline PH27 & 0,40 & 0,28 & A65 & 0,168 & LH17 & 0,37 & 0,72 & 0,10 & 0,82 & 12,24 & 30,60 \\
\hline PH28 & 1,20 & 0,84 & A65 e A77 & 0,717 & LH17 e LH18 & 0,68 & 1,89 & 0,35 & 2,24 & 33,60 & 28,00 \\
\hline $\mathrm{PH} 29$ & 0,80 & 0,56 & A65 e A77 & 0,549 & LH18 & 0,31 & 1,18 & 0,25 & 1,42 & 21,36 & 26,70 \\
\hline PH3O & 1,60 & 1,12 & ---- & 0,000 & --- & 0,00 & 1,12 & 0,00 & 1,12 & 16,80 & 10,50 \\
\hline PH31 & 4,00 & 2,80 & A75 e A90 & 2,480 & $-\cdots-$ & 0,00 & 4,54 & 0,74 & 5,28 & 79,20 & 19,80 \\
\hline PH32 & 4,00 & 2,80 & A76 e A91 & 2,480 & $-\cdots$ & 0,00 & 4,54 & 0,74 & 5,28 & 79,20 & 19,80 \\
\hline PH33 & 0,40 & 0,28 & A80 e A83 & 0,213 & LH19 & 0,25 & 0,62 & 0,13 & 0,75 & 11,20 & 28,00 \\
\hline PH34 & 2,80 & 1,96 & A82 e A85 & 1,020 & -..- & 0,00 & 2,67 & 0,31 & 2,98 & 44,70 & 15,96 \\
\hline PH35 & 3,20 & 2,24 & A98, A102 e A103 & 2,444 & LH2O e LV05 & 0,60 & 4,39 & 0,89 & 5,28 & 79,25 & 24,76 \\
\hline PH36 & 3,20 & 2,24 & A99, A104 e A105 & 2,444 & LH21 e LV07 & 0,60 & 4,39 & 0,89 & 5,28 & 79,25 & 24,76 \\
\hline PH37 & 0,80 & 0,56 & A108 e A112 & 0,400 & LH22 & 0,24 & 1,02 & 0,18 & 1,20 & 18,00 & 22,50 \\
\hline PH38 & 0,80 & 0,56 & A109 e A113 & 0,400 & $\mathrm{LH} 23$ & 0,24 & 1,02 & 0,18 & 1,20 & 18,00 & 22,50 \\
\hline PH39 & 0,40 & 0,28 & A89 & 0,102 & LH24 & 0,30 & 0,62 & 0,06 & 0,68 & 10,26 & 25,65 \\
\hline $\mathrm{PH} 40$ & 2,80 & 1,96 & A89 & 0,714 & $\mathrm{LH} 24$ & 0,30 & 2,73 & 0,24 & 2,98 & 44,64 & 15,94 \\
\hline PH41 & 0,40 & 0,28 & A120 e A127 & 0,227 & $\mathrm{LH} 25$ & 0,53 & 0,84 & 0,20 & 1,04 & 15,60 & 39,00 \\
\hline $\mathrm{PH} 42$ & 0,40 & 0,28 & $\mathrm{~A} 120 \mathrm{e} \mathrm{A} 127$ & 0,227 & LH25 & 0,53 & 0,84 & 0,20 & 1,04 & 15,60 & 39,00 \\
\hline $\mathrm{PH} 43$ & 0,40 & 0,28 & $\mathrm{~A} 121 \mathrm{e} \mathrm{A} 130$ & 0,227 & LH26 & 0,53 & 0,84 & 0,20 & 1,04 & 15,60 & 39,00 \\
\hline PH44 & 0,40 & 0,28 & $\mathrm{~A} 121 \mathrm{e} \mathrm{A} 130$ & 0,227 & LH26 & 0,53 & 0,84 & 0,20 & 1,04 & 15,60 & 39,00 \\
\hline PH45 & 0,80 & 0,56 & A124 & 0,280 & LH27 & 0,45 & 1,14 & 0,15 & 1,29 & 19,35 & 24,19 \\
\hline $\mathrm{PH} 46$ & 1,20 & 0,84 & A124 e A125 & 0,360 & LH27 e LH28 & 0,73 & 1,74 & 0,20 & 1,93 & 28,95 & 24,13 \\
\hline PH47 & 0,40 & 0,28 & A125 & 0,080 & LH28 & 0,28 & 0,59 & 0,05 & 0,64 & 9,60 & 24,00 \\
\hline PH48 & 0,40 & 0,28 & A132 & 0,080 & LH29 & 0,28 & 0,59 & 0,05 & 0,64 & 9,60 & 24,00 \\
\hline $\mathrm{PH} 49$ & 1,20 & 0,84 & $\mathrm{~A} 132 \mathrm{e} A 133$ & 0,360 & LH29 e LH30 & 0,73 & 1,74 & 0,20 & 1,93 & 28,95 & 24,13 \\
\hline PH50 & 0,80 & 0,56 & A133 & 0,280 & LH30 & 0,45 & 1,14 & 0,15 & 1,29 & 19,35 & 24,19 \\
\hline PV01 & 4,00 & 2,80 & A114 e A92 & 1,660 & LV01 & 0,42 & 4,33 & 0,55 & 4,88 & 73,20 & 18,30 \\
\hline PV02 & 0,80 & 0,56 & A92 & 0,240 & LV01 & 0,42 & 1,09 & 0,13 & 1,22 & 18,30 & 22,88 \\
\hline PV03 & 0,80 & 0,56 & A37 & 0,240 & LV02 & 0,42 & 1,09 & 0,13 & 1,22 & 18,30 & 22,88 \\
\hline PV04 & 4,00 & 2,80 & A17 e A37 & 1,660 & LV02 & 0,42 & 4,33 & 0,55 & 4,88 & 73,20 & 18,30 \\
\hline PV05 & 0,40 & 0,28 & A69 & 0,100 & LV03 & 0,39 & 0,70 & 0,08 & 0,77 & 11,55 & 28,88 \\
\hline PV06 & 0,80 & 0,56 & A49 e A69 & 0,200 & LV03 e LV04 & 0,78 & 1,39 & 0,15 & 1,54 & 23,10 & 28,88 \\
\hline PV07 & 0,40 & 0,28 & A49 & 0,100 & LV04 & 0,39 & 0,70 & 0,08 & 0,77 & 11,55 & 28,88 \\
\hline PV08 & 2,80 & 1,96 & A106, A115 e A118 & 1,898 & LV05 & 0,27 & 3,49 & 0,64 & 4,13 & 61,93 & 22,12 \\
\hline $\begin{array}{ll}\text { PV09 } \\
\end{array}$ & 2,80 & 1,96 & $\mathrm{~A} 11, \mathrm{~A} 18 \mathrm{e}$ A27 & 1,898 & LV06 & 0,27 & 3,49 & 0,64 & 4,13 & 61,93 & 22,12 \\
\hline PV10 & 2,40 & 1,68 & A93 e A94 & 3,280 & $\mathrm{LH} 2 \mathrm{O}$ & 0,33 & 4,22 & 1,07 & 5,29 & 79,32 & 33,05 \\
\hline PV11 & 2,40 & 1,68 & A38 e A39 & 3,280 & LHO9 & 0,33 & 4,22 & 1,07 & 5,29 & 79,32 & 33,05 \\
\hline PV12 & 2,40 & 1,68 & A110, A119 e A126 & 1,760 & LH22 & 0,24 & 3,09 & 0,59 & 3,68 & 55,20 & 23,00 \\
\hline PV13 & 2,40 & 1,68 & $\mathrm{~A} 3, \mathrm{~A} 12$ e A23 & 1,760 & LH07 & 0,24 & 3,09 & 0,59 & 3,68 & 55,20 & 23,00 \\
\hline PV14 & 1,60 & 1,12 & A50, A60 e $A 70$ & 1,080 & LH11 e LH15 & 0,80 & 2,46 & 0,54 & 3,00 & 45,00 & 28,13 \\
\hline PV15 & 7,20 & 5,04 & A64, A87, A100 e A128 & 4,260 & LH15 & 0,40 & 8,31 & 1,39 & 9,70 & 145,50 & 20,21 \\
\hline PV16 & 7,20 & 5,04 & $\mathrm{~A} 5, \mathrm{~A} 33$ е $\mathrm{A} 55$ & 3,480 & LH11 & 0,40 & 7,77 & 1,15 & 8,92 & 133,80 & 18,58 \\
\hline PV17 & 2,00 & 1,40 & A78 & 0,440 & $-\cdots-$ & 0,00 & 1,71 & 0,13 & 1,84 & 27,60 & 13,80 \\
\hline PV18 & 0,40 & 0,28 & A81 e A84 & 0,240 & $-\cdots$ & 0,00 & 0,45 & 0,07 & 0,52 & 7,80 & 19,50 \\
\hline PV19 & 7,20 & 5,04 & A66, A79, A88, A101 e A129 & 4,700 & LH16 e LH19 & 0,65 & 8,81 & 1,58 & 10,39 & 155,90 & 21,65 \\
\hline $\mathrm{PV} 20$ & 7,20 & 5,04 & $\mathrm{~A} 6, \mathrm{~A} 34 \mathrm{e}$ A57 & 3,480 & LH14 & 0,40 & 7,77 & 1,15 & 8,92 & 133,80 & 18,58 \\
\hline PV21 & 1,60 & 1,12 & A51, A61 e A71 & 1,080 & LH14 e LH16 & 0,80 & 2,46 & 0,54 & 3,00 & 45,00 & 28,13 \\
\hline $\mathrm{PV} 22$ & 2,40 & 1,68 & A111, A122 e A131 & 1,760 & LH23 & 0,24 & 3,09 & 0,59 & 3,68 & 55,20 & 23,00 \\
\hline $\mathrm{PV} 23$ & 2,40 & 1,68 & $\mathrm{~A} 8, \mathrm{~A} 15$ e A24 & 1,760 & LHO8 & 0,24 & 3,09 & 0,59 & 3,68 & 55,20 & 23,00 \\
\hline $\mathrm{PV} 24$ & 2,40 & 1,68 & A95 e A96 & 3,280 & LH21 & 0,33 & 4,22 & 1,07 & 5,29 & 79,32 & 33,05 \\
\hline $\mathrm{PV} 25$ & 2,40 & 1,68 & A40 e A41 & 3,280 & LH10 & 0,33 & 4,22 & 1,07 & 5,29 & 79,32 & 33,05 \\
\hline PV26 & 2,80 & 1,96 & A107, A116 e A123 & 1,898 & LV07 & 0,27 & 3,49 & 0,64 & 4,13 & 61,93 & 22,12 \\
\hline PV27 & 2,80 & 1,96 & $\mathrm{~A} 16, \mathrm{~A} 19$ e A28 & 1,898 & LV08 & 0,27 & 3,49 & 0,64 & 4,13 & 61,93 & 22,12 \\
\hline PV28 & 0,40 & 0,28 & A72 & 0,100 & LV09 & 0,39 & 0,70 & 0,08 & 0,77 & 11,55 & 28,88 \\
\hline PV29 & 0,80 & 0,56 & $\mathrm{~A} 52 \mathrm{e} A 72$ & 0,200 & LV09 e LV10 & 0,78 & 1,39 & 0,15 & 1,54 & 23,10 & 28,88 \\
\hline PV30 & 0,40 & 0,28 & A52 & 0,100 & LV10 & 0,39 & 0,70 & 0,08 & 0,77 & 11,55 & 28,88 \\
\hline PV31 & 4,00 & 2,80 & A97 e A117 & 1,660 & LV11 & 0,42 & 4,33 & 0,55 & 4,88 & 73,20 & 18,30 \\
\hline PV32 & 0,80 & 0,56 & A97 & 0,240 & LV11 & 0,42 & 1,09 & 0,13 & 1,22 & 18,30 & 22,88 \\
\hline PV33 & 0,80 & 0,56 & $\mathrm{~A} 42$ & 0,240 & LV12 & 0,42 & 1,09 & 0,13 & 1,22 & 18,30 & 22,88 \\
\hline PV34 & 4,00 & 2,80 & $\mathrm{~A} 20 \mathrm{e} A 42$ & 1,660 & LV12 & 0,42 & 4,33 & 0,55 & 4,88 & 73,20 & 18,30 \\
\hline PILAR & 1,00 & 3,50 & A86 & 2,800 & -.-- & 0,00 & 5,46 & 0,84 & 6,30 & 94,50 & 94,50 \\
\hline
\end{tabular}


6.5.2 Grupo Isolado de Paredes (GIP) - (EE)

Tabela 6.6 - GIP-EE - Cargas por grupo: $N_{k, v e r t}$ e $\eta_{k, v e r t}$ ao nível da fundação.

\begin{tabular}{|c|c|c|c|c|c|c|c|c|}
\hline \multicolumn{9}{|c|}{ GIP - EE: CARGAS POR GRUPO $->\mathrm{t}=10 \mathrm{~cm}$} \\
\hline GRUPO & Paredes & L total $(\mathrm{m})$ & $\mathrm{G}(\mathrm{tf})$ & $\mathrm{g}(\mathrm{tf} / \mathrm{m})$ & $Q(t f)$ & $q(\mathrm{tf} / \mathrm{m})$ & $\mathrm{Nk}$,vert (tf) & $\eta \mathrm{k}$, vert $(\mathrm{tf} / \mathrm{m})$ \\
\hline G1 & PH01, PH13 e PV04 & 8,00 & 147,98 & 18,50 & 23,82 & 2,98 & 171,80 & 21,47 \\
\hline G2 & PH02, PH11 e PV09 & 4,80 & 93,68 & 19,52 & 15,21 & 3,17 & 108,88 & 22,68 \\
\hline G3 & PH03, PH07 e PV13 & 3,20 & 67,80 & 21,19 & 12,60 & 3,94 & 80,40 & 25,13 \\
\hline G4 & PHO4, $\mathrm{PH} 10$ e $\mathrm{PV} 23$ & 3,20 & 67,80 & 21,19 & 12,60 & 3,94 & 80,40 & 25,13 \\
\hline G5 & PH05, PH12 e PV27 & 4,80 & 93,68 & 19,52 & 15,21 & 3,17 & 108,88 & 22,68 \\
\hline G6 & PH06, PH14 e PV34 & 8,00 & 147,98 & 18,50 & 23,82 & 2,98 & 171,80 & 21,47 \\
\hline G7 & PH08, PH09, PH15, PH18, PH20, PV16 e PV20 & 20,00 & 319,14 & 15,96 & 44,46 & 2,22 & 363,60 & 18,18 \\
\hline G8 & PH16, PV03, PV07, PV11 & 7,60 & 158,14 & 20,81 & 30,23 & 3,98 & 188,37 & 24,79 \\
\hline G9 & PH17, PV25, PV30 e PV33 & 7,60 & 158,14 & 20,81 & 30,23 & 3,98 & 188,37 & 24,79 \\
\hline G10 & PH19 & 0,80 & 19,02 & 23,78 & 3,78 & 4,73 & 22,80 & 28,50 \\
\hline G11 & PH21 e PV06 & 1,60 & 36,83 & 23,02 & 5,50 & 3,44 & 42,33 & 26,46 \\
\hline G12 & $\mathrm{PH} 22$ & 1,20 & 24,73 & 20,61 & 5,20 & 4,33 & 29,93 & 24,94 \\
\hline G13 & PH23 e PV14 & 2,40 & 52,88 & 22,03 & 11,35 & 4,73 & 64,23 & 26,76 \\
\hline G14 & PH24 e PV21 & 2,40 & 52,88 & 22,03 & 11,35 & 4,73 & 64,23 & 26,76 \\
\hline G15 & $\mathrm{PH} 25$ & 1,20 & 24,73 & 20,61 & 5,20 & 4,33 & 29,93 & 24,94 \\
\hline G16 & PH26 e PV29 & 1,60 & 36,83 & 23,02 & 5,50 & 3,44 & 42,33 & 26,46 \\
\hline G17 & PH31, PV02, PV05 e PV10 & 7,60 & 158,14 & 20,81 & 30,23 & 3,98 & 188,37 & 24,79 \\
\hline G18 & PH32, PV24, PV28 e PV32 & 7,60 & 158,14 & 20,81 & 30,23 & 3,98 & 188,37 & 24,79 \\
\hline G19 & PH27, PH28, PH30, PH33, PH34, PH39, PH42, PV15, PV17 e PV18 & 16,80 & 284,23 & 16,92 & 41,07 & 2,44 & 325,30 & 19,36 \\
\hline G20 & PH29, PH40, PH43 e PV19 & 11,20 & 203,33 & 18,15 & 34,17 & 3,05 & 237,50 & 21,21 \\
\hline G21 & PH35, PH45 e PV01 & 8,00 & 147,98 & 18,50 & 23,82 & 2,98 & 171,80 & 21,47 \\
\hline G22 & PH37, PH46 e PV08 & 4,80 & 93,68 & 19,52 & 15,21 & 3,17 & 108,88 & 22,68 \\
\hline G23 & PH41, PH47 e PV12 & 3,20 & 67,80 & 21,19 & 12,60 & 3,94 & 80,40 & 25,13 \\
\hline G24 & PH44, $\mathrm{PH} 48$ e PV22 & 3,20 & 67,80 & 21,19 & 12,60 & 3,94 & 80,40 & 25,13 \\
\hline G25 & PH38, PH49 e PV26 & 4,80 & 93,68 & 19,52 & 15,21 & 3,17 & 108,88 & 22,68 \\
\hline G26 & PH36, PH50 e PV31 & 8,00 & 147,98 & 18,50 & 23,82 & 2,98 & 171,80 & 21,47 \\
\hline
\end{tabular}

Tabela 6.7 - GIP-EE - Cargas por paredes: $N_{k, v e r t}$ e $\eta_{k, v e r t}$ ao nível da fundação.

\begin{tabular}{|c|c|c|c|c|c|c|c|c|c|c|c|c|c|c|c|}
\hline \multicolumn{16}{|c|}{ GIP - EE: CARGAS POR PAREDE $>\mathrm{t}=10 \mathrm{~cm}$} \\
\hline PAREDE & $L(m)$ & $G(t f)$ & $\mathrm{g}(\mathrm{tf} / \mathrm{m})$ & $Q$ (tf) & $\mathrm{q}(\mathrm{tf} / \mathrm{m})$ & $\mathrm{Nk}$, vert (tf) & $\eta \mathrm{k}, \mathrm{vert}(\mathrm{tf} / \mathrm{m})$ & PAREDE & $L(m)$ & $\mathrm{G}(\mathrm{tf})$ & $\mathrm{g}(\mathrm{tf} / \mathrm{m})$ & $Q(\mathrm{tf})$ & $q(t f / m)$ & $\mathrm{Nk}$,vert (tf) & $\eta \mathrm{k}$, vert $(\mathrm{tf} / \mathrm{m})$ \\
\hline PH01 & 0,80 & 14,80 & 18,50 & 2,38 & 2,98 & 17,18 & 21,47 & $\mathrm{PH} 44$ & 0,40 & 8,48 & 21,19 & 1,58 & 3,94 & 10,05 & 25,13 \\
\hline PH02 & 1,20 & 23,42 & 19,52 & 3,80 & 3,17 & 27,22 & 22,68 & PH45 & 0,80 & 14,80 & 18,50 & 2,38 & 2,98 & 17,18 & 21,47 \\
\hline PHO3 & 0,40 & 8,48 & 21,19 & 1,58 & 3,94 & 10,05 & 25,13 & $\mathrm{PH} 46$ & 1,20 & 23,42 & 19,52 & 3,80 & 3,17 & 27,22 & 22,68 \\
\hline PH04 & 0,40 & 8,48 & 21,19 & 1,58 & 3,94 & 10,05 & 25,13 & $\mathrm{PH} 47$ & 0,40 & 8,48 & 21,19 & 1,58 & 3,94 & 10,05 & 25,13 \\
\hline PH05 & 1,20 & 23,42 & 19,52 & 3,80 & 3,17 & 27,22 & 22,68 & $\mathrm{PH} 48$ & 0,40 & 8,48 & 21,19 & 1,58 & 3,94 & 10,05 & 25,13 \\
\hline PH06 & 0,80 & 14,80 & 18,50 & 2,38 & 2,98 & 17,18 & 21,47 & $\mathrm{PH} 49$ & 1,20 & 23,42 & 19,52 & 3,80 & 3,17 & 27,22 & 22,68 \\
\hline PH07 & 0,40 & 8,48 & 21,19 & 1,58 & 3,94 & 10,05 & 25,13 & PH50 & 0,80 & 14,80 & 18,50 & 2,38 & 2,98 & 17,18 & 21,47 \\
\hline PH08 & 0,40 & 6,38 & 15,96 & 0,89 & 2,22 & 7,27 & 18,18 & PV01 & 4,00 & 73,99 & 18,50 & 11,91 & 2,98 & 85,90 & 21,47 \\
\hline PH09 & 0,40 & 6,38 & 15,96 & 0,89 & 2,22 & 7,27 & 18,18 & PV02 & 0,80 & 16,65 & 20,81 & 3,18 & 3,98 & 19,83 & 24,79 \\
\hline PH10 & 0,40 & 8,48 & 21,19 & 1,58 & 3,94 & 10,05 & 25,13 & PV03 & 0,80 & 16,65 & 20,81 & 3,18 & 3,98 & 19,83 & 24,79 \\
\hline PH11 & 0,80 & 15,61 & 19,52 & 2,53 & 3,17 & 18,15 & 22,68 & PV04 & 4,00 & 73,99 & 18,50 & 11,91 & 2,98 & 85,90 & 21,47 \\
\hline PH12 & 0,80 & 15,61 & 19,52 & 2,53 & 3,17 & 18,15 & 22,68 & PV05 & 0,40 & 8,32 & 20,81 & 1,59 & 3,98 & 9,91 & 24,79 \\
\hline PH13 & 3,20 & 59,19 & 18,50 & 9,53 & 2,98 & 68,72 & 21,47 & PV06 & 0,80 & 18,42 & 23,02 & 2,75 & 3,44 & 21,17 & 26,46 \\
\hline PH14 & 3,20 & 59,19 & 18,50 & 9,53 & 2,98 & 68,72 & 21,47 & $\begin{array}{l}\text { PV07 } \\
\end{array}$ & 0,40 & 8,32 & 20,81 & 1,59 & 3,98 & 9,91 & 24,79 \\
\hline PH15 & 4,00 & 63,83 & 15,96 & 8,89 & 2,22 & 72,72 & 18,18 & PV08 & 2,80 & 54,65 & 19,52 & 8,87 & 3,17 & 63,52 & 22,68 \\
\hline PH16 & 4,00 & 83,23 & 20,81 & 15,91 & 3,98 & 99,14 & 24,79 & PV09 & 2,80 & 54,65 & 19,52 & 8,87 & 3,17 & 63,52 & 22,68 \\
\hline PH17 & 4,00 & 83,23 & 20,81 & 15,91 & 3,98 & 99,14 & 24,79 & PV10 & 2,40 & 49,94 & 20,81 & 9,55 & 3,98 & 59,49 & 24,79 \\
\hline PH18 & 0,40 & 6,38 & 15,96 & 0,89 & 2,22 & 7,27 & 18,18 & PV11 & 2,40 & 49,94 & 20,81 & 9,55 & 3,98 & 59,49 & 24,79 \\
\hline PH19 & 0,80 & 19,02 & 23,78 & 3,78 & 4,73 & 22,80 & 28,50 & PV12 & 2,40 & 50,85 & 21,19 & 9,45 & 3,94 & 60,30 & 25,13 \\
\hline $\mathrm{PH} 20$ & 0,40 & 6,38 & 15,96 & 0,89 & 2,22 & 7,27 & 18,18 & PV13 & 2,40 & 50,85 & 21,19 & 9,45 & 3,94 & 60,30 & 25,13 \\
\hline $\mathrm{PH} 21$ & 0,80 & 18,42 & 23,02 & 2,75 & 3,44 & 21,17 & 26,46 & $\begin{array}{l}\text { PV14 } \\
\end{array}$ & 1,60 & 35,26 & 22,03 & 7,57 & 4,73 & 42,82 & 26,76 \\
\hline $\mathrm{PH} 22$ & 1,20 & 24,73 & 20,61 & 5,20 & 4,33 & 29,93 & 24,94 & PV15 & 7,20 & 121,81 & 16,92 & 17,60 & 2,44 & 139,41 & 19,36 \\
\hline $\mathrm{PH} 23$ & 0,80 & 17,63 & 22,03 & 3,78 & 4,73 & 21,41 & 26,76 & PV16 & 7,20 & 114,89 & 15,96 & 16,01 & 2,22 & 130,90 & 18,18 \\
\hline PH24 & 0,80 & 17,63 & 22,03 & 3,78 & 4,73 & 21,41 & 26,76 & PV17 & 2,00 & 33,84 & 16,92 & 4,89 & 2,44 & 38,73 & 19,36 \\
\hline $\mathrm{PH} 25$ & 1,20 & 24,73 & 20,61 & 5,20 & 4,33 & 29,93 & 24,94 & PV18 & 0,40 & 6,77 & 16,92 & 0,98 & 2,44 & 7,75 & 19,36 \\
\hline PH26 & 0,80 & 18,42 & 23,02 & 2,75 & 3,44 & 21,17 & 26,46 & PV19 & 7,20 & 130,71 & 18,15 & 21,97 & 3,05 & 152,68 & 21,21 \\
\hline PH27 & 0,40 & 6,77 & 16,92 & 0,98 & 2,44 & 7,75 & 19,36 & PV20 & 7,20 & 114,89 & 15,96 & 16,01 & 2,22 & 130,90 & 18,18 \\
\hline $\mathrm{PH} 28$ & 1,20 & 20,30 & 16,92 & 2,93 & 2,44 & 23,24 & 19,36 & PV21 & 1,60 & 35,26 & 22,03 & 7,57 & 4,73 & 42,82 & 26,76 \\
\hline $\mathrm{PH} 29$ & 0,80 & 14,52 & 18,15 & 2,44 & 3,05 & 16,96 & 21,21 & PV22 & 2,40 & 50,85 & 21,19 & 9,45 & 3,94 & 60,30 & 25,13 \\
\hline PH3O & 1,60 & 27,07 & 16,92 & 3,91 & 2,44 & 30,98 & 19,36 & PV23 & 2,40 & 50,85 & 21,19 & 9,45 & 3,94 & 60,30 & 25,13 \\
\hline PH31 & 4,00 & 83,23 & 20,81 & 15,91 & 3,98 & 99,14 & 24,79 & PV24 & 2,40 & 49,94 & 20,81 & 9,55 & 3,98 & 59,49 & 24,79 \\
\hline PH32 & 4,00 & 83,23 & 20,81 & 15,91 & 3,98 & 99,14 & 24,79 & PV25 & 2,40 & 49,94 & 20,81 & 9,55 & 3,98 & 59,49 & 24,79 \\
\hline PH33 & 0,40 & 6,77 & 16,92 & 0,98 & 2,44 & 7,75 & 19,36 & PV26 & 2,80 & 54,65 & 19,52 & 8,87 & 3,17 & 63,52 & 22,68 \\
\hline PH34 & 2,80 & 47,37 & 16,92 & 6,85 & 2,44 & 54,22 & 19,36 & PV27 & 2,80 & 54,65 & 19,52 & 8,87 & 3,17 & 63,52 & 22,68 \\
\hline PH35 & 3,20 & 59,19 & 18,50 & 9,53 & 2,98 & 68,72 & 21,47 & PV28 & 0,40 & 8,32 & 20,81 & 1,59 & 3,98 & 9,91 & 24,79 \\
\hline PH36 & 3,20 & 59,19 & 18,50 & 9,53 & 2,98 & 68,72 & 21,47 & PV29 & 0,80 & 18,42 & 23,02 & 2,75 & 3,44 & 21,17 & 26,46 \\
\hline PH37 & 0,80 & 15,61 & 19,52 & 2,53 & 3,17 & 18,15 & 22,68 & PV30 & 0,40 & 8,32 & 20,81 & 1,59 & 3,98 & 9,91 & 24,79 \\
\hline PH38 & 0,80 & 15,61 & 19,52 & 2,53 & 3,17 & 18,15 & 22,68 & PV31 & 4,00 & 73,99 & 18,50 & 11,91 & 2,98 & 85,90 & 21,47 \\
\hline PH39 & 0,40 & 6,77 & 16,92 & 0,98 & 2,44 & 7,75 & 19,36 & PV32 & 0,80 & 16,65 & 20,81 & 3,18 & 3,98 & 19,83 & 24,79 \\
\hline $\mathrm{PH} 40$ & 2,80 & 50,83 & 18,15 & 8,54 & 3,05 & 59,38 & 21,21 & PV33 & 0,80 & 16,65 & 20,81 & 3,18 & 3,98 & 19,83 & 24,79 \\
\hline PH41 & 0,40 & 8,48 & 21,19 & 1,58 & 3,94 & 10,05 & 25,13 & PV34 & 4,00 & 73,99 & 18,50 & 11,91 & 2,98 & 85,90 & 21,47 \\
\hline $\mathrm{PH} 42$ & 0,40 & 6,77 & 16,92 & 0,98 & 2,44 & 7,75 & 19,36 & PILAR & 1,00 & 81,90 & 81,90 & 12,60 & 12,60 & 94,50 & 94,50 \\
\hline $\mathrm{PH} 43$ & 0,40 & 7,26 & 18,15 & 1,22 & 3,05 & 8,48 & 21,21 & & & & & & & & \\
\hline
\end{tabular}


As Tabelas 6.6 e 6.7 apresentam as cargas verticais totais, concentradas e distribuídas, ao nível da fundação, sendo que na primeira tabela os resultados estão por grupos e na segunda estão por paredes. Neste caso (G) apresenta as cargas permanentes concentradas totais ao nível da fundação e (Q), o mesmo para as cargas variáveis. As colulas (g) e (q) mostram as cargas distribuídas correspondentes a $(G)$ e $(Q)$, respectivamente.

\subsubsection{Modelo Pórtico Tridimensional (MPT) - (EE)}

Tabela 6.8 - MPT-EE: $N_{k, v e r t}$ e $\eta_{k, v e r t}$ ao nível da fundação.

\begin{tabular}{|c|c|c|c|c|c|c|c|c|c|c|c|}
\hline \multicolumn{12}{|c|}{ MPT-EE $->t=10 \mathrm{~cm}$} \\
\hline PAREDE & $L(m)$ & $G(t f)$ & $Q(t f)$ & $\mathrm{Nk}$,vert (tf) & $\eta \mathrm{k}$,vert (tf/m) & PAREDE & $\mathrm{L}(\mathrm{m})$ & $G(t f)$ & $Q(t f)$ & $\mathrm{Nk}$,vert (tf) & $\eta \mathrm{k}$, vert $(\mathrm{tf} / \mathrm{m})$ \\
\hline $\mathrm{PHO1}$ & 0,80 & 15,45 & 2,56 & 18,01 & 22,51 & $\mathrm{PH} 44$ & 0,40 & 7,97 & 1,37 & 9,34 & 23,36 \\
\hline $\mathrm{PHO2}$ & 1,20 & 23,59 & 3,97 & 27,56 & 22,97 & $\mathrm{PH} 45$ & 0,80 & 15,51 & 2,58 & 18,09 & 22,61 \\
\hline $\mathrm{PHO3}$ & 0,40 & 7,92 & 1,36 & 9,28 & 23,19 & $\mathrm{PH} 46$ & 1,20 & 23,73 & 4,02 & 27,76 & 23,13 \\
\hline PHO4 & 0,40 & 7,93 & 1,36 & 9,29 & 23,23 & PH47 & 0,40 & 7,98 & 1,38 & 9,36 & 23,40 \\
\hline PHO5 & 1,20 & 23,70 & 4,03 & 27,74 & 23,11 & PH48 & 0,40 & 7,92 & 1,35 & 9,27 & 23,17 \\
\hline $\mathrm{PH} 06$ & 0,80 & 15,60 & 2,65 & 18,24 & 22,81 & $\mathrm{PH} 49$ & 1,20 & 23,66 & 3,99 & 27,64 & 23,04 \\
\hline $\mathrm{PH} 07$ & 0,40 & 7,94 & 1,37 & 9,31 & 23,28 & PH50 & 0,80 & 15,55 & 2,61 & 18,16 & 22,70 \\
\hline $\mathrm{PH} 08$ & 0,40 & 6,80 & 1,01 & 7,81 & 19,53 & PV01 & 4,00 & 77,63 & 13,00 & 90,63 & 22,66 \\
\hline $\mathrm{PH} 09$ & 0,40 & 6,84 & 1,04 & 7,88 & 19,71 & PV02 & 0,80 & 15,70 & 2,68 & 18,38 & 22,98 \\
\hline $\mathrm{PH} 10$ & 0,40 & 7,95 & 1,37 & 9,32 & 23,29 & PV03 & 0,80 & 15,74 & 2,70 & 18,43 & 23,04 \\
\hline PH11 & 0,80 & 15,73 & 2,69 & 18,42 & 23,03 & PV04 & 4,00 & 77,52 & 12,98 & 90,49 & 22,62 \\
\hline $\mathrm{PH} 12$ & 0,80 & 15,74 & 2,69 & 18,43 & 23,04 & PV05 & 0,40 & 8,02 & 1,42 & 9,43 & 23,58 \\
\hline PH13 & 3,20 & 62,95 & 10,84 & 73,79 & 23,06 & PV06 & 0,80 & 16,18 & 2,83 & 19,02 & 23,77 \\
\hline $\mathrm{PH} 14$ & 3,20 & 63,05 & 10,90 & 73,96 & 23,11 & PV07 & 0,40 & 8,02 & 1,42 & 9,44 & 23,61 \\
\hline $\mathrm{PH} 15$ & 4,00 & 65,84 & 9,50 & 75,35 & 18,84 & PV08 & 2,80 & 55,31 & 9,46 & 64,76 & 23,13 \\
\hline PH16 & 4,00 & 79,83 & 14,12 & 93,95 & 23,49 & PV09 & 2,80 & 55,01 & 9,35 & 64,36 & 22,99 \\
\hline $\mathrm{PH} 17$ & 4,00 & 79,69 & 14,05 & 93,74 & 23,43 & PV10 & 2,40 & 48,94 & 8,99 & 57,94 & 24,14 \\
\hline $\mathrm{PH} 18$ & 0,40 & 6,65 & 0,96 & 7,61 & 19,01 & PV11 & 2,40 & 48,93 & 8,99 & 57,92 & 24,13 \\
\hline PH19 & 0,80 & 14,40 & 2,27 & 16,67 & 20,84 & PV12 & 2,40 & 47,89 & 8,37 & 56,26 & 23,44 \\
\hline $\mathrm{PH} 2 \mathrm{O}$ & 0,40 & 6,68 & 0,98 & 7,65 & 19,13 & PV13 & 2,40 & 47,52 & 8,22 & 55,74 & 23,23 \\
\hline $\mathrm{PH} 21$ & 0,80 & 16,16 & 2,84 & 19,01 & 23,76 & PV14 & 1,60 & 35,28 & 7,58 & 42,86 & 26,79 \\
\hline $\mathrm{PH} 22$ & 1,20 & 24,73 & 5,20 & 29,93 & 24,95 & PV15 & 7,20 & 125,31 & 18,99 & 144,30 & 20,04 \\
\hline $\mathrm{PH} 23$ & 0,80 & 17,60 & 3,77 & 21,37 & 26,72 & PV16 & 7,20 & 118,51 & 17,04 & 135,55 & 18,83 \\
\hline $\mathrm{PH} 24$ & 0,80 & 17,61 & 3,78 & 21,39 & 26,74 & PV17 & 2,00 & 34,71 & 5,27 & 39,97 & 19,99 \\
\hline $\mathrm{PH} 25$ & 1,20 & 24,73 & 5,20 & 29,93 & 24,95 & PV18 & 0,40 & 6,96 & 1,07 & 8,03 & 20,07 \\
\hline $\mathrm{PH} 26$ & 0,80 & 16,14 & 2,83 & 18,97 & 23,71 & PV19 & 7,20 & 128,78 & 20,91 & 149,69 & 20,79 \\
\hline $\mathrm{PH} 27$ & 0,40 & 6,91 & 1,03 & 7,94 & 19,85 & PV20 & 7,20 & 119,20 & 17,50 & 136,71 & 18,99 \\
\hline $\mathrm{PH} 28$ & 1,20 & 20,94 & 3,20 & 24,14 & 20,11 & PV21 & 1,60 & 35,27 & 7,57 & 42,84 & 26,78 \\
\hline $\mathrm{PH} 29$ & 0,80 & 14,33 & 2,33 & 16,66 & 20,83 & PV22 & 2,40 & 47,57 & 8,17 & 55,74 & 23,23 \\
\hline $\mathrm{PH} 30$ & 1,60 & 27,73 & 4,18 & 31,91 & 19,94 & PV23 & 2,40 & 47,53 & 8,20 & 55,73 & 23,22 \\
\hline $\mathrm{PH} 31$ & 4,00 & 79,74 & 14,06 & 93,80 & 23,45 & PV24 & 2,40 & 48,72 & 8,84 & 57,56 & 23,98 \\
\hline $\mathrm{PH} 32$ & 4,00 & 80,03 & 14,22 & 94,25 & 23,56 & PV25 & 2,40 & 48,67 & 8,82 & 57,49 & 23,95 \\
\hline $\mathrm{PH} 33$ & 0,40 & 7,06 & 1,11 & 8,17 & 20,42 & PV26 & 2,80 & 55,19 & 9,40 & 64,59 & 23,07 \\
\hline $\mathrm{PH} 34$ & 2,80 & 48,41 & 7,32 & 55,72 & 19,90 & PV27 & 2,80 & 55,16 & 9,42 & 64,58 & 23,06 \\
\hline PH35 & 3,20 & 63,02 & 10,86 & 73,88 & 23,09 & PV28 & 0,40 & 8,03 & 1,43 & 9,46 & 23,64 \\
\hline $\mathrm{PH} 36$ & 3,20 & 63,17 & 10,95 & 74,12 & 23,16 & PV29 & 0,80 & 16,18 & 2,83 & 19,01 & 23,76 \\
\hline $\mathrm{PH} 37$ & 0,80 & 15,81 & 2,72 & 18,53 & 23,17 & PV30 & 0,40 & 8,00 & 1,41 & 9,41 & 23,53 \\
\hline $\mathrm{PH} 38$ & 0,80 & 15,77 & 2,70 & 18,47 & 23,09 & PV31 & 4,00 & 78,13 & 13,33 & 91,46 & 22,87 \\
\hline PH39 & 0,40 & 7,01 & 1,07 & 8,09 & 20,21 & PV32 & 0,80 & 15,87 & 2,78 & 18,65 & 23,31 \\
\hline $\mathrm{PH} 40$ & 2,80 & 49,63 & 7,85 & 57,48 & 20,53 & PV33 & 0,80 & 15,79 & 2,74 & 18,52 & 23,16 \\
\hline $\mathrm{PH} 41$ & 0,40 & 8,02 & 1,40 & 9,42 & 23,55 & PV34 & 4,00 & 78,10 & 13,35 & 91,45 & 22,86 \\
\hline $\mathrm{PH} 42$ & 0,40 & 7,17 & 1,12 & 8,29 & 20,73 & PILAR & 1,00 & 81,90 & 12,60 & 94,50 & 94,50 \\
\hline $\mathrm{PH} 43$ & 0,40 & 7,28 & 1,18 & 8,46 & 21,15 & & & & & & \\
\hline
\end{tabular}

Os resultados da distribuição de cargas verticais nas paredes, obtidos pelo MPT, são apresentados na Tabela 6.8, onde (G) e (Q) são apresentados conforme Tabelas 6.6 e 6.7 . 
6.5.4 Modelo em Elementos Finitos - (EE)

\section{A distribuição de cargas verticais entre as paredes do edifício exemplo pelo} Modelo em Elementos Finitos (modelo de cascas) é apresentada na Tabela 6.9, da mesma maneira que apresenta-se a Tabela 6.8 para o caso do MPT.

Tabela 6.9 - MEF-EE: $N_{k, v e r t}$ e $\eta_{k, v e r t}$ ao nível da fundação.

\begin{tabular}{|c|c|c|c|c|c|c|c|c|c|c|c|}
\hline \multicolumn{12}{|c|}{ MEF-EE $->t=10 \mathrm{~cm}$} \\
\hline PAREDE & $\mathrm{L}(\mathrm{m})$ & $\mathrm{G}(\mathrm{tf})$ & $Q$ (tf) & Nk,vert (tf) & $\eta k, v e r t(t f / m)$ & PAREDE & $L(m)$ & $G(t f)$ & $\mathrm{Q}(\mathrm{tf})$ & $\mathrm{Nk}$,vert (tf) & $\eta \mathrm{k}, \operatorname{vert}(\mathrm{tf} / \mathrm{m})$ \\
\hline PH01 & 0,80 & 15,46 & 2,56 & 18,02 & 22,53 & $\mathrm{PH} 44$ & 0,40 & 7,66 & 1,32 & 8,97 & 22,44 \\
\hline $\mathrm{PHO2}$ & 1,20 & 24,21 & 4,06 & 28,27 & 23,55 & $\mathrm{PH} 45$ & 0,80 & 15,58 & 2,62 & 18,20 & 22,75 \\
\hline $\mathrm{PHO3}$ & 0,40 & 7,81 & 1,34 & 9,14 & 22,86 & $\mathrm{PH} 46$ & 1,20 & 24,43 & 4,14 & 28,56 & 23,80 \\
\hline $\mathrm{PHO4}$ & 0,40 & 7,82 & 1,35 & 9,17 & 22,92 & $\mathrm{PH} 47$ & 0,40 & 7,90 & 1,37 & 9,27 & 23,17 \\
\hline PH05 & 1,20 & 24,28 & 4,11 & 28,39 & 23,66 & PH48 & 0,40 & 7,89 & 1,37 & 9,26 & 23,15 \\
\hline PHOG & 0,80 & 15,55 & 2,64 & 18,19 & 22,74 & PH49 & 1,20 & 24,45 & 4,14 & 28,58 & 23,82 \\
\hline $\mathrm{PH} 07$ & 0,40 & 7,60 & 1,31 & 8,90 & 22,26 & PH50 & 0,80 & 15,63 & 2,64 & 18,27 & 22,83 \\
\hline PH08 & 0,40 & 6,65 & 1,03 & 7,68 & 19,20 & PV01 & 4,00 & 77,93 & 13,08 & 91,01 & 22,75 \\
\hline PHO9 & 0,40 & 6,68 & 1,05 & 7,73 & 19,33 & PV02 & 0,80 & 15,77 & 2,73 & 18,50 & 23,12 \\
\hline $\mathrm{PH} 10$ & 0,40 & 7,60 & 1,31 & 8,91 & 22,27 & PV03 & 0,80 & 15,78 & 2,74 & 18,52 & 23,15 \\
\hline PH11 & 0,80 & 15,63 & 2,65 & 18,28 & 22,85 & PV04 & 4,00 & 77,59 & 12,99 & 90,59 & 22,65 \\
\hline PH12 & 0,80 & 15,64 & 2,66 & 18,30 & 22,87 & PV05 & 0,40 & 7,63 & 1,35 & 8,98 & 22,45 \\
\hline $\mathrm{PH} 13$ & 3,20 & 62,22 & 10,69 & 72,91 & 22,78 & PV06 & 0,80 & 16,56 & 2,82 & 19,38 & 24,23 \\
\hline PH14 & 3,20 & 62,30 & 10,72 & 73,02 & 22,82 & PV07 & 0,40 & 7,64 & 1,36 & 9,00 & 22,49 \\
\hline PH15 & 4,00 & 67,04 & 10,16 & 77,21 & 19,30 & PV08 & 2,80 & 55,52 & 9,44 & 64,96 & 23,20 \\
\hline PH16 & 4,00 & 78,88 & 13,90 & 92,78 & 23,20 & PV09 & 2,80 & 55,12 & 9,30 & 64,42 & 23,01 \\
\hline PH17 & 4,00 & 78,89 & 13,89 & 92,78 & 23,20 & PV10 & 2,40 & 47,87 & 8,71 & 56,58 & 23,58 \\
\hline PH18 & 0,40 & 6,75 & 1,04 & 7,79 & 19,49 & PV11 & 2,40 & 47,81 & 8,69 & 56,50 & 23,54 \\
\hline PH19 & 0,80 & 14,61 & 2,34 & 16,95 & 21,19 & PV12 & 2,40 & 47,05 & 8,14 & 55,18 & 22,99 \\
\hline $\mathrm{PH} 20$ & 0,40 & 6,77 & 1,05 & 7,83 & 19,56 & PV13 & 2,40 & 46,56 & 7,97 & 54,53 & 22,72 \\
\hline $\mathrm{PH} 21$ & 0,80 & 16,30 & 2,78 & 19,08 & 23,85 & PV14 & 1,60 & 30,51 & 5,48 & 35,99 & 22,49 \\
\hline $\mathrm{PH} 22$ & 1,20 & 24,73 & 5,20 & 29,93 & 24,94 & PV15 & 7,20 & 130,53 & 20,64 & 151,17 & 21,00 \\
\hline $\mathrm{PH} 23$ & 0,80 & 14,98 & 2,68 & 17,66 & 22,07 & PV16 & 7,20 & 125,72 & 19,37 & 145,09 & 20,15 \\
\hline $\mathrm{PH} 24$ & 0,80 & 15,11 & 2,76 & 17,88 & 22,34 & PV17 & 2,00 & 34,72 & 5,43 & 40,15 & 20,08 \\
\hline $\mathrm{PH} 25$ & 1,20 & 24,73 & 5,20 & 29,93 & 24,94 & PV18 & 0,40 & 7,29 & 1,16 & 8,44 & 21,11 \\
\hline $\mathrm{PH} 26$ & 0,80 & 16,30 & 2,77 & 19,07 & 23,84 & PV19 & 7,20 & 132,90 & 21,99 & 154,89 & 21,51 \\
\hline $\mathrm{PH} 27$ & 0,40 & 6,92 & 1,09 & 8,01 & 20,02 & PV20 & 7,20 & 126,18 & 19,69 & 145,86 & 20,26 \\
\hline $\mathrm{PH} 28$ & 1,20 & 21,64 & 3,40 & 25,04 & 20,86 & PV21 & 1,60 & 30,76 & 5,62 & 36,39 & 22,74 \\
\hline $\mathrm{PH} 29$ & 0,80 & 14,36 & 2,39 & 16,75 & 20,94 & PV22 & 2,40 & 47,02 & 8,10 & 55,12 & 22,97 \\
\hline PH30 & 1,60 & 27,54 & 4,29 & 31,84 & 19,90 & PV23 & 2,40 & 46,60 & 8,00 & 54,59 & 22,75 \\
\hline PH31 & 4,00 & 78,83 & 13,84 & 92,67 & 23,17 & PV24 & 2,40 & 47,76 & 8,61 & 56,37 & 23,49 \\
\hline PH32 & 4,00 & 79,02 & 13,98 & 93,00 & 23,25 & PV25 & 2,40 & 47,67 & 8,59 & 56,27 & 23,44 \\
\hline PH33 & 0,40 & 6,97 & 1,10 & 8,07 & 20,18 & PV26 & 2,80 & 55,57 & 9,46 & 65,04 & 23,23 \\
\hline PH34 & 2,80 & 49,17 & 7,72 & 56,89 & 20,32 & PV27 & 2,80 & 55,23 & 9,38 & 64,60 & 23,07 \\
\hline PH35 & 3,20 & 62,36 & 10,70 & 73,06 & 22,83 & PV28 & 0,40 & 7,64 & 1,36 & 9,00 & 22,51 \\
\hline PH36 & 3,20 & 62,55 & 10,83 & 73,37 & 22,93 & PV29 & 0,80 & 16,56 & 2,83 & 19,39 & 24,24 \\
\hline PH37 & 0,80 & 15,72 & 2,68 & 18,40 & 23,00 & PV30 & 0,40 & 7,63 & 1,35 & 8,98 & 22,46 \\
\hline PH38 & 0,80 & 15,73 & 2,68 & 18,41 & 23,02 & PV31 & 4,00 & 78,37 & 13,39 & 91,76 & 22,94 \\
\hline PH39 & 0,40 & 7,00 & 1,13 & 8,13 & 20,33 & PV32 & 0,80 & 15,87 & 2,80 & 18,68 & 23,34 \\
\hline $\mathrm{PH} 40$ & 2,80 & 50,19 & 8,08 & 58,27 & 20,81 & PV33 & 0,80 & 15,84 & 2,78 & 18,62 & 23,28 \\
\hline PH41 & 0,40 & 7,67 & 1,33 & 9,01 & 22,52 & PV34 & 4,00 & 77,99 & 13,26 & 91,25 & 22,81 \\
\hline $\mathrm{PH} 42$ & 0,40 & 6,96 & 1,11 & 8,08 & 20,19 & PILAR & 1,00 & 81,90 & 12,60 & 94,50 & 94,50 \\
\hline $\mathrm{PH} 43$ & 0,40 & 7,09 & 1,17 & 8,26 & 20,65 & & & & & & \\
\hline
\end{tabular}

\subsubsection{Comparação da distribuição de cargas verticais - (EE)}

A Tabela 6.10 permite comparar as forças normais concentradas $\left(N_{k, v e r t}\right)$ obtidas nos itens 6.5.1 a 6.5.4, tomando-se como referência o MEF, por ser 0 modelo mais refinado. 
Tabela 6.10 - EE: Comparação de $N_{k, v e r t}$ ao nível da fundação.

\begin{tabular}{|c|c|c|c|c|c|c|c|c|c|c|c|c|c|c|c|c|c|}
\hline \multicolumn{18}{|c|}{ EE - DISTRIBUIÇÃO DE CARGAS VERTICAIS - $\mathrm{Nk}$,vert (tf) ->t $=10 \mathrm{~cm}$} \\
\hline PAREDE & $L(m)$ & MEF & MPT & $\%$ & GIP & $\%$ & PIS & $\%$ & PAREDE & $L(m)$ & MEF & MPT & $\%$ & GIP & $\%$ & PIS & $\%$ \\
\hline PH01 & 0,80 & 18,02 & 18,01 & $-0,1$ & 17,18 & $-4,7$ & 19,35 & 7,4 & PH45 & 0,80 & 18,20 & 18,09 & $-0,6$ & 17,18 & $-5,6$ & 19,35 & 6,3 \\
\hline PHO2 & 1,20 & 28,27 & 27,56 & $-2,5$ & 27,22 & $-3,7$ & 28,95 & 2,4 & PH46 & 1,20 & 28,56 & 27,76 & $-2,8$ & 27,22 & $-4,7$ & 28,95 & 1,4 \\
\hline $\mathrm{PH} 03$ & 0,40 & 9,14 & 9,28 & 1,4 & 10,05 & 9,9 & 9,60 & 5,0 & PH47 & 0,40 & 9,27 & 9,36 & 1,0 & 10,05 & 8,4 & 9,60 & 3,6 \\
\hline $\mathrm{PHO} 4$ & 0,40 & 9,17 & 9,29 & 1,4 & 10,05 & 9,6 & 9,60 & 4,7 & PH48 & 0,40 & 9,26 & 9,27 & 0,1 & 10,05 & 8,5 & 9,60 & 3,7 \\
\hline PH05 & 1,20 & 28,39 & 27,74 & $-2,3$ & 27,22 & $-4,1$ & 28,95 & 2,0 & PH49 & 1,20 & 28,58 & 27,64 & $-3,3$ & 27,22 & $-4,8$ & 28,95 & 1,3 \\
\hline PH06 & 0,80 & 18,19 & 18,24 & 0,3 & 17,18 & $-5,6$ & 19,35 & 6,4 & PH50 & 0,80 & 18,27 & 18,16 & $-0,6$ & 17,18 & $-6,0$ & 19,35 & 5,9 \\
\hline PH07 & 0,40 & 8,90 & 9,31 & 4,6 & 10,05 & 12,9 & 15,60 & 75,2 & PV01 & 4,00 & 91,01 & 90,63 & $-0,4$ & 85,90 & $-5,6$ & 73,20 & $-19,6$ \\
\hline PH08 & 0,40 & 7,68 & 7,81 & 1,7 & 7,27 & $-5,3$ & 15,60 & 103,1 & PVO2 & 0,80 & 18,50 & 18,38 & $-0,6$ & 19,83 & 7,2 & 18,30 & $-1,1$ \\
\hline PH09 & 0,40 & 7,73 & 7,88 & 2,0 & 7,27 & $-6,0$ & 15,60 & 101,7 & PV03 & 0,80 & 18,52 & 18,43 & $-0,5$ & 19,83 & 7,1 & 18,30 & $-1,2$ \\
\hline PH10 & 0,40 & 8,91 & 9,32 & 4,6 & 10,05 & 12,8 & 15,60 & 75,1 & PV04 & 4,00 & 90,59 & 90,49 & $-0,1$ & 85,90 & $-5,2$ & 73,20 & $-19,2$ \\
\hline PH11 & 0,80 & 18,28 & 18,42 & 0,8 & 18,15 & $-0,7$ & 18,00 & $-1,5$ & PV05 & 0,40 & 8,98 & 9,43 & 5,0 & 9,91 & 10,4 & 11,55 & 28,6 \\
\hline PH12 & 0,80 & 18,30 & 18,43 & 0,7 & 18,15 & $-0,8$ & 18,00 & $-1,6$ & PV06 & 0,80 & 19,38 & 19,02 & $-1,9$ & 21,17 & 9,2 & 23,10 & 19,2 \\
\hline $\mathrm{PH} 13$ & 3,20 & 72,91 & 73,79 & 1,2 & 68,72 & $-5,7$ & 79,25 & 8,7 & PV07 & 0,40 & 9,00 & 9,44 & 5,0 & 9,91 & 10,2 & 11,55 & 28,4 \\
\hline PH14 & 3,20 & 73,02 & 73,96 & 1,3 & 68,72 & $-5,9$ & 79,25 & 8,5 & $\begin{array}{l}\text { PV08 } \\
\text {. }\end{array}$ & 2,80 & 64,96 & 64,76 & $-0,3$ & 63,52 & $-2,2$ & 61,93 & $-4,7$ \\
\hline PH15 & 4,00 & 77,21 & 75,35 & $-2,4$ & 72,72 & $-5,8$ & 42,00 & $-45,6$ & PV09 & 2,80 & 64,42 & 64,36 & $-0,1$ & 63,52 & $-1,4$ & 61,93 & $-3,9$ \\
\hline PH16 & 4,00 & 92,78 & 93,95 & 1,3 & 99,14 & 6,9 & 79,20 & $-14,6$ & PV10 & 2,40 & 56,58 & 57,94 & 2,4 & 59,49 & 5,1 & 79,32 & 40,2 \\
\hline PH17 & 4,00 & 92,78 & 93,74 & 1,0 & 99,14 & 6,9 & 79,20 & $-14,6$ & PV11 & 2,40 & 56,50 & 57,92 & 2,5 & 59,49 & 5,3 & 79,32 & 40,4 \\
\hline PH18 & 0,40 & 7,79 & 7,61 & $-2,4$ & 7,27 & $-6,7$ & 11,40 & 46,3 & PV12 & 2,40 & 55,18 & 56,26 & 1,9 & 60,30 & 9,3 & 55,20 & 0,0 \\
\hline PH19 & 0,80 & 16,95 & 16,67 & $-1,6$ & 22,80 & 34,5 & 22,80 & 34,5 & PV13 & 2,40 & 54,53 & 55,74 & 2,2 & 60,30 & 10,6 & 55,20 & 1,2 \\
\hline $\mathrm{PH} 20$ & 0,40 & 7,83 & 7,65 & $-2,2$ & 7,27 & $-7,1$ & 11,40 & 45,7 & PV14 & 1,60 & 35,99 & 42,86 & 19,1 & 42,82 & 19,0 & 45,00 & 25,0 \\
\hline $\mathrm{PH} 21$ & 0,80 & 19,08 & 19,01 & $-0,4$ & 21,17 & 10,9 & 19,23 & 0,8 & PV15 & 7,20 & 151,17 & 144,30 & $-4,5$ & 139,41 & $-7,8$ & 145,50 & $-3,7$ \\
\hline $\mathrm{PH} 22$ & 1,20 & 29,93 & 29,93 & 0,0 & 29,93 & 0,0 & 29,93 & 0,0 & $\begin{array}{l}\text { PV16 } \\
\text {. }\end{array}$ & 7,20 & 145,09 & 135,55 & $-6,6$ & 130,90 & $-9,8$ & 133,80 & $-7,8$ \\
\hline $\mathrm{PH} 23$ & 0,80 & 17,66 & 21,37 & 21,0 & 21,41 & 21,3 & 19,23 & 8,9 & PV17 & 2,00 & 40,15 & 39,97 & $-0,4$ & 38,73 & $-3,6$ & 27,60 & $-31,3$ \\
\hline $\mathrm{PH} 24$ & 0,80 & 17,88 & 21,39 & 19,7 & 21,41 & 19,8 & 19,23 & 7,6 & PV18 & 0,40 & 8,44 & 8,03 & $-4,9$ & 7,75 & $-8,3$ & 7,80 & $-7,6$ \\
\hline $\mathrm{PH} 25$ & 1,20 & 29,93 & 29,93 & 0,0 & 29,93 & 0,0 & 29,93 & 0,0 & PV19 & 7,20 & 154,89 & 149,69 & $-3,4$ & 152,68 & $-1,4$ & 155,90 & 0,6 \\
\hline $\mathrm{PH} 26$ & 0,80 & 19,07 & 18,97 & $-0,6$ & 21,17 & 11,0 & 19,23 & $0, \varepsilon$ & PV20 & 7,20 & 145,86 & \begin{tabular}{|l|l}
136,71 \\
\end{tabular} & $-6,3$ & 130,90 & $-10,3$ & 133,80 & $-8,3$ \\
\hline $\mathrm{PH} 27$ & 0,40 & 8,01 & 7,94 & $-0,9$ & 7,75 & $-3,3$ & 12,24 & 52,8 & PV21 & 1,60 & 36,39 & 42,84 & 17,7 & 42,82 & 17,7 & 45,00 & 23,7 \\
\hline $\mathrm{PH} 28$ & 1,20 & 25,04 & 24,14 & $-3,6$ & 23,24 & $-7,2$ & 33,60 & 34,2 & PV22 & 2,40 & 55,12 & 55,74 & 1,1 & 60,30 & 9,4 & 55,20 & 0,1 \\
\hline $\mathrm{PH} 29$ & 0,80 & 16,75 & 16,66 & $-0,5$ & 16,96 & 1,3 & 21,36 & 27,5 & PV23 & 2,40 & 54,59 & 55,73 & 2 & 60,30 & 10,5 & 55,20 & 1,1 \\
\hline PH30 & 1,60 & 31,84 & 31,91 & 0,2 & 30,98 & $-2,7$ & 16,80 & $-47,2$ & PV24 & 2,40 & 56,37 & 57,56 & 2,1 & 59,49 & 5,5 & 79,32 & 40,7 \\
\hline PH31 & 4,00 & 92,67 & 93,80 & 1,2 & 99,14 & 7,0 & 79,20 & $-14,5$ & PV25 & 2,40 & 56,27 & 57,49 & 2,2 & 59,49 & 5,7 & 79,32 & 41,0 \\
\hline PH32 & 4,00 & 93,00 & 94,25 & 1,3 & 99,14 & 6,6 & 79,20 & $-14,8$ & PV26 & 2,80 & 65,04 & 64,59 & $-0,7$ & 63,52 & $-2,3$ & 61,93 & $-4,8$ \\
\hline PH33 & 0,40 & 8,07 & 8,17 & 1,2 & 7,75 & $-4,0$ & 11,20 & 38,8 & PV27 & 2,80 & 64,60 & 64,58 & 0,0 & 63,52 & $-1,7$ & 61,93 & $-4,1$ \\
\hline PH34 & 2,80 & 56,89 & 55,72 & $-2,1$ & 54,22 & $-4,7$ & 44,70 & $-21,4$ & & 0,40 & & 9,46 & 5,0 & 9,91 & 10,1 & 11,55 & 28,3 \\
\hline PH35 & 3,20 & 73,06 & 73,88 & 1,1 & 68,72 & $-5,9$ & 79,25 & 8,5 & PV29 & 0,80 & 19,39 & 19,01 & $-2,0$ & 21,17 & 9,1 & 23,10 & 19,1 \\
\hline PH36 & 3,20 & 73,37 & 74,12 & 1,0 & 68,72 & $-6,3$ & 79,25 & 8,0 & PV30 & 0,40 & 8,98 & 9,41 & 4,8 & 9,91 & 10,4 & 11,55 & 28,6 \\
\hline PH37 & 0,80 & 18,40 & 18,53 & 0,7 & 18,15 & $-1,4$ & 18,00 & $-2,2$ & PV31 & 4,00 & 91,76 & 91,46 & $-0,3$ & 85,90 & $-6,4$ & 73,20 & $-20,2$ \\
\hline PH38 & 0,80 & 18,41 & 18,47 & 0,3 & 18,15 & $-1,4$ & 18,00 & $-2,2$ & PV32 & 0,80 & 18,68 & 18,65 & $-0,1$ & 19,83 & 6,2 & 18,30 & $-2,0$ \\
\hline PH39 & 0,40 & 8,13 & 8,09 & $-0,6$ & 7,75 & $-4,7$ & 10,26 & 26,2 & PV33 & 0,80 & 18,62 & 18,52 & $-0,5$ & 19,83 & 6,5 & 18,30 & $-1,7$ \\
\hline PH40 & 2,80 & 58,27 & 57,48 & $-1,3$ & 59,38 & 1,9 & 44,64 & $-23,4$ & PV34 & 4,00 & 91,25 & 91,45 & 0,2 & 85,90 & $-5,9$ & 73,20 & $-19,8$ \\
\hline PH41 & 0,40 & 9,01 & 9,42 & 4,6 & 10,05 & 11,6 & 15,60 & 73,2 & & & & & MPT & & GIP & & PIS \\
\hline PH42 & 0,40 & 8,08 & 8,29 & 2,7 & 7,75 & $-4,1$ & 15,60 & 93,2 & & & & & $5 \%$ & & $6 \%$ & & $44 \%$ \\
\hline PH43 & 0,40 & 8,26 & 8,46 & 2,4 & 8,48 & 2,7 & 15,60 & 88,9 & & & & & $2 \%$ & & $63 \%$ & & $20 \%$ \\
\hline $\mathrm{PH} 44$ & 0,40 & 8,97 & 9,34 & 4,1 & 10,05 & 12,0 & 15,60 & 73,8 & & & & & $93 \%$ & & $31 \%$ & & $36 \%$ \\
\hline
\end{tabular}

As células pintadas em verde significam que a diferença de resultado do modelo comparado em relação ao MEF é menor ou igual, em valor absoluto, a 5\%, mostrando uma excelente aproximação. Aquelas pintadas em amarelo significam que a diferença obtida foi, em valor absoluto, maior que $5 \%$ e menor ou igual a $15 \%$, intervalo que qualifica os resultados como bons. As células pintadas em vermelho mostram diferenças acima de $15 \%$, limite a partir do qual o resultado é considerado ruim.

O limite de $15 \%$ que classifica a diferença de resultados entre modelos de cálculo, como ruim, foi baseado no coeficiente $\gamma_{f 3}$ que considera os possíveis erros de avaliação dos efeitos das ações, seja por problemas construtivos, seja por 
deficiência do método de cálculo empregado. Segundo a NBR 8681:2003 - Ações e segurança nas estruturas - Procedimentos, quando se consideram os estados limites últimos, os coeficientes $\gamma_{f}$ de ponderação das ações podem ser considerados como o produto de $\gamma_{f 1}$, que considera a variabilidade das ações e, $\gamma_{f 3}$, podendo esse último ser adotado igual a 1,18. Isso significa que a precisão de um modelo de cálculo pode variar em até $18 \%$ sem que o grau de segurança da estrutura seja afetado.

No canto inferior direito da Tabela 6.10, apresenta-se um resumo das qualidades dos resultados obtidos em todas as paredes do edifício exemplo, pelos MPT, GIP e PIS, em relação ao MEF, mostrando a porcentagem de resultados excelentes, bons e ruins.

A hierarquia de qualidade constatada no edifício estudo preliminar se repete para o caso do edifício exemplo, o qual é um exemplo real de edificação, a menos das adaptações feitas neste trabalho. O MPT é o que mais se aproxima do MEF, no qual $93 \%$ das paredes têm aproximação de resultados excelentes, $2 \%$ bons e apenas 5\% delas com aproximação de resultados ruins. Em seguida destacam-se os resultados do GIP, com apenas $6 \%$ dos resultados sendo ruins, $63 \%$ bons e $31 \%$ excelentes. Ratifica-se a má qualidade do PIS ao distribuir cargas verticais nos edifícios construídos no sistema Paredes de Concreto. A porcentagem de resultados ruins é de $44 \%$, observando que há diferenças de até $103,1 \%$ como é o caso da parede PH08. O excesso de resultados ruins se justifica pela própria hipótese do modelo, o qual não considera interação entre as paredes de concreto.

Todas as paredes com resultados ruins obtidos pelo MPT também se constataram no GIP (paredes PH23, PH24, PV14 e PV21). No GIP, além dessas, a parede PH19 também apresentou resultado ruim. Analisando a disposição delas em planta (ver Figura 6.6), constata-se que as paredes PH23 e PV14 compõem o grupo treze, e as paredes $\mathrm{PH} 24$ e PV21 compõem o grupo quatorze, o qual é simétrico ao grupo treze. Outro fator comum é que tanto os grupos treze e quatorze, como a parede $\mathrm{PH} 19$, são adjacentes a lintéis que as ligam a grupos muito rígidos (grupo treze é ligado aos grupos sete e dezenove; o grupo quatorze é ligado aos grupos sete e vinte; e a parede PH19 é ligada ao grupo sete).

Uma possível causa dos resultados ruins obtidos pelo MPT e GIP, e que precisa ser avaliada, é a grande diferença de rigidez entre dois grupos de paredes 
que interagem entre si por meio de apenas um lintel. Contudo, em ambos os casos, os resultados classificados como ruins têm diferença acima daqueles obtidos pelo $M E F$, e por isso são a favor da segurança.

Os resultados comparados na Tabela 6.10 são ao nível da fundação, no entanto, os diagramas das Figuras 6.10 e 6.11 mostram que a força normal característica, obtida apenas pelas cargas verticais, é também praticamente igual entre os modelos GIP, MPT e MEF ao longo de toda altura da parede. São apresentados os diagramas apenas das paredes PH13, PH16, PH34, PV08, PV12 e PV15 a fim de exemplificar a qualidade de resultados entre os três métodos citados. Os sinais das forças normais nos diagramas apresentados são negativos, ou seja, a força é de compressão.

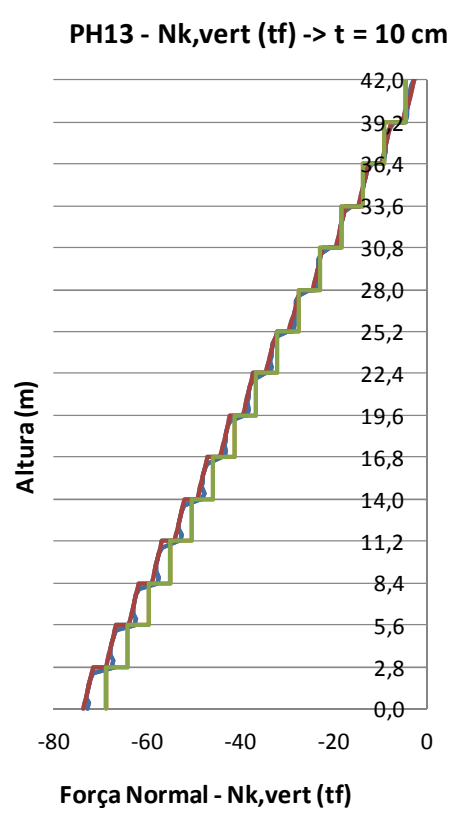

-MEF - Nk,vert

-MPT- Nk,vert

- GIP - Nk,vert

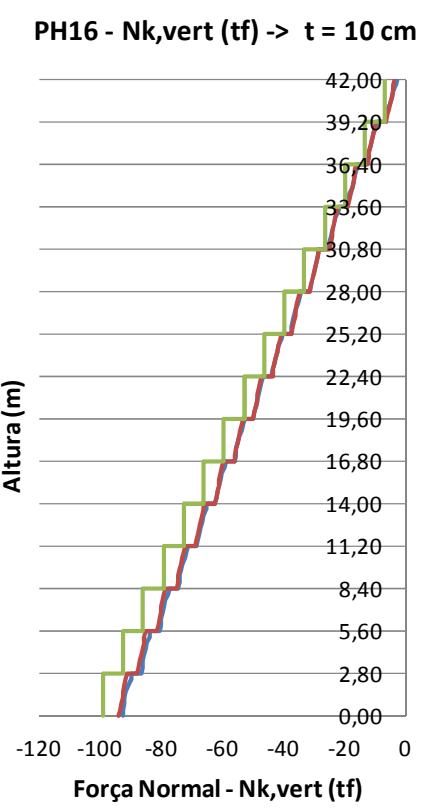

-MEF - Nk,vert

-MPT- Nk,vert

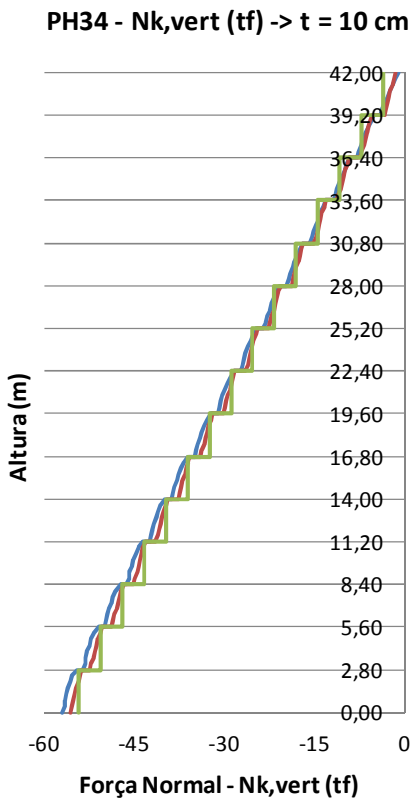

- MEF - Nk,vert

-MPT - Nk,vert

- GIP - Nk,vert

Figura 6.10 - Diagrama de $N_{k, v e r t}$ obtido pelos modelos GIP, MPT e MEF das paredes PH13, $\mathrm{PH} 16$ e $\mathrm{PH} 34$ com espessura de $10 \mathrm{~cm}$.

Destaca-se a qualidade de resultados obtidos pelo GIP, por ser um modelo de distribuição de cargas verticais extremamente simples quando comparado ao MEF, e o excelente grau de aproximação de resultados obtidos pelo MPT. Portanto, conclui-se que tanto o GIP como o MPT podem substituir o MEF para distribuir cargas verticais entre as paredes de um edifício construído no sistema Paredes de Concreto. 


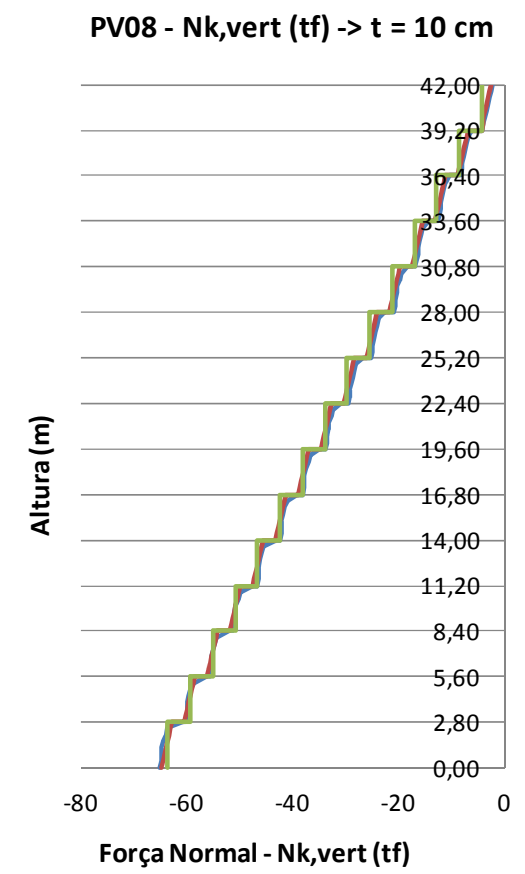

-MEF - Nk,vert

- MPT - Nk,vert

- GIP - Nk,vert

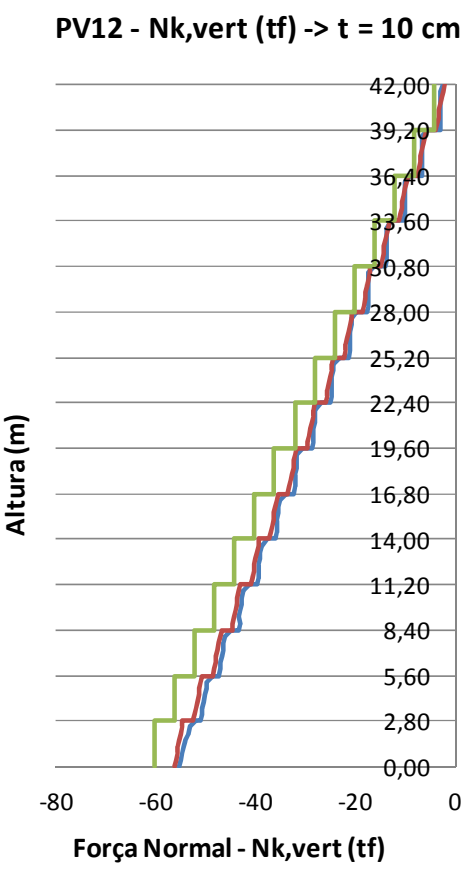

-MEF - Nk,vert

-MPT - Nk,vert

-GIP - Nk,vert

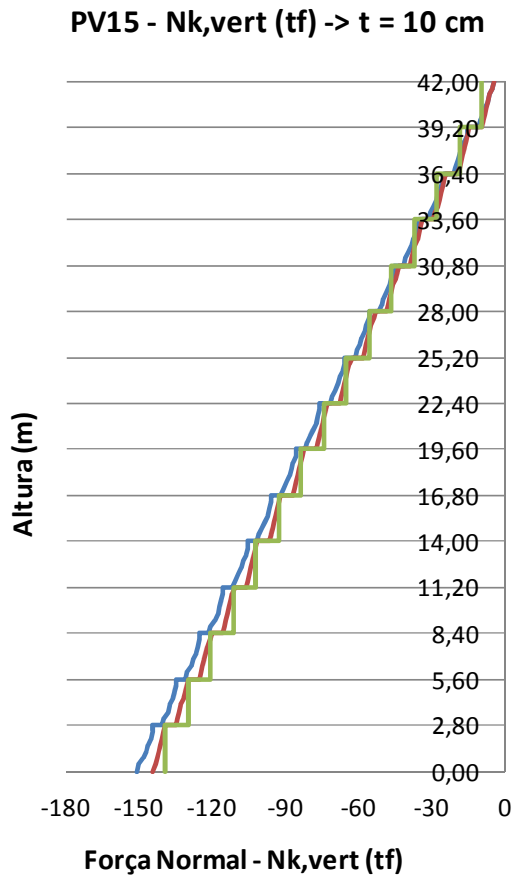

- MEF - Nk,vert

- MPT - Nk,vert

- GIP - Nk,vert

Figura 6.11 - Diagrama de $N_{k, v e r t}$ obtido pelos modelos GIP, MPT e MEF das paredes PV08, PV12 e PV15 com espessura de $10 \mathrm{~cm}$.

\subsubsection{Estimativa da máxima tensão normal de compressão}

Para verificar o pré-dimensionamento das espessuras das paredes, é necessário conferir se a máxima tensão normal de compressão de uma dada seção transversal é menor que a resistência última à compressão. Esse item propõe uma estimativa do acréscimo da força normal distribuída (o que é equivalente à tensão normal de compressão multiplicada pela espessura da parede) obtida apenas por cargas verticais, provocado pelo efeito das ações horizontais. A estimativa é feita multiplicando-se $\eta_{k, v e r t}$ pelo coeficiente $\mathrm{C}_{\mathrm{AH}}$ (coeficiente majorador devido às ações horizontais).

Como neste trabalho analisam-se nas paredes a distribuição de cargas verticais e das ações horizontais, os resultados das tensões normais obtidas considerando a combinação de ações $\mathrm{C}_{1}$ são conhecidos e foram os balizadores da formulação de $\mathrm{C}_{\mathrm{AH}}$. Ressalta-se que esse coeficiente é uma estimativa a ser aplicada no pré-dimensionamento das espessuras das paredes, em uma etapa que o 
projetista desconhece os esforços solicitantes das paredes devido às ações horizontais.

$O$ coeficiente $C_{A H}$ é formulado a partir da razão entre a máxima força normal distribuída de compressão de cálculo $\left(\eta_{C d}\right)$ pela força normal distribuída de cálculo obtida apenas pelas cargas verticais $\left(\eta_{d, v e r t}\right)$, ponderando-se as ações conforme NBR 16055. Essa relação foi analisada ao nível da fundação em paredes com diferentes comprimentos do edifício exemplo. Além disso, variou-se o número de pavimentos do edifício exemplo, para estudar a influência da altura do prédio na razão $\eta_{C d} / \eta_{d, v e r t}$ também ao nível da fundação. Observou-se, em média, que quanto maior o comprimento das paredes e o número de pavimentos do edifício, maior é o valor de $\mathrm{C}_{\mathrm{AH}}$.

Seguindo a hipótese inicial, neste estudo, as paredes foram consideradas com $10 \mathrm{~cm}$ de espessura, e os resultados utilizados para a formulação do $\mathrm{C}_{\mathrm{AH}}$ foram obtidos pelo Modelo Pórtico Tridimensional.

A Tabela 6.11 apresenta a relação citada e o respectivo valor do $C_{A H}$ (que é formulado adiante) para o caso do edifício exemplo com quinze pavimentos, onde ( $I$ ) é o momento de inércia à flexão da parede segundo sua direção principal.

Tabela 6.11 - Estudo para a formulação de $\mathrm{C}_{\mathrm{AH}}$ - Edifício exemplo com 15 pavimentos.

\begin{tabular}{|c|c|c|c|c|c|c|c|c|c|c|c|}
\hline \multicolumn{12}{|c|}{ CAH - 15 PAVs. } \\
\hline PAREDE & $L(m)$ & $I\left(m^{4}\right)$ & $\mathrm{Nk}$,vert (tf) & $\eta d$, vert $(\mathrm{tf} / \mathrm{m})$ & $\mathrm{NCd}(\mathrm{tf})$ & $\operatorname{Mcd}(\mathrm{tf} . \mathrm{m})$ & $\sigma c d(t f / m 2)$ & $\eta \mathrm{Cd}(\mathrm{tf} / \mathrm{m})$ & $\eta \mathrm{Cd} / \mathrm{\eta d}$, vert & $\mathrm{C}_{\mathrm{AH}}$ & $\%$ \\
\hline $\mathrm{PH} 01$ & 0,8 & 0,0043 & 18,01 & 31,51 & 29,11 & 0,96 & 453,53 & 45,35 & 1,44 & 1,24 & $-13,9$ \\
\hline $\mathrm{PH} 02$ & 1,2 & 0,0144 & 27,56 & 32,15 & 36,00 & 2,59 & 408,06 & 40,81 & 1,27 & 1,26 & $-0,9$ \\
\hline PHO3 & 0,4 & 0,0005 & 9,28 & 32,47 & 14,08 & 0,13 & 401,73 & 40,17 & 1,24 & 1,22 & $-1,3$ \\
\hline $\mathrm{PH} 07$ & 0,4 & 0,0005 & 9,31 & 32,59 & 14,17 & 0,17 & 418,39 & 41,84 & 1,28 & 1,22 & $-4,8$ \\
\hline PH11 & 0,8 & 0,0043 & 18,42 & 32,24 & 25,96 & 0,74 & 393,88 & 39,39 & 1,22 & 1,24 & 1,5 \\
\hline PH13 & 3,2 & 0,2731 & 73,79 & 32,28 & 97,58 & 24,36 & 447,66 & 44,77 & 1,39 & 1,35 & $-2,8$ \\
\hline PH15 & 4,0 & 0,5333 & 75,35 & 26,37 & 98,89 & 37,49 & 387,80 & 38,78 & 1,47 & 1,38 & $-5,9$ \\
\hline PH16 & 4,0 & 0,5333 & 93,95 & 32,88 & 127,81 & 41,12 & 473,72 & 47,37 & 1,44 & 1,38 & $-4,0$ \\
\hline $\mathrm{PH} 18$ & 0,4 & 0,0005 & 7,61 & 26,62 & 13,23 & 0,13 & 378,67 & 37,87 & 1,42 & 1,22 & $-14,1$ \\
\hline PH19 & 0,8 & 0,0043 & 16,67 & 29,18 & 21,76 & 0,68 & 335,52 & 33,55 & 1,15 & 1,24 & 7,8 \\
\hline $\mathrm{PH} 21$ & 0,8 & 0,0043 & 19,01 & 33,26 & 27,40 & 0,65 & 403,02 & 40,30 & 1,21 & 1,24 & 2,3 \\
\hline $\mathrm{PH} 22$ & 1,2 & 0,0144 & 29,93 & 34,92 & 38,27 & 1,82 & 394,73 & 39,47 & 1,13 & 1,26 & 11,3 \\
\hline $\mathrm{PH} 23$ & 0,8 & 0,0043 & 21,37 & 37,40 & 28,85 & 0,64 & 420,16 & 42,02 & 1,12 & 1,24 & 10,3 \\
\hline PH28 & 1,2 & 0,0144 & 24,14 & 28,16 & 33,52 & 2,14 & 368,48 & 36,85 & 1,31 & 1,26 & $-3,9$ \\
\hline $\mathrm{PH} 30$ & 1,6 & 0,0341 & 31,91 & 27,92 & 47,79 & 4,38 & 401,42 & 40,14 & 1,44 & 1,28 & $-11,3$ \\
\hline $\mathrm{PH} 34$ & 2,8 & 0,1829 & 55,72 & 27,86 & 73,36 & 16,97 & 391,83 & 39,18 & 1,41 & 1,33 & $-5,5$ \\
\hline $\mathrm{PH} 40$ & 2,8 & 0,1829 & 57,48 & 28,74 & 79,49 & 16,07 & 406,90 & 40,69 & 1,42 & 1,33 & $-6,1$ \\
\hline PV01 & 4,0 & 0,5333 & 90,63 & 31,72 & 137,42 & 25,89 & 440,62 & 44,06 & 1,39 & 1,38 & $-0,4$ \\
\hline PV02 & 0,8 & 0,0043 & 18,38 & 32,17 & 27,28 & 0,65 & 402,34 & 40,23 & 1,25 & 1,24 & $-0,9$ \\
\hline PV05 & 0,4 & 0,0005 & 9,43 & 33,02 & 13,78 & 0,13 & 391,77 & 39,18 & 1,19 & 1,22 & 2,9 \\
\hline PV06 & 0,8 & 0,0043 & 19,02 & 33,28 & 24,64 & 0,83 & 386,16 & 38,62 & 1,16 & 1,24 & 6,8 \\
\hline PV08 & 2,8 & 0,1829 & 64,76 & 32,38 & 92,98 & 11,63 & 421,07 & 42,11 & 1,30 & 1,33 & 2,2 \\
\hline PV10 & 2,4 & 0,1152 & 57,94 & 33,80 & 77,15 & 7,92 & 404,01 & 40,40 & 1,20 & 1,31 & 9,7 \\
\hline PV12 & 2,4 & 0,1152 & 56,26 & 32,82 & 79,10 & 7,93 & 412,25 & 41,22 & 1,26 & 1,31 & 4,4 \\
\hline PV14 & 1,6 & 0,0341 & 42,86 & 37,50 & 54,71 & 2,68 & 404,83 & 40,48 & 1,08 & 1,28 & 18,2 \\
\hline PV15 & 7,2 & 3,1104 & 144,30 & 28,06 & 200,41 & 124,49 & 422,44 & 42,24 & 1,51 & 1,53 & 1,4 \\
\hline PV17 & 2,0 & 0,0667 & 39,97 & 27,98 & 62,37 & 5,12 & 388,62 & 38,86 & 1,39 & 1,29 & $-6,9$ \\
\hline PV18 & 0,4 & 0,0005 & 8,03 & 28,10 & 11,15 & 0,04 & 293,02 & 29,30 & 1,04 & 1,22 & 17,2 \\
\hline PV19 & 7,2 & 3,1104 & 149,69 & 29,11 & 196,52 & 125,20 & 417,84 & 41,78 & 1,44 & 1,53 & 6,4 \\
\hline PV20 & 7,2 & 3,1104 & 136,71 & 26,58 & 185,84 & 131,83 & 410,70 & 41,07 & 1,55 & 1,53 & $-1,2$ \\
\hline
\end{tabular}


A Figura 6.12 resume a Tabela 6.11. Uma reta de tendência é traçada, via regressão linear, para se estipular a média do acréscimo da tensão de compressão nas paredes devido às ações horizontais.

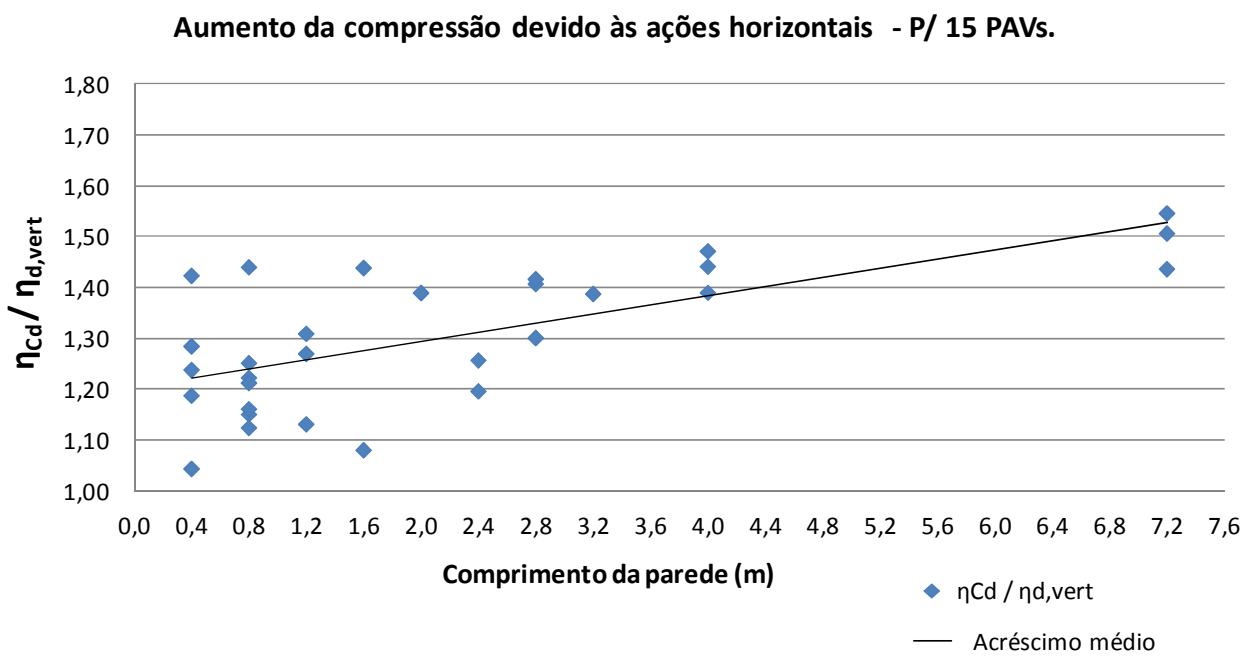

Figura 6.12 - Acréscimo médio da tensão normal de compressão em função do comprimento das paredes do edifício exemplo com 15 pavimentos.

O estudo da Tabela 6.11 também foi aplicado ao edifício exemplo considerando doze, dez, oito, cinco e dois pavimentos, a fim de verificar a influência da altura do prédio no acréscimo da tensão de compressão devido às ações horizontais. Para evitar o excesso de tabelas, esse estudo é apresentado no Anexo A deste trabalho, nas Tabelas $6 \mathrm{~A}-1$ a $6 \mathrm{~A}-5$. No entanto, o resumo do estudo é apresentado nas Figuras 6.13 a 6.17.

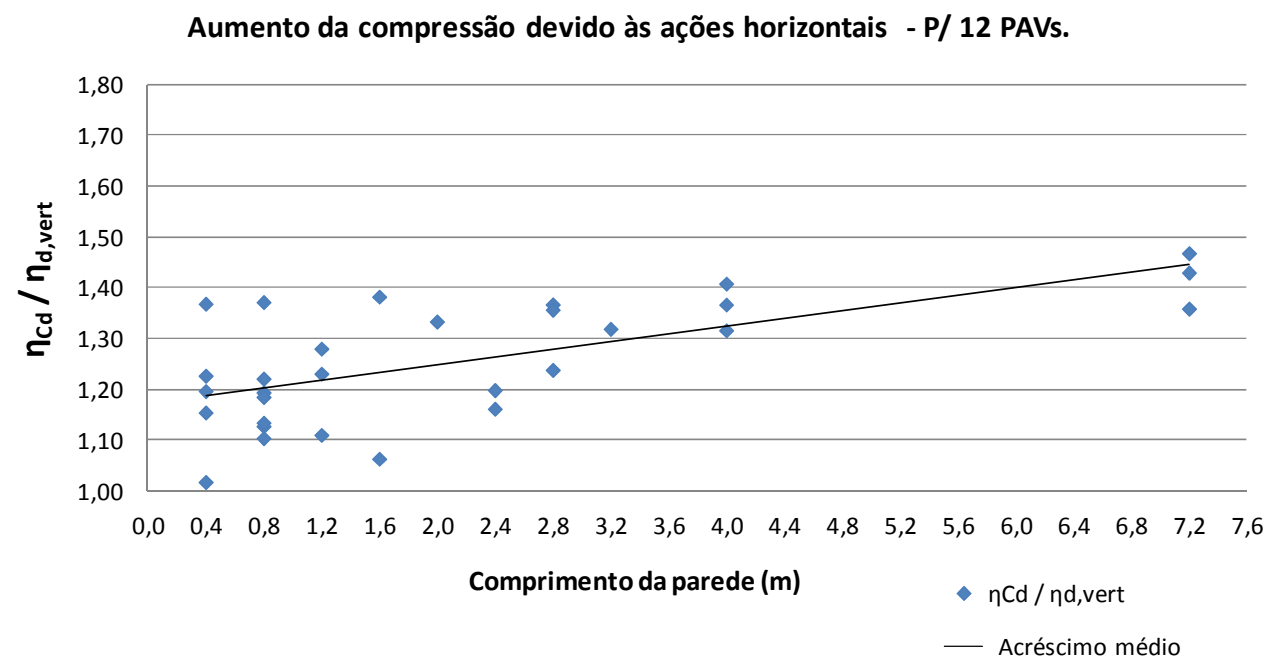

Figura 6.13 - Acréscimo médio da tensão normal de compressão em função do comprimento das paredes do edifício exemplo com 12 pavimentos. 


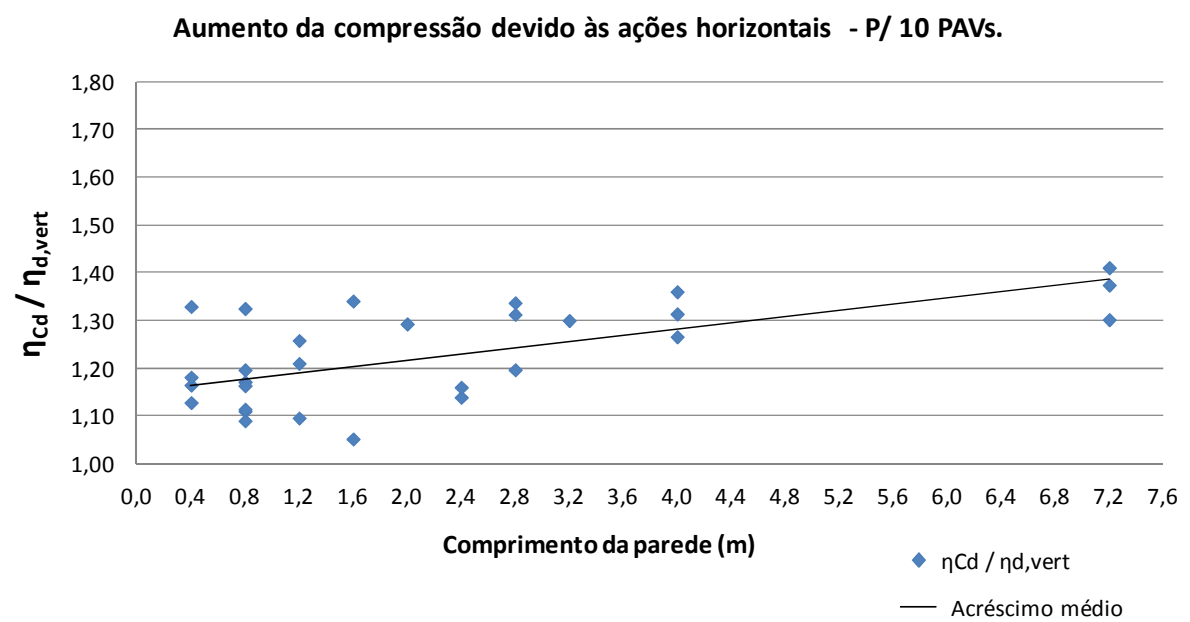

Figura 6.14 - Acréscimo médio da tensão normal de compressão em função do comprimento das paredes do edifício exemplo com 10 pavimentos.

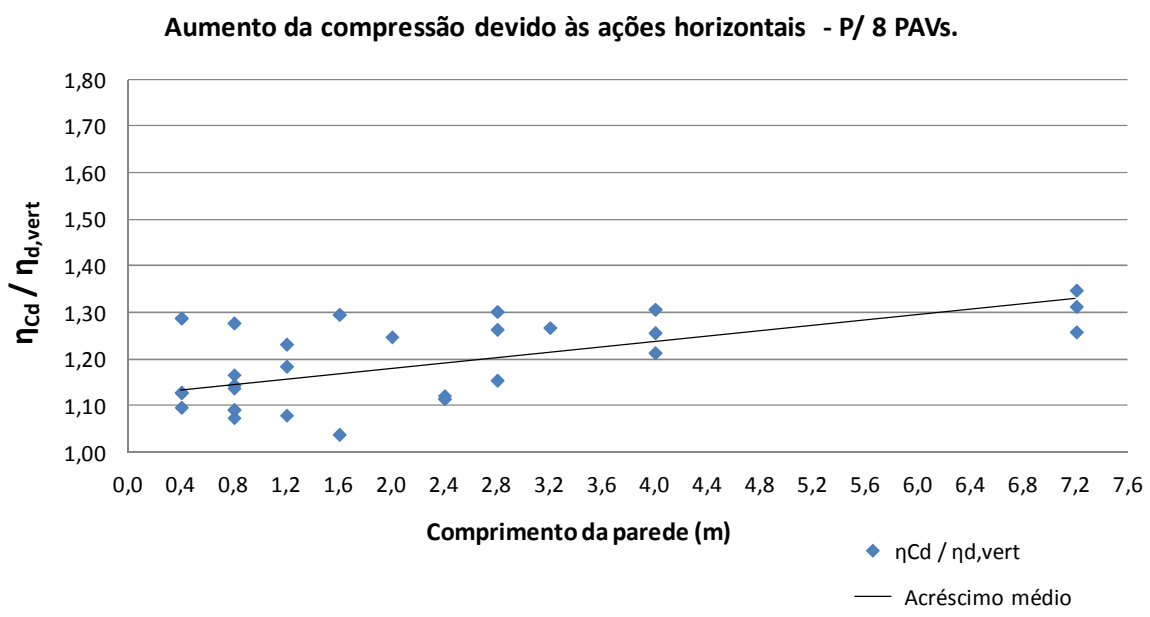

Figura 6.15 - Acréscimo médio da tensão normal de compressão em função do comprimento das paredes do edifício exemplo com 8 pavimentos.

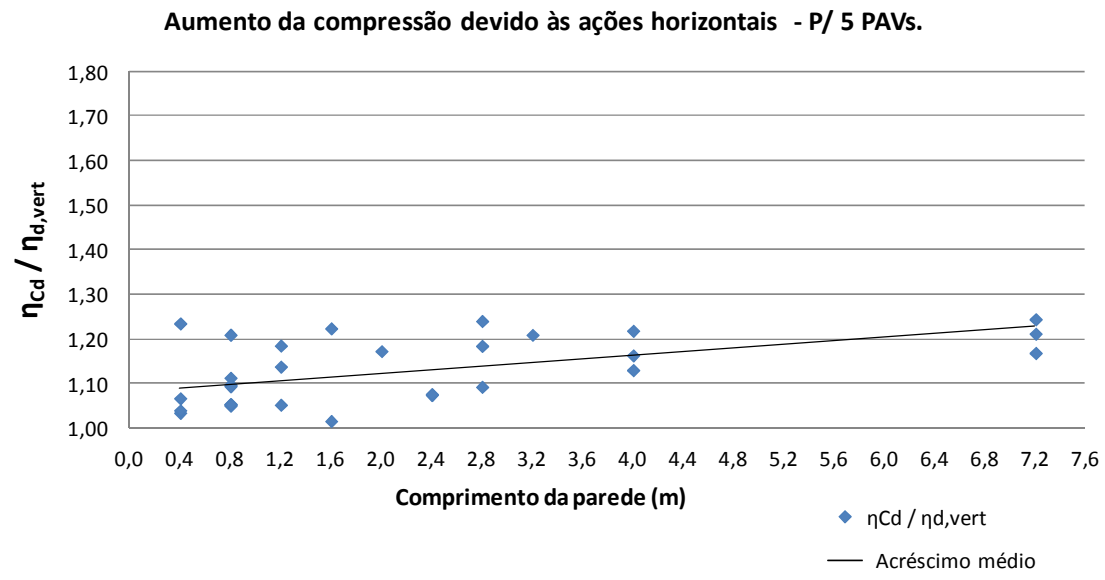

Figura 6.16 - Acréscimo médio da tensão normal de compressão em função do comprimento das paredes do edifício exemplo com 5 pavimentos. 


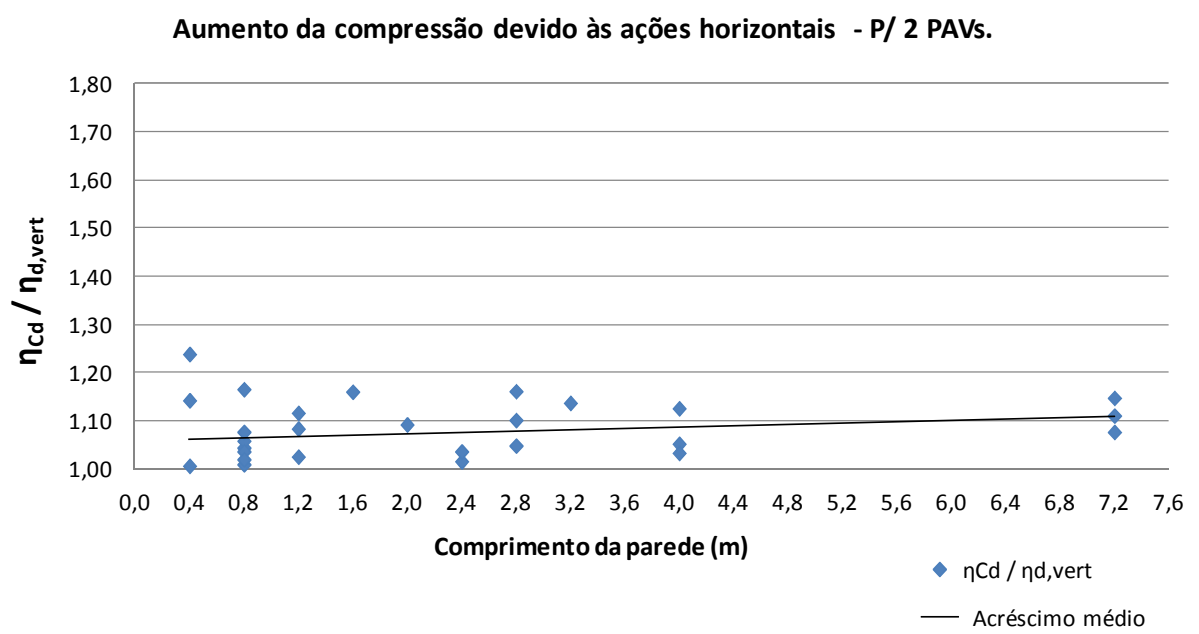

Figura 6.17 - Acréscimo médio da tensão normal de compressão em função do comprimento das paredes do edifício exemplo com 2 pavimentos.

Considerando a equação da reta $y=a \cdot x+b$ e analisando-se os gráficos das Figuras 6.12 a 6.17 , percebe-se que a reta do acréscimo médio tem coeficiente angular (a) e coeficiente constante (b), decrescentes conforme o número de pavimentos diminui. Essa variação é clara na Figura 6.18, a qual apresenta as retas de acréscimo médio para os seis casos estudados.

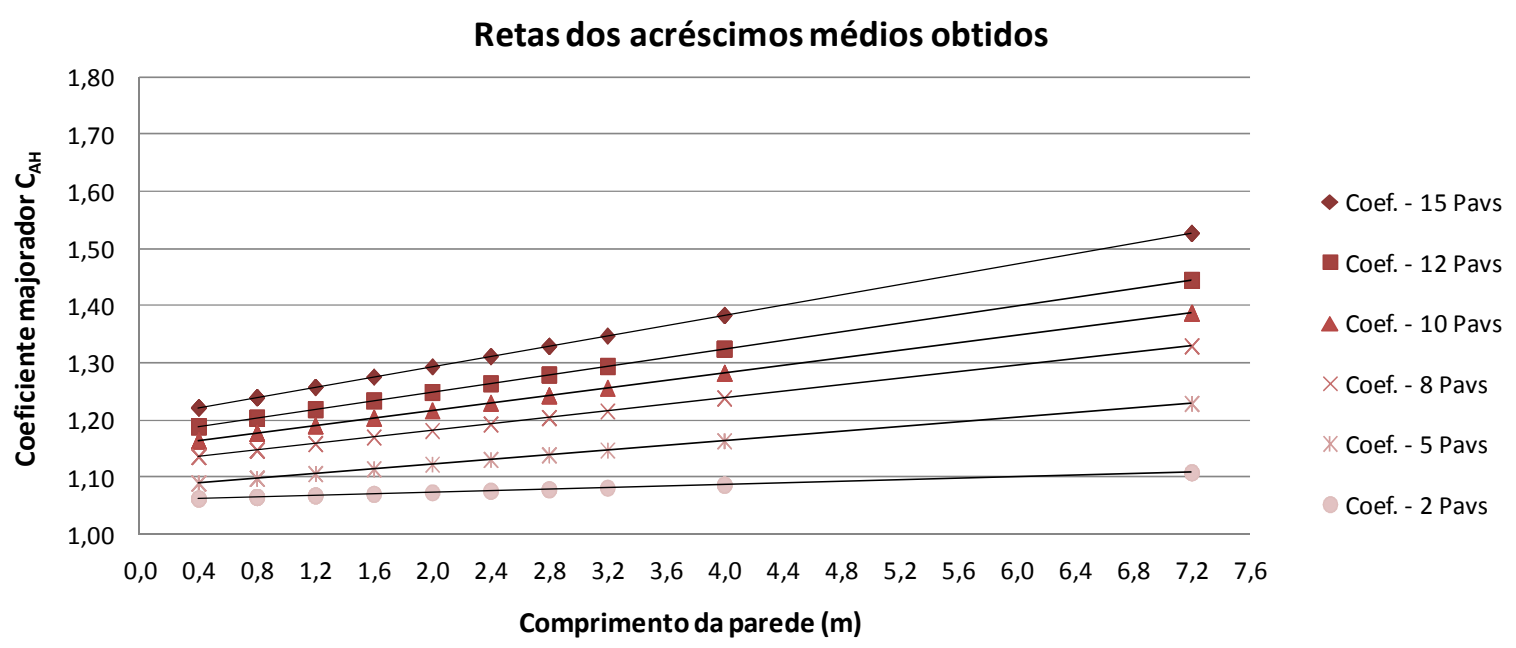

Figura 6.18 - Resumo do acréscimo médio da tensão de compressão nas paredes, devido às ações horizontais, para as alturas do edifício exemplo estudadas.

Os gráficos das Figuras 6.19 e 6.20 mostram que a variação dos coeficientes angular e constante, da reta de acréscimo médio, é praticamente linear, crescendo à medida que o número de pavimentos também cresce. A reta aproximada de $a=f(n)$ e $\mathrm{b}=\mathrm{f}(\mathrm{n})$ são traçadas nessas Figuras, respectivamente, onde $\mathrm{n}$ é número de pavimentos. 
Variação do coeficiente angular (a) das retas de acréscimo médio

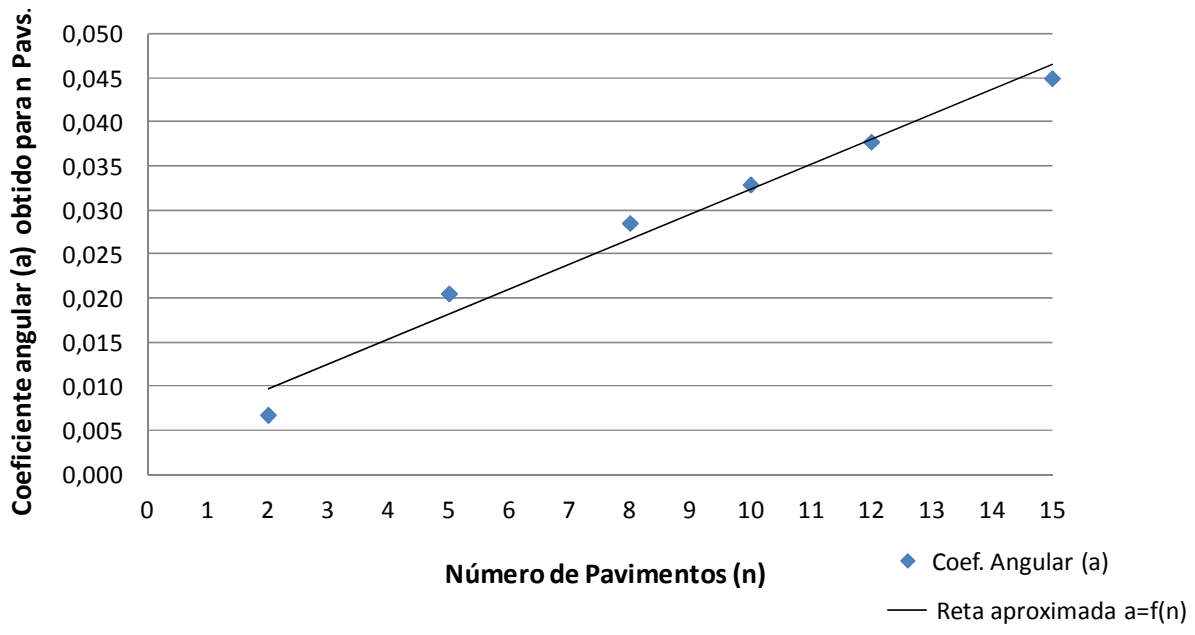

Figura 6.19 - Reta do coeficiente angular do acréscimo médio em função de n Pavs.

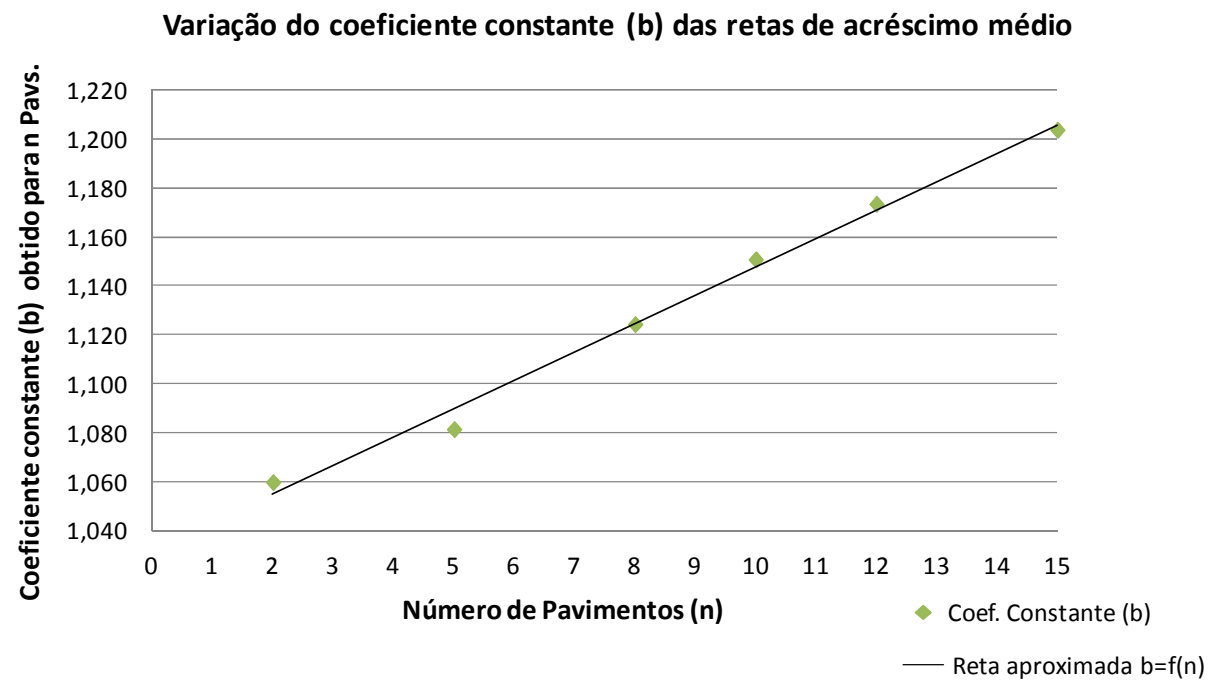

Figura 6.20 - Reta do coeficiente constante do acréscimo médio em função de n Pavs.

Primeiramente, analisando os acréscimos médios, nos gráficos das Figuras 6.12 a 6.17, pode-se escrever $\mathrm{C}_{\mathrm{AH}}$ em função do comprimento das paredes, seguindo o comportamento de uma reta, onde (a) é o coeficiente angular e (b) constante, como mostra a Equação (6.1).

$$
C_{A H}=a \cdot(L)+b
$$

Os coeficientes angulares (a) e constantes (b), das retas de acréscimo médio, crescem linearmente à medida que o número de pavimentos $(n)$ do edifício estudado 
aumenta. Os gráficos das Figuras 6.19 e 6.20 mostram esse fato e definem 0 comportamento desses coeficientes conforme Equações (6.2) e (6.3).

$a=m_{a} \cdot(n)+c_{a}$

$b=m_{b} \cdot(n)+c_{b}$

onde:

$m_{a}$ : é o coeficiente angular da reta $\mathrm{a}=\mathrm{f}(\mathrm{n})$ que vale $m_{a}=0,0028$;

$c_{a}$ : é o coeficiente constante da reta $\mathrm{a}=\mathrm{f}(\mathrm{n})$ que vale $c_{a}=0,0040$

$m_{b}$ : é o coeficiente angular da reta $\mathrm{b}=\mathrm{f}(\mathrm{n})$ que vale $m_{b}=0,0116$;

$c_{b}$ : é o coeficiente constante da reta $\mathrm{b}=\mathrm{f}(\mathrm{n})$ que vale $c_{b}=1,0317$

$n$ : número de pavimentos;

Substituindo as Equações (6.2) e (6.3) na Equação (6.1) se obtêm a Equação (6.4), que define $C_{A H}$ em função do comprimento das paredes analisadas e da altura do edifício que ela está contida.

$C_{A H}=\left[m_{a} \cdot(n)+c_{a}\right] \cdot(L)+m_{b} \cdot(n)+c_{b}$

Aplicando-se os valores de $m_{a}, c_{a}, m_{b}$ e $c_{b}$, na Equação (6.4), finalmente chega-se na expressão de $\mathrm{C}_{\mathrm{AH}}$, apresentada na Equação (6.5).

$$
C_{A H}=[0,0028(n)+0,0040 .(L)+0,0116(n)+1,0317
$$

Portanto, como a reta do acréscimo médio da tensão de compressão nas paredes, devido às ações horizontais, foi obtida em função do comprimento das paredes, e que seus coeficientes angulares e constantes, variam linearmente em função do número de pavimentos do edifício exemplo estudado, conclui-se que $\mathrm{C}_{\mathrm{AH}}$ 
pode ser resumido em função do comprimento das paredes e do número de pavimentos, como mostrado nas Equações (6.4) e (6.5).

Como citado anteriormente, a estimativa foi baseada nos acréscimos reais da tensão de compressão, fazendo-se a relação de $\eta_{C d} / \eta_{d, v e r t}$ que é apresentada na antepenúltima coluna das Tabelas 6.11 e $6 \mathrm{~A}-1$ a $6 \mathrm{~A}-5$ (Anexo A). O estudo é feito praticamente em todas as paredes do edifício exemplo, já que as simétricas, por apresentarem resultados repetidos, não foram consideradas (ver as paredes estudadas na Tabela 6.9 e a nomenclatura de todas elas na Figura 6.2).

A última coluna das Tabelas 6.11 e 6A-1 a $6 \mathrm{~A}-5$ apresenta a qualidade da estimativa obtida por $\mathrm{C}_{\mathrm{AH}}$ (penúltima coluna), comparando o coeficiente com 0 acréscimo real da tensão de compressão (antepenúltima coluna). Analisando a Tabela 6.11, a qual apresenta os maiores acréscimos, por considerar o maior número de pavimentos no estudo realizado, mostra que $76,67 \%$ das paredes têm $\mathrm{C}_{\mathrm{AH}}$ mais ou menos $10 \%$ iguais aos acréscimos reais, resultado considerado muito bom para uma fase de pré-dimensionamento. Quando a aproximação fica abaixo do acréscimo real, o pior resultado é da parede $\mathrm{PH} 18$ em que $\mathrm{C}_{\mathrm{AH}}$ fica $14,1 \%$ menor que o valor real. Quando a aproximação ultrapassa o acréscimo real, o pior resultado é da parede PV14 em que $\mathrm{C}_{A H}$ fica $18,1 \%$ acima do valor real.

É necessário relembrar que a expressão proposta de $\mathrm{C}_{A H}$ foi desenvolvida baseada no edifício exemplo deste trabalho. Consideraram-se, também, as ponderações das ações conforme NBR 16055.

Como o pior resultado difere do real em $18,1 \%$ e a maioria dos resultados difere do real em maios ou menos $10 \%$, para efeito do pré-dimensionamento das paredes, realizado neste trabalho, utilizou-se a expressão proposta de $\mathrm{C}_{\mathrm{AH}}$, conforme Equação (6.5). No entanto, é necessário avaliar a validade dessa expressão, aplicando-a em edifícios de diferentes geometrias, alturas e ações horizontais.

\subsubsection{Verificação ao pré-dimensionamento}

A verificação ao pré-dimensionamento das espessuras das paredes é feita comparando a força normal distribuída de cálculo obtida apenas pelas cargas verticais $\left(\eta_{d, v e r t}\right)$, ao nível da fundação, majorada por $\mathrm{C}_{\mathrm{AH}}, \mathrm{com}$ a resistência última à 
compressão dada pelas normas australiana, americana, europeia e brasileira, conforme item 3.3. Ao multiplicar $\eta_{d, \text { vert }}$ por $\mathrm{C}_{\mathrm{AH}}$, obtém-se a estimativa da máxima força normal distribuída de cálculo $\eta_{C d, \text { est }}$. Convém lembrar que as ponderações das ações e resistências, a fim de transformá-las em valores de cálculo, foram feitas seguindo os coeficientes das respectivas normas utilizadas.

A verificação ao pré-dimensionamento é feito nas paredes $\mathrm{PH} 13, \mathrm{PH} 16$, PH22, PH34, PH40, PV01, PV08, PV10, PV12 e PV15, por serem representativas e apresentarem diferentes condições de vinculação em suas extremidades laterais. As resistências últimas à compressão das paredes PH16, PH34, PV01, PV08, PV12 e PV15 são calculadas por trechos representados pelas letras, a, b, c etc., que consideram a mudança da vinculação lateral provocada por paredes que thes são transversais. Consequentemente, o comprimento dessas paredes é dado por trechos e definido pelas paredes transversais. Nos casos em que a norma utilizada não considera a hipótese de vinculações laterais, ambas extremidades laterais dos trechos dessas paredes foram consideradas livres.

Os resultados de resistência última à compressão, obtidos pelas normas citadas, encontram-se nas Tabelas 6.12 a 6.16. A nomenclatura de alguns parâmetros foi padronizada a fim de facilitar a análise de resultados:

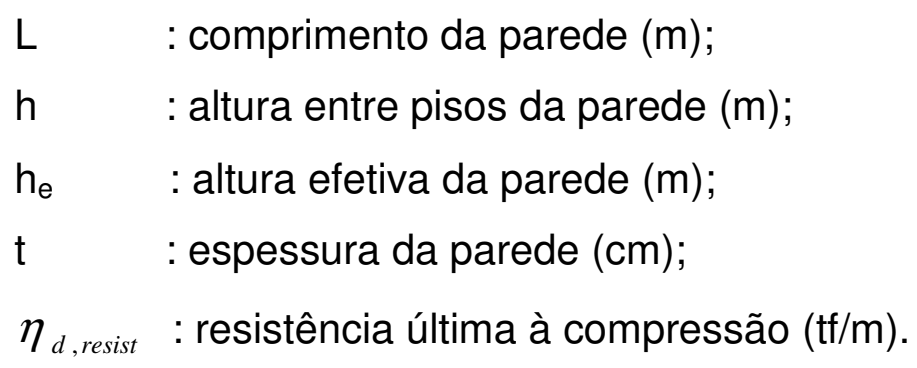

Mesmo nos casos em que a esbeltez das paredes (relação altura/espessura) ultrapasse o limite especificado por determinada norma, o cálculo da resistência última à compressão foi realizado para efeito de comparação de resultados.

Os resultados da Tabela 6.12 foram obtidos pelas expressões apresentadas no item 3.3.1 (AS 3600:2001), considerando que as vinculações da base e topo das paredes impedem apenas as translações horizontais, ou seja, $k=1,00$.

A Tabela 6.13 apresenta os resultados pelo código australiano revisado em 2009. A segunda coluna mostra qual é o tipo de vinculação existente na parede i, ii 
ou iii, e seu respectivo coeficiente $k$ para o cálculo da altura efetiva, conforme item 3.3.1. Para as duas versões da norma australiana, foi considerada excentricidade inicial de $e=10 / 6 \mathrm{~cm}$.

Tabela 6.12 - $\eta_{d, \text { resist }}$ conforme AS 3600:2001.

\begin{tabular}{|c|c|c|c|c|c|}
\hline \multicolumn{5}{|c|}{ Resistência última à compressão - AS 3600:2001 - t $=10 \mathrm{~cm}$} \\
\hline PAREDES & $\mathrm{L}(\mathrm{m})$ & $\mathrm{h}_{\mathrm{e}}(\mathrm{m})$ & $\mathrm{h}_{\mathrm{e}} / \mathrm{t}$ & $\mathrm{e}_{\mathrm{a}}(\mathrm{cm})$ & $\eta \mathrm{d}$, resist $(\mathrm{tf} / \mathrm{m})$ \\
\hline PH13 & 3,2 & 2,8 & 28,0 & 3,14 & 15,55 \\
\hline PH16a & 2,4 & 2,4 & 24,0 & 2,30 & 30,53 \\
\hline PH16b & 1,6 & 1,6 & 16,0 & 1,02 & 53,57 \\
\hline PH22 & 1,2 & 2,8 & 28,0 & 3,14 & 15,55 \\
\hline PH34a & 1,6 & 1,6 & 16,0 & 1,02 & 53,57 \\
\hline PH34b & 1,2 & 1,2 & 12,0 & 0,58 & 61,63 \\
\hline PH40 & 2,8 & 2,8 & 28,0 & 3,14 & 15,55 \\
\hline PV01a & 3,6 & 2,8 & 28,0 & 3,14 & 15,55 \\
\hline PV01b & 0,4 & 2,8 & 28,0 & 3,14 & 15,55 \\
\hline PV08a & 2,4 & 2,4 & 24,0 & 2,30 & 30,53 \\
\hline PV08b & 0,4 & 2,8 & 28,0 & 3,14 & 15,55 \\
\hline PV10 & 2,4 & 2,8 & 28,0 & 3,14 & 15,55 \\
\hline PV12a & 0,8 & 0,8 & 8,0 & 0,26 & 67,39 \\
\hline PV12b & 1,6 & 2,8 & 28,0 & 3,14 & 15,55 \\
\hline PV15a & 0,8 & 2,8 & 28,0 & 3,14 & 15,55 \\
\hline PV15b & 0,8 & 0,8 & 8,0 & 0,26 & 67,39 \\
\hline PV15c & 3,2 & 2,8 & 28,0 & 3,14 & 15,55 \\
\hline PV15d & 1,6 & 1,6 & 16,0 & 1,02 & 53,57 \\
\hline PV15e & 0,4 & 0,4 & 4,0 & 0,06 & 70,85 \\
\hline PV15f & 0,4 & 2,8 & 28,0 & 3,14 & 15,55 \\
\hline
\end{tabular}

Tabela $6.13-\eta_{d, \text { resist }}$ conforme AS 3600:2009.

\begin{tabular}{|c|c|c|c|c|c|c|c|}
\hline \multicolumn{7}{|c|}{ Resistência última à compressão - $\mathrm{AS} 3600: 2009->\mathrm{t}=10 \mathrm{~cm}$} \\
\hline PAREDES & Vinculação & $\mathrm{L}(\mathrm{m})$ & $\mathrm{k}$ & $\mathrm{h}_{\mathrm{e}}(\mathrm{m})$ & $\mathrm{h}_{\mathrm{e}} / \mathrm{t}$ & $\mathrm{e}_{\mathrm{a}}(\mathrm{cm})$ & $\eta$ d,resist $(\mathrm{tf} / \mathrm{m})$ \\
\hline PH13 & $\mathrm{ii}$ & 3,2 & 0,92 & 2,58 & 25,8 & 2,66 & 24,06 \\
\hline PH16a & $\mathrm{iii}$ & 2,4 & 0,43 & 1,20 & 12,0 & 0,58 & 61,63 \\
\hline PH16b & $\mathrm{iii}$ & 1,6 & 0,29 & 0,80 & 8,0 & 0,26 & 67,39 \\
\hline PH22 & $\mathrm{i}$ & 1,2 & 1,00 & 2,80 & 28,0 & 3,14 & 15,55 \\
\hline PH34a & $\mathrm{iii}$ & 1,6 & 0,29 & 0,80 & 8,0 & 0,26 & 67,39 \\
\hline PH34b & $\mathrm{ii}$ & 1,2 & 0,62 & 1,74 & 17,4 & 1,22 & 50,09 \\
\hline PH40 & $\mathrm{ii}$ & 2,8 & 0,90 & 2,52 & 25,2 & 2,54 & 26,28 \\
\hline PV01a & $\mathrm{iii}$ & 3,6 & 0,62 & 1,74 & 17,4 & 1,22 & 50,09 \\
\hline PV01b & $\mathrm{ii}$ & 0,4 & 0,30 & 0,84 & 8,4 & 0,28 & 66,92 \\
\hline PV08a & $\mathrm{iii}$ & 2,4 & 0,43 & 1,20 & 12,0 & 0,58 & 61,63 \\
\hline PV08b & $\mathrm{ii}$ & 0,4 & 0,30 & 0,84 & 8,4 & 0,28 & 66,92 \\
\hline PV10 & $\mathrm{ii}$ & 2,4 & 0,87 & 2,43 & 24,3 & 2,37 & 29,41 \\
\hline PV12a & $\mathrm{iii}$ & 0,8 & 0,14 & 0,40 & 4,0 & 0,06 & 70,85 \\
\hline PV12b & $\mathrm{ii}$ & 1,6 & 0,75 & 2,09 & 20,9 & 1,75 & 40,58 \\
\hline PV15a & $\mathrm{ii}$ & 0,8 & 0,42 & 1,19 & 11,9 & 0,56 & 61,87 \\
\hline PV15b & $\mathrm{iii}$ & 0,8 & 0,14 & 0,40 & 4,0 & 0,06 & 70,85 \\
\hline PV15c & $\mathrm{iii}$ & 3,2 & 0,57 & 1,59 & 15,9 & 1,01 & 53,89 \\
\hline PV15d & $\mathrm{iii}$ & 1,6 & 0,29 & 0,80 & 8,0 & 0,26 & 67,39 \\
\hline PV15e & $\mathrm{iii}$ & 0,4 & 0,07 & 0,20 & 2,0 & 0,02 & 71,71 \\
\hline PV15f & $\mathrm{ii}$ & 0,4 & 0,30 & 0,84 & 8,4 & 0,28 & 66,92 \\
\hline
\end{tabular}


Os resultados provenientes do $\mathrm{ACl} 318: 2011$ estão na Tabela 6.14. Nesse caso, também se adotou $k=1,00$ no cálculo das alturas efetivas das paredes, ou seja, os apoios nas bases e nos topos impedem apenas as translações horizontais.

Tabela $6.14-\eta_{d, \text { resist }}$ conforme ACI 318:2011.

\begin{tabular}{|c|c|c|c|c|c|c|}
\hline \multicolumn{7}{|c|}{ Resistência última à compressão $-\mathrm{ACl} 318->\mathrm{t}=10 \mathrm{~cm}$} \\
\hline PAREDES & $\mathrm{L}(\mathrm{m})$ & $\mathrm{Ag}\left(\mathrm{cm}^{2}\right)$ & $\mathrm{h}_{\mathrm{e}}(\mathrm{m})$ & $\mathrm{h}_{\mathrm{e}} / \mathrm{t}$ & $\mathrm{L} / \mathrm{t}$ & $\eta \mathrm{d}$, resist $(\mathrm{tf} / \mathrm{m})$ \\
\hline PH13 & 3,2 & 3200,0 & 2,8 & 28,0 & 32,0 & 20,95 \\
\hline PH16a & 2,4 & 2400,0 & 2,8 & 28,0 & 24,0 & 20,95 \\
\hline PH16b & 1,6 & 1600,0 & 2,8 & 28,0 & 16,0 & 20,95 \\
\hline PH22 & 1,2 & 1200,0 & 2,8 & 28,0 & 12,0 & 20,95 \\
\hline PH34a & 1,6 & 1600,0 & 2,8 & 28,0 & 16,0 & 20,95 \\
\hline PH34b & 1,2 & 1200,0 & 2,8 & 28,0 & 12,0 & 20,95 \\
\hline PH40 & 2,8 & 2800,0 & 2,8 & 28,0 & 28,0 & 20,95 \\
\hline PV01a & 3,6 & 3600,0 & 2,8 & 28,0 & 36,0 & 20,95 \\
\hline PV01b & 0,4 & 400,0 & 2,8 & 28,0 & 4,0 & 20,95 \\
\hline PV08a & 2,4 & 2400,0 & 2,8 & 28,0 & 24,0 & 20,95 \\
\hline PV08b & 0,4 & 400,0 & 2,8 & 28,0 & 4,0 & 20,95 \\
\hline PV10 & 2,4 & 2400,0 & 2,8 & 28,0 & 24,0 & 20,95 \\
\hline PV12a & 0,8 & 800,0 & 2,8 & 28,0 & 8,0 & 20,95 \\
\hline PV12b & 1,6 & 1600,0 & 2,8 & 28,0 & 16,0 & 20,95 \\
\hline PV15a & 0,8 & 800,0 & 2,8 & 28,0 & 8,0 & 20,95 \\
\hline PV15b & 0,8 & 800,0 & 2,8 & 28,0 & 8,0 & 20,95 \\
\hline PV15c & 3,2 & 3200,0 & 2,8 & 28,0 & 32,0 & 20,95 \\
\hline PV15d & 1,6 & 1600,0 & 2,8 & 28,0 & 16,0 & 20,95 \\
\hline PV15e & 0,4 & 400,0 & 2,8 & 28,0 & 4,0 & 20,95 \\
\hline PV15f & 0,4 & 400,0 & 2,8 & 28,0 & 4,0 & 20,95 \\
\hline
\end{tabular}

A Tabela 6.15 mostra os resultados obtidos pelo EN 1992:2004, seguindo as expressões do item 3.3.3. Foi considerada excentricidade de $1^{\text {a }}$ ordem $e_{0}=10 / 6 \mathrm{~cm}$.

Tabela $6.15-\eta_{d, \text { resist }}$ conforme EN 1992:2004

\begin{tabular}{|c|c|c|c|c|c|c|c|c|c|}
\hline \multicolumn{7}{|c|}{ Resistência última à compressão - EN $1992->\mathrm{t}=10 \mathrm{~cm}$} \\
\hline PAREDES & Vinculação & $\mathrm{L}(\mathrm{m})$ & $\beta$ & $\mathrm{h}_{\mathrm{e}}(\mathrm{m})$ & $\mathrm{h}_{\mathrm{e}} / \mathrm{t}$ & $\mathrm{e}_{\mathrm{i}}(\mathrm{cm})$ & $\mathrm{e}_{\text {tot }}(\mathrm{cm})$ & $\Phi$ & $\eta$ d,resist $(\mathrm{tf} / \mathrm{m})$ \\
\hline PH13 & II & 3,2 & 0,92 & 2,58 & 25,8 & 0,65 & 2,31 & 0,10 & 16,14 \\
\hline PH16a & III & 2,4 & 0,43 & 1,20 & 12,0 & 0,30 & 1,97 & 0,45 & 75,27 \\
\hline PH16b & III & 1,6 & 0,29 & 0,80 & 8,0 & 0,20 & 1,87 & 0,55 & 92,40 \\
\hline PH22 & I & 1,2 & 1,00 & 2,80 & 28,0 & 0,70 & 2,37 & 0,04 & 6,73 \\
\hline PH34a & III & 1,6 & 0,29 & 0,80 & 8,0 & 0,20 & 1,87 & 0,55 & 92,40 \\
\hline PH34b & II & 1,2 & 0,62 & 1,74 & 17,4 & 0,44 & 2,10 & 0,31 & 51,94 \\
\hline PH40 & II & 2,8 & 0,90 & 2,52 & 25,2 & 0,63 & 2,30 & 0,11 & 18,73 \\
\hline PV01a & III & 3,6 & 0,62 & 1,74 & 17,4 & 0,44 & 2,10 & 0,31 & 51,94 \\
\hline PV01b & II & 0,4 & 0,26 & 0,73 & 7,3 & 0,18 & 1,85 & 0,57 & 95,48 \\
\hline PV08a & III & 2,4 & 0,43 & 1,20 & 12,0 & 0,30 & 1,97 & 0,45 & 75,27 \\
\hline PV08b & II & 0,4 & 0,26 & 0,73 & 7,3 & 0,18 & 1,85 & 0,57 & 95,48 \\
\hline PV10 & II & 2,4 & 0,87 & 2,43 & 24,3 & 0,61 & 2,27 & 0,13 & 22,49 \\
\hline PV12a & III & 0,8 & 0,14 & 0,40 & 4,0 & 0,10 & 1,77 & 0,65 & 107,78 \\
\hline PV12b & II & 1,6 & 0,75 & 2,09 & 20,9 & 0,52 & 2,19 & 0,22 & 37,18 \\
\hline PV15a & II & 0,8 & 0,42 & 1,19 & 11,9 & 0,30 & 1,96 & 0,46 & 75,87 \\
\hline PV15b & III & 0,8 & 0,14 & 0,40 & 4,0 & 0,10 & 1,77 & 0,65 & 107,78 \\
\hline PV15c & III & 3,2 & 0,57 & 1,59 & 15,9 & 0,40 & 2,06 & 0,35 & 58,74 \\
\hline PV15d & III & 1,6 & 0,29 & 0,80 & 8,0 & 0,20 & 1,87 & 0,55 & 92,40 \\
\hline PV15e & III & 0,4 & 0,10 & 0,28 & 2,8 & 0,07 & 1,74 & 0,65 & 108,78 \\
\hline PV15f & II & 0,4 & 0,26 & 0,73 & 7,3 & 0,18 & 1,85 & 0,57 & 95,48 \\
\hline
\end{tabular}


Tabela $6.16-\eta_{d, \text { resist }}$ conforme NBR 16055:2012

\begin{tabular}{|c|c|c|c|c|c|c|c|c|c|}
\hline \multicolumn{10}{|c|}{ Resistência última à compressão - NBR $16055->\mathrm{t}=10 \mathrm{~cm}$} \\
\hline PAREDES & Vinculacões & $\mathrm{L}(\mathrm{m})$ & $\beta=\mathrm{h} / \mathrm{L}$ & $\mathrm{h}_{\mathrm{e}}(\mathrm{m})$ & $\mathrm{h} / \mathrm{t}$ & $\lambda$ & $\mathrm{k} 1$ & $\mathrm{k} 2$ & $\eta \mathrm{hdresist}(\mathrm{tf} / \mathrm{m})$ \\
\hline PH13 & II & 3,2 & 0,88 & 2,58 & 25,8 & 89,4 & 2,55 & 0,10 & 32,81 \\
\hline PH16a & III & 2,4 & 1,17 & 1,20 & 12,0 & 41,6 & 1,19 & 0,00 & 59,52 \\
\hline PH16b & III & 1,6 & 1,75 & 0,80 & 8,0 & 27,7 & 0,79 & 0,00 & 59,52 \\
\hline PH22 & $\mathrm{I}$ & 1,2 & 2,33 & 2,80 & 28,0 & 97,0 & 2,77 & 0,31 & 18,14 \\
\hline PH34a & III & 1,6 & 1,75 & 0,80 & 8,0 & 27,7 & 0,79 & 0,00 & 59,52 \\
\hline PH34b & II & 1,2 & 2,33 & 1,74 & 17,4 & 60,4 & 1,73 & 0,00 & 59,52 \\
\hline PH40 & II & 2,8 & 1,00 & 2,52 & 25,2 & 87,3 & 2,49 & 0,04 & 42,84 \\
\hline PV01a & III & 3,6 & 0,78 & 1,74 & 17,4 & 60,4 & 1,73 & 0,00 & 59,52 \\
\hline PV01b & II & 0,4 & 7,00 & 0,84 & 8,4 & 29,1 & 0,83 & 0,00 & 59,52 \\
\hline PV08a & III & 2,4 & 1,17 & 1,20 & 12,0 & 41,6 & 1,19 & 0,00 & 59,52 \\
\hline PV08b & II & 0,4 & 7,00 & 0,84 & 8,4 & 29,1 & 0,83 & 0,00 & 59,52 \\
\hline PV10 & II & 2,4 & 1,17 & 2,43 & 24,3 & 84,3 & 2,41 & 0,00 & 54,06 \\
\hline PV12a & III & 0,8 & 3,50 & 0,40 & 4,0 & 13,9 & 0,40 & 0,00 & 59,52 \\
\hline PV12b & II & 1,6 & 1,75 & 2,09 & 20,9 & 72,4 & 2,07 & 0,00 & 59,52 \\
\hline PV15a & II & 0,8 & 3,50 & 1,19 & 11,9 & 41,1 & 1,17 & 0,00 & 59,52 \\
\hline PV15b & III & 0,8 & 3,50 & 0,40 & 4,0 & 13,9 & 0,40 & 0,00 & 59,52 \\
\hline PV15c & III & 3,2 & 0,88 & 1,59 & 15,9 & 54,9 & 1,57 & 0,00 & 59,52 \\
\hline PV15d & III & 1,6 & 1,75 & 0,80 & 8,0 & 27,7 & 0,79 & 0,00 & 59,52 \\
\hline PV15e & III & 0,4 & 7,00 & 0,20 & 2,0 & 6,9 & 0,20 & 0,00 & 59,52 \\
\hline PV15f & II & 0,4 & 7,00 & 0,84 & 8,4 & 29,1 & 0,83 & 0,00 & 59,52 \\
\hline
\end{tabular}

Os resultados obtidos pela NBR 16055:2012, quanto às resistências últimas à compressão, das paredes estudadas, são apresentados na Tabela 6.16, seguindo as expressões do item 3.3.4. O módulo de elasticidade do aço foi considerado $E_{s}=$ $210 \mathrm{GPa}$, e a taxa geométrica da armadura vertical de $\rho=0,001$.

Finalmente, a verificação ao pré-dimensionamento é apresentada na Tabela 6.17 , onde $\eta_{C d, \text { est }}$ é comparada com $\eta_{d \text {,resist }}$. Abaixo do nome de cada norma utilizada para tal verificação são indicados seus respectivos coeficientes de majoração das cargas permanentes $\gamma_{g}$ e das cargas variáveis $\gamma_{q}$.

Ao analisar a Tabela 6.17, fica claro que tanto o modelo de distribuição de cargas verticais quanto a norma utilizada são determinantes ao se fazer o prédimensionamento. As células pintadas em vermelho significam que as paredes não puderam ser pré-dimensionadas com espessura de $10 \mathrm{~cm}$ e, portanto, devem ter essa dimensão aumentada. No caso das paredes divididas por trechos, considerouse a menor resistência última à compressão entre as calculadas.

A hipótese de que a parede trabalhe com dois planos de flexão, por ter vinculações em todas suas extremidades, resulta em maior resistência última à compressão. Esse fato fica claro comparando os resultados da antiga norma australiana AS 3600:2001, a qual não considerava vinculações laterais, com a 
recente AS 3600:2009, cuja expressão de resistência última à compressão engloba este efeito por meio do cálculo da altura efetiva da parede; em mais da metade dos casos o pré-dimensionamento pela AS 3600:2009 é admitido, enquanto que pela AS 3600:2001 a grande maioria dos casos não é satisfeito.

Outra evidência são os resultados obtidos pelo ACI 318:2011; nenhuma parede pôde ser pré-dimensionada com espessura de $10 \mathrm{~cm}$. O AS 3600:2001, apesar de não considerar vinculações laterais igualmente faz o $\mathrm{ACl}$ 318:2011, diferencia-se na consideração da distância entre paredes transversais (quando essas existirem) no cálculo da altura efetiva da parede. Quando a distância entre paredes transversais for menor que a altura da parede em análise, a altura efetiva da parede é igual a distância horizontal entre os eixos das paredes transversais. Desta maneira a esbeltez da parede é diminuída e a resistência aumentada. Nessas situações o AS 3600:2001 apresenta resultados maiores que o ACl 318:2001, como ocorre no caso da parede $\mathrm{PH} 34$.

Tabela $6.17-\eta_{C d, \text { est }} \times \eta_{d, \text { resist }}$ para paredes com $10 \mathrm{~cm}$ de espessura.

\begin{tabular}{|c|c|c|c|c|c|c|c|c|c|c|c|c|c|c|c|}
\hline & & & & & & \multicolumn{2}{|c|}{ NBR 16055:2012 } & \multicolumn{2}{|c|}{ EN 1992:2004 } & \multicolumn{2}{|c|}{$\mathrm{ACl} 318: 2011$} & \multicolumn{2}{|c|}{ AS $3600: 2001$} & \multicolumn{2}{|c|}{ AS 3600:2009 } \\
\hline & & & & & & $\gamma_{\mathrm{g}}$ & $\gamma_{a}$ & $\gamma_{\mathrm{g}}$ & $\gamma_{q}$ & $\gamma_{\mathrm{g}}$ & $\gamma_{q}$ & $\gamma_{\mathrm{g}}$ & $\gamma_{q}$ & $\gamma_{\mathrm{g}}$ & $\gamma_{a}$ \\
\hline & & & & & & 1,40 & 1,40 & 1,35 & 1,50 & 1,20 & 1,60 & 1,20 & 1,60 & 1,20 & 1,60 \\
\hline PAR. & $L(m)$ & $\mathrm{C}_{\mathrm{AH}}$ & MODELO & $\mathrm{G}(\mathrm{tf})$ & $Q$ (tf) & $\eta$ Cd,est & $\eta$ d, resist & $\eta$ Cd,est & $\eta d$, resist & $\eta$ Cd,est & $\eta$ d, resist & $\eta$ Cd,est & $\eta d$,resist & $\eta$ Cd,est & $\eta d$,resist \\
\hline \multirow{4}{*}{ PH13 } & \multirow{4}{*}{3,2} & \multirow{4}{*}{1,35} & PIS & 65,91 & 13,33 & 46,95 & \multirow{4}{*}{32,81} & 46,12 & \multirow{4}{*}{16,14} & 42,50 & \multirow{4}{*}{20,95} & 42,50 & \multirow{4}{*}{15,55} & 42,50 & \multirow{4}{*}{24,06} \\
\hline & & & GIP & 59,19 & 9,53 & 40,71 & & 39,86 & & 36,51 & & 36,51 & & 36,51 & \\
\hline & & & MPT & 62,95 & 10,84 & 43,72 & & 42,84 & & 39,30 & & 39,30 & & 39,30 & \\
\hline & & & MEF & 62,22 & 10,69 & 43,19 & & 42,33 & & 38,83 & & 38,83 & & 38,83 & \\
\hline \multirow{4}{*}{ PH16 } & \multirow{4}{*}{4,0} & \multirow{4}{*}{1,39} & PIS & 68,04 & 11,16 & 38,57 & \multirow{4}{*}{59,52} & 37,77 & \multirow{4}{*}{75,27} & 34,61 & \multirow{4}{*}{20,95} & 34,61 & & 34,61 & \\
\hline & & & GIP & 83,23 & 15,91 & 48,28 & & 47,38 & & 43,59 & & 43,59 & 305 & 43,59 & 010 \\
\hline & & & MPT & 79,83 & 14,12 & 45,75 & & 44,85 & & 41,18 & & 41,18 & 30,53 & 41,18 & 61,63 \\
\hline & & & MEF & 78,88 & 13,90 & 45,18 & & 44,29 & & 40,66 & & 40,66 & & 40,66 & \\
\hline & & & PIS & 24,73 & 5,20 & 44,05 & & 43,29 & & 39,94 & & 39,94 & & 39,94 & \\
\hline $\mathrm{PH} 2$ & 12 & 126 & GIP & 24,73 & 5,20 & 44,05 & 1811 & 43,29 & 672 & 39,94 & 2095 & 39,94 & 1555 & 39,94 & 155 \\
\hline PHZL & 1,2 & 1,20 & MPT & 24,73 & 5,20 & 44,05 & 18,14 & 43,29 & 0,13 & 39,94 & 20,95 & 39,94 & 10,35 & 39,94 & 15,35 \\
\hline & & & MEF & 24,73 & 5,20 & 44,05 & & 43,29 & & 39,94 & & 39,94 & & 39,94 & \\
\hline & & & PIS & 40,11 & 4,59 & 29,85 & & 29,11 & & 26,46 & & 26,46 & & 26,46 & \\
\hline D & 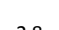 & 92 & GIP & 47,37 & 6,85 & 36,20 & 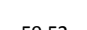 & 35,40 & 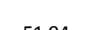 & 32,34 & (200 & 32,34 & בתרינ & 32,34 & 500 \\
\hline PH34 & 2,8 & 1,34 & MPT & 48,41 & 7,32 & 37,21 & 59,52 & 36,41 & 51,94 & 33,29 & 20,95 & 33,29 & (5, & 33,29 & 50,09 \\
\hline & & & MEF & 49,17 & 7,72 & 37,99 & & 37,19 & & 34,04 & & 34,04 & & 34,04 & \\
\hline & & & PIS & 40,97 & 3,67 & 29,81 & & 29,01 & & 26,25 & & 26,25 & & 26,25 & \\
\hline DHO & 20 & 120 & GIP & 50,83 & 8,54 & 39,65 & 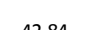 & 38,84 & 1077 & 35,62 & 200 & 35,62 & 155 & 35,62 & 262 \\
\hline $\mathrm{PH} 40$ & 2,8 & 1,34 & MPT & 49,63 & 7,85 & 38,39 & 42,84 & 37,58 & $18, / 3$ & 34,40 & 20,95 & 34,40 & 15,55 & 34,40 & 26,28 \\
\hline & & & MEF & 50,19 & 8,08 & 38,91 & & 38,10 & & 34,89 & & 34,89 & & 34,89 & \\
\hline & & & PIS & 64,92 & 8,28 & 35,65 & & 34,80 & & 31,70 & & 31,70 & & 31,70 & \\
\hline DY01 & 10 & 130 & GIP & 73,99 & 11,91 & 41,83 & 5052 & 40,96 & 510 & 37,51 & 2005 & 37,51 & 155 & 37,51 & 500 \\
\hline PVOI & 4,0 & 1,39 & MPT & 77,63 & 13,00 & 44,13 & 5,52 & 43,23 & 51,94 & 39,64 & 20,95 & 39,64 & 15,55 & 39,64 & 50,09 \\
\hline & & & MEF & 77,93 & 13,08 & 44,32 & & 43,42 & & 39,81 & & 39,81 & & 39,81 & \\
\hline & & & PIS & 52,35 & 9,58 & 41,36 & & 40,57 & & 37,28 & & 37,28 & & 37,28 & \\
\hline PYos & 28 & 134 & GIP & 54,65 & 8,87 & 42,41 & 5952 & 41,53 & 752 & 38,05 & 2095 & 38,05 & 155 & 38,05 & 6163 \\
\hline PVuo & 2,0 & 1,34 & MPT & 55,31 & 9,46 & 43,25 & 29,כ2 & 42,38 & 13,27 & 38,87 & 20,93 & 38,87 & 10,30 & 38,87 & 01,03 \\
\hline & & & MEF & 55,52 & 9,44 & 43,38 & & 42,50 & & 38,98 & & 38,98 & & 38,98 & \\
\hline & & & PIS & 63,26 & 16,06 & 60,94 & & 60,08 & & 55,76 & & 55,76 & & 55,76 & \\
\hline مומר & 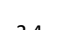 & 20 & GIP & 49,94 & 9,55 & 45,70 & 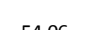 & 44,85 & 0 & 41,27 & & 41,27 & 155 & 41,27 & 0 \\
\hline PV10 & 2,4 & 1,32 & MPT & 48,94 & 8,99 & 44,51 & 54,06 & 43,66 & 22,49 & 40,12 & 20,95 & 40,12 & 15,55 & 40,12 & 29,41 \\
\hline & & & MEF & 47,87 & 8,71 & 43,47 & & 42,63 & & 39,17 & & 39,17 & & 39,17 & \\
\hline & & & PIS & 46,38 & 8,82 & 42,41 & & 41,62 & & 38,28 & & 38,28 & & 38,28 & \\
\hline בו1קס & 2 & 132 & GIP & 50,85 & 9,45 & 46,32 & 5057 & 45,45 & 3718 & 41,78 & 200 & 41,78 & 155 & 41,78 & 0058 \\
\hline$P V 12$ & 2,4 & 1,32 & MPT & 47,89 & 8,37 & 43,22 & 59,52 & 42,36 & 3,18 & 38,88 & 20,95 & 38,88 & 15,55 & 38,88 & 40,58 \\
\hline & & & MEF & 47,05 & 8,14 & 42,39 & & 41,55 & & 38,12 & & 38,12 & & 38,12 & \\
\hline & & & PIS & 124,71 & 20,79 & 43,57 & & 42,68 & & 39,12 & & 39,12 & & 39,12 & \\
\hline PY15 & 72 & 154 & GIP & 121,81 & 17,60 & 41,74 & 5952 & 40,82 & 5874 & 37,29 & 2090 & 37,29 & 155 & 37,29 & 5380 \\
\hline PVIJ & , & 1,34 & MPT & 125,31 & 18,99 & 43,21 & 59,52 & 42,27 & 38,14 & 38,66 & 20,95 & 38,66 & 13,35 & 38,66 & 33,89 \\
\hline & & & MEF & 130,53 & 20,64 & 45,26 & & 44,31 & & 40,56 & & 40,56 & & 40,56 & \\
\hline
\end{tabular}


Em três casos, para uma mesma parede, o pré-dimensionamento é admitido para alguns modelos de distribuição de cargas verticais, mas para outros não. A parede PV12, quando verificada pelo AS 3600:2009, não pode ser pré-dimensionada quando utilizado o GIP para distribuir cargas verticais, enquanto que a solicitação de cálculo obtida pelos outros modelos é menor que a resistência última à compressão, satisfazendo desta maneira a condição ao pré-dimensionamento. O procedimento PIS influencia no pré-dimensionamento das paredes PV10 e PH40. No primeiro caso, a espessura da parede deve ser aumentada quando a verificação é feita pela NBR 16055:2012. No segundo caso, o PIS é o único modelo de cálculo de distribuição de cargas verticais que possibilita o pré-dimensionamento pela AS 3600:2009.

Um aspecto comum entre as normas NBR 16055:2012, EN 1992:2004 e AS 3600:2009, além de fornecerem, em geral, maiores valores de resistência última à compressão em relação às outras aqui estudadas, a resistência é penalizada ao atingir determinados limites de esbeltez, estabelecidos pelas respectivas normas. As paredes PH13, PH22 e PH40 têm esbeltez maior que 25, o que equivale dizer $\lambda>$ 86. A norma brasileira admite índice de esbeltez até 120 , no entanto, quando esse índice atinge 86, a resistência última à compressão decresce consideravelmente, por meio do coeficiente $k_{2}$ como pode ser visto no gráfico da Figura 3.13 no item 3.3.4. A norma europeia limita a esbeltez em 25 , e por essa razão as resistências das três paredes citadas caem bastante. O AS3600:2009 limita a esbeltez em 30, no entanto, quando essa atinge 25 , os valores de resistência também tendem a decrescer mais rapidamente, embora sejam maiores que os obtidos pelo EN 1992:2004. Isso justifica o fato de que as resistências de paredes com esbeltez maior que 25, no caso as paredes $\mathrm{PH} 13, \mathrm{PH} 22$ e $\mathrm{PH} 40$, têm valores maiores primeiramente pela NBR16055:2012, em seguida pela AS 3600:2009 e por último pelo EN 1992:2004. Observa-se que essa comparação foi feita apenas nas normas que consideram vinculações nas quatro bordas das paredes.

A norma brasileira é a que fornece maiores resultados de resistência última à compressão, por considerar vinculações nas quatro extremidades das paredes. Além disso, admite limites de esbeltez maiores em relação às outras, no entanto com considerável diminuição da resistência última à compressão devido às 
instabilidades localizadas (efeitos de $2^{\mathrm{a}}$ ordem), quando 0 índide de esbeltez ultrapassa o limite de 86 .

As diferenças de resultados são evidentes, o que torna a expressão de cada norma determinante ao dimensionar uma parede de concreto armado.

No estudo proposto, nota-se que nem todas as paredes são prédimensionadas com $10 \mathrm{~cm}$ de espessura. Conclui-se que é necessário aumentar as suas espessuras, de forma a obter o pré-dimensionamento em $100 \%$ dos casos. Observa-se que é recomendável definir uma mesma espessura para todas as paredes de um edifício construído pelo sistema Paredes de Concreto, visando facilitar a fabricação das formas, padronizar geometrias, otimizar a execução das paredes e por fim garantir maior qualidade e produtividade.

De acordo com as conclusões tomadas a partir dos resultados apresentados na Tabela 6.17, a espessura das paredes do edifício exemplo foi aumentada para 12 $\mathrm{cm}$. Com o objetivo de evitar o excesso de tabelas, os resultados quanto à distribuição de cargas verticais, pelos modelos, PIS, GIP, MPT e MEF, considerando agora espessura de $12 \mathrm{~cm}$ para as paredes do edifício exemplo, apresentam-se nas Tabelas 6B-1 a 6B-6 do Anexo B, que são análogas às Tabelas 6.4 a 6.9, respectivamente. A comparação desses resultados é apresentada também no Anexo $\mathrm{B}$, na Tabela 6B-7 a qual é análoga à Tabela 6.10. Também no Anexo $\mathrm{B}$, apresentam-se os diagramas de $N_{k, \text { vert }}$ das paredes PH13, PH16 e PH34 na Figura 6B-1, análoga à Figura 6.10, e os diagramas de $N_{k, \text { vert }}$ das paredes PV08, PV12 e PV15 na Figura 6B-2, análoga à Figura 6.11.

O cálculo da resistência última à compressão, considerando as paredes com espessura de $12 \mathrm{~cm}$, também é apresentado no Anexo B, nas Tabelas 6B-8 a 6B-12, as quais são análogas às Tabelas 6.12 a 6.16.

A Tabela 6.18 resume os resultados para a verificação ao prédimensionamento das paredes PH13, PH16, PH22, PH34, PH40, PV01, PV08, PV10, PV12 e PV15, agora as considerando com espessura de $12 \mathrm{~cm}$.

Conclui-se novamente que a norma brasileira detém os maiores valores de resistência última à compressão quando comparada com as normas americana, europeia e australiana. Fica clara a grande perda de resistência no caso do código europeu quando as paredes ultrapassam o limite de esbeltez estabelecido (no caso do código europeu essa limite é igual a 25). Nesses casos, os valores de resistência 
última à compressão calculados ficam abaixo do AS 3600:2009, o qual limita a esbeltez em 30.

Pela grande diferença de resultados obtidos pelas normas, ressalta-se a importância de se continuar investigando, através de ensaios experimentais e modelagens numéricas, quais hipóteses são as mais adequadas para o cálculo da resistência última à compressão de paredes de concreto armado. A expressão da norma brasileira se demonstrou mais arrojada, porém ao mesmo tempo, é coerente com as outras ao penalizar consideravelmente a resistência última à compressão a partir de $\lambda=86$.

Tabela $6.18-\eta_{C d, e s t} \times \eta_{d, \text { resist }}$ para paredes com $12 \mathrm{~cm}$ de espessura.

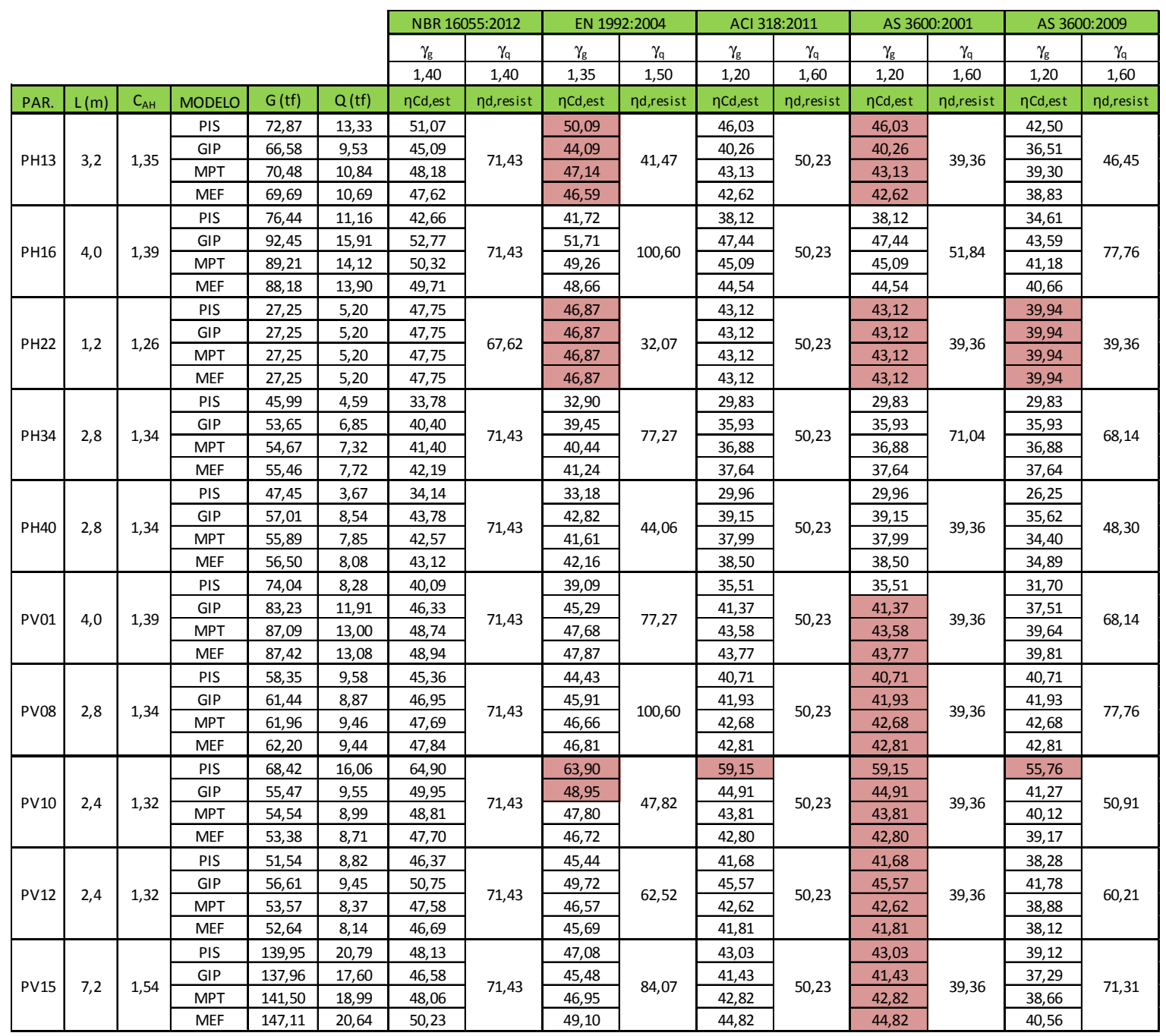

Como um dos objetivos deste trabalho é apresentar o dimensionamento das paredes do edifício exemplo, pela NBR 16055, suas espessuras são adotadas igual a $12 \mathrm{~cm}$, pelo fato da condição $\eta_{C d, \text { est }} \leq \eta_{d, \text {,resist }}$, apresentada na Tabela 6.18, estar satisfeita quando considerada a norma brasileira. 


\subsection{Esforços solicitantes devido às ações horizontais - edifício exemplo}

A seguir são apresentados e comparados os diagramas dos esforços característicos, momento fletor, força cortante e força normal, obtido pelos modelos MEF e MPT, das paredes PH13, PH16, PH34, PV08, PV12 e PV15, considerando apenas as ações horizontais. Nas paredes horizontais (PHxx), os esforços foram obtidos considerando as forças do vento e devido ao desaprumo na direção $X$ e no sentido $0^{\circ}$. Nas paredes verticais ( $P V y y$ ), os esforços foram obtidos considerando as ações horizontais na direção $Y$ e no sentido $90^{\circ}$. Os esforços seguem a notação vetorial, considerando o eixo global de coordenadas, conforme Figura 6.2.

O modelo adotado como referência para a comparação de resultados é o MEF, por ser o mais refinado.

\subsubsection{Resultados da parede $\mathrm{PH} 13$}

A Figura 6.21 mostra os diagramas característicos dos esforços solicitantes obtidos pelas ações horizontais na direção $\mathrm{X}$ e no sentido $0^{\circ}$ da parede $\mathrm{PH} 13$.
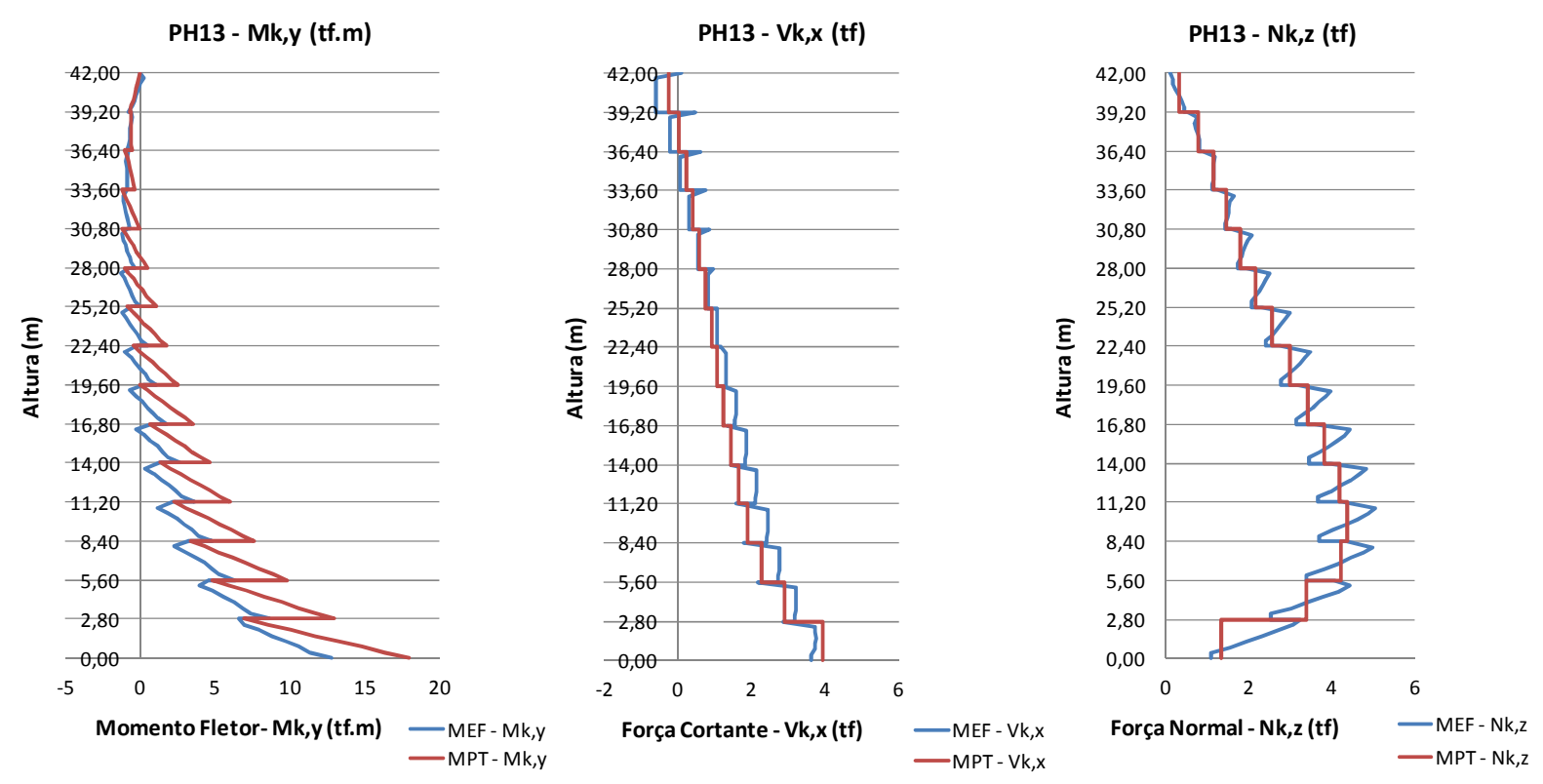

Figura 6.21 - Diagramas de $M_{k, y}, V_{k, x}$ e $N_{k, z}$ da parede $\mathrm{PH} 13$.

O diagrama de momento fletor obtido pelo MPT tende ao comportamento visto no diagrama obtido pelo MEF. O maior $M_{k, y}$ observado nos modelos, ocorre 
ao nível da fundação, sendo 12,78 tf.m o valor obtido pelo MEF e 17,95 tf.m o valor obtido pelo MPT, ou seja, 40,45\% maior que o $M_{k, y}$ obtido pelo modelo de cascas.

O diagrama de força cortante é muito parecido entre os dois modelos. No primeiro tramo da parede, ou seja, entre o Térreo e o $1^{\circ}$ Pavimento, ocorre a maior força cortante, sendo 3,75 tf o valor obtido pelo MEF e 3,93 tf o valor obtido pelo MPT, cuja diferença é de apenas 4,87\% maior em relação ao MEF.

Como comentado no capítulo cinco, para o caso do edifício estudo preliminar, os diagramas de força normal entres os dois modelos são diferentes, no entanto mostram um mesmo comportamento. Neste caso da parede PH13 do EE, a maior força normal ocorre no $4^{\circ}$ tramo dela, sendo 5,05 tf o valor obtido pelo MEF e 4,36 tf a força normal obtida pelo MPT, uma diferença de $13,68 \%$ aquém do modelo de referência.

\subsubsection{Resultados da parede PH16}

Os resultados dos esforços solicitantes característicos da parede PH16, considerando somente as ações horizontais, são apresentados na Figura 6.22.
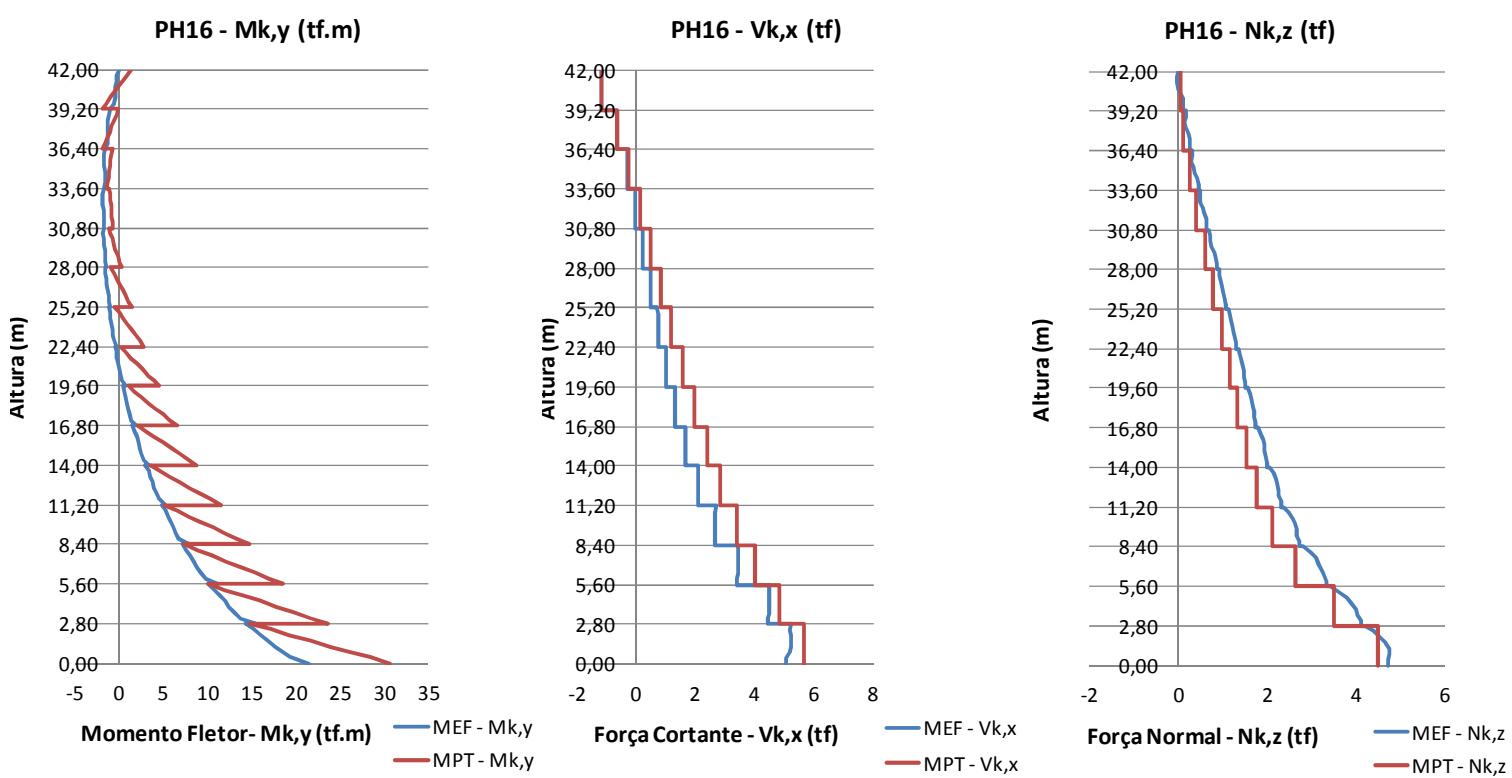

Figura 6.22 - Diagramas de $M_{k, y}, V_{k, x}$ e $N_{k, z}$ da parede $\mathrm{PH} 16$.

Nota-se que os resultados são semelhantes aos obtidos no capítulo cinco e no item anterior. As curvas dos diagramas entre os dois modelos tendem ao mesmo comportamento. 
A Tabela 6.19 compara o máximo de cada esforço obtido pelo MEF e MPT, apontando o nível onde eles ocorrem e a diferença em porcentagem, tomando como referência o modelo MEF.

Tabela 6.19 - Comparação entre os esforços máximos característicos da PH16.

\begin{tabular}{|c|c|c|c|c|}
\hline \multicolumn{5}{|c|}{ Comparação dos esforços máximos da PH16 } \\
\hline Esforço & nível & MEF & MPT & $\%$ \\
\hline $\mathrm{Mk}, \mathrm{y}$ & 0,00 & 21,37 & 30,60 & 43,21 \\
\hline $\mathrm{Vk}, \mathrm{x}$ & 2,80 & 5,25 & 5,67 & 7,86 \\
\hline $\mathrm{Nk}, \mathrm{z}$ & 0,80 & 4,76 & 4,49 & $-5,74$ \\
\hline
\end{tabular}

\subsubsection{Resultados da parede PH34}

A Figura 6.23 apresenta os diagramas característicos da parede $\mathrm{PH} 34$.
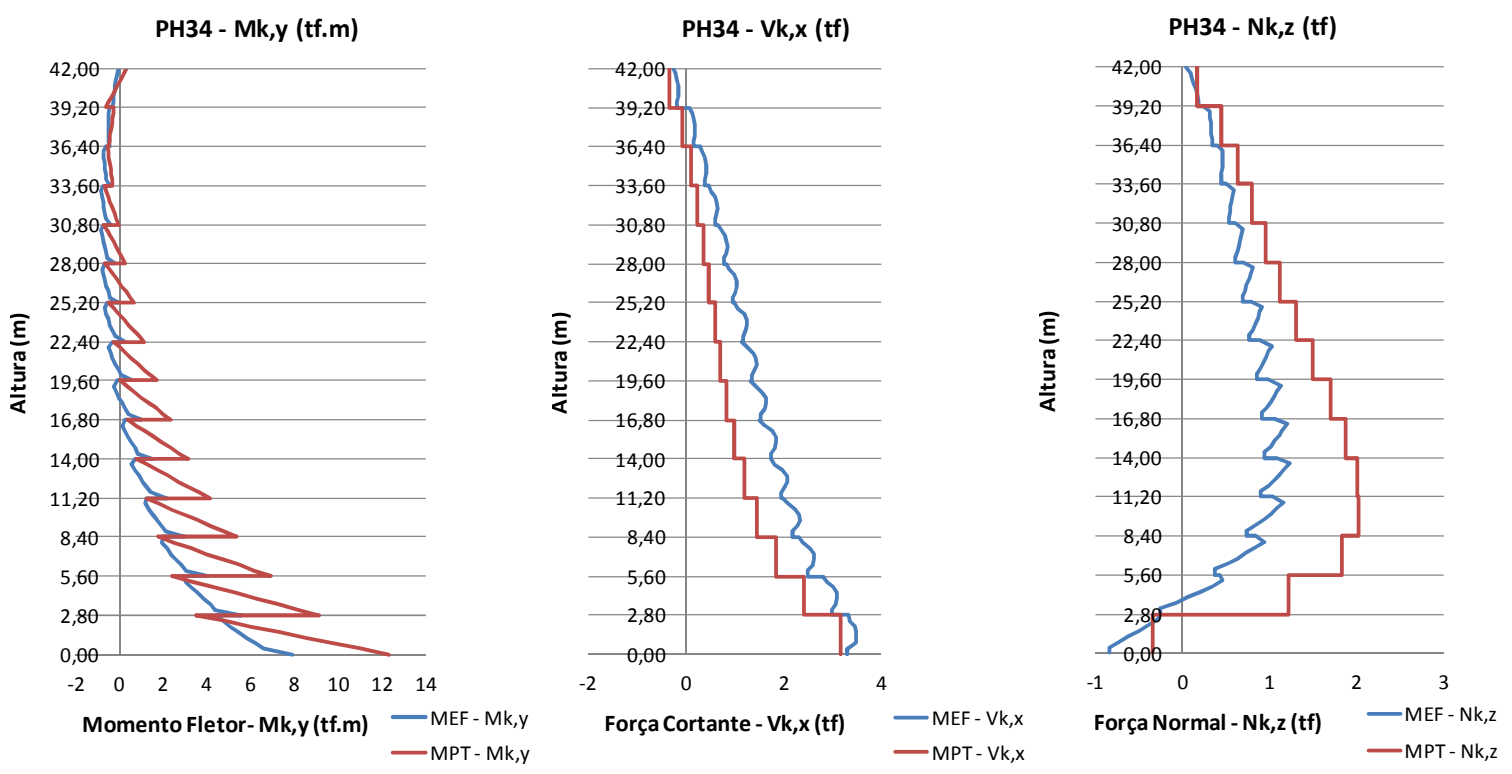

Figura 6.23 - Diagramas de $M_{k, y}, V_{k, x}$ e $N_{k, z}$ da parede PH34.

O diagrama de momentos fletor apresenta tendência semelhante entre os dois modelos, sendo que os valores obtidos pelo MPT em geral são maiores aos obtidos pelo MEF, o que faz, neste caso, o modelo de barras ser a favor da segurança. O maior $M_{k, y}$ ocorre ao nível da fundação, sendo 7,90 tf.m 0 valor obtido pelo MEF e 12,33 tf.m o valor obtido pelo MPT (uma diferença de 56,21\%).

O modelo de cascas tem máxima força cortante igual a 3,49 tf, enquanto que o MPT tem máxima força cortante igual a 3,16 tf, significando $9,54 \%$ menor que o MEF. Esses dois máximos ocorrem ao nível 1,20 m. 
A maior força normal obtida pelo MEF ocorre ao nível 13,60 m, com valor de 1,23 tf. Este esforço correspondente ao modelo MPT, no mesmo nível, vale 2,01 ff (63,05\% maior). Ressalta-se o pequeno valor da força normal característica obtida apenas pelas ações horizontais, conforme diagrama da Figura 6.23 (maior valor é $\left.N_{k, z}=2,01 \mathrm{tf}\right)$, quando comparada com a força normal característica obtida apenas pelas cargas verticais, conforme diagrama da Figura 6B-1 do Anexo B ( $N_{k, z}=-44,05 \mathrm{tf}$ ao nível 13,60 m, nível correspondente à maior força normal obtida quando consideradas apenas as ações horizontais e o modelo MPT).

\subsubsection{Resultados da parede PV08}

A Figura 6.24 mostra os diagramas característicos da parede PV08, ao longo de sua altura.
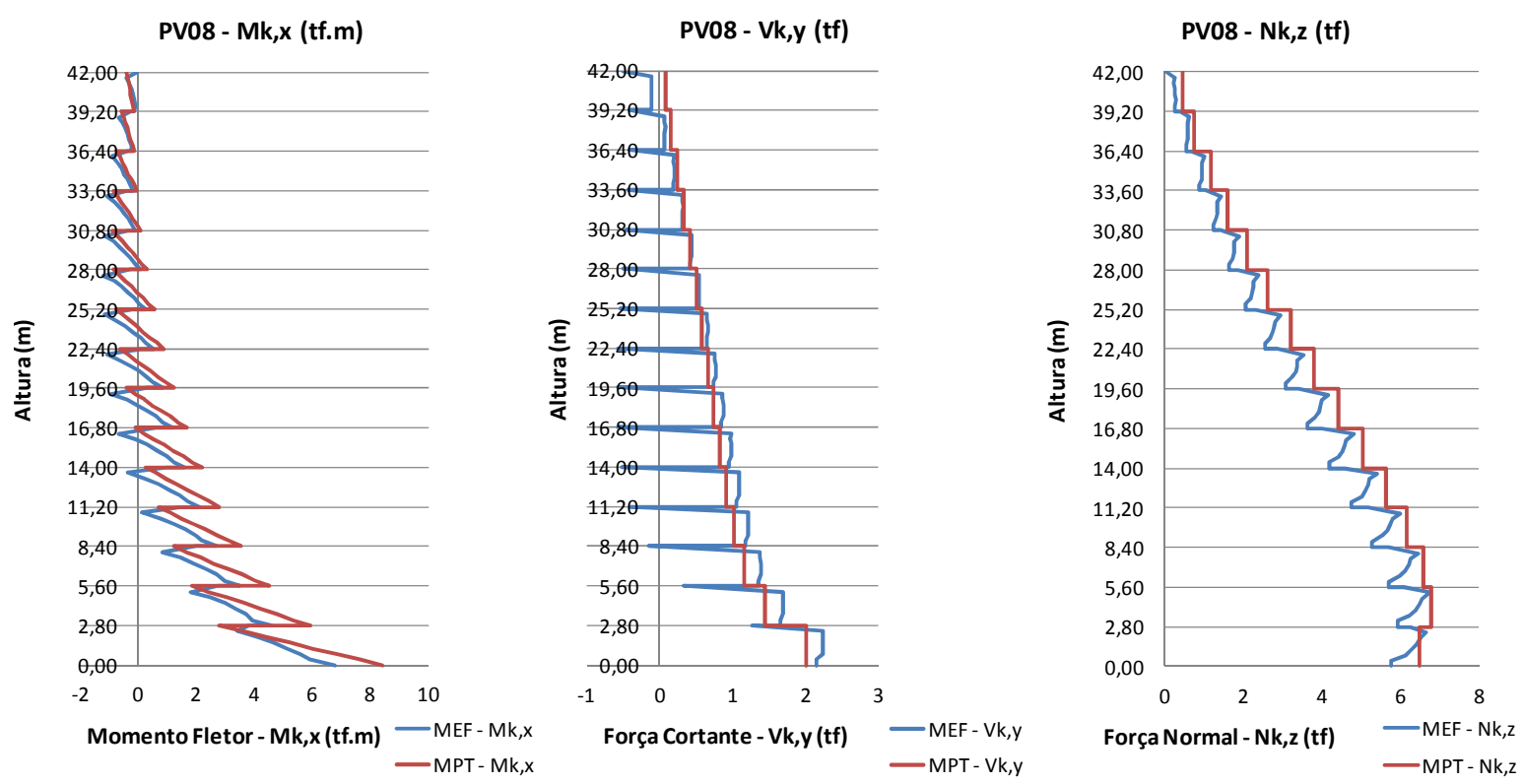

Figura 6.24 - Diagramas de $M_{k, x}, V_{k, y}$ e $N_{k, z}$ da parede PV08.

As curvas obtidas pelos dois modelos, para os três casos de esforços são parecidas. Isso reforça 0 fato dos dois modelos apresentarem comportamento semelhante, apesar de um discretizar as paredes com elementos de casca e o outro com elementos de barra.

A Tabela 6.20 apresenta o valor máximo de cada esforço (obtido pelos dois modelos) e o nível em que cada máximo ocorre. 
Tabela 6.20 - Comparação entre os esforços máximos característicos da PV08.

\begin{tabular}{|c|c|c|c|c|}
\hline \multicolumn{5}{|c|}{ Comparação dos esforços máximos da PV08 } \\
\hline Esforço & nível & MEF & MPT & $\%$ \\
\hline $\mathrm{Mk}, \mathrm{x}$ & 0,00 & 6,77 & 8,44 & 24,64 \\
\hline $\mathrm{Vk}, \mathrm{y}$ & 1,60 & 2,25 & 2,02 & $-10,27$ \\
\hline $\mathrm{Nk}, \mathrm{z}$ & 5,20 & 6,74 & 6,79 & 0,72 \\
\hline
\end{tabular}

\subsubsection{Resultados da parede PV12}

Os diagramas da parede PV12 são apresentados na Figura 6.25.
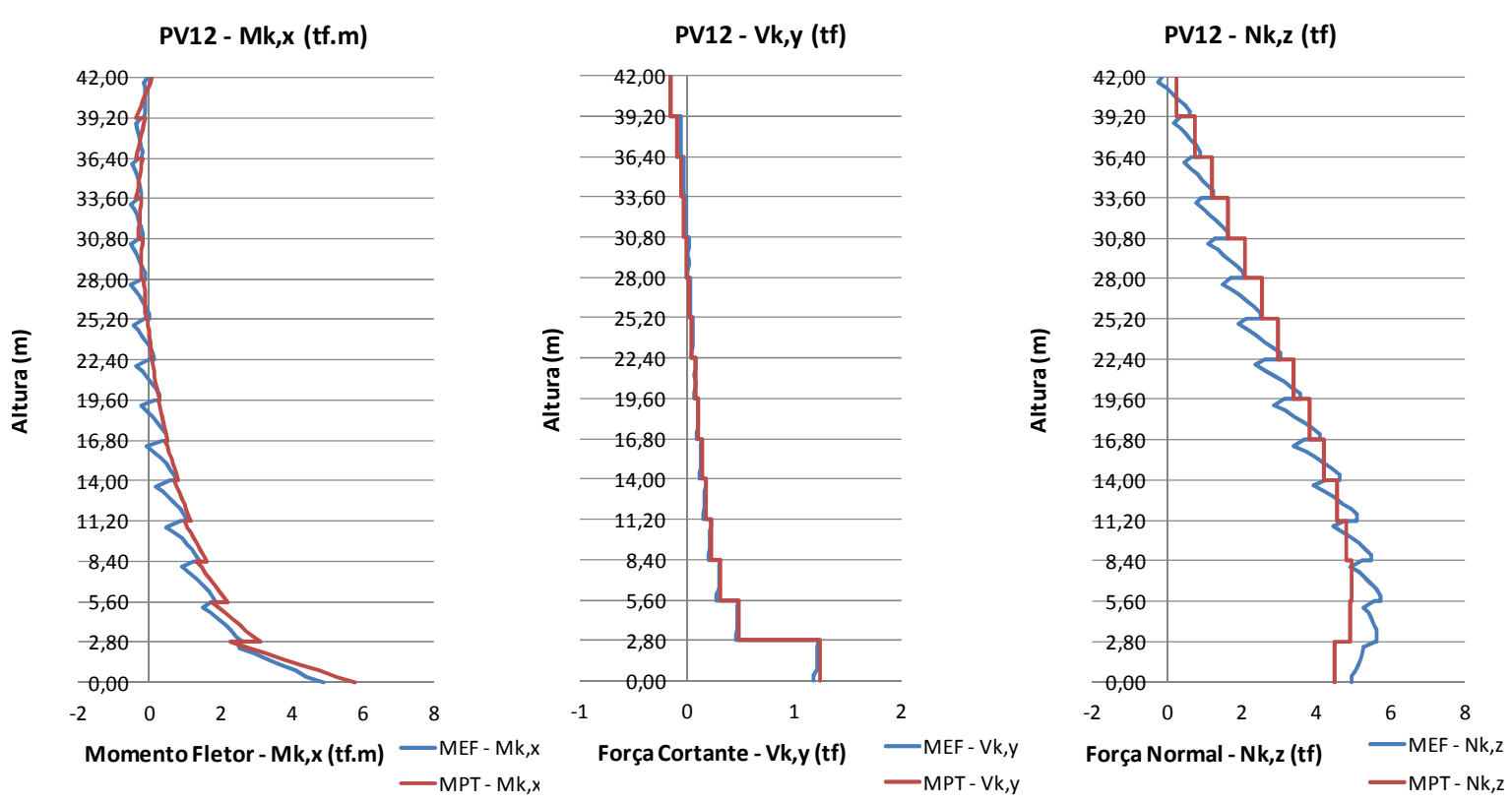

Figura 6.25 - Diagramas de $M_{k, x}, V_{k, y}$ e $N_{k, z}$ da parede PV12.

A diferença do maior momento fletor, entre os modelos MPT e MEF, é de $17,73 \%$. O valor obtido pelo MPT é de 5,77 tf.m, e o valor obtido pelo MEF é de 4,90 tf.m, obtidos ao nível da fundação.

O diagrama de força cortante resultante dos dois modelos é praticamente coincidente ao longo de toda altura da parede. Os maiores resultados ocorrem no primeiro tramo da parede, sendo 1,23 tf o valor obtido pelo MEF, e 1,25 tf o valor obtido pelo MPT, significando diferença de mais 1,60\%.

A maior força normal verificada nos dois modelos ocorre ao nível 5,60m. Conforme diagrama da Figura 6.25, o MPT tem maior valor de força normal igual a 4,97 tf, a qual é 13,43\% menor que o valor obtido pelo MEF, que é de 5,74 tf. 


\subsubsection{Resultados da parede PV15}

A Figura 6.26 apresenta os diagramas característicos da parede PV15.
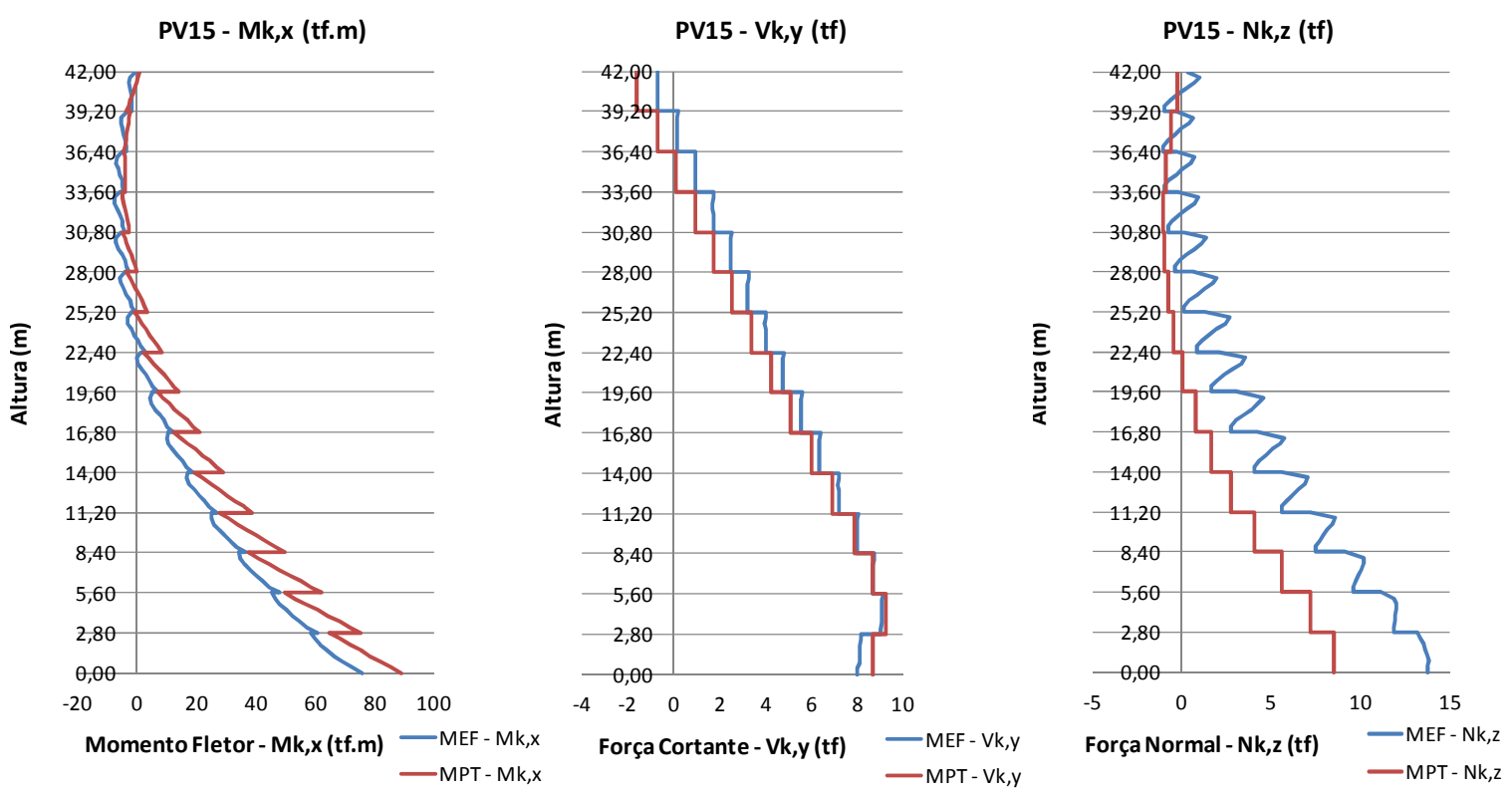

Figura 6.26 - Diagramas de $M_{k, x}, V_{k, y}$ e $N_{k, z}$ da parede PV15.

Os maiores resultados dos esforços apresentados na Figura 6.26 são apresentados e comparados entre os modelos MEF e MPT, na Tabela 6.21. Observa-se a diferença de $-38,43 \%$ da máxima força normal obtida pelo MPT em relação ao MEF. No entanto, ressalta-se que os valores de força normal obtidos pelas ações horizontais são muito menores daqueles obtidos pelas cargas verticais. A maior força normal oriunda apenas de cargas verticais, ao nível 0,80 m (mesmo nível da maior força normal obtida apenas pelas ações horizontais), é de $-164,8 \mathrm{tf}$, como pode ser visto na Figura 6B-2 do Anexo B. Constata-se neste caso que $N_{k, v e r t}$ é mais de dez vezes maior que $N_{k, z}$, considerando os valores absolutos. Portanto, a diferença percebida no diagrama da Figura 6.26 se reduz significativamente quando os esforços são combinados.

Tabela 6.21 - Comparação entre os esforços máximos característicos da PV15.

\begin{tabular}{|c|c|c|c|c|}
\hline \multicolumn{5}{|c|}{ Comparação dos esforços máximos da PV15 } \\
\hline Esforço & nível & MEF & MPT & $\%$ \\
\hline $\mathrm{Mk}, \mathrm{x}$ & 0,00 & 75,47 & 88,90 & 17,80 \\
\hline $\mathrm{Vk}, \mathrm{y}$ & 5,60 & 9,12 & 9,28 & 1,75 \\
\hline $\mathrm{Nk}, \mathrm{z}$ & 0,80 & 13,79 & 8,49 & $-38,43$ \\
\hline
\end{tabular}




\subsection{Verificação da máxima tensão normal de compressão}

O dimensionamento quanto às tensões normais precisa ser verificado em determinada seção transversal da parede, para o pior caso de compressão e também para o eventual pior caso de tração.

Neste item são verificadas as máximas tensões normais de compressão das paredes PH13, PH16, PH34, PV08, PV12 e PV15. Primeiramente os diagramas de momentos fletores e forças normais são obtidos pela combinação $C_{1}$ de ações conforme Equação (5.3). Em seguida, o diagrama de tensões normais é traçado para a seção transversal mais crítica das paredes analisadas. Por fim, a máxima tensão de compressão é comparada com a resistência última à compressão calculada pela NBR 16055:2012.

6.7.1 Resultados de cálculo considerando a combinação de ações $C_{1}$

A Figura 6.27 apresenta os diagramas de momento fletor de cálculo para as paredes $\mathrm{PH} 13$, $\mathrm{PH} 16$ e $\mathrm{PH} 34$.
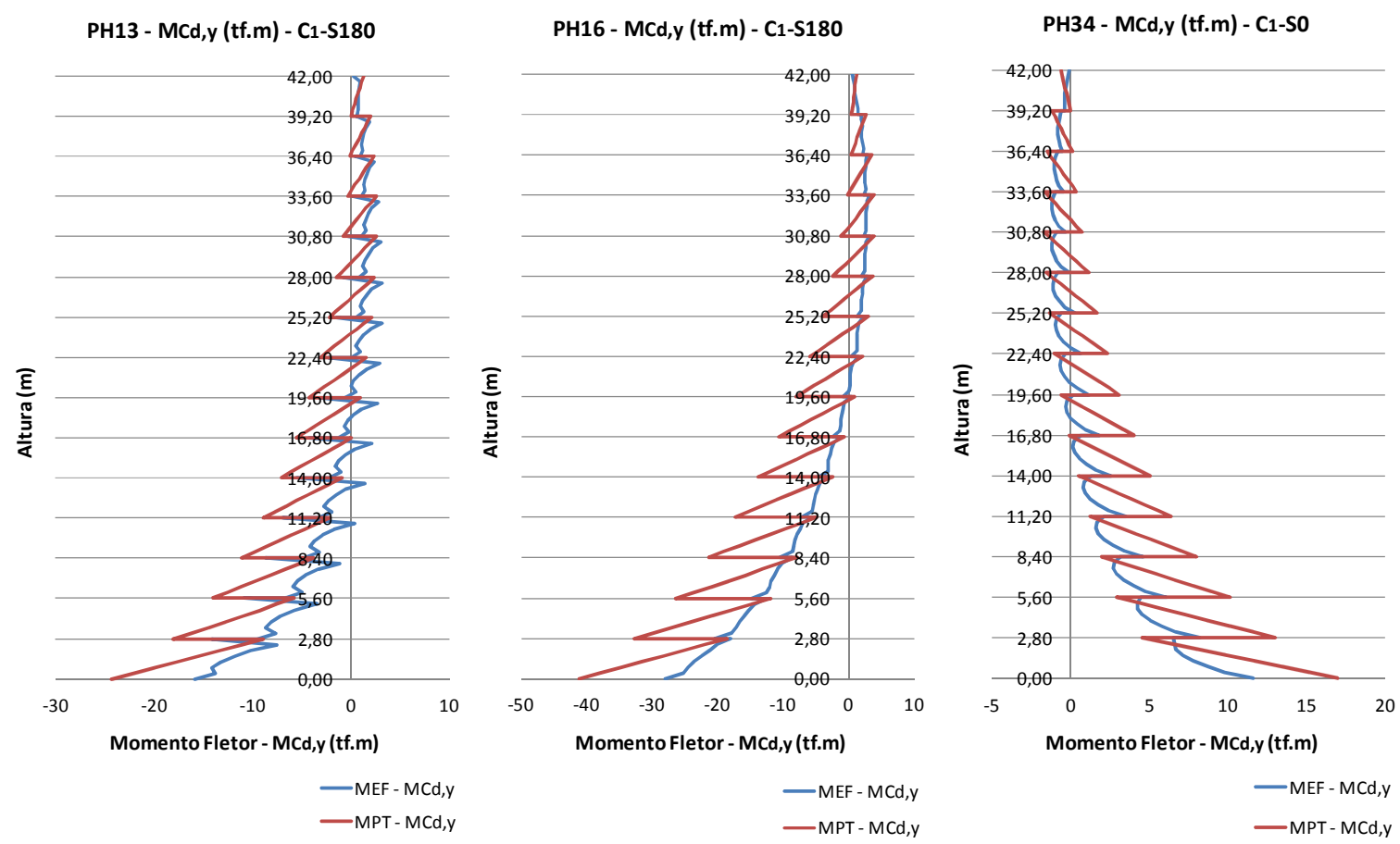

Figura 6.27 - Diagrama de $M_{C d, y}$ das $\mathrm{PH} 13, \mathrm{PH} 16$ e PH34 conforme combinação $\mathrm{C}_{1}$. 
As ações horizontais na direção $180^{\circ}$ são mais desfavoráveis em relação à máxima tensão de compressão para as paredes $\mathrm{PH} 13$ e $\mathrm{PH} 16$, enquanto que para parede $\mathrm{PH} 34$ o sentido mais desfavorável é $0^{\circ}$.

A Tabela 6.22 compara, nas paredes $\mathrm{PH} 13$, PH16 e PH34, as diferenças obtidas entre os modelos MPT e MEF, dos máximos momentos fletores característicos calculados considerando apenas as ações horizontais, e os máximos momentos fletores de cálculo, considerando a combinação de ações $C_{1}$, mostrando o nível onde eles ocorrem, e a diferença percentual.

Tabela 6.22 - Comparação dos máximos $M_{k, y}$ e $M_{C d, y}$ nas paredes PH13, PH16 e PH34.

\begin{tabular}{|c|c|c|c|c|c|c|c|c|}
\cline { 2 - 9 } \multicolumn{1}{c|}{} & \multicolumn{4}{c|}{ Mk,y (tf.m) } & \multicolumn{4}{c|}{ MCd,y (tf.m) } \\
\hline PAREDE & nível (m) & MEF & MPT & $\%$ & nível (m) & MEF & MPT & $\%$ \\
\hline PH13 & 0,00 & 12,78 & 17,95 & 40,46 & 0,00 & $-15,82$ & $-24,39$ & 54,18 \\
\hline PH16 & 0,00 & 21,37 & 30,60 & 43,21 & 0,00 & $-28,09$ & $-41,19$ & 46,62 \\
\hline PH34 & 0,00 & 7,90 & 12,33 & 56,21 & 0,00 & 11,57 & 16,98 & 46,81 \\
\hline
\end{tabular}

Como o Momento Fletor é praticamente influenciado apenas pelas ações horizontais, a ordem de grandeza das diferenças obtidas quando se comparam os valores característicos e os valores de cálculo é praticamente a mesma.

A mesma comparação é feita nas paredes PV08, PV12 e PV15. O diagrama dos momentos fletores de cálculo dessas paredes é apresentado na Figura 6.28, e a mesma comparação feita na Tabela 6.22 é feita na Tabela 6.23.

Os resultados da Tabela 6.23 são semelhantes aos obtidos na Tabela 6.22, ou seja, as diferenças entre os dois modelos quando comparados os momentos característicos se mantêm quando comparados os momentos de cálculo.

Tabela 6.23 - Comparação dos máximos $M_{k, x}$ e $M_{C d, x}$ nas paredes PV08, PV12 e PV15.

\begin{tabular}{|c|c|c|c|c|c|c|c|c|}
\cline { 2 - 9 } \multicolumn{1}{c|}{} & \multicolumn{4}{c|}{ Mk,x (tf.m) } & \multicolumn{4}{c|}{ MCd,x (tf.m) } \\
\hline PAREDE & nível (m) & MEF & MPT & $\%$ & nível (m) & MEF & MPT & $\%$ \\
\hline PV08 & 0,00 & 6,77 & 8,44 & 24,64 & 0,00 & $-7,99$ & $-11,63$ & 45,65 \\
\hline PV12 & 0,00 & 4,90 & 5,77 & 17,73 & 0,00 & $-6,61$ & $-7,94$ & 19,98 \\
\hline PV15 & 0,00 & 75,47 & 88,90 & 17,80 & 0,00 & $-105,01$ & $-124,53$ & 18,59 \\
\hline
\end{tabular}




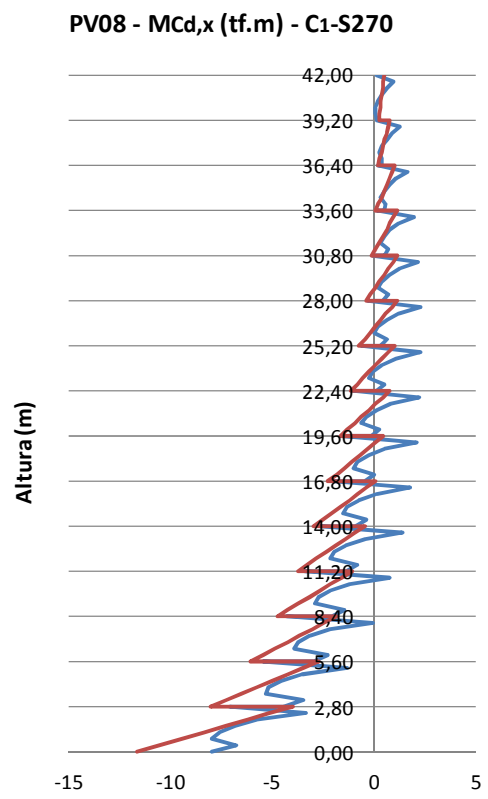

Momento Fletor - MCd, x (tf.m)

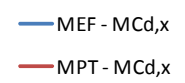

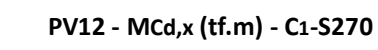

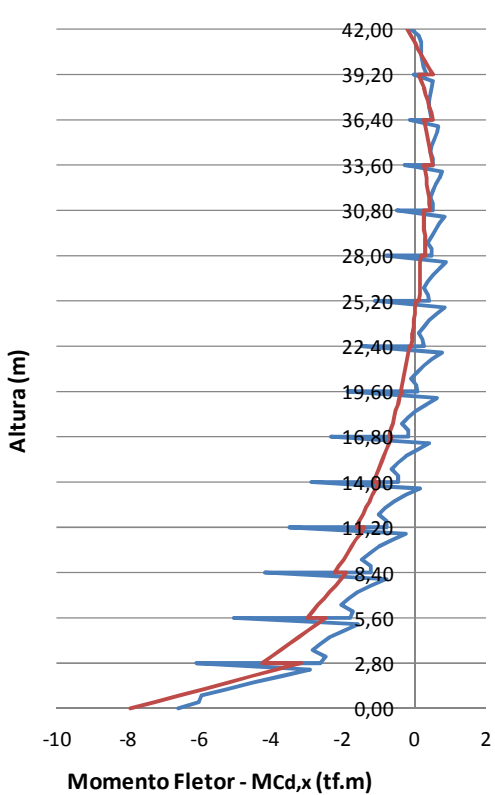

- MEF - MCd, $x$

-MPT-MCd,x
PV15 - MCd,x (tf.m) - C1-S270

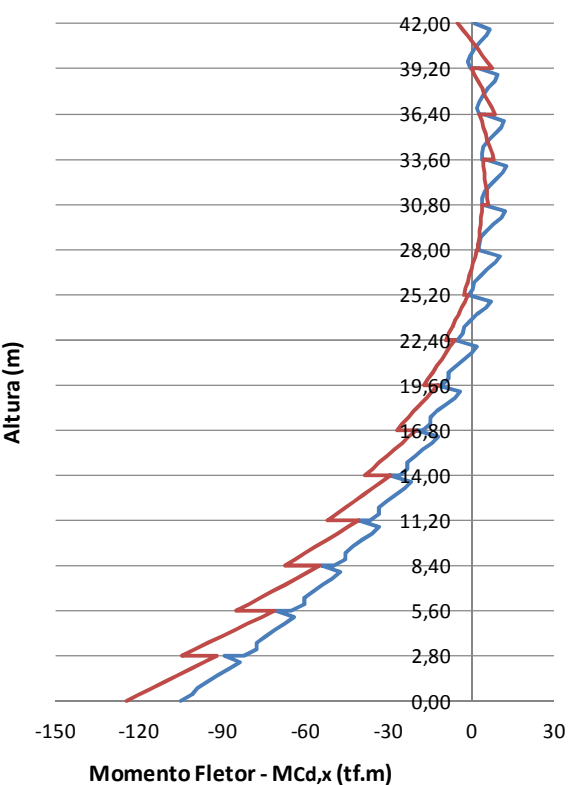

-MEF - MCd, $x$

Figura 6.28 - Diagrama de $M_{C d, x}$ das PV08, PV12 e PV15 conforme combinação $\mathrm{C}_{1}$.

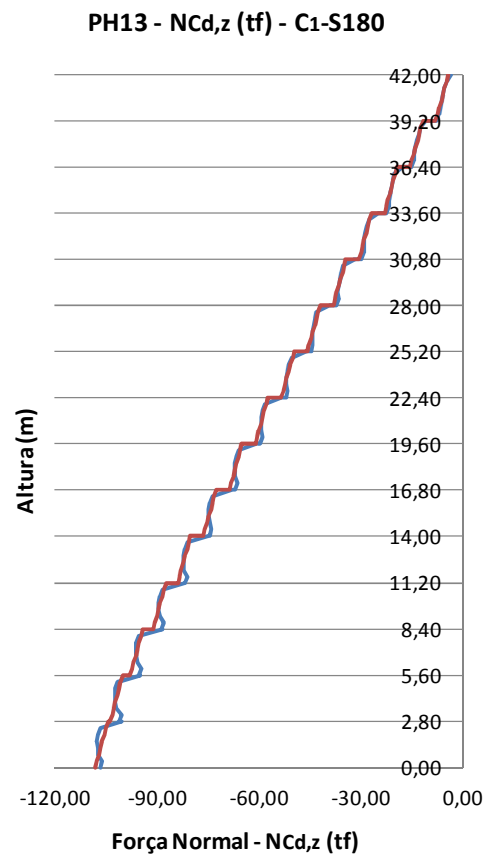

- MEF - NCd, 2
PH16 - NCd,z (tf) - C1-S180

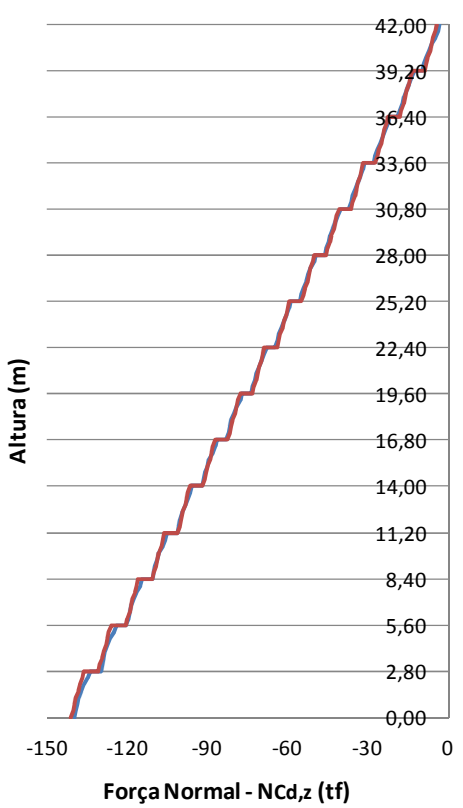

- MEF - NCd, ,
PH34 - NCd,z (tf) - C1-SO

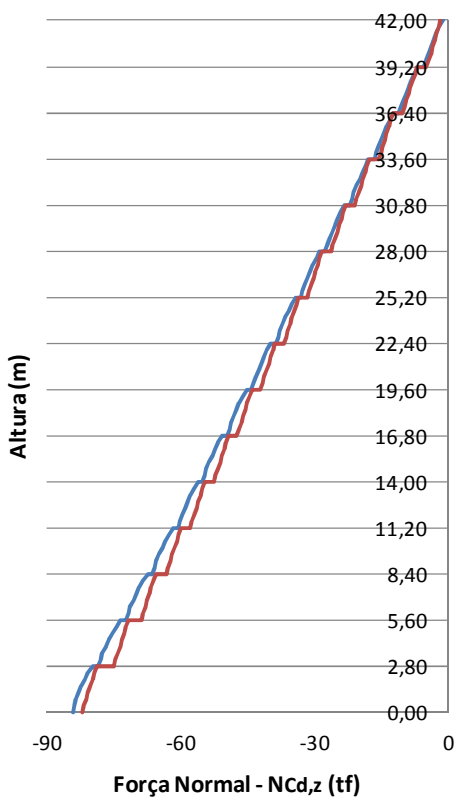

- MEF - NCd, 2

-MPT- NCd,z

Figura 6.29 - Diagrama de $N_{C d, z}$ das $\mathrm{PH} 13, \mathrm{PH} 16$ e PH34 conforme combinação $\mathrm{C}_{1}$. 

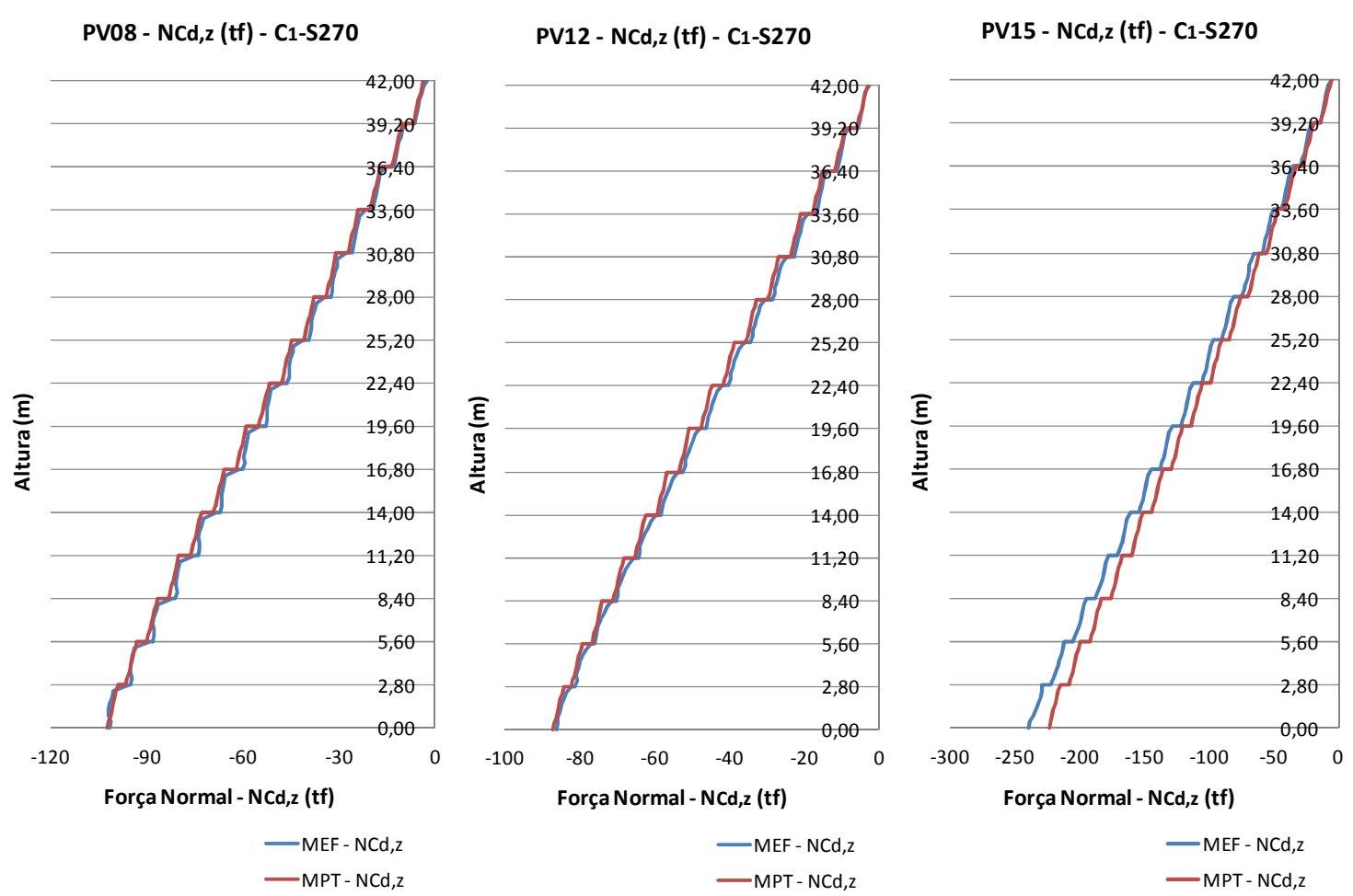

Figura 6.30 - Diagrama de $N_{C d, z}$ das PV08, PV12 e PV15 conforme combinação $\mathrm{C}_{1}$.

Os diagramas das forças normais de cálculo das paredes $\mathrm{PH} 13, \mathrm{PH} 16$ e PH34 são apresentados na Figura 6.29, e os das paredes PV08, PV12 e PV15 na Figura 6.30. Todos eles apresentam curvas quase coincidentes, significando que as diferenças entre os dois modelos são pequenas. A Tabela 6.24 compara as diferenças obtidas entre os modelos MPT e MEF, das máximas forças normais características calculadas considerando apenas as ações horizontais, e das máximas forças normais de cálculo, considerando a combinação de ações $C_{1}$, mostrando o nível onde elas ocorrem, e a diferença percentual.

Os resultados da Tabela 6.24 evidenciam que quando as forças normais oriundas das ações horizontais são combinadas com as forças normais provenientes das cargas verticais, as diferenças entre os modelos MPT e MEF se reduzem significativamente gerando resultados muito próximos. Isso porque, como visto nos diagramas das Figuras 6B-1 e 6B-2 (Anexo B), as diferenças entre os modelos são muito pequenas quando comparadas as forças normais obtidas apenas por cargas verticais. Além disso, elas são muito maiores em relação às forças normais obtidas apenas pelas ações horizontais. Vale lembrar que a relação da altura do edifício exemplo, pelo menor comprimento em planta é de 2,625 (42 m/16 m), mostrando 
que o edifício possui pequena esbeltez, conforme classificação de Fonte et al (2005).

Tabela 6.24 - Comparação dos máximos $N_{k, z}$ e $N_{C d, z}$ nas paredes $\mathrm{PH} 13, \mathrm{PH} 16, \mathrm{PH} 34$, PV08, PV12 e PV15.

\begin{tabular}{|c|c|c|c|c|c|c|c|c|}
\cline { 2 - 9 } \multicolumn{1}{c|}{} & \multicolumn{4}{c|}{ Nk,z (tf) } & \multicolumn{4}{c|}{ NCd,z (tf) } \\
\hline PAREDE & nível (m) & MEF & MPT & $\%$ & nível (m) & MEF & MPT & $\%$ \\
\hline PH13 & 10,80 & 5,05 & 4,36 & $-13,68$ & 0,00 & $-106,54$ & $-108,12$ & 1,48 \\
\hline PH16 & 0,80 & 4,76 & 4,49 & $-5,74$ & 0,00 & $-139,64$ & $-140,94$ & 0,93 \\
\hline PH34 & 13,60 & 1,23 & 2,01 & 63,05 & 0,00 & $-84,21$ & $-82,13$ & $-2,47$ \\
\hline PV08 & 5,20 & 6,74 & 6,79 & 0,72 & 0,00 & $-101,66$ & $-102,29$ & 0,62 \\
\hline PV12 & 5,60 & 5,74 & 4,97 & $-13,43$ & 0,00 & $-86,21$ & $-87,05$ & 0,97 \\
\hline PV15 & 0,80 & 13,79 & 8,49 & $-38,43$ & 0,00 & $-239,30$ & $-223,09$ & $-6,78$ \\
\hline
\end{tabular}

Com os momentos fletores e forças normais de cálculo apresentados, o diagrama de tensões normais da seção transversal, ao nível da fundação, a qual é a crítica em todas as paredes, é traçado conforme Figuras 6.31 a 6.34.
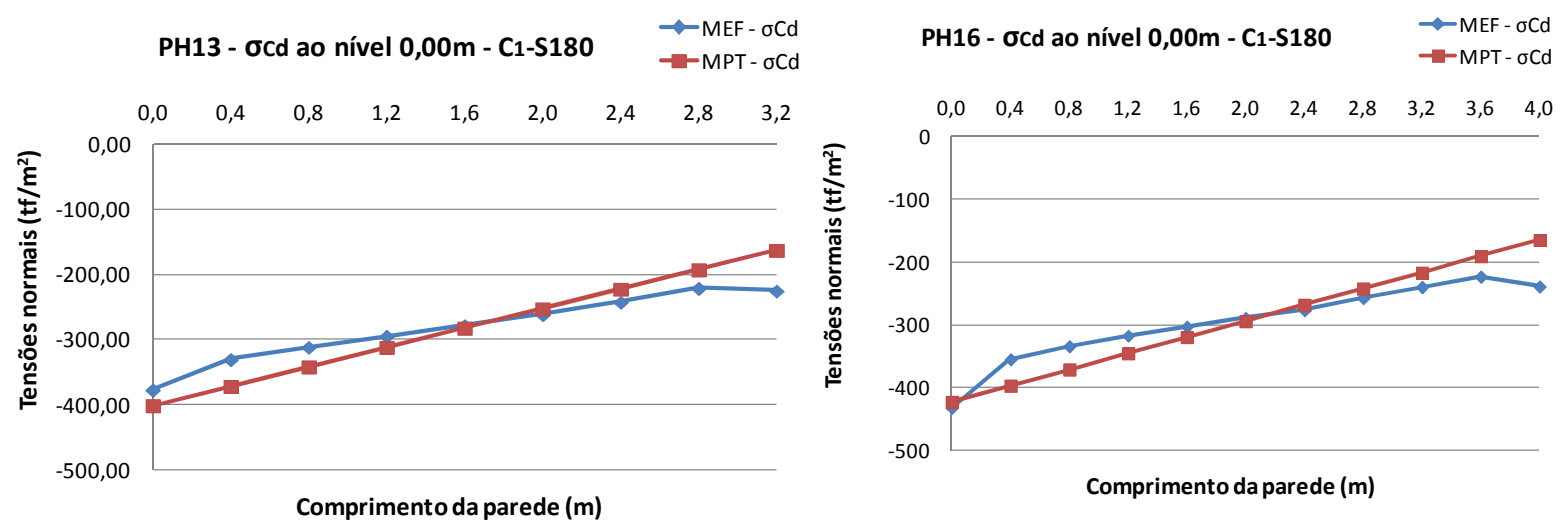

Figura 6.31 - Diagrama de $\sigma_{C d}$ das paredes $\mathrm{PH} 13$ e $\mathrm{PH} 16$.
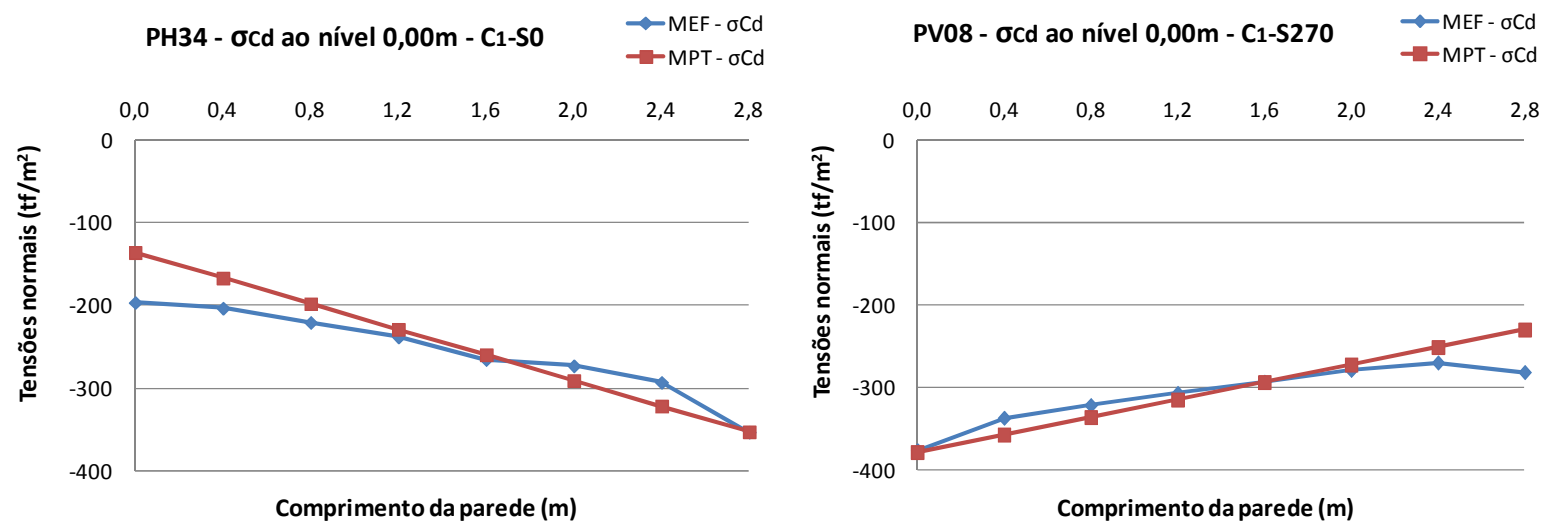

Figura 6.32 - Diagrama de $\sigma_{C d}$ das paredes PH34 e PV08. 


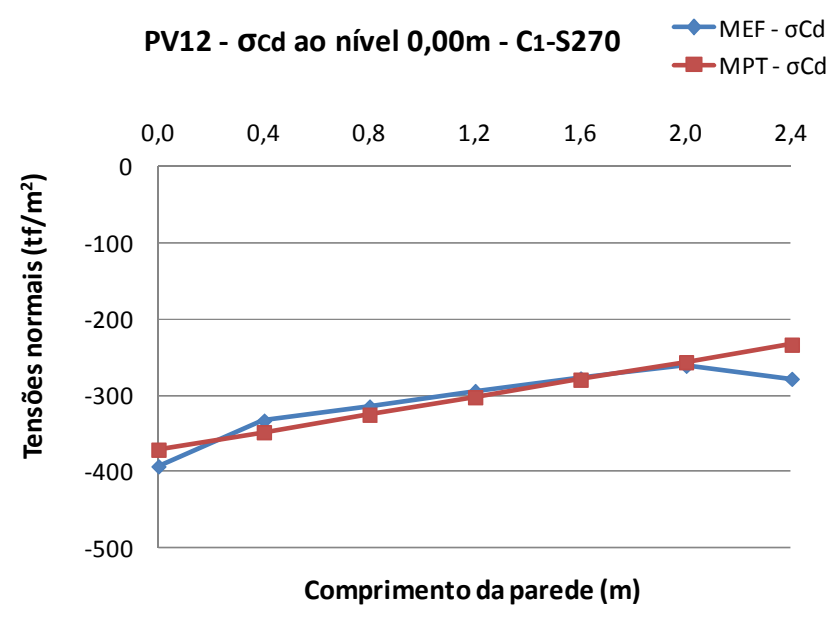

Figura 6.33 - Diagrama de $\sigma_{C d}$ da parede PV12.

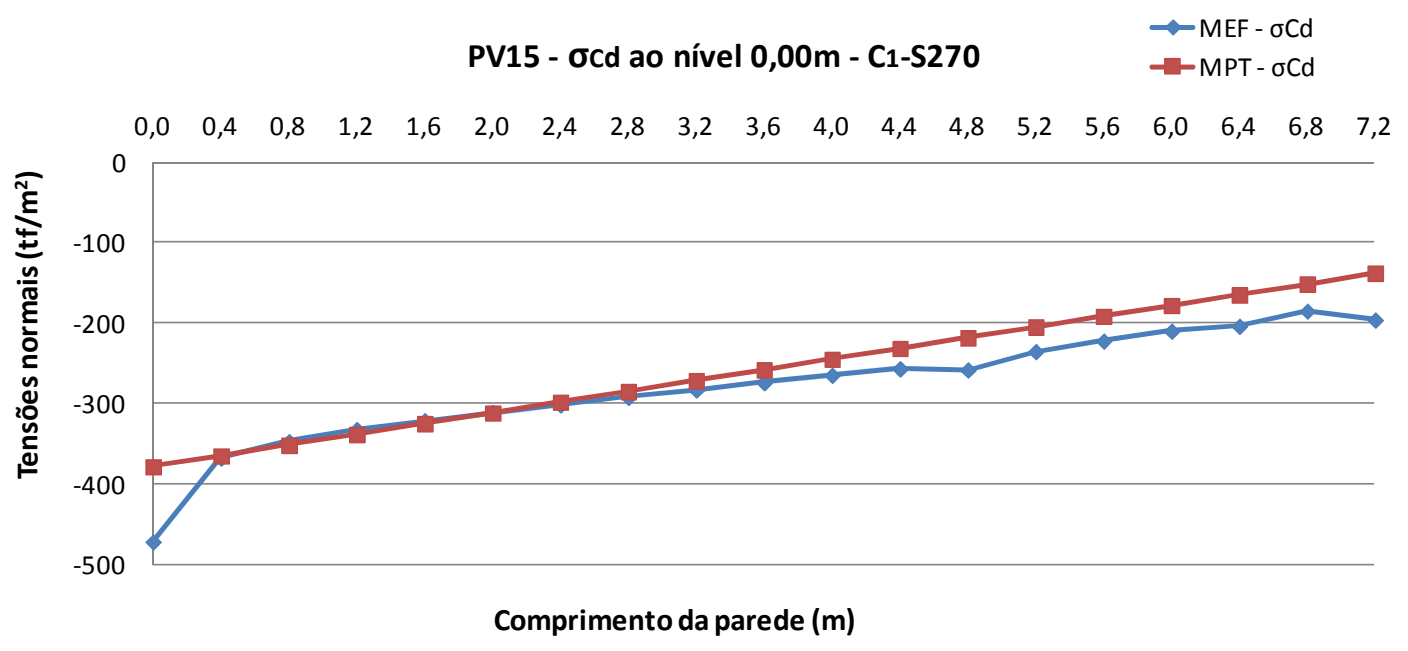

Figura 6.34 - Diagrama de $\sigma_{C d}$ da parede PV15.

\subsubsection{Discussões sobre os resultados}

Ratifica-se a qualidade do MPT pela proximidade ao MEF verificada nos diagramas de tensões normais traçados. As máximas tensões de compressão, comparadas na Tabela 6.25 reforçam esse fato. A maior diferença ocorre na parede PV15, onde a tensão máxima de compressão obtida pelo MPT é 19,78\% menor que a obtida pelo MEF. Essa comparação é feita no ponto onde a seção transversal da parede está mais comprimida. Ao se comparar a distribuição das tensões normais ao longo de toda seção da parede PV15, essa diferença cai e chega próximo a zero em vários pontos, como mostra o diagrama da Figura 6.34. A máxima tensão de compressão nas outras paredes tem resultados muito próximos entre os dois 
modelos, sendo $6,42 \%$ a maior diferença (depois da obtida na parede PV15) e $0,13 \%$ a menor.

Verifica-se ainda na Tabela 6.25 que a condição ao dimensionamento quanto à máxima tensão de compressão é satisfeita em todas as paredes, nos dois modelos utilizados, já que os valores das tensões máximas são menores que a tensão última à compressão calculada pela NBR 16055:2012 (tensão última à compressão é obtida dividindo-se a resistência última à compressão pela espessura da parede).

Tabela 6.25 - Verificação ao dimensionamento quanto à tensão normal de compressão.

\begin{tabular}{|c|c|c|c|c|c|c|}
\hline & \multicolumn{4}{|c|}{$\sigma c d$, máx $\left(t f / m^{2}\right)-C 1$} & \multirow{2}{*}{$\frac{\sigma_{d, \text { resist }}\left(\mathrm{tf} / \mathrm{m}^{2}\right)}{\text { NBR } 16055: 2012}$} & \multirow{2}{*}{ STATUS } \\
\hline PAREDES & nível (m) & MEF & MPT & $\%$ & & \\
\hline $\mathrm{PH} 13$ & 0,00 & $-376,49$ & $-400,68$ & 6,42 & $-595,24$ & OK \\
\hline $\mathrm{PH} 16$ & 0,00 & $-431,59$ & $-422,34$ & $-2,14$ & $-595,24$ & OK \\
\hline PH34 & 0,00 & $-353,19$ & $-352,73$ & $-0,13$ & $-595,24$ & OK \\
\hline PV08 & 0,00 & $-376,28$ & $-378,64$ & 0,63 & $-595,24$ & OK \\
\hline PV12 & 0,00 & $-392,86$ & $-371,14$ & $-5,53$ & $-595,24$ & OK \\
\hline PV15 & 0,00 & $-471,62$ & $-378,31$ & $-19,78$ & $-595,24$ & OK \\
\hline
\end{tabular}

Outra conclusão importante é sobre a distribuição das cargas atuantes nas paredes em suas estruturas de apoio. Multiplicando-se os valores de tensões normais ao longo do comprimento da parede pela sua espessura obtém-se o carregamento distribuído por metro na base da parede. Como os diagramas de tensões normais dos dois modelos são muito próximos, o carregamento a ser aplicado nas estruturas de apoio tem mesmo aspecto da distribuição de tensões normais ao longo da parede e, portanto, também se verifica uma proximidade muito boa.

Sendo assim, as diferenças consideráveis quando comparados os momentos fletores obtidos pelo MPT e MEF não causam problemas nem quando a parede é dimensionada, nem quando se pretende distribuir as ações normais das paredes nas estruturas de apoio, pois, para esses dois procedimentos, utilizam-se as tensões normais, as quais têm uma proximidade muito grande entre os dois modelos. 


\subsection{Verificação da eventual máxima tensão normal de tração}

Investiga-se a máxima tensão de tração nas paredes $\mathrm{PH} 13, \mathrm{PH} 16, \mathrm{PH} 34$, PV08, PV12 e PV15, obtendo-se os momentos fletores e forças normais de cálculo, considerando a combinação de ações $C_{2}$, descrita na Equação (5.4).

\subsubsection{Resultados de cálculo considerando a combinação de ações $C_{2}$}

As Figuras 6.35 a 6.38 apresentam os diagramas dos esforços citados.

Quando se aplica a Equação (5.6), a fim de calcular a eventual máxima tensão de tração em determinada seção transversal da parede, observa-se que a parcela correspondente da tensão normal obtida pela força normal é sempre maior (em valor absoluto) que a parcela correspondente de tensão normal obtida pelo momento fletor. Como a força normal é sempre de compressão, ao longo da altura da parede, constata-se que não há tensão normal de tração nas paredes analisadas.
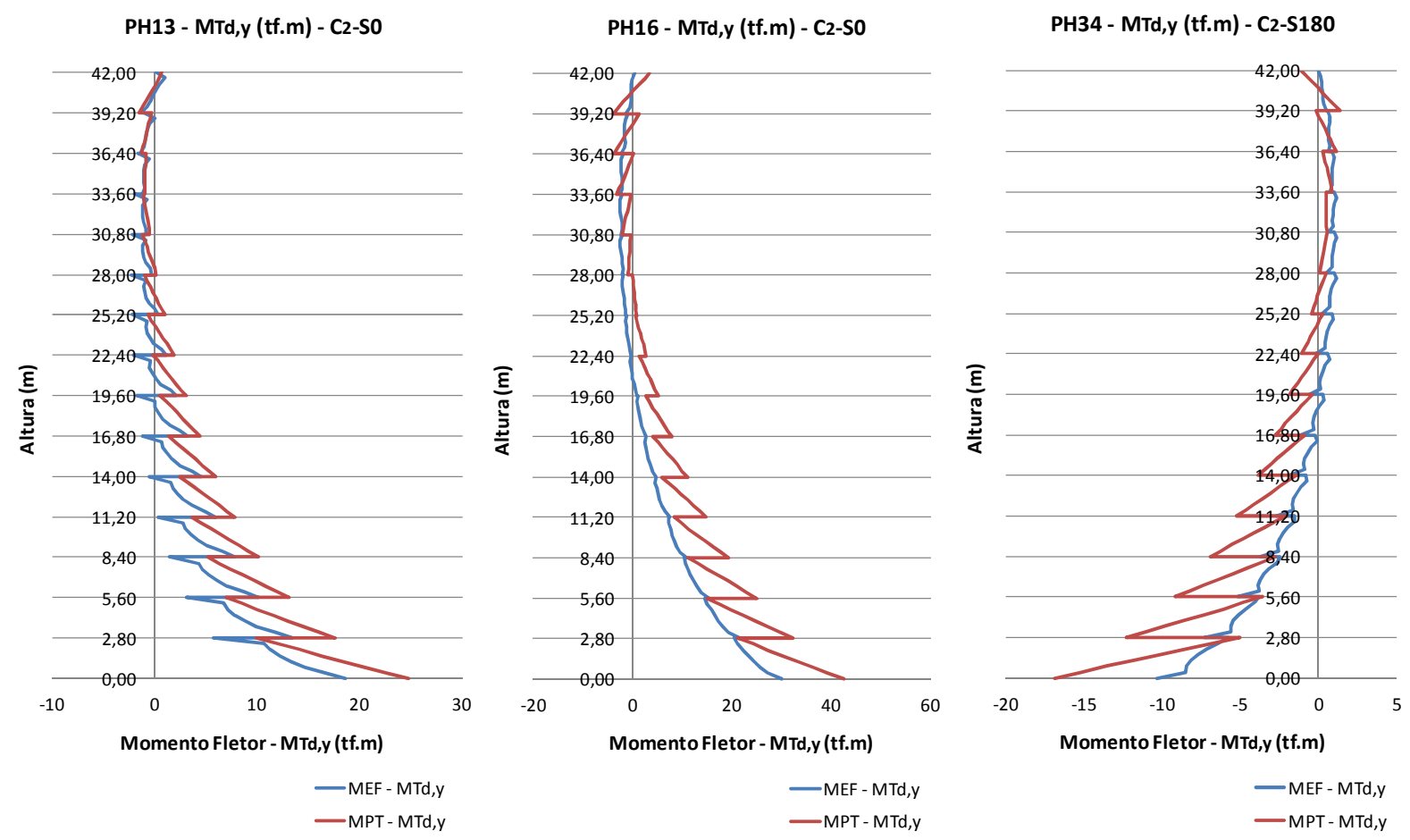

Figura 6.35 - Diagrama de $M_{T d, y}$ das $\mathrm{PH} 13$, PH16 e PH34 conforme combinação $\mathrm{C}_{2}$. 


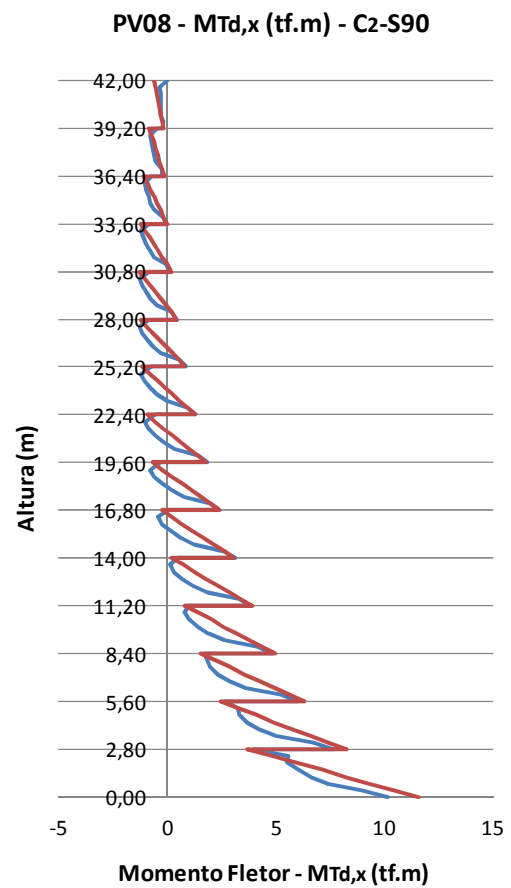

-MEF - MTd, $x$
- MPT - MTd, $x$
PV12 - MTd,x (tf.m) - C2-S90

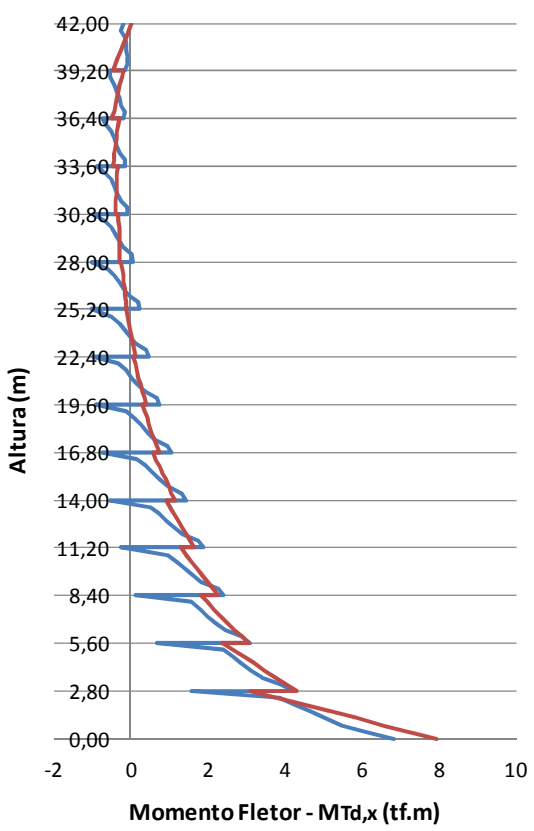

- MEF - MTd, $x$
PV15 - MTd,x (tf.m) - C2-S90

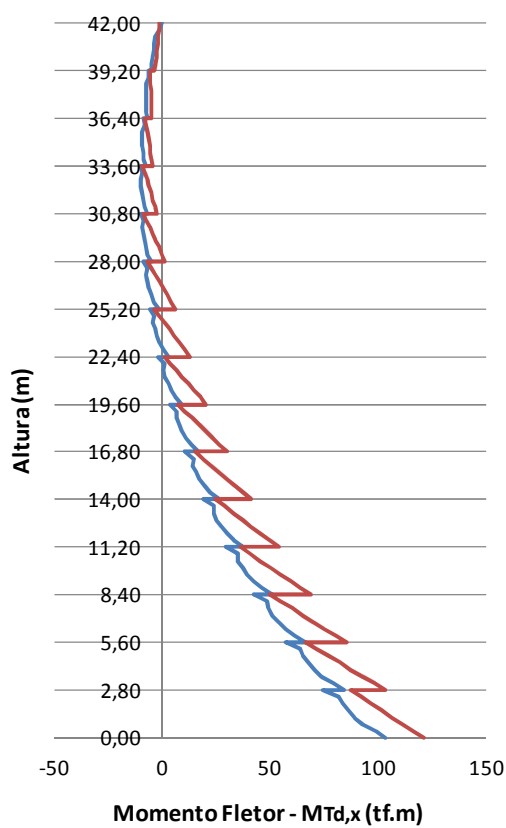

- MEF - MTd, $x$

Figura 6.36 - Diagrama de $M_{T d, x}$ das PV08, PV12 e PV15 conforme combinação $\mathrm{C}_{2}$.

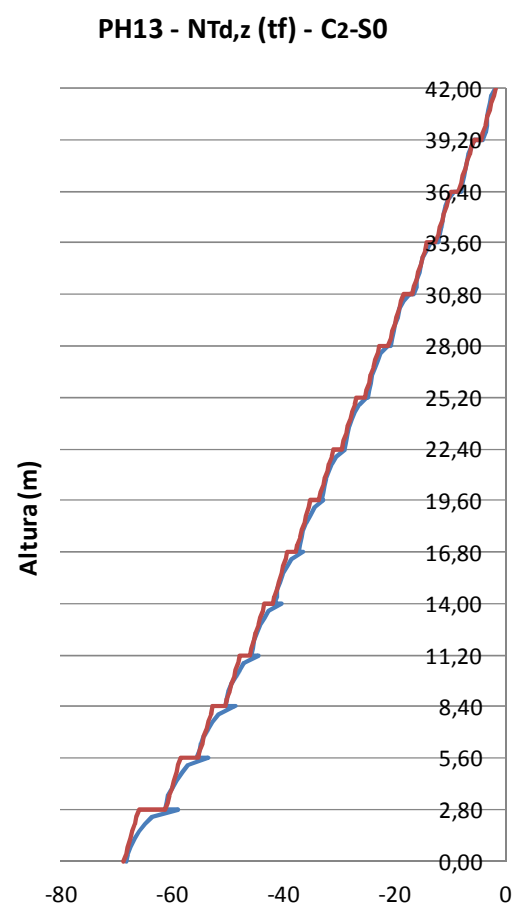

Força Normal - NTd,z (tf)
PH16 - NTd,z (tf) - C2-SO

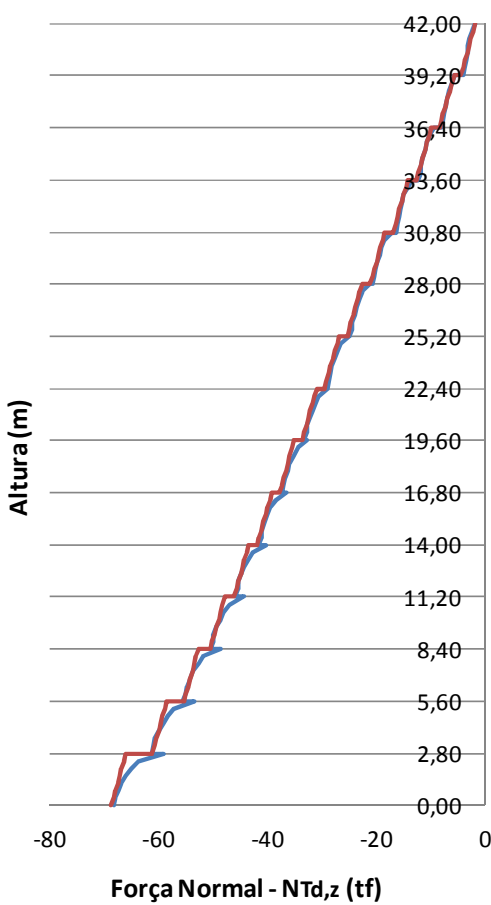

MEF - NTd,z
PH34 - NTd,z (tf) - C2-S180

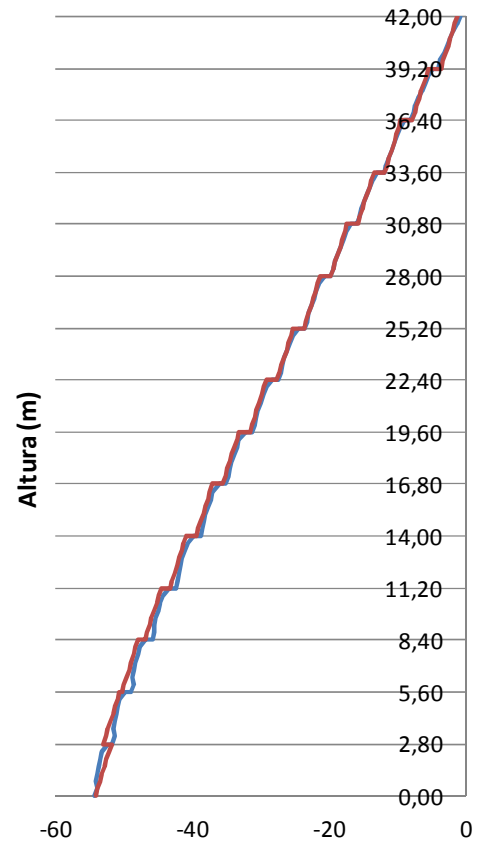

Força Normal - NTd,z (tf)

-MEF - NTd, Z -MPT - NTd, z

MEF - NTd,z

-MPT - NTd,z

Figura 6.37 - Diagrama de $N_{T d, z}$ das $\mathrm{PH} 13, \mathrm{PH} 16$ e PH34 conforme combinação $\mathrm{C}_{2}$. 


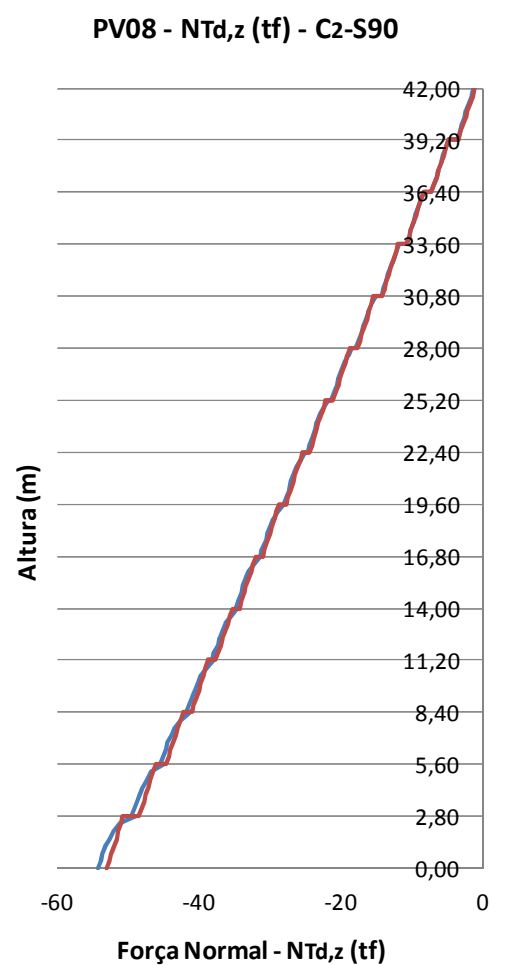

- MEF - NTd, $\mathrm{z}$ -MPT - NTd, $\mathrm{z}$

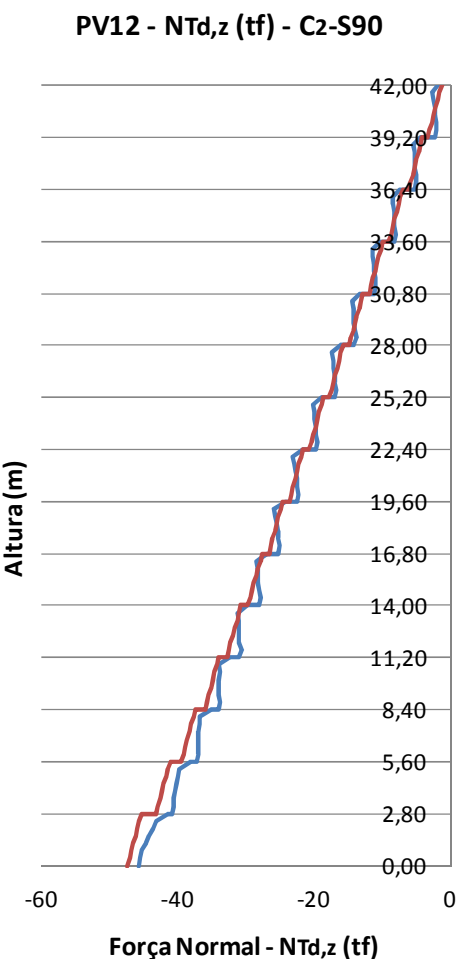

-MEF - NTd, z
PV15 - NTd,z (tf) - C2-S90

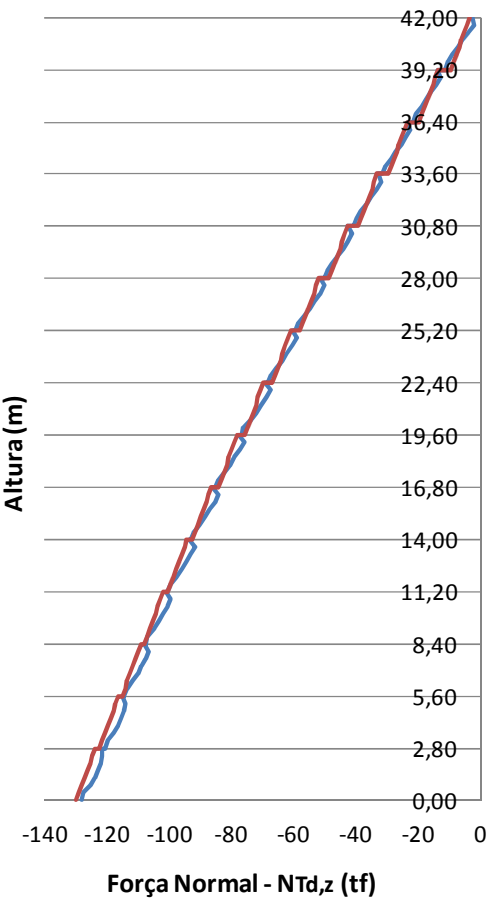

-MEF - NTd,

Figura 6.38 - Diagrama de $N_{T d, z}$ das PV08, PV12 e PV15 conforme combinação $\mathrm{C}_{2}$.

Entre as paredes analisadas, o diagrama de tensões normais da parede PV15 é o que mais se aproxima da condição de tração quando a análise é feita ao nível da fundação, como mostra a Figura 6.39. Na mesma Figura, pode-se perceber novamente a proximidade dos valores obtidos pelos dois modelos.

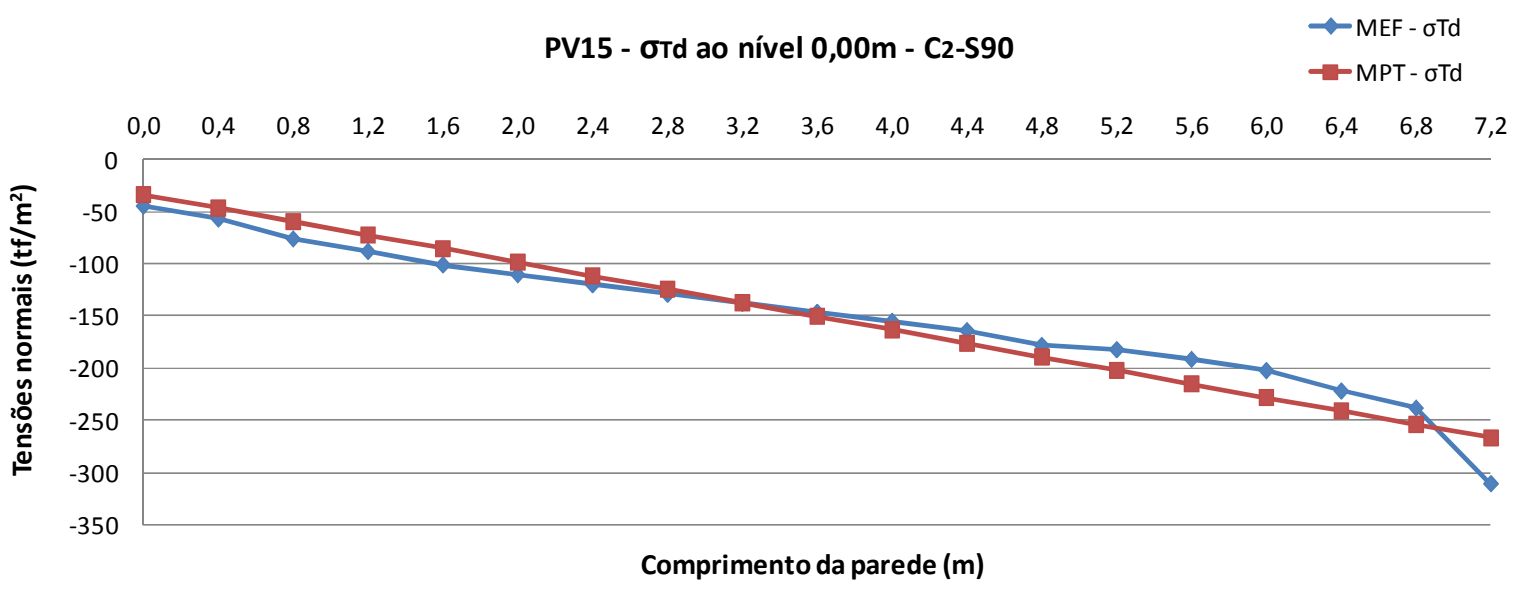

Figura 6.39 - Diagrama de $\sigma_{T d}$ da parede PV15. 
A Figura 6.40 mostra o diagrama de tensões normais da parede PV15, obtido pelo MEF, ao longo de toda altura da parede e nos dois primeiros pavimentos. Considerou-se a combinação de ações $\mathrm{C}_{2}$ e as ações horizontais aplicadas no sentido $90^{\circ}$ (por ser mais desfavorável quanto às possíveis tensões normais de tração desta parede).

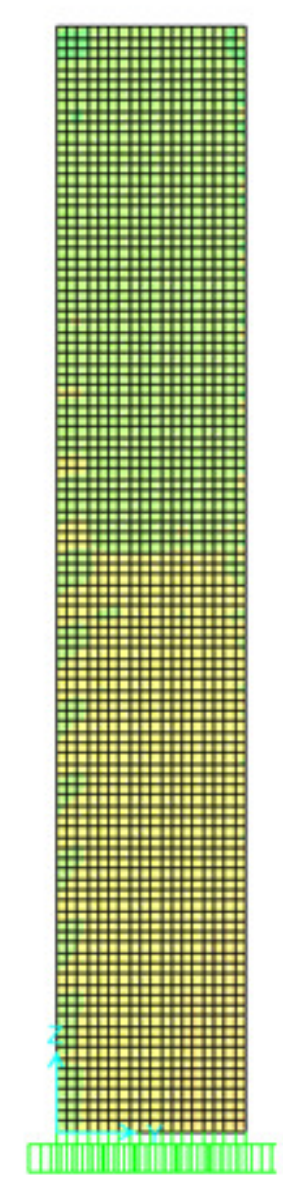

a) PV15 - Altura total

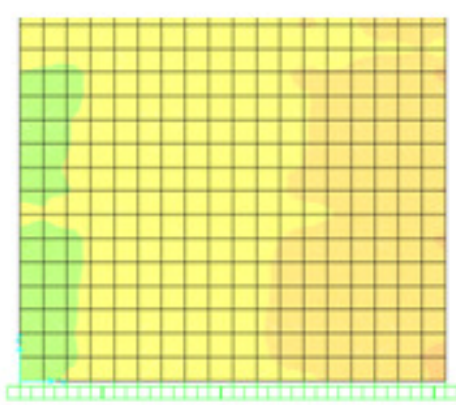

b) PV15 - Até $6 \mathrm{~m}$ de altura

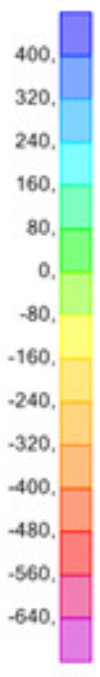

Figura 6.40 - Diagrama de $\sigma_{T d}$ da parede PV15 (tt $\left./ \mathrm{m}^{2}\right)$; a) Diagrama ao longo de toda altura da parede; b) Diagrama até $6 \mathrm{~m}$ de altura da parede;

Na Figura 6.40, as tensões positivas (cor azul) são de tração. Como citado no início deste item, não há tensões normais de tração ao longo de toda a altura da parede.

Os diagramas equivalentes aos apresentados para a parede PV15, nas Figuras 6.39 e 6.40, são apresentados para as outras paredes analisadas nas Figuras 6C-1 a 6C-8 do Anexo C. 
Conclui-se, portanto, que nas paredes analisadas não são necessárias armaduras para resistir às forças de tração causadas por tensões normais de tração. Desta maneira, a parede deve ser armada com as armaduras mínimas determinadas pela NBR 16055.

\subsection{Verificação ao cisalhamento}

6.9.1 Verificação da força cortante nas almas das paredes de contraventamento

Os diagramas de força cortante de cálculo, das paredes $\mathrm{PH} 13, \mathrm{PH} 16, \mathrm{PH} 34$, PV08, PV12 e PV15, considerando a combinação de ações $\mathrm{C}_{2}$, são apresentados nas Figuras 6.41 e 6.42. Para as paredes horizontais, as ações horizontais foram consideradas no sentido $0^{\circ}$; e para as verticais, no sentido $90^{\circ}$.
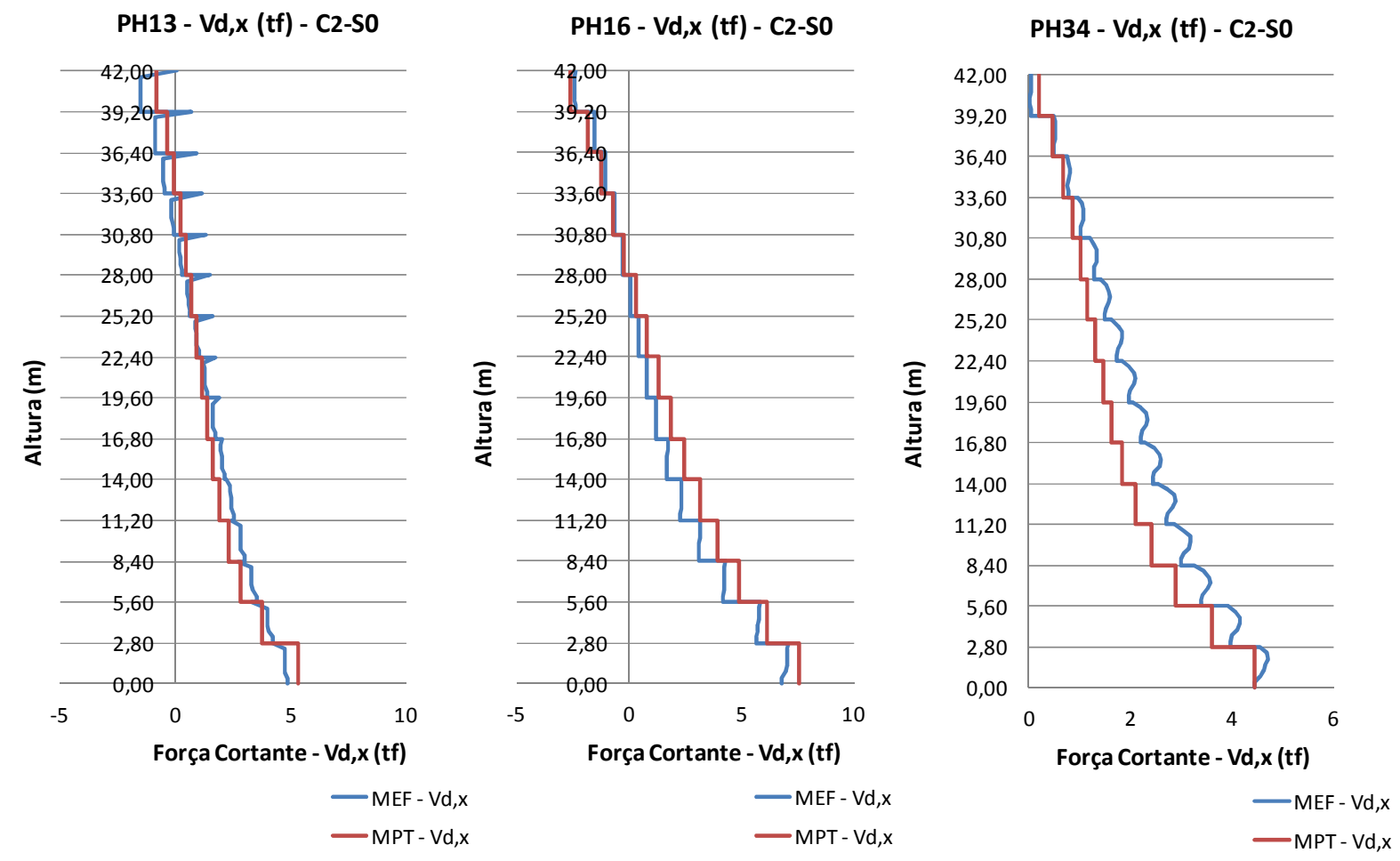

Figura 6.41 - Diagrama de $V_{d, x}$ das $\mathrm{PH} 13, \mathrm{PH} 16$ e $\mathrm{PH} 34$ conforme combinação $\mathrm{C}_{2}$. 

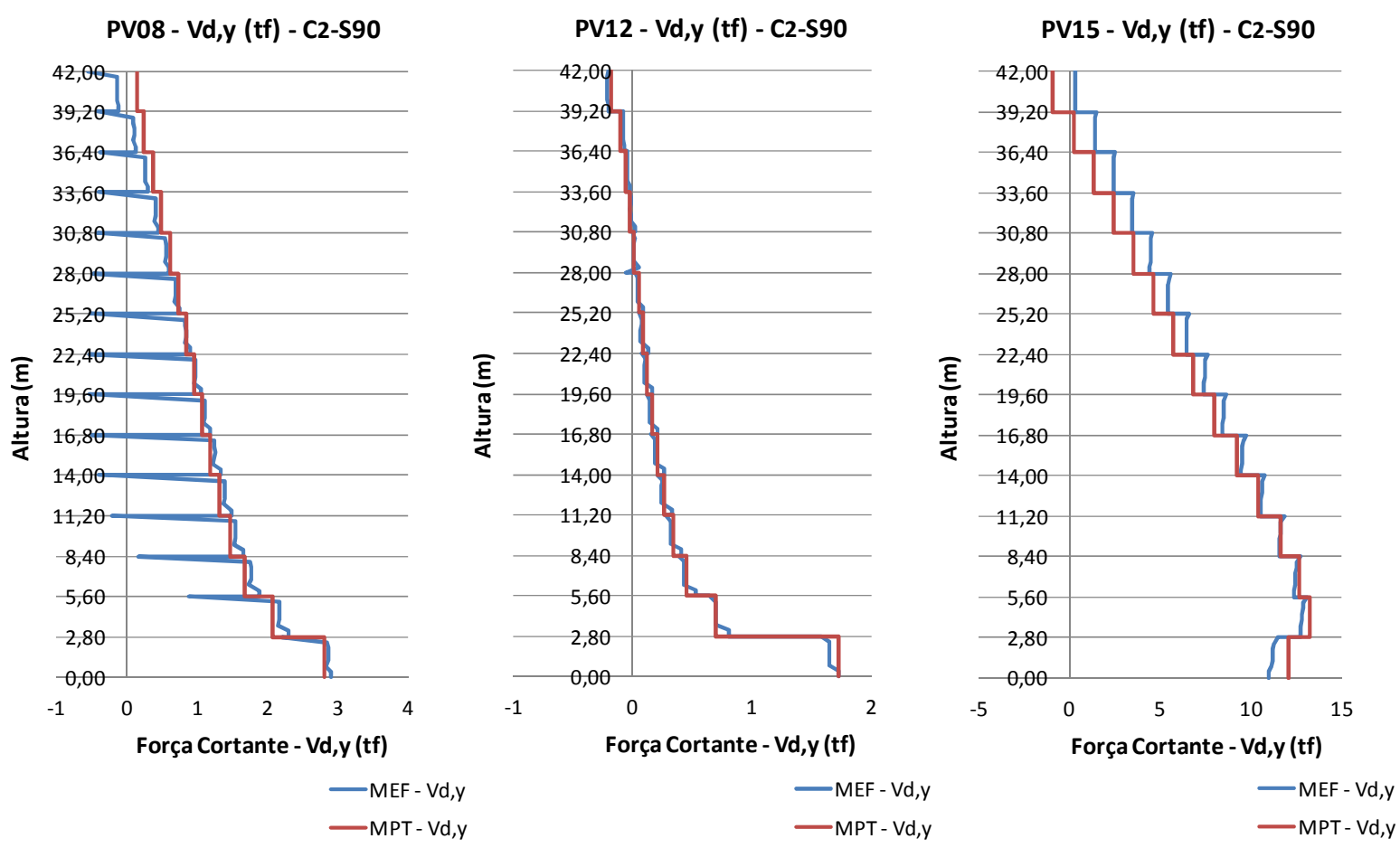

Figura 6.42 - Diagrama de $V_{d, y}$ das PV08, PV12 e PV15 conforme combinação $\mathrm{C}_{2}$.

A Tabela 6.26 verifica a máxima força cortante de cálculo, obtida na alma da parede da seção transversal mais crítica, com a força cortante resistente de cálculo, conforme NBR 16055:2012 (Equação 3.15). Para todos os casos, o dimensionamento é satisfeito.

Relembra-se que a tensão média de cálculo no concreto comprimido $\left(\sigma_{c m d}\right)$ foi calculada dividindo-se a força normal na parede, oriunda apenas das cargas permanentes verticais, no nível considerado, por sua seção transversal.

Tabela 6.26 - Verificação ao dimensionamento quanto à força cortante na alma das paredes de contraventamento.

\begin{tabular}{|c|c|c|c|c|c|c|c|c|c|c|}
\cline { 2 - 12 } \multicolumn{1}{c|}{} & \multicolumn{4}{c|}{$V_{\text {d,máx (tf) }}$} & \multicolumn{2}{c|}{ Omd (Mpa) } & \multicolumn{2}{c|}{$f_{\text {vd }}(\mathrm{tf})$} & \multicolumn{2}{c|}{ STATUS } \\
\hline PAREDES & nível (m) & MEF & MPT & $\%$ & MEF & MPT & MEF & MPT & MEF & MPT \\
\hline PH13 & 0,00 & 4,87 & 5,30 & 8,78 & 2,54 & 2,57 & 19,28 & 19,33 & OK & OK \\
\hline PH16 & 2,80 & 7,10 & 7,59 & 6,93 & 2,46 & 2,50 & 23,93 & 24,02 & OK & OK \\
\hline PH34 & 1,20 & $-4,88$ & $-4,25$ & $-13,02$ & 2,28 & 2,36 & 16,47 & 16,59 & OK & OK \\
\hline PV08 & 0,00 & 2,91 & 2,81 & $-3,39$ & 2,59 & 2,58 & 16,95 & 16,93 & OK & OK \\
\hline PV12 & 0,00 & 1,72 & 1,72 & 0,05 & 2,56 & 2,60 & 14,48 & 14,54 & OK & OK \\
\hline PV15 & 5,60 & 13,09 & 13,24 & 1,20 & 2,11 & 2,04 & 41,66 & 41,40 & OK & OK \\
\hline
\end{tabular}


Além disso, a Tabela 6.26 compara as máximas forças cortantes de cálculo obtidas entre os modelos MEF e MPT. Novamente os resultados são próximos com diferenças abaixo de $15 \%$.

Pela proximidade dos resultados obtidos pelo MEF, conclui-se que o MPT é um modelo confiável para o dimensionamento das almas das paredes de contraventamento quanto à força cortante (Figuras 6.41 e 6.42 e Tabela 6.26).

6.9.2 Verificação da força cortante na interface vertical do encontro de paredes

Para que haja a interação entre paredes, é necessário que a interface vertical do encontro de paredes seja capaz de resistir às tensões de cisalhamento oriundas da transferência de forças nesta região. Essas forças podem ser ocasionadas tanto por ações horizontais quanto por cargas verticais. Segundo Oliveira (2000), no caso das ações horizontais, a interação é atribuída à colaboração dos flanges provenientes das paredes que apresentam intersecções, os quais aumentam a inércia dos painéis de contraventamento. No caso das cargas verticais, a interação entre paredes tende a uniformizar as tensões normais ao longo da altura do edifício.

A verificação é feita comparando-se a tensão de cisalhamento média solicitante de cálculo $\tau_{d, \text { med }}$ com a tensão de cisalhamento resistente de cálculo $\tau_{d, \text { resist }}$, conforme Equações (6.6) e (6.7).

$$
\begin{gathered}
\tau_{d, \text { med }}=\frac{V_{d, \mathrm{int}}}{A_{\mathrm{int}}} \\
\tau_{d, \text { resist }}=\frac{f_{v d, \mathrm{int}}}{A_{\mathrm{int}}}
\end{gathered}
$$

onde:

$V_{d, \text { int }}:$ força cortante solicitante de cálculo na interface;

$A_{\text {int }} \quad$ : área da interface vertical;

$f_{v d, \text { int }}$ : força cortante resistente de cálculo na interface; 
A força cortante resistente de cálculo na interface $\left(f_{v d, \text { int }}\right)$ difere da força cortante resistente de cálculo $\left(f_{v d}\right)$ apenas por não considerar a tensão média de cálculo no concreto comprimido $\left(\sigma_{c m d}\right)$, simplesmente por não haver cargas permanentes que comprimem a parede na direção horizontal (direção da alma).

A Figura 6.43 exemplifica como se obteve a força cortante pelo MPT na interface PH13-PV04.

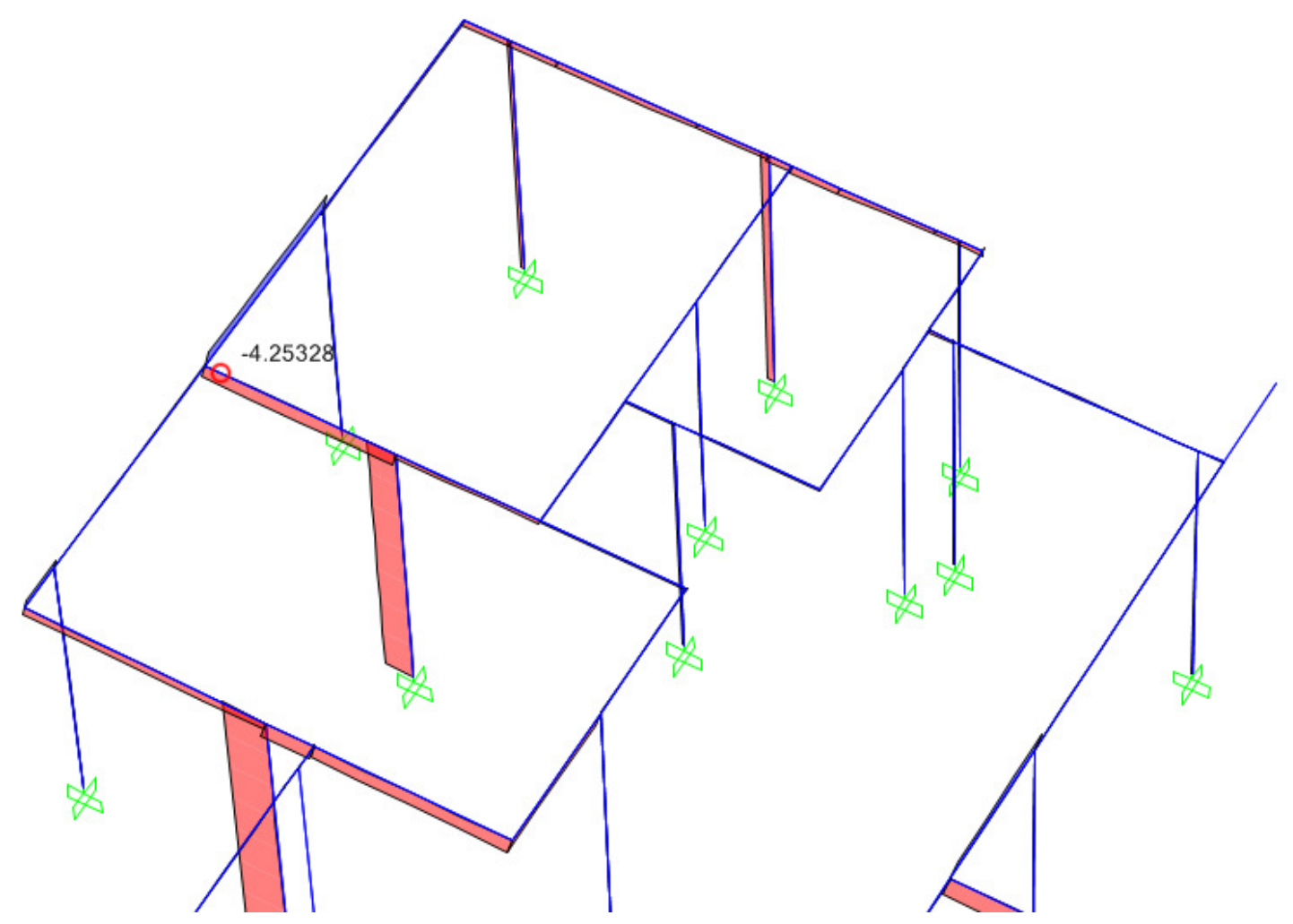

Figura $6.43-V_{d \text {,int }}$ na interface PH13-PV04, considerando combinação de ações $\mathrm{C}_{1} \mathrm{e}$ sentido das ações horizontais $180^{\circ}$, obtida pelo MPT.

No MEF, para se obter a força cortante na interface desejada, é preciso integrar as tensões de cisalhamento ao longo da interface vertical. A Figura 6.44 apresenta o procedimento adotado para integrar as tensões de cisalhamento da interface da parede $\mathrm{PH} 13$ com a parede PV04, onde os elementos da parede $\mathrm{PH} 13$ e os nós da interface foram selecionados. 


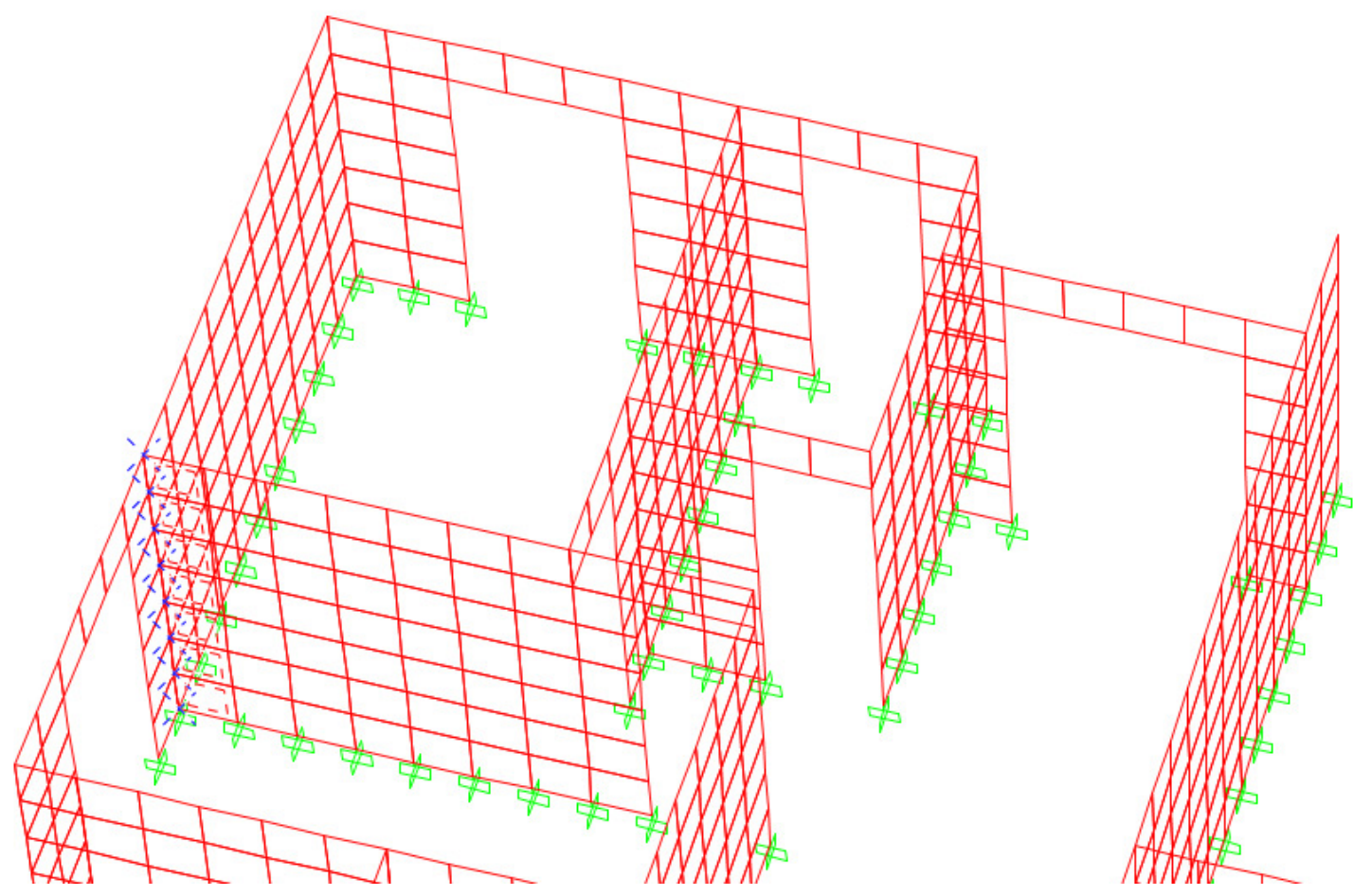

Figura 6.44 - Procedimento para obter a força cortante de cálculo na interface PH13-PV04, pelo MEF.

A condição necessária para que haja interação entre as paredes $\tau_{d, \text { med }} \leq \tau_{d, \text { resist }}$ é verificada na Tabela 6.27. As principais interfaces são verificadas, todas ao nível do $1^{\circ}$ pavimento, ou seja, ao nível 2,80 m. A representação da interface indica primeiramente a parede em que se considera a força cortante vertical na interface, ou seja, a força cortante no encontro com a parede em que se quer interagir, e em seguida a parede de encontro. A segunda coluna desta tabela indica qual combinação de ações e qual sentido das ações horizontais foram consideradas.

Tabela 6.27 - Verificação da tensão de cisalhamento em algumas interfaces verticais.

\begin{tabular}{|c|c|c|c|c|c|c|c|c|}
\hline \multirow[b]{2}{*}{ INTERFACE } & \multirow[b]{2}{*}{ Combinação de ações } & \multicolumn{3}{|c|}{ Vd,int (tf) } & \multicolumn{2}{|c|}{$\tau d, \operatorname{med}\left(\mathrm{tf} / \mathrm{m}^{2}\right)$} & \multirow[b]{2}{*}{$\tau d$, resit $\left(t f / m^{2}\right)$} & \multirow[b]{2}{*}{ STATUS } \\
\hline & & MEF & MPT & $\%$ & MEF & MPT & & \\
\hline PH13-PV04 & $C_{1}-180^{\circ}$ & 4,41 & 4,25 & $-3,55$ & 13,12 & 12,66 & \multirow{7}{*}{38,47} & OK \\
\hline PH31-PV10 & $C_{1}-180^{\circ}$ & 3,99 & 4,22 & 5,80 & 11,88 & 12,57 & & OK \\
\hline PV10-PH31 & $C_{1}-90^{\circ}$ & 3,22 & 3,08 & $-4,41$ & 9,58 & 9,16 & & OK \\
\hline PH15-PV16 & $C_{1}-0^{\circ}$ & 6,45 & 8,75 & 35,71 & 19,19 & 26,04 & & OK \\
\hline PV09-PH02 & $\mathrm{C}_{1}-270^{\circ}$ & 2,74 & 1,99 & $-27,38$ & 8,15 & 5,92 & & OK \\
\hline PH34-PV15 & $\mathrm{C}_{1}-0^{\circ}$ & 4,32 & 4,87 & 12,78 & 12,85 & 14,49 & & OK \\
\hline PV17-PH34 & $C_{1}-90^{\circ}$ & 3,03 & 3,33 & 10,02 & 9,00 & 9,91 & & OK \\
\hline
\end{tabular}


Apesar de haver diferenças razoáveis entre os modelos MPT e MEF, a ordem de grandeza das tensões de cisalhamento obtida é a mesma. Verifica-se que a condição $\tau_{d, \text { med }} \leq \tau_{d, \text { resist }}$ é satisfeita em todos os casos, garantindo desta maneira que o comportamento conjunto das paredes é possível.

Observa-se que o modelo MPT é muito simplificado em relação ao MEF, representando a interface entre as paredes através de apenas um nó ao nível do pavimento. Mesmo assim, as diferenças em relação ao MEF não são muito altas, e a verificação ao dimensionamento, no caso estudado, foi feita com relativa folga.

\subsection{Verificação quanto ao Estado Limite de Serviço de deformações excessivas globais}

Verifica-se o Estado Limite de Serviço das deformações excessivas globais, de maneira simplificada, comparando as translações horizontais ao longo da altura do edifício, com a translação limite dada pela NBR 6118:2007. Segundo essa norma, deslocamentos limites são valores práticos para a verificação em serviço do estado limite de deformações excessivas da estrutura.

Conforme item 17.3.2 da NBR 6118:2007, no Estado Limite de deformação deve-se considerar a rigidez efetiva da seção do elemento, considerando as fissuras e as deformações diferidas no tempo. Nesta mesma norma, em seu item 15.7.3, permite-se considerar a não-linearidade física do concreto armado, de maneira simplificada, multiplicando-se o módulo de elasticidade do elemento estrutural analisado por um redutor. No caso de pilares, esse coeficiente redutor vale 0,8 . Por essas razões, a análise das deformações excessivas globais no edifício exemplo é feita multiplicando-se a rigidez das paredes por 0,8 .

As Figuras 6.45 e 6.46 comparam as translações horizontais na direção $X$ $\left(\delta_{x}\right)$ e $\mathrm{Y}\left(\delta_{y}\right)$, respectivamente, ao longo da altura do edifício exemplo, em função apenas das ações horizontais (ações do vento mais as forças devido ao desaprumo). 
Translações na direção X - sentido $0^{\circ}$

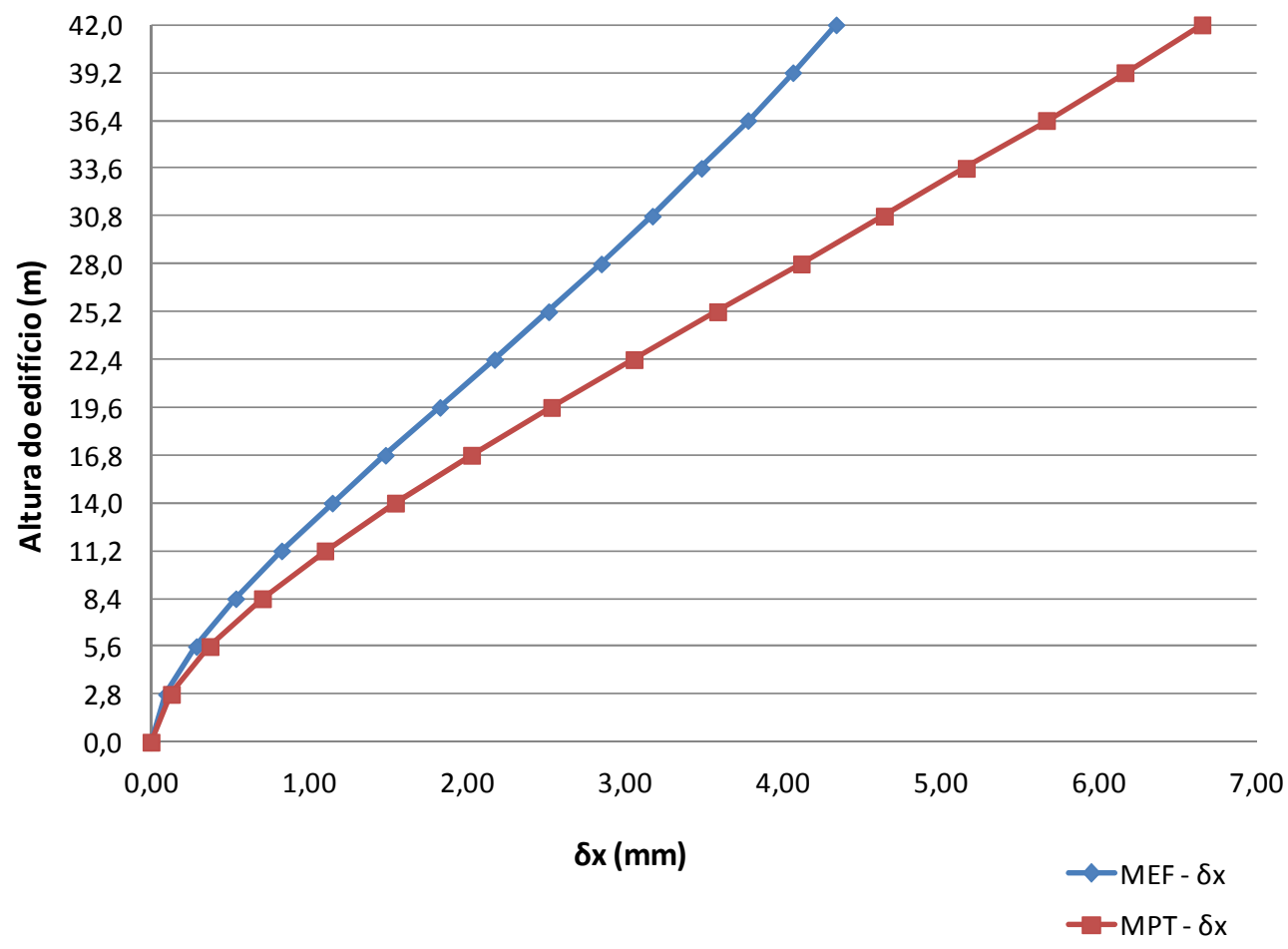

Figura 6.45 - Translações horizontais na direção X - (EE).

Translações na direção Y- sentido $90^{\circ}$

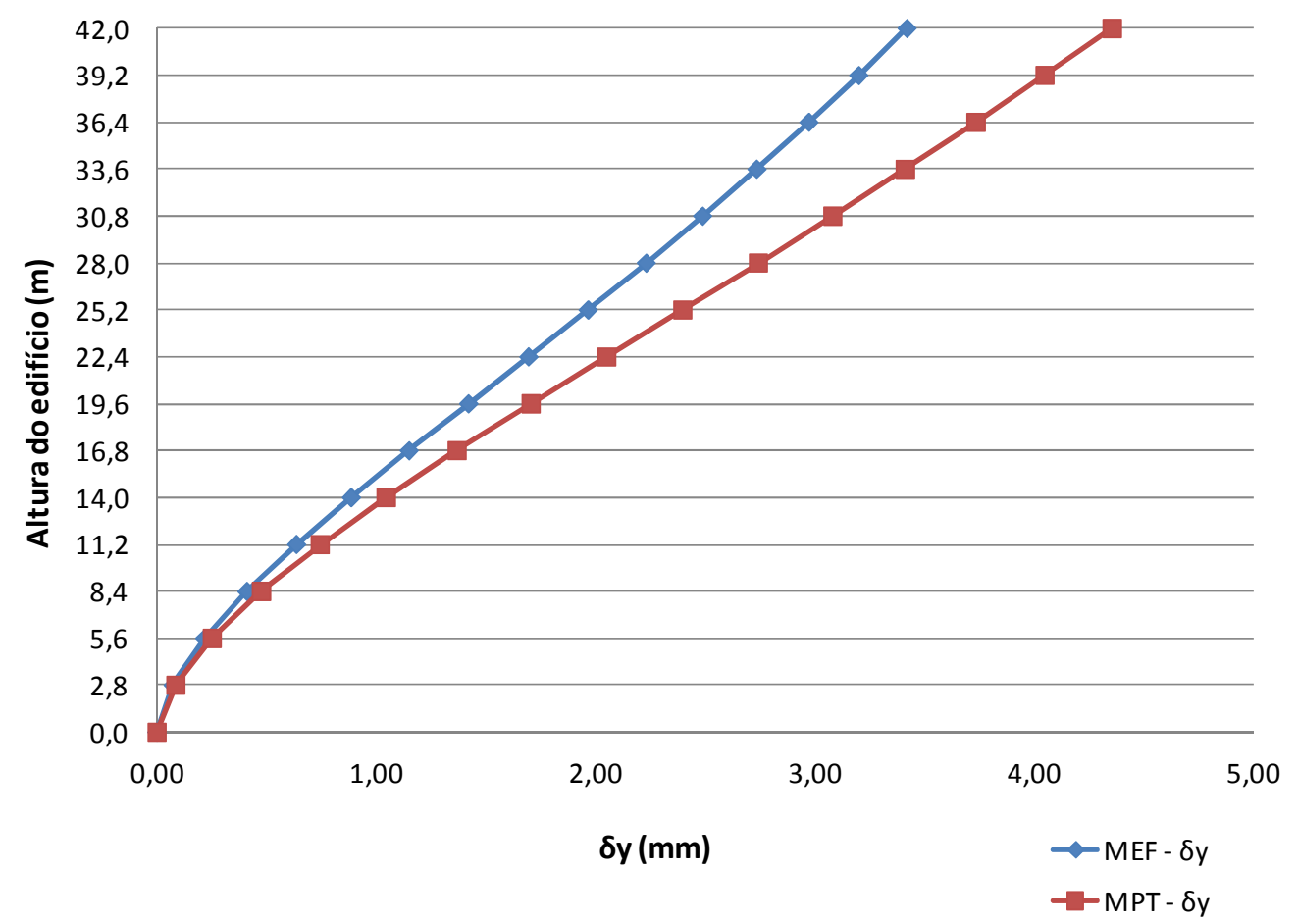

Figura 6.46 - Translações horizontais na direção Y - (EE). 
Tabela 6.28 - Verificação das translações horizontais - (EE).

\begin{tabular}{|c|c|c|c|c|c|c|c|c|}
\cline { 2 - 8 } \multicolumn{1}{c|}{} & \multicolumn{3}{c|}{$\delta x(\mathrm{~mm})$} & \multicolumn{3}{c|}{$\delta \mathrm{y}(\mathrm{mm})$} & \\
\hline nível $(\mathrm{m})$ & MEF & MPT & $\%$ & MEF & MPT & $\%$ & $\delta \lim (\mathrm{mm})$ & STATUS \\
\hline 42,00 & 4,34 & 6,66 & 53,42 & 3,42 & 4,36 & 27,34 & 24,71 & OK \\
\hline
\end{tabular}

Conforme Tabela 6.28, apesar de haver uma diferença razoável entre as translações horizontais obtidas pelos MEF e MPT, no topo do edifício (principalmente na direção $X$, que é de $53,42 \%$ ), os valores são muito menores em relação à translação horizontal limite $\left(\delta_{\lim }\right)$, definida na Tabela 13.2 da NBR 6118:2007 a qual vale $\mathrm{H} / 1700$, onde $\mathrm{H}$ é a altura total do edifício e, portanto, $\delta_{\mathrm{lim}}=$ $24,71 \mathrm{~mm}$.

As Figuras 6.47 e 6.48 mostram as translações horizontais, na direção $X$ $\left(\delta_{C F, x}\right)$ e na direção $\mathrm{Y}\left(\delta_{C F, y}\right)$, respectivamente, considerando-se a combinação de serviço, classificada como frequente, a qual é definida na Equação (6.8):

$$
F_{d, s e r}=\sum F_{g k}+\psi_{1} \cdot F_{q 1 k}+\sum \psi_{2} \cdot F_{q k}
$$

onde:

$F_{d, s e r}:$ valor de cálculo das ações para a combinação de serviço;

$F_{g k}:$ ações permanentes diretas;

$F_{q 1 k}$ : valor característico da ação variável principal direta; neste caso $F_{q 1 k}$ corresponde às ações do vento;

$F_{q k}$ : ações variáveis diretas; neste caso se considera apenas as forças devido ao desaprumo;

Os coeficientes $\psi_{1}$ e $\psi_{2}$ são iguais a 0,3 e 0,0, respectivamente, conforme Tabela 11.2 da NBR 6118:2007. Dessa maneira, as forças devido ao desaprumo são desconsideradas na verificação. 


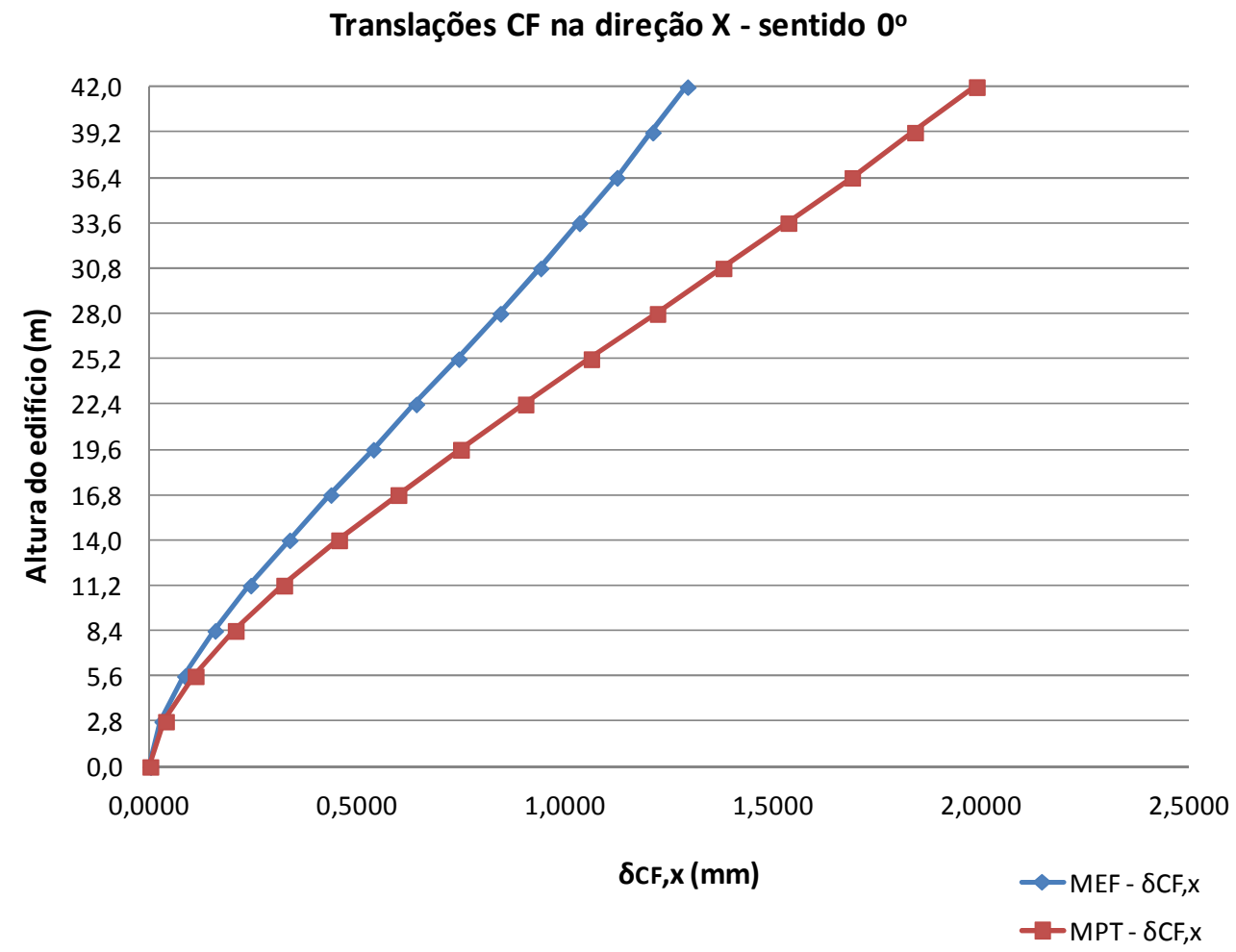

Figura 6.47 - Translações horizontais na direção $X$ considerando a combinação frequente de ações - (EE).

Translações CF na direção Y - sentido $90^{\circ}$

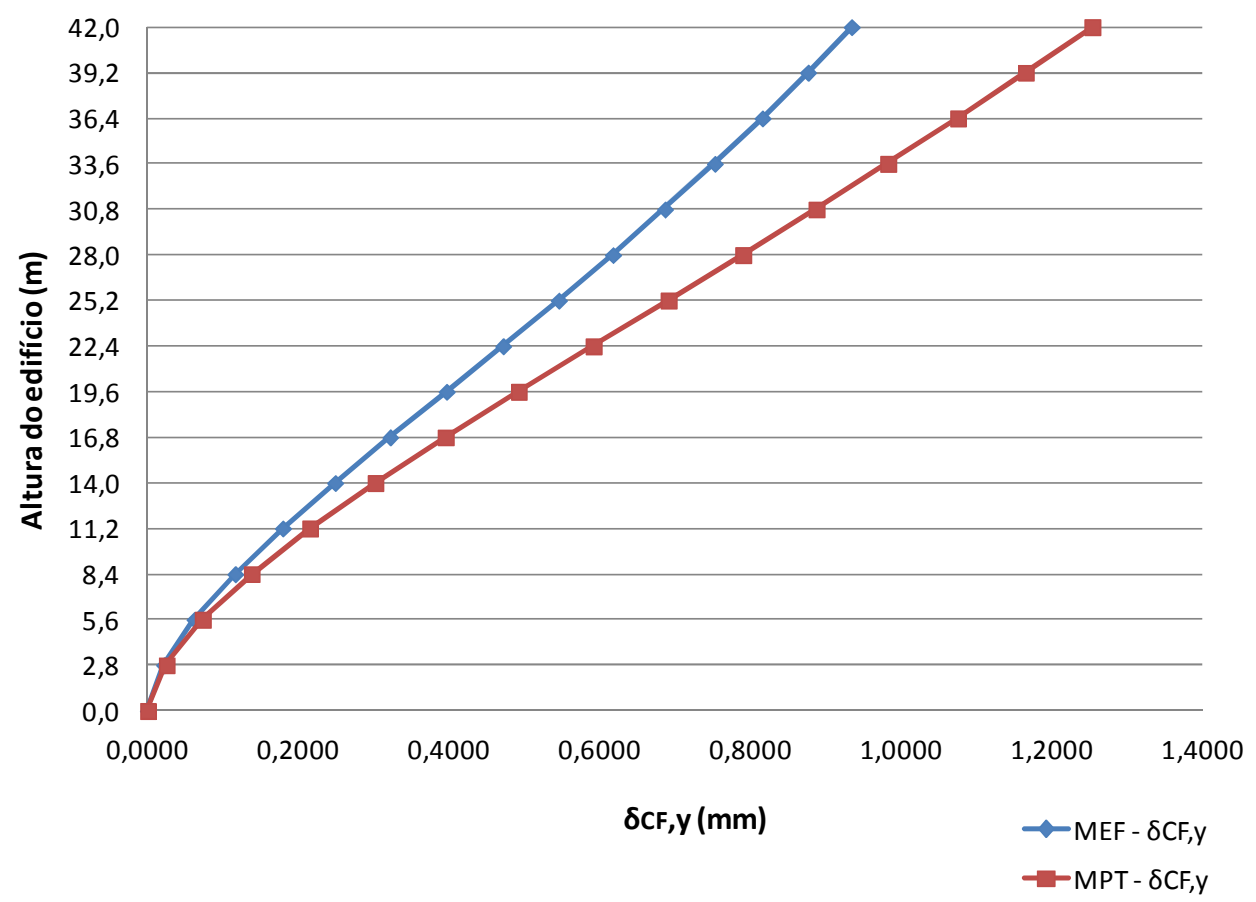

Figura 6.48 - Translações horizontais na direção $Y$ considerando a combinação frequente de ações - (EE). 
A verificação ao dimensionamento do Estado Limite de deformações excessivas globais, considerando a combinação frequente (CF) de ações, é apresentada na Tabela 6.29. Constata-se que os dois modelos apresentam translações muito inferiores à translação limite definida pela NBR 6118:2007 satisfazendo, portanto, a condição necessária para o dimensionamento.

Tabela 6.29 - Verificação das translações horizontais considerando a CF - (EE).

\begin{tabular}{|c|c|c|c|c|c|c|c|c|}
\cline { 2 - 9 } \multicolumn{1}{c|}{} & \multicolumn{3}{c|}{$\delta C F, x(\mathrm{~mm})$} & \multicolumn{3}{c|}{$\delta C F, \mathrm{~mm})$} & \\
\hline nível (m) & MEF & MPT & $\%$ & MEF & MPT & $\%$ & $\delta \lim (\mathrm{mm})$ & STATUS \\
\hline 42,00 & 1,29 & 1,99 & 53,80 & 0,93 & 1,25 & 34,19 & 24,71 & OK \\
\hline
\end{tabular}

Conclui-se que o MPT é mais flexível que o MEF estando, portanto, a favor da segurança. Os resultados quanto às translações horizontais, obtidos pelos dois modelos, têm a mesma ordem de grandeza e estão muito abaixo da translação limite indicada pela NBR 6118:2007. Desta maneira, o MPT também é apropriado para esse tipo de análise.

\subsection{Verificação da estabilidade global}

A NBR 16055:2012 permite a verificação da estabilidade global de edifícios construído no sistema Paredes de Concreto, calculando-se o coeficiente $\gamma_{z}$ conforme item 15.5.3 da NBR 6118:2007, cuja expressão é definida na Equação (6.9):

$$
\gamma_{z}=\frac{1}{1-\frac{\Delta M_{t o t, d}}{M_{1, t o t, d}}}
$$

onde:

$\Delta M_{t o t, d}$ : é a soma dos produtos de todas as forças verticais atuantes na estrutura, na combinação considerada, com seus valores de cálculo, pelas translações horizontais de seus respectivos pontos de aplicação, obtidos na análise de $1^{\text {a }}$ ordem; 
$M_{1, t o t, d}$ : é o momento de tombamento, ou seja, a soma dos momentos de todas as forças horizontais da combinação considerada, com seus valores de cálculo, em relação à base da estrutura.

A NBR 6118:2007 classifica estrutura de nós fixos, aquelas em que as translações horizontais são pequenas e por isso os efeitos globais de $2^{a}$ ordem são desprezíveis. Nas estruturas de nós fixos o acréscimo dos esforços de $1^{\text {a }}$ ordem, decorrentes do efeito global de $2^{a}$ ordem, é menor que $10 \%$. O coeficiente $\gamma_{z}$ é uma ferramenta para aferir a estabilidade global de um edifício, e medir aproximadamente qual seria 0 acréscimo necessário aos esforços de $1^{a}$ ordem, provocados pelos efeitos globais de $2^{\mathrm{a}}$ ordem. Por essas razões a NBR 6118:2007 classifica estruturas de nós fixos aquelas em que $\gamma_{z} \leq 1,1$.

Por ser o modelo mais flexível utilizou-se o MPT para o cálculo dos coeficientes $\gamma_{z}$ nas direções $\mathrm{X}$ e $\mathrm{Y}$ do edifício exemplo. Considerou-se a nãolinearidade física aproximada (igualmente ao item 6.10), para obtenção das translações horizontais ao longo da altura do edifício.

Os resultados de $\gamma_{z, x}$ e $\gamma_{z, y}$ são apresentados respectivamente nas Tabelas 6.30 e 6.31. Em ambos os casos obteve-se $\gamma_{z} \leq 1,1$, limite a partir do qual os efeitos globais de $2^{\mathrm{a}}$ ordem devem ser considerados.

Portanto os resultados de $\gamma_{z}$ obtidos para o EE, justificam a análise linear realizada no edifício exemplo e a não consideração dos efeitos globais de $2^{\mathrm{a}}$ ordem.

Tabela 6.30 - Cálculo de $\gamma_{z, x}$.

\begin{tabular}{|c|c|c|}
\hline \multicolumn{3}{|c|}{$\gamma_{z}$ na direção $\mathrm{X}$} \\
\hline$\Delta$ Mtot,d $\times(\mathrm{tf})$ & $\mathrm{M} 1, \mathrm{tot}, \mathrm{d} \times(\mathrm{tf})$ & $\gamma_{z, x}$ \\
\hline 25,91 & 2186,11 & 1,012 \\
\hline
\end{tabular}

Tabela 6.31 - Cálculo de $\gamma_{z, y}$.

\begin{tabular}{|c|c|c|}
\hline \multicolumn{3}{|c|}{$\gamma_{z}$ na direção $\mathrm{Y}$} \\
\hline$\Delta$ Mtot,d y (tf) & M1,tot,d y $(\mathrm{tf})$ & $\gamma_{z, y}$ \\
\hline 17,23 & 2492,10 & 1,007 \\
\hline
\end{tabular}




\section{CONCLUSÕES}

A comparação entre os resultados obtidos pelos modelos de cálculo estudados foi realizada com o objetivo de avaliá-los qualitativamente quando aplicados ao pré-dimensionamento e dimensionamento de paredes de concreto armado, de um edifício construído no sistema Paredes de Concreto.

Todas as comparações de resultados foram feitas em relação ao Modelo em Elementos Finitos, considerado como o mais próximo do comportamento real por discretizar as paredes com elementos de casca.

Primeiramente, analisou-se a distribuição de cargas verticais entre as paredes de concreto dos edifícios estudados. A força normal concentrada ao nível da fundação foi obtida por modelos de cálculo e comparada. Constatou-se excelente aproximação entre os modelos MPT e MEF e boa aproximação entre os modelos GIP e MEF. O modelo PIS apresentou resultados ruins em relação ao MEF. Portanto, os modelos MPT e GIP são confiáveis e seguros para distribuir cargas verticais nas paredes de concreto de um edifício construído no sistema Paredes de Concreto. Ressalta-se a qualidade de resultados do modelo GIP, por ser simples, rápido e não exigir a discretização da estrutura. Recomenda-se a utilização do MPT e GIP em projeto estrutural para o tipo de edificação estudada, por serem bem mais simples e possibilitarem fácil análise de resultados, em comparação com o MEF.

$\mathrm{Na}$ etapa do pré-dimensionamento das espessuras das paredes, a estimativa da máxima tensão normal de compressão (obtida pelos quatro modelos de cálculo), foi comparada com a resistência última à compressão calculada pelas normas AS 3600:2001, AS 3600:2009, ACl 318:2011, EN 1992:2004 e NBR 16055:2012. A estimativa da máxima tensão normal de compressão foi obtida multiplicando-se a tensão normal de compressão, calculada apenas pelas cargas verticais, pelo coeficiente $\mathrm{C}_{\mathrm{AH}}$, $\circ$ qual estima $\mathrm{O}$ acréscimo dessa tensão devido às ações horizontais. Esse procedimento se mostrou adequado para o edifício exemplo estudado, visto que na maioria dos casos as estimativas das máximas tensões normais de compressão ficaram muito próximas às reais máximas tensões normais de compressão obtidas. Observa-se que o coeficiente $\mathrm{C}_{\mathrm{AH}}$ foi formulado em função das geometrias e carregamentos do edifício exemplo, e deve ser validado para outros casos. 
Como esperado, o pré-dimensionamento foi bastante influenciado pelo limite da máxima tensão normal de compressão, estabelecido pelas normas citadas. As hipóteses de cálculo da resistência última à compressão são diferentes e, portanto, os resultados também. As normas que apresentam a hipótese de que as paredes de concreto possam ser vinculadas apenas em sua base e topo, como é o caso do $\mathrm{ACl}$ 318:2011 e AS 3600:2001, em geral apresentaram resultados menores de resistência última à compressão. Já aquelas que consideram a possível vinculação nas quatro bordas, como é o caso da NBR 16055:2012, EN 1992:2004 e AS 3600:2009, apresentaram, em geral, resultados maiores. Essa conclusão fica evidente ao compararem-se as normas AS 3600:2001 e AS 3600:2009. A última versão do código australiano, apresentou resultados maiores em relação à versão de 2001, justamente pela alteração feita no cálculo da altura efetiva da parede, que agora considera a possibilidade de vinculação em todo contorno. A NBR 16055:2012 se mostrou mais arrojada, porém ao mesmo tempo, coerente com as outras que consideram vinculação nas quatro bordas das paredes. Os resultados de resistência última à compressão obtidos pela norma brasileira, em geral foram maiores, porém percebeu-se uma considerável diminuição de resistência quando o índice de esbeltez das paredes ultrapassa o valor 86 , limite a partir do qual a influência da instabilidade localizada é bem maior. Essa penalidade de resistência em função do índice de esbeltez também ficou clara nos EN 1992:2004 e AS 3600:2009. Pela grande diferença de resultados obtidos pelas diferentes normas concluiu-se que é importante continuar investigando quais hipóteses são as mais adequadas para o cálculo da resistência última à compressão de paredes de concreto armado, para que seja possível uma avaliação mais aprofundada da expressão apresentada pela NBR 16055:2012.

A distribuição de ações horizontais nas paredes de concreto foi estudada através de seus diagramas de esforços solicitantes característicos, considerando apenas as forças devido ao vento e ao desaprumo. Observaram-se diferenças consideráveis entre os valores obtidos pelos modelos MEF e MPT de momentos fletores e forças normais. O momento fletor ao nível da fundação da PH34 do edifício exemplo diferiu entre os modelos em $56,21 \%$. O mesmo ocorreu com a máxima força normal obtida nesta parede, cuja diferença chegou em 63,05\%. Apesar das diferenças verificadas nos resultados desses dois esforços, as curvas dos respectivos diagramas foram próximas e tenderam a um mesmo 
comportamento. Os diagramas de forças cortantes apresentaram resultados muito próximos, exceto nas regiões que configuram nós de pórtico, as quais não foram discutidas neste trabalho.

As diferenças percebidas entre o MEF e 0 MPT quando se obtiveram momentos fletores e forças normais, considerando apenas as ações horizontais, tornaram-se insignificantes quando a verificação ao dimensionamento de tensões normais das paredes foi realizada. Para tanto, foi necessário combinar as ações verticais e horizontais de modo a obter as máximas tensões normais de compressão e as possíveis máximas tensões normais de tração. Quando a composição da força normal de cálculo com o momento fletor de cálculo foi feita, conforme as devidas combinações de ações, os valores de tensão normal obtidos pelos dois modelos ficaram muito próximos. No caso da parede $\mathrm{PH} 34$ do edifício exemplo, a diferença entre os dois modelos referente à máxima tensão normal de compressão foi de apenas $0,13 \%$. Os diagramas das tensões normais, traçados nas seções transversais críticas de algumas paredes, também evidenciaram a proximidade entre os modelos. Essa semelhança das tensões foi justificada pela grande proximidade obtida nas forças normais oriundas apenas de cargas verticais. Além disso, as forças normais devidas às cargas verticais foram muito maiores que os outros esforços obtidos pelas ações horizontais. Ressalta-se que os edifícios estudados neste trabalho, não possuem alta esbeltez. A máxima tensão normal de compressão foi sempre menor que a resistência última à compressão calculada pela NBR 16055:2012, considerando as paredes com $12 \mathrm{~cm}$ de espessura, o que satisfez, portanto, a condição mínima para o dimensionamento. Nas paredes estudadas, não se observou tensão normal de tração. Assim, nos resultados de interesse para o dimensionamento das paredes, as diferenças obtidas entre os modelos MEF e MPT foram muito pequenas, o que mostrou a qualidade e a confiabilidade do modelo MPT.

A verificação das tensões tangencias nas almas das paredes de contraventamento foi realizada comparando-se a maior força cortante de cálculo, obtida pelos dois modelos numéricos, com a força cortante resistente de cálculo obtida pela NBR 16055:2012. Os resultados das forças cortantes de cálculo obtidos pelos modelos MEF e MPT foram próximos, com diferenças sempre abaixo de $15 \%$. Foram, também, sempre menores que a força cortante resistente de cálculo, satisfazendo a condição para o dimensionamento. 
A tensão de cisalhamento na interface vertical nos principais encontros de paredes foi verificada, a fim de validar a interação entre paredes. Para tanto, foi obtida a tensão média de cisalhamento na interface vertical e comparada à tensão de cisalhamento resistente de cálculo. Os resultados obtidos pelos dois modelos numéricos apresentaram considerável diferença em alguns casos. Observou-se que o modelo MPT é muito simplificado em relação ao MEF, representando a interface entre as paredes através de apenas um nó ao nível do pavimento. Mesmo assim, os resultados obtidos pelos dois modelos tiveram mesma ordem de grandeza e estiveram sempre abaixo da tensão de cisalhamento resistente de cálculo, com certa folga. Observa-se que a NBR 16055:2012 exige que as paredes de concreto sejam monolíticas e para tanto é necessário armadura de ligação entre elas. Isso faz com que a resistência ao cisalhamento na interface seja maior ainda (contribuição da armadura).

Concluiu-se, portanto, que o MPT pode ser usado para o dimensionamento das tensões tangencias, tanto na alma, quanto na interface vertical, de paredes de concreto armado de um edifício.

O Estado Limite de Serviço das deformações excessivas globais, referentes à movimentação lateral do edifício, foi verificado comparando-se as translações horizontais ao longo da altura do edifício estudado, com a translação horizontal limite definida pela NBR 6118:2007. Em ambos os modelos constatou-se uma grande rigidez global do edifício, já que as translações horizontais obtidas ficaram muito abaixo do valor limite. O MPT se mostrou mais flexível em relação ao MEF, estando, portanto, a favor da segurança para este tipo de análise.

Por fim, verificou-se a estabilidade global do edifício exemplo por meio do coeficiente $\gamma_{z}$, calculado apenas com o emprego do MPT (modelo mais flexível). Nas duas direções analisadas, o coeficiente ficou bem abaixo do limite a partir do qual as considerações dos efeitos globais de $2^{\mathrm{a}}$ ordem e, portanto, a análise não linear, são necessárias.

Portanto, conclui-se que o Modelo Pórtico Tridimensional pode ser usado na análise estrutural de edifícios construídos no sistema Paredes de Concreto. O MPT se mostrou um modelo confiável pela proximidade de resultados quando comparado com o MEF. A análise de resultados via MEF é complexa, tornando-o muitas vezes uma ferramenta não utilizada no cotidiano de um escritório de cálculo. Recomenda- 
se a utilização do MEF para análises locais e que requerem maiores detalhes. Juntamente ao MPT, a utilização do Grupo Isolado de Paredes no desenvolvimento do projeto estrutural de um edifício de Paredes de Concreto, é altamente recomendada quando o objetivo é distribuir cargas verticais.

\subsection{Sugestões para trabalhos futuros}

Os efeitos de torção não foram considerados ou foram desprezados por serem muito pequenos, nos dois edifícios estudados. Sugere-se o estudo de edifício de Paredes de Concreto, contendo geometria em planta não simétrica e submetida a ações horizontais excêntricas a fim de se investigar o efeito do momento torçor nas paredes de concreto.

Como os modelos numéricos deste trabalho não consideraram a interação solo-estrutura, sugere-se a inclusão deste efeito na avaliação dos esforços solicitantes de cálculo e das translações horizontais ao longo da altura do edifício, em função dessa alteração nas condições de contorno dos modelos.

Outro estudo de interesse é a consideração da hipótese de não linearidade física e geométrica nos modelos numéricos de edifício de Paredes de Concreto mais altos, com o objetivo de verificar os efeitos de $2^{\mathrm{a}}$ ordem globais.

Sugere-se uma avaliação mais aprofundada da expressão de resistência última à compressão dada pela NBR 16055:2012. Para tanto, sugere-se uma comparação teórica entre os procedimentos da NBR 6118:2007 para a análise de pilares-parede, com as premissas de dimensionamento de paredes de concreto definidas na NBR 16055:2012. Estudos comparativos de resultados entre modelos numéricos e experimentais também seriam de grande utilidade. 


\section{REFERÊNCIAS BIBLIOGRÁFICAS}

ASSOCIAÇÃO BRASILEIRA DE CIMENTO PORTLAND (2013). Colaborativo Portal. Disponível em: http://www.abcp.org.br/colaborativo-portal/download.php. Acesso em maio de 2013.

ALVES, C. O.; PEIXOTO, E. J. S. (2011). Estudo comparativo de custo entre alvenaria estrutural e paredes de concreto armado moldadas no local com formas de alumínio. Trabalho de Conclusão de Curso (Graduação em Engenharia Civil) - Centro de Ciências Exatas e Tecnologia, Universidade da Amazônia, Belém, 2011.

AMERICAN CONCRETE INSTITUTE. ACI 318: Building Code Requirements for Reinforced concrete. Farmigton Hills, 2011.

ASSOCIAÇÃO BRASILEIRA DE NORMAS TÉCNICAS. NBR 6118: Projeto de estruturas de concreto - Procedimentos. Rio de Janeiro, 2007.

ASSOCIAÇÃO BRASILEIRA DE NORMAS TÉCNICAS. NBR 6120: Cargas para o cálculo de estruturas de edificações. Rio de Janeiro, 1980.

ASSOCIAÇÃO BRASILEIRA DE NORMAS TÉCNICAS. NBR 8681: Ações e segurança nas estruturas - Procedimentos. Rio de Janeiro, 2003.

ASSOCIAÇÃO BRASILEIRA DE NORMAS TÉCNICAS. NBR 15961-1: Alvenaria estrutural - Blocos de concreto Parte 1: Projeto. Rio de Janeiro, 2011.

ASSOCIAÇÃO BRASILEIRA DE NORMAS TÉCNICAS. NBR 16055: Parede de concreto moldada no local para a construção de edificações - Requisitos e procedimentos. Rio de Janeiro, 2012.

BARRIGA, D. E. J. (2009). Análisis comparativo entre sistema aporticado y sistema de paredes portantes de hormigón.Proyectoprevio a laobtencióndel título de ingeniero civil - Facultad de Ingeniería Civil y Ambiental, Escuela Politécnica Nacional, Quito (2009).

BLESSMANN, J. (1989). Efeitos do vento em edificações. 2.ed. Porto Alegre, Editora da UFRGS. (Série Engenharia Estrutural, 7).

CAPUZZO NETO, V. (2000). Estudo teórico e experimental da interação de paredes de alvenaria estrutural submetidas a ações verticais. Dissertação (Mestrado) - Escola de Engenharia de São Carlos, da Universidade de São Paulo, São Carlos, 2000.

COMUNIDADE DA CONSTRUÇÃO (2013). Sistemas Construtivos; Paredes de Concreto. Disponível em: http://www.comunidadedaconstrucao.com.br/sistemasconstrutivos/2/parede-de-concretol. Acesso em maio de 2013. 
CORELHANO, A. G. B. (2010). Análise não linear geométrica e física de núcleos rígidos de edifícios altos em concreto armado. Dissertação (Mestrado) - Escola de Engenharia de São Carlos, da Universidade de São Paulo, São Carlos, 2000.

CORRÊA, M. R. S. (1991). Aperfeiçoamento de modelos usualmente empregados no projeto de sistemas estruturais de edifícios. Tese (Doutorado) Escola de Engenharia de São Carlos, Universidade de São Paulo, 1991.

CORRÊA, M. R. S. (2003). Fluxo de forças em edifícios de alvenaria estrutural. 156f. Texto apresentado para o concurso de Professor Livre Docente do departamento de Engenharia de Estruturas da Escola de Engenharia de São Carlos, Universidade de São Paulo, 2003.

CORRÊA, M.R.S.; RAMALHO, M.A. (2003). Projeto de edifícios de alvenaria estrutural. São Paulo: Pini, 2003.

COMPUTERS \& STRUCTURES INC. (2011). CSI Analysis reference manual for SAP2000. Berkeley, California, USA, 2011.

$\mathrm{DOH}, \mathrm{J}$. H. (2002). Experimental and theoretical studies of normal and high strength concrete wall panels. Thesis (Doctor of Philosophy), Griffith University.

FONTE, A. O. C.; FONTE, F. L. F.; CASTILlO, A. A. H., PEDROSA, A. V. A. C. (2005). Características e parâmetros estruturais de edifícios de múltiplos andares em concreto armado, construídos na cidade de Recife. $47^{\circ}$ Congresso Brasileiro do Concreto. Recife, IBRACON, 2005.

FRAGOMENI, S. (1995). Design of normal and high strength reinforced concrete walls.Ph.D. Thesis, University of Melbourne, Melbourne, Australia, 1995.

FRAGOMENI, S.; MENDIS, P. A.; GRAYSON, W. R. (1994). Review of Reinforced Concrete Wall Design Formulas.American Concrete Institute Structural Journal, v. 91, No 5, p. 521-528, October 1994.

FRAGOMENI, S.; DOH, J. H. (2010). Evaluation of the Simplified Concrete Wall Design Equation in AS3600-2009.Australian Journal of Structural Engineering, v. 10, No 3, p. 253-261, Australia, 2010.

GETHAL (2013). Histórico. Disponível em: http://gethal.com.br/2013/?page id=21. Acesso em maio de 2013.

HENDRY, A.W. (1981). Structural Brickwork.London, MacMillan Press Ltd, 1981.

INSTITUTO BRASILEIRO DE TELAS SOLDADAS (2013). Rodobens investe no sistema construtivo Paredes de Concreto. Disponível em: http://www.ibts.org.br/noticias01.asp. Acesso em maio de 2013.

EUROPEAN STANDARD. EN1992:2004 - Eurocode 2: Design of Concrete Structures-part 1-1: General Rules and Rules for Buildings.London, 2004. 
KALITA, U.C.; HENDRY, A.W. (1970). An investigation of the stresses and deflections in model cross-wall structure subjected to lateral load and torsion.The British Ceramic Research Association.The British Ceramic Research Association.Technical note.No. 161.

KESKIN, O. (1974). Torsional effects in masonry structures under lateral loading.Ph.D., Thesis, Edinburgh, University of Edinburgh.

NACIMBA, D. G. G. (2009). Comparación económica entre metodologías de vivienda unifamiliar de tipo tradicional de hormigón armado (columnas, vigas y losasalivianadas) Vs. paredes portantes de hormigón (paredes de hormigón armado y losasmacizas), enelestudio de laurbanizaciónOrión.Proyectoprevio a laobtencióndel titulo de tecnologoenadministración de proyectos de construcción Escuela de Formación de Tecnólogos, Escuela Politécnica Nacional, Quito (2009).

NASCIMENTO NETO, J. A. (1999). Investigação das solicitações de cisalhamento em edifícios de alvenaria estrutural submetidos a ações horizontais. Dissertação (Mestrado) - Escola de Engenharia de São Carlos Universidade de São Paulo, São Carlos, 1999.

NASCIMENTO NETO, J.A.; CORRÊA, M.R.S. (2002). Análise tridimensional de edifícios em alvenaria estrutural submetidos à ação do vento. Cadernos de Engenharia de São Carlos, n.19, p. 81-100, São Carlos, 2002.

NUNES, V.Q.G. (2011). Análise estrutural de edifícios de paredes de concreto armado. Dissertação (Mestrado) - Escola de Engenharia de São Carlos, da Universidade de São Paulo, São Carlos, 2011.

OLIVEIRA, L. M. F. (2009). Cisalhamento nas interfaces verticais de paredes de edifícios de alvenaria estrutural. Dissertação (Mestrado) - Escola de Engenharia de São Carlos, da Universidade de São Paulo, São Carlos, 2009.

PEREIRA, A. C. O. (2000). Estudo da influência da modelagem estrutural do núcleo nos painéis de contraventamento de edifícios altos. Dissertação (Mestrado) - Escola de Engenharia de São Carlos, Universidade de São Paulo, São Carlos, 2000.

SACH, H.M.; ROSSIGNOLO, J.A.; BUENO,C. (2011). Vedações verticais em concreto moldadas in loco: avaliação do conforto térmico de habitações térreas no Estado de São Paulo.Revista Ibracon de Estruturas e Materiais, v.4, p.31-48, São Paulo, 2011.

SAHEB, S. M.; DESAYI, P. (1989). Ultimate Strength of R.C. Wall Panels in Oneway In-Plane Action. Journal of Structural Engineering, ASCE, v. 115, No 10, p. 2617-2630, October 1989.

SERRA, J. L. F. A. (1994). Contribuição ao estudo de núcleos resistentes de concreto armado.Tese (Doutorado) - Escola de Engenharia de São Carlos, Universidade de São Paulo, 1994. 
SILVA, R. C.; GIONGO, J. S. (2000). Modelos de bielas e tirantes aplicados a estruturas de concreto armado. São Carlos: EESC-USP.

SOUZA, R. A. (2004). Concreto estrutural: análise e dimensionamento de elementos com descontinuidades. Tese (Doutorado) - Departamento de Engenharia de Estruturas e Fundações, Escola Politécnica da Universidade de São Paulo, São Paulo, 2004.

STANDARDS AUSTRALIA (2001). AS 3600: Concrete Structures.North Sydney, NSW, Australia, 2001.

STANDARDS AUSTRALIA (2009). AS 3600: Concrete Structures.North Sydney, NSW, Australia, 2009.

TIMOSHENKO S. P. (1966). Resistência dos materiais. Vol. 2. Ed. LTC, Rio de Janeiro, 1966.

UNIVERSIDAD NACIONAL DE COLUMBIA (2013). Archivo particular. Disponível em:http://www.virtual.unal.edu.co/cursos/sedes/manizales/4020001/Clases/capitulo \%205/05.htm. Acesso em maio de 2013.

YAGUI, T. (1971). Estruturas constituídas de paredes delgadas com diafragmas transversais. Tese (Doutorado) - Escola de Engenharia de São Carlos, Universidade de São Paulo, 1971. 
ANEXOS

\section{ANEXO A}

\section{A) Tabelas do item 6.5.6}

Tabela 6A-1 - Estudo para a formulação de $\mathrm{C}_{\mathrm{AH}}$ - Edifício exemplo com 12 pavimentos.

\begin{tabular}{|c|c|c|c|c|c|c|c|c|c|c|c|}
\hline \multicolumn{12}{|c|}{ CAH - 12 PAVs. } \\
\hline PAREDE & $L(m)$ & $\mathrm{I}\left(\mathrm{m}^{4}\right)$ & Nk,vert (tf) & $\eta \mathrm{d}$, vert $(\mathrm{tf} / \mathrm{m})$ & $\mathrm{NCd}(\mathrm{tf})$ & $\operatorname{Mcd}$ (tf.m) & $\sigma c d(t f / m 2)$ & $\eta \mathrm{Cd}(\mathrm{tf} / \mathrm{m})$ & $\eta \subset d / \eta d$,vert & $\mathrm{C}_{\mathrm{AH}}$ & $\%$ \\
\hline $\mathrm{PHO1}$ & 0,8 & 0,004267 & 14,35 & 25,11 & 22,23 & 0,71 & 344,57 & 34,46 & 1,37 & 1,20 & $-12,3$ \\
\hline PHO2 & 1,2 & 0,0144 & 22,09 & 25,78 & 28,72 & 1,87 & 317,38 & 31,74 & 1,23 & 1,22 & $-1,0$ \\
\hline $\mathrm{PHO3}$ & 0,4 & 0,000533 & 7,46 & 26,11 & 11,04 & 0,10 & 312,52 & 31,25 & 1,20 & 1,19 & $-0,7$ \\
\hline PH07 & 0,4 & 0,000533 & 7,51 & 26,28 & 11,13 & 0,12 & 322,52 & 32,25 & 1,23 & 1,19 & $-3,1$ \\
\hline PH11 & 0,8 & 0,004267 & 14,77 & 25,85 & 20,64 & 0,54 & 308,77 & 30,88 & 1,19 & 1,20 & 0,7 \\
\hline PH13 & 3,2 & 0,273067 & 59,07 & 25,84 & 76,71 & 17,29 & 341,00 & 34,10 & 1,32 & 1,29 & $-1,9$ \\
\hline PH15 & 4,0 & 0,533333 & 59,72 & 20,90 & 78,43 & 26,22 & 294,43 & 29,44 & 1,41 & 1,32 & $-6,0$ \\
\hline PH16 & 4,0 & 0,533333 & 75,48 & 26,42 & 101,35 & 28,75 & 361,19 & 36,12 & 1,37 & 1,32 & $-3,1$ \\
\hline PH18 & 0,4 & 0,000533 & 6,05 & 21,18 & 10,10 & 0,10 & 289,85 & 28,99 & 1,37 & 1,19 & $-13,2$ \\
\hline PH19 & 0,8 & 0,004267 & 13,56 & 23,73 & 17,68 & 0,50 & 267,72 & 26,77 & 1,13 & 1,20 & 6,7 \\
\hline $\mathrm{PH} 21$ & 0,8 & 0,004267 & 15,31 & 26,78 & 21,83 & 0,48 & 317,58 & 31,76 & 1,19 & 1,20 & 1,5 \\
\hline $\mathrm{PH} 22$ & 1,2 & 0,0144 & 23,95 & 27,94 & 30,61 & 1,33 & 310,38 & 31,04 & 1,11 & 1,22 & 9,7 \\
\hline PH23 & 0,8 & 0,004267 & 17,09 & 29,91 & 22,91 & 0,47 & 330,37 & 33,04 & 1,10 & 1,20 & 9,0 \\
\hline PH28 & 1,2 & 0,0144 & 19,21 & 22,41 & 26,61 & 1,57 & 286,95 & 28,69 & 1,28 & 1,22 & $-4,8$ \\
\hline PH3O & 1,6 & 0,034133 & 25,35 & 22,18 & 37,08 & 3,20 & 306,65 & 30,66 & 1,38 & 1,23 & $-10,8$ \\
\hline PH34 & 2,8 & 0,182933 & 44,22 & 22,11 & 58,69 & 12,12 & 302,37 & 30,24 & 1,37 & 1,28 & $-6,5$ \\
\hline $\mathrm{PH} 40$ & 2,8 & 0,182933 & 45,92 & 22,96 & 62,63 & 11,49 & 311,62 & 31,16 & 1,36 & 1,28 & $-5,8$ \\
\hline PV01 & 4,0 & 0,533333 & 72,20 & 25,27 & 105,86 & 18,14 & 332,68 & 33,27 & 1,32 & 1,32 & 0,6 \\
\hline PV02 & 0,8 & 0,004267 & 14,70 & 25,72 & 21,53 & 0,48 & 314,22 & 31,42 & 1,22 & 1,20 & $-1,5$ \\
\hline PV05 & 0,4 & 0,000533 & 7,58 & 26,54 & 10,91 & 0,09 & 306,49 & 30,65 & 1,15 & 1,19 & 2,9 \\
\hline PV06 & 0,8 & 0,004267 & 15,32 & 26,80 & 19,84 & 0,60 & 304,17 & 30,42 & 1,13 & 1,20 & 6,1 \\
\hline PV08 & 2,8 & 0,182933 & 51,87 & 25,93 & 72,09 & 8,33 & 321,23 & 32,12 & 1,24 & 1,28 & 3,3 \\
\hline PV10 & 2,4 & 0,1152 & 46,79 & 27,30 & 61,87 & 5,71 & 317,23 & 31,72 & 1,16 & 1,26 & 8,7 \\
\hline PV12 & 2,4 & 0,1152 & 45,22 & 26,38 & 61,62 & 5,71 & 316,23 & 31,62 & 1,20 & 1,26 & 5,4 \\
\hline PV14 & 1,6 & 0,034133 & 34,30 & 30,01 & 43,78 & 1,95 & 319,23 & 31,92 & 1,06 & 1,23 & 16,0 \\
\hline PV15 & 7,2 & 3,1104 & 114,77 & 22,32 & 158,13 & 86,02 & 319,18 & 31,92 & 1,43 & 1,44 & 1,0 \\
\hline PV17 & 2,0 & 0,066667 & 31,76 & 22,23 & 48,18 & 3,71 & 296,55 & 29,66 & 1,33 & 1,25 & $-6,4$ \\
\hline PV18 & 0,4 & 0,000533 & 6,38 & 22,34 & 8,73 & 0,02 & 227,42 & 22,74 & 1,02 & 1,19 & 16,7 \\
\hline PV19 & 7,2 & 3,1104 & 119,88 & 23,31 & 156,71 & 85,68 & 316,82 & 31,68 & 1,36 & 1,44 & 6,3 \\
\hline PV20 & 7,2 & 3,1104 & 108,47 & 21,09 & 146,70 & 91,51 & 309,65 & 30,97 & 1,47 & 1,44 & $-1,6$ \\
\hline
\end{tabular}

Tabela 6A-2 - Estudo para a formulação de $\mathrm{C}_{\mathrm{AH}}$ - Edifício exemplo com 10 pavimentos.

\begin{tabular}{|c|c|c|c|c|c|c|c|c|c|c|c|}
\hline \multicolumn{12}{|c|}{ CAH - 10 PAVs. } \\
\hline PAREDE & $\mathrm{L}(\mathrm{m})$ & $I\left(m^{4}\right)$ & $\mathrm{Nk}$,vert (tf) & $\eta d$, vert $(\mathrm{tf} / \mathrm{m})$ & $\mathrm{NCd}$ (tf) & $\operatorname{Mcd}(t f . m)$ & $\sigma c d(t f / m 2)$ & $\eta \mathrm{Cd}(\mathrm{tf} / \mathrm{m})$ & $\eta \mathrm{Cd} /$ nd,vert & $\mathrm{C}_{\mathrm{AH}}$ & $\%$ \\
\hline PH01 & 0,8 & 0,004267 & 11,90 & 20,83 & 17,88 & 0,56 & 276,02 & 27,60 & 1,33 & 1,18 & $-11,2$ \\
\hline $\mathrm{PHO2}$ & 1,2 & 0,0144 & 18,43 & 21,50 & 24,01 & 1,45 & 260,28 & 26,03 & 1,21 & 1,19 & $-1,7$ \\
\hline PHO3 & 0,4 & 0,000533 & 6,24 & 21,85 & 9,05 & 0,08 & 254,49 & 25,45 & 1,16 & 1,16 & $-0,1$ \\
\hline PH07 & 0,4 & 0,000533 & 6,30 & 22,06 & 9,14 & 0,09 & 260,70 & 26,07 & 1,18 & 1,16 & $-1,5$ \\
\hline PH11 & 0,8 & 0,004267 & 12,32 & 21,57 & 17,07 & 0,42 & 252,70 & 25,27 & 1,17 & 1,18 & 0,4 \\
\hline PH13 & 3,2 & 0,273067 & 49,20 & 21,53 & 64,41 & 13,41 & 279,89 & 27,99 & 1,30 & 1,26 & $-3,4$ \\
\hline PH15 & 4,0 & 0,533333 & 49,45 & 17,31 & 64,97 & 19,48 & 235,49 & 23,55 & 1,36 & 1,28 & $-5,8$ \\
\hline PH16 & 4,0 & 0,533333 & 63,09 & 22,08 & 84,08 & 21,32 & 290,16 & 29,02 & 1,31 & 1,28 & $-2,4$ \\
\hline PH18 & 0,4 & 0,000533 & 5,03 & 17,60 & 8,12 & 0,08 & 233,95 & 23,40 & 1,33 & 1,16 & $-12,4$ \\
\hline PH19 & 0,8 & 0,004267 & 11,52 & 20,15 & 15,00 & 0,39 & 223,80 & 22,38 & 1,11 & 1,18 & 6,0 \\
\hline $\mathrm{PH} 21$ & 0,8 & 0,004267 & 12,82 & 22,44 & 18,11 & 0,37 & 261,20 & 26,12 & 1,16 & 1,18 & 1,1 \\
\hline $\mathrm{PH} 22$ & 1,2 & 0,0144 & 19,96 & 23,28 & 25,51 & 1,02 & 255,22 & 25,52 & 1,10 & 1,19 & 8,6 \\
\hline $\mathrm{PH} 23$ & 0,8 & 0,004267 & 14,24 & 24,92 & 18,99 & 0,37 & 271,69 & 27,17 & 1,09 & 1,18 & 7,9 \\
\hline $\mathrm{PH} 28$ & 1,2 & 0,0144 & 15,94 & 18,60 & 22,04 & 1,21 & 234,05 & 23,40 & 1,26 & 1,19 & $-5,4$ \\
\hline $\mathrm{PH} 30$ & 1,6 & 0,034133 & 21,01 & 18,38 & 30,19 & 2,47 & 246,50 & 24,65 & 1,34 & 1,20 & $-10,3$ \\
\hline PH34 & 2,8 & 0,182933 & 36,61 & 18,30 & 48,86 & 9,18 & 244,73 & 24,47 & 1,34 & 1,24 & $-7,1$ \\
\hline $\mathrm{PH} 40$ & 2,8 & 0,182933 & 38,26 & 19,13 & 51,66 & 8,71 & 251,14 & 25,11 & 1,31 & 1,24 & $-5,3$ \\
\hline PV01 & 4,0 & 0,533333 & 59,87 & 20,95 & 85,87 & 13,51 & 265,34 & 26,53 & 1,27 & 1,28 & 1,2 \\
\hline PV02 & 0,8 & 0,004267 & 12,23 & 21,41 & 17,70 & 0,37 & 256,24 & 25,62 & 1,20 & 1,18 & $-1,7$ \\
\hline PV05 & 0,4 & 0,000533 & 6,34 & 22,20 & 9,01 & 0,07 & 250,55 & 25,05 & 1,13 & 1,16 & 3,1 \\
\hline PV06 & 0,8 & 0,004267 & 12,84 & 22,46 & 16,63 & 0,45 & 250,34 & 25,03 & 1,11 & 1,18 & 5,6 \\
\hline PV08 & 2,8 & 0,182933 & 43,24 & 21,62 & 58,88 & 6,33 & 258,74 & 25,87 & 1,20 & 1,24 & 3,8 \\
\hline PV10 & 2,4 & 0,1152 & 39,33 & 22,94 & 51,83 & 4,36 & 261,36 & 26,14 & 1,14 & 1,23 & 7,9 \\
\hline PV12 & 2,4 & 0,1152 & 37,82 & 22,06 & 50,55 & 4,36 & 256,03 & 25,60 & 1,16 & 1,23 & 6,0 \\
\hline PV14 & 1,6 & 0,034133 & 28,58 & 25,01 & 36,49 & 1,50 & 263,12 & 26,31 & 1,05 & 1,20 & 14,4 \\
\hline PV15 & 7,2 & 3,1104 & 95,25 & 18,52 & 130,47 & 63,36 & 254,54 & 25,45 & 1,37 & 1,39 & 0,9 \\
\hline PV17 & 2,0 & 0,066667 & 26,32 & 18,42 & 39,09 & 2,85 & 238,18 & 23,82 & 1,29 & 1,22 & $-5,9$ \\
\hline PV18 & 0,4 & 0,000533 & 5,29 & 18,52 & 7,16 & 0,02 & 184,96 & 18,50 & 1,00 & 1,16 & 16,5 \\
\hline PV19 & 7,2 & 3,1104 & 100,12 & 19,47 & 130,52 & 62,37 & 253,46 & 25,35 & 1,30 & 1,39 & 6,5 \\
\hline PV20 & 7,2 & 3,1104 & 89,88 & 17,48 & 121,14 & 67,66 & 246,56 & 24,66 & 1,41 & 1,39 & $-1,7$ \\
\hline
\end{tabular}


Tabela 6A-3 - Estudo para a formulação de $\mathrm{C}_{\mathrm{AH}}$ - Edifício exemplo com 8 pavimentos.

\begin{tabular}{|c|c|c|c|c|c|c|c|c|c|c|c|}
\hline \multicolumn{12}{|c|}{ CAH - 8 PAVs. } \\
\hline PAREDE & $\mathrm{L}(\mathrm{m})$ & $\mathrm{I}\left(\mathrm{m}^{4}\right)$ & $\mathrm{Nk}$,vert (tf) & $\eta \mathrm{d}$,vert $(\mathrm{tf} / \mathrm{m})$ & $\mathrm{NCd}(\mathrm{tf})$ & $\operatorname{MCd}(t f . m)$ & $\sigma c d(t f / m 2)$ & $\eta \mathrm{Cd}(\mathrm{tf} / \mathrm{m})$ & $\eta \mathrm{Cd} / \eta \mathrm{d}$,vert & $\mathrm{C}_{\mathrm{AH}}$ & $\%$ \\
\hline $\mathrm{PH} 01$ & 0,8 & 0,004267 & 9,45 & 16,53 & 13,75 & 0,42 & 211,25 & 21,13 & 1,28 & 1,15 & $-10,3$ \\
\hline $\mathrm{PH} 02$ & 1,2 & 0,0144 & 14,76 & 17,22 & 19,24 & 1,05 & 204,10 & 20,41 & 1,19 & 1,16 & $-2,3$ \\
\hline $\mathrm{PHO3}$ & 0,4 & 0,000533 & 5,02 & 17,57 & 7,11 & 0,06 & 198,34 & 19,83 & 1,13 & 1,14 & 0,6 \\
\hline PH07 & 0,4 & 0,000533 & 5,10 & 17,83 & 7,21 & 0,06 & 201,40 & 20,14 & 1,13 & 1,14 & 0,6 \\
\hline PH11 & 0,8 & 0,004267 & 9,87 & 17,27 & 13,53 & 0,31 & 197,76 & 19,78 & 1,15 & 1,15 & 0,2 \\
\hline $\mathrm{PH} 13$ & 3,2 & 0,273067 & 39,29 & 17,19 & 51,88 & 9,54 & 218,01 & 21,80 & 1,27 & 1,22 & $-4,2$ \\
\hline PH15 & 4,0 & 0,533333 & 39,29 & 13,75 & 51,64 & 13,52 & 179,78 & 17,98 & 1,31 & 1,24 & $-5,3$ \\
\hline PH16 & 4,0 & 0,533333 & 50,64 & 17,72 & 67,04 & 14,73 & 222,83 & 22,28 & 1,26 & 1,24 & $-1,5$ \\
\hline $\mathrm{PH} 18$ & 0,4 & 0,000533 & 4,02 & 14,06 & 6,25 & 0,07 & 181,21 & 18,12 & 1,29 & 1,14 & $-11,9$ \\
\hline PH19 & 0,8 & 0,004267 & 9,49 & 16,61 & 12,35 & 0,29 & 181,29 & 18,13 & 1,09 & 1,15 & 5,1 \\
\hline $\mathrm{PH} 21$ & 0,8 & 0,004267 & 10,33 & 18,08 & 14,40 & 0,28 & 205,83 & 20,58 & 1,14 & 1,15 & 0,7 \\
\hline $\mathrm{PH} 22$ & 1,2 & 0,0144 & 15,96 & 18,63 & 20,41 & 0,75 & 201,16 & 20,12 & 1,08 & 1,16 & 7,3 \\
\hline $\mathrm{PH} 23$ & 0,8 & 0,004267 & 11,39 & 19,92 & 15,10 & 0,27 & 214,21 & 21,42 & 1,08 & 1,15 & 6,7 \\
\hline $\mathrm{PH} 28$ & 1,2 & 0,0144 & 12,70 & 14,81 & 17,50 & 0,88 & 182,61 & 18,26 & 1,23 & 1,16 & $-6,0$ \\
\hline $\mathrm{PH} 30$ & 1,6 & 0,034133 & 16,69 & 14,61 & 23,54 & 1,80 & 189,34 & 18,93 & 1,30 & 1,17 & $-9,8$ \\
\hline PH34 & 2,8 & 0,182933 & 29,04 & 14,52 & 38,96 & 6,53 & 189,10 & 18,91 & 1,30 & 1,20 & $-7,6$ \\
\hline $\mathrm{PH} 40$ & 2,8 & 0,182933 & 30,63 & 15,31 & 40,91 & 6,21 & 193,63 & 19,36 & 1,26 & 1,20 & $-4,8$ \\
\hline PV01 & 4,0 & 0,533333 & 47,52 & 16,63 & 66,72 & 9,37 & 201,95 & 20,19 & 1,21 & 1,24 & 2,0 \\
\hline PV02 & 0,8 & 0,004267 & 9,77 & 17,09 & 13,90 & 0,27 & 199,48 & 19,95 & 1,17 & 1,15 & $-1,7$ \\
\hline PV05 & 0,4 & 0,000533 & 5,10 & 17,85 & 7,13 & 0,05 & 195,87 & 19,59 & 1,10 & 1,14 & 3,5 \\
\hline PV06 & 0,8 & 0,004267 & 10,35 & 18,11 & 13,40 & 0,32 & 197,81 & 19,78 & 1,09 & 1,15 & 5,0 \\
\hline PV08 & 2,8 & 0,182933 & 34,58 & 17,29 & 46,22 & 4,53 & 199,73 & 19,97 & 1,16 & 1,20 & 4,2 \\
\hline PV10 & 2,4 & 0,1152 & 31,83 & 18,57 & 41,87 & 3,14 & 207,12 & 20,71 & 1,12 & 1,19 & 6,9 \\
\hline PV12 & 2,4 & 0,1152 & 30,41 & 17,74 & 39,94 & 3,13 & 199,04 & 19,90 & 1,12 & 1,19 & 6,3 \\
\hline PV14 & 1,6 & 0,034133 & 22,87 & 20,01 & 29,19 & 1,09 & 207,94 & 20,79 & 1,04 & 1,17 & 12,6 \\
\hline PV15 & 7,2 & 3,1104 & 75,86 & 14,75 & 103,24 & 43,53 & 193,77 & 19,38 & 1,31 & 1,33 & 1,2 \\
\hline PV17 & 2,0 & 0,066667 & 20,91 & 14,64 & 30,34 & 2,07 & 182,68 & 18,27 & 1,25 & 1,18 & $-5,4$ \\
\hline PV18 & 0,4 & 0,000533 & 4,20 & 14,72 & 5,62 & 0,01 & 143,72 & 14,37 & 0,98 & 1,14 & 16,3 \\
\hline PV19 & 7,2 & 3,1104 & 80,41 & 15,63 & 104,62 & 44,53 & 196,85 & 19,68 & 1,26 & 1,33 & 5,6 \\
\hline PV20 & 7,2 & 3,1104 & 71,46 & 13,90 & 95,95 & 46,71 & 187,34 & 18,73 & 1,35 & 1,33 & $-1,4$ \\
\hline
\end{tabular}

Tabela 6A-4 - Estudo para a formulação de $\mathrm{C}_{\mathrm{AH}}$ - Edifícico exemplo com 5 pavimentos.

\begin{tabular}{|c|c|c|c|c|c|c|c|c|c|c|c|}
\hline \multicolumn{12}{|c|}{ CAH - 5 PAVs. } \\
\hline PAREDE & $L(m)$ & $1\left(\mathrm{~m}^{4}\right)$ & $\mathrm{Nk}$,vert (tf) & $\eta \mathrm{d}$, vert $(\mathrm{tf} / \mathrm{m})$ & $\mathrm{NCd}(\mathrm{tf})$ & $\operatorname{Mcd}(\mathrm{tf} . \mathrm{m})$ & $\sigma c d(t f / m 2)$ & $\eta \mathrm{Cd}(\mathrm{tf} / \mathrm{m})$ & $\eta \mathrm{Cd} / \eta \mathrm{d}$,vert & $\mathrm{C}_{\mathrm{AH}}$ & $\%$ \\
\hline PH01 & 0,8 & 0,0043 & 5,77 & 10,09 & 8,01 & 0,23 & 122,04 & 12,20 & 1,21 & 1,10 & $-9,2$ \\
\hline $\mathrm{PHO2}$ & 1,2 & 0,0144 & 9,24 & 10,78 & 12,04 & 0,54 & 122,69 & 12,27 & 1,14 & 1,11 & $-2,8$ \\
\hline $\mathrm{PHO3}$ & 0,4 & 0,0005 & 3,18 & 11,14 & 4,33 & 0,03 & 118,83 & 11,88 & 1,07 & 1,09 & 2,1 \\
\hline PH07 & 0,4 & 0,0005 & 3,27 & 11,46 & 4,45 & 0,02 & 118,53 & 11,85 & 1,03 & 1,09 & 5,3 \\
\hline PH11 & 0,8 & 0,0043 & 6,17 & 10,80 & 8,30 & 0,16 & 118,55 & 11,86 & 1,10 & 1,10 & 0,0 \\
\hline $\mathrm{PH} 13$ & 3,2 & 0,2731 & 24,40 & 10,67 & 32,47 & 4,71 & 129,08 & 12,91 & 1,21 & 1,15 & $-5,2$ \\
\hline PH15 & 4,0 & 0,5333 & 24,21 & 8,47 & 31,85 & 6,30 & 103,23 & 10,32 & 1,22 & 1,16 & $-4,5$ \\
\hline PH16 & 4,0 & 0,5333 & 31,81 & 11,13 & 41,77 & 6,69 & 129,51 & 12,95 & 1,16 & 1,16 & 0,0 \\
\hline $\mathrm{PH} 18$ & 0,4 & 0,0005 & 2,51 & 8,80 & 3,67 & 0,05 & 108,64 & 10,86 & 1,23 & 1,09 & $-11,8$ \\
\hline PH19 & 0,8 & 0,0043 & 6,43 & 11,25 & 8,34 & 0,15 & 118,59 & 11,86 & 1,05 & 1,10 & 4,2 \\
\hline $\mathrm{PH} 21$ & 0,8 & 0,0043 & 6,56 & 11,48 & 8,92 & 0,15 & 125,63 & 12,56 & 1,09 & 1,10 & 0,3 \\
\hline $\mathrm{PH} 22$ & 1,2 & 0,0144 & 9,98 & 11,64 & 12,76 & 0,39 & 122,53 & 12,25 & 1,05 & 1,11 & 5,1 \\
\hline $\mathrm{PH} 23$ & 0,8 & 0,0043 & 7,11 & 12,44 & 9,33 & 0,15 & 130,68 & 13,07 & 1,05 & 1,10 & 4,5 \\
\hline $\mathrm{PH} 28$ & 1,2 & 0,0144 & 7,87 & 9,18 & 10,77 & 0,46 & 108,83 & 10,88 & 1,19 & 1,11 & $-6,7$ \\
\hline $\mathrm{PH} 30$ & 1,6 & 0,0341 & 10,29 & 9,00 & 14,08 & 0,95 & 110,18 & 11,02 & 1,22 & 1,11 & $-9,0$ \\
\hline PH34 & 2,8 & 0,1829 & 17,79 & 8,89 & 24,02 & 3,20 & 110,29 & 11,03 & 1,24 & 1,14 & $-8,2$ \\
\hline $\mathrm{PH} 40$ & 2,8 & 0,1829 & 19,20 & 9,60 & 25,24 & 3,08 & 113,75 & 11,37 & 1,18 & 1,14 & $-3,9$ \\
\hline PV01 & 4,0 & 0,5333 & 29,00 & 10,15 & 39,51 & 4,26 & 114,75 & 11,47 & 1,13 & 1,16 & 2,9 \\
\hline PV02 & 0,8 & 0,0043 & 6,06 & 10,60 & 8,36 & 0,14 & 117,98 & 11,80 & 1,11 & 1,10 & $-1,4$ \\
\hline PV05 & 0,4 & 0,0005 & 3,22 & 11,29 & 4,37 & 0,02 & 117,40 & 11,74 & 1,04 & 1,09 & 4,7 \\
\hline PV06 & 0,8 & 0,0043 & 6,58 & 11,52 & 8,53 & 0,16 & 121,39 & 12,14 & 1,05 & 1,10 & 4,2 \\
\hline PV08 & 2,8 & 0,1829 & 21,58 & 10,79 & 28,20 & 2,24 & 117,90 & 11,79 & 1,09 & 1,14 & 4,2 \\
\hline PV10 & 2,4 & 0,1152 & 20,50 & 11,96 & 26,90 & 1,58 & 128,50 & 12,85 & 1,07 & 1,13 & 5,2 \\
\hline PV12 & 2,4 & 0,1152 & 19,24 & 11,22 & 25,00 & 1,60 & 120,82 & 12,08 & 1,08 & 1,13 & 5,0 \\
\hline PV14 & 1,6 & 0,0341 & 14,31 & 12,52 & 18,26 & 0,56 & 127,20 & 12,72 & 1,02 & 1,11 & 9,6 \\
\hline PV15 & 7,2 & 3,1104 & 47,05 & 9,15 & 63,29 & 19,85 & 110,87 & 11,09 & 1,21 & 1,23 & 1,4 \\
\hline PV17 & 2,0 & 0,0667 & 12,87 & 9,01 & 17,95 & 1,06 & 105,68 & 10,57 & 1,17 & 1,12 & $-4,3$ \\
\hline PV18 & 0,4 & 0,0005 & 2,59 & 9,06 & 3,40 & 0,00 & 85,64 & 8,56 & 0,95 & 1,09 & 15,2 \\
\hline PV19 & 7,2 & 3,1104 & 50,81 & 9,88 & 66,24 & 20,27 & 115,46 & 11,55 & 1,17 & 1,23 & 5,1 \\
\hline PV20 & 7,2 & 3,1104 & 44,15 & 8,59 & 58,87 & 21,65 & 106,83 & 10,68 & 1,24 & 1,23 & $-1,2$ \\
\hline
\end{tabular}


Tabela $6 \mathrm{~A}-5$ - Estudo para a formulação de $\mathrm{C}_{\mathrm{AH}}$ - Edifício exemplo com 2 pavimentos.

\begin{tabular}{|c|c|c|c|c|c|c|c|c|c|c|c|}
\hline \multicolumn{12}{|c|}{ CAH - 2 PAVs. } \\
\hline PAREDE & $\mathrm{L}(\mathrm{m})$ & $I\left(m^{4}\right)$ & $\mathrm{Nk}$,vert (tf) & $\eta d$,vert $(\mathrm{tf} / \mathrm{m})$ & $\mathrm{NCd}(\mathrm{tf})$ & $\operatorname{Mcd}(t f . m)$ & $\sigma c d(t f / m 2)$ & $\eta \mathrm{Cd}(\mathrm{tf} / \mathrm{m})$ & nCd / nd, vert & $\mathrm{C}_{\mathrm{AH}}$ & $\%$ \\
\hline PH01 & 0,8 & 0,0043 & 2,18 & 3,81 & 2,90 & 0,09 & 44,32 & 4,43 & 1,16 & 1,07 & $-8,5$ \\
\hline PHO2 & 1,2 & 0,0144 & 3,71 & 4,33 & 4,85 & 0,16 & 46,85 & 4,68 & 1,08 & 1,07 & $-1,3$ \\
\hline $\mathrm{PH} 03$ & 0,4 & 0,0005 & 1,30 & 4,56 & 1,71 & 0,01 & 45,83 & 4,58 & 1,01 & 1,06 & 5,7 \\
\hline $\mathrm{PH} 07$ & 0,4 & 0,0005 & 1,41 & 4,94 & 1,85 & 0,01 & 48,93 & 4,89 & 0,99 & 1,06 & 7,3 \\
\hline PH11 & 0,8 & 0,0043 & 2,46 & 4,30 & 3,24 & 0,05 & 44,88 & 4,49 & 1,04 & 1,07 & 2,2 \\
\hline $\mathrm{PH} 13$ & 3,2 & 0,2731 & 9,82 & 4,30 & 13,01 & 1,39 & 48,81 & 4,88 & 1,14 & 1,08 & $-4,8$ \\
\hline $\mathrm{PH} 15$ & 4,0 & 0,5333 & 9,38 & 3,28 & 12,37 & 1,60 & 36,91 & 3,69 & 1,12 & 1,09 & $-3,4$ \\
\hline PH16 & 4,0 & 0,5333 & 12,55 & 4,39 & 16,39 & 1,38 & 46,15 & 4,62 & 1,05 & 1,09 & 3,4 \\
\hline PH18 & 0,4 & 0,0005 & 1,01 & 3,52 & 1,37 & 0,02 & 43,56 & 4,36 & 1,24 & 1,06 & $-14,1$ \\
\hline PH19 & 0,8 & 0,0043 & 2,99 & 5,23 & 3,85 & 0,05 & 52,72 & 5,27 & 1,01 & 1,07 & 5,6 \\
\hline $\mathrm{PH} 21$ & 0,8 & 0,0043 & 2,69 & 4,70 & 3,56 & 0,06 & 49,71 & 4,97 & 1,06 & 1,07 & 0,8 \\
\hline $\mathrm{PH} 22$ & 1,2 & 0,0144 & 3,99 & 4,66 & 5,10 & 0,12 & 47,68 & 4,77 & 1,02 & 1,07 & 4,3 \\
\hline $\mathrm{PH} 23$ & 0,8 & 0,0043 & 2,83 & 4,94 & 3,67 & 0,06 & 51,18 & 5,12 & 1,03 & 1,07 & 2,9 \\
\hline $\mathrm{PH} 28$ & 1,2 & 0,0144 & 3,14 & 3,66 & 4,23 & 0,13 & 40,83 & 4,08 & 1,11 & 1,07 & $-4,2$ \\
\hline $\mathrm{PH} 30$ & 1,6 & 0,0341 & 4,01 & 3,51 & 5,35 & 0,31 & 40,64 & 4,06 & 1,16 & 1,07 & $-7,6$ \\
\hline PH34 & 2,8 & 0,1829 & 6,73 & 3,36 & 9,09 & 0,86 & 39,02 & 3,90 & 1,16 & 1,08 & $-7,0$ \\
\hline $\mathrm{PH} 40$ & 2,8 & 0,1829 & 7,71 & 3,85 & 10,06 & 0,84 & 42,39 & 4,24 & 1,10 & 1,08 & $-1,9$ \\
\hline PV01 & 4,0 & 0,5333 & 10,99 & 3,84 & 14,58 & 0,86 & 39,67 & 3,97 & 1,03 & 1,09 & 5,3 \\
\hline PV02 & 0,8 & 0,0043 & 2,30 & 4,02 & 3,07 & 0,05 & 43,27 & 4,33 & 1,08 & 1,07 & $-1,0$ \\
\hline PV05 & 0,4 & 0,0005 & 1,30 & 4,54 & 1,71 & 0,00 & 44,24 & 4,42 & 0,97 & 1,06 & 9,1 \\
\hline PV06 & 0,8 & 0,0043 & 2,72 & 4,75 & 3,53 & 0,05 & 48,41 & 4,84 & 1,02 & 1,07 & 4,6 \\
\hline PV08 & 2,8 & 0,1829 & 8,59 & 4,29 & 11,22 & 0,64 & 44,95 & 4,50 & 1,05 & 1,08 & 3,0 \\
\hline PV10 & 2,4 & 0,1152 & 8,89 & 5,19 & 11,52 & 0,45 & 52,62 & 5,26 & 1,01 & 1,08 & 6,1 \\
\hline PV12 & 2,4 & 0,1152 & 7,86 & 4,59 & 10,20 & 0,48 & 47,47 & 4,75 & 1,03 & 1,08 & 4,0 \\
\hline PV14 & 1,6 & 0,0341 & 5,74 & 5,02 & 7,32 & 0,17 & 49,67 & 4,97 & 0,99 & 1,07 & 8,2 \\
\hline PV15 & 7,2 & 3,1104 & 18,77 & 3,65 & 24,81 & 5,20 & 40,47 & 4,05 & 1,11 & 1,11 & $-0,1$ \\
\hline PV17 & 2,0 & 0,0667 & 4,98 & 3,49 & 6,67 & 0,31 & 38,03 & 3,80 & 1,09 & 1,07 & $-1,6$ \\
\hline PV18 & 0,4 & 0,0005 & 1,01 & 3,53 & 1,33 & 0,02 & 40,24 & 4,02 & 1,14 & 1,06 & $-6,9$ \\
\hline PV19 & 7,2 & 3,1104 & 20,62 & 4,01 & 26,84 & 5,04 & 43,11 & 4,31 & 1,08 & 1,11 & 3,0 \\
\hline PV20 & 7,2 & 3,1104 & 17,38 & 3,38 & 22,98 & 5,89 & 38,73 & 3,87 & 1,15 & 1,11 & $-3,3$ \\
\hline
\end{tabular}




\section{ANEXO B}

\section{B) Tabelas do item 6.5.7}

Paredes Isoladas $-E E(t=12 \mathrm{~cm})$

Tabela 6B-1 - EE: Carga vertical total nos lintéis em apenas um pavimento tipo $(\mathrm{t}=12 \mathrm{~cm})$.

\begin{tabular}{|c|c|c|c|c|c|c|c|c|}
\hline \multicolumn{9}{|c|}{ CARGAS TOTAIS DOS LINTÉIS - EE $->t=12 \mathrm{~cm}$} \\
\hline LINTÉL & $\mathrm{L}_{\mathrm{LI}}(\mathrm{m})$ & $h_{L I}(m)$ & $\mathrm{PP}_{1 \mathrm{PAV}}(\mathrm{tf})$ & Areas laje & P lajes (tf) & $\mathrm{G}(\mathrm{tf})$ & $Q(t f)$ & P lintel (tf) \\
\hline LH01 & 1,20 & 1,60 & 0,58 & A1 & 0,42 & 0,87 & 0,13 & 1,00 \\
\hline LHO2 & 0,80 & 2,00 & 0,48 & A2 & 0,16 & 0,59 & 0,05 & 0,64 \\
\hline LHO3 & 0,80 & 2,00 & 0,48 & A9 & 0,16 & 0,59 & 0,05 & 0,64 \\
\hline LHO4 & 1,20 & 1,60 & 0,58 & A10 & 0,42 & 0,87 & 0,13 & 1,00 \\
\hline LH05 & 1,60 & 0,40 & 0,19 & A4 e $\mathrm{A} 13$ & 0,91 & 0,83 & 0,27 & 1,10 \\
\hline LH06 & 1,60 & 0,40 & 0,19 & A7 e A14 & 0,91 & 0,83 & 0,27 & 1,10 \\
\hline LH07 & 0,80 & 0,40 & 0,10 & A21 e A25 & 0,40 & 0,38 & 0,12 & 0,50 \\
\hline LH08 & 0,80 & 0,40 & 0,10 & $\mathrm{~A} 22$ e $\mathrm{A} 26$ & 0,40 & 0,38 & 0,12 & 0,50 \\
\hline LHO9 & 0,80 & 0,40 & 0,10 & A30 e A35 & 0,58 & 0,50 & 0,17 & 0,67 \\
\hline LH10 & 0,80 & 0,40 & 0,10 & A31 e A36 & 0,58 & 0,50 & 0,17 & 0,67 \\
\hline LH11 & 0,80 & 0,40 & 0,10 & A47 e A54 & 0,72 & 0,60 & 0,22 & 0,82 \\
\hline LH12 & 1,20 & 0,40 & 0,14 & A56 & 0,50 & 0,50 & 0,15 & 0,65 \\
\hline LH13 & 1,20 & 0,40 & 0,14 & A56 & 0,50 & 0,50 & 0,15 & 0,65 \\
\hline LH14 & 0,80 & 0,40 & 0,10 & A48 e A58 & 0,72 & 0,60 & 0,22 & 0,82 \\
\hline LH15 & 0,80 & 0,40 & 0,10 & A63 e A73 & 0,72 & 0,60 & 0,22 & 0,82 \\
\hline LH16 & 0,80 & 0,40 & 0,10 & A67 e A74 & 0,72 & 0,60 & 0,22 & 0,82 \\
\hline LH17 & 0,80 & 2,00 & 0,48 & A65 & 0,34 & 0,72 & 0,10 & 0,82 \\
\hline LH18 & 0,80 & 0,40 & 0,10 & A65 e A77 & 0,55 & 0,48 & 0,16 & 0,65 \\
\hline LH19 & 0,80 & 0,40 & 0,10 & A80 e A83 & 0,43 & 0,39 & 0,13 & 0,52 \\
\hline $\mathrm{LH} 20$ & 0,80 & 0,40 & 0,10 & A98 e A103 & 0,58 & 0,50 & 0,17 & 0,67 \\
\hline LH21 & 0,80 & 0,40 & 0,10 & A99 е A104 & 0,58 & 0,50 & 0,17 & 0,67 \\
\hline LH22 & 0,80 & 0,40 & 0,10 & A108 e A112 & 0,40 & 0,38 & 0,12 & 0,50 \\
\hline LH23 & 0,80 & 0,40 & 0,10 & A109 e A113 & 0,40 & 0,38 & 0,12 & 0,50 \\
\hline LH24 & 0,80 & 2,00 & 0,48 & A89 & 0,20 & 0,62 & 0,06 & 0,68 \\
\hline LH25 & 1,60 & 0,40 & 0,19 & A120 e A127 & 0,91 & 0,83 & 0,27 & 1,10 \\
\hline LH26 & 1,60 & 0,40 & 0,19 & A121 e A130 & 0,91 & 0,83 & 0,27 & 1,10 \\
\hline LH27 & 1,20 & 1,60 & 0,58 & A124 & 0,42 & 0,87 & 0,13 & 1,00 \\
\hline LH28 & 0,80 & 2,00 & 0,48 & A125 & 0,16 & 0,59 & 0,05 & 0,64 \\
\hline LH29 & 0,80 & 2,00 & 0,48 & A132 & 0,16 & 0,59 & 0,05 & 0,64 \\
\hline LH30 & 1,20 & 1,60 & 0,58 & A133 & 0,42 & 0,87 & 0,13 & 1,00 \\
\hline LV01 & 1,20 & 1,60 & 0,58 & A92 & 0,36 & 0,83 & 0,11 & 0,94 \\
\hline LV02 & 1,20 & 1,60 & 0,58 & A37 & 0,36 & 0,83 & 0,11 & 0,94 \\
\hline LV03 & 1,20 & 1,60 & 0,58 & A69 & 0,30 & 0,79 & 0,09 & 0,88 \\
\hline LV04 & 1,20 & 1,60 & 0,58 & A49 & 0,30 & 0,79 & 0,09 & 0,88 \\
\hline LV05 & 0,80 & 0,40 & 0,10 & A106 e A115 & 0,46 & 0,42 & 0,14 & 0,56 \\
\hline LV06 & 0,80 & 0,40 & 0,10 & A18 e A27 & 0,46 & 0,42 & 0,14 & 0,56 \\
\hline LV07 & 0,80 & 0,40 & 0,10 & A107 e A116 & 0,46 & 0,42 & 0,14 & 0,56 \\
\hline LV08 & 0,80 & 0,40 & 0,10 & A19 e A28 & 0,46 & 0,42 & 0,14 & 0,56 \\
\hline LV09 & 1,20 & 1,60 & 0,58 & A72 & 0,30 & 0,79 & 0,09 & 0,88 \\
\hline LV10 & 1,20 & 1,60 & 0,58 & A52 & 0,30 & 0,79 & 0,09 & 0,88 \\
\hline LV11 & 1,20 & 1,60 & 0,58 & A97 & 0,36 & 0,83 & 0,11 & 0,94 \\
\hline LV12 & 1,20 & 1,60 & 0,58 & A42 & 0,36 & 0,83 & 0,11 & 0,94 \\
\hline
\end{tabular}


Tabela 6B-2 - PIS-EE: $N_{k, v e r t}$ e $\eta_{k, v e r t}$ ao nível da fundação (t=12cm).

\begin{tabular}{|c|c|c|c|c|c|c|c|c|c|c|c|}
\hline & & & & PIS - & $E \mathrm{E}-\mathrm{t}=12 \mathrm{~cm}$ & & & & & & \\
\hline PAREDE & $L(m)$ & $\mathrm{PP}_{1 \mathrm{PAV}}(\mathrm{tf})$ & Areas laje & P lajes (tf) & Lintéis & Plintel (tf) & $G(t f)$ & $Q(t f)$ & P parede (tf) & $\mathrm{Nk}$,vert (tf) & $\eta k$, vert $(\mathrm{tf} / \mathrm{m})$ \\
\hline PH01 & 0,80 & \begin{tabular}{|c|}
0,67 \\
\end{tabular} & $\mathrm{~A} 1$ & 0,280 & LH01 & 0,50 & 1,30 & 0,15 & 1,45 & \begin{tabular}{|l|}
21,75 \\
\end{tabular} & 27,19 \\
\hline PHO2 & 1,20 & 1,01 & $\mathrm{~A} 1 \mathrm{e} A 2$ & 0,360 & LH01 e LH02 & 0,818 & 1,99 & 0,20 & 2,19 & 32,79 & 27,33 \\
\hline PHO3 & 0,40 & 0,34 & A2 & 0,080 & LH02 & 0,32 & 0,69 & 0,05 & 0,74 & 11,04 & 27,60 \\
\hline PH04 & 0,40 & 0,34 & A9 & 0,080 & LHO3 & 0,32 & 0,69 & 0,05 & 0,74 & 11,04 & 27,60 \\
\hline PH05 & 1,20 & 1,01 & A9 e A10 & 0,360 & LHO3 e LHO4 & 0,818 & 1,99 & 0,20 & 2,19 & 32,79 & 27,33 \\
\hline PHOG & 0,80 & 0,67 & $\mathrm{~A} 10$ & 0,280 & LH04 & 0,498 & 1,30 & 0,15 & 1,45 & 21,75 & 27,19 \\
\hline PH07 & 0,40 & 0,34 & A4 e A13 & 0,227 & LHO5 & 0,55 & 0,91 & 0,20 & 1,11 & 16,68 & 41,70 \\
\hline PH08 & 0,40 & 0,34 & A4 e A13 & 0,227 & LHO5 & 0,55 & 0,91 & 0,20 & 1,11 & 16,68 & 41,70 \\
\hline PHO9 & 0,40 & 0,34 & A7 e A14 & 0,227 & LHO6 & 0,55 & 0,91 & 0,20 & 1,11 & 16,68 & 41,70 \\
\hline PH10 & 0,40 & 0,34 & A7 e A14 & 0,227 & LH06 & 0,55 & 0,91 & 0,20 & 1,11 & 16,68 & 41,70 \\
\hline PH11 & 0,80 & 0,67 & A21 e A25 & 0,400 & LH07 & 0,248 & 1,14 & 0,18 & 1,32 & 19,80 & 24,75 \\
\hline $\mathrm{PH} 12$ & 0,80 & 0,67 & $\mathrm{~A} 22$ e A26 & 0,400 & LH08 & 0,248 & 1,14 & 0,18 & 1,32 & 19,80 & 24,75 \\
\hline PH13 & 3,20 & 2,69 & $\mathrm{~A} 29, \mathrm{~A} 30$ e A35 & 2,444 & LH09 e LV06 & 0,62 & 4,86 & 0,89 & 5,75 & 86,21 & 26,94 \\
\hline PH14 & 3,20 & 2,69 & $\mathrm{~A} 31, \mathrm{~A} 32$ e A36 & 2,444 & LH10 e LV08 & 0,62 & 4,86 & 0,89 & 5,75 & 86,21 & 26,94 \\
\hline PH15 & 4,00 & 3,36 & $-\cdots$ & 0,000 & ---- & 0,00 & 3,36 & 0,00 & 3,36 & 50,40 & 12,60 \\
\hline PH16 & 4,00 & 3,36 & A43 e A45 & 2,480 & --.- & 0,00 & 5,10 & 0,74 & 5,84 & 87,60 & 21,90 \\
\hline PH17 & 4,00 & 3,36 & A44 e A46 & 2,480 & $-\cdots$ & 0,00 & 5,10 & 0,74 & 5,84 & 87,60 & 21,90 \\
\hline PH18 & 0,40 & 0,34 & A56 & 0,168 & LH12 & 0,32 & 0,70 & 0,13 & 0,83 & 12,42 & 31,05 \\
\hline PH19 & 0,80 & 0,67 & A56 & 0,336 & LH12 e LH13 & 0,65 & 1,40 & 0,25 & 1,66 & 24,84 & 31,05 \\
\hline $\mathrm{PH} 20$ & 0,40 & 0,34 & A56 & 0,168 & LH13 & 0,32 & 0,70 & 0,13 & 0,83 & 12,42 & 31,05 \\
\hline $\mathrm{PH} 21$ & 0,80 & 0,67 & A53 e A62 & 0,722 & 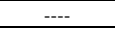 & 0,00 & 1,18 & 0,22 & 1,39 & 20,91 & 26,14 \\
\hline $\mathrm{PH} 22$ & 1,20 & 1,01 & A53 e $A 62$ & 1,156 & --.- & 0,00 & 1,82 & 0,35 & 2,16 & 32,45 & 27,04 \\
\hline $\mathrm{PH} 23$ & 0,80 & 0,67 & A53 e $A 62$ & 0,722 & --.- & 0,00 & 1,18 & 0,22 & 1,39 & 20,91 & 26,14 \\
\hline $\mathrm{PH} 24$ & 0,80 & 0,67 & A59 e A68 & 0,722 & -.-- & 0,00 & 1,18 & 0,22 & 1,39 & 20,91 & 26,14 \\
\hline $\mathrm{PH} 25$ & 1,20 & 1,01 & A59 e A68 & 1,156 & -.-- & 0,00 & 1,82 & 0,35 & 2,16 & 32,45 & 27,04 \\
\hline $\mathrm{PH} 26$ & 0,80 & 0,67 & A59 e A68 & 0,722 & ---- & 0,00 & 1,18 & 0,22 & 1,39 & 20,91 & 26,14 \\
\hline $\mathrm{PH} 27$ & 0,40 & 0,34 & A65 & 0,168 & LH17 & 0,41 & 0,81 & 0,10 & 0,91 & 13,68 & 34,20 \\
\hline $\mathrm{PH} 28$ & 1,20 & 1,01 & A65 e A77 & 0,717 & LH17 e LH18 & 0,73 & 2,11 & 0,35 & 2,46 & 36,84 & 30,70 \\
\hline $\mathrm{PH} 29$ & 0,80 & 0,67 & A65 e A77 & 0,549 & LH18 & 0,32 & 1,30 & 0,25 & 1,54 & 23,16 & 28,95 \\
\hline $\mathrm{PH} 30$ & 1,60 & 1,34 & ---- & 0,000 & -..- & 0,00 & 1,34 & 0,00 & 1,34 & 20,16 & 12,60 \\
\hline PH31 & 4,00 & 3,36 & A75 e A90 & 2,480 & --.- & 0,00 & 5,10 & 0,74 & 5,84 & 87,60 & 21,90 \\
\hline PH32 & 4,00 & 3,36 & A76 e A91 & 2,480 & $\begin{array}{l}--- \\
\end{array}$ & 0,00 & 5,10 & 0,74 & 5,84 & 87,60 & 21,90 \\
\hline PH33 & 0,40 & 0,34 & A80 e A83 & 0,213 & LH19 & 0,26 & 0,68 & 0,13 & 0,81 & 12,16 & 30,40 \\
\hline PH34 & 2,80 & 2,35 & A82 e A85 & 1,020 & 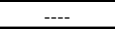 & 0,00 & 3,07 & 0,31 & 3,37 & 50,58 & 18,06 \\
\hline $\mathrm{PH} 35$ & 3,20 & 2,69 & A98, A102 e A103 & 2,444 & LH20 e LV05 & 0,62 & 4,86 & 0,89 & 5,75 & 86,21 & 26,94 \\
\hline $\mathrm{PH} 36$ & 3,20 & 2,69 & A99, A104 e A105 & 2,444 & LH21 e LV07 & 0,62 & 4,86 & 0,89 & 5,75 & 86,21 & 26,94 \\
\hline PH37 & 0,80 & 0,67 & $\mathrm{~A} 108 \mathrm{e}$ A112 & 0,400 & LH22 & 0,248 & 1,14 & 0,18 & 1,32 & 19,80 & 24,75 \\
\hline $\mathrm{PH} 38$ & 0,80 & 0,67 & A109 e A113 & 0,400 & LH23 & 0,248 & 1,14 & 0,18 & 1,32 & 19,80 & 24,75 \\
\hline PH39 & 0,40 & 0,34 & A89 & 0,102 & LH24 & 0,34 & 0,72 & 0,06 & 0,78 & 11,70 & 29,25 \\
\hline $\mathrm{PH} 40$ & 2,80 & 2,35 & A89 & 0,714 & LH24 & 0,34 & 3,16 & 0,24 & 3,41 & 51,12 & 18,26 \\
\hline $\mathrm{PH} 41$ & 0,40 & 0,34 & A120 e A127 & 0,227 & LH25 & 0,55 & 0,91 & 0,20 & 1,11 & 16,68 & 41,70 \\
\hline $\mathrm{PH} 42$ & 0,40 & 0,34 & A120 e A127 & 0,227 & LH25 & 0,55 & 0,91 & 0,20 & 1,11 & 16,68 & 41,70 \\
\hline $\mathrm{PH} 43$ & 0,40 & 0,34 & $\mathrm{~A} 121 \mathrm{e}$ A130 & 0,227 & LH26 & 0,55 & 0,91 & 0,20 & 1,11 & 16,68 & 41,70 \\
\hline PH44 & 0,40 & 0,34 & A121 e A130 & 0,227 & LH26 & 0,55 & 0,91 & 0,20 & 1,11 & 16,68 & 41,70 \\
\hline $\mathrm{PH} 45$ & 0,80 & 0,67 & A124 & 0,280 & LH27 & 0,498 & 1,30 & 0,15 & 1,45 & 21,75 & 27,19 \\
\hline $\mathrm{PH} 46$ & 1,20 & 1,01 & A124 e A125 & 0,360 & LH27 e LH28 & 0,818 & 1,99 & 0,20 & 2,19 & 32,79 & 27,33 \\
\hline $\mathrm{PH} 47$ & 0,40 & 0,34 & A125 & 0,080 & LH28 & 0,32 & 0,69 & 0,05 & 0,74 & 11,04 & 27,60 \\
\hline $\mathrm{PH} 48$ & 0,40 & 0,34 & A132 & 0,080 & LH29 & 0,32 & 0,69 & 0,05 & 0,74 & 11,04 & 27,60 \\
\hline $\mathrm{PH} 49$ & 1,20 & 1,01 & A132 e A133 & 0,360 & LH29 e LH30 & 0,818 & 1,99 & 0,20 & 2,19 & 32,79 & 27,33 \\
\hline PH50 & 0,80 & 0,67 & $\mathrm{~A} 133$ & 0,280 & LH30 & 0,498 & 1,30 & 0,15 & 1,45 & 21,75 & 27,19 \\
\hline PV01 & 4,00 & 3,36 & A114 e A92 & 1,660 & LV01 & 0,468 & 4,94 & 0,55 & 5,49 & 82,32 & 20,58 \\
\hline PV02 & 0,80 & 0,67 & A92 & 0,240 & LV01 & 0,468 & 1,25 & 0,13 & 1,38 & 20,70 & 25,88 \\
\hline PV03 & 0,80 & 0,67 & A37 & 0,240 & LV02 & 0,468 & 1,25 & 0,13 & 1,38 & 20,70 & 25,88 \\
\hline PV04 & 4,00 & 3,36 & A17 e A37 & 1,660 & LV02 & 0,468 & 4,94 & 0,55 & 5,49 & 82,32 & 20,58 \\
\hline PV05 & 0,40 & 0,34 & A69 & 0,100 & LV03 & 0,438 & 0,80 & 0,08 & 0,87 & 13,11 & 32,78 \\
\hline PV06 & 0,80 & 0,67 & A49 e A69 & 0,200 & LV03 e LV04 & 0,876 & 1,60 & 0,15 & 1,75 & 26,22 & 32,78 \\
\hline PV07 & 0,40 & 0,34 & A49 & 0,100 & LV04 & 0,438 & 0,80 & 0,08 & 0,87 & 13,11 & 32,78 \\
\hline PV08 & 2,80 & 2,35 & A106, A115 e A118 & 1,898 & LV05 & 0,28 & 3,89 & 0,64 & 4,53 & 67,93 & 24,26 \\
\hline PV09 & 2,80 & 2,35 & $\mathrm{~A} 11, \mathrm{~A} 18$ e A27 & 1,898 & LV06 & 0,28 & 3,89 & 0,64 & 4,53 & 67,93 & 24,26 \\
\hline PV10 & 2,40 & 2,02 & A93 e A94 & 3,280 & LH2O & 0,34 & 4,56 & 1,07 & 5,63 & 84,48 & 35,20 \\
\hline PV11 & 2,40 & 2,02 & A38 e A39 & 3,280 & LHO9 & 0,34 & 4,56 & 1,07 & 5,63 & 84,48 & 35,20 \\
\hline PV12 & 2,40 & 2,02 & A110, A119 e A126 & 1,760 & LH22 & 0,248 & 3,44 & 0,59 & 4,02 & 60,36 & 25,15 \\
\hline PV13 & 2,40 & 2,02 & $\mathrm{~A} 3, \mathrm{~A} 12 \mathrm{e} A 23$ & 1,760 & LH07 & 0,248 & 3,44 & 0,59 & 4,02 & 60,36 & 25,15 \\
\hline PV14 & 1,60 & 1,34 & $\mathrm{~A} 50, \mathrm{~A} 60$ e A70 & 1,080 & LH11 e LH15 & 0,82 & 2,70 & 0,54 & 3,24 & 48,60 & 30,38 \\
\hline PV15 & 7,20 & 6,05 & $\mathrm{~A} 64, \mathrm{~A} 87, \mathrm{~A} 100$ e $\mathrm{A} 128$ & 4,260 & LH15 & 0,41 & 9,33 & 1,39 & 10,72 & 160,74 & 22,33 \\
\hline PV16 & 7,20 & 6,05 & $\mathrm{~A} 5, \mathrm{~A} 33$ e $\mathrm{A} 55$ & 3,480 & LH11 & 0,41 & 8,78 & 1,15 & 9,94 & 149,04 & 20,70 \\
\hline PV17 & 2,00 & 1,68 & A78 & 0,440 & ---- & 0,00 & 1,99 & 0,13 & 2,12 & 31,80 & 15,90 \\
\hline PV18 & 0,40 & 0,34 & A81 e A84 & 0,240 & ---- & 0,00 & 0,50 & 0,07 & 0,58 & 8,64 & 21,60 \\
\hline PV19 & 7,20 & 6,05 & A66, A79, A88, A101 e A129 & 4,700 & LH16 e LH19 & 0,67 & 9,84 & 1,58 & 11,42 & 171,26 & 23,79 \\
\hline PV20 & 7,20 & 6,05 & $\mathrm{~A} 6, \mathrm{~A} 34$ e $\mathrm{A} 57$ & 3,480 & LH14 & 0,41 & 8,78 & 1,15 & 9,94 & 149,04 & 20,70 \\
\hline PV21 & 1,60 & 1,34 & A51, A61 e A71 & 1,080 & LH14 e LH16 & 0,82 & 2,70 & 0,54 & 3,24 & 48,60 & 30,38 \\
\hline PV22 & 2,40 & 2,02 & A111, A122 e A131 & 1,760 & $\mathrm{LH} 23$ & 0,248 & 3,44 & 0,59 & 4,02 & 60,36 & 25,15 \\
\hline PV23 & 2,40 & 2,02 & $\mathrm{~A} 8, \mathrm{~A} 15 \mathrm{e}$ A24 & 1,760 & LHO8 & 0,248 & 3,44 & 0,59 & 4,02 & 60,36 & 25,15 \\
\hline PV24 & 2,40 & 2,02 & A95 e A96 & 3,280 & LH21 & 0,34 & 4,56 & 1,07 & 5,63 & 84,48 & 35,20 \\
\hline PV25 & 2,40 & 2,02 & $\mathrm{~A} 40$ e $\mathrm{A} 41$ & 3,280 & LH10 & 0,34 & 4,56 & 1,07 & 5,63 & 84,48 & 35,20 \\
\hline PV26 & 2,80 & 2,35 & A107, A116 e A123 & 1,898 & LV07 & 0,28 & 3,89 & 0,64 & 4,53 & 67,93 & 24,26 \\
\hline PV27 & 2,80 & 2,35 & A16, A19 e A28 & 1,898 & LV08 & 0,28 & 3,89 & 0,64 & 4,53 & 67,93 & 24,26 \\
\hline PV28 & 0,40 & 0,34 & A72 & 0,100 & LV09 & 0,438 & 0,80 & 0,08 & 0,87 & 13,11 & 32,78 \\
\hline PV29 & 0,80 & 0,67 & A52 e A72 & 0,200 & LV09 e LV10 & 0,876 & 1,60 & 0,15 & 1,75 & 26,22 & 32,78 \\
\hline PV30 & 0,40 & 0,34 & A52 & 0,100 & LV10 & 0,438 & 0,80 & 0,08 & 0,87 & 13,11 & 32,78 \\
\hline PV31 & 4,00 & 3,36 & A97 e A117 & 1,660 & LV11 & 0,468 & 4,94 & 0,55 & 5,49 & 82,32 & 20,58 \\
\hline PV32 & 0,80 & 0,67 & A97 & 0,240 & LV11 & 0,468 & 1,25 & 0,13 & 1,38 & 20,70 & 25,88 \\
\hline PV33 & 0,80 & 0,67 & A42 & 0,240 & LV12 & 0,468 & 1,25 & 0,13 & 1,38 & 20,70 & 25,88 \\
\hline PV34 & 4,00 & 3,36 & $\mathrm{~A} 20$ e $\mathrm{A} 42$ & 1,660 & LV12 & 0,468 & 4,94 & 0,55 & 5,49 & 82,32 & 20,58 \\
\hline PILAR & 1,00 & 3,50 & A86 & 2,800 & --- & 0,00 & 5,46 & 0,84 & 6,30 & 94,50 & 94,50 \\
\hline
\end{tabular}


Grupo Isolado de Paredes - EE $(t=12 \mathrm{~cm})$

Tabela 6B-3 - GIP-EE - Cargas por grupo: $N_{k, v e r t}$ e $\eta_{k, v e r t}$ ao nível da fundação ( $\left.\mathrm{t}=12 \mathrm{~cm}\right)$.

\begin{tabular}{|c|c|c|c|c|c|c|c|c|}
\hline \multicolumn{9}{|c|}{ GIP - EE: CARGAS POR GRUPO $->t=12 \mathrm{~cm}$} \\
\hline GRUPO & Paredes & L total $(\mathrm{m})$ & $\mathrm{G}(\mathrm{tf})$ & $\mathrm{g}(\mathrm{tf} / \mathrm{m})$ & $\mathrm{Q}(\mathrm{tf})$ & $q(t f / m)$ & $\mathrm{Nk}$,vert (tf) & $\eta \mathrm{k}$, vert (tf/m) \\
\hline G1 & PH01, PH13 e PV04 & 8,00 & 166,46 & 20,81 & 23,82 & 2,98 & 190,28 & 23,78 \\
\hline G2 & PH02, PH11 e PV09 & 4,80 & 105,32 & 21,94 & 15,21 & 3,17 & 120,52 & 25,11 \\
\hline G3 & PH03, PH07 e PV13 & 3,20 & 75,48 & 23,59 & 12,60 & 3,94 & 88,08 & 27,53 \\
\hline G4 & PH04, PH10 e PV23 & 3,20 & 75,48 & 23,59 & 12,60 & 3,94 & 88,08 & 27,53 \\
\hline G5 & PH05, PH12 e PV27 & 4,80 & 105,32 & 21,94 & 15,21 & 3,17 & 120,52 & 25,11 \\
\hline G6 & PH06, PH14 e PV34 & 8,00 & 166,46 & 20,81 & 23,82 & 2,98 & 190,28 & 23,78 \\
\hline G7 & PH08, PH09, PH15, PH18, PH20, PV16 e PV20 & 20,00 & 362,22 & 18,11 & 44,46 & 2,22 & 406,68 & 20,33 \\
\hline G8 & PH16, PV03, PV07, PV11 & 7,60 & 175,66 & 23,11 & 30,23 & 3,98 & 205,89 & 27,09 \\
\hline G9 & PH17, PV25, PV30 e PV33 & 7,60 & 175,66 & 23,11 & 30,23 & 3,98 & 205,89 & 27,09 \\
\hline G10 & PH19 & 0,80 & 21,06 & 26,33 & 3,78 & 4,73 & 24,84 & 31,05 \\
\hline G11 & PH21 e PV06 & 1,60 & 41,63 & 26,02 & 5,50 & 3,44 & 47,13 & 29,46 \\
\hline G12 & $\mathrm{PH} 22$ & 1,20 & 27,25 & 22,71 & 5,20 & 4,33 & 32,45 & 27,04 \\
\hline G13 & PH23 e PV14 & 2,40 & 58,16 & 24,23 & 11,35 & 4,73 & 69,51 & 28,96 \\
\hline G14 & $\mathrm{PH} 24$ e PV21 & 2,40 & 58,16 & 24,23 & 11,35 & 4,73 & 69,51 & 28,96 \\
\hline G15 & $\mathrm{PH} 25$ & 1,20 & 27,25 & 22,71 & 5,20 & 4,33 & 32,45 & 27,04 \\
\hline G16 & PH26 e PV29 & 1,60 & 41,63 & 26,02 & 5,50 & 3,44 & 47,13 & 29,46 \\
\hline G17 & PH31, PV02, PV05 e PV10 & 7,60 & 175,66 & 23,11 & 30,23 & 3,98 & 205,89 & 27,09 \\
\hline G18 & PH32, PV24, PV28 e PV32 & 7,60 & 175,66 & 23,11 & 30,23 & 3,98 & 205,89 & 27,09 \\
\hline G19 & PH27, PH28, PH30, PH33, PH34, PH39, PH42, PV15, PV17 e PV18 & 16,80 & 321,91 & 19,16 & 41,07 & 2,44 & 362,98 & 21,61 \\
\hline G20 & PH29, PH40, PH43 e PV19 & 11,20 & 228,05 & 20,36 & 34,17 & 3,05 & 262,22 & 23,41 \\
\hline G21 & PH35, PH45 e PV01 & 8,00 & 166,46 & 20,81 & 23,82 & 2,98 & 190,28 & 23,78 \\
\hline G22 & PH37, PH46 e PV08 & 4,80 & 105,32 & 21,94 & 15,21 & 3,17 & 120,52 & 25,11 \\
\hline G23 & PH41, PH47 e PV12 & 3,20 & 75,48 & 23,59 & 12,60 & 3,94 & 88,08 & 27,53 \\
\hline G24 & PH44, PH48 e PV22 & 3,20 & 75,48 & 23,59 & 12,60 & 3,94 & 88,08 & 27,53 \\
\hline G25 & $\mathrm{PH} 38, \mathrm{PH} 49$ e PV26 & 4,80 & 105,32 & 21,94 & 15,21 & 3,17 & 120,52 & 25,11 \\
\hline G26 & PH36, PH50 e PV31 & 8,00 & 166,46 & 20,81 & 23,82 & 2,98 & 190,28 & 23,78 \\
\hline
\end{tabular}

Tabela 6B-4 - GIP-EE - Cargas por paredes: $N_{k, v e r t}$ e $\eta_{k, v e r t}$ ao nível da fundação (t=12cm).

\begin{tabular}{|c|c|c|c|c|c|c|c|c|c|c|c|c|c|c|c|}
\hline \multicolumn{16}{|c|}{ GIP - EE: CARGAS POR PAREDE $->t=12 \mathrm{~cm}$} \\
\hline PAREDE & $L(m)$ & $G(t f)$ & $\mathrm{g}(\mathrm{tf} / \mathrm{m})$ & $Q$ (tf) & $q(t f / m)$ & $\mathrm{Nk}$,vert (tf) & $\eta \mathrm{k}$, vert $(\mathrm{tf} / \mathrm{m})$ & PAREDE & $L(m)$ & $\mathrm{G}(\mathrm{tf})$ & $g(t f / m)$ & $Q(t f)$ & $q(t f / m)$ & $N k$,vert (tf) & $\eta k$,vert $(\mathrm{tf} / \mathrm{m})$ \\
\hline PH01 & 0,80 & 16,65 & 20,81 & 2,38 & 2,98 & 19,03 & 23,78 & $\mathrm{PH} 44$ & 0,40 & 9,44 & 23,59 & 1,58 & 3,94 & 11,01 & 27,53 \\
\hline PHO2 & 1,20 & 26,33 & 21,94 & 3,80 & 3,17 & 30,13 & 25,11 & PH45 & 0,80 & 16,65 & 20,81 & 2,38 & 2,98 & 19,03 & 23,78 \\
\hline PHO3 & 0,40 & 9,44 & 23,59 & 1,58 & 3,94 & 11,01 & 27,53 & PH46 & 1,20 & 26,33 & 21,94 & 3,80 & 3,17 & 30,13 & 25,11 \\
\hline PHO4 & 0,40 & 9,44 & 23,59 & 1,58 & 3,94 & 11,01 & 27,53 & PH47 & 0,40 & 9,44 & 23,59 & 1,58 & 3,94 & 11,01 & 27,53 \\
\hline PH05 & 1,20 & 26,33 & 21,94 & 3,80 & 3,17 & 30,13 & 25,11 & $\mathrm{PH} 48$ & 0,40 & 9,44 & 23,59 & 1,58 & 3,94 & 11,01 & 27,53 \\
\hline PH06 & 0,80 & 16,65 & 20,81 & 2,38 & 2,98 & 19,03 & 23,78 & PH49 & 1,20 & 26,33 & 21,94 & 3,80 & 3,17 & 30,13 & 25,11 \\
\hline PH07 & 0,40 & 9,44 & 23,59 & 1,58 & 3,94 & 11,01 & 27,53 & $\mathrm{PH} 50$ & 0,80 & 16,65 & 20,81 & 2,38 & 2,98 & 19,03 & 23,78 \\
\hline PH08 & 0,40 & 7,24 & 18,11 & 0,89 & 2,22 & 8,13 & 20,33 & PV01 & 4,00 & 83,23 & 20,81 & 11,91 & 2,98 & 95,14 & 23,78 \\
\hline PH09 & 0,40 & 7,24 & 18,11 & 0,89 & 2,22 & 8,13 & 20,33 & PV02 & 0,80 & 18,49 & 23,11 & 3,18 & 3,98 & 21,67 & 27,09 \\
\hline PH10 & 0,40 & 9,44 & 23,59 & 1,58 & 3,94 & 11,01 & 27,53 & PV03 & 0,80 & 18,49 & 23,11 & 3,18 & 3,98 & 21,67 & 27,09 \\
\hline PH11 & 0,80 & 17,55 & 21,94 & 2,53 & 3,17 & 20,09 & 25,11 & $\begin{array}{l}\text { PV04 } \\
\end{array}$ & 4,00 & 83,23 & 20,81 & 11,91 & 2,98 & 95,14 & 23,78 \\
\hline $\mathrm{PH} 12$ & 0,80 & 17,55 & 21,94 & 2,53 & 3,17 & 20,09 & 25,11 & PV05 & 0,40 & 9,25 & 23,11 & 1,59 & 3,98 & 10,84 & 27,09 \\
\hline PH13 & 3,20 & 66,58 & 20,81 & 9,53 & 2,98 & 76,11 & 23,78 & PV06 & 0,80 & 20,82 & 26,02 & 2,75 & 3,44 & 23,57 & 29,46 \\
\hline PH14 & 3,20 & 66,58 & 20,81 & 9,53 & 2,98 & 76,11 & 23,78 & PV07 & 0,40 & 9,25 & 23,11 & 1,59 & 3,98 & 10,84 & 27,09 \\
\hline PH15 & 4,00 & 72,44 & 18,11 & 8,89 & 2,22 & 81,34 & 20,33 & PV08 & 2,80 & 61,44 & 21,94 & 8,87 & 3,17 & 70,31 & 25,11 \\
\hline PH16 & 4,00 & 92,45 & 23,11 & 15,91 & 3,98 & 108,36 & 27,09 & PV09 & 2,80 & 61,44 & 21,94 & 8,87 & 3,17 & 70,31 & 25,11 \\
\hline PH17 & 4,00 & 92,45 & 23,11 & 15,91 & 3,98 & 108,36 & 27,09 & PV10 & 2,40 & 55,47 & 23,11 & 9,55 & 3,98 & 65,02 & 27,09 \\
\hline PH18 & 0,40 & 7,24 & 18,11 & 0,89 & 2,22 & 8,13 & 20,33 & PV11 & 2,40 & 55,47 & 23,11 & 9,55 & 3,98 & 65,02 & 27,09 \\
\hline PH19 & 0,80 & 21,06 & 26,33 & 3,78 & 4,73 & 24,84 & 31,05 & PV12 & 2,40 & 56,61 & 23,59 & 9,45 & 3,94 & 66,06 & 27,53 \\
\hline $\mathrm{PH} 2 \mathrm{O}$ & 0,40 & 7,24 & 18,11 & 0,89 & 2,22 & 8,13 & 20,33 & PV13 & 2,40 & 56,61 & 23,59 & 9,45 & 3,94 & 66,06 & 27,53 \\
\hline PH21 & 0,80 & 20,82 & 26,02 & 2,75 & 3,44 & 23,57 & 29,46 & $\begin{array}{l}\text { PV14 } \\
\end{array}$ & 1,60 & 38,78 & 24,23 & 7,57 & 4,73 & 46,34 & 28,96 \\
\hline PH22 & 1,20 & 27,25 & 22,71 & 5,20 & 4,33 & 32,45 & 27,04 & PV15 & 7,20 & 137,96 & 19,16 & 17,60 & 2,44 & 155,56 & 21,61 \\
\hline $\mathrm{PH} 23$ & 0,80 & 19,39 & 24,23 & 3,78 & 4,73 & 23,17 & 28,96 & PV16 & 7,20 & 130,40 & 18,11 & 16,01 & 2,22 & 146,40 & 20,33 \\
\hline PH24 & 0,80 & 19,39 & 24,23 & 3,78 & 4,73 & 23,17 & 28,96 & PV17 & 2,00 & 38,32 & 19,16 & 4,89 & 2,44 & 43,21 & 21,61 \\
\hline $\mathrm{PH} 25$ & 1,20 & 27,25 & 22,71 & 5,20 & 4,33 & 32,45 & 27,04 & PV18 & 0,40 & 7,66 & 19,16 & 0,98 & 2,44 & 8,64 & 21,61 \\
\hline PH26 & 0,80 & 20,82 & 26,02 & 2,75 & 3,44 & 23,57 & 29,46 & PV19 & 7,20 & 146,60 & 20,36 & 21,97 & 3,05 & 168,57 & 23,41 \\
\hline PH27 & 0,40 & 7,66 & 19,16 & 0,98 & 2,44 & 8,64 & 21,61 & PV20 & 7,20 & 130,40 & 18,11 & 16,01 & 2,22 & 146,40 & 20,33 \\
\hline PH28 & 1,20 & 22,99 & 19,16 & 2,93 & 2,44 & 25,93 & 21,61 & PV21 & 1,60 & 38,78 & 24,23 & 7,57 & 4,73 & 46,34 & 28,96 \\
\hline PH29 & 0,80 & 16,29 & 20,36 & 2,44 & 3,05 & 18,73 & 23,41 & PV22 & 2,40 & 56,61 & 23,59 & 9,45 & 3,94 & 66,06 & 27,53 \\
\hline PH30 & 1,60 & 30,66 & 19,16 & 3,91 & 2,44 & 34,57 & 21,61 & PV23 & 2,40 & 56,61 & 23,59 & 9,45 & 3,94 & 66,06 & 27,53 \\
\hline PH31 & 4,00 & 92,45 & 23,11 & 15,91 & 3,98 & 108,36 & 27,09 & PV24 & 2,40 & 55,47 & 23,11 & 9,55 & 3,98 & 65,02 & 27,09 \\
\hline PH32 & 4,00 & 92,45 & 23,11 & 15,91 & 3,98 & 108,36 & 27,09 & PV25 & 2,40 & 55,47 & 23,11 & 9,55 & 3,98 & 65,02 & 27,09 \\
\hline PH33 & 0,40 & 7,66 & 19,16 & 0,98 & 2,44 & 8,64 & 21,61 & PV26 & 2,80 & 61,44 & 21,94 & 8,87 & 3,17 & 70,31 & 25,11 \\
\hline PH34 & 2,80 & 53,65 & 19,16 & 6,85 & 2,44 & 60,50 & 21,61 & PV27 & 2,80 & 61,44 & 21,94 & 8,87 & 3,17 & 70,31 & 25,11 \\
\hline PH35 & 3,20 & 66,58 & 20,81 & 9,53 & 2,98 & 76,11 & 23,78 & PV28 & 0,40 & 9,25 & 23,11 & 1,59 & 3,98 & 10,84 & 27,09 \\
\hline PH36 & 3,20 & 66,58 & 20,81 & 9,53 & 2,98 & 76,11 & 23,78 & PV29 & 0,80 & 20,82 & 26,02 & 2,75 & 3,44 & 23,57 & 29,46 \\
\hline PH37 & 0,80 & 17,55 & 21,94 & 2,53 & 3,17 & 20,09 & 25,11 & PV30 & 0,40 & 9,25 & 23,11 & 1,59 & 3,98 & 10,84 & 27,09 \\
\hline PH38 & 0,80 & 17,55 & 21,94 & 2,53 & 3,17 & 20,09 & 25,11 & PV31 & 4,00 & 83,23 & 20,81 & 11,91 & 2,98 & 95,14 & 23,78 \\
\hline PH39 & 0,40 & 7,66 & 19,16 & 0,98 & 2,44 & 8,64 & 21,61 & PV32 & 0,80 & 18,49 & 23,11 & 3,18 & 3,98 & 21,67 & 27,09 \\
\hline $\mathrm{PH} 40$ & 2,80 & 57,01 & 20,36 & 8,54 & 3,05 & 65,56 & 23,41 & PV33 & 0,80 & 18,49 & 23,11 & 3,18 & 3,98 & 21,67 & 27,09 \\
\hline PH41 & 0,40 & 9,44 & 23,59 & 1,58 & 3,94 & 11,01 & 27,53 & PV34 & 4,00 & 83,23 & 20,81 & 11,91 & 2,98 & 95,14 & 23,78 \\
\hline $\mathrm{PH} 42$ & 0,40 & 7,66 & 19,16 & 0,98 & 2,44 & 8,64 & 21,61 & PILAR & 1,00 & 81,90 & 81,90 & 12,60 & 12,60 & 94,50 & 94,50 \\
\hline $\mathrm{PH} 43$ & 0,40 & 8,14 & 20,36 & 1,22 & 3,05 & 9,37 & 23,41 & & & & & & & & \\
\hline
\end{tabular}


Modelo Pórtico Tridimensional - EE $(t=12 \mathrm{~cm})$

Tabela 6B-5 - MPT-EE: $N_{k, v e r t}$ e $\eta_{k, v e r t}$ ao nível da fundação ( $\left.\mathrm{t}=12 \mathrm{~cm}\right)$.

\begin{tabular}{|c|c|c|c|c|c|c|c|c|c|c|c|}
\hline \multicolumn{12}{|c|}{ MPT-EE $\rightarrow \mathrm{t}=12 \mathrm{~cm}$} \\
\hline PAREDE & $\mathrm{L}(\mathrm{m})$ & $G(t f)$ & $Q(t f)$ & $\mathrm{Nk}$,vert (tf) & $\eta \mathrm{k}$, vert $(\mathrm{tf} / \mathrm{m})$ & PAREDE & $\mathrm{L}(\mathrm{m})$ & $G(t f)$ & $Q(t f)$ & $N k$,vert (tf) & $\eta \mathrm{k}, \operatorname{vert}(\mathrm{tf} / \mathrm{m})$ \\
\hline $\mathrm{PHO1}$ & 0,80 & 17,34 & 2,56 & 19,90 & 24,88 & $\mathrm{PH} 44$ & 0,40 & 8,93 & 1,37 & 10,30 & 25,75 \\
\hline $\mathrm{PHO2}$ & 1,20 & 26,46 & 3,97 & 30,43 & 25,36 & $\mathrm{PH} 45$ & 0,80 & 17,41 & 2,58 & 19,99 & 24,98 \\
\hline $\mathrm{PHO3}$ & 0,40 & 8,86 & 1,36 & 10,22 & 25,56 & $\mathrm{PH} 46$ & 1,20 & 26,60 & 4,02 & 30,63 & 25,52 \\
\hline $\mathrm{PHO4}$ & 0,40 & 8,88 & 1,36 & 10,24 & 25,61 & $\mathrm{PH} 47$ & 0,40 & 8,93 & 1,38 & 10,31 & 25,78 \\
\hline $\mathrm{PH} 05$ & 1,20 & 26,56 & 4,03 & 30,60 & 25,50 & $\mathrm{PH} 48$ & 0,40 & 8,87 & 1,35 & 10,22 & 25,55 \\
\hline $\mathrm{PHO6}$ & 0,80 & 17,48 & 2,65 & 20,13 & 25,16 & $\mathrm{PH} 49$ & 1,20 & 26,53 & 3,99 & 30,51 & 25,43 \\
\hline $\mathrm{PH} 07$ & 0,40 & 8,89 & 1,37 & 10,26 & 25,66 & $\mathrm{PH} 50$ & 0,80 & 17,44 & 2,61 & 20,05 & 25,06 \\
\hline $\mathrm{PH} 08$ & 0,40 & 7,69 & 1,01 & 8,70 & 21,75 & PV01 & 4,00 & 87,09 & 13,00 & 100,09 & 25,02 \\
\hline PH09 & 0,40 & 7,73 & 1,04 & 8,77 & 21,92 & PV02 & 0,80 & 17,60 & 2,68 & 20,27 & 25,34 \\
\hline $\mathrm{PH} 10$ & 0,40 & 8,90 & 1,37 & 10,27 & 25,67 & PV03 & 0,80 & 17,62 & 2,70 & 20,32 & 25,40 \\
\hline $\mathrm{PH} 11$ & 0,80 & 17,62 & 2,69 & 20,31 & 25,39 & PV04 & 4,00 & 86,97 & 12,98 & 99,94 & 24,99 \\
\hline $\mathrm{PH} 12$ & 0,80 & 17,63 & 2,69 & 20,32 & 25,41 & PV05 & 0,40 & 8,96 & 1,42 & 10,37 & 25,94 \\
\hline $\mathrm{PH} 13$ & 3,20 & 70,48 & 10,84 & 81,32 & 25,41 & PV06 & 0,80 & 18,10 & 2,83 & 20,93 & 26,16 \\
\hline $\mathrm{PH} 14$ & 3,20 & 70,58 & 10,90 & 81,48 & 25,46 & PV07 & 0,40 & 8,96 & 1,42 & 10,39 & 25,96 \\
\hline $\mathrm{PH} 15$ & 4,00 & 74,57 & 9,50 & 84,08 & 21,02 & PV08 & 2,80 & 61,96 & 9,46 & 71,41 & 25,50 \\
\hline $\mathrm{PH} 16$ & 4,00 & 89,21 & 14,12 & 103,33 & 25,83 & PV09 & 2,80 & 61,65 & 9,35 & 71,00 & 25,36 \\
\hline PH17 & 4,00 & 89,07 & 14,05 & 103,12 & 25,78 & PV10 & 2,40 & 54,54 & 8,99 & 63,53 & 26,47 \\
\hline PH18 & 0,40 & 7,53 & 0,96 & 8,49 & 21,22 & PV11 & 2,40 & 54,52 & 8,99 & 63,51 & 26,46 \\
\hline PH19 & 0,80 & 16,23 & 2,27 & 18,50 & 23,12 & PV12 & 2,40 & 53,57 & 8,37 & 61,93 & 25,81 \\
\hline $\mathrm{PH} 20$ & 0,40 & 7,56 & 0,98 & 8,53 & 21,33 & PV13 & 2,40 & 53,19 & 8,22 & 61,41 & 25,59 \\
\hline $\mathrm{PH} 21$ & 0,80 & 18,07 & 2,84 & 20,91 & 26,14 & PV14 & 1,60 & 38,80 & 7,58 & 46,38 & 28,99 \\
\hline $\mathrm{PH} 22$ & 1,20 & 27,25 & 5,20 & 32,45 & 27,05 & PV15 & 7,20 & 141,50 & 18,99 & 160,50 & 22,29 \\
\hline $\mathrm{PH} 23$ & 0,80 & 19,36 & 3,77 & 23,13 & 28,92 & PV16 & 7,20 & 134,26 & 17,04 & 151,30 & 21,01 \\
\hline $\mathrm{PH} 24$ & 0,80 & 19,37 & 3,78 & 23,15 & 28,94 & PV17 & 2,00 & 39,19 & 5,27 & 44,46 & 22,23 \\
\hline $\mathrm{PH} 25$ & 1,20 & 27,25 & 5,20 & 32,45 & 27,05 & PV18 & 0,40 & 7,85 & 1,07 & 8,92 & 22,30 \\
\hline $\mathrm{PH} 26$ & 0,80 & 18,05 & 2,83 & 20,88 & 26,09 & PV19 & 7,20 & 144,78 & 20,91 & 165,68 & 23,01 \\
\hline $\mathrm{PH} 27$ & 0,40 & 7,81 & 1,03 & 8,84 & 22,10 & PV20 & 7,20 & 134,88 & 17,51 & 152,38 & 21,16 \\
\hline $\mathrm{PH} 28$ & 1,20 & 23,64 & 3,20 & 26,83 & 22,36 & PV21 & 1,60 & 38,79 & 7,57 & 46,36 & 28,98 \\
\hline $\mathrm{PH} 29$ & 0,80 & 16,12 & 2,33 & 18,44 & 23,05 & PV22 & 2,40 & 53,27 & 8,17 & 61,44 & 25,60 \\
\hline $\mathrm{PH} 30$ & 1,60 & 31,32 & 4,18 & 35,50 & 22,19 & PV23 & 2,40 & 53,21 & 8,20 & 61,41 & 25,59 \\
\hline PH31 & 4,00 & 89,13 & 14,06 & 103,19 & 25,80 & PV24 & 2,40 & 54,34 & 8,84 & 63,18 & 26,32 \\
\hline $\mathrm{PH} 32$ & 4,00 & 89,40 & 14,22 & 103,62 & 25,91 & PV25 & 2,40 & 54,29 & 8,82 & 63,11 & 26,30 \\
\hline $\mathrm{PH} 33$ & 0,40 & 7,95 & 1,11 & 9,06 & 22,66 & PV26 & 2,80 & 61,84 & 9,40 & 71,24 & 25,44 \\
\hline PH34 & 2,80 & 54,67 & 7,32 & 61,99 & 22,14 & PV27 & 2,80 & 61,79 & 9,42 & 71,21 & 25,43 \\
\hline PH35 & 3,20 & 70,56 & 10,86 & 81,42 & 25,44 & PV28 & 0,40 & 8,97 & 1,43 & 10,40 & 25,99 \\
\hline PH36 & 3,20 & 70,70 & 10,95 & 81,65 & 25,51 & PV29 & 0,80 & 18,10 & 2,83 & 20,92 & 26,15 \\
\hline PH37 & 0,80 & 17,70 & 2,72 & 20,43 & 25,53 & PV30 & 0,40 & 8,94 & 1,41 & 10,35 & 25,89 \\
\hline PH38 & 0,80 & 17,67 & 2,70 & 20,37 & 25,46 & PV31 & 4,00 & 87,53 & 13,33 & 100,87 & 25,22 \\
\hline PH39 & 0,40 & 7,91 & 1,07 & 8,99 & 22,46 & PV32 & 0,80 & 17,75 & 2,78 & 20,53 & 25,66 \\
\hline $\mathrm{PH} 40$ & 2,80 & 55,89 & 7,85 & 63,75 & 22,77 & PV33 & 0,80 & 17,67 & 2,74 & 20,40 & 25,50 \\
\hline $\mathrm{PH} 41$ & 0,40 & 8,98 & 1,40 & 10,37 & 25,94 & PV34 & 4,00 & 87,49 & 13,35 & 100,84 & 25,21 \\
\hline $\mathrm{PH} 42$ & 0,40 & 8,09 & 1,12 & 9,20 & 23,01 & PILAR & 1,00 & 81,90 & 12,60 & 94,50 & 94,50 \\
\hline $\mathrm{PH} 43$ & 0,40 & 8,18 & 1,18 & 9,36 & 23,41 & & & & & & \\
\hline
\end{tabular}


Modelo em Elementos Finitos - EE $(t=12 \mathrm{~cm})$

Tabela 6B-6 - MEF-EE: $N_{k, v e r t}$ e $\eta_{k, v e r t}$ ao nível da fundação ( $\left.\mathrm{t}=12 \mathrm{~cm}\right)$.

\begin{tabular}{|c|c|c|c|c|c|c|c|c|c|c|c|}
\hline \multicolumn{12}{|c|}{ MEF-EE $->t=12 \mathrm{~cm}$} \\
\hline PAREDE & $\mathrm{L}(\mathrm{m})$ & $G(t f)$ & $Q(t f)$ & 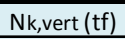 & $\eta k$,vert (tf/m) & PAREDE & $\mathrm{L}(\mathrm{m})$ & $\mathrm{G}(\mathrm{tf})$ & $Q(t f)$ & $N k$,vert (tf) & $\eta k$,vert $(t f / m)$ \\
\hline $\mathrm{PHO1}$ & 0,80 & 17,35 & 2,56 & 19,91 & 24,89 & $\mathrm{PH} 44$ & 0,40 & 8,59 & 1,32 & 9,91 & 24,77 \\
\hline $\mathrm{PHO2}$ & 1,20 & 27,13 & 4,06 & 31,19 & 25,99 & $\mathrm{PH} 45$ & 0,80 & 17,49 & 2,62 & 20,10 & 25,13 \\
\hline $\mathrm{PHO3}$ & 0,40 & 8,75 & 1,34 & 10,09 & 25,22 & $\mathrm{PH} 46$ & 1,20 & 27,38 & 4,14 & 31,51 & 26,26 \\
\hline $\mathrm{PHO4}$ & 0,40 & 8,76 & 1,35 & 10,11 & 25,27 & $\mathrm{PH} 47$ & 0,40 & 8,85 & 1,37 & 10,22 & 25,55 \\
\hline $\mathrm{PH} 05$ & 1,20 & 27,19 & 4,11 & 31,30 & 26,09 & $\mathrm{PH} 48$ & 0,40 & 8,85 & 1,37 & 10,21 & 25,54 \\
\hline $\mathrm{PHO6}$ & 0,80 & 17,43 & 2,64 & 20,06 & 25,08 & PH49 & 1,20 & 27,40 & 4,14 & 31,54 & 26,28 \\
\hline $\mathrm{PH} 07$ & 0,40 & 8,52 & 1,31 & 9,83 & 24,57 & PH50 & 0,80 & 17,54 & 2,64 & 20,17 & 25,22 \\
\hline $\mathrm{PH} 08$ & 0,40 & 7,53 & 1,03 & 8,55 & 21,38 & PV01 & 4,00 & 87,42 & 13,08 & 100,50 & 25,13 \\
\hline PH09 & 0,40 & 7,55 & 1,05 & 8,60 & 21,51 & PV02 & 0,80 & 17,65 & 2,73 & 20,38 & 25,48 \\
\hline $\mathrm{PH} 10$ & 0,40 & 8,53 & 1,31 & 9,83 & 24,58 & PV03 & 0,80 & 17,67 & 2,74 & 20,40 & 25,50 \\
\hline $\mathrm{PH} 11$ & 0,80 & 17,51 & 2,65 & 20,17 & 25,21 & PV04 & 4,00 & 87,01 & 12,99 & 100,01 & 25,00 \\
\hline $\mathrm{PH} 12$ & 0,80 & 17,52 & 2,66 & 20,18 & 25,23 & PV05 & 0,40 & 8,54 & 1,35 & 9,89 & 24,73 \\
\hline $\mathrm{PH} 13$ & 3,20 & 69,69 & 10,69 & 80,37 & 25,12 & PV06 & 0,80 & 18,53 & 2,82 & 21,35 & 26,69 \\
\hline $\mathrm{PH} 14$ & 3,20 & 69,77 & 10,72 & 80,49 & 25,15 & PV07 & 0,40 & 8,55 & 1,36 & 9,91 & 24,77 \\
\hline $\mathrm{PH} 15$ & 4,00 & 75,91 & 10,16 & 86,08 & 21,52 & PV08 & 2,80 & 62,20 & 9,44 & 71,64 & 25,59 \\
\hline $\mathrm{PH} 16$ & 4,00 & 88,18 & 13,90 & 102,07 & 25,52 & PV09 & 2,80 & 61,76 & 9,30 & 71,06 & 25,38 \\
\hline $\mathrm{PH} 17$ & 4,00 & 88,19 & 13,89 & 102,08 & 25,52 & PV10 & 2,40 & 53,38 & 8,71 & 62,10 & 25,87 \\
\hline $\mathrm{PH} 18$ & 0,40 & 7,65 & 1,04 & 8,70 & 21,74 & PV11 & 2,40 & 53,32 & 8,69 & 62,01 & 25,84 \\
\hline PH19 & 0,80 & 16,46 & 2,34 & 18,80 & 23,49 & PV12 & 2,40 & 52,64 & 8,14 & 60,78 & 25,32 \\
\hline $\mathrm{PH} 20$ & 0,40 & 7,67 & 1,05 & 8,73 & 21,81 & PV13 & 2,40 & 52,12 & 7,97 & 60,09 & 25,04 \\
\hline $\mathrm{PH} 21$ & 0,80 & 18,25 & 2,78 & 21,03 & 26,29 & PV14 & 1,60 & 33,69 & 5,48 & 39,17 & 24,48 \\
\hline $\mathrm{PH} 22$ & 1,20 & 27,25 & 5,20 & 32,45 & 27,04 & PV15 & 7,20 & 147,11 & 20,64 & 167,75 & 23,30 \\
\hline $\mathrm{PH} 23$ & 0,80 & 16,55 & 2,68 & 19,23 & 24,04 & PV16 & 7,20 & 142,10 & 19,37 & 161,47 & 22,43 \\
\hline $\mathrm{PH} 24$ & 0,80 & 16,68 & 2,76 & 19,45 & 24,31 & PV17 & 2,00 & 39,14 & 5,43 & 44,58 & 22,29 \\
\hline $\mathrm{PH} 25$ & 1,20 & 27,25 & 5,20 & 32,45 & 27,04 & PV18 & 0,40 & 8,18 & 1,16 & 9,34 & 23,35 \\
\hline $\mathrm{PH} 26$ & 0,80 & 18,25 & 2,77 & 21,02 & 26,28 & PV19 & 7,20 & 149,21 & 21,99 & 171,20 & 23,78 \\
\hline $\mathrm{PH} 27$ & 0,40 & 7,81 & 1,09 & 8,89 & 22,23 & PV20 & 7,20 & 142,52 & 19,69 & 162,20 & 22,53 \\
\hline $\mathrm{PH} 28$ & 1,20 & 24,39 & 3,40 & 27,78 & 23,15 & PV21 & 1,60 & 33,94 & 5,62 & 39,56 & 24,73 \\
\hline $\mathrm{PH} 29$ & 0,80 & 16,12 & 2,39 & 18,51 & 23,14 & PV22 & 2,40 & 52,61 & 8,10 & 60,71 & 25,30 \\
\hline $\mathrm{PH} 30$ & 1,60 & 31,07 & 4,29 & 35,37 & 22,10 & PV23 & 2,40 & 52,15 & 8,00 & 60,15 & 25,06 \\
\hline PH31 & 4,00 & 88,11 & 13,84 & 101,95 & 25,49 & PV24 & 2,40 & 53,29 & 8,61 & 61,90 & 25,79 \\
\hline PH32 & 4,00 & 88,27 & 13,98 & 102,25 & 25,56 & PV25 & 2,40 & 53,20 & 8,59 & 61,79 & 25,75 \\
\hline PH33 & 0,40 & 7,88 & 1,10 & 8,99 & 22,47 & PV26 & 2,80 & 62,25 & 9,46 & 71,72 & 25,61 \\
\hline PH34 & 2,80 & 55,46 & 7,72 & 63,18 & 22,57 & PV27 & 2,80 & 61,86 & 9,38 & 71,23 & 25,44 \\
\hline PH35 & 3,20 & 69,84 & 10,70 & 80,54 & 25,17 & PV28 & 0,40 & 8,55 & 1,36 & 9,91 & 24,78 \\
\hline PH36 & 3,20 & 70,01 & 10,83 & 80,84 & 25,26 & PV29 & 0,80 & 18,53 & 2,83 & 21,36 & 26,70 \\
\hline PH37 & 0,80 & 17,61 & 2,68 & 20,29 & 25,37 & PV30 & 0,40 & 8,55 & 1,35 & 9,90 & 24,74 \\
\hline PH38 & 0,80 & 17,62 & 2,68 & 20,30 & 25,38 & PV31 & 4,00 & 87,81 & 13,39 & 101,20 & 25,30 \\
\hline PH39 & 0,40 & 7,90 & 1,13 & 9,03 & 22,58 & PV32 & 0,80 & 17,75 & 2,80 & 20,55 & 25,68 \\
\hline $\mathrm{PH} 40$ & 2,80 & 56,50 & 8,08 & 64,57 & 23,06 & PV33 & 0,80 & 17,72 & 2,78 & 20,50 & 25,63 \\
\hline PH41 & 0,40 & 8,60 & 1,33 & 9,94 & 24,84 & PV34 & 4,00 & 87,37 & 13,26 & 100,64 & 25,16 \\
\hline $\mathrm{PH} 42$ & 0,40 & 7,87 & 1,11 & 8,98 & 22,44 & PILAR & 1,00 & 81,90 & 12,60 & 94,50 & 94,50 \\
\hline $\mathrm{PH} 43$ & 0,40 & 8,00 & 1,17 & 9,17 & 22,91 & & & & & & \\
\hline
\end{tabular}


Comparação da distribuição de cargas verticais - EE $(t=12 \mathrm{~cm})$

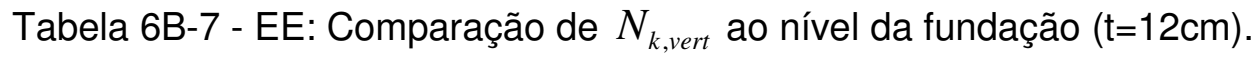

\begin{tabular}{|c|c|c|c|c|c|c|c|c|c|c|c|c|c|c|c|c|c|}
\hline \multicolumn{18}{|c|}{ EE - DISTRIBUIÇÃO DE CARGAS VERTICAIS - Nk,vert (tf) $->t=12 \mathrm{~cm}$} \\
\hline PAREDE & $\mathrm{L}(\mathrm{m})$ & MEF & MPT & $\%$ & GIP & $\%$ & PIS & $\%$ & PAREDE & $L(m)$ & MEF & MPT & $\%$ & GIP & $\%$ & PIS & $\%$ \\
\hline PH01 & 0,80 & 19,91 & 19,90 & 0,0 & 19,03 & $-4,4$ & 21,75 & 9,2 & PH45 & 0,80 & 20,10 & 19,99 & $-0,6$ & 19,03 & $-5,4$ & 21,75 & 8,2 \\
\hline $\mathrm{PH} 02$ & 1,20 & 31,19 & 30,43 & $-2,4$ & 30,13 & $-3,4$ & 32,79 & 5,1 & $\mathrm{PH} 46$ & 1,20 & 31,51 & 30,63 & $-2,8$ & 30,13 & $-4,4$ & 32,79 & 4,1 \\
\hline $\mathrm{PHO3}$ & 0,40 & 10,09 & 10,22 & 1,3 & 11,01 & 9,1 & 11,04 & 9,4 & $\mathrm{PH} 47$ & 0,40 & 10,22 & 10,31 & 0,9 & 11,01 & 7,7 & 11,04 & 8,0 \\
\hline $\mathrm{PHO4}$ & 0,40 & 10,11 & 10,24 & 1,3 & 11,01 & 8,9 & 11,04 & 9,2 & $\mathrm{PH} 48$ & 0,40 & 10,21 & 10,22 & 0,1 & 11,01 & 7,8 & 11,04 & 8,1 \\
\hline PH05 & 1,20 & 31,30 & 30,60 & $-2,3$ & 30,13 & $-3,7$ & 32,79 & 4,8 & $\mathrm{PH} 49$ & 1,20 & 31,54 & 30,51 & $-3,2$ & 30,13 & $-4,5$ & 32,79 & 4,0 \\
\hline PHOG & 0,80 & 20,06 & 20,13 & 0,3 & 19,03 & $-5,2$ & 21,75 & 8,4 & PH50 & 0,80 & 20,17 & 20,05 & $-0,6$ & 19,03 & $-5,7$ & 21,75 & 7,8 \\
\hline PH07 & 0,40 & 9,83 & 10,26 & 4,4 & 11,01 & 12,0 & 16,68 & 69,7 & PV01 & 4,00 & 100,50 & 100,09 & $-0,4$ & 95,14 & $-5,3$ & 82,32 & $-18,1$ \\
\hline PH08 & 0,40 & 8,55 & 8,70 & 1,7 & 8,13 & $-4,9$ & 16,68 & 95,0 & PV02 & 0,80 & 20,38 & 20,27 & $-0,5$ & 21,67 & 6,3 & 20,70 & 1,6 \\
\hline $\mathrm{PH} 09$ & 0,40 & 8,60 & 8,77 & 1,9 & 8,13 & $-5,4$ & 16,68 & 93,9 & PV03 & 0,80 & 20,40 & 20,32 & $-0,4$ & 21,67 & 6,2 & 20,70 & 1,5 \\
\hline PH10 & 0,40 & 9,83 & 10,27 & 4,4 & 11,01 & 12,0 & 16,68 & 69,6 & PV04 & 4,00 & 100,01 & 99,94 & $-0,1$ & 95,14 & $-4,9$ & 82,32 & $-17,7$ \\
\hline PH11 & 0,80 & 20,17 & 20,31 & 0,7 & 20,09 & $-0,4$ & 19,80 & $-1,8$ & PV05 & 0,40 & 9,89 & 10,37 & 4,9 & 10,84 & 9,6 & 13,11 & 32,5 \\
\hline PH12 & 0,80 & 20,18 & 20,32 & 0,7 & 20,09 & $-0,5$ & 19,80 & $-1,9$ & PV06 & 0,80 & 21,35 & 20,93 & $-2,0$ & 23,57 & 10,4 & 26,22 & 22,8 \\
\hline $\mathrm{PH} 13$ & 3,20 & 80,37 & 81,32 & 1,2 & 76,11 & $-5,3$ & 86,21 & 7,3 & PV07 & 0,40 & 9,91 & 10,39 & 4,8 & 10,84 & 9,4 & 13,11 & 32,3 \\
\hline PH14 & 3,20 & 80,49 & 81,48 & 1,2 & 76,11 & $-5,4$ & 86,21 & 7,1 & PV08 & 2,80 & 71,64 & 71,41 & $-0,3$ & 70,31 & $-1,9$ & 67,93 & $-5,2$ \\
\hline $\mathrm{PH} 15$ & 4,00 & 86,08 & 84,08 & $-2,3$ & 81,34 & $-5,5$ & 50,40 & $-41,4$ & PV09 & 2,80 & 71,06 & 71,00 & $-0,1$ & 70,31 & $-1,1$ & 67,93 & $-4,4$ \\
\hline $\mathrm{PH} 16$ & 4,00 & 102,07 & 103,33 & 1,2 & 108,36 & 6,2 & 87,60 & $-14,2$ & PV10 & 2,40 & 62,10 & 63,53 & 2,3 & 65,02 & 4,7 & 84,48 & 36,0 \\
\hline $\mathrm{PH} 17$ & 4,00 & 102,08 & 103,12 & 1,0 & 108,36 & 6,2 & 87,60 & $-14,2$ & PV11 & 2,40 & 62,01 & 63,51 & 2,4 & 65,02 & 4,8 & 84,48 & 36,2 \\
\hline $\mathrm{PH} 18$ & 0,40 & 8,70 & 8,49 & $-2,4$ & 8,13 & $-6,5$ & 12,42 & 42,8 & PV12 & 2,40 & 60,78 & 61,93 & 1,9 & 66,06 & 8,7 & 60,36 & $-0,7$ \\
\hline PH19 & 0,80 & 18,80 & 18,50 & $-1,6$ & 24,84 & 32,2 & 24,84 & 32,2 & PV13 & 2,40 & 60,09 & 61,41 & 2,2 & 66,06 & 9,9 & 60,36 & 0,4 \\
\hline $\mathrm{PH} 2 \mathrm{O}$ & 0,40 & 8,73 & 8,53 & $-2,2$ & 8,13 & $-6,8$ & 12,42 & 42,3 & PV14 & 1,60 & 39,17 & 46,38 & 18,4 & 46,34 & 18,3 & 48,60 & 24,1 \\
\hline $\mathrm{PH} 21$ & 0,80 & 21,03 & 20,91 & $-0,6$ & 23,57 & 12,1 & 20,91 & $-0,6$ & PV15 & 7,20 & 167,75 & 160,50 & $-4,3$ & 155,56 & $-7,3$ & 160,74 & $-4,2$ \\
\hline $\mathrm{PH} 22$ & 1,20 & 32,45 & 32,45 & 0,0 & 32,45 & 0,0 & 32,45 & 0,0 & PV16 & 7,20 & 161,47 & 151,30 & $-6,3$ & 146,40 & $-9,3$ & 149,04 & $-7,7$ \\
\hline $\mathrm{PH} 23$ & 0,80 & 19,23 & 23,13 & 20,3 & 23,17 & 20,5 & 20,91 & 8,7 & PV17 & 2,00 & 44,58 & 44,46 & $-0,3$ & 43,21 & $-3,1$ & 31,80 & $-28,7$ \\
\hline $\mathrm{PH} 24$ & 0,80 & 19,45 & 23,15 & 19,1 & 23,17 & 19,2 & 20,91 & 7,6 & PV18 & 0,40 & 9,34 & 8,92 & $-4,5$ & 8,64 & $-7,5$ & 8,64 & $-7,5$ \\
\hline $\mathrm{PH} 25$ & 1,20 & 32,45 & 32,45 & 0,0 & 32,45 & 0,0 & 32,45 & 0,0 & PV19 & 7,20 & 171,20 & 165,68 & $-3,2$ & 168,57 & $-1,5$ & 171,26 & 0,0 \\
\hline $\mathrm{PH} 26$ & 0,80 & 21,02 & 20,88 & $-0,7$ & 23,57 & 12,1 & 20,91 & $-0,5$ & PV20 & 7,20 & 162,20 & 152,38 & $-6,1$ & 146,40 & $-9,7$ & 149,04 & $-8,1$ \\
\hline $\mathrm{PH} 27$ & 0,40 & 8,89 & 8,84 & $-0,6$ & 8,64 & $-2,8$ & 13,68 & 53,8 & PV21 & 1,60 & 39,56 & 46,36 & 17,2 & 46,34 & 17,1 & 48,60 & 22,8 \\
\hline $\mathrm{PH} 28$ & 1,20 & 27,78 & 26,83 & $-3,4$ & 25,93 & $-6,7$ & 36,84 & 32,6 & PV22 & 2,40 & 60,71 & 61,44 & 1,2 & 66,06 & 8,8 & 60,36 & $-0,6$ \\
\hline $\mathrm{PH} 29$ & 0,80 & 18,51 & 18,44 & $-0,4$ & 18,73 & 1,2 & 23,16 & 25,1 & PV23 & 2,40 & 60,15 & 61,41 & 2,1 & 66,06 & 9,8 & 60,36 & 0,3 \\
\hline $\mathrm{PH} 30$ & 1,60 & 35,37 & 35,50 & 0,4 & 34,57 & $-2,3$ & 20,16 & $-43,0$ & PV24 & 2,40 & 61,90 & 63,18 & 2,1 & 65,02 & 5,0 & 84,48 & 36,5 \\
\hline PH31 & 4,00 & 101,95 & 103,19 & 1,2 & 108,36 & 6,3 & 87,60 & $-14,1$ & PV25 & 2,40 & 61,79 & 63,11 & 2,1 & 65,02 & 5,2 & 84,48 & 36,7 \\
\hline $\mathrm{PH} 32$ & 4,00 & 102,25 & 103,62 & 1,3 & 108,36 & 6,0 & 87,60 & $-14,3$ & PV26 & 2,80 & 71,72 & 71,24 & $-0,7$ & 70,31 & $-2,0$ & 67,93 & $-5,3$ \\
\hline $\mathrm{PH} 33$ & 0,40 & 8,99 & 9,06 & 0,8 & 8,64 & $-3,8$ & 12,16 & 35,3 & PV27 & 2,80 & 71,23 & 71,21 & 0,0 & 70,31 & $-1,3$ & 67,93 & $-4,6$ \\
\hline $\mathrm{PH} 34$ & 2,80 & 63,18 & 61,99 & $-1,9$ & 60,50 & $-4,3$ & 50,58 & $-19,9$ & PV28 & 0,40 & 9,91 & 10,40 & 4,9 & 10,84 & 9,3 & 13,11 & 32,3 \\
\hline PH35 & 3,20 & 80,54 & 81,42 & 1,1 & 76,11 & $-5,5$ & 86,21 & 7,0 & PV29 & 0,80 & 21,36 & 20,92 & $-2,1$ & 23,57 & 10,3 & 26,22 & 22,7 \\
\hline $\mathrm{PH} 36$ & 3,20 & 80,84 & 81,65 & 1,0 & 76,11 & $-5,8$ & 86,21 & 6,6 & PV30 & 0,40 & 9,90 & 10,35 & 4,6 & 10,84 & 9,5 & 13,11 & 32,5 \\
\hline $\mathrm{PH} 37$ & 0,80 & 20,29 & 20,43 & 0,7 & 20,09 & $-1,0$ & 19,80 & $-2,4$ & PV31 & 4,00 & 101,20 & 100,87 & $-0,3$ & 95,14 & $-6,0$ & 82,32 & $-18,7$ \\
\hline $\mathrm{PH} 38$ & 0,80 & 20,30 & 20,37 & 0,3 & 20,09 & $-1,1$ & 19,80 & $-2,5$ & PV32 & 0,80 & 20,55 & 20,53 & $-0,1$ & 21,67 & 5,5 & 20,70 & 0,7 \\
\hline PH39 & 0,40 & 9,03 & 8,99 & $-0,5$ & 8,64 & $-4,3$ & 11,70 & 29,6 & PV33 & 0,80 & 20,50 & 20,40 & $-0,5$ & 21,67 & 5,7 & 20,70 & 1,0 \\
\hline $\mathrm{PH} 40$ & 2,80 & 64,57 & 63,75 & $-1,3$ & 65,56 & 1,5 & 51,12 & $-20,8$ & PV34 & 4,00 & 100,64 & 100,84 & 0,2 & 95,14 & $-5,5$ & 82,32 & $-18,2$ \\
\hline $\mathrm{PH} 41$ & 0,40 & 9,94 & 10,37 & 4,4 & 11,01 & 10,8 & 16,68 & 67,9 & & & & & MPT & & GIP & & PIS \\
\hline $\mathrm{PH} 42$ & 0,40 & 8,98 & 9,20 & 2,5 & 8,64 & $-3,7$ & 16,68 & 85,8 & & & & & $5 \%$ & & $6 \%$ & & $44 \%$ \\
\hline $\mathrm{PH} 43$ & 0,40 & 9,17 & 9,36 & 2,2 & 9,37 & 2,2 & 16,68 & 82,0 & & & & & $2 \%$ & & $57 \%$ & & $29 \%$ \\
\hline $\mathrm{PH} 44$ & 0,40 & 9,91 & 10,30 & 3,9 & 11,01 & 11,1 & 16,68 & 68,3 & & & & & $93 \%$ & & $37 \%$ & & $27 \%$ \\
\hline
\end{tabular}


Diagrama de $N_{k, v e r t}$ das paredes PH13, PH16, PH34, PV08, PV12 e PV15 - EE $(t=12 \mathrm{~cm})$

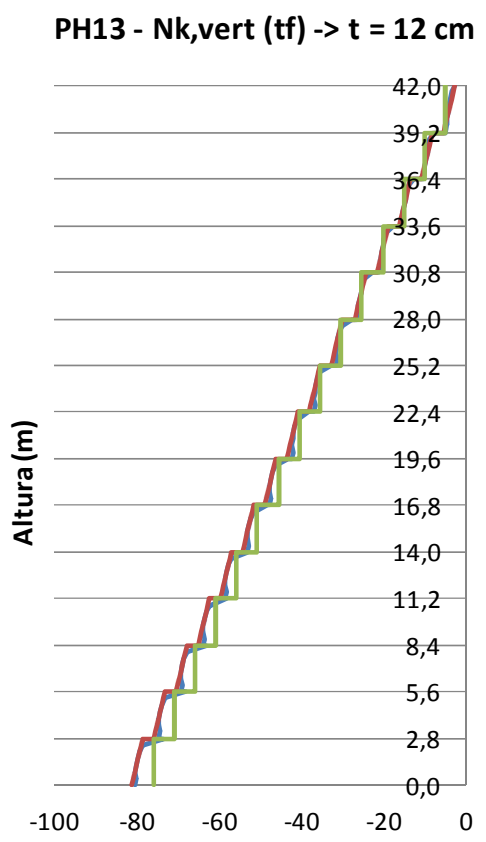

Força Normal - Nk,vert (tf)

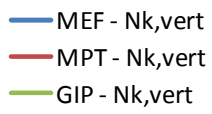

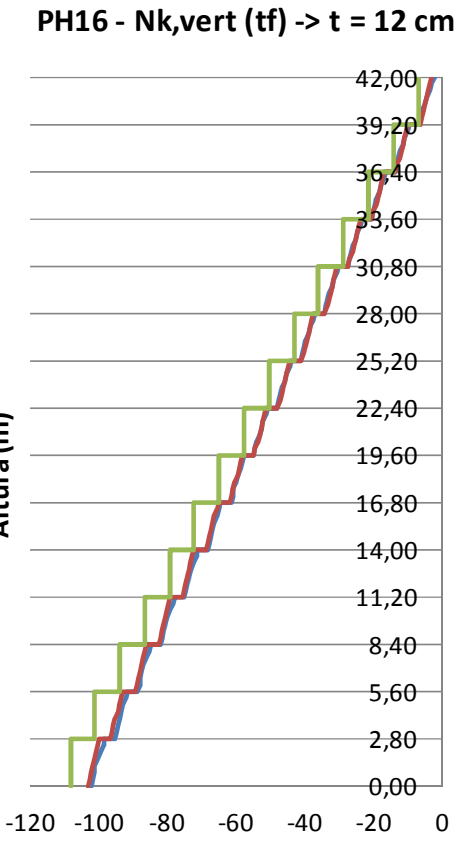

Força Normal - Nk,vert (tf)

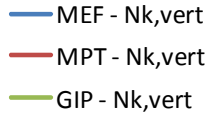

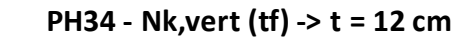

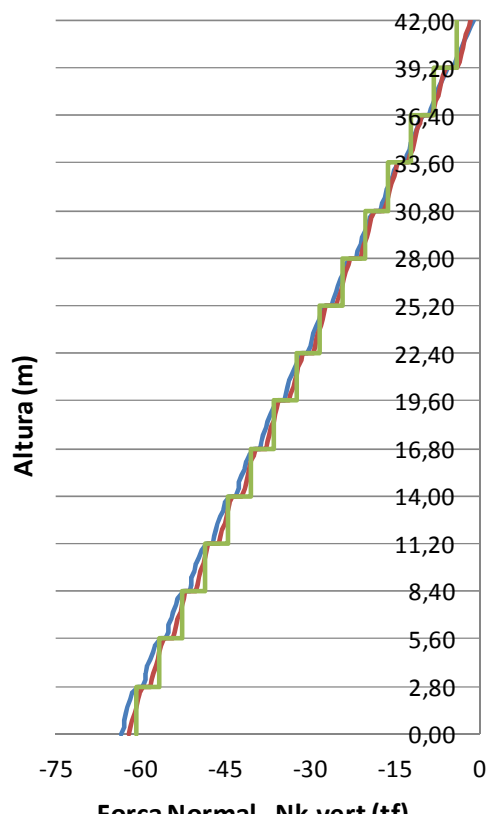

Força Normal - Nk,vert (tf)

$\longrightarrow \mathrm{MEF}-\mathrm{Nk}$,vert

- MPT - Nk,vert

GIP - Nk,vert

Figura 6B-1 - Diagrama de $N_{k, v e r t}$ obtido pelos modelos GIP, MPT e MEF das paredes $\mathrm{PH} 13, \mathrm{PH} 16$ e $\mathrm{PH} 34$ com espessura de $12 \mathrm{~cm}$. 


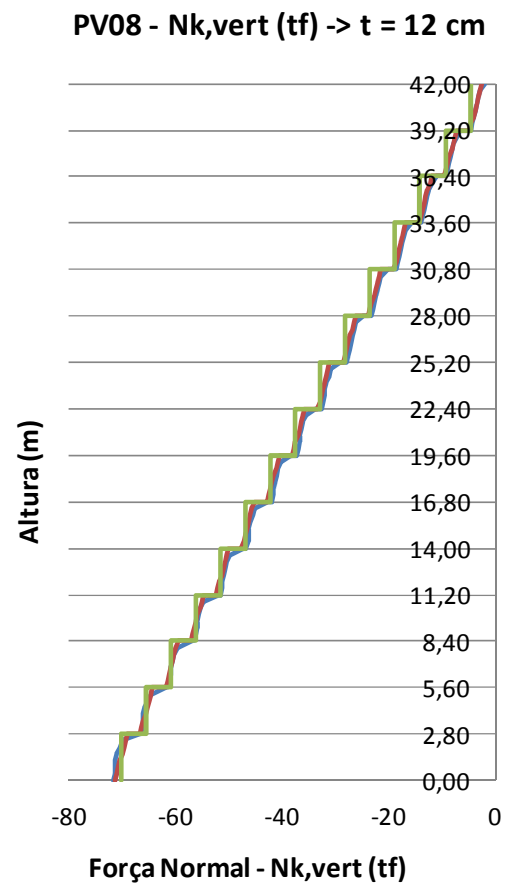

$$
\begin{aligned}
& \text {-MEF - Nk,vert } \\
& \text { MPT - Nk,vert } \\
& \text { GIP - Nk,vert }
\end{aligned}
$$
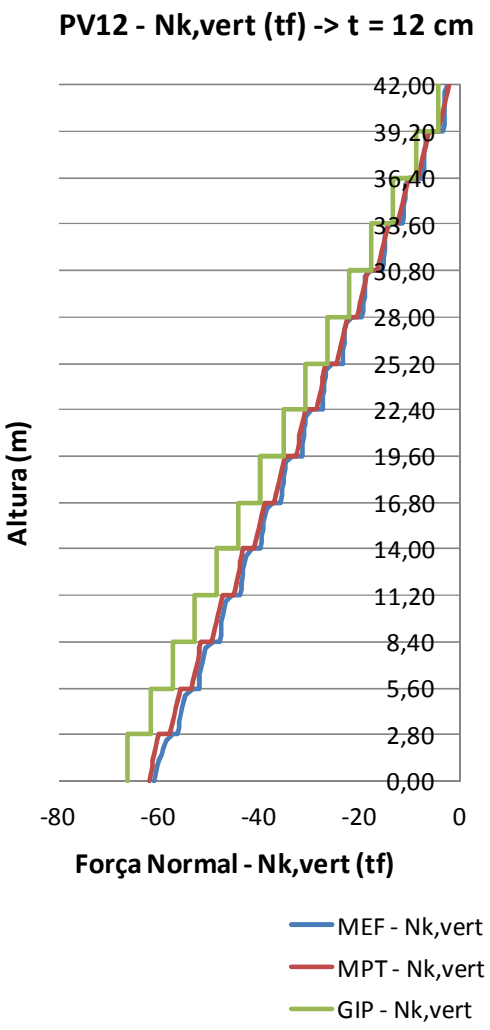

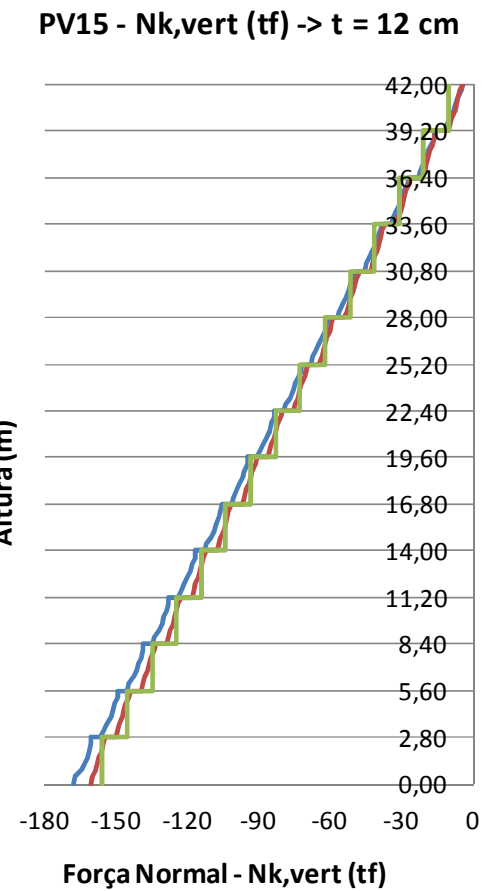

- MEF - Nk,vert

- MPT - Nk, vert

- GIP - Nk,vert

Figura 6B-2 - Diagrama de $N_{k, v e r t}$ obtido pelos modelos GIP, MPT e MEF das paredes PV08, PV12 e PV15 com espessura de $12 \mathrm{~cm}$. 
Resistência última à compressão conforme normas de projeto $(t=12 \mathrm{~cm})$

Tabela 6B-8 - $\eta_{d, \text { resist }}$ conforme AS 3600:2001 ( $\left.\mathrm{t}=12 \mathrm{~cm}\right)$.

\begin{tabular}{|c|c|c|c|c|c|}
\hline \multicolumn{5}{|c|}{ Resistência última à compressão - AS 3600:2001 -> t = 12 cm } \\
\hline PAREDES & $\mathrm{L}(\mathrm{m})$ & $\mathrm{h}_{\mathrm{e}}(\mathrm{m})$ & $\mathrm{h}_{\mathrm{e}} / \mathrm{t}$ & $\mathrm{e}_{\mathrm{a}}(\mathrm{cm})$ & $\eta \mathrm{d}$, resist $(\mathrm{tf} / \mathrm{m})$ \\
\hline PH13 & 3,2 & 2,8 & 23,3 & 2,61 & 39,36 \\
\hline PH16a & 2,4 & 2,4 & 20,0 & 1,92 & 51,84 \\
\hline PH16b & 1,6 & 1,6 & 13,3 & 0,85 & 71,04 \\
\hline PH22 & 1,2 & 2,8 & 23,3 & 2,61 & 39,36 \\
\hline PH34a & 1,6 & 1,6 & 13,3 & 0,85 & 71,04 \\
\hline PH34b & 1,2 & 1,2 & 10,0 & 0,48 & 77,76 \\
\hline PH40 & 2,8 & 2,8 & 23,3 & 2,61 & 39,36 \\
\hline PV01a & 3,6 & 2,8 & 23,3 & 2,61 & 39,36 \\
\hline PV01b & 0,4 & 2,8 & 23,3 & 2,61 & 39,36 \\
\hline PV08a & 2,4 & 2,4 & 20,0 & 1,92 & 51,84 \\
\hline PV08b & 0,4 & 2,8 & 23,3 & 2,61 & 39,36 \\
\hline PV10 & 2,4 & 2,8 & 23,3 & 2,61 & 39,36 \\
\hline PV12a & 0,8 & 0,8 & 6,7 & 0,21 & 82,56 \\
\hline PV12b & 1,6 & 2,8 & 23,3 & 2,61 & 39,36 \\
\hline PV15a & 0,8 & 2,8 & 23,3 & 2,61 & 39,36 \\
\hline PV15b & 0,8 & 0,8 & 6,7 & 0,21 & 82,56 \\
\hline PV15c & 3,2 & 2,8 & 23,3 & 2,61 & 39,36 \\
\hline PV15d & 1,6 & 1,6 & 13,3 & 0,85 & 71,04 \\
\hline PV15e & 0,4 & 0,4 & 3,3 & 0,05 & 85,44 \\
\hline PV15f & 0,4 & 2,8 & 23,3 & 2,61 & 39,36 \\
\hline
\end{tabular}

Tabela 6B-9 - $\eta_{d, \text { resist }}$ conforme AS 3600:2009 ( $\left.\mathrm{t}=12 \mathrm{~cm}\right)$.

\begin{tabular}{|c|c|c|c|c|c|c|c|}
\hline \multicolumn{8}{|c|}{ Resistência última à compressão - AS 3600:2009 ->t = $12 \mathrm{~cm}$} \\
\hline PAREDES & Vinculação & $L(m)$ & k & $h_{e}(m)$ & $h_{e} / t$ & $e_{a}(c m)$ & $\eta d$,resist $(\mathrm{tf} / \mathrm{m})$ \\
\hline $\mathrm{PH} 13$ & $\mathrm{ii}$ & 3,2 & 0,92 & 2,58 & 21,5 & 2,22 & 46,45 \\
\hline PH16a & iii & 2,4 & 0,43 & 1,20 & 10,0 & 0,48 & 77,76 \\
\hline $\mathrm{PH} 16 \mathrm{~b}$ & iii & 1,6 & 0,29 & 0,80 & 6,7 & 0,21 & 82,56 \\
\hline $\mathrm{PH} 22$ & $\mathrm{i}$ & 1,2 & 1,00 & 2,80 & 23,3 & 2,61 & 39,36 \\
\hline PH34a & $\mathrm{iii}$ & 1,6 & 0,29 & 0,80 & 6,7 & 0,21 & 82,56 \\
\hline $\mathrm{PH} 34 \mathrm{~b}$ & $\mathrm{ii}$ & 1,2 & 0,62 & 1,74 & 14,5 & 1,01 & 68,14 \\
\hline $\mathrm{PH} 40$ & ii & 2,8 & 0,90 & 2,52 & 21,0 & 2,12 & 48,30 \\
\hline PV01a & $\mathrm{iii}$ & 3,6 & 0,62 & 1,74 & 14,5 & 1,01 & 68,14 \\
\hline PV01b & ii & 0,4 & 0,30 & 0,84 & 7,0 & 0,24 & 82,17 \\
\hline PV08a & iii & 2,4 & 0,43 & 1,20 & 10,0 & 0,48 & 77,76 \\
\hline PV08b & ii & 0,4 & 0,30 & 0,84 & 7,0 & 0,24 & 82,17 \\
\hline PV10 & $\mathrm{ii}$ & 2,4 & 0,87 & 2,43 & 20,3 & 1,97 & 50,91 \\
\hline PV12a & iii & 0,8 & 0,14 & 0,40 & 3,3 & 0,05 & 85,44 \\
\hline PV12b & $\mathrm{ii}$ & 1,6 & 0,75 & 2,09 & 17,4 & 1,45 & 60,21 \\
\hline PV15a & $\mathrm{ii}$ & 0,8 & 0,42 & 1,19 & 9,9 & 0,47 & 77,96 \\
\hline PV15b & $\mathrm{iii}$ & 0,8 & 0,14 & 0,40 & 3,3 & 0,05 & 85,44 \\
\hline PV15c & iii & 3,2 & 0,57 & 1,59 & 13,2 & 0,84 & 71,31 \\
\hline PV15d & $\mathrm{iii}$ & 1,6 & 0,29 & 0,80 & 6,7 & 0,21 & 82,56 \\
\hline PV15e & iii & 0,4 & 0,07 & 0,20 & 1,7 & 0,01 & 86,16 \\
\hline PV15f & ii & 0,4 & 0,30 & 0,84 & 7,0 & 0,24 & 82,17 \\
\hline
\end{tabular}


Tabela 6B-10 - $\eta_{d, \text { resist }}$ conforme ACl 318:2011 ( $\left.\mathrm{t}=12 \mathrm{~cm}\right)$.

\begin{tabular}{|c|c|c|c|c|c|c|}
\hline \multicolumn{7}{|c|}{ Resistência última à compressão $-\mathrm{ACl} 318->\mathrm{t}=12 \mathrm{~cm}$} \\
\hline PAREDES & $\mathrm{L}(\mathrm{m})$ & $\mathrm{Ag}\left(\mathrm{cm}^{2}\right)$ & $\mathrm{h}_{\mathrm{e}}(\mathrm{m})$ & $\mathrm{h}_{\mathrm{e}} / \mathrm{t}$ & $\mathrm{L} / \mathrm{t}$ & $\eta \mathrm{d}$, resist $(\mathrm{tf} / \mathrm{m})$ \\
\hline PH13 & 3,2 & 3840,0 & 2,8 & 23,3 & 26,7 & 50,23 \\
\hline PH16a & 2,4 & 2880,0 & 2,8 & 23,3 & 20,0 & 50,23 \\
\hline PH16b & 1,6 & 1920,0 & 2,8 & 23,3 & 13,3 & 50,23 \\
\hline PH22 & 1,2 & 1440,0 & 2,8 & 23,3 & 10,0 & 50,23 \\
\hline PH34a & 1,6 & 1920,0 & 2,8 & 23,3 & 13,3 & 50,23 \\
\hline PH34b & 1,2 & 1440,0 & 2,8 & 23,3 & 10,0 & 50,23 \\
\hline PH40 & 2,8 & 3360,0 & 2,8 & 23,3 & 23,3 & 50,23 \\
\hline PV01a & 3,6 & 4320,0 & 2,8 & 23,3 & 30,0 & 50,23 \\
\hline PV01b & 0,4 & 480,0 & 2,8 & 23,3 & 3,3 & 50,23 \\
\hline PV08a & 2,4 & 2880,0 & 2,8 & 23,3 & 20,0 & 50,23 \\
\hline PV08b & 0,4 & 480,0 & 2,8 & 23,3 & 3,3 & 50,23 \\
\hline PV10 & 2,4 & 2880,0 & 2,8 & 23,3 & 20,0 & 50,23 \\
\hline PV12a & 0,8 & 960,0 & 2,8 & 23,3 & 6,7 & 50,23 \\
\hline PV12b & 1,6 & 1920,0 & 2,8 & 23,3 & 13,3 & 50,23 \\
\hline PV15a & 0,8 & 960,0 & 2,8 & 23,3 & 6,7 & 50,23 \\
\hline PV15b & 0,8 & 960,0 & 2,8 & 23,3 & 6,7 & 50,23 \\
\hline PV15c & 3,2 & 3840,0 & 2,8 & 23,3 & 26,7 & 50,23 \\
\hline PV15d & 1,6 & 1920,0 & 2,8 & 23,3 & 13,3 & 50,23 \\
\hline PV15e & 0,4 & 480,0 & 2,8 & 23,3 & 3,3 & 50,23 \\
\hline PV15f & 0,4 & 480,0 & 2,8 & 23,3 & 3,3 & 50,23 \\
\hline
\end{tabular}

Tabela 6B-11 $-\eta_{d, \text { resist }}$ conforme EN 1992:2004 ( $\left.\mathrm{t}=12 \mathrm{~cm}\right)$.

\begin{tabular}{|c|c|c|c|c|c|c|c|c|c|}
\hline \multicolumn{7}{|c|}{ Resistência última à compressão - EN $1992->\mathrm{t}=12 \mathrm{~cm}$} \\
\hline PAREDES & Vinculação & $\mathrm{L}(\mathrm{m})$ & $\beta$ & $\mathrm{h}_{\mathrm{e}}(\mathrm{m})$ & $\mathrm{h}_{\mathrm{e}} / \mathrm{t}$ & $\mathrm{e}_{\mathrm{i}}(\mathrm{cm})$ & $\mathrm{e}_{\text {tot }}(\mathrm{cm})$ & $\Phi$ & $\eta$ d,resist (tf/m) \\
\hline PH13 & $\mathrm{II}$ & 3,2 & 0,92 & 2,58 & 21,5 & 0,65 & 2,65 & 0,21 & 41,47 \\
\hline PH16a & III & 2,4 & 0,43 & 1,20 & 10,0 & 0,30 & 2,30 & 0,50 & 100,60 \\
\hline PH16b & III & 1,6 & 0,29 & 0,80 & 6,7 & 0,20 & 2,20 & 0,59 & 117,73 \\
\hline PH22 & I & 1,2 & 1,00 & 2,80 & 23,3 & 0,70 & 2,70 & 0,16 & 32,07 \\
\hline PH34a & III & 1,6 & 0,29 & 0,80 & 6,7 & 0,20 & 2,20 & 0,59 & 117,73 \\
\hline PH34b & II & 1,2 & 0,62 & 1,74 & 14,5 & 0,44 & 2,44 & 0,39 & 77,27 \\
\hline PH40 & II & 2,8 & 0,90 & 2,52 & 21,0 & 0,63 & 2,63 & 0,22 & 44,06 \\
\hline PV01a & III & 3,6 & 0,62 & 1,74 & 14,5 & 0,44 & 2,44 & 0,39 & 77,27 \\
\hline PV01b & II & 0,4 & 0,26 & 0,73 & 6,1 & 0,18 & 2,18 & 0,60 & 120,82 \\
\hline PV08a & III & 2,4 & 0,43 & 1,20 & 10,0 & 0,30 & 2,30 & 0,50 & 100,60 \\
\hline PV08b & II & 0,4 & 0,26 & 0,73 & 6,1 & 0,18 & 2,18 & 0,60 & 120,82 \\
\hline PV10 & II & 2,4 & 0,87 & 2,43 & 20,3 & 0,61 & 2,61 & 0,24 & 47,82 \\
\hline PV12a & III & 0,8 & 0,14 & 0,40 & 3,3 & 0,10 & 2,10 & 0,65 & 130,00 \\
\hline PV12b & II & 1,6 & 0,75 & 2,09 & 17,4 & 0,52 & 2,52 & 0,31 & 62,52 \\
\hline PV15a & II & 0,8 & 0,42 & 1,19 & 9,9 & 0,30 & 2,30 & 0,51 & 101,20 \\
\hline PV15b & III & 0,8 & 0,14 & 0,40 & 3,3 & 0,10 & 2,10 & 0,65 & 130,00 \\
\hline PV15c & III & 3,2 & 0,57 & 1,59 & 13,2 & 0,40 & 2,40 & 0,42 & 84,07 \\
\hline PV15d & III & 1,6 & 0,29 & 0,80 & 6,7 & 0,20 & 2,20 & 0,59 & 117,73 \\
\hline PV15e & III & 0,4 & 0,10 & 0,28 & 2,3 & 0,07 & 2,07 & 0,66 & 131,00 \\
\hline PV15f & II & 0,4 & 0,26 & 0,73 & 6,1 & 0,18 & 2,18 & 0,60 & 120,82 \\
\hline
\end{tabular}


Tabela 6B-12 - $\eta_{d, \text { resist }}$ conforme NBR 16055:2012 ( $\left.\mathrm{t}=12 \mathrm{~cm}\right)$.

\begin{tabular}{|c|c|c|c|c|c|c|c|c|c|}
\hline \multicolumn{10}{|c|}{ Resistência última à compressão - NBR $16055->t=12 \mathrm{~cm}$} \\
\hline PAREDES & Vinculacões & $L(m)$ & $\beta=h / L$ & $h_{e}(m)$ & $\mathrm{h}_{\mathrm{e}} / \mathrm{t}$ & $\lambda$ & k1 & k2 & $\eta \mathrm{d}$,resist $(\mathrm{tf} / \mathrm{m})$ \\
\hline $\mathrm{PH} 13$ & II & 3,2 & 0,88 & 2,58 & 21,5 & 74,5 & 2,13 & 0,00 & 71,43 \\
\hline $\mathrm{PH} 16 \mathrm{a}$ & III & 2,4 & 1,17 & 1,20 & 10,0 & 34,6 & 0,99 & 0,00 & 71,43 \\
\hline PH16b & III & 1,6 & 1,75 & 0,80 & 6,7 & 23,1 & 0,66 & 0,00 & 71,43 \\
\hline $\mathrm{PH} 22$ & 1 & 1,2 & 2,33 & 2,80 & 23,3 & 80,8 & 2,31 & 0,00 & 67,62 \\
\hline PH34a & III & 1,6 & 1,75 & 0,80 & 6,7 & 23,1 & 0,66 & 0,00 & 71,43 \\
\hline $\mathrm{PH} 34 \mathrm{~b}$ & II & 1,2 & 2,33 & 1,74 & 14,5 & 50,4 & 1,44 & 0,00 & 71,43 \\
\hline $\mathrm{PH} 40$ & II & 2,8 & 1,00 & 2,52 & 21,0 & 72,7 & 2,08 & 0,00 & 71,43 \\
\hline PV01a & III & 3,6 & 0,78 & 1,74 & 14,5 & 50,4 & 1,44 & 0,00 & 71,43 \\
\hline PV01b & II & 0,4 & 7,00 & 0,84 & 7,0 & 24,2 & 0,69 & 0,00 & 71,43 \\
\hline PV08a & III & 2,4 & 1,17 & 1,20 & 10,0 & 34,6 & 0,99 & 0,00 & 71,43 \\
\hline PV08b & II & 0,4 & 7,00 & 0,84 & 7,0 & 24,2 & 0,69 & 0,00 & 71,43 \\
\hline PV10 & II & 2,4 & 1,17 & 2,43 & 20,3 & 70,2 & 2,01 & 0,00 & 71,43 \\
\hline PV12a & III & 0,8 & 3,50 & 0,40 & 3,3 & 11,5 & 0,33 & 0,00 & 71,43 \\
\hline PV12b & II & 1,6 & 1,75 & 2,09 & 17,4 & 60,3 & 1,72 & 0,00 & 71,43 \\
\hline PV15a & II & 0,8 & 3,50 & 1,19 & 9,9 & 34,2 & 0,98 & 0,00 & 71,43 \\
\hline PV15b & III & 0,8 & 3,50 & 0,40 & 3,3 & 11,5 & 0,33 & 0,00 & 71,43 \\
\hline PV15c & III & 3,2 & 0,88 & 1,59 & 13,2 & 45,8 & 1,31 & 0,00 & 71,43 \\
\hline PV15d & III & 1,6 & 1,75 & 0,80 & 6,7 & 23,1 & 0,66 & 0,00 & 71,43 \\
\hline PV15e & III & 0,4 & 7,00 & 0,20 & 1,7 & 5,8 & 0,16 & 0,00 & 71,43 \\
\hline PV15f & II & 0,4 & 7,00 & 0,84 & 7,0 & 24,2 & 0,69 & 0,00 & 71,43 \\
\hline
\end{tabular}




\section{ANEXO C}

\section{C) Figuras do item 6.8.1}
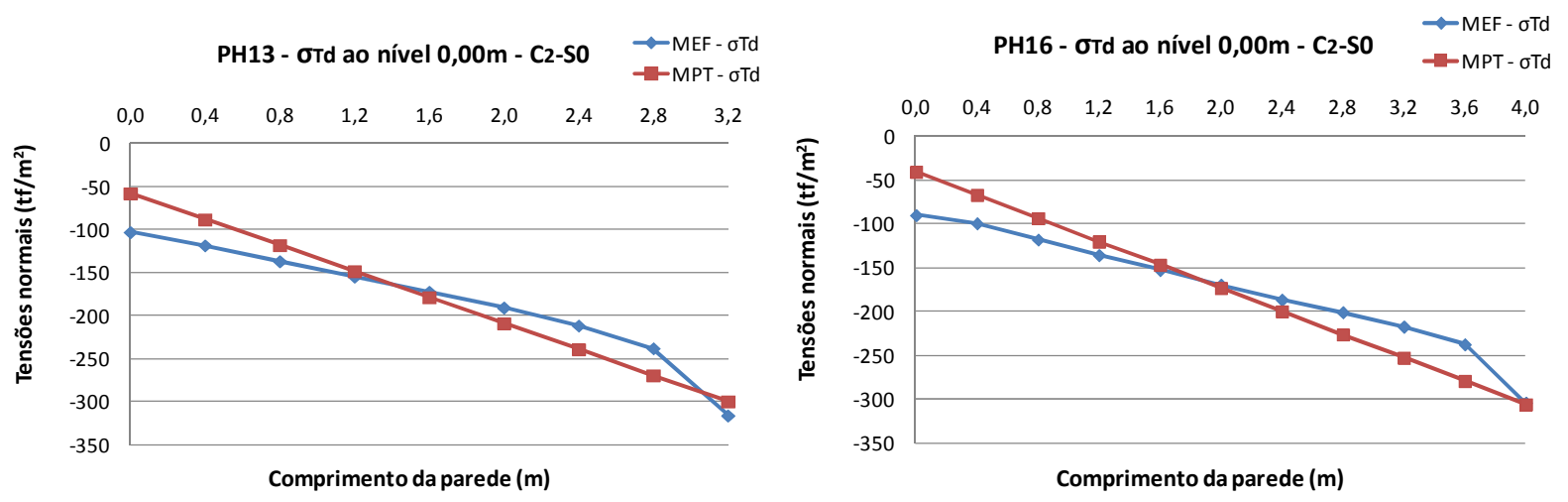

Figura 6C-1 - Diagrama de $\sigma_{T d}$ das paredes $\mathrm{PH} 13$ e $\mathrm{PH} 16$.
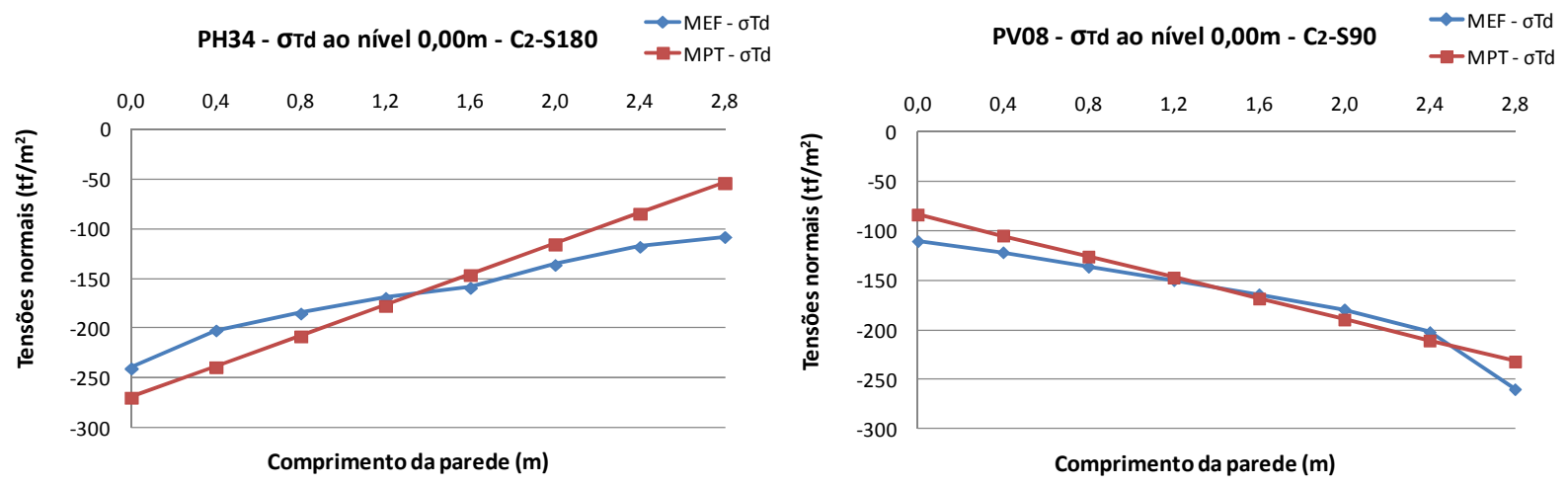

Figura 6C-2 - Diagrama de $\sigma_{T d}$ das paredes PH34 e PV08.

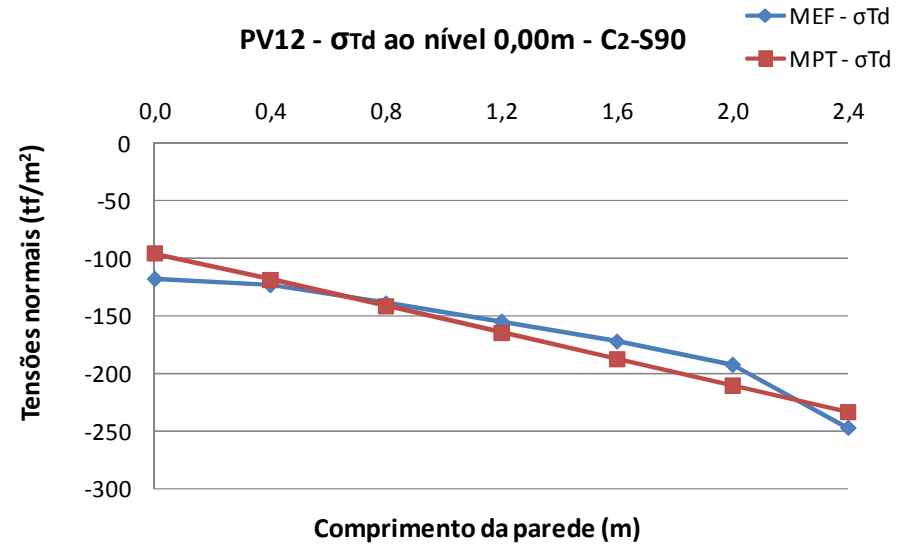

Figura 6C-3 - Diagrama de $\sigma_{T d}$ da parede PV12. 


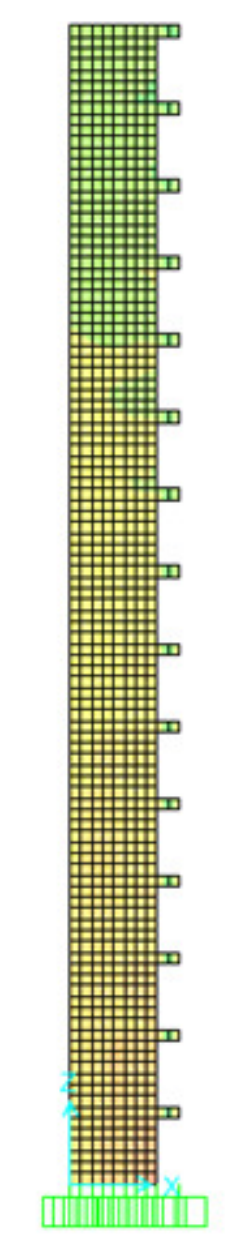

a) $\mathrm{PH} 13$ - Altura total

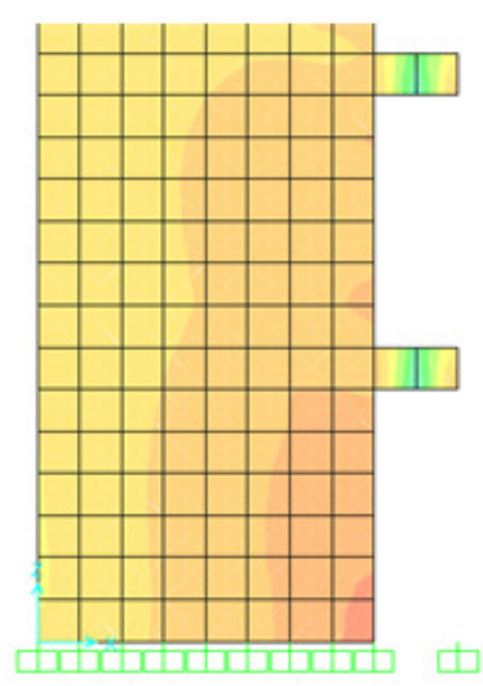

250,
200,
150,
100,
50,
0,
-50,
-100,
-150,
-200,
-250.
-300
-350
-400
-

Figura 6C-4 - Diagrama de $\sigma_{T d}$ da parede $\mathrm{PH} 13\left(\mathrm{tf} / \mathrm{m}^{2}\right)$; a) Diagrama ao longo de toda altura da parede; b) Diagrama até $6 \mathrm{~m}$ de altura da parede; 

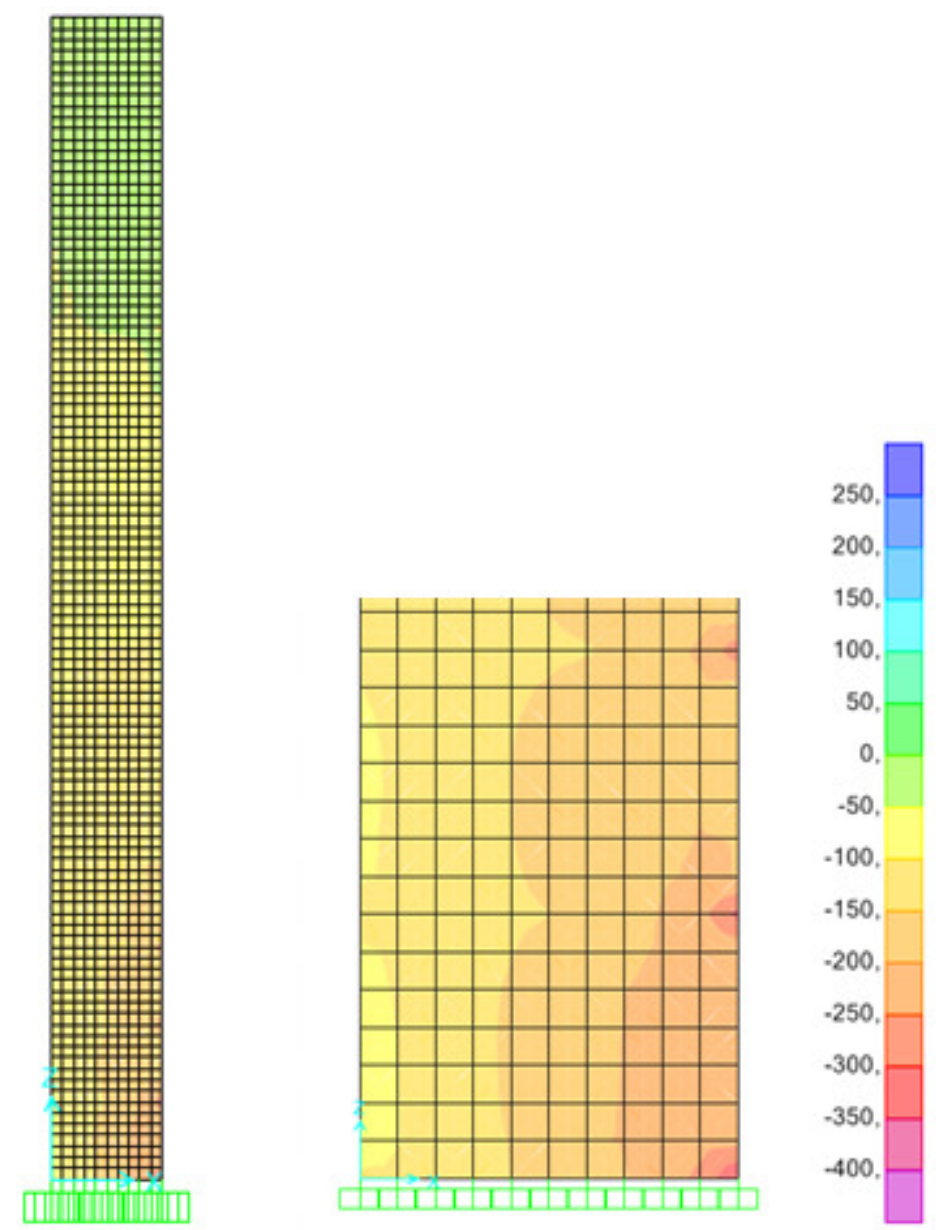

a) $\mathrm{PH} 16$ - Altura total

b) PH16 - Até $6 \mathrm{~m}$ de altura

Figura 6C-5 - Diagrama de $\sigma_{T d}$ da parede $\mathrm{PH} 16\left(\mathrm{tf} / \mathrm{m}^{2}\right)$; a) Diagrama ao longo de toda altura da parede; b) Diagrama até $6 \mathrm{~m}$ de altura da parede; 


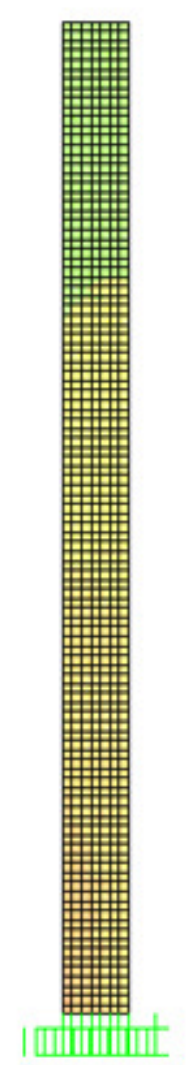

a) $\mathrm{PH} 34-$ Altura total

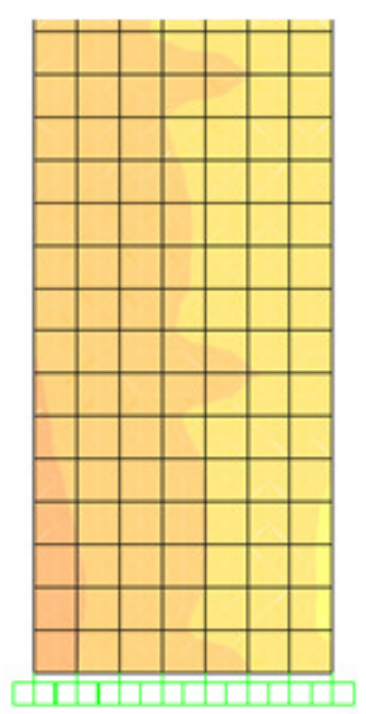

b) $\mathrm{PH} 34$ - Até $6 \mathrm{~m}$ de altura

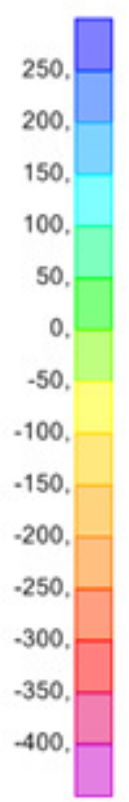

Figura 6C-6 - Diagrama de $\sigma_{T d}$ da parede PH34 (tf/ $\left.\mathrm{m}^{2}\right)$; a) Diagrama ao longo de toda altura da parede; b) Diagrama até $6 \mathrm{~m}$ de altura da parede; 


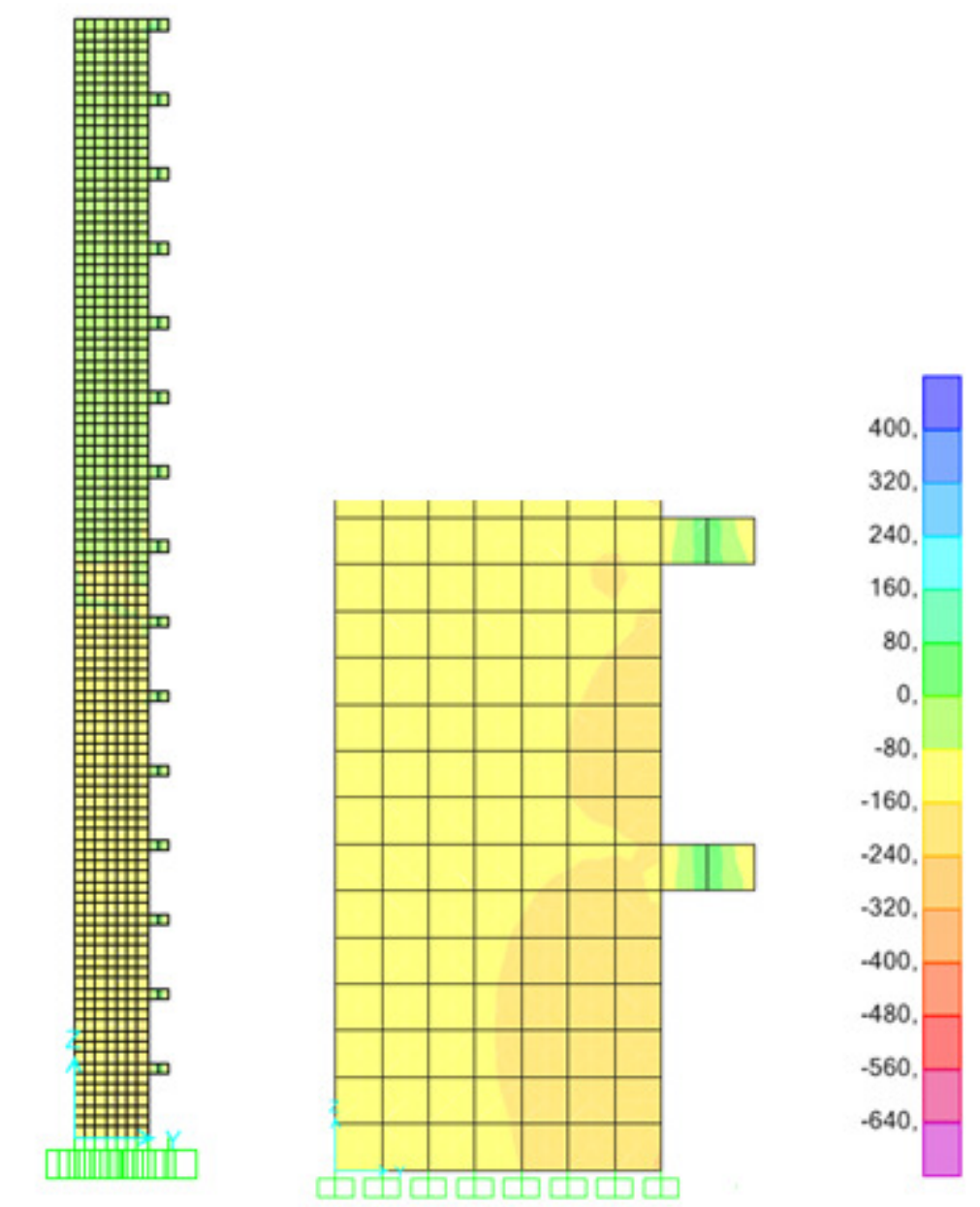

$\begin{array}{lll}\text { a) PV08-Altura total } & \text { b) PV08-Até } 6 \mathrm{~m} \text { de altura }\end{array}$

Figura 6C-7 - Diagrama de $\sigma_{T d}$ da parede PV08 (tf $\left./ \mathrm{m}^{2}\right)$; a) Diagrama ao longo de toda altura da parede; b) Diagrama até $6 \mathrm{~m}$ de altura da parede; 


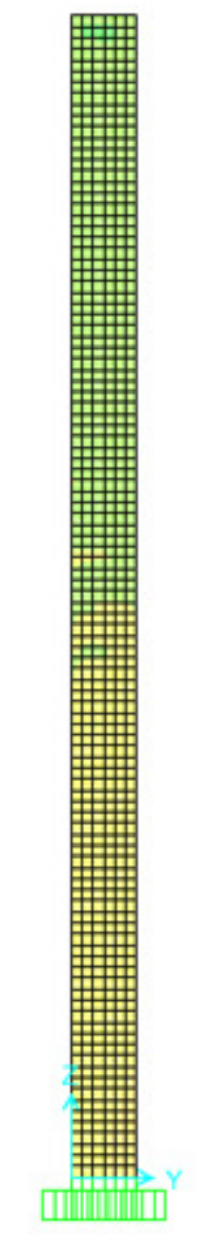

a) PV12-Altura total

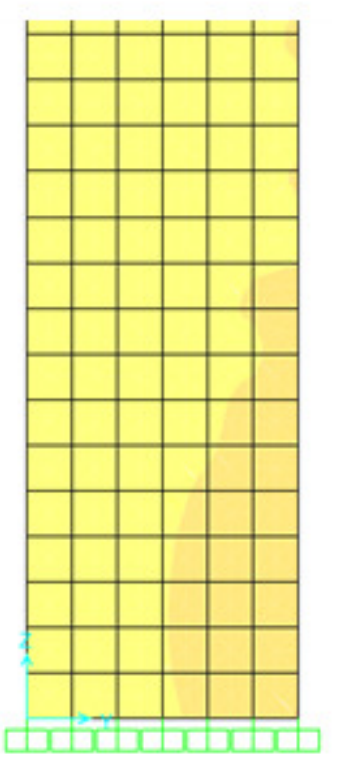

b) PV12 - Até $6 \mathrm{~m}$ de altura

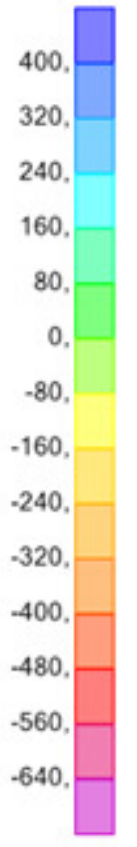

Figura 6C-8 - Diagrama de $\sigma_{T d}$ da parede PV12 (tf/m²); a) Diagrama ao longo de toda altura da parede; b) Diagrama até $6 \mathrm{~m}$ de altura da parede; 